\title{
Intermittent Inhaled Corticosteroids and Long-Acting Muscarinic Antagonists for Asthma
}




\section{Comparative Effectiveness Review}

Number 194

\section{Intermittent Inhaled Corticosteroids and Long-Acting Muscarinic Antagonists for Asthma}

Prepared for:

Agency for Healthcare Research and Quality

U.S. Department of Health and Human Services

5600 Fishers Lane

Rockville, MD 20857

www.ahrq.gov

Contract No. 290-2015-00012-I

Prepared by:

University of Connecticut Evidence-based Practice Center

Storrs, CT

Investigators:

Diana M. Sobieraj, Pharm.D.

William L. Baker, Pharm.D.

Erin R. Weeda, Pharm.D.

Elaine Nguyen, Pharm.D., M.P.H.

Craig I. Coleman, Pharm.D.

C. Michael White, Pharm.D.

Stephen C. Lazarus, M.D.

Kathryn V. Blake, Pharm.D.

Jason E. Lang, M.D., M.P.H.

AHRQ Publication No. 17(18)-EHC027-EF

March 2018 


\section{Addendum}

An updated search was conducted for studies to address Key Questions (KQs) 1c and 2a-c. These KQs were related to the combined use of inhaled corticosteroids and long-acting beta agonists as controller and quick relief therapy and to the use of long-acting muscarinic antagonists as add-on therapy to inhaled corticosteroids. The original search was conducted in August 2016 using the earliest date for each database. This update was made on November 28, 2017. No new studies met inclusion criteria. 


\section{Key Messages}

\section{Purpose of Review}

To assess the efficacy of intermittent inhaled corticosteroids in different populations of patients with asthma and to assess whether adding long-acting muscarinic antagonists improves outcomes for patients with uncontrolled, persistent asthma.

\section{Key Messages}

- In children less than 5 years old with recurrent wheezing, intermittent use of inhaled corticosteroids during an upper respiratory tract infection decreases asthma exacerbations

- In patients 12 years and older with persistent asthma:

o using inhaled corticosteroids intermittently may be as effective as using them as a controller medication

o using inhaled corticosteroids and long-acting beta-agonists together as controller and quick relief therapy reduces asthma exacerbations compared to using inhaled corticosteroids alone or with long-acting beta agonist as a controller

- In patients 12 years and older with uncontrolled, persistent asthma, adding long-acting muscarinic antagonist to:

o inhaled corticosteroids reduces exacerbations and improves lung function

o inhaled corticosteroids and long-acting beta-agonist controllers improves asthma control and lung function 
This report is based on research conducted by the University of Connecticut Evidence-based Practice Center (EPC) under contract to the Agency for Healthcare Research and Quality (AHRQ), Rockville, MD (Contract No. 290-2015-00012-I). The National Institutes of Health (NIH) National Heart, Lung, and Blood Institute (NHLBI) sponsored the report. The findings and conclusions in this document are those of the authors, who are responsible for its contents; the findings and conclusions do not necessarily represent the views of AHRQ or NIH/NHLBI. Therefore, no statement in this report should be construed as an official position of AHRQ, NIH/NHLBI, or the U.S. Department of Health and Human Services.

\section{None of the investigators have any affiliations or financial involvement that conflicts with the material presented in this report.}

The information in this report is intended to help health care decisionmakers-patients and clinicians, health system leaders, and policymakers, among others-make well-informed decisions and thereby improve the quality of health care services. This report is not intended to be a substitute for the application of clinical judgment. Anyone who makes decisions concerning the provision of clinical care should consider this report in the same way as any medical reference and in conjunction with all other pertinent information, i.e., in the context of available resources and circumstances presented by individual patients.

This report is made available to the public under the terms of a licensing agreement between the author and the Agency for Healthcare Research and Quality. This report may be used and reprinted without permission except those copyrighted materials that are clearly noted in the report. Further reproduction of those copyrighted materials is prohibited without the express permission of copyright holders.

AHRQ or U.S. Department of Health and Human Services endorsement of any derivative products that may be developed from this report, such as clinical practice guidelines, other quality enhancement tools, or reimbursement or coverage policies, may not be stated or implied.

This report may periodically be assessed for the currency of conclusions. If an assessment is done, the resulting surveillance report describing the methodology and findings will be found on the Effective Health Care Program Web site at www.effectivehealthcare.ahrq.gov. Search on the title of the report.

Persons using assistive technology may not be able to fully access information in this report. For assistance contact EffectiveHealthCare@ahrq.hhs.gov.

Suggested citation: Sobieraj DM, Baker WL, Weeda ER, Nguyen E, Coleman CI, White CM, Lazarus SC, Blake KV, Lang JE. Intermittent Inhaled Corticosteroids and Long-Acting Muscarinic Antagonists for Asthma. Comparative Effectiveness Review No. 194. (Prepared by the University of Connecticut Evidence-based Practice Center under Contract No. 290-201500012-I.) AHRQ Publication No. 17(18)-EHC027-EF. Rockville, MD: Agency for Healthcare Research and Quality; March 2018. Posted final reports are located on the Effective Health Care Program search page. DOI: https://doi.org/10.23970/AHRQEPCCER194. 


\section{Preface}

The Agency for Healthcare Research and Quality (AHRQ), through its Evidence-based Practice Centers (EPCs), sponsors the development of evidence reports and technology assessments to assist public- and private-sector organizations in their efforts to improve the quality of health care in the United States. The National Institutes of Health (NIH) National Heart, Lung, and Blood Institute (NHLBI) requested and provided funding for the report.

The reports and assessments provide organizations with comprehensive, evidence-based information on common medical conditions and new health care technologies and strategies. They also identify research gaps in the selected scientific area, identify methodological and scientific weaknesses, suggest research needs, and move the field forward through an unbiased, evidence-based assessment of the available literature. The EPCs systematically review the relevant scientific literature on topics assigned to them by AHRQ and conduct additional analyses when appropriate prior to developing their reports and assessments.

To bring the broadest range of experts into the development of evidence reports and health technology assessments, AHRQ encourages the EPCs to form partnerships and enter into collaborations with other medical and research organizations. The EPCs work with these partner organizations to ensure that the evidence reports and technology assessments they produce will become building blocks for health care quality improvement projects throughout the Nation. The reports undergo peer review and public comment prior to their release as a final report.

AHRQ expects that the EPC evidence reports and technology assessments, when appropriate, will inform individual health plans, providers, and purchasers as well as the health care system as a whole by providing important information to help improve health care quality.

If you have comments on this evidence report, they may be sent by mail to the Task Order Officers named below at: Agency for Healthcare Research and Quality, 5600 Fishers Lane, Rockville, MD 20857, or by email to epc@ahrq.hhs.gov.

Gopal Khanna M.B.A

Director

Agency for Healthcare Research and Quality

Stephanie Chang, M.D., M.P.H.

Director

Evidence-based Practice Center Program

Center for Evidence and Practice Improvement Agency for Healthcare Research and Quality
Arlene S. Bierman, M.D., M.S.

Director

Center for Evidence and Practice

Improvement

Agency for Healthcare Research and Quality

Aysegul Gozu, M.D., M.P.H.

Task Order Officer

Center for Evidence and Practice

Improvement

Agency for Healthcare Research and Quality

David W. Niebuhr, M.D., M.P.H., M.Sc.

Task Order Officer

Center for Evidence and Practice

Improvement

Agency for Healthcare Research and Quality 


\section{Acknowledgments}

The authors gratefully acknowledge the contribution of the EPC librarian, Sharon Giovenale, for her contribution to the literature search and citation retrieval process. We would like to acknowledge the affiliations of our content experts:

Stephen C. Lazarus, M.D.

Professor of Medicine

Division of Pulmonary \& Critical Care Medicine

University of California, San Francisco

San Francisco, CA

Kathryn V. Blake, Pharm.D.

Director, Center for Pharmacogenomics and Translational Research

Nemours Children's Specialty Care

Jacksonville, FL

Jason E. Lang, M.D., M.P.H.

Division of Allergy, Immunology and Pulmonary Medicine

Duke University School of Medicine

Duke Children’s Hospital and Health Center

\section{Technical Expert Panel}

In designing the study questions and methodology at the outset of this report, the EPC consulted several technical and content experts. Broad expertise and perspectives were sought. Divergent and conflicted opinions are common and perceived as healthy scientific discourse that results in a thoughtful, relevant systematic review. Therefore, in the end, study questions, design, methodologic approaches, and/or conclusions do not necessarily represent the views of individual technical and content experts.

Technical Experts must disclose any financial conflicts of interest greater than $\$ 10,000$ and any other relevant business or professional conflicts of interest. Because of their unique clinical or content expertise, individuals with potential conflicts may be retained. The TOO and the EPC work to balance, manage, or mitigate any potential conflicts of interest identified.

The list of Technical Experts who provided input to this report follows:

Robyn Cohen, M.D., M.P.H.

Assistant Professor of Pediatrics

Boston University School of Medicine

Boston, MA

Nicola Hanania, M.B.B.S.

Associate Professor of Medicine-Pulmonary

Baylor College of Medicine

Houston, TX 
H. William Kelly, Pharm.D.*

Professor Emeritus of Pediatrics and Pharmacy

University of New Mexico Health Sciences Center

Albuquerque, NM

Wendy C. Moore, M.D.

Associate Professor of Pulmonary, Critical Care and Allergy and Immunologic Medicine

Wake Forest University School of Medicine

Winston-Salem, NC

Michael Schatz, M.D., M.S.*

Kaiser Permanente Medical Care Program

San Diego, CA

Stanley Szefler, M.D.*

Director

Pediatric Asthma Research Program at Children's Hospital Colorado

Aurora, CO

*Provided input on Draft Report

\section{Peer Reviewers}

Prior to publication of the final evidence report, EPCs sought input from independent Peer Reviewers without financial conflicts of interest. However, the conclusions and synthesis of the scientific literature presented in this report do not necessarily represent the views of individual reviewers.

Peer Reviewers must disclose any financial conflicts of interest greater than $\$ 10,000$ and any other relevant business or professional conflicts of interest. Because of their unique clinical or content expertise, individuals with potential nonfinancial conflicts may be retained. The TOO and the EPC work to balance, manage, or mitigate any potential nonfinancial conflicts of interest identified.

The list of Peer Reviewers follows:

William Busse, M.D.

Professor

Department of Medicine

School of Medicine and Public Health

University of Wisconsin

Fernando Martinez, M.D.

Regent's Professor

Director, Asthma and Airways Disease Research Center

Swift-McNear Professor of Pediatrics

College of Medicine, Tucson

The University of Arizona Health Sciences

Tucson, AZ 
Natalie Napolitano, M.P.H., RRT-NPS, FAARC

Research Clinical Specialist

Respiratory Therapy Department

The Children's Hospital of Philadelphia

Philadelphia, PA 


\section{Intermittent Inhaled Corticosteroids and Long-Acting Muscarinic Antagonists for Asthma}

\section{Structured Abstract}

Objective. To assess efficacy of intermittent inhaled corticosteroid (ICS) therapy in different populations ( 0 to 4 years old with recurrent wheezing, 5 years and older with persistent asthma, with or without long-acting beta agonist [LABA]), and to assess efficacy of added long-acting muscarinic antagonist (LAMA) in patients 12 years and older with uncontrolled, persistent asthma.

Data sources. MEDLINE ${ }^{\circledR}$, Embase ${ }^{\circledR}$, Cochrane Central, and Cochrane Database of Systematic Reviews bibliographic databases from earliest date through March 23, 2017; hand searches of references of relevant studies; $\underline{w w w . c l i n i c a l t r i a l s . g o v}$ and the International Controlled Trials Registry Platform.

Review methods. Two investigators screened abstracts of identified references for eligibility and subsequently reviewed full-text files. We abstracted data, performed meta-analyses when appropriate, assessed the risk of bias of each individual study, and graded the strength of evidence for each comparison and outcome. Outcomes for which data were extracted included exacerbations, mortality, asthma control composite scores, spirometry, asthma-specific quality of life, and rescue medication use.

Results. We included 56 unique studies (54 randomized controlled trials, 2 observational studies) in this review. Compared to rescue short-acting beta-agonist (SABA) use, adding intermittent ICS reduces the risk of exacerbation requiring oral steroids and improves caregiver quality of life in children less than 5 years old with recurrent wheezing in the setting of a respiratory tract infection (RTI). In patients 12 years and older with persistent asthma, differences in intermittent ICS versus controller use of ICS were not detected, although few studies provided evidence, leading to primarily low strength of evidence ratings. Using ICS and LABA as both a controller and quick relief therapy reduced the risk of exacerbations and improved symptom control in patients 12 years and older compared to ICS controller (with or without LABA). Data in patients 4 to 11 years old suggest lower risk of exacerbations with ICS and LABA controller and quick relief use, but with a lower strength of evidence than in the older population. In patients 12 years and older with uncontrolled, persistent asthma, LAMA versus placebo as add-on to ICS reduces the risk of exacerbations requiring systemic corticosteroids and improves lung function measure through spirometry. Current evidence does not suggest that a difference exists in the efficacy of LAMA versus LABA as add-on to ICS. Triple therapy of ICS, LAMA, and LABA improves lung function measured through spirometry, although the risk of exacerbation was not different versus ICS and LABA.

Conclusions. Intermittent ICS added to SABA during an RTI provides benefit to patients less than 5 years of age with recurrent wheezing. In patients 12 years and older with persistent asthma, differences in intermittent ICS versus controller use of ICS were not detected, although few studies provided evidence for this question. In patients 12 years and older with persistent asthma, using ICS and LABA as both a controller and quick relief therapy may be more effective 
at preventing exacerbations than ICS controller (with or without LABA). LAMA is effective in the management of uncontrolled, persistent asthma in patients 12 years of age and older, and current evidence does not suggest a difference between LAMA and LABA as add-on to ICS. 


\section{Contents}

Evidence Summary...........................................................................

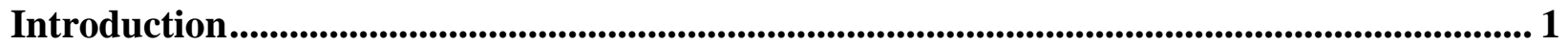

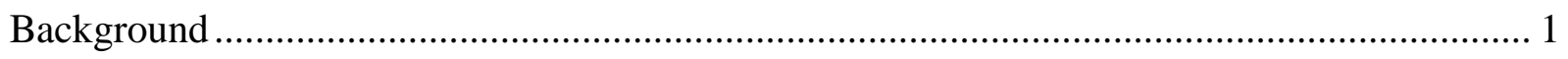

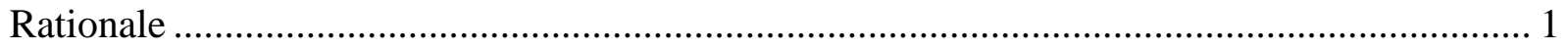

Intermittent Inhaled Corticosteroid (ICS) Dosing ……….................................................... 1

Long-Acting Muscarinic Antagonist (LAMA) Added to ICS or to ICS Plus LABA ............... 2

Key Questions (KQs) .................................................................................................. 2

Population, Intervention, Comparator, Outcomes .................................................................... 3

Methods..................................................................................................................................... 6

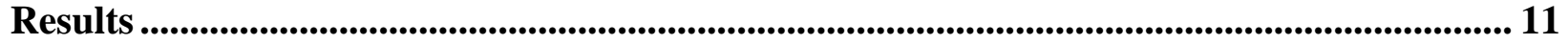

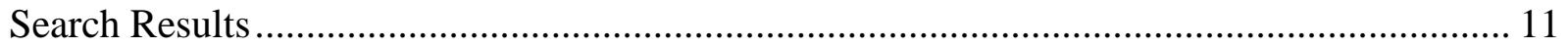

Organization of This Report .............................................................................................. 12

KQ1a: What is the comparative effectiveness of intermittent inhaled corticosteroid

(ICS) compared to no treatment, pharmacologic, or nonpharmacologic therapy in

children 0 to 4 years old with recurrent wheezing? .................................................................. 13

Key Points...................................................................................................................... 13

Intermittent ICS With As-Needed SABA Versus As-Needed SABA .................................... 13

Intermittent ICS With As-Needed SABA Versus ICS Controller With As-Needed SABA 15

Intermittent ICS Versus No Therapy ............................................................................. 16

KQ1b: What is the comparative effectiveness of intermittent ICS compared to ICS controller therapy in patients 5 years of age and older with persistent asthma?........................ 16

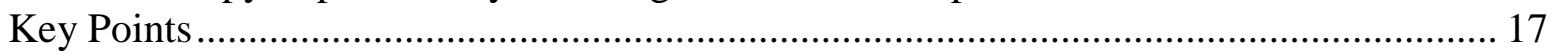

Intermittent ICS and ICS Controller Versus ICS Controller .................................................. 17

Intermittent ICS Versus ICS Controller.............................................................................. 20

KQ1c: What is the comparative effectiveness of ICS with long-acting beta agonist (LABA) used as both controller and quick relief therapy compared to ICS with or without LABA used as controller therapy in patients 5 years of age and older with persistent asthma? ................... 23

Key Points-ICS and LABA Controller and Quick Relief Versus ICS Controller .............. 24

Key Points-ICS and LABA Controller and Quick Relief Versus ICS and LABA Controller

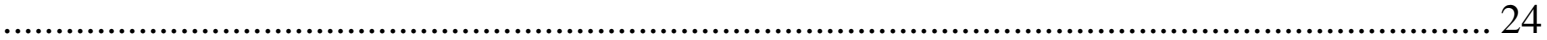

Key Points-ICS and LABA Controller and Quick Relief Versus CBP .............................. 24

ICS and LABA as Controller and Quick Relief Versus ICS Controller at the Same

Comparative ICS Dose ...................................................................................................... 25

ICS and LABA as Controller and Quick Relief Versus ICS Controller at a Higher

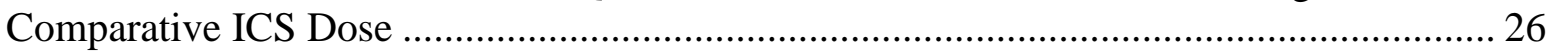

ICS and LABA as Controller and Quick Relief Versus ICS and LABA Controller at the

Same Comparative ICS Dose............................................................................................. 28

ICS and LABA as Controller and Quick Relief Versus ICS and LABA Controller at a

Higher Comparative ICS Dose ............................................................................................. 33

ICS and LABA as Controller and Quick Relief Versus ICS and LABA Controller at a

Lower Comparative ICS Dose ........................................................................................... 35

ICS and LABA as Controller and Quick Relief Versus CBP ............................................. 36

KQ2a: What is the comparative effectiveness of long-acting muscarinic antagonist (LAMA) as add-on to ICS controller therapy compared to placebo or increased ICS dose in patients 12 years of age and older with uncontrolled, persistent asthma? 
Key Points_LAMA Versus Placebo as Add-on to ICS ................................................ 39

Key Points-LAMA Add-on to ICS Versus Increasing ICS Dose .................................. 40

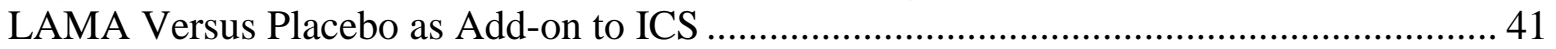

LAMA as Add-on to ICS Versus Increasing the ICS Dose .......................................... 43

KQ2b: What is the comparative effectiveness of LAMA compared to other controller therapy as add-on to ICS in patients 12 years of age and older with uncontrolled, persistent asthma? 43

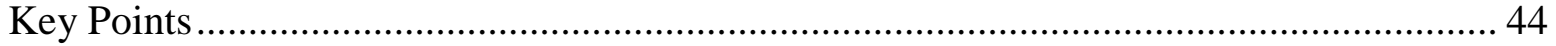

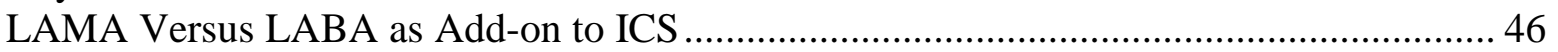

LAMA Versus Other Controllers as Add-on to ICS.................................................... 47

KQ2c: What is the comparative effectiveness of LAMA as add-on to ICS plus LABA compared to ICS plus LABA as controller therapy in patients 12 years of age and older with

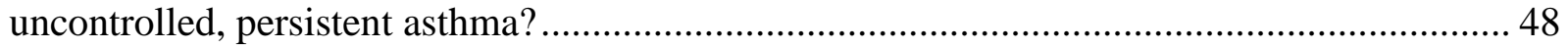

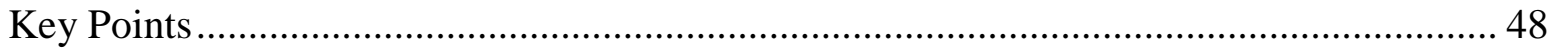

LAMA as Add-on to ICS Plus LABA Versus ICS Plus LABA ....................................... 49

LAMA as Add-on to ICS Plus LABA Versus ICS Plus LABA With a Higher ICS Dose... 51

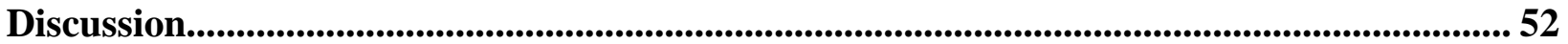

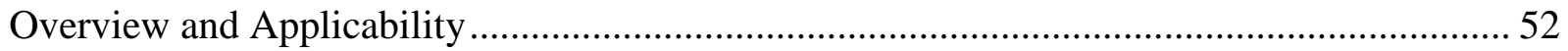

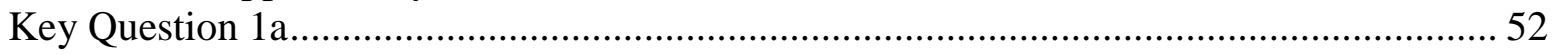

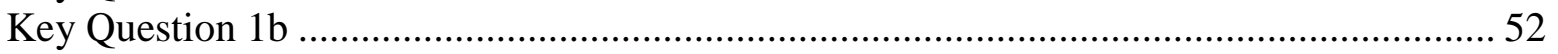

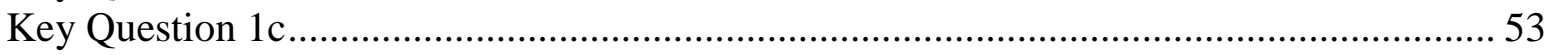

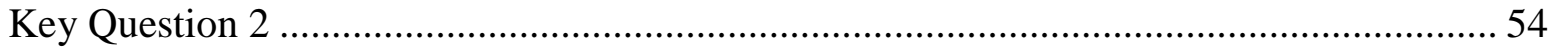

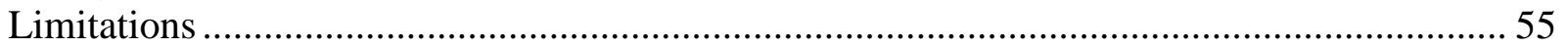

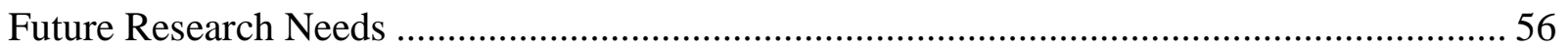

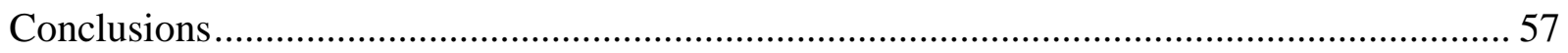

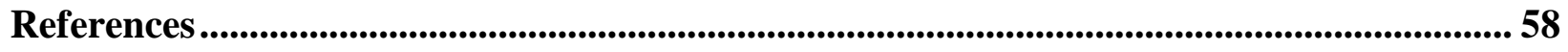

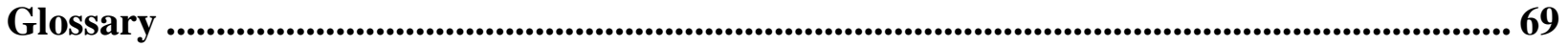

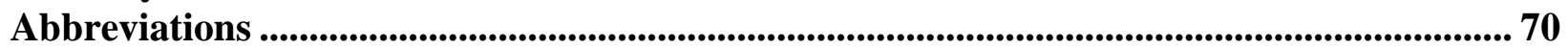

Tables

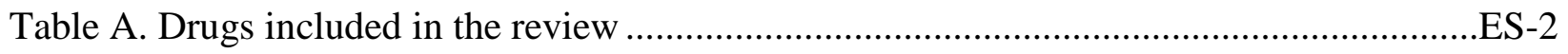

Table B. Results for patients 0 to 4 years of age with recurrent wheezing …...........................ES-3

Table C. Results for patients 5 to 11 years of age with persistent asthma ................................S-3

Table D. Results for patients 12 years of age and older with persistent asthma ......................ES-3

Table E. Results for patients 12 years of age and older with uncontrolled, persistent asthma .ES-4

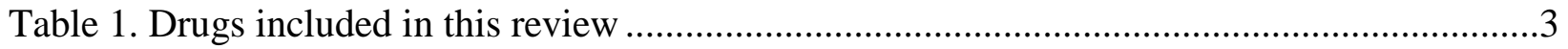

Table 2. Intervention and comparator per Key Question....................................................4

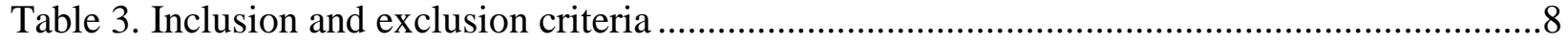

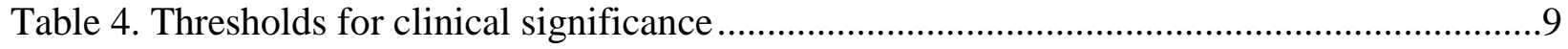

Table 5. Number of studies included per KQ, study design, and age group ..............................12

Table 6. Evidence overview for KQ1a, intermittent ICS with as-needed SABA versus as-needed

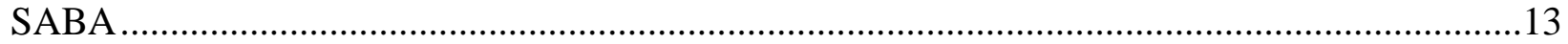

Table 7. Evidence overview for KQ1a, intermittent ICS with as-needed SABA versus ICS

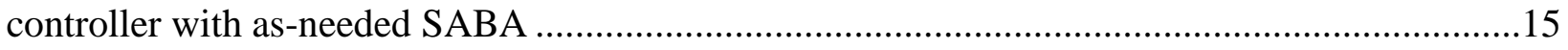

Table 8. Evidence overview for KQ1a, intermittent ICS versus no therapy ..............................16

Table 9. Evidence overview for KQ1b, intermittent ICS with ICS controller versus ICS controller in patients 12 years of age and older 
Table 10. Evidence overview for KQ1b, intermittent ICS with ICS controller versus ICS controller in patients 4 to 11 years of age

Table 11. Evidence overview for KQ1b, intermittent ICS versus ICS controller in patients 12 years of age and older

Table 12. Evidence overview for KQ1b, intermittent ICS versus ICS controller in patients 4 to 11 years of age .....

Table 13. Evidence overview for KQ1c, ICS and LABA controller and quick relief versus ICS controller (same dose) in patients 12 years of age and older

Table 14. Evidence overview for KQ1c, ICS and LABA controller and quick relief versus ICS controller (higher dose) in patients 12 years of age and older

Table 15. Evidence overview for KQ1c, ICS and LABA controller and quick relief versus ICS controller (higher dose) in patients 4 to 11 years of age....

Table 16. Evidence overview for KQ1c, ICS and LABA controller and quick relief versus ICS and LABA controller (same dose) in patients 12 years of age and older

Table 17. Evidence overview for KQ1c, ICS and LABA controller and quick relief versus ICS and LABA controller (same dose) in patients 4 to 11 years old.

Table 18. Evidence overview for KQ1c, ICS and LABA controller and quick relief versus ICS and LABA controller (higher dose) in patients 12 years of age and older

Table 19. Evidence overview for KQ1c, ICS and LABA controller and quick relief versus ICS and LABA controller (lower dose) in patients 12 years of age and older

Table 20. Evidence overview for KQ1c, ICS and LABA controller and quick relief versus CBP

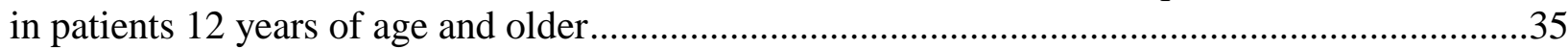

Table 21. Evidence overview for KQ2a, LAMA as add-on to ICS versus placebo ......................39

Table 22. Evidence overview for KQ2a, LAMA as add-on to ICS versus doubling the ICS dose40 Table 23. Evidence overview for KQ2b, LAMA versus LABA as add-on to ICS.......................42

Table 24. Evidence overview for KQ2b, LAMA versus montelukast as add-on to ICS ..............44

Table 25. Evidence overview for KQ2b, LAMA versus doxofylline as add-on to ICS ...............46

Table 26. Evidence overview for KQ2c, LAMA added to ICS plus LABA versus ICS plus

LABA.

Table 27. Evidence overview for KQ2c, LAMA added to ICS plus LABA versus doubling the ICS dose plus LABA

\section{Figures}

Figure A. Scope of review

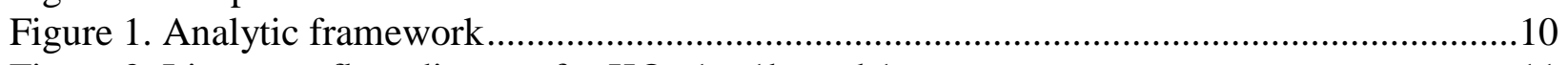

Figure 2. Literature flow diagram for KQs 1a, 1b, and 1c..................................................11

Figure 3. Literature flow diagram for KQs 2a, 2b, and 2c.................................................12

Figure 4. Risk of requiring a course of oral steroids: intermittent ICS with as-needed SABA versus as-needed SABA

Figure 5. Risk of exacerbations requiring oral corticosteroid: Intermittent ICS and ICS controller

versus ICS controller

Figure 6. Figure 6. Risk of exacerbation: ICS and LABA controller and quick relief versus ICS and LABA controller (same dose)

Figure 7. Risk of exacerbation: ICS and LABA controller and quick relief versus ICS and LABA

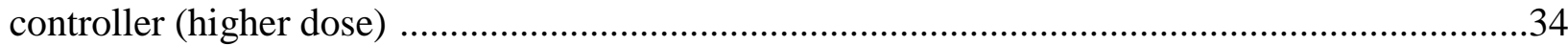

Figure 8. Risk of exacerbation: ICS and LABA controller and quick relief versus CBP .............38 
Figure 9. Risk of exacerbation and of asthma worsening with LAMA versus placebo as add-on to

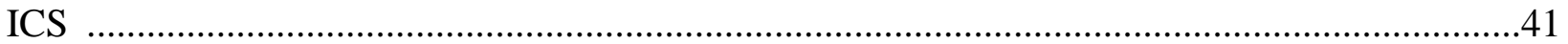

Figure 10. Risk of exacerbation with LAMA versus LABA as add-on to ICS ........................45

Figure 11. Risk of exacerbation and of asthma worsening with LAMA as add-on to ICS and LABA versus ICS and LABA

\section{Appendixes}

Appendix A. Search Strategy

Appendix B. List of Excluded Studies

Appendix C. Study Characteristics

Appendix D. Risk of Bias Assessment

Appendix E. Strength of Evidence Assessments

Appendix F. Forest Plots 


\section{Evidence Summary}

\section{Objectives and Rationale for the Review}

This report summarizes a systematic review of intermittent inhaled corticosteroids and longacting muscarinic antagonists for asthma, and identifies needs for future research. This was one of the six high priority topics within asthma identified by a National Heart, Lung, and Blood Institute Advisory Council Asthma Expert Working group. ${ }^{1}$

The objectives of the systematic review are:

- To assess efficacy of intermittent inhaled corticosteroid (ICS) therapy in different populations:

o Patients 0 to 4 years old with recurrent wheezing

o Patients 5 years and older with persistent asthma (with or without long-acting beta agonist (LABA)

- To assess efficacy of adding long-acting muscarinic antagonist (LAMA) to ICS with or without LABA in:

o Patients 12 years and older with uncontrolled, persistent asthma.

\section{Background}

Scheduled, daily dosing of ICS is the preferred pharmacologic controller therapy for persistent asthma in patients of all ages. ${ }^{1}$

“Controller therapy" describes medications taken daily on a long-term basis to achieve and maintain control of persistent asthma. ${ }^{2}$ Rather than being taken for immediate symptom relief, controller therapy is intended to reduce future exacerbations and the need for immediate symptom relief. In this report, controller medications are defined by the timing and indication for use rather than by mechanism of action.

“Quick relief” therapy describes medications used as needed upon onset of symptoms for acute symptom relief. Likewise, for this report, quick relief therapy is defined by the timing and indication for use rather than by mechanism of action.

Worsening control of asthma or other criteria may prompt changes in prescription therapy, such as intermittent dosing.

"Intermittent" dosing describes the use of medication that may vary in the dose, frequency, or duration of administration. Some examples of intermittent ICS dosing include initiating a temporary course of ICS or temporarily increasing the dose of ICS that is otherwise taken as controller therapy.

An extension of intermittent ICS therapy is the use of ICS and LABA as controller therapy both on a regular basis and on immediate symptom onset for quick relief therapy. ${ }^{3}$

LAMA represents a new pharmacologic class of long-acting bronchodilators that have been studied as a controller therapy for asthma. At least one LAMA has gained Food and Drug 
Administration (FDA) approval for the long-term maintenance treatment of asthma in patients 6 years and older. ${ }^{4}$

The review focuses on drugs as a class, as described in Table A.

Table A. Drugs included in the review

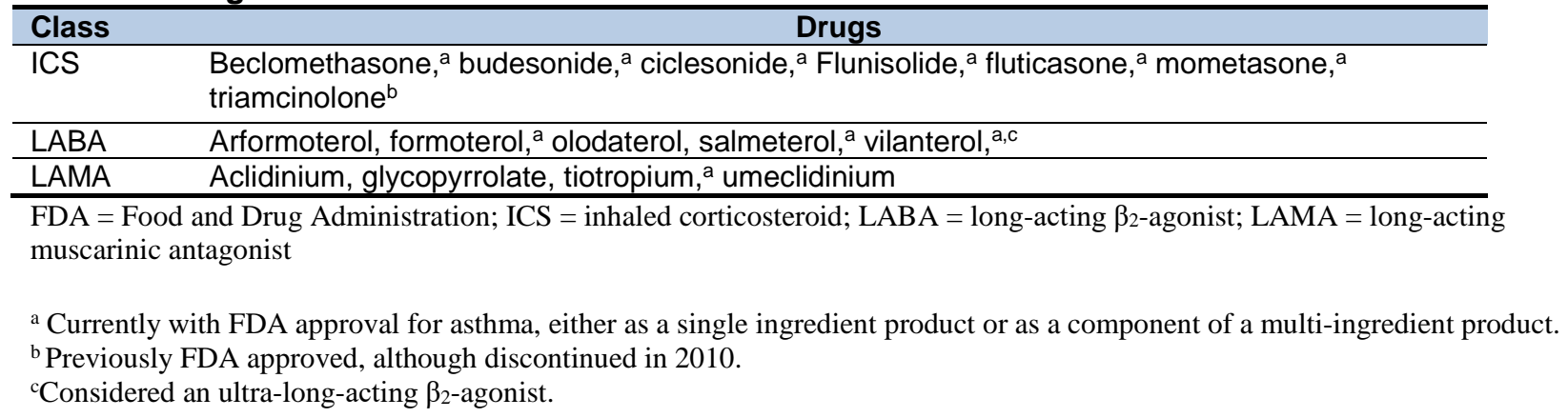

Figure A. Scope of review

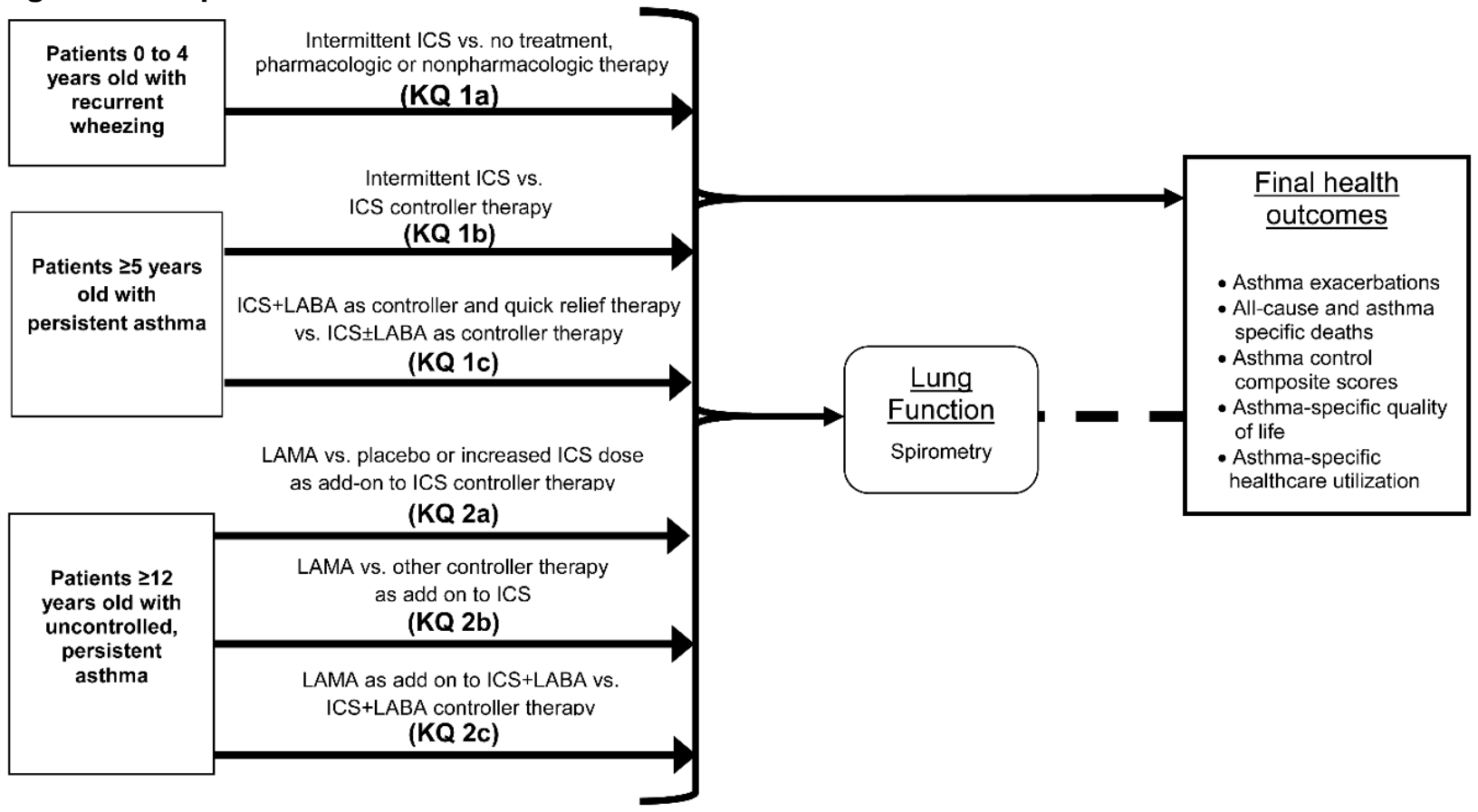

ICS = inhaled corticosteroid; KQ = Key Question; LABA = long-acting beta agonist; LAMA = long-acting muscarinic antagonist

\section{Data Sources}

Data sources were MEDLINE ${ }^{\circledR}$, Embase ${ }^{\circledR}$, Cochrane Central, and Cochrane Database of Systematic Reviews bibliographic databases from earliest date through March 23, 2017; hand searches of references of relevant studies; www.clinicaltrials.gov and the International Controlled Trials Registry Platform. The systematic review protocol is available in the full report. 


\section{Results}

We found 56 unique studies (54 randomized controlled trials, 2 observational studies) in this review. Fifteen randomized controlled trials were specific to LAMA therapy in patients 12 years and older with persistent uncontrolled asthma. An overview of the results is presented in Tables B through E.

Table B. Results for patients 0 to 4 years of age with recurrent wheezing

\begin{tabular}{|c|c|}
\hline Intervention & Effect \\
\hline $\begin{array}{l}\text { Intermittent ICS with SABA prn vs. SABA prn } \\
\text { at the onset of a URI }\end{array}$ & $\begin{array}{l}\text { - } \text { Reduces the risk of exacerbation requiring oral } \\
\text { corticosteroids (moderate SOE) } \\
\text { - } \quad \text { Improves QOL (low SOE) } \\
\text { - Does not affect: } \\
\text { o Other measures of exacerbation (low or high SOE) } \\
\text { o Rescue medication use (low SOE) }\end{array}$ \\
\hline Intermittent ICS vs. ICS controller & $\begin{array}{ll}\text { - } & \text { Does affect: } \\
\text { o } & \text { The risk of exacerbations requiring oral corticosteroids } \\
& \text { (low SOE) } \\
\text { o } & \text { Hospitalization (low SOE) } \\
\text { o } & \text { Rescue medication use (low SOE) }\end{array}$ \\
\hline Intermittent ICS vS. no therapy & No conclusion possible (insufficient SOE) \\
\hline $\begin{array}{l}\text { Intermittent ICS vs. nonpharmacologic } \\
\text { therapy }\end{array}$ & - $\quad$ No conclusion possible (insufficient SOE) \\
\hline
\end{tabular}

Table C. Results for patients 5 to 11 years of age with persistent asthma

\begin{tabular}{lll}
\hline Intervention & & \multicolumn{1}{c}{ Effect } \\
\hline Intermittent ICS vS. ICS controller & $\begin{array}{l}\text { Does not affect: } \\
\text { o QOL (low SOE) }\end{array}$ \\
& o Rescue medication use (low SOE) \\
& $\bullet \quad$ No conclusion possible for other outcomes (insufficient SOE) \\
\hline $\begin{array}{l}\text { ICS combined with LABA as controller and } \\
\text { quick relief vs. a higher ICS controller dose }\end{array}$ & $\begin{array}{l}\text { Reduces the risk of exacerbations measured as a composite } \\
\text { outcome (low SOE) }\end{array}$ \\
\hline $\begin{array}{l}\text { ICS combined with LABA as controller and } \\
\text { quick relief vs. ICS and LABA as controller at } \\
\text { the same ICS dose }\end{array}$ & $\begin{array}{l}\text { Reduces the risk of exacerbations measured as a composite } \\
\text { outcome (low SOE) }\end{array}$ \\
\hline ICS = inhaled corticosteroid; LABA = long-acting beta agonist; QOL = quality of life; SOE = strength of evidence
\end{tabular}

Table D. Results for patients 12 years of age and older with persistent asthma

\begin{tabular}{|c|c|}
\hline Intervention & Effect \\
\hline $\begin{array}{l}\text { Intermittent ICS and ICS controller vS. ICS } \\
\text { controller }\end{array}$ & $\begin{array}{l}\text { Does not affect the risk of exacerbations, regardless of } \\
\text { definition (low SOE) } \\
\text { - } \quad \text { Decreases asthma-related outpatient visits (low SOE). }\end{array}$ \\
\hline Intermittent ICS vs. ICS controller & $\begin{array}{ll}\text { - } & \text { Does not affect: } \\
\text { o } & \text { The risk of exacerbation regardless of definition (low } \\
& \text { SOE) } \\
\text { o } & \text { Asthma control scores (low SOE) } \\
\text { O } & \text { Spirometry (low to high SOE) } \\
\text { o } & \text { QOL (moderate SOE) } \\
\text { o } & \text { Rescue medication use (moderate SOE) }\end{array}$ \\
\hline $\begin{array}{l}\text { ICS combined with LABA as controller and } \\
\text { quick relief vs. the same ICS controller dose }\end{array}$ & $\begin{array}{l}\text { - Reduces: } \\
\text { o The risk of exacerbations defined as a composite } \\
\text { outcome (moderate SOE) } \\
\text { o Rescue medication use (low SOE) } \\
\text { - Improves spirometry (moderate SOE) }\end{array}$ \\
\hline $\begin{array}{l}\text { ICS combined with LABA as controller and } \\
\text { quick relief vs. a higher ICS controller dose }\end{array}$ & $\begin{array}{l}\text { - } \quad \text { Reduces the risk of exacerbations defined as a composite } \\
\text { outcome (low SOE) }\end{array}$ \\
\hline
\end{tabular}




\begin{tabular}{|c|c|}
\hline Intervention & Effect \\
\hline $\begin{array}{l}\text { ICS combined with LABA as controller and } \\
\text { quick relief vs. ICS and LABA as controller at } \\
\text { the same ICS dose }\end{array}$ & $\begin{array}{l}\text { - Reduces: } \\
\text { o The risk of exacerbations defined as a composite } \\
\quad \text { outcome (high SOE) } \\
\text { o Rescue medication use (low SOE) } \\
\text { - Improves asthma control scores (moderate SOE) }\end{array}$ \\
\hline $\begin{array}{l}\text { ICS combined with LABA as controller and } \\
\text { quick relief vs. ICS and LABA as controller at } \\
\text { a higher ICS dose }\end{array}$ & $\begin{array}{l}\text { - } \quad \text { Reduces the risk of exacerbations defined as a composite } \\
\text { outcome (high SOE) }\end{array}$ \\
\hline $\begin{array}{l}\text { ICS combined with LABA as controller and } \\
\text { quick relief vs. conventional best practice of } \\
\text { ICS with or without LABA as controller }\end{array}$ & $\begin{array}{l}\text { Reduces: } \\
\text { o The risk of exacerbations defined as a composite } \\
\quad \text { outcome (moderate SOE) } \\
\text { o } \quad \text { Rescue medication use (moderate SOE) } \\
\text { - Improves asthma control scores (moderate SOE) }\end{array}$ \\
\hline
\end{tabular}

Table E. Results for patients 12 years of age and older with uncontrolled, persistent asthma

\begin{tabular}{|c|c|}
\hline Intervention & Effect \\
\hline Adding LAMA to ICS vs. adding placebo & $\begin{array}{l}\text { - } \\
\text { Reduces the risk of exacerbations requiring systemic } \\
\text { - } \\
\text { Improvicosteroids (high SOE) } \\
\text { Does not affect: } \\
\text { o Asthma control scores (moderate SOE) } \\
\text { O QOL (low to high SOE) } \\
\text { o Rescue medication use (moderate SOE) }\end{array}$ \\
\hline Adding LAMA to ICS vs. doubling ICS dose & $\begin{array}{ll}\text { Does not affect: } \\
\text { o } & \text { The risk of exacerbations requiring systemic } \\
& \text { corticosteroids (low SOE) } \\
\text { o } & \text { Asthma control scores (low SOE) } \\
\text { o } & \text { Spirometry (low SOE) } \\
\text { O } & \text { QOL (low SOE) } \\
\end{array}$ \\
\hline Adding LAMA to ICS vs. adding LABA & \begin{tabular}{ll} 
- & \multicolumn{2}{l}{ Does not affect: } \\
o & The risk of exacerbations requiring systemic \\
& corticosteroids (low SOE) \\
o & Death (low SOE) \\
o & Asthma control scores (low to high SOE) \\
o & Spirometry (low to high SOE) \\
o & QOL (low to high SOE) \\
o & Rescue medication use (low SOE)
\end{tabular} \\
\hline $\begin{array}{l}\text { Adding LAMA to ICS and LABA vs. ICS and } \\
\text { LABA }\end{array}$ & $\begin{array}{l}\text { - Does not affect } \\
\text { o The risk of exacerbations requiring systemic } \\
\text { o corticosteroids (moderate SOE) } \\
\text { - Hospitalization (low SOE) } \\
\text { Improves } \\
\text { o Asthma control scores (low to moderate SOE) } \\
0 \quad \text { Spirometry (high SOE) }\end{array}$ \\
\hline
\end{tabular}

ICS = inhaled corticosteroid; LABA = long-acting beta agonist; LAMA = long-acting muscarinic antagonist; QOL = quality of life; $\mathrm{SOE}=$ strength of evidence

\section{Discussion}

This review evaluated different ICS dosing strategies and LAMA therapy in people of various ages with persistent asthma. Comparisons were class-based and thus this review does not inform the impact of specific doses on outcomes; rather, it more globally addresses classes and broad dosing strategies (i.e. intermittent dosing of ICS). Although effectiveness is an important part of decision-making, this report did not include harms associated with drug therapies, which should also be taken into consideration. 
There is a relatively smaller amount of published evidence on intermittent ICS dosing as compared to the amount of evidence on combined ICS and LABA as quick relief and controller therapy or LAMA therapy. This lack of evidence should not be equated to lack of benefit necessarily. Given most outcomes were rated with low strength of evidence, future research could change the direction or magnitude of effect or the strength of evidence as the consistency and precision in effect estimates improve.

\section{Conclusions}

Compared to rescue SABA use, adding intermittent ICS use appears to benefit children less than 5 years old with recurrent wheezing in the setting of an RTI. In patients 12 years and older with persistent asthma, differences in intermittent ICS versus controller use of ICS were not detected, although few studies provided evidence leading to primarily low strength of evidence ratings. Using ICS and LABA combined as both a controller and quick relief therapy showed benefits over use as a controller medication alone (ICS or ICS and LABA controller). In patients 12 years and older with uncontrolled, persistent asthma, adding LAMA to ICS controller or ICS plus LABA controller compared to ICS or ICS plus LABA alone improves some outcomes. However, adding LAMA to ICS controller compared to adding LABA to ICS controller or increasing dosage of ICS controller did not improve outcomes.

\section{References}

1. National Heart, Lung and Blood Advisory Council Asthma Expert Working Group. Needs Assessment Report for Potential Update of the Expert Panel Report-3 (2007): Guidelines for the Diagnosis and Management of Asthma. 2015.

2. Expert Panel Report 3: guidelines for the diagnosis and management of asthma. National Asthma Education and Prevention Program, Third Expert Panel on the Diagnosis and Management of Asthma. Bethesda (MD). Report No: 07-4051. Washington, DC: National Heart, Lung, and Blood Institute; 2007.
3. Peters M. Single-inhaler combination therapy for maintenance and relief of asthma. Drugs 2009;69:137-150. PMID: 19228072.

4. Spiriva Respimat [package insert]. Boehringer Ingelheim Pharmaceuticals, Inc. Ridgefield, CT. 2016. 


\section{Introduction}

\section{Background}

Asthma is a chronic inflammatory disorder of the airways, characterized by varying degrees of airflow obstruction. Bronchoconstriction, inflammatory cell infiltration, and airway edema reduce airflow intermittently, often in response to specific exposures, resulting in respiratory symptoms. ${ }^{1}$ In the United States, the prevalence of asthma has increased over the past decade, from an estimated 22.2 million Americans in 2005 to 24.6 million Americans in 2015. ${ }^{2}$ Asthma can significantly impact patients' and families' quality of life and ability to pursue activities such as school, work, and exercise. Globally, asthma ranks 14th based on the burden of disease, as measured by disability adjusted life years. ${ }^{3}$ In the US, asthma contributes significantly to health care resource utilization and associated costs. For example, in 2012, asthma was one of the top twenty leading diagnosis groups for primary care visits and was the main reason for 1.8 million emergency department visits and 439,000 hospitalizations. While the severity of disease varies between patients and over time in the same patient, asthma can be fatal, accounting for approximately 1 death per 100,000 Americans. ${ }^{4}$ In 2015, 3,651 Americans died from asthma. $^{4}$

\section{Rationale}

In 1989, the National Heart, Lung and Blood Institute (NHLBI) initiated the National Asthma Education and Prevention Program (NAEPP) to address growing concern about asthma in the US. One of the first accomplishments of the NAEPP was to convene a panel of experts who summarized their recommendations in a document, National Asthma Education and Prevention Program Expert Panel Report (EPR): Guidelines for the Diagnosis and Management of Asthma, in 1991. The guidelines address the diagnosis, evaluation, and treatment of asthma. The most recent report, EPR-3, was published in 2007. ${ }^{1}$ NHLBI assessed the need for an update by requesting information from the public, NAEPP Coordinating Committee Members and its affiliates, and members of the 2007 Expert Panel. Collected information was provided to the NHLBI Advisory Council Asthma Expert Working Group, which produced a report to summarize the process and recommendations from their needs assessment. ${ }^{5}$ The Working Group identified six high priority topics that should be updated. For each topic, Key Questions meriting a systematic literature review were formulated. NHLBI engaged the Agency for Healthcare Research and Quality (AHRQ) to perform the systematic reviews through its Evidence-based Practice Centers (EPC). This report summarizes the systematic review of "Intermittent inhaled corticosteroids and of long-acting muscarinic antagonists for asthma” and highlights areas of controversy and identifies needs for future research on these priority areas.

\section{Intermittent Inhaled Corticosteroid (ICS) Dosing}

ICS are highly effective for improving asthma control and reducing exacerbation frequency, yet adherence is often reported to be less than 49 percent to 73 percent in young children and pre-adolescents and less than 50 percent in adolescents and adults. ${ }^{6-10}$ Published data suggest that an increase in ICS adherence to between 60 percent and 80 
percent results in reduced emergency department visits for asthma. ${ }^{6,7,11,12}$ As suggested by the World Health Organization, 'increasing the effectiveness of adherence interventions may have a far greater impact on the health of the population than any improvement in specific medical treatments'. ${ }^{13}$ Despite known barriers to the clinical management of asthma, like nonadherence, continued investigation to alternate dosing strategies for ICS or in the development of novel adjunctive therapies as discussed below continues.

Scheduled, daily dosing of ICS is the preferred pharmacologic controller therapy for persistent asthma in patients of all ages. " "Controller therapy" will be used in this document to describe medications to be taken daily on a long-term basis to achieve and maintain control of persistent asthma. "Intermittent" ICS dosing will be used in this document to describe the prescribed use of ICS that is not the same on a daily basis. As prescribed, intermittent ICS dosing may specify variations in the dose, frequency, or duration of administration of ICS. The determinant of ICS use with intermittent ICS dosing may be a patient decision (based on need), an index of worsening asthma or some other predefined criteria. Some examples of intermittent ICS dosing include initiating a temporary course of ICS in a patient not regularly taking ICS controller therapy or temporarily increasing the dose of ICS that is otherwise taken as controller therapy, either strategy in response to a measure of worsening asthma. ${ }^{1,14,15}$ An extension of the use of intermittent ICS therapy is the combined use of ICS plus long-acting $\beta_{2}$-agonist (LABA) as both a controller and quick relief therapy, particularly when the LABA is considered fast-acting. ${ }^{16}$ "Quick relief” therapy will be used in this document to describe inhaled medication to be used as-needed for acute symptom relief.

EPR-3 suggests that intermittent ICS dosing schedules may be useful in some settings though the evidence at that time was insufficient to support the recommendation beyond experts' consensus. ${ }^{1}$ Since the EPR-3, it was determined by the NHLBI Needs Assessment Workgroup that a sufficient number of studies have been published on intermittent ICS dosing to warrant a systematic literature review.

\section{Long-Acting Muscarinic Antagonist (LAMA) Added to ICS or to ICS Plus LABA}

LAMAs were not included in the EPR-3 although since then, they have been studied as controller therapy for asthma and at least one LAMA has gained Food and Drug Administration (FDA) approval for the long-term maintenance treatment of asthma in patients 6 years of age and older. ${ }^{17}$ This represents a new pharmacologic class of longacting bronchodilators for consideration in the stepwise approach to asthma management and the NHLBI Needs Assessment Workgroup determined this topic to be of importance for a potential EPR-3 update.

\section{Key Questions (KQs)}

KQ1a: What is the comparative effectiveness of intermittent ICS compared to no treatment, pharmacologic, or nonpharmacologic therapy in children 0 to 4 years old with recurrent wheezing? 
KQ1b: What is the comparative effectiveness of intermittent ICS compared to ICS controller therapy in patients 5 years of age and older with persistent asthma?

KQ1c: What is the comparative effectiveness of ICS with LABA used as both controller and quick relief therapy compared to ICS with or without LABA used as controller therapy in patients 5 years of age and older with persistent asthma?

KQ2a: What is the comparative effectiveness of LAMA as add-on to ICS controller therapy compared to placebo or increased ICS dose in patients 12 years of age and older with uncontrolled, persistent asthma?

KQ2b: What is the comparative effectiveness of LAMA compared to other controller therapy as add-on to ICS in patients 12 years of age and older with uncontrolled, persistent asthma?

KQ2c: What is the comparative effectiveness of LAMA as add-on to ICS plus LABA compared to ICS plus LABA as controller therapy in patients 12 years of age and older with uncontrolled, persistent asthma?

\section{Population, Intervention, Comparator, Outcomes}

Populations: We included all patients that meet the KQ specific criteria regardless of gender, race and ethnicity. Age thresholds per KQ were selected to be consistent with the EPR-3 guidelines.

- KQ1a: Patients 0 to 4 years old with recurrent wheezing

- KQ1b-c: Patients 5 years old and older with persistent asthma

- KQ2a-c: Patients 12 years old and older with uncontrolled, persistent asthma

Interventions: This review focuses on pharmacologic interventions at the class level and includes ICS and inhaled LABA and LAMA, regardless of FDA approval (Table 1).

Table 1. Drugs included in this review

\begin{tabular}{|c|c|}
\hline Class & Drugs \\
\hline ICS & $\begin{array}{l}\text { Beclomethasone, }{ }^{a} \text { budesonide },{ }^{a} \text { ciclesonide, }{ }^{a} \text { flunisolide, }{ }^{a} \text { fluticasone },{ }^{a} \text { mometasone, }{ }^{a} \\
\text { triamcinolone }{ }^{b}\end{array}$ \\
\hline LABA & Arformoterol, formoterol, ${ }^{\mathrm{a}}$ olodaterol, salmeterol, ${ }^{\mathrm{a}}$ vilanterol $^{\mathrm{a}, \mathrm{c}}$ \\
\hline LAMA & Aclidinium, glycopyrrolate, tiotropium ${ }^{\mathrm{a}}{ }^{\mathrm{u}}$ umeclidinium \\
\hline $\begin{array}{l}\text { ICS }=\text { in } \\
\text { a Curren } \\
\text { product. } \\
\text { b Previol }\end{array}$ & $\begin{array}{l}\text { corticosteroid; LABA = long-acting } \beta_{2} \text {-agonist; LAMA = long-acting muscarinic antagonist } \\
\text { h FDA approval for asthma, either as a single ingredient product or as a component of a multi-ingredient } \\
\text { DA approved although discontinued in } 2010\end{array}$ \\
\hline
\end{tabular}

The interventions for each of the KQs is as follows (Table 2):

- KQ1a-b: Intermittent ICS dosing

- KQ1c: ICS and LABA used as controller and quick relief therapy

- KQ2a-b: ICS and LAMA as controller therapy

- KQ2c: ICS and LABA and LAMA as controller therapy 
Table 2. Intervention and comparator per Key Question

\begin{tabular}{|c|c|c|c|c|}
\hline & $\begin{array}{c}\text { Comparator: No } \\
\text { treatment, } \\
\text { pharmacologic or } \\
\text { nonpharmacologic } \\
\text { therapy }\end{array}$ & $\begin{array}{l}\text { Comparator: ICS } \\
\text { controller } \\
\text { therapy }\end{array}$ & $\begin{array}{l}\text { Comparator: ICS } \\
\text { and LABA } \\
\text { controller } \\
\text { therapy }\end{array}$ & $\begin{array}{l}\text { Comparator: } \\
\text { ICS and other } \\
\text { controller } \\
\text { therapy }\end{array}$ \\
\hline $\begin{array}{l}\text { Intervention: } \\
\text { Intermittent ICS }\end{array}$ & KQ 1a & KQ 1a, 1b & --- & --- \\
\hline $\begin{array}{l}\text { Intervention: ICS } \\
\text { and LABA used as } \\
\text { controller and quick } \\
\text { relief therapy }\end{array}$ & --- & KQ 1c & KQ 1c & --- \\
\hline $\begin{array}{l}\text { Intervention: ICS } \\
\text { and LAMA controller } \\
\text { therapy }\end{array}$ & --- & $\mathrm{KQ} 2 \mathrm{a}^{\mathrm{c}}$ & KQ 2b & KQ 2b \\
\hline $\begin{array}{l}\text { Intervention: ICS } \\
\text { and LAMA and LABA } \\
\text { controller therapy }\end{array}$ & --- & -- & KQ 2c & --- \\
\hline
\end{tabular}

Note: The first column represents interventions and the first row represents comparators of interest in this review. The key questions for each intervention are listed below the relevant comparator(s).

ICS = inhaled corticosteroid; KQ = Key Question; LAMA = long-acting muscarinic antagonist; --- = not applicable

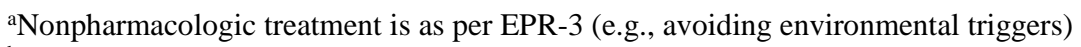

bother controllers include cromolyn, leukotriene modifiers, immunomodulators, methylxanthines, and systemic corticosteroids

'Same or increased ICS dose in the comparator arm relative to intervention dose

Comparators: We are interested in direct comparisons of therapies as described per KQ. Table 2 demonstrates the intervention and comparator for each KQ in a tabular format. The definition of "controller therapy" is provided in the Glossary.

- KQ1a: No treatment (placebo or control) OR pharmacologic therapy which includes controller therapy or as-needed short-acting $\beta_{2}$-agonist (SABA) OR nonpharmacologic therapy. Controller therapies include ICS, inhaled LABA, leukotriene modifiers, cromolyn, methylxanthines, immunomodulators, and systemic corticosteroids. Nonpharmacologic treatment is as per EPR-3 (e.g., avoiding environmental triggers).

- KQ1b: ICS controller therapy

- KQ1c: ICS controller therapy OR ICS and LABA controller therapy

- KQ2a: ICS controller therapy, with or without placebo, where the ICS dose is the same or increased relative to the intervention arm dose

- KQ2b: ICS and another controller therapy, including LABA, leukotriene modifiers, cromolyn, methylxanthines, immunomodulators and systemic corticosteroids

- KQ2c: ICS and LABA controller therapy

Outcomes: We included outcomes that fell into the categories below, using definitions provided by the study.

- Asthma exacerbations

o Requiring systemic (oral and/or parenteral) corticosteroids, requiring hospitalization, requiring emergency room (ER) visit, requiring intensive care unit or intubation, or as defined by the study 
o Asthma-related hospitalizations, ER visits, urgent care and outpatient visits

- Death

o All-cause, asthma-specific

- Asthma control

o Composite Measures: Asthma Control Test (ACT), Asthma Control Questionnaire (ACQ), various versions

o Spirometry: forced expiratory volume in 1 second (FEV1) forced vital capacity (FVC), FEV1/FVC

- Asthma-specific quality of life:

o Asthma Quality of Life Questionnaire (AQLQ), Pediatric Asthma Quality of Life Questionnaire (PAQLQ), Pediatric Asthma Caregiver’s Asthma Quality of Life Questionnaire (PACQLQ)

- Health care utilization:

o Additional asthma-medication use/need

o Additional resource use related to intervention (e.g. personnel time, equipment)

Timing/Setting: There were no requirements based on time or setting. 


\section{Methods}

The protocol for this review is registered as PROSPERO 2016:CRD42016047985. We developed an analytic framework a priori to guide the systematic review process (Figure 1). We searched Ovid MEDLINE, Ovid MEDLINE In-Process \& Other Nonindexed Citations, EMBASE via www.embase.com, Cochrane Central Register of Controlled Trials and Cochrane Database of Systematic Reviews via OVID using subject headings and natural language terms reflecting asthma and the drugs of interest (Appendix A). We supplemented the bibliographic database searches with backwards citation tracking of relevant publications. We searched cliniclatrials.gov and the World Health Organization International Controlled Trials Registry Platform (ICTRP) for ongoing studies and those completed with reported results. We reviewed scientific information packets. Searches were updated March 23, 2017 while the draft report was under public/peer review.

We screened titles and abstracts using two independent investigators to determine if the citation met inclusion/exclusion criteria (Table 3). Citations that both reviewers agreed met inclusion criteria were reviewed at the full text level for inclusion into the review. Disagreements were resolved through consensus in consultation with a third reviewer. Corresponding authors were contacted for clarification when needed to assess the inclusion criteria. All authors were given a minimum of 2 weeks to acknowledge queries. Abstracts and meeting presentations were matched to their corresponding full text publication and reviewed for supplemental data.

Data were extracted into standardized collection forms, evidence and outcomes tables by one investigator and verified by a second investigator. Data for crossover trials were extracted from treatment period 1 when available, otherwise authors were contacted for period 1 outcomes. Risk of bias was assessed by two independent reviewers using the Cochrane Collaboration's Risk of Bias Tool ${ }^{18}$ for randomized controlled trials (RCTs) and Newcastle Ottawa Scale ${ }^{19}$ for observational studies. Overall risk of bias for each study was classified as low, moderate or high, according to the collective risk of bias per evaluated domain and the investigator's confidence in the study results given the identified limitations. ${ }^{20}$ Risk of bias was considered unclear if the majority of domains evaluated were unclear.

We assessed clinical and methodologic heterogeneity to determine appropriateness of metaanalysis. We based data synthesis on pharmacologic class (e.g., long-acting muscarinic antagonists [LAMA], long-acting $\beta_{2}$-agonists [LABA], inhaled corticosteroids [ICS]). When a trial included more than one intervention arm for the same drug but with different doses (e.g., tiotropium $2.5 \mu \mathrm{g}$ and $5 \mu \mathrm{g}$ ) we combined the arms into a single intervention group using recommended formulae. ${ }^{21}$ Synthesis was also based on age categories consistent with the Expert Panel Report-3 of 0 to $4 \mathrm{y}$ old, 5 to $11 \mathrm{y}$ old and $12 \mathrm{y}$ of age and older. When there were 3 or more trials of similar pharmacologic comparisons and outcomes, we pooled data using a HartungKnapp $^{22,23}$ method random effects model using the 'meta' package in $\mathrm{R}$ version 3.1.3 (The $\mathrm{R}$ Project for Statistical Computing). Relative risks (RR) with corresponding 95 percent confidence intervals (CI) were estimated for binary outcomes and mean differences (MD) with corresponding 95 percent CI were estimated for continuous outcomes. Peto’s odds ratio (OR) and 95 percent confidence intervals were estimated for binary outcomes with rare events $(<5 \%)$ in place of a RR. ${ }^{24}$ We pooled hazard ratios and corresponding 95 percent CI reported by studies for time to first exacerbation and rate ratios for studies reporting number of exacerbations over follow-up. We assessed presence of statistical heterogeneity using the Cochrane $\mathrm{p}$-value $(\mathrm{p}<0.10$ significant) and the degree of heterogeneity using the $\mathrm{I}^{2}$ statistic with a value $>50$ percent considered substantial. ${ }^{25}$ Publication bias was assessed using funnel plot inspection and Egger's 
weighted regression test when 10 or more trials were pooled. ${ }^{21,26}$ A priori determined subgroups of interest included asthma severity, asthma control, age, ICS dose, onset of asthma, obesity, atopy, smoking history, race, pulmonary function, LAMA dose/delivery device, the determinant of ICS use with intermittent ICS dosing and concomitant asthma medications. Subgroup analysis was performed when 3 or more trials per subgroup were available for a given outcome. Studies that fit into more than one predefined age category were not included in the main analysis, unless they were the only source of data, but were added to the age category consistent with the reported mean or median age of the study as a sensitivity analysis. If a study fit into more than one age category but reported results separately for the different age subgroups, those subgroups were considered for the main analyses. Included studies that were not amenable to pooling were qualitatively summarized. Interpretation of results was made in the context of established thresholds that indicate clinical significance where available (Table 4). Data from the crossover trial by Peters et al., ${ }^{27}$ were provided by the National Heart, Lung and Blood Institute (NHLBI) Biologic Specimen and Data Repository Information Coordinating Center and independently analyzed by the Evidence-based Practice Center to generate outcomes for period 1 since this data was not reported in the primary manuscript. These results do not necessarily reflect the opinions or views of the BASALT-TALC investigators or the NHLBI.

Strength of evidence (SOE) for each outcome within each comparison was evaluated independently by two senior investigators and then discussed to arrive at the final grading using established guidance. ${ }^{28}$ We graded the SOE for asthma exacerbations, mortality, asthma control composite scores, spirometry, asthma-specific quality of life and health care utilization. Five required domains included study risk of bias, consistency, directness, precision and publication bias. Based on these elements we assessed the SOE for each comparison and outcome as:

- High: We are very confident that the estimate of effect lies close to the true effect for this outcome. The body of evidence has few or no deficiencies. We believe that the findings are stable, i.e., another study would not change the conclusions.

- Moderate: We are moderately confident that the estimate of effect lies close to the true effect for this outcome. The body of evidence has some deficiencies. We believe the findings are likely to be stable, but some doubt remains.

- Low: We have limited confidence that the estimate of effect lies close to the true effect for this outcome. The body of evidence has major or numerous deficiencies (or both). We believe that additional evidence is needed before concluding either that the findings are stable or that the estimate of effect is close to the true effect.

- Insufficient: We have no evidence, we are unable to estimate an effect, or we have no confidence in the estimate of the effect for this outcome. No evidence is available or the body of evidence has unacceptable deficiencies, precluding reaching a conclusion.

We assessed applicability of studies using the population, intervention, comparator, outcomes, timing, setting (PICOTS) framework. ${ }^{29}$ Characteristics that may influence applicability include but are not limited to age, gender, race, ethnicity, severity and control of asthma and co-interventions. 
Table 3. Inclusion and exclusion criteria

\begin{tabular}{|c|c|c|}
\hline Category & Inclusion criteria & Exclusion criteria \\
\hline Population & $\begin{array}{l}\text { KQ1a: Patients } 0 \text { to } 4 y \text { old }^{\mathrm{a}} \text { with recurrent } \\
\text { wheezing } \\
\text { KQ1b-c: Patients } \geq 5 y \text { old }{ }^{\mathrm{a}} \text { with persistent asthma } \\
\text { KQ2a-c: Patients } \geq 12 \mathrm{y} \text { old }{ }^{\mathrm{a}} \text { with uncontrolled, } \\
\text { persistent asthma }\end{array}$ & $\begin{array}{l}\text { KQ1a: Patients } \geq 5 y \text { old } \\
\text { KQ1b-c: Patients } \leq 4 y \text { old; Patients with } \\
\text { intermittent asthma } \\
\text { KQ2a-c: Patients } \leq 11 \text { y old; Patients with } \\
\text { controlled, persistent asthma or with } \\
\text { intermittent asthma }\end{array}$ \\
\hline Intervention & $\begin{array}{l}\text { KQ1a-b: Intermittent dosing of an ICS } \\
\text { KQ1c: ICS and LABA used as both controller and } \\
\text { quick relief therapy } \\
\text { KQ2a-b: ICS and LAMA controller therapy } \\
\text { KQ2c: ICS and LABA and LAMA controller } \\
\text { therapy }\end{array}$ & $\begin{array}{l}\text { KQ1C: ICS and LABA used as controller } \\
\text { therapy but not quick relief therapy } \\
\text { All KQs: All other interventions outside of } \\
\text { pharmacologic therapies listed in PICOTS; } \\
\text { Combinations of interventions other than those } \\
\text { listed in the PICOTS }\end{array}$ \\
\hline Comparator & $\begin{array}{l}\text { KQ1a: No treatment OR pharmacologic therapy } \\
\text { OR nonpharmacologic therapy (see PICOTS) } \\
\text { KQ1b: ICS controller therapy } \\
\text { KQ1c: ICS and LABA controller therapy } \\
\text { KQ2a: ICS controller therapy, with or without } \\
\text { placebo, where the ICS dose is the same or } \\
\text { higher than in the intervention arm } \\
\text { KQ2b: ICS and another controller therapy as } \\
\text { defined in PICOTS } \\
\text { KQ2c: ICS and LABA controller therapy }\end{array}$ & $\begin{array}{l}\text { KQ1c: ICS and LABA used as both controller } \\
\text { and quick relief therapy } \\
\text { All KQs: All other comparators outside of those } \\
\text { specified in PICOTS; Combinations of } \\
\text { comparators other than those listed in the } \\
\text { PICOTS }\end{array}$ \\
\hline Outcomes & $\begin{array}{l}\text { All KQ: Asthma exacerbations (systemic } \\
\text { corticosteroid, hospitalization, ER visit, ICS or } \\
\text { intubation or as defined by the study) or asthma- } \\
\text { related hospitalizations, ER visits, urgent care and } \\
\text { outpatient visits; death (all-cause and asthma- } \\
\text { specific); spirometry (FEV1, FVC and FEV1/FVC); } \\
\text { asthma symptom control composite measures } \\
\text { (ACT, ACQ); asthma-specific quality of life } \\
\text { (AQLQ, PAQLQ, PACQLQ); health care utilization } \\
\text { (additional asthma medication use, resource use) }\end{array}$ & $\begin{array}{l}\text { Studies that do not include at least one of the } \\
\text { outcomes listed in the PICOTS }\end{array}$ \\
\hline $\begin{array}{l}\text { Timing, } \\
\text { Setting }\end{array}$ & $\begin{array}{l}\text { All settings, study durations and follow-up lengths } \\
\text { will be included }\end{array}$ & None \\
\hline Study design & $\begin{array}{l}\text { Randomized-controlled trials, cross-over trials, }{ }^{\text {b }} \\
\text { prospective or retrospective observational cohort } \\
\text { studies, case-controlled studies }\end{array}$ & $\begin{array}{l}\text { Case series, case reports, nonsystematic } \\
\text { reviews, systematic reviews with or without } \\
\text { meta-analysis }^{c}\end{array}$ \\
\hline $\begin{array}{l}\text { Publication } \\
\text { language and } \\
\text { dates }\end{array}$ & $\begin{array}{l}\text { No restriction in publication language or date of } \\
\text { publication }\end{array}$ & $\begin{array}{l}\text { Publications in a non-English language } \\
\text { without an English language abstract }{ }^{d}\end{array}$ \\
\hline
\end{tabular}

ACT = asthma control test; ACQ = Asthma Control Questionnaire; AQLQ = Asthma Quality of Life Questionnaire; ER = emergency room; FDA = Food and Drug Administration; FEV1 = forced expiratory volume over 1 second; FVC = forced vital capacity; ICS = inhaled corticosteroids; KQ = Key Question; LABA = long-acting $\beta_{2}$-agonist; LAMA = long-acting muscarinic antagonist; PACQLQ = Pediatric Asthma Caregiver’s Quality of Life Questionnaire; PAQLQ = Pediatric Asthma Quality of Life Questionnaire; PICOTS = population, intervention, comparator, outcomes

aStudies with age inclusion criteria close to the a prior defined age cut-offs for the given KQ were included in the review if the mean age of the population was within the a priori defined age cut-offs.

${ }^{b}$ Crossover trials were included if the outcomes data can be abstracted after the first period. If data cannot be abstracted after the first period, the trial will be included based on the following criteria, to minimize carry-over effects: for ICS-if the washout period is at least 6 weeks, ${ }^{30}$ for LABA or LAMA- if the washout period is at least 4 weeks ${ }^{31}$

'Systematic reviews w/meta-analysis were flagged for backwards citation tracking but will not be included in this review. ${ }^{\mathrm{d}}$ English language abstracts of non-English language articles were reviewed at the abstract stage and translated when needed to determine eligibility of the full text ${ }^{32}$ 
Table 4. Thresholds for clinical significance

\begin{tabular}{|c|c|c|c|}
\hline Instrument/outcome & Range (points) & Final score & Threshold \\
\hline ACT & 5 to 25 & $\begin{array}{l}\text { Well controlled: } \geq 20 \\
\text { Not well controlled: } \leq 19\end{array}$ & $\geq 12 \mathrm{y}: \Delta 3$ points $^{\mathrm{a}, 33}$ \\
\hline ACQ5, ACQ6 & 0 to 6 & $\begin{array}{l}\text { Uncontrolled: } \geq 1.5 \\
\text { Well-controlled: }<0.75\end{array}$ & $\geq 18 \mathrm{y}: \Delta 0.5$ points $^{\mathrm{a}, 34}$ \\
\hline ACQ7 & 0 to 6 & $\begin{array}{l}\text { Uncontrolled: } \geq 1.5 \\
\text { Well-controlled: }<0.75\end{array}$ & $\geq 6 y: \Delta 0.5$ points $^{a, 34,35}$ \\
\hline AQLQ, AQLQ(S), AQLQ-mini & 1 to 7 & $\begin{array}{l}\text { Severe impairment }=1 \\
\text { No impairment }=7\end{array}$ & $\geq 18 \mathrm{y}: \Delta 0.5$ points $^{\mathrm{a}, 36-38}$ \\
\hline AQLQ12+ & 1 to 7 & $\begin{array}{l}\text { Severe impairment }=1 \\
\text { No impairment }=7\end{array}$ & $\geq 12 \mathrm{y}: \Delta 0.5$ points $^{\mathrm{a}, 39,40}$ \\
\hline PAQLQ, PACQLQ & 1 to 7 & $\begin{array}{l}\text { Severe impairment }=1 \\
\text { No impairment }=7\end{array}$ & 7-17y: $\Delta 0.5$ points $^{a, 41,42}$ \\
\hline FEV1 & Continuous measure, $\mathrm{L}$ & NA & $\geq 18 y:-0.2 L^{b, 43}$ \\
\hline Rescue medication use & $\begin{array}{l}\text { Continuous measure, } \\
\text { puffs per unit of time }\end{array}$ & NA & $\geq 18 y:-0.81$ puffs/day ${ }^{b, 43}$ \\
\hline
\end{tabular}

ACT = asthma control test; ACQ = Asthma Control Questionnaire; AQLQ: Asthma Quality of Life Questionnaire; FEV1 = forced expiratory volume in 1 second; L = liter; PACQLQ = Pediatric Asthma Caregiver's Quality of Life Questionnaire;

PAQLQ = Pediatric Asthma Quality of Life Questionnaire; $y=$ year

${ }^{a}$ Minimal important difference.

${ }^{\mathrm{b}}$ Average minimal patient perceived improvement 
Figure 1. Analytic framework

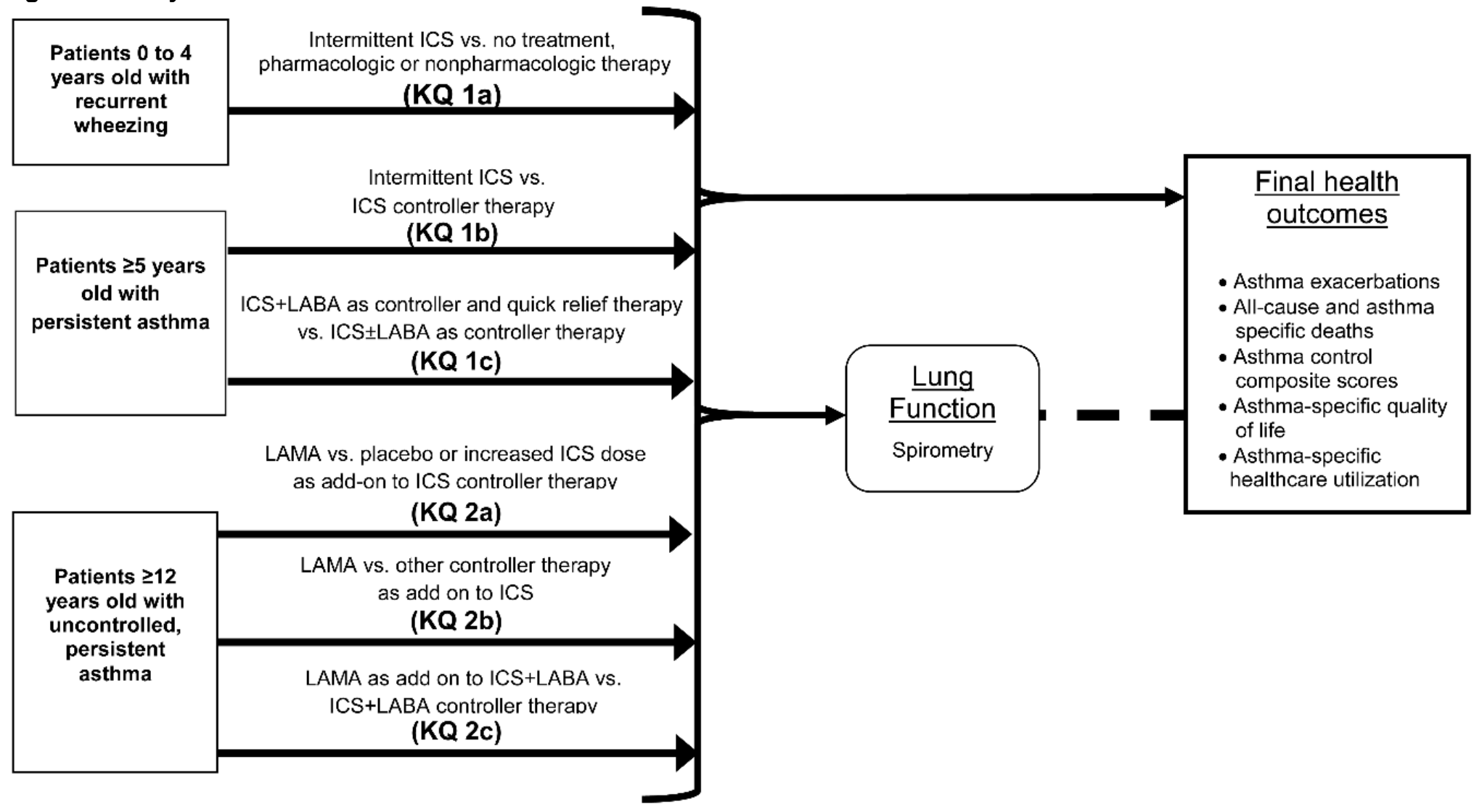

ICS = inhaled corticosteroid; KQ = Key Question; LABA = long-acting $\beta_{2}$-agonist; LAMA = long-acting muscarinic antagonist; vs = versus 


\section{Results}

\section{Search Results}

Our search for Key Question (KQ) 1a-c identified 10,763 nonduplicate records, of which 913 required full text review after title and abstract screening, and 74 met eligibility criteria for inclusion in this review (Figure 2). These 74 citations reported results from 41 unique studies, 39 randomized controlled trials (RCTs) and 2 observational studies. Of these 41 studies, 6 met criteria for KQ1a (reported in 7 citations), ${ }^{44-50} 11$ met criteria for KQ1b (reported in 18 citations), ${ }^{51-68}$ and 24 met criteria for KQ1c (reported in 49 citations). ${ }^{69-117}$ Citations excluded at the full-text review stage are presented in Appendix B.

Figure 2. Literature flow diagram for Key Questions 1a, 1b, and 1c

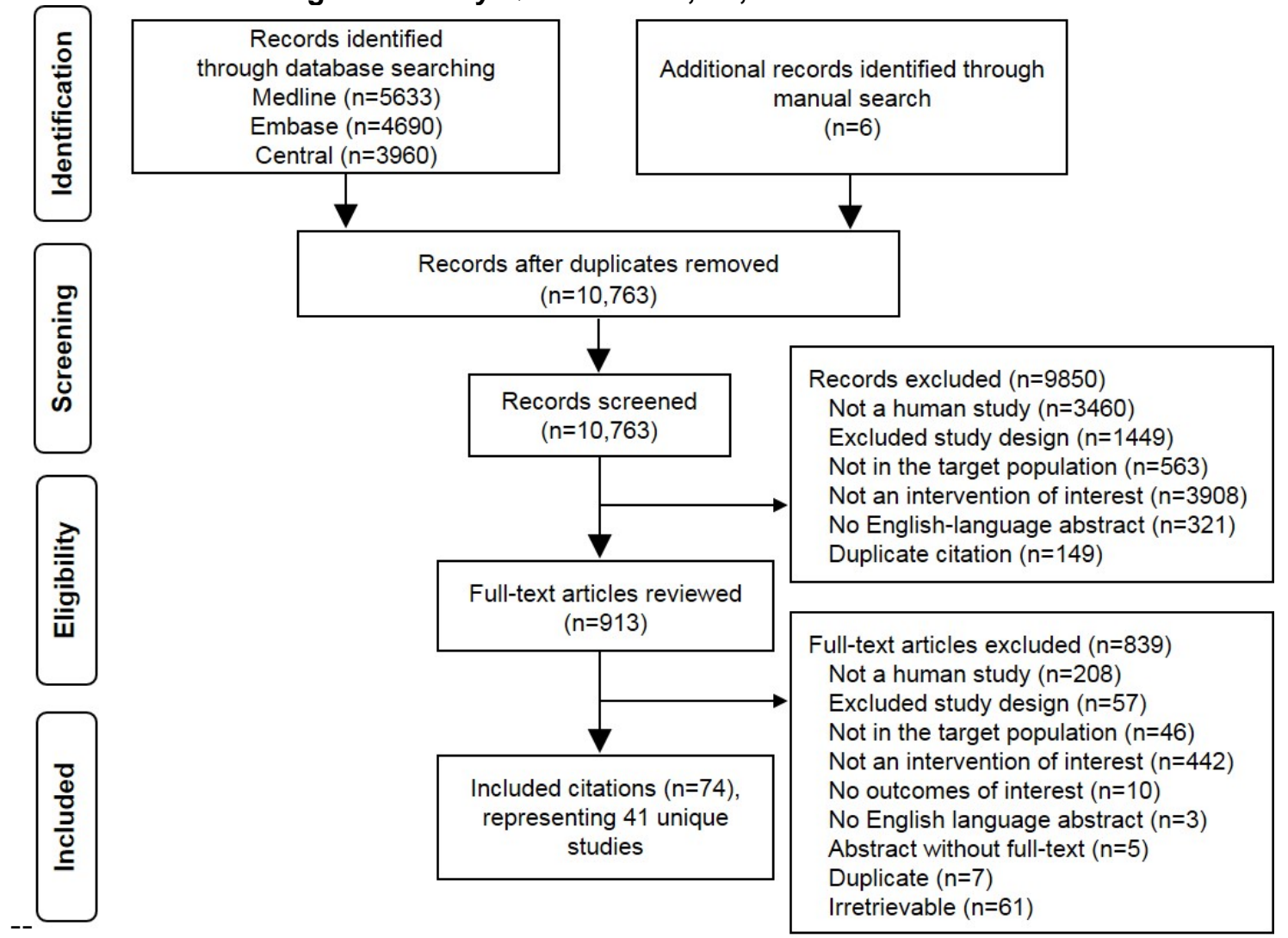

Our search for KQ2a-c identified 854 nonduplicate records, of which 146 required full text review after title and abstract screening, and 58 met eligibility criteria for inclusion in this review (Figure 3). These 58 citations reported results from 15 unique studies, all of which were RCTs. Of these 15 RCTs, 8 met criteria for KQ2a (reported in 29 citations), ${ }^{27,118-145} 8$ met criteria for KQ2b (reported in 21 citations), ${ }^{27,118-120,124-126,130-137,144-149 ~ a n d ~} 4$ met criteria for KQ2c (reported in 26 citations). ${ }^{145,150-174}$ Citations excluded at the full-text review stage are presented in Appendix B. 
Figure 3. Literature flow diagram for Key Questions 2a, 2b, and 2c

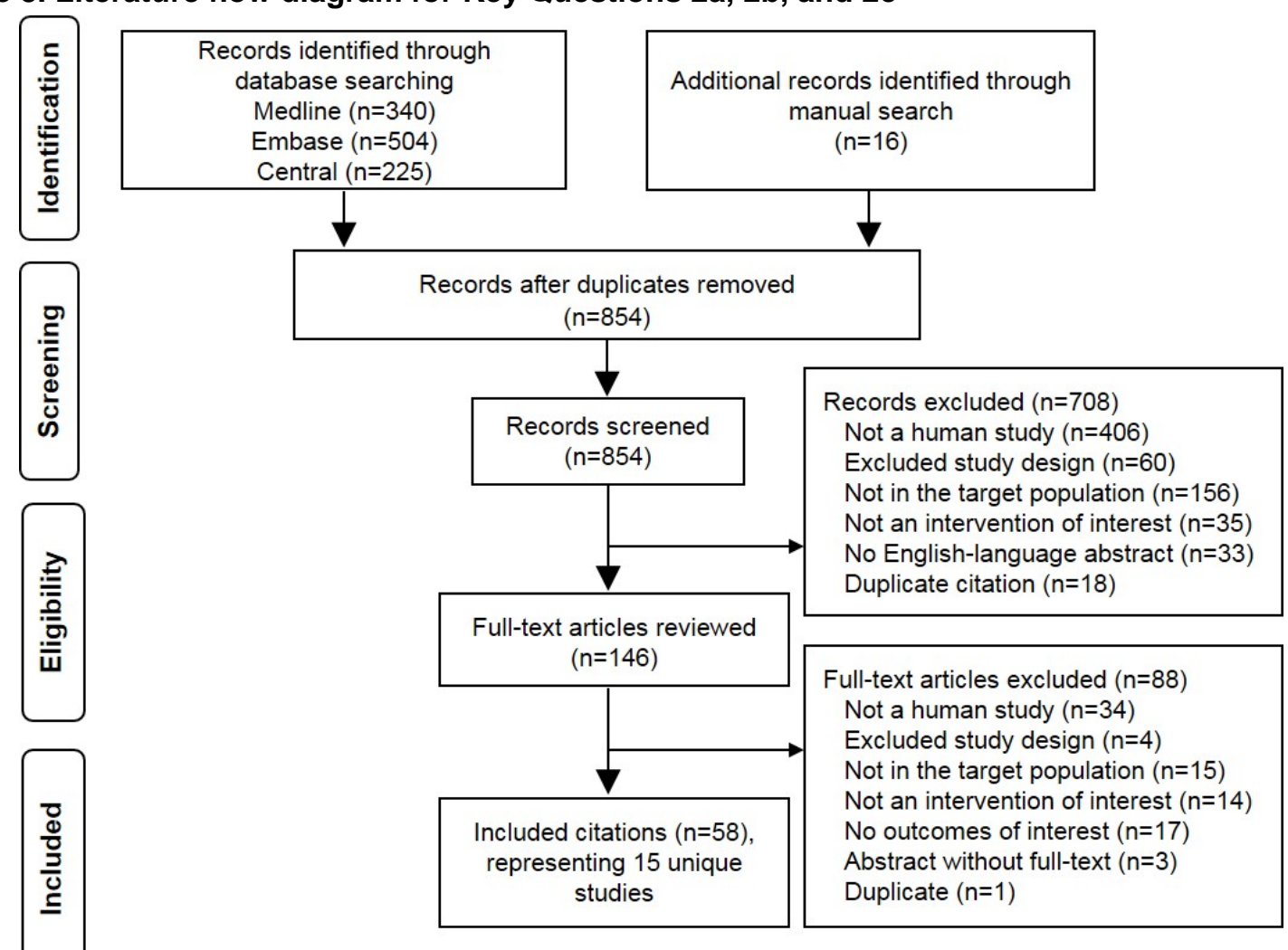

In total, 56 unique studies were included, 54 RCTs and 2 observational studies. The distribution of studies by study design and age category are presented in Table 5.

Table 5. Number of studies included per KQ, study design, and age group

\begin{tabular}{|c|c|c|c|c|c|c|c|}
\hline & Characteristic & KQ1a & KQ1b & $\begin{array}{c}\text { KQ1c } \\
\text { (RCT/NonRCT) }\end{array}$ & KQ2a & KQ2b & KQ2C \\
\hline \multirow{2}{*}{$\begin{array}{l}\text { Study } \\
\text { Design }\end{array}$} & RCTs & 6 & 11 & 22 & 8 & 8 & 4 \\
\hline & Non RCTs & 0 & 0 & 2 & 0 & 0 & 0 \\
\hline \multirow{4}{*}{$\begin{array}{l}\text { Age } \\
\text { Group }\end{array}$} & $\geq 12 y$ & NA & 9 & $22(20 / 2)$ & 8 & 8 & 4 \\
\hline & $5-11 y$ & NA & 0 & 0 & NA & $\mathrm{NA}$ & NA \\
\hline & $0-4 y$ & 5 & 0 & 0 & NA & NA & NA \\
\hline & Mixed & 1 & 2 & $2(2 / 0)$ & 0 & 0 & 0 \\
\hline TOTAL & & 6 & 11 & 24 & 8 & 8 & 4 \\
\hline
\end{tabular}

KQ = Key Question; NA = not applicable; RCT = randomized controlled trial; $y=$ years

\section{Organization of This Report}

The results are presented in order of KQ and furthermore by intervention/comparator combinations. The same outcomes were sought from all studies regardless of the KQ and are reported when data were available. Supporting tables and figures relevant to the results appear in Tables 6 through 27 and in Appendices C-F, including study and population characteristics, study level outcomes data, study risk of bias assessments and details regarding the strength of evidence grading of each outcome. 
KQ1a: What is the comparative effectiveness of intermittent inhaled corticosteroid (ICS) compared to no treatment, pharmacologic, or nonpharmacologic therapy in children 0 to 4 years old with recurrent wheezing?

Results of this KQ are reported separately based on whether the comparator was pharmacologic or nonpharmacologic therapy. There were two distinct pharmacologic comparators: as-needed short-acting $\beta_{2}$-agonist (SABA) and ICS controller, and data were analyzed separately. We found no studies in which the comparator was nonpharmacologic therapy. While this KQ focuses on the age category of 0 to $4 \mathrm{y}$, one included trial ${ }^{45}$ allowed enrollment of patients up to the age of $6 y$ but because the mean age was $2 \mathrm{y}$ we determined the population was considered to represent that of interest.

\section{Key Points}

- Intermittent ICS with as-needed SABA versus as-needed SABA, initiated with onset of a respiratory tract infection (RTI), reduces the risk of exacerbation requiring oral corticosteroids (moderate strength of evidence [SOE]) and improves Pediatric Asthma Caregiver's Quality of Life Questionnaire (PACQLQ) scores (low SOE).

- Intermittent ICS with as-needed SABA versus ICS controller with as-needed SABA did not significantly differ in effect on the risk of exacerbation requiring oral corticosteroid, the risk of exacerbation requiring hospitalization or daytime or nighttime rescue medication use (all low SOE).

- There is insufficient evidence to determine the impact of intermittent ICS versus no therapy on outcomes.

\section{Intermittent ICS With As-Needed SABA Versus As-Needed SABA}

Table 6. Evidence overview for KQ1a, intermittent ICS with as-needed SABA vs. as-needed SABA

\begin{tabular}{|c|c|c|c|c|}
\hline $\begin{array}{l}\text { Outcome } \\
\text { category }\end{array}$ & Outcome & $\begin{array}{c}\text { Quantity and } \\
\text { type of } \\
\text { evidence (n) }\end{array}$ & $\begin{array}{c}\text { Conclusion } \\
\text { Effect estimate }(95 \% \mathrm{Cl})\end{array}$ & $\begin{array}{l}\text { Strength of } \\
\text { evidence } \\
\text { (rationale) }\end{array}$ \\
\hline \multirow[t]{3}{*}{ Exacerbations } & $\begin{array}{l}\text { Requiring oral } \\
\text { corticosteroid therapy }\end{array}$ & $\begin{array}{l}3 \mathrm{RCTs}^{44,45,48} \\
(324)\end{array}$ & $\begin{array}{l}\text { Favors intermittent ICS } \\
\text { RR } 0.67(0.46 \text { to } 0.98)\end{array}$ & $\begin{array}{l}\text { Moderate } \\
\text { (imprecise) }\end{array}$ \\
\hline & $\begin{array}{l}\text { Asthma-related acute } \\
\text { care visits }\end{array}$ & $\begin{array}{l}\text { 3 RCTs }{ }^{44,45,48} \\
(324)\end{array}$ & $\begin{array}{l}\text { No difference } \\
\text { RR } 0.90 \text { (0.77 to } 1.05)\end{array}$ & High \\
\hline & $\begin{array}{l}\text { Asthma-related hospital } \\
\text { admissions }\end{array}$ & $\begin{array}{l}3 \mathrm{RCT}^{44,45,48} \\
(324)\end{array}$ & $\begin{array}{l}\text { No difference } \\
\text { RR } 0.77 \text { (0.06 to 9.68) }\end{array}$ & $\begin{array}{l}\text { Low } \\
\text { (inconsistent, } \\
\text { imprecise) }\end{array}$ \\
\hline Quality of life & PACQLQ score & $\begin{array}{l}2 \mathrm{RCTS}^{44,48} \\
(270)\end{array}$ & $\begin{array}{l}\text { Favors intermittent ICS } \\
\text { Bacharier, } 2008^{44} \\
\text { MD }-0.10(-0.36 \text { to } 0.34) \\
\text { Ducharme, } 2009^{48} \\
\text { MD } 0.49(0.10 \text { to } 0.86)\end{array}$ & $\begin{array}{l}\text { Low } \\
\text { (inconsistent, } \\
\text { imprecise) }\end{array}$ \\
\hline \multirow[t]{2}{*}{$\begin{array}{l}\text { Health care } \\
\text { utilization }\end{array}$} & $\begin{array}{l}\text { Daytime rescue } \\
\text { medication use, number } \\
\text { of inhalations/day }\end{array}$ & $\begin{array}{l}1 \mathrm{RCT}^{47} \\
(166)\end{array}$ & $\begin{array}{l}\text { No difference } \\
\text { Papi, } 2009^{47} \\
\text { MD }-0.08(-0.21 \text { to } 0.05)\end{array}$ & $\begin{array}{l}\text { Low } \\
\text { (unknown } \\
\text { consistency) }\end{array}$ \\
\hline & $\begin{array}{l}\text { Nighttime rescue } \\
\text { medication use, number } \\
\text { of inhalations/night }\end{array}$ & $\begin{array}{l}1 \mathrm{RCT}^{47} \\
(166)\end{array}$ & $\begin{array}{l}\text { No difference } \\
\frac{\text { Papi, } 2009^{47}}{\text { MD }-0.04(-0.11 \text { to } 0.03)}\end{array}$ & $\begin{array}{l}\text { Low } \\
\text { (unknown } \\
\text { consistency) }{ }^{\mathrm{b}}\end{array}$ \\
\hline
\end{tabular}

$\mathrm{CI}=$ confidence interval; $\mathrm{ICS}=$ inhaled corticosteroid; $\mathrm{MD}=$ mean difference; $\mathrm{n}=$ patient sample size; PACQLQ $=$ Pediatric Asthma Caregiver's Quality of Life Questionnaire; PRN = pro re nata (i.e., as-needed); RCT = randomized controlled trial; RR = relative risk; $\mathrm{SABA}=$ short-acting $\beta_{2}$-agonist 


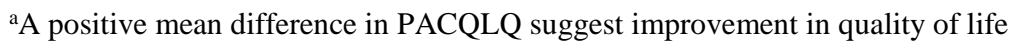

bStrength of evidence was low even with only one domain downgraded due to the small sample size and lack of confidence in the true effect estimate

\section{Overview of Studies}

Four trials ( $n=493$ ) were included in the analysis of intermittent ICS with as-needed SABA versus as-needed SABA. ${ }^{44,45,47,48}$ Three trials ${ }^{44,45,48}$ required a history of recurrent wheezing in the context of RTI and randomized patients to ICS treatment every day for a defined length of time (ranging from 7 to 10d or until symptom free for 48 hours) in addition to SABA as-needed versus placebo with SABA as-needed. Svedmyr et al., ${ }^{48}$ also required patients to be diagnosed with wheezy bronchitis or asthma and allowed continued use of theophylline or cromoglycate during the trial. Bacharier et al., reported that 61 percent of enrolled patients were modified Asthma Prediction Index (mAPI) positive and 64 percent were diagnosed with asthma by a physician. ${ }^{44}$ The fourth trial ${ }^{47}$ did not specify a requirement of RTI co-occurrence although did require that patients were referred to a specialist due to recurrent wheezing. In this trial, patients were randomized to beclomethasone/salbutamol as-needed for symptom relief versus salbutamol as-needed for symptom relief. Race was reported as 78 percent Caucasian in one trial ${ }^{45}$ and as 25 percent minority in a second trial ${ }^{44}$. All trials were multicenter and were conducted in single countries including United States (US), Italy, Sweden and Canada. Two trials ${ }^{45,47}$ were industry sponsored, one ${ }^{44}$ was nonindustry sponsored, and one trial ${ }^{48}$ did not report funding. Studies were $12 \mathrm{~m}$ in duration except one ${ }^{47}$ which was 12 weeks. Risk of bias was low with the exception of Svedmyer et al., ${ }^{48}$ which was determined to be unclear.

\section{Results}

In patients 0 to 4 years old with recurrent wheezing, intermittent ICS with as-needed SABA, initiated with and continued during RTI, reduces the risk of exacerbation requiring oral corticosteroids by 33 percent compared to as-needed SABA (moderate SOE) (Figure 4). The risk of asthma-related acute care visits or asthma-related hospitalizations was no different between groups. Mean difference (MD) in PACQLQ score improved in the group receiving intermittent ICS versus as-needed SABA (MD $=0.49$, low $\mathrm{SOE}$ ) in one trial but was not different in a second trial. Change in either daytime or nighttime rescue medication inhalations was no different between groups (low SOE).

Figure 4. Risk of requiring a course of oral steroids: intermittent ICS with as-needed SABA versus as-needed SABA

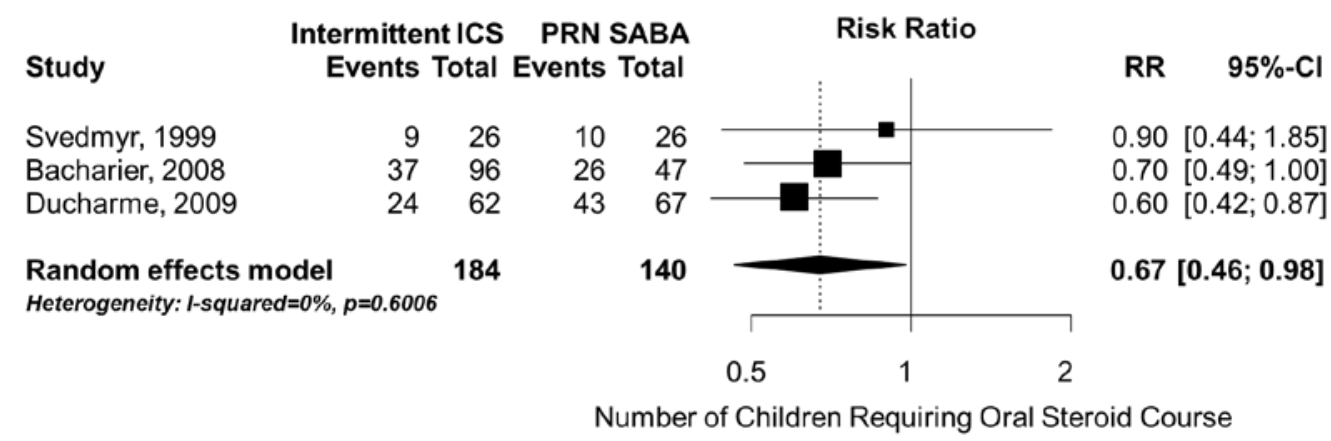

$\mathrm{CI}$ = confidence interval; ICS = inhaled corticosteroids; PRN = as needed; RR = relative risk; SABA = short-acting beta-agonist 


\section{Intermittent ICS With As-Needed SABA Versus ICS Controller With As-Needed SABA}

Table 7. Evidence overview for KQ1a, intermittent ICS with as-needed SABA versus ICS controller with as-needed SABA

\begin{tabular}{|c|c|c|c|c|}
\hline $\begin{array}{l}\text { Outcome } \\
\text { category }\end{array}$ & Outcome & $\begin{array}{c}\text { Quantity and } \\
\text { type of } \\
\text { evidence (n) }\end{array}$ & $\begin{array}{c}\text { Conclusion } \\
\text { Effect estimate (95\% } \\
\mathrm{Cl})\end{array}$ & $\begin{array}{l}\text { Strength of } \\
\text { evidence } \\
\text { (rationale) }\end{array}$ \\
\hline \multirow[t]{2}{*}{ Exacerbations } & $\begin{array}{l}\text { Requiring oral } \\
\text { corticosteroid }\end{array}$ & $\begin{array}{l}1 \mathrm{RCT}^{49} \\
(278)\end{array}$ & $\begin{array}{l}\text { No difference } \\
\text { Zeiger, } 2011^{49} \\
\text { RR } 0.99(0.80 \text { to } 1.22)\end{array}$ & $\begin{array}{l}\text { Low } \\
\text { (unknown }_{\text {consistency) }}{ }^{\mathrm{a}}\end{array}$ \\
\hline & $\begin{array}{l}\text { Requiring } \\
\text { hospitalization }\end{array}$ & $\begin{array}{l}1 \mathrm{RCT}^{49} \\
(278)\end{array}$ & $\begin{array}{l}\text { No difference } \\
\text { Zeiger, } 2011^{49} \\
\text { RR } 1.25(0.34 \text { to } 4.56)\end{array}$ & $\begin{array}{l}\text { Low } \\
\text { (unknown } \\
\text { consistency, } \\
\text { imprecise) }\end{array}$ \\
\hline \multirow[t]{2}{*}{$\begin{array}{l}\text { Health care } \\
\text { utilization }\end{array}$} & $\begin{array}{l}\text { Daytime rescue } \\
\text { medication use, } \\
\text { number of } \\
\text { inhalations/day }\end{array}$ & $\begin{array}{l}1 \mathrm{RCT}^{47} \\
(220)\end{array}$ & $\begin{array}{l}\text { No difference } \\
\text { Papi, } 2009^{47} \\
\text { MD } 0.07(-0.4 \text { to } 1.8)\end{array}$ & $\begin{array}{l}\text { Low } \\
\text { (unknown } \\
\text { consistency, } \\
\text { imprecise) }\end{array}$ \\
\hline & $\begin{array}{l}\text { Nighttime rescue } \\
\text { medication use, } \\
\text { number of } \\
\text { inhalations/night }\end{array}$ & $\begin{array}{l}1 \mathrm{RCT}^{47} \\
(220)\end{array}$ & $\begin{array}{l}\text { No difference } \\
\text { Papi, } 2009^{47} \\
\text { MD -0.02 (-0.7 to } 0.3)\end{array}$ & $\begin{array}{l}\text { Low } \\
\text { (unknown } \\
\text { consistency, } \\
\text { imprecise) }\end{array}$ \\
\hline
\end{tabular}

CI = confidence interval; ICS = inhaled corticosteroid; $\mathrm{MD}$ = mean difference; $\mathrm{n}$ = patient sample size; $\mathrm{RCT}$ = randomized controlled trial; $\mathrm{RR}=$ relative risk

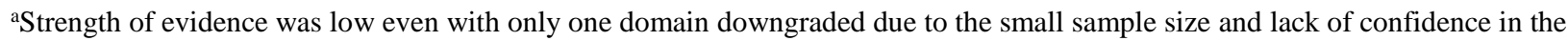
true effect estimate

\section{Overview of Studies}

Two trials ( $n=498)$ were included in the analysis of intermittent ICS with as-needed SABA versus ICS controller with as-needed SABA. ${ }^{47,49}$ Papi et al., ${ }^{47}$ was a multicenter trial in Italy of 12 weeks duration, with industry sponsorship and low risk of bias. Patients were required to be referred to a specialist due to recurrent wheezing. They were randomized to the use of beclomethasone/salbutamol on an as-needed basis for symptom relief versus beclomethasone twice daily plus as-needed salbutamol for symptom relief. Race was not reported. Zeiger et al., ${ }^{49}$ was a multicenter trial conducted in the US with 52 weeks duration, nonindustry sponsorship, and low risk of bias. Patients were required to have a history of frequent wheezing and to be positive on the mAPI. They were randomized to budesonide for $7 \mathrm{~d}$ with onset of RTI versus budesonide controller, both groups received albuterol four times daily for the first 48h of RTI then as-needed. Most patients were Caucasian (62 percent).

\section{Results}

The risk of exacerbation requiring oral corticosteroid and the risk of exacerbation requiring hospitalization was no different between intermittent ICS and ICS controller in a single trial (low SOE). ${ }^{49}$ Daytime and nighttime rescue medication use was no different between intermittent ICS and ICS controller in a single trial (low SOE). ${ }^{49}$ Mean cumulative salbutamol (mg) was similar between intermittent ICS and ICS controller [30.1 (43.0) versus 34.2 (42.3)]. ${ }^{47}$ 


\section{Intermittent ICS Versus No Therapy}

Table 8. Evidence overview for KQ1a, intermittent ICS versus no therapy

\begin{tabular}{|c|c|c|c|c|}
\hline $\begin{array}{l}\text { Outcome } \\
\text { category }\end{array}$ & Outcome & $\begin{array}{c}\text { Quantity and type } \\
\text { of evidence (n) }\end{array}$ & $\begin{array}{c}\text { Conclusion } \\
\text { Effect estimate }(95 \% \mathrm{Cl})\end{array}$ & $\begin{array}{c}\text { Strength of evidence } \\
\text { (rationale) }\end{array}$ \\
\hline \multirow[t]{3}{*}{ Exacerbations } & $\begin{array}{l}\text { Requiring } \\
\text { systemic } \\
\text { corticosteroid }\end{array}$ & $\begin{array}{l}1 \mathrm{RCT}^{46} \\
(26)\end{array}$ & $\begin{array}{l}\text { Inconclusive } \\
\text { Ghirga, } 2002^{46} \\
\text { RR } 0.54(0.12 \text { to } 2.44)\end{array}$ & $\begin{array}{l}\text { Insufficient } \\
\text { (unknown consistency, } \\
\text { imprecise) }\end{array}$ \\
\hline & $\begin{array}{l}\text { Asthma-related } \\
\text { ER visit }\end{array}$ & $\begin{array}{l}1 \mathrm{RCT}^{46} \\
(26)\end{array}$ & $\begin{array}{l}\text { Inconclusive } \\
\text { Ghirga, } 2002^{46} \\
\text { RR } 0.27(0.04 \text { to } 2.10)\end{array}$ & $\begin{array}{l}\text { Insufficient } \\
\text { (unknown consistency, } \\
\text { imprecise) }\end{array}$ \\
\hline & $\begin{array}{l}\text { Asthma-related } \\
\text { hospitalization }\end{array}$ & $\begin{array}{l}1 \mathrm{RCT}^{46} \\
(26)\end{array}$ & $\begin{array}{l}\text { Inconclusive } \\
\text { Ghirga, } 2002^{46} \\
\text { No events occurred }\end{array}$ & $\begin{array}{l}\text { Insufficient } \\
\text { (no events occurred) }\end{array}$ \\
\hline
\end{tabular}

CI = confidence interval; ER = emergency room; ICS = inhaled corticosteroid; $\mathrm{n}$ = patient sample size; RCT = randomized controlled trial; $\mathrm{RR}=$ relative risk

\section{Overview of Studies}

One trial ${ }^{46}(n=26)$ was included in the analysis of intermittent ICS versus no therapy. Patients were 7 to $12 \mathrm{~m}$ in age, presented with a history of recurrent wheezing during RTI and were randomized to beclomethasone $400 \mu \mathrm{g}$ three times daily for $5 \mathrm{~d}$ at the first sign of RTI versus no preventative treatment. Ethnicity and sponsorship were not reported and the risk of bias was medium because it was open-label.

\section{Results}

Although the outcomes of exacerbation requiring oral steroid and the risk of asthma-related emergency room (ER) visits were reported, the evidence is insufficient to draw a conclusion. No asthma-related hospitalizations occurred.

\section{KQ1b: What is the comparative effectiveness of intermittent ICS compared to ICS controller therapy in patients 5 years of age and older with persistent asthma?}

Results of this KQ are reported separately based on the comparators. The first group of studies reported below under the subheading of "Intermittent ICS and ICS controller versus ICS controller” compared the addition of intermittent ICS to ICS controller therapy versus ICS controller therapy. The second group of studies reported below under the subheading "Intermittent ICS versus ICS controller" compared intermittent ICS where the patient was not otherwise on ICS controller versus ICS controller therapy. One study was included in both groups because three arms were reported. ${ }^{60}$ Although this KQ focuses on 2 of the 3 EPR-3 age categories ( 5 to $11 \mathrm{y}, 12 \mathrm{y}$ or older), all but two studies ${ }^{54,60}$ were specific to the age category of $12 \mathrm{y}$ or older. One trial ${ }^{54}$ allowed enrollment of patients as young as $4 \mathrm{y}$ old although this study was included in the analysis for 5 to $11 \mathrm{y}$ because the mean age was $7 \mathrm{y}$ and the populations was determined to represent that of interest. One trial ${ }^{60}$ enrolled 6 to $18 \mathrm{y}$ olds and represents a mixed population based on age and the mean was 10 to $11 \mathrm{y}$, thus this trial was considered under the age category of 5 to 11y. We report results separately per age group when possible. 


\section{Key Points}

- In patients $12 \mathrm{y}$ of age or older, intermittent ICS and ICS controller versus ICS controller does not significantly differ in effect on the risk of exacerbations (low SOE) with exception of asthma-related outpatient visits (low SOE) which favors intermittent ICS with ICS controller versus ICS controller. Evidence is insufficient to draw conclusions in patients 5 to $11 \mathrm{y}$ old.

- In patients $12 \mathrm{y}$ of age or older, intermittent ICS versus ICS controller therapy does not significantly differ in the risk of exacerbations (low SOE), Asthma Control Questionnaire (ACQ)-7 or ACQ-5 score (low SOE), spirometry (low to high SOE), Asthma Quality of Life Questionnaire (AQLQ)-(S) score (moderate SOE), albuterol rescue use (moderate $\mathrm{SOE}$ ). Evidence is insufficient to draw conclusions in patients 5 to $11 \mathrm{y}$ old aside from Pediatric Asthma Quality of Life Questionnaire (PAQLQ) score and rescue inhaler use which was no different between groups (low SOE).

\section{Intermittent ICS and ICS Controller Versus ICS Controller}

Table 9. Evidence overview for KQ1b, intermittent ICS with ICS controller versus ICS controller in patients 12 years of age and older

\begin{tabular}{|c|c|c|c|c|}
\hline $\begin{array}{l}\text { Outcome } \\
\text { category }\end{array}$ & Outcome & $\begin{array}{l}\text { Quantity and } \\
\text { type of } \\
\text { evidence }(n)\end{array}$ & $\begin{array}{c}\text { Conclusion } \\
\text { Effect estimate (95\% } \\
\text { Cl) }\end{array}$ & $\begin{array}{l}\text { Strength of evidence } \\
\text { (rationale) }\end{array}$ \\
\hline \multirow[t]{8}{*}{ Exacerbations } & $\begin{array}{l}\text { Requiring oral } \\
\text { corticosteroid (full } \\
\text { population)a }\end{array}$ & $\begin{array}{l}3 \text { RCTs } \\
\text { (908) }\end{array}$ & $\begin{array}{l}\text { No difference } \\
\text { RR } 0.68 \text { (0.31 to } 1.49)\end{array}$ & $\begin{array}{l}\text { Low } \\
\text { (inconsistent, imprecise) }\end{array}$ \\
\hline & $\begin{array}{l}\text { Requiring oral } \\
\text { corticosteroid (of those } \\
\text { starting study inhaler) }\end{array}$ & $\begin{array}{l}\begin{array}{l}\text { 3 RCTs } \\
\text { (399,59,62 }\end{array} \\
\text { (399) }\end{array}$ & $\begin{array}{l}\text { No difference } \\
\text { RR } 0.64 \text { (0.26 to 1.57) }\end{array}$ & $\begin{array}{l}\text { Low } \\
\text { (inconsistent, imprecise) }\end{array}$ \\
\hline & $\begin{array}{l}\text { Requiring oral } \\
\text { corticosteroid, } \\
\text { unscheduled doctor } \\
\text { visit, ER, or having } \\
\text { unstable asthma }\end{array}$ & $\begin{array}{l}1 R^{1 R T^{55}} \\
\text { (98) }\end{array}$ & $\begin{array}{l}\text { No difference } \\
\text { Fitzgerald, } 2004^{55} \\
\text { RR } 1.03 \text { (0.63 to } 1.65)\end{array}$ & $\begin{array}{l}\text { Low } \\
\text { (unknown consistency, } \\
\text { imprecise) }\end{array}$ \\
\hline & $\begin{array}{l}\text { Asthma-related } \\
\text { hospitalization }\end{array}$ & $\begin{array}{l}1 \mathrm{RCT}^{67} \\
(115)\end{array}$ & $\begin{array}{l}\text { Inconclusive } \\
\text { Lahdensuo, } 1996^{67} \\
\text { RR } 0.70(0.12 \text { to } 4.05)\end{array}$ & $\begin{array}{l}\text { Insufficient } \\
\text { (medium ROB, } \\
\text { unknown consistency, } \\
\text { imprecise) }\end{array}$ \\
\hline & $\begin{array}{l}\text { Asthma-related } \\
\text { outpatient visit }\end{array}$ & $\begin{array}{l}2 \mathrm{RCTs}^{59,67} \\
(505)\end{array}$ & $\begin{array}{l}\text { Favors intermittent ICS } \\
\text { and ICS controller } \\
\text { Lahdensuo, } 1996^{67} \\
\text { RR } 0.53(0.29 \text { to } 0.96) \\
\text { Harrison, } 2004^{59} \\
\text { RR } 1.14 \text { (0.71 to } 1.83)\end{array}$ & (inconsistent, imprecise) \\
\hline & Unstable asthmab & $\begin{array}{l}1 \mathrm{RCT}^{55} \\
(98)\end{array}$ & $\begin{array}{l}\text { No difference } \\
\text { Fitzgerald, } 2004^{55} \\
\text { RR } 0.57 \text { (0.23 to } 1.38)\end{array}$ & $\begin{array}{l}\text { Low } \\
\text { (unknown consistency, } \\
\text { imprecise) }\end{array}$ \\
\hline & $\begin{array}{l}2 \text { or } 3 \text { exacerbations } \\
\text { requiring oral } \\
\text { corticosteroid (full } \\
\text { population) }\end{array}$ & $\begin{array}{l}1 \mathrm{RCT}^{62} \\
(403)\end{array}$ & $\begin{array}{l}\text { No difference } \\
\text { Oborne, } 2009^{62} \\
\text { RR } 0.63 \text { (0.15 to 2.59) }\end{array}$ & $\begin{array}{l}\text { Low } \\
\text { (unknown consistency, } \\
\text { imprecise) }\end{array}$ \\
\hline & $\begin{array}{l}2 \text { or } 3 \text { exacerbations } \\
\text { requiring oral } \\
\text { corticosteroid (of those } \\
\text { starting study inhaler) }^{a}\end{array}$ & $\begin{array}{l}1 \mathrm{RCT}^{62} \\
(403)\end{array}$ & $\begin{array}{l}\text { No difference } \\
\text { Oborne, } 2009^{62} \\
\text { RR } 0.34 \text { (0.07 to 1.76) }\end{array}$ & $\begin{array}{l}\text { Low } \\
\text { (unknown consistency, } \\
\text { imprecise) }\end{array}$ \\
\hline
\end{tabular}




\begin{tabular}{|l|l|l|l|l|}
\hline $\begin{array}{l}\text { Outcome } \\
\text { category }\end{array}$ & \multicolumn{1}{|c|}{ Outcome } & $\begin{array}{l}\text { Quantity and } \\
\text { type of } \\
\text { evidence (n) }\end{array}$ & $\begin{array}{c}\text { Conclusion } \\
\text { Effect estimate (95\% } \\
\text { Cl) }\end{array}$ & $\begin{array}{c}\text { Strength of evidence } \\
\text { (rationale) }\end{array}$ \\
\hline & $\begin{array}{l}\text { Fall in PEF }<70 \% \text { from } \\
\text { baseline }\end{array}$ & $\begin{array}{l}1 \mathrm{RCT}^{56} \\
(134)\end{array}$ & $\begin{array}{l}\text { No difference } \\
\text { Foresi, 2000 }\end{array}$ & $\begin{array}{l}\text { Low } \\
\text { (unknown consistency, } \\
\text { imprecise) }\end{array}$ \\
\hline
\end{tabular}

$\mathrm{CI}=$ confidence interval; ICS = inhaled corticosteroid; $\mathrm{MD}=$ mean difference; $\mathrm{n}$ = patient sample size; OR = odds ratio; $\mathrm{RCT}=$ randomized controlled trial; $\mathrm{ROB}=$ risk of bias; $\mathrm{RR}=$ relative risk; $\mathrm{y}=\mathrm{year}$

aThe full population reflects all patients randomized in that trial, regardless if they ever initiated the study inhaler which would have provided the intermittent ICS dose. The population which started the study inhaler reflects the patients randomized who actually initiated the study inhaler and thus received the intermittent ICs dose they were randomized too.

bDefined as lack of stability, where stability was defined as morning peak expiratory flow 90 percent or more of mean baseline value on either of the two previous days, $<4$ inhalations of inhaled corticosteroid per day over the past 2 days, no nocturnal awakenings in the prior 2 nights, and a total symptom score not exceeding mean baseline value more than 2 ordinal values over the previous 2 days

Table 10. Evidence overview for KQ1b, intermittent ICS with ICS controller versus ICS controller in patients 4 to 11 years of age

\begin{tabular}{|c|c|c|c|c|}
\hline $\begin{array}{l}\text { Outcome } \\
\text { category }\end{array}$ & Outcome & $\begin{array}{l}\text { Quantity and type } \\
\text { of evidence (n) }\end{array}$ & $\begin{array}{c}\text { Conclusion } \\
\text { Effect estimate }(95 \% \mathrm{Cl})\end{array}$ & $\begin{array}{l}\text { Strength of evidence } \\
\text { (rationale) }\end{array}$ \\
\hline \multirow[t]{3}{*}{ Exacerbation } & $\begin{array}{l}\text { Requiring oral } \\
\text { corticosteroids }\end{array}$ & $\begin{array}{l}1 \mathrm{RCT}^{60} \\
(143)\end{array}$ & $\begin{array}{l}\text { Inconclusive } \\
\text { Martinez, } 2011^{60} \\
\text { RR } 1.12(0.67 \text { to } 1.86)\end{array}$ & $\begin{array}{l}\text { Insufficient } \\
\text { (unknown consistency, } \\
\text { imprecise, indirect) }{ }^{\mathrm{a}}\end{array}$ \\
\hline & $\begin{array}{l}\text { Requiring } \\
\text { hospitalization }\end{array}$ & $\begin{array}{l}1 \mathrm{RCT}^{54} \\
\text { (29) }\end{array}$ & $\begin{array}{l}\text { Inconclusive } \\
\text { Colland, } 2004^{54} \\
\text { OR } 0.14(0.003 \text { to } 7.31)\end{array}$ & $\begin{array}{l}\text { Insufficient } \\
\text { (unclear ROB, } \\
\text { unknown consistency, } \\
\text { imprecise) }\end{array}$ \\
\hline & Treatment failure $^{b}$ & $\begin{array}{l}1 \mathrm{RCT}^{60} \\
(143)\end{array}$ & $\begin{array}{l}\text { Inconclusive } \\
\text { Martinez, } 2011^{60} \\
\text { RR } 2.03(0.39 \text { to } 10.72)\end{array}$ & $\begin{array}{l}\text { Insufficient } \\
\text { (unknown consistency, }^{\text {imprecise, indirect) }}{ }^{\mathrm{a}}\end{array}$ \\
\hline Spirometry & FEV1 \% predicted & $\begin{array}{l}1 \mathrm{RCT}^{54} \\
(29)\end{array}$ & $\begin{array}{l}\text { Inconclusive } \\
\text { Colland, } 2004^{54} \\
\text { MD } 5(-6.01 \text { to } 16.01)\end{array}$ & $\begin{array}{l}\text { Insufficient } \\
\text { (unclear ROB, } \\
\text { unknown consistency, } \\
\text { imprecise) }\end{array}$ \\
\hline Quality of life & PAQLQ score & $\begin{array}{l}1 \mathrm{RCT}^{60} \\
(143)\end{array}$ & $\begin{array}{l}\text { No difference } \\
\text { Martinez, } 2011^{60} \\
\text { MD -0.003 (-0.25 to } 0.25)\end{array}$ & $\begin{array}{l}\text { Low } \\
\text { (unknown consistency, } \\
\text { Indirect) }^{\mathrm{a}}\end{array}$ \\
\hline $\begin{array}{l}\text { Health care } \\
\text { utilization }\end{array}$ & Albuterol puffs/day & $\begin{array}{l}1 \mathrm{RCT}^{60} \\
(143)\end{array}$ & $\begin{array}{l}\text { Inconclusive } \\
\text { Martinez, } 2011^{60} \\
\text { MD } 0.04(-0.33 \text { to } 0.40)\end{array}$ & $\begin{array}{l}\text { Insufficient } \\
\text { (unknown consistency, }^{\text {(imprecise, indirect) }}{ }^{\mathrm{a}}\end{array}$ \\
\hline
\end{tabular}

$\mathrm{CI}$ = confidence interval; ER = emergency room; FEV1 = forced expiratory volume in one second; ICS = inhaled corticosteroid; $\mathrm{MD}=$ mean difference; $\mathrm{n}$ = patient sample size; OR = odds ratio; PAQLQ = Pediatric Asthma Quality of Life Questionnaire;

$\mathrm{RCT}=$ randomized controlled trial; $\mathrm{ROB}=$ risk of bias; $\mathrm{RR}=$ relative risk; $\mathrm{y}=$ year

${ }^{a}$ Martinez et al. enrolled patients 6 to 18 years of age, with mean of 10 and 11y per arm although since this is the only trial that provides data for the EPR-3 age group of 5-11y old, we used the data but downgraded strength of evidence for indirectness befined as any of following: (1) Hospitalization due to asthma; (2) Hypoxic seizure due to asthma; (3) Intubation due to asthma; (4) Requirement for a second burst of prednisone within any $6 \mathrm{~m}$ period; (5) Significant adverse event related to the use of a study medication. The only criterion for assignment of treatment failure during the trial was the requirement for a second burst of prednisone within any six-month period

\section{Overview of Studies}

Seven RCTs54-56,59,60,62,67 ( $\mathrm{n}=1312)$ were included in the analysis of intermittent ICS plus ICS controller versus ICS controller. Five RCTs55,56,59,62,67 enrolled patients 12 years of age and older (mean 31 to 55 years). One trial54 enrolled patients 4 to 11y old and 1 trial60 enrolled a mixed population of 6 to $18 \mathrm{y}$ olds (mean 10 to 11y); thus, results of these trials are presented separately from results of patients $12 \mathrm{y}$ of age or older. The trial60 that enrolled 
patients 6 to 18 years of age was the only source of data for the population of 4 to $11 \mathrm{y}$ old for some of the outcomes evaluated thus we used this data and downgraded the SOE for indirectness. Of the 7 trials, one further specified persistent asthma to be mild,60 one67 specified mild to moderate, and two54,56 specified moderate severity. One trial60 required patients to be well controlled, one59 described patients as stable, two trials54,56 considered patients symptomatic, and the others did not specify asthma control. Race was reported in one trial60 and was mostly Caucasian (71\%). In all trials, patients were taking ICS controller therapy and in the intervention arm peak expiratory flow (PEF),55,56,59,62,67 prodromal symptoms,54 or real-life scenarios where the patient would normally use albuterol or treat a reduced PEF60 triggered a temporary increase in the ICS dose. Of the trials that used PEF to trigger additional ICS, trigger values ranged from $<70$ percent to $<85$ percent. The duration of increased ICS dose was either 7 or 14d except in a single trial60 instructing patients to use the inhaler whenever albuterol would be normally used. The increase in ICS dose was equivalent to doubling, 54,55,59,67 quadrupling,56,62 or patient driven60. In 5 trials55,56,59,62,67 PEF (either $<60 \%$ or $<70 \%$ ) also triggered oral corticosteroid initiation for a duration ranging from 3 to $10 \mathrm{~d}$. The control arm was randomized to a set ICS dose in all trials except one67 where physicians modified therapy according to their judgement. All trials were multicenter, of either 6 or $12 \mathrm{~m}$ duration, and conducted in a single country (Canada, US, United Kingdom [UK], Netherlands, Finland, Italy). Three trials were industry sponsored55,56,67 and 4 were nonindustry sponsored.54,59,60,62 Risk of bias was low in 4 trials,55,59,60,62 medium in 1 trial67 and unclear in 2 trials.54,56

\section{Results}

In patients $12 \mathrm{y}$ of age or older, intermittent ICS and ICS controller versus ICS controller does not significantly differ in the effect on risk of exacerbation requiring oral corticosteroid, for the full study population (Figure 5, Panel A) or in those patients who actually initiated the study inhaler (Figure 5, Panel B) (low SOE), or other measures of asthma exacerbation (low SOE) with exception of asthma-related outpatient visits which decreased with intermittent ICS and ICS controller versus ICS controller (low SOE). In patients 5 to $11 \mathrm{y}$ old, there is insufficient evidence to draw conclusions on the impact of intermittent ICS and ICS controller versus ICS controller. The exception is PAQLQ, where there is a low SOE that there is no difference in effect between groups. 
Figure 5. Risk of exacerbations requiring oral corticosteroid: Intermittent ICS and ICS controller versus ICS controller

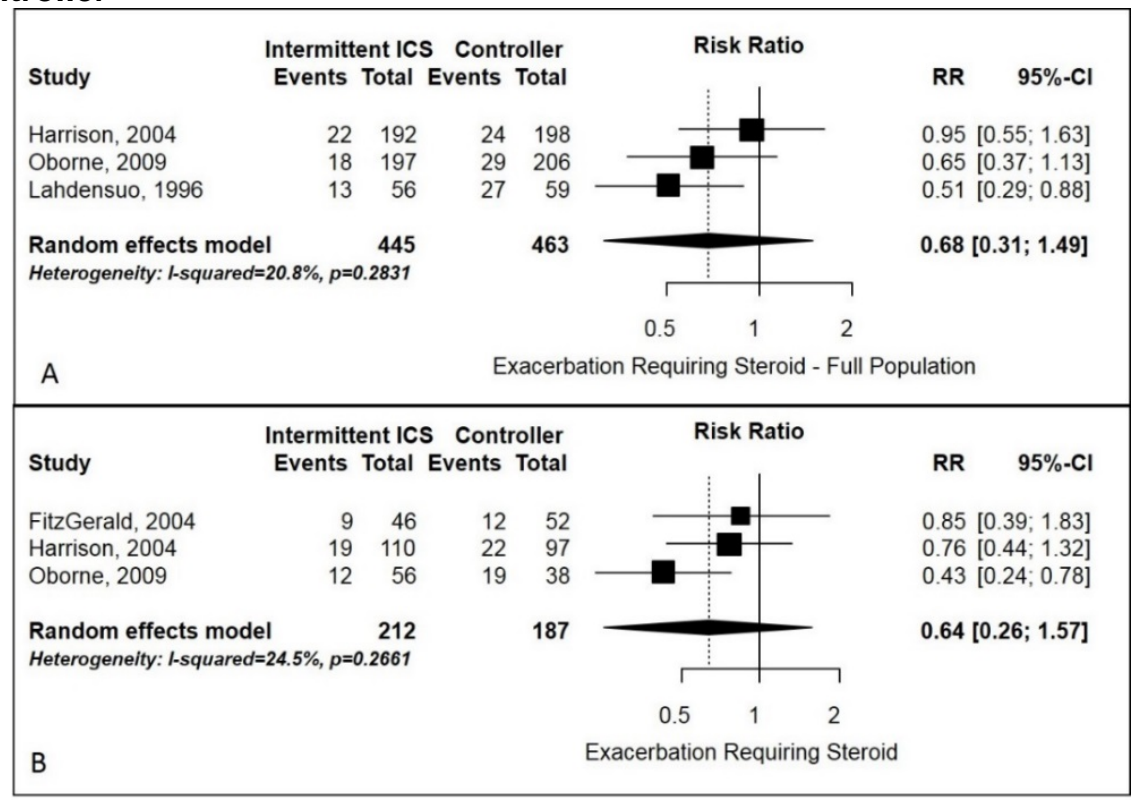

Panel A represents the comparison of intermittent ICS and ICS controller vs. ICS controller on the outcome of exacerbations requiring steroid in the full population, which is all patients regardless if they initiated their intermittent ICS therapy. Panel B represents the same comparison and outcome but only in patients who actually initiated their intermittent ICS therapy.

\section{Subgroup Data}

ICS dose: Harrison et al., analyzed a subgroup of patients on ICS doses up to $1000 \mu \mathrm{g}$ of beclomethasone equivalents (considered low to moderate ICS dose) and the risk of starting oral corticosteroids was similar to the main analysis. ${ }^{59}$ Fitzgerald et al., compared patients on ICS doses less than or equal to $400 \mu \mathrm{g} / \mathrm{d}$ vs. greater than $400 \mu \mathrm{g} / \mathrm{d}$ and found the subgroup receiving less that or equal to $400 \mu \mathrm{g} / \mathrm{d}$ were less likely to experience treatment failure during the trial ${ }^{55}$ In this study, treatment failure was defined as any one of the following: hospitalization due to asthma, hypoxic seizure due to asthma, intubation due to asthma, requirement for a second burst of prednisone within any $6 \mathrm{~m}$ period, or significant adverse event related to the use of a study medication.

Age: Fitzgerald et al., also compared adolescents versus adults and found no effect on the outcome of treatment failure (as defined above). ${ }^{55}$

\section{Intermittent ICS Versus ICS Controller}

Table 11. Evidence overview for KQ1b, intermittent ICS versus ICS controller in patients 12 years of age and older

\begin{tabular}{|c|c|c|c|c|}
\hline $\begin{array}{l}\text { Outcome } \\
\text { category }\end{array}$ & Outcome & $\begin{array}{l}\text { Quantity and } \\
\text { type of } \\
\text { evidence (n) }\end{array}$ & $\begin{array}{c}\text { Conclusion } \\
\text { Effect estimate }(95 \% \mathrm{Cl})\end{array}$ & $\begin{array}{l}\text { Strength of evidence } \\
\text { (rationale) }\end{array}$ \\
\hline \multirow[t]{3}{*}{ Exacerbations } & $\begin{array}{l}\text { Requiring oral } \\
\text { corticosteroid }\end{array}$ & $\begin{array}{l}1 \mathrm{RCT}^{51} \\
(149)\end{array}$ & $\begin{array}{l}\text { No difference } \\
\text { Boushey, } 2005^{51} \\
\text { RR } 0.70(0.30 \text { to } 1.64)\end{array}$ & $\begin{array}{l}\text { Low } \\
\text { (unknown consistency, } \\
\text { imprecise) }\end{array}$ \\
\hline & $\begin{array}{l}\text { Requiring } \\
\text { hospitalization }\end{array}$ & $\begin{array}{l}1 \mathrm{RCT}^{51} \\
(149)\end{array}$ & $\begin{array}{l}\text { Boushey, } 2005^{51} \\
\text { No events occurred }\end{array}$ & $\begin{array}{l}\text { Insufficient } \\
\text { (no events occurred) }\end{array}$ \\
\hline & $\begin{array}{l}\text { Asthma-related } \\
\text { urgent care visit }\end{array}$ & $\begin{array}{l}1 \mathrm{RCT}^{52} \\
(227)\end{array}$ & $\begin{array}{l}\text { No difference } \\
\text { Calhoun, } 2012^{52} \\
\text { RR } 0.25(0.05 \text { to } 1.16)\end{array}$ & $\begin{array}{l}\text { Low } \\
\text { (unknown consistency, } \\
\text { imprecise) }\end{array}$ \\
\hline
\end{tabular}




\begin{tabular}{|c|c|c|c|c|}
\hline $\begin{array}{l}\text { Outcome } \\
\text { category }\end{array}$ & Outcome & $\begin{array}{l}\text { Quantity and } \\
\text { type of } \\
\text { evidence (n) }\end{array}$ & $\begin{array}{c}\text { Conclusion } \\
\text { Effect estimate }(95 \% \mathrm{Cl})\end{array}$ & $\begin{array}{l}\text { Strength of evidence } \\
\text { (rationale) }\end{array}$ \\
\hline & $\begin{array}{l}\text { Milda }^{\mathrm{a}} \text { or severe } \\
\text { exacerbation }\end{array}$ & $\begin{array}{l}1 \mathrm{RCT}^{63} \\
(228)\end{array}$ & $\begin{array}{l}\text { No difference } \\
\text { Papi, } 2007^{63} \\
\text { RR } 0.87(0.29 \text { to } 2.61)\end{array}$ & $\begin{array}{l}\text { Low } \\
\text { (unknown consistency, } \\
\text { imprecise) }\end{array}$ \\
\hline & $\begin{array}{l}\text { Severe } \\
\text { exacerbation }^{b}\end{array}$ & $\begin{array}{l}1 \mathrm{RCT}^{63} \\
(228)\end{array}$ & $\begin{array}{l}\text { No difference } \\
\text { Papi, } 2007^{63} \\
\text { OR } 0.11(0.01 \text { to } 1.11)\end{array}$ & $\begin{array}{l}\text { Low } \\
\text { (unknown consistency, } \\
\text { imprecise) }\end{array}$ \\
\hline \multirow[t]{2}{*}{$\begin{array}{l}\text { Asthma control } \\
\text { composite } \\
\text { scores }\end{array}$} & ACQ-7 score & $\begin{array}{l}1 \mathrm{RCT}^{51} \\
(149)\end{array}$ & $\begin{array}{l}\text { No difference } \\
\text { Boushey, } 2005^{51} \\
\text { MD } 0.1(-0.12 \text { to } 0.32)\end{array}$ & $\begin{array}{l}\text { Low } \\
\text { (unknown consistency) }^{c}\end{array}$ \\
\hline & ACQ-5 score & $\begin{array}{l}1 \mathrm{RCT}^{52} \\
(227)\end{array}$ & $\begin{array}{l}\text { No difference } \\
\text { Calhoun, } 2012^{52} \\
\text { MD }-0.01(-0.17 \text { to } 0.15)^{d}\end{array}$ & $\begin{array}{l}\text { Low } \\
\text { (unknown consistency) }^{c}\end{array}$ \\
\hline \multirow[t]{4}{*}{ Spirometry } & FEV1, trough & $\begin{array}{l}2 \mathrm{RCTS}^{52,63} \\
(564)\end{array}$ & $\begin{array}{l}\text { No difference } \\
\text { Papi, } 2007^{63} \\
\text { MD 0.09 (-0.01 to 0.18) } \\
\frac{\text { Calhoun, } 2012^{52}}{\text { MD 0.01 (-0.13 to } 0.15)^{d}}\end{array}$ & High \\
\hline & FEV1 \% predicted & $\begin{array}{l}2 \mathrm{RCTS}^{52,63} \\
(564)\end{array}$ & $\begin{array}{l}\text { No difference } \\
\text { Papi, } 2007^{63} \\
\text { MD 2.04 (-0.71 to } 4.79) \\
\frac{\text { Calhoun, } 2012^{52}}{\text { MD } 0.01(-1.89 \text { to } 1.91)^{d}}\end{array}$ & $\begin{array}{l}\text { Moderate } \\
\text { (imprecise) }\end{array}$ \\
\hline & FVC, trough & $\begin{array}{l}1 \mathrm{RCT}^{63} \\
(228)\end{array}$ & $\begin{array}{l}\text { No difference } \\
\text { Papi, } 2007^{63} \\
\text { MD } 0.07(-0.03 \text { to } 0.18)^{d}\end{array}$ & $\begin{array}{l}\text { Low } \\
\text { (unknown consistency) }\end{array}$ \\
\hline & FVC \% predicted & $\begin{array}{l}1 \mathrm{RCT}^{63} \\
(228)\end{array}$ & $\begin{array}{l}\text { No difference } \\
\text { Papi, } 2007^{63} \\
\text { MD } 1.72(-1.04 \text { to } 4.48)\end{array}$ & $\begin{array}{l}\text { Low } \\
\text { (Unknown consistency, } \\
\text { imprecise) }\end{array}$ \\
\hline Quality of life & AQLQ(S) score & $\begin{array}{l}2 \mathrm{RCT}^{51,52} \\
(376)\end{array}$ & $\begin{array}{l}\text { No difference } \\
\text { Boushey, } 2005^{51} \\
\text { MD -0.2 (-0.48 to } 0.08) \\
\text { Calhoun, } 2012^{52} \\
\text { MD } 0.01(-0.19 \text { to } 0.21)^{d}\end{array}$ & $\begin{array}{l}\text { Moderate } \\
\text { (inconsistent) }\end{array}$ \\
\hline $\begin{array}{l}\text { Health care } \\
\text { utilization }\end{array}$ & $\begin{array}{l}\text { Rescue albuterol } \\
\text { puffs/day }\end{array}$ & $\begin{array}{l}2 \mathrm{RCT}^{52,63} \\
(564)\end{array}$ & $\begin{array}{l}\text { No difference } \\
\text { Papi, } 2007^{63} \\
\text { MD } 0.07(-0.13 \text { to } 0.26) \\
\frac{\text { Calhoun, } 2012^{52}}{\text { MD }-0.04(-0.11 \text { to } 0.03)^{d}}\end{array}$ & $\begin{array}{l}\text { Moderate } \\
\text { (imprecise) }\end{array}$ \\
\hline
\end{tabular}

ACQ = Asthma Control Questionnaire; AQLQ(S) = Standardized Asthma Quality of Life Questionnaire; CI = confidence interval; FEV1 = forced expiratory volume in one second; FVC = forced vital capacity; ICS = inhaled corticosteroid; MD = mean difference; $\mathrm{n}$ = patient sample size; $\mathrm{OR}$ = odds ratio; $\mathrm{RCT}$ = randomized controlled trial; $\mathrm{RR}$ = relative risk; $\mathrm{y}=\mathrm{year}$

a Defined as awakening at night owing to asthma or as a decrease in the morning peak expiratory flow rate to more than 20 percent below the baseline value, the use of more than three additional puffs per day of rescue medication (either albuterol or beclomethasone and albuterol) as compared with during the baseline for 2 or more consecutive days, or both. Single, isolated day on which mild exacerbation occurred were not counted.

${ }^{b}$ Defined as a decrease in the morning peak expiratory flow rate to more than 30 percent below the baseline value on 2 consecutive days or more than eight puffs per day of rescue medication for 3 consecutive days or the need for treatment with oral corticosteroids, as judged by the investigator.

c Strength of evidence was low even with only one domain downgraded due to the small sample size and lack of confidence in the true effect estimate

${ }^{\mathrm{d} S t u d y}$ reported 97.5 percent confidence intervals which were converted to 95 percent confidence intervals 
Table 12. Evidence overview for KQ1b, intermittent ICS versus ICS controller in patients 4 to 11 years of age

\begin{tabular}{|c|c|c|c|c|}
\hline $\begin{array}{l}\text { Outcome } \\
\text { category }\end{array}$ & Outcome & $\begin{array}{l}\text { Quantity and } \\
\text { type of } \\
\text { evidence (n) }\end{array}$ & $\begin{array}{c}\text { Conclusion } \\
\text { Effect estimate }(95 \% \mathrm{Cl})\end{array}$ & $\begin{array}{l}\text { Strength of evidence } \\
\text { (rationale) }\end{array}$ \\
\hline \multirow[t]{2}{*}{ Exacerbations } & $\begin{array}{l}\text { Requiring oral } \\
\text { corticosteroids }\end{array}$ & $\begin{array}{l}1 \mathrm{RCT}^{60} \\
(143)\end{array}$ & $\begin{array}{l}\text { Inconclusive } \\
\text { Martinez, } 2011^{60} \\
\text { RR } 1.27 \text { (0.78 to } 2.07)\end{array}$ & $\begin{array}{l}\text { Insufficient } \\
\text { (unknown consistency, } \\
\text { imprecise, indirect) }\end{array}$ \\
\hline & Treatment failure $^{\mathrm{e}}$ & $\begin{array}{l}1 \mathrm{RCT}^{60} \\
(143)\end{array}$ & $\begin{array}{l}\text { Inconclusive } \\
\text { Martinez, } 2011^{60} \\
\text { RR } 3.04(0.64 \text { to } 14.57)\end{array}$ & $\begin{array}{l}\text { Insufficient } \\
\text { (unknown consistency, } \\
\text { imprecise, indirect) }\end{array}$ \\
\hline Spirometry & FEV1 \% predicted & $\begin{array}{l}1 \mathrm{RCT}^{60} \\
(143)\end{array}$ & $\begin{array}{l}\text { Inconclusive } \\
\text { Martinez, } 2011^{60} \\
\text { MD -1.30 (-4.24 to } 1.64)\end{array}$ & $\begin{array}{l}\text { Insufficient } \\
\text { (unknown consistency, } \\
\text { imprecise, indirect) }\end{array}$ \\
\hline Quality of life & PAQLQ score & $\begin{array}{l}1 \mathrm{RCT}^{60} \\
(143)\end{array}$ & $\begin{array}{l}\text { No difference } \\
\text { Martinez, } 2011^{60} \\
\text { MD } 0.04(-0.25 \text { to } 0.33)\end{array}$ & $\begin{array}{l}\text { Low } \\
\text { (unknown consistency, } \\
\text { Indirect) }\end{array}$ \\
\hline $\begin{array}{l}\text { Health care } \\
\text { utilization }\end{array}$ & $\begin{array}{l}\text { Rescue albuterol } \\
\text { puffs/day }\end{array}$ & $\begin{array}{l}\text { 1 RCT60 } \\
\text { (143) }\end{array}$ & $\begin{array}{l}\text { No difference } \\
\text { Martinez, } 2011^{60} \\
\text { MD } 0.003(-0.24 \text { to } 0.25)\end{array}$ & $\begin{array}{l}\text { Low } \\
\text { (unknown consistency, } \\
\text { indirect) }\end{array}$ \\
\hline
\end{tabular}

$\mathrm{CI}=$ confidence interval; FEV1 = forced expiratory volume in one second; $\mathrm{MD}=$ mean difference; $\mathrm{n}$ = patient sample size; PAQLQ = Pediatric Asthma Quality of Life Questionnaire; RCT = randomized controlled trial; RR = relative risk; y = year

aDefined as any of following: (1) Hospitalization due to asthma; (2) Hypoxic seizure due to asthma; (3) Intubation due to asthma; (4) Requirement for a second burst of prednisone within any $6 \mathrm{~m}$ period; (5) Significant adverse event related to the use of a study medication. The only criterion for assignment of treatment failure during the trial was the requirement for a second burst of prednisone within any six-month period.

\section{Overview of Studies}

Five RCTs ${ }^{51,52,60,63,64}$ ( $n=972$ ) were included in the analysis of intermittent ICS versus ICS controller. Three trials ${ }^{51,52,63}$ enrolled patients $12 \mathrm{y}$ of age or older (mean 32 to $39 \mathrm{y}$ ), all requiring an age of at least $18 \mathrm{y}$ to enter the trial. One trial enrolled patients 5 to $10 \mathrm{y}$ old and one trial ${ }^{60}$ enrolled a mixed population (6 to 18y, mean 10 to 11y); thus, results of these trials are presented separately from results of patients $12 \mathrm{y}$ of age or older. Three trials ${ }^{51,60,63}$ specified asthma to be mild persistent, two of which ${ }^{60,63}$ required asthma to be controlled. One trial evaluated patients with mild to moderate persistent asthma that was well or partially well controlled ${ }^{52}$ and the final trial $^{64}$ evaluated mostly mild persistent asthmatics, symptomatic at the start of the trial. Race was specified as Caucasian in 3 trials ${ }^{60,63,64}$ ranging from 64 to 100 percent of subjects. In all trials, patients in the intervention arm were not on controller therapy. In 3 trials, intermittent ICS was triggered by the need for symptom relief where albuterol would normally be used, and ICS doses were taken with SABA doses as-needed. ${ }^{52,60,63}$ ICS use was triggered by action plan specified symptoms consistent with the yellow zone in one trial ${ }^{51}$ and upon symptom development that prompted contact with study physician who decided if intermittent ICS should be initiated in another trial $^{64}$. In both of these trials ${ }^{51,64}$ intermittent ICS duration was fixed (10 and 14d). In one trial, the control arm received physician-modified therapy according to the step-wise approach ${ }^{52}$ while in the others patients were randomized to a fixed ICS dose. Duration of trials ranged from 6 to $18 \mathrm{~m}$. All but 1 trial $^{64}$ were multicenter, 3 trials ${ }^{51,52,60}$ conducted in the US and the others outside of the US. Two trials ${ }^{63,64}$ were industry sponsored while the others were nonindustry sponsored. Risk of bias was low in all trials. 


\section{Results}

In patients $12 \mathrm{y}$ of age and older, intermittent ICS versus ICS controller therapy does not significantly differ in effect on the risk of exacerbations (low SOE), ACQ-7 or ACQ-5 score (low SOE), spirometry (low to high SOE), AQLQ(S) score (moderate SOE), or albuterol rescue use (moderate SOE).

In patients 5 to $11 \mathrm{y}$ old, there is insufficient evidence to draw conclusions on the impact of intermittent ICS versus ICS controller for all endpoints except for rescue albuterol use where there is a low SOE of no difference between the two strategies.

\section{Subgroup Data}

Race/ethnicity, albuterol reversibility, baseline FEV1, peak flow, symptoms, nitric oxide, sputum eosinophils: Calhoun et al., found that race/ethnicity and albuterol reversibility predicted the outcome of treatment failure. The odds of treatment failure were increased in Hispanics [Odds Ratio (OR) 3.6 (1.8 to 7.0)] and in blacks [OR 2.1 (1.2 to 4.0)] compared to non-Hispanic white subjects, $\mathrm{p}<0.02$ for both comparisons. ${ }^{52}$ There was also a significant interaction between race and efficacy suggesting a in non-Hispanic whites, intermittent ICS prevented treatment failure better than ICS controller [HR 4.50 (1.42 to 14.30)] whereas in Hispanics the opposite was found [HR 0.30 (0.04 to 1.80), $\mathrm{p}=0.01$ comparing the two groups). ${ }^{52}$ In this study, treatment failure was defined as a composite of asthma exacerbations, FEV1 measurement at home or in the office, SABA use, or use of additional asthma medications. ${ }^{52}$ The following characteristics were not predictive of treatment failure: baseline forced expiratory volume in 1 second (FEV1), peak flow, symptoms, exhaled nitric oxide, sputum eosinophils.

FEV1 percent predicted: Boushey et al., compared subgroups of patients with FEV1 percent predicted 70 to 79 vs. greater than 80 percent and found no impact on the outcome of postbronchodilatory FEV1. ${ }^{51}$

KQ1c: What is the comparative effectiveness of ICS with long-acting beta agonist (LABA) used as both controller and quick relief therapy compared to ICS with or without LABA used as controller therapy in patients 5 years of age and older with persistent asthma?

Results for this KQ are reported separately based on the comparator being ICS controller, ICS and LABA controller, or either comparator (conventional best practice [CBP]). CBP describes the comparator arm in a trial when either ICS or ICS and LABA controller was allowed. The estimated comparative daily ICS dose ${ }^{1}$ was used to further categorize studies into the following 6 groups:

- ICS and LABA controller and quick relief versus ICS controller at the same comparative ICS dose (same dose)

- ICS and LABA controller and quick relief versus ICS controller at a higher comparative ICS dose (higher dose)

- ICS and LABA controller and quick relief versus ICS and LABA controller at the same comparative ICS dose (same dose)

- ICS and LABA controller and quick relief versus ICS and LABA controller at a higher comparative ICS dose (higher dose)

- ICS and LABA controller and quick relief versus ICS and LABA controller at a lower comparative ICS dose (lower dose) 
- ICS and LABA controller and quick relief versus conventional best practice (CBP) Some studies met criteria for more than one of the above 6 groups when multiple arms were reported. Although this KQ focuses on 2 of the 3 EPR-3 age categories ( 5 to $11 \mathrm{y}, 12 \mathrm{y}$ of age and older), all but two studies ${ }^{83,115}$ were specific to the age category of 12 years of age and older. One trial $^{115}$ enrolled patients as young as $6 y$ while the second trial ${ }^{83}$ enrolled patients as young as $4 \mathrm{y}$. This latter trial ${ }^{83}$ was included because the mean age was $36 y$ and the populations was considered to represent that of interest. We report results separately per age group when possible.

\section{Key Points-ICS and LABA Controller and Quick Relief Versus ICS Controller}

- In patients 12 years of age and older, ICS and LABA controller and quick relief versus ICS controller at the same comparative ICS dose reduces the risk of exacerbations as composite outcomes (all moderate SOE), improves FEV1 (moderate SOE) and reduces rescue medication inhalations per day (low SOE).

- In patients 12 years of age and older and in patients 4 to 11y old, ICS and LABA controller and quick relief versus ICS controller at a higher comparative ICS dose reduces the risk of exacerbations as composite outcomes (all low SOE).

\section{Key Points-ICS and LABA Controller and Quick Relief Versus ICS and LABA Controller}

- In patients 12 years of age and older, ICS and LABA controller and quick relief versus ICS and LABA controller at the same comparative ICS dose reduces the risk of composite exacerbations including systemic corticosteroid, hospitalization, or ER visits (high SOE) as well as each of the individual components of the composite outcome (moderate to high SOE). The chance of being an ACQ-5 responder (moderate SOE) and the mean inhalations per week of rescue inhaler (low SOE) also favored controller and quick relief therapy. Results of a subgroup of patients 4-11y old favor ICS and LABA controller and quick relief on composite exacerbation outcomes and on mild exacerbation risk (all low SOE).

- In patients 12 years of age and older, ICS and LABA controller and quick relief versus ICS and LABA controller at a higher comparative ICS dose reduces the risk of composite exacerbations including systemic corticosteroid, hospitalization, or ER visits (high SOE) but not individual components of the composite outcome (moderate SOE).

- There is insufficient evidence to determine the impact of ICS and LABA controller and quick relief versus ICS and LABA controller at a lower comparative ICS dose.

\section{Key Points-ICS and LABA Controller and Quick Relief Versus CBP}

- In patients 12 years of age and older, ICS and LABA as controller and quick relief versus CBP reduces the risk of composite exacerbations (requiring systemic corticosteroids, hospitalization, ER visit, moderate SOE) but not of the individual components of the composite outcome (low SOE). ACQ-5 scores were improved with ICS and LABA controller and quick relief (moderate SOE) and rescue medication use also favored ICS and LABA controller and quick relief (moderate SOE). 


\section{ICS and LABA as Controller and Quick Relief Versus ICS Controller at the Same Comparative ICS Dose}

Table 13. Evidence overview for KQ1c, ICS and LABA controller and quick relief versus ICS controller (same dose) in patients 12 years of age and older

\begin{tabular}{|c|c|c|c|c|}
\hline $\begin{array}{l}\text { Outcome } \\
\text { category }\end{array}$ & Outcome & $\begin{array}{c}\text { Quantity and } \\
\text { type of } \\
\text { evidence (n) }\end{array}$ & $\begin{array}{c}\text { Conclusion } \\
\text { Effect estimate (95\% } \\
\mathrm{Cl})\end{array}$ & $\begin{array}{l}\text { Strength of evidence } \\
\text { (rationale) }\end{array}$ \\
\hline \multirow[t]{2}{*}{ Exacerbations } & $\begin{array}{l}\text { Requiring systemic } \\
\text { corticosteroids, } \\
\text { hospitalization, ER } \\
\text { visit, or having a } \\
\text { PEF<70\% }\end{array}$ & $\begin{array}{l}2 \mathrm{RCTs}^{94,96} \\
(2586)\end{array}$ & $\begin{array}{l}\text { Favors controller and } \\
\text { quick relief } \\
\text { Scicchitano, } 2004^{96} \\
\text { RR } 0.65(0.55 \text { to } 0.78) \\
\text { Rabe, } 2006^{94} \\
\text { RR } 0.49(0.32 \text { to } 0.76) \\
\end{array}$ & $\begin{array}{l}\text { Moderate } \\
\text { (imprecise) }\end{array}$ \\
\hline & $\begin{array}{l}\text { Requiring systemic } \\
\text { corticosteroids, } \\
\text { hospitalization, or ER } \\
\text { visit }\end{array}$ & $\begin{array}{l}1 \mathrm{RCT}^{96} \\
(1890)\end{array}$ & $\begin{array}{l}\text { Favors controller and } \\
\text { quick relief } \\
\text { Scicchitano, } 2004^{96} \\
\text { RR } 0.64(0.53 \text { to } 0.78)\end{array}$ & $\begin{array}{l}\text { Moderate } \\
\text { (unknown consistency) }\end{array}$ \\
\hline \multirow[t]{2}{*}{ Death } & All-cause & $\begin{array}{l}\text { 1 RCT } \\
\text { (1890) }\end{array}$ & $\begin{array}{l}\text { Inconclusive } \\
\text { Scicchitano, } 2004^{96} \\
\text { OR } 0.51(0.05 \text { to } 4.92)\end{array}$ & $\begin{array}{l}\text { Insufficient } \\
\text { (unknown consistency, } \\
\text { imprecise) }\end{array}$ \\
\hline & Asthma-specific & $\begin{array}{l}1 \mathrm{RCT}^{96} \\
(1890)\end{array}$ & $\begin{array}{l}\text { Scicchitano, } 2004^{96} \\
\text { No events occurred }\end{array}$ & $\begin{array}{l}\text { Insufficient } \\
\text { (no events occurred) }\end{array}$ \\
\hline Spirometry & FEV1 & $\begin{array}{l}1 \mathrm{RCT}^{96} \\
(1890)\end{array}$ & $\begin{array}{l}\text { Favors controller and } \\
\text { quick relief } \\
\text { Scicchitano, } 2004^{96} \\
\text { MD } 0.1(0.07 \text { to } 0.13)\end{array}$ & $\begin{array}{l}\text { Moderate } \\
\text { (unknown consistency) }\end{array}$ \\
\hline $\begin{array}{l}\text { Health care } \\
\text { utilization }\end{array}$ & $\begin{array}{l}\text { Rescue mediation use, } \\
\text { number of } \\
\text { inhalations/day }\end{array}$ & $\begin{array}{l}1 \mathrm{RCT}^{94} \\
(697)\end{array}$ & $\begin{array}{l}\text { Favors controller and } \\
\text { quick relief } \\
\frac{\text { Rabe, } 2006^{94}}{\text { MD }-0.34(-0.51 \text { to }-0.17)}\end{array}$ & $\begin{array}{l}\text { Low } \\
\text { (unknown consistency, } \\
\text { imprecise) }\end{array}$ \\
\hline
\end{tabular}

CI = confidence interval; ER = emergency room; FEV1 = forced expiratory volume in one second; MD = mean difference; $\mathrm{n}$ = patient sample size; $\mathrm{OR}$ = odds ratio; $\mathrm{PEF}$ = peak expiratory flow; RCT = randomized controlled trial; $\mathrm{RR}=$ relative risk

aStrength of evidence was rated insufficient in the setting of downgrading only one domain because this is a single trial with rare events.

\section{Overview of Studies}

Three RCTs ${ }^{94,96,99}(\mathrm{n}=2658)$ were included in the analysis of ICS and LABA controller and quick relief versus ICS at the same comparative dose, all fitting in the age group of 12 years of age and older (mean 38 to $43 y$ ). Two trials ${ }^{94,96}$ included patients 12 to $80 \mathrm{y}$ old and the third trial $^{99}$ included patients 18 to 70 years old. Sovani et al., ${ }^{99}$ enrolled patients with suboptimally controlled persistent asthma but also required patients to have evidence of poor adherence to medications and thus results are separately described from the other two trials. Poor adherence was defined in that trial as having collected less than 70 percent of the expected number of prescriptions for ICS in the year prior to the study. ${ }^{99}$ The remaining two trials enrolled symptomatic patients, one ${ }^{94}$ with mild to moderate persistent asthma and the other ${ }^{96}$ with moderate to severe persistent asthma. Race was not reported. All trials compared budesonide/formoterol controller and quick relief to budesonide controller and short-acting $\beta_{2}$ agonist (SABA) quick relief. Two trials ${ }^{94,96}$ were multicenter, multinational while the third ${ }^{99}$ was multicenter in the UK. All trials were industry sponsored and were either 6 or $12 \mathrm{mo}$ in duration. Risk of bias was low in two trials ${ }^{94,96}$ but high in one trial ${ }^{99}$ due to the open-label design, high attrition, and lack of intention-to-treat analysis. 


\section{Results}

In patients 12 years of age and older, a single trial ${ }^{96}$ found the risk of exacerbation requiring systemic corticosteroid, hospitalization or ER visit was reduced by 36 percent with ICS and LABA controller and quick relief versus ICS at the same comparative dose (moderate SOE). Time to first exacerbation [hazard ratio (HR) 0.61 (0.49 to 0.75)] and exacerbation rate [incident rate ratio (IRR) 0.55 (0.46 to 0.66)] favored ICS and LABA controller and quick relief. ${ }^{96}$ Addition of $\mathrm{PEF}<70$ percent to that composite outcome also found a reduction in exacerbation risk favoring ICS and LABA controller and quick relief (moderate SOE). Time to first exacerbation including the PEF component [HR 0.61 (0.50 to 0.74)] and time to first mild exacerbation [HR 0.68 (0.61 to 0.75)] also favored ICS and LABA controller and quick relief versus ICS at the same comparative ICS dose. ${ }^{96}$ One trial ${ }^{96}$ reported death as an outcome but few events occurred (1 versus 2 deaths, in ICS and LABA controller and quick relief versus ICS controller), none of which were asthma-specific, thus data were insufficient to draw conclusions. Mean change in FEV1 improved (MD $=0.10 \mathrm{~L}$ ) with ICS and LABA controller and quick relief in a single trial ${ }^{96}$ (moderate SOE) as did rescue medication use inhalations/day (MD -0.34, low SOE).${ }^{94}$ Two trials ${ }^{94,96}$ reported the total number of oral corticosteroid days which were numerically lower in the ICS and LABA controller and quick relief group (114 versus 498, 1176 versus 3177).

Sovani et al., found no difference in the mean change in ACQ-7 score, FEV1, or AQLQ-mini score. ${ }^{99}$ The total number of oral corticosteroid courses was 6 per group.

\section{ICS and LABA as Controller and Quick Relief Versus ICS Controller at a Higher Comparative ICS Dose}

Table 14. Evidence overview for KQ1c, ICS and LABA controller and quick relief versus ICS controller (higher dose) in patients 12 years of age and older

\begin{tabular}{|c|c|c|c|c|}
\hline $\begin{array}{l}\text { Outcome } \\
\text { category }\end{array}$ & Outcome & $\begin{array}{l}\text { Quantity and } \\
\text { type of evidence } \\
\text { (n) }\end{array}$ & $\begin{array}{c}\text { Conclusion } \\
\text { Effect estimate }(95 \% \mathrm{Cl})\end{array}$ & $\begin{array}{c}\text { Strength of } \\
\text { evidence } \\
\text { (rationale) }\end{array}$ \\
\hline \multirow[t]{2}{*}{ Exacerbations } & $\begin{array}{l}\text { Requiring systemic } \\
\text { corticosteroid, } \\
\text { hospitalization, ER visit, } \\
\text { or having a PEF }<70 \%\end{array}$ & $\begin{array}{l}1 \mathrm{RCT}^{83} \\
(1851)\end{array}$ & $\begin{array}{l}\text { Favors controller and } \\
\text { quick relief } \\
\text { O'Byrne, } 2005^{a, 83} \\
\text { RR } 0.57(0.48 \text { to } 0.69)\end{array}$ & $\begin{array}{l}\text { Low } \\
\text { (unknown } \\
\text { consistency, } \\
\text { indirect) }\end{array}$ \\
\hline & $\begin{array}{l}\text { Requiring systemic } \\
\text { corticosteroid, } \\
\text { hospitalization, or ER } \\
\text { visit }\end{array}$ & $\begin{array}{l}1 \mathrm{RCT}^{83} \\
(1847)\end{array}$ & $\begin{array}{l}\text { Favors controller and } \\
\text { quick relief } \\
\text { O'Byrne, } 2005^{\mathrm{a}, 83} \\
\text { RR } 0.58(0.46 \text { to } 0.72)\end{array}$ & $\begin{array}{l}\text { Low } \\
\text { (unknown } \\
\text { consistency, } \\
\text { indirect) }\end{array}$ \\
\hline
\end{tabular}

$\mathrm{CI}$ = confidence interval; ER = emergency room;; $\mathrm{n}$ = patient sample size; PEF = peak expiratory flow; $\mathrm{RCT}$ = randomized controlled trial; $\mathrm{RR}=$ relative risk; $\mathrm{y}=$ year

aO'Byrne enrolled patients 4 to $80 \mathrm{y}$ old although given this is the only trial that provides data for the EPR-3 age group of 12 years of age and older, we used the data but downgraded strength of evidence for indirectness 
Table 15. Evidence overview for KQ1c, ICS and LABA controller and quick relief versus ICS controller (higher dose) in patients 4 to 11 years of age

\begin{tabular}{|c|c|c|c|c|}
\hline $\begin{array}{l}\text { Outcome } \\
\text { category }\end{array}$ & Outcome & $\begin{array}{c}\text { Quantity and } \\
\text { type of } \\
\text { evidence }(n)\end{array}$ & $\begin{array}{c}\text { Conclusion } \\
\text { Effect estimate (95\% } \\
\mathrm{Cl})\end{array}$ & $\begin{array}{l}\text { Strength of evidence } \\
\text { (rationale) }\end{array}$ \\
\hline \multirow[t]{3}{*}{ Exacerbations } & $\begin{array}{l}\text { Requiring systemic } \\
\text { corticosteroid, } \\
\text { hospitalization, ER visit, } \\
\text { increase in ICS or other } \\
\text { medication or having a } \\
\text { PEF }<70 \%\end{array}$ & $\begin{array}{l}1 \mathrm{RCT}^{75} \\
(224)\end{array}$ & $\begin{array}{l}\text { Favors controller and } \\
\text { quick relief } \\
\text { Bisgaard, } 2006^{75} \\
\text { RR } 0.55(0.32 \text { to } 0.94)\end{array}$ & $\begin{array}{l}\text { Low }^{\mathrm{a}} \\
\text { (unknown consistency, } \\
\text { indirect, imprecise) }\end{array}$ \\
\hline & $\begin{array}{l}\text { Requiring systemic } \\
\text { corticosteroid, } \\
\text { hospitalization, ER visit } \\
\text { or increase in ICS or } \\
\text { other medication }\end{array}$ & $\begin{array}{l}1 \mathrm{RCT}^{75} \\
(224)\end{array}$ & $\begin{array}{l}\text { Favors controller and } \\
\text { quick relief } \\
\text { Bisgaard, } 2006^{75} \\
\text { RR } 0.43(0.21 \text { to } 0.87)\end{array}$ & $\begin{array}{l}\text { Low }{ }^{\mathrm{a}} \\
\text { (unknown consistency, } \\
\text { indirect, imprecise) }\end{array}$ \\
\hline & Mild exacerbations $^{b}$ & $\begin{array}{l}1 \mathrm{RCT}^{75} \\
(224)\end{array}$ & $\begin{array}{l}\text { No difference } \\
\text { Bisgaard, } 2006^{75} \\
\text { RR } 0.86(0.72 \text { to } 1.04)\end{array}$ & $\begin{array}{l}\text { Low }{ }^{\mathrm{a}} \\
\text { (unknown consistency, } \\
\text { indirect) }\end{array}$ \\
\hline
\end{tabular}

CI = confidence interval; EPR = Expert Panel Review (Guidelines for the Diagnosis and Management of Asthma); ER = emergency room; ICS = inhaled corticosteroid; $\mathrm{n}=$ patient sample size; $\mathrm{PEF}=$ peak expiratory flow; RCT = randomized controlled trial; $\mathrm{RR}=$ relative risk; $\mathrm{y}$ = year

a Strength of evidence was downgraded for indirectness due to the dose used in this study, which is lower than that approved in the package insert as well as what the EPR-3 considers "low dose" for this age group.

${ }^{\text {b}}$ Defined as 2 consecutive days with one of the following: morning PEF greater than or equal to 20 percent below the average run-in value, as-needed medication use two or more inhalations a day above baseline, or awakenings due to asthma

\section{Overview of Studies}

One multicenter, multinational trial ${ }^{83}(\mathrm{n}=1851)$ of $12 \mathrm{~m}$ duration was included. The patients represented a mixed age ( 4 to $80 \mathrm{y}$, mean $36 \mathrm{y}, 12 \%$ of patients $<12 \mathrm{y}$ ) although given this is the only source of data for patients 12 years of age and older, we utilized the data but downgraded SOE for being indirect. Patients had persistent, symptomatic asthma and race was not reported. Patients were randomized to ICS and LABA (budesonide/formoterol) controller and quick relief versus ICS (budesonide) controller at a higher comparative dose with SABA quick relief. The trial reported industry sponsorship and had low risk of bias.

\section{Results}

Using the full trial population data to suggest effect in patients 12 years of age and older, the risk of exacerbation requiring systemic corticosteroid, hospitalization or ER visit was reduced by 42 percent with ICS and LABA controller and quick relief versus ICS at a higher comparative dose (low SOE). ${ }^{83}$ Time to first exacerbation [HR 0.55 (0.43 to 0.70)] and exacerbation rate [IRR 0.54 (0.44 to 0.66)] favored ICS and LABA controller and quick relief. Addition of PEF $<70$ percent to that composite outcome also found a reduction in exacerbation risk favoring ICS and LABA controller and quick relief (low SOE). Time to first exacerbation including the PEF component [HR $0.53(0.43$ to 0.65$)$ ] and exacerbation rate [IRR 0.53 (0.44 to 0.64$)$ ] and the rate of mild exacerbation [IRR 0.64 (0.57 to 0.73)] also favored ICS and LABA controller and quick relief. In the pre-planned subgroup analysis of patients 4 to 11y old (mean 8y), the same two composite exacerbation outcomes also favored ICS and LABA (both low SOE) controller and quick relief although risk of mild exacerbations was no different. ${ }^{75}$ Time to first composite exacerbation that included the PEF component favored ICS and LABA controller and quick relief [HR 0.49 (0.27 to 0.90)]. 


\section{ICS and LABA as Controller and Quick Relief Versus ICS and LABA Controller at the Same Comparative ICS Dose}

Table 16. Evidence overview for KQ1c, ICS and LABA controller and quick relief versus ICS and LABA controller (same dose) in patients 12 years of age and older

\begin{tabular}{|c|c|c|c|c|}
\hline $\begin{array}{l}\text { Outcome } \\
\text { category }\end{array}$ & Outcome & $\begin{array}{c}\text { Quantity and } \\
\text { type of } \\
\text { evidence (n) }\end{array}$ & $\begin{array}{c}\text { Conclusion } \\
\text { Effect estimate (95\% } \\
\mathrm{Cl})\end{array}$ & $\begin{array}{l}\text { Strength of evidence } \\
\text { (rationale) }\end{array}$ \\
\hline \multirow[t]{8}{*}{ Exacerbations } & $\begin{array}{l}\text { Requiring systemic } \\
\text { corticosteroid }\end{array}$ & $\begin{array}{l}2 \mathrm{RCTs}^{70,84} \\
(3792)\end{array}$ & $\begin{array}{l}\text { Favors controller and } \\
\text { quick relief } \\
\text { Atienza, } 2013^{70} \\
\text { RR } 0.77(0.62 \text { to } 0.95) \\
\text { Papi, } 2013^{84} \\
\text { RR } 0.62(0.49 \text { to } 0.79)\end{array}$ & High \\
\hline & $\begin{array}{l}\text { Requiring } \\
\text { hospitalization }\end{array}$ & $\begin{array}{l}2 \mathrm{RCTs}^{70,86} \\
(2224)\end{array}$ & $\begin{array}{l}\text { Favors controller and } \\
\text { quick relief } \\
\text { Atienza, } 2013^{70} \\
\text { RR } 0.33(0.17 \text { to } 0.65) \\
\text { Patel, } 2013^{86} \\
\text { RR } 1.01(0.14 \text { to } 7.05)\end{array}$ & $\begin{array}{l}\text { Low } \\
\text { (inconsistent, } \\
\text { imprecise) }\end{array}$ \\
\hline & Requiring ER visit & $\begin{array}{l}1 \mathrm{RCT}^{70} \\
(2091)\end{array}$ & $\begin{array}{l}\text { Favors controller and } \\
\text { quick relief } \\
\text { Atienza, } 2013^{70} \\
\text { RR } 0.74(0.59 \text { to } 0.93)\end{array}$ & $\begin{array}{l}\text { Moderate } \\
\text { (unknown consistency) }\end{array}$ \\
\hline & Requiring intubation & $\begin{array}{l}1 \mathrm{RCT}^{86} \\
(1701)\end{array}$ & $\frac{\text { Papi, } 2013^{86}}{\text { No events occurred }}$ & $\begin{array}{l}\text { Insufficient } \\
\text { (no events occurred) }\end{array}$ \\
\hline & $\begin{array}{l}\text { Requiring systemic } \\
\text { corticosteroid, } \\
\text { hospitalization, or ER } \\
\text { visit }\end{array}$ & $\begin{array}{l}5 \text { RCTs } \\
70,84,86,93,103 \\
(8483)\end{array}$ & $\begin{array}{l}\text { Favors controller and } \\
\text { quick relief } \\
\text { RR } 0.68(0.58 \text { to } 0.80)\end{array}$ & High \\
\hline & $\begin{array}{l}\text { Requiring } \\
\text { hospitalization or ER } \\
\text { visit }\end{array}$ & $\begin{array}{l}5 \text { RCTs } \\
70,84,86,93,103 \\
(8313) \\
\end{array}$ & $\begin{array}{l}\text { Favors controller and } \\
\text { quick relief } \\
\text { RR } 0.69(0.63 \text { to } 0.76)\end{array}$ & High \\
\hline & $\begin{array}{l}\text { Requiring systemic } \\
\text { corticosteroid, } \\
\text { hospitalization, ER, or } \\
\text { unscheduled visit } \\
\end{array}$ & $\begin{array}{l}1 \mathrm{RCT}^{103} \\
(2143)\end{array}$ & $\begin{array}{l}\text { Favors controller and } \\
\text { quick relief } \\
\text { Vogelmeier, } 2005^{103} \\
\text { RR } 0.79(0.65 \text { to } 0.95)\end{array}$ & $\begin{array}{l}\text { Moderate } \\
\text { (unknown consistency) }\end{array}$ \\
\hline & Mild exacerbation $^{\mathrm{a}}$ & $\begin{array}{l}\text { RCTs } \mathrm{RC}^{70,84,93} \\
(6037)\end{array}$ & $\begin{array}{l}\text { No difference } \\
\text { RR } 0.94 \text { (0.81 to } 1.09)\end{array}$ & $\begin{array}{l}\text { Moderate } \\
\text { (inconsistent) }\end{array}$ \\
\hline \multirow[t]{2}{*}{ Death } & All-cause & $\begin{array}{l}4 \mathrm{RCTs}^{70,86,93,103} \\
(6782)\end{array}$ & $\begin{array}{l}\text { No difference } \\
\text { OR } 0.43(0.04 \text { to } 4.49)\end{array}$ & $\begin{array}{l}\text { Moderate } \\
\text { (imprecise) }\end{array}$ \\
\hline & Asthma-specific & $\begin{array}{l}4 \mathrm{RCTs}^{70,86,93,103} \\
(6782)\end{array}$ & No events occurred & $\begin{array}{l}\text { Insufficient } \\
\text { (no events occurred) }\end{array}$ \\
\hline \multirow[t]{3}{*}{$\begin{array}{l}\text { Asthma control } \\
\text { composite } \\
\text { scores }\end{array}$} & ACT score & $\begin{array}{l}1 \mathrm{RCT}^{102} \\
(63)\end{array}$ & $\begin{array}{l}\text { Inconclusive } \\
\text { Takeyama, } 2014^{102} \\
\text { MD } 6.3(5.15 \text { to } 7.45)\end{array}$ & $\begin{array}{l}\text { Insufficient } \\
\text { (unclear ROB, } \\
\text { unknown consistency) }\end{array}$ \\
\hline & ACQ-5 score & $\begin{array}{l}3 \mathrm{RCT}^{70,78,93} \\
(4353)\end{array}$ & $\begin{array}{l}\text { No difference } \\
\text { MD }-0.16(-0.39 \text { to } 0.06)\end{array}$ & $\begin{array}{l}\text { Low } \\
\text { (inconsistent, } \\
\text { imprecise) }\end{array}$ \\
\hline & ACQ-5 responder ${ }^{b}$ & $\begin{array}{l}1 \mathrm{RCT}^{70} \\
(2091)\end{array}$ & $\begin{array}{l}\text { Favors controller and } \\
\text { quick relief } \\
\text { Atienza, } 2013^{70} \\
\text { RR } 1.14(1.05 \text { to } 1.24)\end{array}$ & $\begin{array}{l}\text { Moderate } \\
\text { (unknown consistency) }\end{array}$ \\
\hline Spirometry & FEV1 & $\begin{array}{l}5 \mathrm{RCTs}^{70,84,86,93} \\
101 \\
(6343) \\
\end{array}$ & $\begin{array}{l}\text { No difference } \\
\text { MD } 0.04 \text { (0.00 to } 0.09)\end{array}$ & $\begin{array}{l}\text { Low } \\
\text { (inconsistent, } \\
\text { imprecise) }\end{array}$ \\
\hline
\end{tabular}




\begin{tabular}{|c|c|c|c|c|}
\hline $\begin{array}{l}\text { Outcome } \\
\text { category }\end{array}$ & Outcome & $\begin{array}{c}\text { Quantity and } \\
\text { type of } \\
\text { evidence (n) }\end{array}$ & $\begin{array}{c}\text { Conclusion } \\
\text { Effect estimate (95\% } \\
\mathrm{Cl})\end{array}$ & $\begin{array}{l}\text { Strength of evidence } \\
\text { (rationale) }\end{array}$ \\
\hline & FEV1 \% predicted & $\begin{array}{l}2 \mathrm{RCTs}^{78,86} \\
(304)\end{array}$ & $\begin{array}{l}\text { No difference } \\
\text { Patel, } 2013^{86} \\
\text { MD 1.8 (-2.8 to } 6.4) \\
\text { Hozawa, } 2014^{78} \\
\text { MD 1.9 (-4.27 to 8.07) }\end{array}$ & $\begin{array}{l}\text { Moderate } \\
\text { (medium ROB) }\end{array}$ \\
\hline & FVC & $\begin{array}{l}\text { 1 RCT }{ }^{84} \\
(1701)\end{array}$ & $\begin{array}{l}\text { No difference } \\
\text { Papi, } 2013^{84} \\
\text { MD }-0.01(-0.07 \text { to } 0.04)\end{array}$ & $\begin{array}{l}\text { Low } \\
\text { (unknown consistency, } \\
\text { imprecise) }\end{array}$ \\
\hline \multirow[t]{2}{*}{$\begin{array}{l}\text { Health care } \\
\text { utilization }\end{array}$} & $\begin{array}{l}\text { Rescue medication } \\
\text { use, number of } \\
\text { inhalations/day }\end{array}$ & $\begin{array}{l}3 \mathrm{RCT}^{70,84,93} \\
(6006)\end{array}$ & $\begin{array}{l}\text { No difference } \\
\text { MD }-0.16(-0.45 \text { to } 0.14)\end{array}$ & $\begin{array}{l}\text { Low } \\
\text { (inconsistent, } \\
\text { imprecise) }\end{array}$ \\
\hline & $\begin{array}{l}\text { Rescue medication } \\
\text { use, number of } \\
\text { inhalations/week }\end{array}$ & $\begin{array}{l}2 \mathrm{RCTs}^{78,101} \\
(93)\end{array}$ & $\begin{array}{l}\text { Favors controller and } \\
\text { quick relief } \\
\text { Hozawa, } 2014^{78} \\
\text { MD }-0.73(-1.42 \text { to }-0.04) \\
\text { Takeyama, } 2014^{101} \\
\text { MD }-2.2(-3.92 \text { to }-0.48)\end{array}$ & $\begin{array}{l}\text { Low } \\
\text { (medium ROB, } \\
\text { imprecise) }\end{array}$ \\
\hline
\end{tabular}

$\mathrm{ACQ}$ = Asthma Control Questionnaire; ACT = Asthma Control Test; CI = confidence interval; ER = emergency room; FEV1 = forced expiratory volume in one second; $\mathrm{FVC}=$ forced vital capacity; $\mathrm{MD}=$ mean difference; $\mathrm{n}$ = patient sample size; OR = odds ratio; $\mathrm{PEF}=$ peak expiratory flow; $\mathrm{RCT}=$ randomized controlled trial; $\mathrm{ROB}=$ risk of bias; $\mathrm{RR}=$ relative risk; $\mathrm{y}=$ year

aDefined as meeting one of the following: the need for 2 or more as-needed medication inhalations over baseline, nighttime awakening from asthma or PEF decrease by at least 20 percent

${ }^{b}$ Defined as a reduction in score by 0.5 or more

Table 17. Evidence overview for KQ1c, ICS and LABA controller and quick relief versus ICS and LABA controller (same dose) in patients 4 to 11 years of age

\begin{tabular}{|c|c|c|c|c|}
\hline $\begin{array}{l}\text { Outcome } \\
\text { category }\end{array}$ & Outcome & $\begin{array}{c}\text { Quantity and } \\
\text { type of } \\
\text { evidence (n) }\end{array}$ & $\begin{array}{c}\text { Conclusion } \\
\text { Effect estimate }(95 \% \mathrm{Cl})\end{array}$ & $\begin{array}{c}\text { Strength of } \\
\text { evidence (rationale) }\end{array}$ \\
\hline \multirow[t]{3}{*}{ Exacerbations } & $\begin{array}{l}\text { Requiring systemic } \\
\text { corticosteroids, } \\
\text { hospitalization, ER visit, } \\
\text { increase in ICS or other } \\
\text { medication or having a } \\
\text { PEF }<70 \%\end{array}$ & $\begin{array}{l}1 \mathrm{RCT}^{75} \\
(341)\end{array}$ & $\begin{array}{l}\text { Favors controller and } \\
\text { quick relief } \\
\text { Bisgaard, } 2006^{75} \\
\text { RR } 0.38(0.23 \text { to } 0.63)\end{array}$ & $\begin{array}{l}\text { Low } \\
\text { (unknown } \\
\text { consistency, indirect) }\end{array}$ \\
\hline & $\begin{array}{l}\text { Requiring } \\
\text { hospitalization, systemic } \\
\text { corticosteroids, ER visit, } \\
\text { or increase in ICS or } \\
\text { other medications }\end{array}$ & $\begin{array}{l}1 \mathrm{RCT}^{75} \\
(341)\end{array}$ & $\begin{array}{l}\text { Favors controller and } \\
\text { quick relief } \\
\text { Bisgaard, } 2006^{75} \\
\text { RR } 0.28(0.14 \text { to } 0.53)\end{array}$ & $\begin{array}{l}\text { Low } \\
\text { (unknown } \\
\text { consistency, indirect) }\end{array}$ \\
\hline & Mild exacerbations ${ }^{b}$ & $\begin{array}{l}1 \mathrm{RCT}^{75} \\
(341)\end{array}$ & $\begin{array}{l}\text { Favors controller and } \\
\text { quick relief } \\
\text { Bisgaard, } 2006^{75} \\
\text { RR } 0.75(0.64 \text { to } 0.88)\end{array}$ & $\begin{array}{l}\text { Low } \\
\text { (unknown } \\
\text { consistency, indirect) }\end{array}$ \\
\hline
\end{tabular}

$\mathrm{CI}$ = confidence interval; $\mathrm{ER}=$ emergency room; $\mathrm{n}$ = patient sample size; OR = odds ratio; $\mathrm{PEF}$ = peak expiratory flow; RCT = randomized controlled trial; $\mathrm{RR}=$ relative risk; $\mathrm{y}=$ year

a Strength of evidence was downgraded for indirectness due to the dose used in this study, which is lower than that approved in the package insert as well as what the EPR-3 considers "low dose" for this age group. ${ }^{\mathrm{b}}$ Defined as meeting one of the following: the need for 2 or more as-needed medication inhalations over baseline, nighttime awakening from asthma or PEF decrease by at least 20 percent 


\section{Overview of Studies}

Nine RCTs ${ }^{70,78,83,84,86,93,100,101,103}(n=12,902)$ were included in the analysis of ICS and LABA controller and quick relief versus ICS and LABA controller at the same comparative ICS dose, all but one fitting the age group of 12 years of age and older (mean 39 to 49y). O’Byrne et al., ${ }^{83}$ enrolled patients 4 to $80 \mathrm{y}$ old thus was not pooled with the base analysis but added in a sensitivity analysis given the mean age was $36 \mathrm{y}$. The trial provided data from a pre-planned subgroup analysis of 4 to $11 \mathrm{y}$ olds which are presented separately. ${ }^{75}$ Of the trials meeting the age group 12 years of age and older, most required the age of $12 y^{93,100,104}$ or $16 y^{70,86,101}$ for inclusion. Vogelmeier et al., ${ }^{103}$ although fitting into this group based on ICS comparative doses at the start of the trial, allowed dose titration in the comparator group; and thus we conducted sensitivity analysis excluding this trial. Of the 9 trials, 1 trial $^{101}$ further specified persistent asthma severity as moderate to severe. Six trials enrolled patients with symptomatic asthma, ${ }^{70,78,83,93,101,103} 1$ trial $^{100}$ enrolled patients regardless of symptom presence, 4 trials ${ }^{70,78,84,101}$ specified patients were not controlled, and 1 trial $^{86}$ did specify control or symptom presence. Race was reported in one trial $^{70}$ and was 31.8 percent Caucasian and 62.3 percent Asian. Six trials used budesonide/formoterol in both arms ${ }^{70,83,86,93,100,101}$ and 1 trial $^{84}$ compared beclomethasone/formoterol in both arms. Two trials compared budesonide/formoterol controller and quick relief to fluticasone/salmeterol controller. ${ }^{78,103}$ The comparator in Stallberg et al., ${ }^{100}$ included both similar and a higher comparative ICS dose thus this trial was excluded from pooled analysis. Seven trials ${ }^{70,78,83,84,93,100,103}$ were industry sponsored and 2 trials $^{86,101}$ were nonindustry sponsored. Five trials ${ }^{70,83,84,93,103}$ were multicenter, multinational while the others were conducted in a single country (Japan, Sweden, New Zealand). Trials were mostly $12 \mathrm{~m}$ in duration but ranged from 8 weeks to 1 year. Risk of bias was low in all trials except $4^{78,86,100,103}$ considered medium risk of bias due to the open-label design and 1 trial $^{101}$ had an unclear risk of bias.

\section{Results}

In patients $12 \mathrm{y}$ and older, ICS and LABA controller and quick relief versus ICS and LABA controller at the same comparative ICS dose reduces the risk of exacerbation requiring systemic corticosteroids by 23 percent to 38 percent (high SOE), the risk of exacerbation requiring hospitalization by 67 percent (moderate SOE), the risk of exacerbation requiring ER visit by 26 percent (moderate SOE) and the composite outcome of all three exacerbation types by 32 percent (high SOE) (Figure 6, Panel A). Time to first composite exacerbation was reduced in favor of controller and quick relief [HR 0.65 (0.54 to 0.78)] as was rate of composite exacerbations [IRR $0.54(0.42$ to 0.69$)]$. One trial reported that no patients required intubation from exacerbation. ${ }^{84}$ Additional composite outcomes for exacerbation also suggest reduction in risk favoring ICS and LABA as controller and quick relief (moderate to high SOE) (Figure 6, Panel B) although no difference was found for the risk of mild exacerbations (Figure 6, Panel C) or in the time to first mild exacerbation [HR 0.88 (0.71 to 1.10)]. Deaths were infrequent and occurred in 3 of the 4 trials reporting this outcome $\mathrm{f}^{70,86,93,103}$ and no difference was found (moderate SOE). No asthma specific deaths occurred. Sensitivity analysis adding O’Byrne et al., ${ }^{83}$ to the composite of exacerbations requiring systemic steroids, hospitalization or ER visits [relative risk (RR) 0.65 (0.55 to 0.77 ), HR 0.62 (0.52 to 0.74 ), IRR 0.52 (0.44 to 0.63 )] did not impact the magnitude or direction of effect for any results. Sensitivity analysis removing Vogelmeier et al., ${ }^{103}$ did not impact magnitude or direction of effect for the composite of exacerbations requiring systemic steroids, hospitalization or ER visits [RR 0.66 (0.55 to 0.78), HR 0.62 (0.51 to 0.76)], 
exacerbation requiring hospitalization or ER visit [RR 0.69 (0.60 to 0.79)] or death [OR 0.68 (0.01 to 34.96)].

Mean difference in ACQ-5 score was no different between groups although 1 trial $^{86}$ found the chance of being an ACQ-5 responder to favor ICS and LABA controller and quick relief (moderate SOE). Asthma Control Test (ACT) score was reported by a single trial with unclear risk of bias thus impact of ICS and LABA controller and quick relief is undetermined. Mean change in FEV1, FEV1 percent predicted and FVC were no different between groups although the lower limit of the confidence interval for FEV1 was at zero. Mean inhalations of rescue medication per day was no different between groups but when evaluated as mean inhalations per week, favored ICS and LABA controller and quick relief therapy (low SOE).

Stallberg et al., found no difference in the composite exacerbation outcome of those requiring systemic corticosteroids, hospitalization or ER visit with ICS and LABA controller and quick relief versus ICS and LABA controller and a similar or higher comparative ICS dose, in patients $12 \mathrm{y}$ old and older. ${ }^{100}$

In patients 4 to 11 years old ICS and LABA controller and quick relief versus ICS and LABA controller reduces the risk of three exacerbation types (all low SOE): the composite of exacerbations requiring systemic corticosteroids, hospitalization, ER visit, increase in ICS or other medication or having a PEF less than 70 percent; the composite of exacerbations requiring hospitalization, systemic corticosteroids, ER, or increase in ICS or other medications; and finally mild exacerbations. ${ }^{75}$ 
Figure 6. Risk of exacerbation: ICS and LABA controller and quick relief versus ICS and LABA controller (same dose)

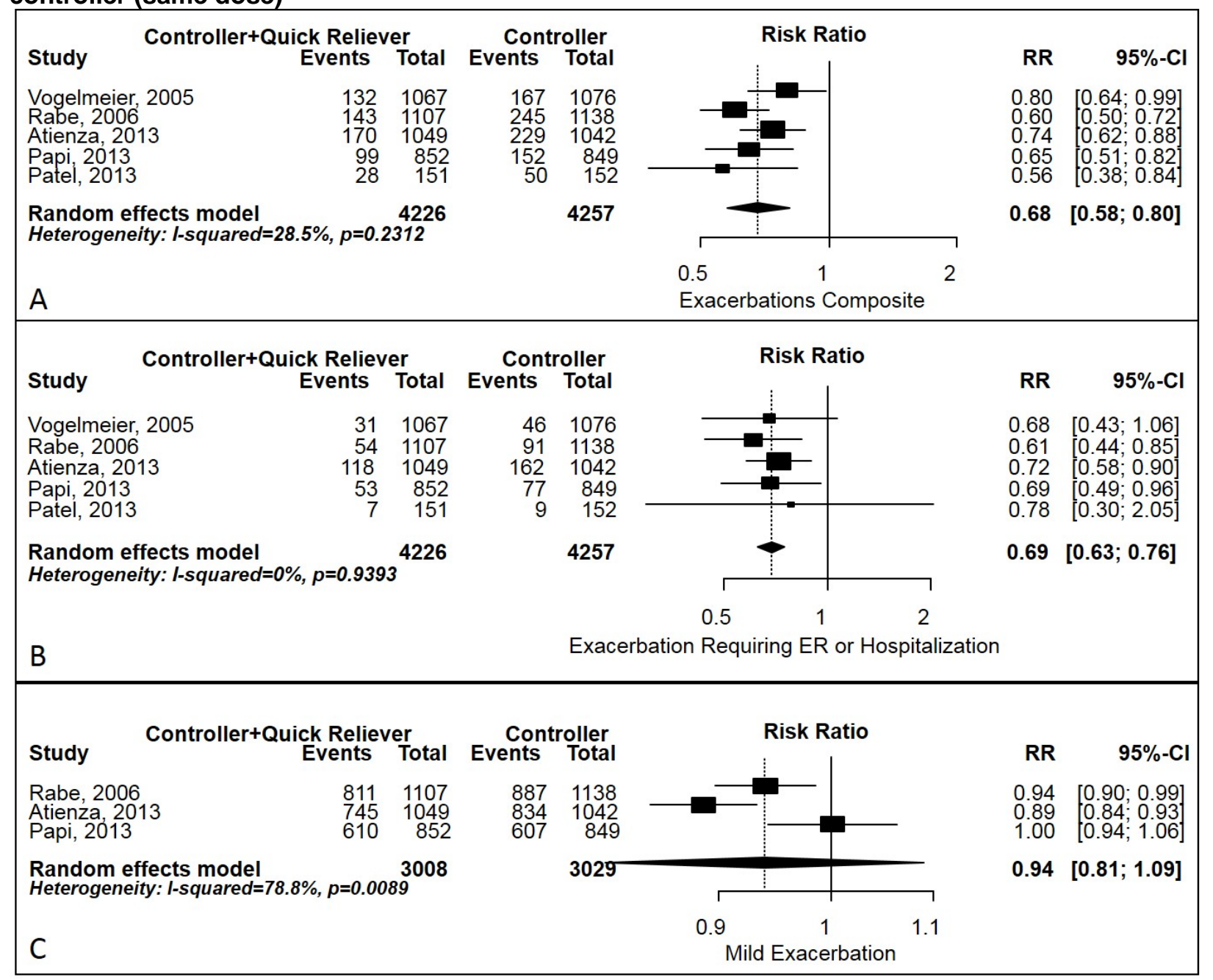

$\mathrm{CI}=$ confidence interval; $\mathrm{ER}$ = emergency room; $\mathrm{RR}=$ relative risk

\section{Subgroup Data}

Race/ethnicity: Pilcher et al., ${ }^{90}$ conducted an analysis of a prior trial ${ }^{86}$ for ethnicity-treatment interaction with specific interest in Maori versus non-Maori people. Maori are indigenous Polynesians of New Zealand. Maori had a greater improvement in ACQ-7 score than non-Maori [-1.01 $(-1.55$ to -0.51$)$ versus $-0.10(-0.31$ to 0.11$), \mathrm{p}<0.001]$ at the end of the trial. Vogelmeier et al., conducted a post-hoc subgroup analysis ${ }^{104}$ of patients 16 years of age and older old in Asian countries (China, Taiwan, Korea and Thailand) from a prior international trial that enrolled patients 12 years of age and older . ${ }^{103}$ Being Asian vs. the international population did not affect the composite exacerbation outcome. ${ }^{104}$

Baseline ICS dose: Papi et al., ${ }^{84}$ found that regardless if maintenance ICS dose on entry was less than or equal to $500 \mu \mathrm{g}$ or greater than $500 \mu \mathrm{g}$ beclomethasone equivalents, the rate of and time to first exacerbation requiring systemic corticosteroid, hospitalization or ER visit favored ICS and LABA controller and quick relief versus ICS and LABA controller, consistent with the main results study results. 
Smoking status: Pilcher et al., ${ }^{116}$ conducted an analysis of a prior trial ${ }^{86}$ regarding the effect of smoking status on outcomes. Being a current, former or never smoker did not impact treatment efficacy for the outcomes of exacerbations, hospital or ER attendance, ACQ-7 or FEV1.

FEV1 percent predicted, exacerbation history and gender: Patel et al., ${ }^{87}$ analyzed data from a prior trial $^{86}$ and found the following patient characteristics to increase the risk of exacerbation requiring systemic corticosteroids or hospitalization/ER visit for treatment: lower baseline FEV1 percent predicted per 10 percent [rate ratio 1.14 (1.03 to 1.27)], higher number of exacerbations in the prior year per 1 exacerbation [rate ratio 1.15 (1.01 to 1.13)], treatment with ICS and LABA controller as opposed to controller and quick relief [rate ratio 1.62 (1.07 to 2.47)], and female gender [rate ratio 2.18 (1.29 to 3.67)].

\section{ICS and LABA as Controller and Quick Relief Versus ICS and LABA Controller at a Higher Comparative ICS Dose}

Table 18. Evidence overview for KQ1C, ICS and LABA controller and quick relief versus ICS and LABA controller (higher dose) in patients 12 years of age and older

\begin{tabular}{|c|c|c|c|c|}
\hline $\begin{array}{l}\text { Outcome } \\
\text { categories }\end{array}$ & Outcome & $\begin{array}{c}\text { Quantity and } \\
\text { type of } \\
\text { evidence (n) }\end{array}$ & $\begin{array}{c}\text { Conclusion } \\
\text { Effect estimate (95\% } \\
\mathrm{Cl})\end{array}$ & $\begin{array}{l}\text { Strength of } \\
\text { evidence } \\
\text { (rationale) }\end{array}$ \\
\hline \multirow[t]{4}{*}{ Exacerbations } & $\begin{array}{l}\text { Requiring systemic } \\
\text { corticosteroid }\end{array}$ & $\begin{array}{l}1 \mathrm{RCT}^{76} \\
(2304)\end{array}$ & $\begin{array}{l}\text { No difference } \\
\text { Bousquet, } 2007^{76} \\
\text { RR } 0.82(0.62 \text { to } 1.07)\end{array}$ & $\begin{array}{l}\text { Moderate } \\
\text { (unknown } \\
\text { consistency) }\end{array}$ \\
\hline & $\begin{array}{l}\text { Requiring systemic } \\
\text { corticosteroid, } \\
\text { hospitalization, or ER } \\
\text { visit }\end{array}$ & $\begin{array}{l}3 \operatorname{RCTs}^{76,81} \\
(6742)\end{array}$ & $\begin{array}{l}\text { Favors controller and } \\
\text { quick relief } \\
\text { RR } 0.75(0.59 \text { to } 0.96)\end{array}$ & High \\
\hline & $\begin{array}{l}\text { Requiring hospitalization } \\
\text { or ER visit }\end{array}$ & $\begin{array}{l}3 \mathrm{RCTs}^{76,81} \\
(6742)\end{array}$ & $\begin{array}{l}\text { No difference } \\
\text { RR } 0.76 \text { (0.46 to } 1.25)\end{array}$ & $\begin{array}{l}\text { Moderate } \\
\text { (imprecise) }\end{array}$ \\
\hline & Mild exacerbation ${ }^{\mathrm{a}}$ & $\begin{array}{l}2 \mathrm{RCTs}^{81} \\
(3321)\end{array}$ & $\begin{array}{l}\text { No difference } \\
\text { Kuna, } 2007 a^{81} \\
\text { RR } 0.97(0.91 \text { to } 1.04) \\
\text { Kuna, } 2007 b^{81} \\
\text { RR } 1.04(0.97 \text { to } 1.11)\end{array}$ & $\begin{array}{l}\text { Moderate } \\
\text { (unknown } \\
\text { consistency because } \\
\text { single trial) }\end{array}$ \\
\hline \multirow[t]{2}{*}{ Death } & All-cause & $\begin{array}{l}4 \mathrm{RCTs}^{76,81,89} \\
(5757)\end{array}$ & $\begin{array}{l}\text { No difference } \\
\text { OR } 2.72 \text { (0.38 to } 19.31)\end{array}$ & $\begin{array}{l}\text { Moderate } \\
\text { (imprecise) }\end{array}$ \\
\hline & Asthma-specific & $\begin{array}{l}4 \mathrm{RCTs}^{76,81,89} \\
(5757)\end{array}$ & No events occurred & $\begin{array}{l}\text { Insufficient } \\
\text { (no events occurred) }\end{array}$ \\
\hline $\begin{array}{l}\text { Asthma control } \\
\text { composite } \\
\text { scores }\end{array}$ & ACQ-5 score & $\begin{array}{l}3 \mathrm{RCTs}^{76,81} \\
(6559)\end{array}$ & $\begin{array}{l}\text { No difference } \\
\text { Bousquet, } 2007^{76} \\
\text { MD }-0.02(-0.07 \text { to } 0.04) \\
\text { Kuna, } 2007 a^{81} \\
\text { MD }-0.02(-0.08 \text { to } 0.05) \\
\frac{\text { Kuna, } 2007 b^{81}}{\text { MD } 0.03(-0.03 \text { to } 0.09)}\end{array}$ & High \\
\hline Spirometry & FEV1 & $\begin{array}{l}2 \mathrm{RCTs}^{81} \\
(4424)\end{array}$ & $\begin{array}{l}\text { No difference } \\
\text { Kuna, } 2007 a^{81} \\
\frac{\text { MD } 0.01(-0.03}{\text { Kuna }, 2007 b^{81}} \\
\left.\frac{\text { MD } 0.01(-0.03}{} \text { to } 0.04\right)\end{array}$ & $\begin{array}{l}\text { Moderate } \\
\text { (unknown } \\
\text { consistency) }\end{array}$ \\
\hline Quality of life & AQLQ(S) score & $\begin{array}{l}2 \mathrm{RCTs}^{81} \\
(4270)\end{array}$ & $\begin{array}{l}\text { No difference } \\
\text { Kuna, } 2007 a^{81} \\
\frac{\text { MD } 0.01(-0.07}{\text { Kuna, } 2007 b^{81}} \\
\left.\frac{\text { MD }-0.02(-0.09)}{} \text { to } 0.06\right)\end{array}$ & $\begin{array}{l}\text { Moderate } \\
\text { (unknown } \\
\text { consistency because } \\
\text { single trial) }\end{array}$ \\
\hline
\end{tabular}




\begin{tabular}{|c|c|c|c|c|}
\hline $\begin{array}{l}\text { Outcome } \\
\text { categories }\end{array}$ & Outcome & $\begin{array}{c}\text { Quantity and } \\
\text { type of } \\
\text { evidence (n) }\end{array}$ & $\begin{array}{c}\text { Conclusion } \\
\text { Effect estimate (95\% } \\
\mathrm{Cl})\end{array}$ & $\begin{array}{c}\text { Strength of } \\
\text { evidence } \\
\text { (rationale) }\end{array}$ \\
\hline $\begin{array}{l}\text { Heath care } \\
\text { utilization }\end{array}$ & $\begin{array}{l}\text { Rescue medication use, } \\
\text { number of } \\
\text { inhalations/day }\end{array}$ & $\begin{array}{l}\text { RCTs }{ }^{76,81} \\
(6559)\end{array}$ & $\begin{array}{l}\text { No difference } \\
\text { Bousquet, } 2007^{76} \\
\text { MD }-0.04(-0.12 \text { to } 0.04) \\
\frac{\text { Kuna, } 2007 a^{81}}{\text { MD }-0.03(-0.12 \text { to } 0.06)} \\
\left.\frac{\text { Kuna, } 2007 b^{81}}{\text { MD } 0.07(-0.02} \text { to } 0.16\right)\end{array}$ & High \\
\hline
\end{tabular}

ACQ = Asthma Control Questionnaire; AQLQ = Asthma Quality of Life Questionnaire; CI = confidence interval; ER = emergency room; FEV1 = forced expiratory volume in one second; MD = mean difference; $\mathrm{n}$ = patient sample size; OR = odds ratio; $\mathrm{RCT}=$ randomized controlled trial; $\mathrm{RR}=$ relative risk

aDefined as meeting one of the following: the need for 2 or more as-needed medication inhalations over baseline, nighttime awakening from asthma or a PEF decrease by at least 20 percent

\section{Overview of Studies}

Five RCTs ${ }^{76,81,89,100,115}$ ( $\left.\mathrm{n}=7605\right)$ were included in the analysis of ICS and LABA as controller and quick relief versus ICS and LABA controller at a higher comparative ICS dose. Kuna et al., contributed two unique comparisons which were considered independently for analysis. ${ }^{81}$ All trials fit the age group of 12 years of age and older (mean 38 to $45 \mathrm{y}$ ) except Lundborg et al., ${ }^{115}$ which studied a mixed age group ( $\geq 6 \mathrm{y}$ old). However, this trial ${ }^{115}$ used formoterol instead of SABA as quick relief in the control arm thus the trial was not pooled with the others. Three trials enrolled patients with symptomatic persistent asthma ${ }^{76,81,89}$ and two trials enrolled patients with persistent asthma and mixed control/presence of symptoms. ${ }^{100,115}$ Race was not reported. All studies compared budesonide/formoterol as controller and quick relief to either fluticasone/salmeterol controller ${ }^{76,81}$ or budesonide/formoterol controller. ${ }^{81,89,100,115}$ The comparator in Stallberg et al., ${ }^{100}$ included both similar and a higher comparative ICS dose thus this trial was excluded from pooled analysis. All trials were multicenter and industry sponsored, 3 trials ${ }^{76,81,89}$ were multinational and $2^{100,115}$ were conducted in Sweden. Trials ranged from 6 to $12 \mathrm{~m}$ in duration. Risk of bias was low in 3 trials $^{76,81,89}$ and medium in 2 trials ${ }^{100,115}$ due to the open-label design and the risk of performance and detection bias.

\section{Results}

In patients 12 years of age and older, ICS and LABA as controller and quick relief versus ICS and LABA controller at a higher comparative ICS dose did not significantly differ in effect on the risk of exacerbations requiring systemic corticosteroids or requiring hospitalization/ER visit (Figure 7, Panel B) (both moderate SOE) but when evaluated as a composite outcome requiring systemic corticosteroids, hospitalization or ER visit risk was reduced by 25 percent (high SOE) (Figure 7, Panel A). The risk of mild exacerbations was no different (moderate SOE). Deaths occurred in 3 of the 4 trials reporting this outcome ${ }^{76,81}$ and no difference was found (moderate SOE). No asthma-specific deaths occurred. There was no difference in ACQ-5 score (high SOE), FEV1 (moderate SOE), AQLQ(S) score (moderate SOE) or rescue medication use (high SOE).

Lundborg et al., ${ }^{115}$ provided data for patients $6 \mathrm{y}$ and older and compared two approaches to controller and quick relief therapy, budesonide/formoterol once daily or twice daily, both compared to ICS and LABA controller and formoterol quick relief. ACQ-5 was no different with either controller and quick relief approach compared to ICS and LABA controller. Stallberg et al., found no difference in the composite exacerbation outcome of those requiring systemic corticosteroids, hospitalization or ER visit with ICS and LABA controller and quick relief versus 
ICS and LABA controller and a similar or higher comparative ICS dose, in patients $12 \mathrm{y}$ old and older. ${ }^{100}$

Figure 7. Risk of exacerbation: ICS and LABA controller and quick relief versus ICS and LABA controller (higher dose)

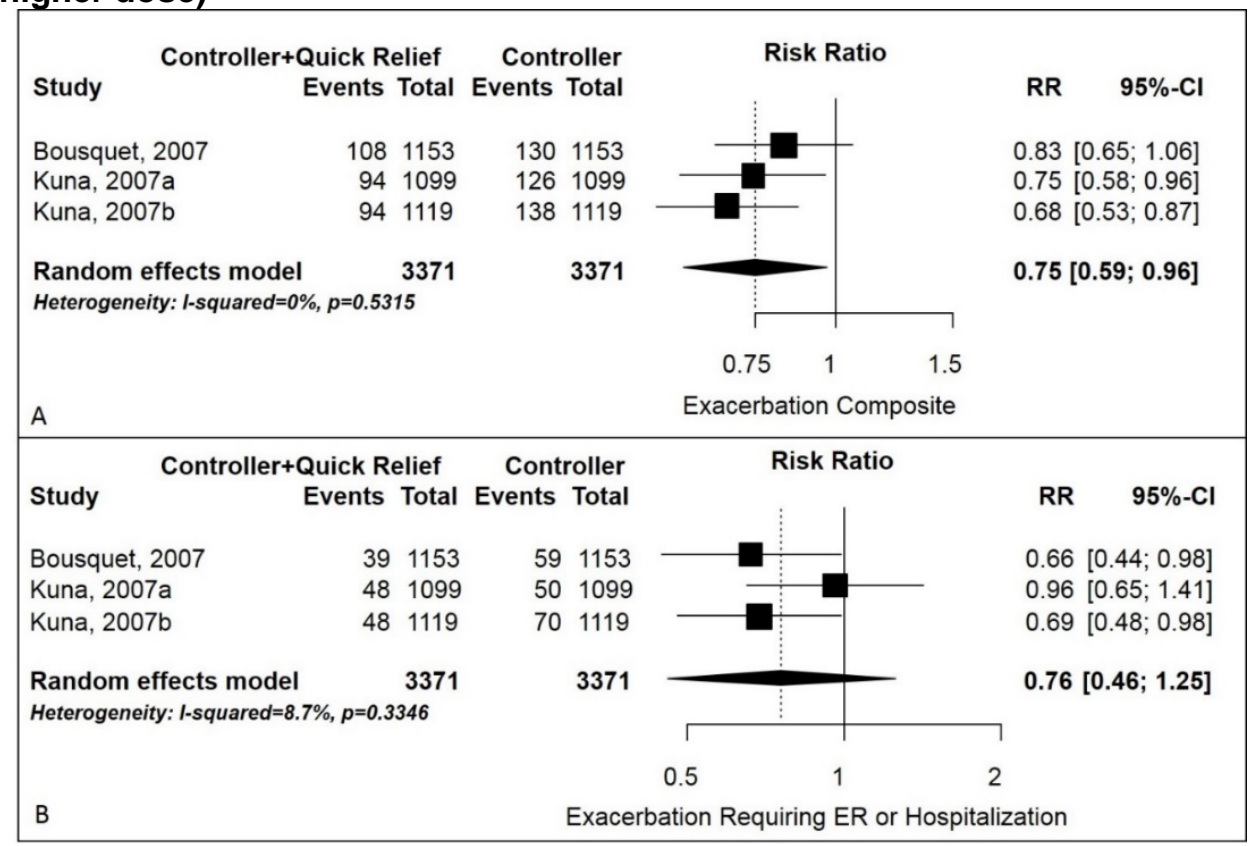

$\mathrm{CI}=$ confidence interval; $\mathrm{ER}=$ emergency room; $\mathrm{RR}=$ relative risk

\section{Subgroup Data}

Race/ethnicity: Lin et al., ${ }^{113}$ conducted a post-hoc subgroup analyses comparing Chinese patients vs. the full international population and found no impact on the outcomes of exacerbation and ACQ-5 score.

$\underline{\text { Age: Kuna et al., }}{ }^{80}$ conducted a post-hoc subgroup analysis of a prior trial ${ }^{81}$ in patients $16 \mathrm{y}$ of age and older old vs. the original population of 12 years of age and older and found no impact on the outcomes of exacerbations, ACQ-5, AQLQ(S) or rescue medication use inhalations/d.

\section{ICS and LABA as Controller and Quick Relief Versus ICS and LABA Controller at a Lower Comparative ICS Dose}

Table 19. Evidence overview for KQ1c, ICS and LABA controller and quick relief_versus ICS and LABA controller (lower dose) in patients 12 years of age and older

\begin{tabular}{|c|c|c|c|c|}
\hline $\begin{array}{l}\text { Outcome } \\
\text { category }\end{array}$ & Outcome & $\begin{array}{c}\text { Quantity and } \\
\text { type of } \\
\text { evidence (n) }\end{array}$ & $\begin{array}{c}\text { Conclusion } \\
\text { Effect estimate (95\% } \\
\mathrm{Cl}) \\
\end{array}$ & $\begin{array}{l}\text { Strength of evidence } \\
\text { (rationale) }\end{array}$ \\
\hline $\begin{array}{l}\text { Asthma control } \\
\text { composite } \\
\text { scores }\end{array}$ & ACQ-5 score & $\begin{array}{l}1 \mathrm{RCT}^{117} \\
(30)\end{array}$ & $\begin{array}{l}\text { Inconclusive } \\
\frac{\text { Hozawa, } 2016^{117}}{\text { MD }-0.40(-0.53 \text { to }-0.27)}\end{array}$ & $\begin{array}{l}\text { Insufficient } \\
\text { (medium ROB, } \\
\text { unknown consistency, } \\
\text { imprecise) }\end{array}$ \\
\hline Spirometry & FEV1 \% predicted & $\begin{array}{l}1 \mathrm{RCT}^{117} \\
(30)\end{array}$ & $\begin{array}{l}\text { Inconclusive } \\
\frac{\text { Hozawa, } 2016^{117}}{\text { MD } 3.10(-1.36 \text { to } 7.56)}\end{array}$ & $\begin{array}{l}\text { Insufficient } \\
\text { (medium ROB, } \\
\text { unknown consistency) }\end{array}$ \\
\hline
\end{tabular}




\begin{tabular}{|c|c|c|c|c|}
\hline $\begin{array}{l}\text { Outcome } \\
\text { category }\end{array}$ & Outcome & $\begin{array}{c}\text { Quantity and } \\
\text { type of } \\
\text { evidence }(n)\end{array}$ & $\begin{array}{c}\text { Conclusion } \\
\text { Effect estimate (95\% } \\
\mathrm{Cl})\end{array}$ & $\begin{array}{l}\text { Strength of evidence } \\
\text { (rationale) }\end{array}$ \\
\hline $\begin{array}{l}\text { Health care } \\
\text { utilization }\end{array}$ & $\begin{array}{l}\text { Rescue medication } \\
\text { use, number of } \\
\text { inhalations/week }\end{array}$ & $\begin{array}{l}1 \mathrm{RCT}^{117} \\
(30)\end{array}$ & $\begin{array}{l}\text { Inconclusive } \\
\frac{\text { Hozawa, } 2016^{117}}{\text { MD -0.9 (-1.48 to }-0.32)}\end{array}$ & $\begin{array}{l}\text { Insufficient } \\
\text { (medium ROB, } \\
\text { unknown consistency, } \\
\text { imprecise) }\end{array}$ \\
\hline
\end{tabular}

ACQ = Asthma Control Questionnaire; CI = confidence interval; FEV1 = forced expiratory volume in one second; MD = mean difference; $\mathrm{n}$ = patient sample size; $\mathrm{RCT}$ = randomized controlled trial; $\mathrm{ROB}$ = risk of bias; RR = relative risk

\section{Overview of Studies}

One $\mathrm{RCT}^{117}(\mathrm{n}=30)$ was included in the analysis of ICS and LABA as controller and quick relief versus ICS and LABA controller at a lower comparative ICS dose. Hozawa et al., studied patients 20y of age and older, with a mean age of 41y. Patients were considered to have symptomatic, persistent asthma. Race was not reported. Patient were randomized to budesonide/formoterol as controller and quick relief or fluticasone/vilanterol as controller with procaterol as needed. The trial was single center, industry-sponsored in Japan for 4 weeks. Risk of bias was medium due to the open-label design and the risk of performance and detection bias.

\section{Results}

Although the outcomes of ACQ-5 score, FEV1 percent predicted, and rescue medication use were reported, the evidence is insufficient to draw a conclusion.

\section{ICS and LABA as Controller and Quick Relief Versus CBP}

Table 20. Evidence overview for KQ1c, ICS and LABA controller and quick relief versus CBP in patients 12 years of age and older

\begin{tabular}{|c|c|c|c|c|}
\hline $\begin{array}{l}\text { Outcome } \\
\text { category }\end{array}$ & Outcome & $\begin{array}{c}\text { Quantity and } \\
\text { type of } \\
\text { evidence (n) }\end{array}$ & $\begin{array}{c}\text { Conclusion } \\
\text { Effect estimate }(95 \% \mathrm{Cl})\end{array}$ & $\begin{array}{l}\text { Strength of evidence } \\
\text { (rationale) }\end{array}$ \\
\hline \multirow[t]{4}{*}{ Exacerbations } & $\begin{array}{l}\text { Requiring systemic } \\
\text { corticosteroid }\end{array}$ & $\begin{array}{l}4 \mathrm{RCTS}^{82,91,97,98} \\
(4935)\end{array}$ & $\begin{array}{l}\text { No difference } \\
\text { RR } 0.84 \text { (0.61 to } 1.17)\end{array}$ & $\begin{array}{l}\text { Low } \\
\text { (medium ROB, } \\
\text { imprecise) }\end{array}$ \\
\hline & $\begin{array}{l}\text { Requiring } \\
\text { hospitalization }\end{array}$ & $\begin{array}{l}4 \mathrm{RCTS}^{82,91,97,98} \\
(4935)\end{array}$ & $\begin{array}{l}\text { No difference } \\
\text { OR } 0.89 \text { (0.34 to } 2.30)\end{array}$ & $\begin{array}{l}\text { Low } \\
\text { (medium ROB, } \\
\text { imprecise) }\end{array}$ \\
\hline & Requiring ER visit & $\begin{array}{l}4 \mathrm{RCTS}^{82,91,97,98} \\
(4935)\end{array}$ & $\begin{array}{l}\text { No difference } \\
\text { RR } 0.78 \text { (0.50 to } 1.21)\end{array}$ & $\begin{array}{l}\text { Low } \\
\text { (medium ROB, } \\
\text { imprecise) }\end{array}$ \\
\hline & $\begin{array}{l}\text { Requiring systemic } \\
\text { corticosteroid, } \\
\text { hospitalization, or } \\
\text { ER visit }\end{array}$ & $\begin{array}{l}6 \\
\mathrm{RCTs} \\
100(6354) 91,95,97,98 \\
\end{array}$ & $\begin{array}{l}\text { Favors controller and } \\
\text { quick relief } \\
\text { RR } 0.78 \text { (0.64 to 0.95) }\end{array}$ & $\begin{array}{l}\text { Moderate } \\
\text { (medium ROB) }\end{array}$ \\
\hline \multirow[t]{2}{*}{ Death } & All-cause & $\begin{array}{l}4 \mathrm{RCTs}^{82,91,97,98} \\
(4935)\end{array}$ & $\begin{array}{l}\text { No difference } \\
\text { OR } 2.20(0.32 \text { to } 14.96)\end{array}$ & $\begin{array}{l}\text { Moderate } \\
\text { (imprecise) }\end{array}$ \\
\hline & Asthma-specific & $\begin{array}{l}4 \mathrm{RCTs}^{82,91,97,98} \\
(4935)\end{array}$ & No events occurred & $\begin{array}{l}\text { Insufficient } \\
\text { (no events occurred) }\end{array}$ \\
\hline $\begin{array}{l}\text { Asthma control } \\
\text { composite } \\
\text { scores }\end{array}$ & ACQ-5 score & $\begin{array}{l}5 \mathrm{RCTs}^{82,91,95,97,} \\
98 \\
(4996)\end{array}$ & $\begin{array}{l}\text { Favors controller and } \\
\text { quick relief } \\
\text { MD }-0.09(-0.14 \text { to }-0.03)\end{array}$ & $\begin{array}{l}\text { Moderate } \\
\text { (medium ROB) }\end{array}$ \\
\hline
\end{tabular}




\begin{tabular}{|c|c|c|c|c|}
\hline $\begin{array}{l}\text { Outcome } \\
\text { category }\end{array}$ & Outcome & $\begin{array}{c}\text { Quantity and } \\
\text { type of } \\
\text { evidence }(n)\end{array}$ & $\begin{array}{c}\text { Conclusion } \\
\text { Effect estimate }(95 \% \mathrm{Cl})\end{array}$ & $\begin{array}{l}\text { Strength of evidence } \\
\text { (rationale) }\end{array}$ \\
\hline & ACQ-5 responder ${ }^{a}$ & $\begin{array}{l}2 \mathrm{RCTs}^{91,97} \\
(2166)\end{array}$ & $\begin{array}{l}\text { Favors controller and } \\
\text { quick relief } \\
\text { Sears, } 2008^{97} \\
\text { RR } 1.22(1.03 \text { to } 1.44) \\
\text { Quirce, } 2011^{91} \\
\text { RR } 1.09(0.92 \text { to } 1.30)\end{array}$ & $\begin{array}{l}\text { Moderate } \\
\text { (medium ROB) }\end{array}$ \\
\hline \multirow[t]{2}{*}{ Spirometry } & FEV1 & $\begin{array}{l}1 \mathrm{RCT}^{82} \\
(271)\end{array}$ & $\begin{array}{l}\text { No difference } \\
\text { Louis, } 2009^{82} \\
\text { MD }-0.03(-0.12 \text { to } 0.06)\end{array}$ & $\begin{array}{l}\text { Low } \\
\text { (unknown }^{\text {consistency) }} \\
\text { con }^{\text {b }}\end{array}$ \\
\hline & FEV1 \% predicted & $\begin{array}{l}1 \mathrm{RCT}^{95} \\
(102)\end{array}$ & $\begin{array}{l}\text { No difference } \\
\text { Riemersma, } 2012^{95} \\
\text { MD } 0.70(-1.80 \text { to } 3.20)\end{array}$ & $\begin{array}{l}\text { Low } \\
\text { (unknown } \\
\text { consistency) }^{\mathrm{b}} \\
\end{array}$ \\
\hline \multirow[t]{2}{*}{$\begin{array}{l}\text { Health care } \\
\text { utilization }\end{array}$} & $\begin{array}{l}\text { Rescue medication } \\
\text { use, number of } \\
\text { inhalations/day }\end{array}$ & $\begin{array}{l}2 \mathrm{RCTS}^{82,97} \\
(2404)\end{array}$ & $\begin{array}{l}\text { Favors controller and } \\
\text { quick relief } \\
\text { Sears, } 2008^{97} \\
\text { MD }-0.16(-0.26 \text { to }-0.05) \\
\text { Louis, } 2009^{82} \\
\text { MD }-0.10(-0.24 \text { to } 0.03)\end{array}$ & $\begin{array}{l}\text { Moderate } \\
\text { (medium ROB) }\end{array}$ \\
\hline & $\begin{array}{l}\geq 1 \text { day } w / P R N \\
\text { inhalation }\end{array}$ & $\begin{array}{l}2 \mathrm{RCTs}^{82,91} \\
(1562)\end{array}$ & $\begin{array}{l}\text { Favors CBP } \\
\text { Louis, } 2009^{82} \\
\text { RR } 2.96(2.42 \text { to } 3.61) \\
\text { Quirce, } 2011^{91} \\
\text { RR } 0.96(0.90 \text { to } 1.01)\end{array}$ & $\begin{array}{l}\text { Low } \\
\text { (medium ROB, } \\
\text { inconsistent) }\end{array}$ \\
\hline
\end{tabular}

Abbreviations: $\mathrm{ACQ}=$ Asthma Control Questionnaire; $\mathrm{CBP}=$ conventional best practice; $\mathrm{CI}=$ confidence interval; $\mathrm{ER}=\mathrm{emergency}$ room; FEV1=forced expiratory volume in one second; $\mathrm{MD}=$ mean difference; $\mathrm{n}=$ patient sample size; $\mathrm{OR}=\mathrm{odds}$ ratio; $\mathrm{PRN}=\mathrm{pro}$ re nata (as-needed); RCT=randomized controlled trial; ROB=risk of bias; RR=relative risk

${ }^{a}$ Responder was defined as a reduction in score by 0.5 or more

bStrength of evidence was rated low even in the setting of one domain downgraded because of the small sample size within a single trial for this outcome and thus lack of confidence in the true effect estimate.

\section{Overview of Studies}

Six RCTs ${ }^{82,91,95,97,98,100}(n=6832)$ and two observational studies ${ }^{79,114}(n=536)$ were included in the analysis of ICS and LABA as controller and quick relief versus CBP, all fitting the age category of 12 years of age and older (mean age 40 to 51y). Two trials enrolled patients with mild to severe asthma, ${ }^{91,97} 1$ enrolled mild to moderate asthma, ${ }^{95}$ and the remaining trials did not further classify persistent asthma severity. Two trials enrolled patients considered to have suboptimal asthma control ${ }^{91,97}$ and the remaining trials enrolled a mixed population in terms of control and/or symptom presence ${ }^{82,95,98,100}$ One trial reported race, which was 94 percent Caucasian.${ }^{97}$ All trials compared budesonide/formoterol as both controller and quick relief to what we refer to as "CBP". All patients in the CBP groups received at a minimum ICS and of the trials reporting further details ${ }^{82,91,97,98}$ greater than 80 percent were also on LABA. Changes in medications and doses were determined by the physician throughout the course of the trial. All trials were multicenter industry sponsored. Trials ranged from 6 to $12 \mathrm{~m}$ in duration. Risk of bias was medium in all trials due to the open-label design and the risk of performance and detection bias.

\section{Results}

ICS and LABA as controller and quick relief versus CBP did not significantly differ in the effect on the risk of exacerbations requiring systemic corticosteroids, requiring hospitalization, or requiring ER visits (all low SOE) (Figure 8, Panels A-C) but when evaluated as a composite 
outcome reduces the risk of exacerbations by 22 percent (moderate SOE) (Figure 8, Panel D). Time to first composite exacerbation was not significantly reduced [HR 0.85 (0.58 to 1.23)] while the IRR was in favor of ICS and LABA as controller and quick relief therapy [IRR 0.83 ( 0.70 to 0.99$)$ ]. Deaths were infrequent and occurred in 3 of the 4 trials reporting this outcome $^{82,97,98}$ and no difference was detected. No asthma-specific deaths occurred. Spirometry was infrequently reported and in the single trial that measured FEV1 and FEV1 percent predicted, no difference was found (both low SOE). Mean difference in ACQ-5 favored ICS and LABA as controller and quick relief therapy (MD -0.09, moderate SOE) while the chance of being an ACQ-5 responder was increased in 1 trial $^{97}$ with ICS and LABA as controller and quick relief by 22 percent (moderate SOE) but a second trial ${ }^{91}$ found no difference.

Asthma-specific quality of life was not reported in these trials. The mean difference in rescue medication use favored ICS and LABA controller and quick relief therapy in 1 trial $^{97}$ but was no different in a second trial ${ }^{82}$ (moderate SOE). The chance of needing at least 1 day with as-needed inhaler use favored CBP in 1 trial $^{82}$ but found no difference in a second trial ${ }^{91}$. Three trials ${ }^{82,91,97}$ reported the total number of oral corticosteroid days during the trial which was numerically higher with CBP in each trial and one trial provided a p-value indicating statistical significance.

Two observational studies evaluated patients who were treated with ICS and LABA as a controller and quick relief medication versus ICS and LABA as controller with SABA quick relief. ${ }^{79,114}$ In both studies, the mean age was 50y, race was not reported, and asthma was described as requiring step 3 treatment according to the Global Initiative for Asthma guidelines. Kardos et al., ${ }^{79}$ was industry sponsored and determined to have low risk of bias while Loh et al., ${ }^{114}$ was nonindustry sponsored but with medium risk of bias due to incomparability of the groups compared. Kardos et al., ${ }^{79}$ found that mean annual exacerbation rate was not significantly different with ICS and LABA controller and quick relief ([0.20 (0.14 to 0.29)] compared to ICS and LABA controller [0.17 (0.10 to 0.29)], $\mathrm{p}=0.66)$. Rescue medication use was reduced with ICS and LABA controller and quick relief versus ICS and LABA controller [MD -0.266 (-0.474 to -0.057), $\mathrm{p}=0.013]$. AQLQ(S) change from baseline was greater in the ICS and LABA controller group [mean change $0.42(0.89)$ ] than in the ICS and LABA controller and quick relief group [mean change $0.25(0.82)]$. FEV1 improved in both groups and the difference was greater in the ICS and LABA controller and quick relief group [mean change $0.13(0.48)$ versus 0.07 (0.431)]. Two patients (0.6\%) needed ER treatment in the ICS and LABA controller and quick relief group and one (0.6\%) needed hospitalization in the ICS and LABA controller group. Loh et al., ${ }^{114}$ found that rescue medication use was reduced significantly in both patients treated with ICS and LABA controller and quick relief and those treated with ICS and LABA controller. In the ICS and LABA controller and quick relief group, FEV1 significantly improved (median difference $90 \mathrm{~mL}, \mathrm{p}=0.013$ ) as did the rate of hospitalizations ( $\mathrm{p}=0.039)$ compared with ICS and LABA controller, although the rate of ER visits did not differ. 
Figure 8. Risk of exacerbation: ICS and LABA controller and quick relief versus CBP

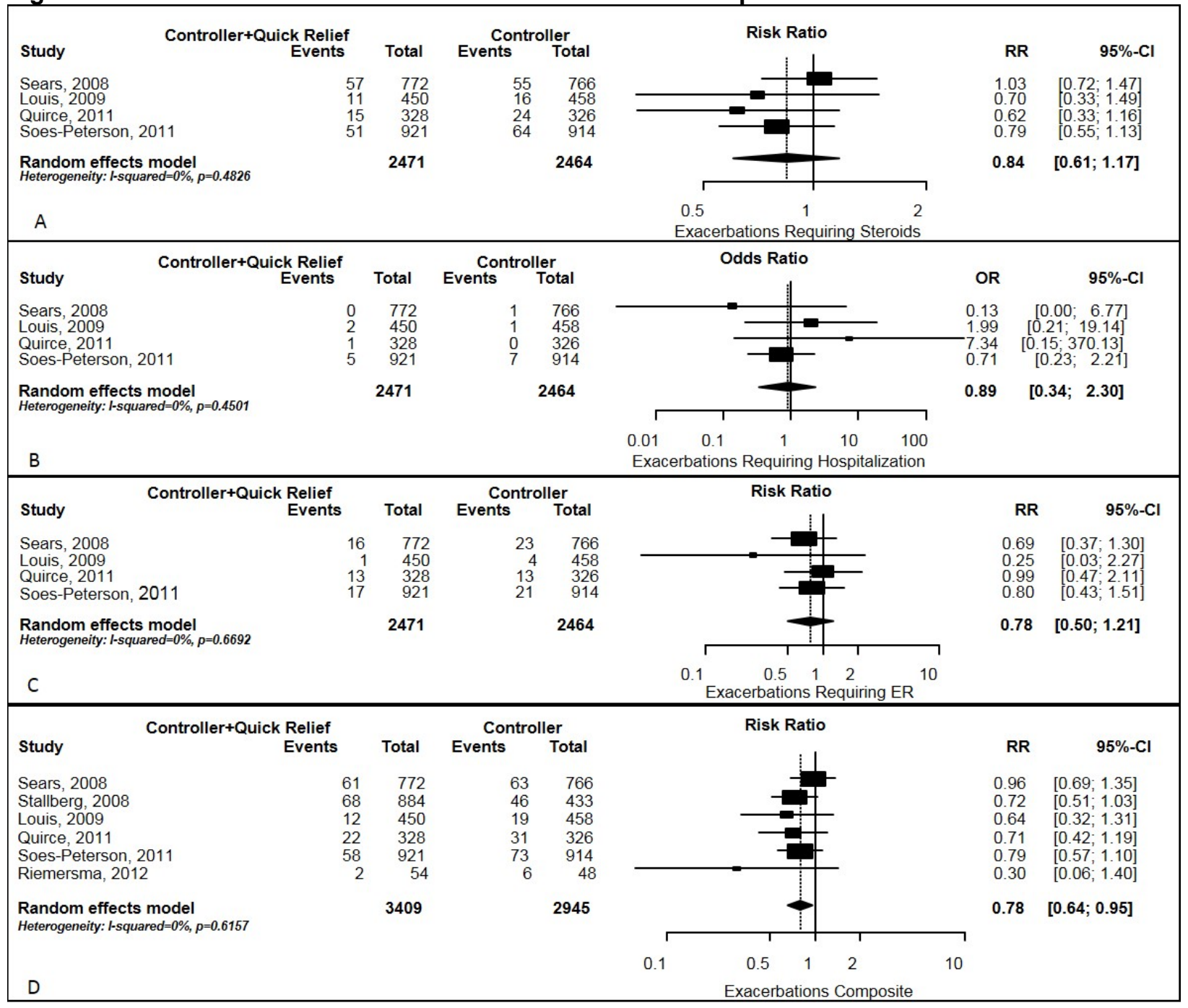

$\mathrm{CI}$ = confidence interval; ER = emergency room; RR = relative risk

KQ2a: What is the comparative effectiveness of long-acting muscarinic antagonist (LAMA) as add-on to ICS controller therapy compared to placebo or increased ICS dose in patients 12 years of age and older with uncontrolled, persistent asthma?

\section{Key Points-LAMA Versus Placebo as Add-on to ICS}

- LAMA versus placebo as add-on to ICS reduces the risk of exacerbations requiring systemic corticosteroids (high SOE) and the risk of asthma worsening (high SOE), and leads to improved mean differences in peak, trough and area under the curve (AUC) for FEV1 and FVC (all high SOE).

- LAMA versus placebo as add-on to ICS does not significantly differ in effect on asthma control composite scores (moderate SOE), asthma-specific quality of life (low to high $\mathrm{SOE}$ ) or rescue medication use (moderate SOE). 


\section{Key Points-LAMA Add-on to ICS Versus Increasing ICS Dose}

- LAMA added on to ICS versus doubling the ICS dose does not significantly differ in effect on the risk of exacerbations requiring systemic corticosteroids or the mean difference in ACQ-6 score, FEV1 trough or AQLQ score (all low SOE).

Table 21. Evidence overview for KQ2a, LAMA as add-on to ICS versus placebo

\begin{tabular}{|c|c|c|c|c|}
\hline $\begin{array}{l}\text { Outcome } \\
\text { category }\end{array}$ & Outcome & $\begin{array}{l}\text { Quantity and type } \\
\text { of evidence } \\
\text { (n) }\end{array}$ & $\begin{array}{c}\text { Conclusion } \\
\text { Effect estimate }(95 \% \mathrm{Cl})\end{array}$ & $\begin{array}{l}\text { Strength of } \\
\text { evidence } \\
\text { (rationale) }\end{array}$ \\
\hline \multirow[t]{2}{*}{ Exacerbations } & $\begin{array}{l}\text { Requiring systemic } \\
\text { corticosteroid }\end{array}$ & $\begin{array}{l}5 \text { RCTs }^{118-120,122,123} \\
(3036)\end{array}$ & $\begin{array}{l}\text { Favors LAMA } \\
\text { RR } 0.67 \text { (0.48 to 0.92) }\end{array}$ & High \\
\hline & Asthma worsening ${ }^{a}$ & $\begin{array}{l}3 \mathrm{RCTs}^{119,122,123} \\
(2420)\end{array}$ & $\begin{array}{l}\text { Favors LAMA } \\
\text { RR } 0.81 \text { (0.68 to 0.97) }\end{array}$ & High \\
\hline \multirow[t]{2}{*}{ Death } & All-cause & $\begin{array}{l}6 \mathrm{RCTs}^{119-123} \\
(3065)\end{array}$ & No deaths occurred & $\begin{array}{l}\text { Insufficient } \\
\text { (no events } \\
\text { occurred) }\end{array}$ \\
\hline & Asthma-specific & $\begin{array}{l}6 \text { RCTs } \\
\text { (3065) }\end{array}$ & No deaths occurred & $\begin{array}{l}\text { Insufficient } \\
\text { (no events } \\
\text { occurred) } \\
\end{array}$ \\
\hline \multirow{2}{*}{$\begin{array}{l}\text { Asthma control } \\
\text { composite } \\
\text { scores }\end{array}$} & ACQ-7 score & $\begin{array}{l}4 \mathrm{RCTs}^{119,122,123} \\
(2304)\end{array}$ & $\begin{array}{l}\text { No difference } \\
\text { MD }-0.10 \text { (-0.28 to } 0.07)\end{array}$ & $\begin{array}{l}\text { Moderate } \\
\text { (inconsistent) }\end{array}$ \\
\hline & ACQ-7 responder ${ }^{b}$ & $\begin{array}{l}5 \mathrm{RCTs}^{119-123} \\
(2680)\end{array}$ & $\begin{array}{l}\text { No difference } \\
\text { RR } 1.08 \text { (0.96 to } 1.21)\end{array}$ & $\begin{array}{l}\text { Moderate } \\
\text { (inconsistent) }\end{array}$ \\
\hline \multirow[t]{7}{*}{ Spirometry } & FEV1 peak & $\begin{array}{l}4 \mathrm{RCTs}^{119,122,123} \\
(2310)\end{array}$ & $\begin{array}{l}\text { Favors LAMA } \\
\text { MD } 0.18(0.13 \text { to } 0.24)\end{array}$ & High \\
\hline & FEV1 trough & $\begin{array}{l}7 \mathrm{RCTs}^{119-123} \\
(3173)\end{array}$ & $\begin{array}{l}\text { Favors LAMA } \\
\text { MD } 0.13(0.10 \text { to } 0.17)\end{array}$ & High \\
\hline & FEV1 AUC & $\begin{array}{l}\text { 3 RCTs }{ }^{119,122,123} \\
(2310)\end{array}$ & $\begin{array}{l}\text { Favors LAMA } \\
\text { MD } 0.18(0.13 \text { to } 0.23)\end{array}$ & High \\
\hline & FEV1 \% predicted & $\begin{array}{l}1 \mathrm{RCT}^{122} \\
(457)\end{array}$ & $\begin{array}{l}\text { Favors LAMA } \\
\text { Paggiaro, } 2016^{112} \\
\text { MD } 3.5 \text { (1.58 to } 5.42)\end{array}$ & $\begin{array}{l}\text { Low } \\
\text { (unknown } \\
\text { consistency) }\end{array}$ \\
\hline & FVC peak & $\begin{array}{l}3 \mathrm{RCTs}^{119,123} \\
(1853)\end{array}$ & $\begin{array}{l}\text { Favors LAMA } \\
\text { MD } 0.11(0.05 \text { to } 0.18)\end{array}$ & High \\
\hline & FVC trough & $\begin{array}{l}5 \mathrm{RCTs}^{118,119,121,123} \\
(2390)\end{array}$ & $\begin{array}{l}\text { Favors LAMA } \\
\text { MD } 0.08(0.04 \text { to } 0.13)\end{array}$ & High \\
\hline & FVC AUC & $\begin{array}{l}\text { 3 RCTs }{ }^{119,123} \\
1859)\end{array}$ & $\begin{array}{l}\text { Favors LAMA } \\
\text { MD } 0.11(0.05 \text { to } 0.17)\end{array}$ & High \\
\hline \multirow[t]{2}{*}{ Quality of life } & AQLQ score & $\begin{array}{l}2 \mathrm{RCTs}^{119} \\
(1461)\end{array}$ & $\begin{array}{l}\text { No difference } \\
\text { Kerstjens Trial } 1,2015^{119} \\
\text { MD } 0.07(-0.06 \text { to } 0.20) \\
\text { Kerstjens Trial } 2,2015^{119} \\
\text { MD } 0.11 \text { (-0.03 to } 0.25)\end{array}$ & High \\
\hline & AQLQ-mini score & $\begin{array}{l}1 \mathrm{RCT}^{118} \\
(253)\end{array}$ & $\begin{array}{l}\text { No difference } \\
\text { Bateman, } 2011^{118} \\
\text { MD }-0.09(-0.27 \text { to } 0.08)\end{array}$ & $\begin{array}{l}\text { Low } \\
\text { (unknown }_{\text {consistency) }}\end{array}$ \\
\hline $\begin{array}{l}\text { Health care } \\
\text { utilization }\end{array}$ & $\begin{array}{l}\text { Rescue medication use, } \\
\text { number of puffs in } 24 \mathrm{~h}\end{array}$ & $\begin{array}{l}7 \text { RCTs } 119-123 \\
(3104)\end{array}$ & $\begin{array}{l}\text { No difference } \\
\text { MD }-0.08(-0.23 \text { to } 0.07)\end{array}$ & $\begin{array}{l}\text { Moderate } \\
\text { (inconsistent) }\end{array}$ \\
\hline
\end{tabular}

ACQ = Asthma Control Questionnaire; AQLQ = Asthma Quality of Life Questionnaire; AUC = area under the curve; CI = confidence interval; FEV1 = forced expiratory volume in one second; ICS = inhaled corticosteroid; LAMA = long-acting muscarinic antagonist; $\mathrm{MD}=$ mean difference; $\mathrm{n}$ = patient sample size; $\mathrm{PEF}=$ peak expiratory flow; RCT = randomized controlled trial; $\mathrm{RR}=$ relative risk

${ }^{\text {a }}$ Defined as progressive increase in asthma symptoms compared to day-to-day symptoms or a decrease in morning PEF greater than or equal to 30 percent for 2 or more days

bDefined as a decrease in score by 0.5 or more 
'Strength of evidence was rated low even in the setting of one domain downgraded because of the small sample size within a single trial for this outcome and thus lack of confidence in the true effect estimate.

Table 22. Evidence overview for KQ2a, LAMA as add-on to ICS versus doubling the ICS dose

\begin{tabular}{|c|c|c|c|c|}
\hline $\begin{array}{l}\text { Outcome } \\
\text { category }\end{array}$ & Outcome & $\begin{array}{l}\text { Quantity and } \\
\text { type of } \\
\text { evidence } \\
\text { (n) }\end{array}$ & $\begin{array}{c}\text { Conclusion } \\
\text { Effect estimate }(95 \% \mathrm{Cl})\end{array}$ & $\begin{array}{l}\text { Strength of evidence } \\
\text { (rationale) }\end{array}$ \\
\hline \multirow[t]{2}{*}{ Exacerbations } & $\begin{array}{l}\text { Requiring systemic } \\
\text { corticosteroid }\end{array}$ & $\begin{array}{l}1 \mathrm{RCT}^{27} \\
(210)\end{array}$ & $\begin{array}{l}\text { No difference } \\
\text { Peters, } 2010^{27} \\
\text { RR } 0.48(0.12 \text { to } 1.84)\end{array}$ & $\begin{array}{l}\text { Low } \\
\text { (unknown } \\
\text { consistency, } \\
\text { imprecise) }\end{array}$ \\
\hline & $\begin{array}{l}\text { Requiring oral } \\
\text { corticosteroid or } \\
\text { increase in ICS or other } \\
\text { asthma medication }\end{array}$ & $\begin{array}{l}1 \mathrm{RCT}^{27} \\
(210)\end{array}$ & $\begin{array}{l}\text { No difference } \\
\text { Peters, } 2010^{27} \\
\text { RR } 0.32(0.09 \text { to } 1.13)\end{array}$ & $\begin{array}{l}\text { Low } \\
\text { (unknown } \\
\text { consistency, } \\
\text { imprecise) }\end{array}$ \\
\hline $\begin{array}{l}\text { Asthma } \\
\text { control } \\
\text { composite } \\
\text { scores }\end{array}$ & ACQ-6 score & $\begin{array}{l}1 \mathrm{RCT}^{27} \\
(127)\end{array}$ & $\begin{array}{l}\text { No difference } \\
\text { Peters, } 2010^{27} \\
\text { MD }-0.15(-0.45 \text { to } 0.15)\end{array}$ & $\begin{array}{l}\text { Low } \\
\text { (unknown }^{\text {consistency) }}\end{array}$ \\
\hline Spirometry & FEV1 trough & $\begin{array}{l}1^{1 \mathrm{RCT}^{27}} \\
(118)\end{array}$ & $\begin{array}{l}\text { No difference } \\
\text { Peters, } 2010^{27} \\
\text { MD 0.09 }(-0.20 \text { to } 0.38)\end{array}$ & $\begin{array}{l}\text { Low } \\
\text { (unknown }_{\text {consistency) }} \text { a }\end{array}$ \\
\hline Quality of life & AQLQ score & $\begin{array}{l}1 \mathrm{RCT}^{27} \\
(122)\end{array}$ & $\begin{array}{l}\text { No difference } \\
\text { Peters, } 2010^{27} \\
\text { MD 0.04 (-0.32 to } 0.40)\end{array}$ & $\begin{array}{l}\text { Low } \\
\text { (unknown } \\
\text { consistency)a }\end{array}$ \\
\hline
\end{tabular}

ACQ = Asthma Control Questionnaire; AQLQ = Asthma Quality of Life Questionnaire; AUC = area under the curve; CI = confidence interval; FEV1 = forced expiratory volume in one second; ICS = inhaled corticosteroid; LAMA = long-acting muscarinic antagonist; $\mathrm{MD}=$ mean difference; $\mathrm{n}=$ patient sample size; $\mathrm{PEF}=$ peak expiratory flow; $\mathrm{RCT}=$ randomized controlled trial; $\mathrm{RR}=$ relative risk

a Strength of evidence was rated low even in the setting of one domain downgraded because of the small sample size within a single trial for this outcome and thus lack of confidence in the true effect estimate.

\section{LAMA Versus Placebo as Add-on to ICS}

\section{Overview of Studies}

Seven RCTs ${ }^{118-123}$ ( $\left.n=3321\right)$ were included in the analysis of LAMA versus placebo as addon to ICS, one had a crossover design. ${ }^{120}$ Two replicate trials were reported in a single publication and each trial results were considered unique except for the results that were only reported in a combined way. ${ }^{119}$ Six trials were multicenter, multinational trials ${ }^{118-120,122,123}$ and 1 trial was conducted in Japan. ${ }^{121}$ All trials reported industry sponsorship. Trials ranged from 15d to 52 weeks in duration. All trials required an age of at least 18 years for inclusion except (mean age 41 to $47 \mathrm{y}$ ) one trial ${ }^{123}$ which focused on patients 12 to $17 \mathrm{y}$ old (mean age $14 \mathrm{y}$ ). Patients in the trials reporting race ${ }^{118,120}$ were mostly Caucasian (87\% to $\left.93.3 \%\right)$. One trial ${ }^{121}$ allowed the continued use of pretrial LABA while a second trial ${ }^{123}$ did so for pretrial leukotriene receptor antagonist (LTRA). One trial ${ }^{120}$ studied the LAMA umeclidinium while the others studied tiotropium. Risk of bias was low in 6 trials $^{118,119,121,-123}$ and unclear in 1 trial. $^{120}$

\section{Results}

As add-on to ICS, LAMA decreases the risk of exacerbation requiring systemic corticosteroid by 33 percent (high SOE) (Figure 9, Panel A) and decreases the risk of asthma worsening by 19 percent (high SOE) (Figure 9, Panel B versus placebo. No deaths occurred in the six trials reporting this outcome. 
Most measures of lung function obtained from spirometry were improved with LAMA versus placebo, including peak FEV1 (MD 0.18L), trough FEV1 (MD 0.13L) and FEV1 AUC (MD 0.18L), peak FVC (MD 0.11 L), trough FVC (MD 0.08L) and FVC AUC (MD 0.11L) (all with high SOE). FEV1 percent predicted was reported in one trial ${ }^{122}$ and was increased with LAMA versus placebo (MD 3.5\%, low SOE). Despite these improvements, the mean difference in ACQ7 score (moderate SOE) was no different with LAMA versus placebo nor was the chance of being a responder (moderate SOE).

Asthma-specific quality of life was no different with LAMA versus placebo, regardless of AQLQ tool version or when evaluated as a mean difference or as a responder (low to high SOE). The only health care utilization outcome reported was the use of rescue medication defined as the mean number of puffs per 24 hours. The mean difference in rescue medication use was no different with LAMA versus placebo (moderate SOE).

\section{Subgroup Data}

Tiotropium dose: We conducted preplanned subgroup analysis based on the dose of tiotropium because the a priori base analysis combined tiotropium doses as one intervention arm. Overall, the data do not suggests any substantial differences in the overall conclusions when tiotropium doses were compared separately versus placebo or against each other (Appendix Table 21).

Disease duration, age, smoking status, FEV1 percent predicted, allergic status, BMI: Four ${ }^{119,122,123}$ of the 8 included RCTs conducted subgroup analysis within the original trial.

Kertjens et al., ${ }^{119}$ combined data from the two replicate trials and in a pre-planned subgroup analysis found the following did not influence outcomes of FEV1 peak and trough: disease duration, age, smoking history, FEV1 percent predicted at baseline, allergic status and body mass index (BMI). Hamelmann et al., ${ }^{123}$ also found that age did not influence outcomes of FEV1 peak and trough. Paggiaro et al., ${ }^{122}$ also found that age did not influence outcomes of FEV1 peak, trough and percent predicted, neither did smoking history. 
Figure 9. Risk of exacerbation and of asthma worsening with LAMA versus placebo as add-on to ICS

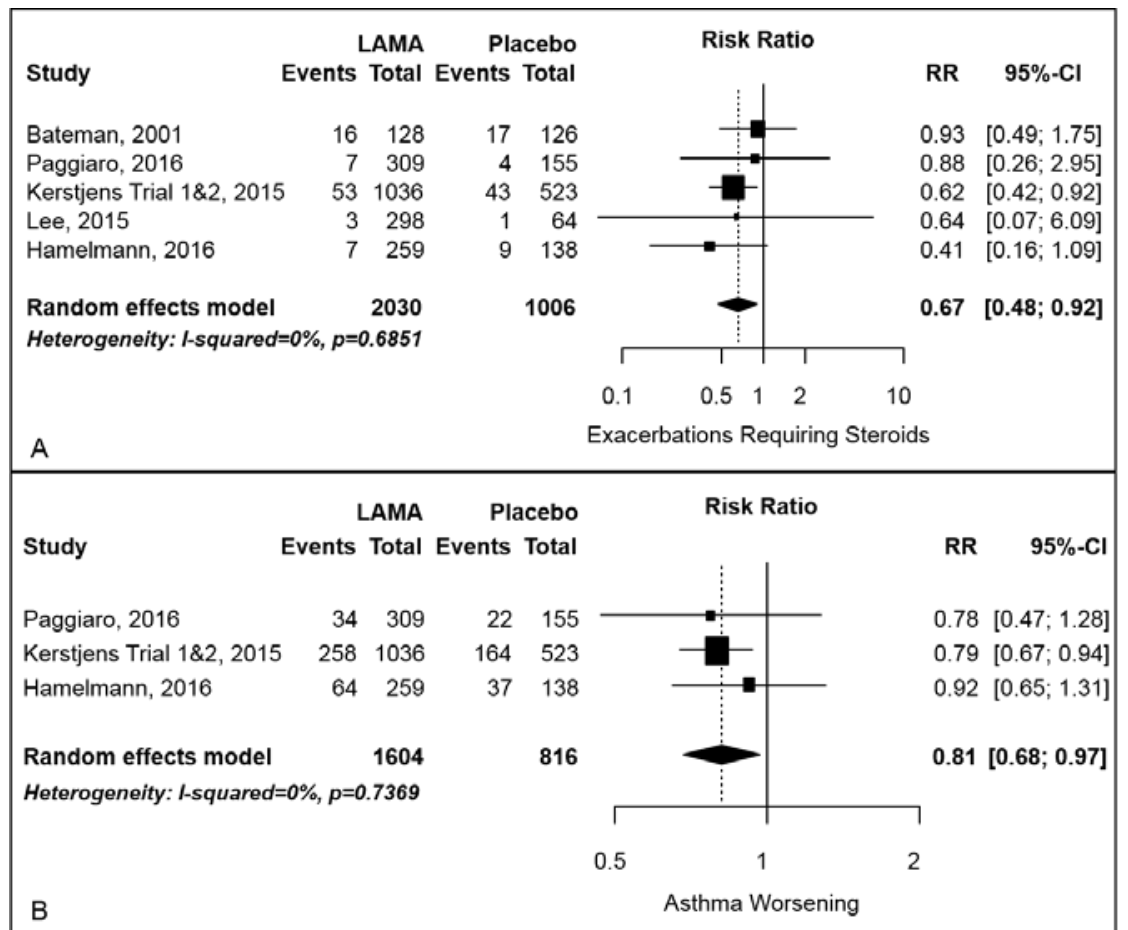

$\mathrm{CI}=$ confidence interval; LAMA = long-acting muscarinic antagonists; RR = relative risk

\section{LAMA as Add-on to ICS Versus Increasing the ICS Dose}

\section{Overview of Studies}

One cross-over trial ${ }^{27}(n=210)$ compared the addition of tiotropium $18 m c g$ daily to the run-in dose of ICS versus doubling the dose of ICS for a treatment period of 15 weeks. This study was conducted in the US with nonindustry sponsorship and had a low risk of bias. Patients were required to be at least 18y old for enrollment (mean age 42y). Race was Caucasian in 54.8 percent of patients.

\section{Results}

There was no difference in the risk of exacerbations requiring oral or intravenous corticosteroids with tiotropium added to ICS versus doubling the ICS dose (low SOE). This $\operatorname{trial}^{27}$ also reported the number of patients with exacerbations that required oral corticosteroids or increased use of ICS or other asthma medications, which was not different with tiotropium added to ICS versus doubling the ICS dose (low SOE). No other exacerbation outcomes or death were reported. There was no difference with tiotropium added to ICS versus doubling the ICS dose for any other outcome analyzed including mean difference in ACQ-6, FEV1 trough and AQLQ (all low SOE).

KQ2b: What is the comparative effectiveness of LAMA compared to other controller therapy as add-on to ICS in patients 12 years of age and older with uncontrolled, persistent asthma? 


\section{Key Points}

- LAMA versus LABA as add-on to ICS does not significantly differ in their effect on the risk of exacerbations requiring systemic corticosteroids (low SOE) or risk of asthma worsening (moderate SOE), death (low SOE), asthma control composite scores (low to high SOE), spirometry measures (low to high SOE), asthma-specific quality of life (low to high SOE) or rescue medication use (low SOE).

- Few studies, limited to outcomes of FEV1 percent predicted and rescue medication use, compared LAMA to controllers other than LABA as add-on to ICS.

Table 23. Evidence overview for KQ2b, LAMA versus LABA as add-on to ICS

\begin{tabular}{|c|c|c|c|c|}
\hline $\begin{array}{l}\text { Outcome } \\
\text { category }\end{array}$ & Outcome & $\begin{array}{l}\text { Quantity and } \\
\text { type of } \\
\text { evidence (n) }\end{array}$ & $\begin{array}{c}\text { Conclusion } \\
\text { Effect estimate }(95 \% \mathrm{Cl})\end{array}$ & $\begin{array}{l}\text { Strength of } \\
\text { evidence } \\
\text { (rationale) }\end{array}$ \\
\hline \multirow[t]{3}{*}{ Exacerbations } & $\begin{array}{l}\text { Requiring systemic } \\
\text { corticosteroid }\end{array}$ & $\begin{array}{l}4 \mathrm{RCTS}^{27,118-120} \\
(2574)\end{array}$ & $\begin{array}{l}\text { No difference } \\
\text { RR } 0.87 \text { (0.53 to } 1.42 \text { ) }\end{array}$ & $\begin{array}{l}\text { Low } \\
\text { (inconsistent, } \\
\text { imprecise) }\end{array}$ \\
\hline & Asthma worsening $^{\mathrm{a}}$ & $\begin{array}{l}1 \mathrm{RCT}^{119} \\
(1577)\end{array}$ & $\begin{array}{l}\text { No difference } \\
\text { Kerstjens Trial } 1 \& 2,2015^{119} \\
\text { RR } 1.00(0.84 \text { to } 1.20)\end{array}$ & $\begin{array}{l}\text { Moderate } \\
\text { (unknown } \\
\text { consistency) }\end{array}$ \\
\hline & $\begin{array}{l}\text { Requiring oral } \\
\text { corticosteroid or } \\
\text { increase in ICS or } \\
\text { other asthma } \\
\text { medication }\end{array}$ & $\begin{array}{l}1 \mathrm{RCT}^{27} \\
(210)\end{array}$ & $\begin{array}{l}\text { No difference } \\
\text { Peters, } 2010^{27} \\
\text { RR } 0.60(0.15 \text { to } 2.42)\end{array}$ & $\begin{array}{l}\text { Low } \\
\text { (unknown } \\
\text { consistency } \\
\text { imprecise) }\end{array}$ \\
\hline \multirow[t]{2}{*}{ Death } & All-cause & $\begin{array}{l}4 \mathrm{RCTs}^{119,120,148} \\
(3572)\end{array}$ & $\begin{array}{l}\text { No difference } \\
\text { OR } 7.50 \text { (0.78 to } 72.27)\end{array}$ & $\begin{array}{l}\text { Low } \\
\text { (inconsistent, } \\
\text { imprecise) }\end{array}$ \\
\hline & Asthma-specific & $\begin{array}{l}4 \mathrm{RCTs}^{119,120,148} \\
(3572)\end{array}$ & $\begin{array}{l}\text { No difference } \\
\text { OR } 7.49(0.47 \text { to } 119.86)\end{array}$ & $\begin{array}{l}\text { Low } \\
\text { (inconsistent, } \\
\text { imprecise) }\end{array}$ \\
\hline \multirow[t]{3}{*}{$\begin{array}{l}\text { Asthma control } \\
\text { composite } \\
\text { scores }\end{array}$} & ACQ-6 score & $\begin{array}{l}1 \mathrm{RCT}^{27} \\
(126)\end{array}$ & $\begin{array}{l}\text { No difference } \\
\text { Peters, } 2010^{27} \\
\text { MD } 0.30(0.00 \text { to } 0.60)\end{array}$ & $\begin{array}{l}\text { Low } \\
\text { (unknown } \\
\text { consistency, } \\
\text { imprecise) }\end{array}$ \\
\hline & ACQ-7 score & $\begin{array}{l}2 \mathrm{RCTs}^{119} \\
(1577)\end{array}$ & $\begin{array}{l}\text { No difference } \\
\text { Kerstjens Trial } 1,2015^{119} \\
\text { MD } 0.04(-0.05 \text { to } 0.13) \\
\text { Kerstjens Trial } 2,2015^{119} \\
\text { MD } 0.00(-0.09 \text { to } 0.09) \\
\end{array}$ & High \\
\hline & ACQ-7 responder ${ }^{b}$ & $\begin{array}{l}2 \mathrm{RCTs}^{119} \\
(1577)\end{array}$ & $\begin{array}{l}\text { No difference } \\
\text { Kerstjens Trial } 1,2015^{119} \\
\text { RR } 1.06(0.96 \text { to } 1.18) \\
\text { Kerstjens Trial } 2,2015^{119} \\
\text { RR } 1.00 \text { (0.90 to } 1.12)\end{array}$ & High \\
\hline \multirow[t]{3}{*}{ Spirometry } & FEV1 peak & $\begin{array}{l}2 \mathrm{RCTs}^{119} \\
(1483)\end{array}$ & $\begin{array}{l}\text { No difference } \\
\text { Kerstjens Trial } 1,2015^{119} \\
\text { MD } 0.004 \text { (-0.05 to } 0.05) \\
\text { Kerstjens Trial } 2,2015^{119} \\
\text { MD } 0.014 \text { (-0.03 to } 0.06)\end{array}$ & High \\
\hline & FEV1 trough & $\begin{array}{l}6 \mathrm{RCTs}^{27,118-} \\
120,148 \\
(3261) \\
\end{array}$ & $\begin{array}{l}\text { No difference } \\
\text { MD } 0.02(-0.03 \text { to } 0.06)\end{array}$ & High \\
\hline & FEV1 AUC & $\begin{array}{l}2 \mathrm{RCTs}^{119} \\
(1483)\end{array}$ & $\begin{array}{l}\text { No difference } \\
\text { Kerstjens Trial } 1,2015^{119} \\
\text { MD }-0.004(-0.05 \text { to } 0.04) \\
\text { Kerstjens Trial } 2,2015^{119} \\
\text { MD } 0.004 \text { (-0.04 to } 0.05)\end{array}$ & High \\
\hline
\end{tabular}




\begin{tabular}{|c|c|c|c|c|}
\hline $\begin{array}{l}\text { Outcome } \\
\text { category }\end{array}$ & Outcome & $\begin{array}{c}\text { Quantity and } \\
\text { type of } \\
\text { evidence }(n)\end{array}$ & $\begin{array}{c}\text { Conclusion } \\
\text { Effect estimate }(95 \% \mathrm{Cl})\end{array}$ & $\begin{array}{c}\text { Strength of } \\
\text { evidence } \\
\text { (rationale) }\end{array}$ \\
\hline & FEV1 \% predicted & $\begin{array}{l}3 \mathrm{RCTS}^{146-148} \\
(542)\end{array}$ & $\begin{array}{l}\text { No difference } \\
\text { MD }-4.54(-12.69 \text { to } 3.61)\end{array}$ & $\begin{array}{l}\text { Low } \\
\text { (medium ROB, } \\
\text { inconsistent) }\end{array}$ \\
\hline & FVC peak & $\begin{array}{l}2 \mathrm{RCTs}^{119} \\
(1483)\end{array}$ & $\begin{array}{l}\text { No difference } \\
\text { Kerstjens Trial } 1,2015^{119} \\
\text { MD } 0.02(-0.04 \text { to } 0.07) \\
\text { Kerstjens Trial } 2,2015^{119} \\
\text { MD -0.02 (-0.07 to } 0.03)\end{array}$ & High \\
\hline & FVC trough & $\begin{array}{l}\text { 3 RCTs } 118-119 \\
(1745)\end{array}$ & $\begin{array}{l}\text { No difference } \\
\text { MD } 0.02(0.00 \text { to } 0.05)\end{array}$ & High \\
\hline & FVC AUC & $\begin{array}{l}2 \mathrm{RCTs}^{119} \\
(1483)\end{array}$ & $\begin{array}{l}\text { No difference } \\
\text { Kerstjens Trial } 1,2015^{119} \\
\text { MD } 0.005(-0.05 \text { to } 0.06) \\
\text { Kerstjens Trial } 2,2015^{119} \\
\text { MD }-0.03 \text { (-0.09 to } 0.03)\end{array}$ & High \\
\hline \multirow[t]{2}{*}{ Quality of life } & AQLQ score & $\begin{array}{l}4 \mathrm{RCTs}^{27,118,119} \\
(1982)\end{array}$ & $\begin{array}{l}\text { No difference } \\
\text { MD }-0.06(-0.15 \text { to } 0.03)\end{array}$ & High \\
\hline & AQLQ-mini score & $\begin{array}{l}1 \mathrm{RCT}^{118} \\
(262)\end{array}$ & $\begin{array}{l}\text { No difference } \\
\text { Bateman, } 2011^{118} \\
\text { MD -0.15 (-0.32 to } 0.02)\end{array}$ & $\begin{array}{l}\text { Low } \\
\text { (unknown }^{\text {consistency) }} \\
\text { c }^{2}\end{array}$ \\
\hline $\begin{array}{l}\text { Health care } \\
\text { utilization }\end{array}$ & $\begin{array}{l}\text { Rescue medication } \\
\text { use, number of puffs } \\
\text { in } 24 \mathrm{~h}\end{array}$ & $\begin{array}{l}7 \mathrm{RCT}^{118-120,146-} \\
148 \\
(2450)\end{array}$ & $\begin{array}{l}\text { No difference } \\
\text { MD } 0.61(-0.12 \text { to } 1.35)\end{array}$ & $\begin{array}{l}\text { Low } \\
\text { (inconsistent, } \\
\text { imprecise) }\end{array}$ \\
\hline
\end{tabular}

ACQ = Asthma Control Questionnaire; AQLQ = Asthma Quality of Life Questionnaire; AUC = area under the curve; CI = confidence interval; FEV1 = forced expiratory volume in one second; FVC = forced vital capacity; ICS = inhaled corticosteroid; LABA = long-acting $\beta_{2}$-agonist; LAMA = long-acting muscarinic antagonist; $\mathrm{MD}=$ mean difference; $\mathrm{n}=$ patient sample size; $\mathrm{RCT}=$ randomized controlled trial; $\mathrm{ROB}=$ risk of bias; $\mathrm{RR}=$ relative risk

${ }^{\text {a }}$ Defined as progressive worsening of asthma symptoms compared to day-to-day symptoms or a decrease in morning PEF greater than or equal to 30 percent for 2 or more days

bDefined as a decrease in score by 0.5 or more

${ }^{\mathrm{c}}$ Graded with low strength of evidence in the setting of one domain downgraded due to the small sample size in a single trial and lack of confidence in the true effect estimate.

Table 24. Evidence overview for KQ2b, LAMA versus montelukast as add-on to ICS

\begin{tabular}{|c|c|c|c|c|}
\hline $\begin{array}{l}\text { Outcome } \\
\text { category }\end{array}$ & Outcome & $\begin{array}{l}\text { Quantity and type } \\
\text { of evidence (n) }\end{array}$ & $\begin{array}{c}\text { Conclusion } \\
\text { Effect estimate }(95 \% \mathrm{Cl})\end{array}$ & $\begin{array}{c}\text { Strength of } \\
\text { evidence } \\
\text { (rationale) }\end{array}$ \\
\hline Spirometry & FEV1 \% predicted & $\begin{array}{l}2 \mathrm{RCTs}^{146,147} \\
(214)\end{array}$ & $\begin{array}{l}\text { Favors montelukast } \\
\text { Rajanandh, } 2014^{146} \\
\text { MD }-2.14(-2.93 \text { to }-1.35) \\
\text { Rajanandh, } 2015^{147} \\
\text { MD }-0.87(-2.77 \text { to } 1.03)\end{array}$ & $\begin{array}{l}\text { Moderate } \\
\text { (medium ROB) }\end{array}$ \\
\hline $\begin{array}{l}\text { Health care } \\
\text { utilization }\end{array}$ & $\begin{array}{l}\text { Rescue medication } \\
\text { use, number of puffs } \\
\text { in } 24 \mathrm{~h}\end{array}$ & $\begin{array}{l}2 \mathrm{RCTs}^{146,147} \\
(214)\end{array}$ & $\begin{array}{l}\text { Favors montelukast } \\
\text { Rajanandh, } 2014^{146} \\
\text { MD } 0.26(-0.25 \text { to } 0.77) \\
\text { Rajanandh, } 2015^{147} \\
\text { MD } 1.19(0.88 \text { to } 1.50)\end{array}$ & $\begin{array}{l}\text { Low } \\
\text { (medium ROB, } \\
\text { inconsistent) }\end{array}$ \\
\hline
\end{tabular}

$\mathrm{CI}$ = confidence interval; FEV1 = forced expiratory volume in one second; MD = mean difference; $\mathrm{n}$ = patient sample size; RCT $=$ randomized controlled trial; $\mathrm{ROB}=$ risk of bias; $\mathrm{RR}=$ relative risk 
Table 25. Evidence overview for KQ2b, LAMA versus doxofylline as add-on to ICS

\begin{tabular}{|c|c|c|c|c|}
\hline $\begin{array}{l}\text { Outcome } \\
\text { category }\end{array}$ & Outcome & $\begin{array}{l}\text { Quantity and type } \\
\text { of evidence (n) }\end{array}$ & $\begin{array}{c}\text { Conclusion } \\
\text { Effect estimate }(95 \% \mathrm{Cl})\end{array}$ & $\begin{array}{c}\text { Strength of } \\
\text { evidence } \\
\text { (rationale) }\end{array}$ \\
\hline Spirometry & FEV1 \% predicted & $\begin{array}{l}2 \mathrm{RCTs}^{146,147} \\
(209)\end{array}$ & $\begin{array}{l}\text { Favors doxofylline } \\
\text { Rajanandh, } 2014^{146} \\
\text { MD }-3.87(-4.6 \text { to }-3.14) \\
\text { Rajanandh, } 2015^{147} \\
\text { MD }-2.69(-4.79 \text { to }-0.59)\end{array}$ & $\begin{array}{l}\text { Moderate } \\
\text { (medium ROB) }\end{array}$ \\
\hline $\begin{array}{l}\text { Health care } \\
\text { utilization }\end{array}$ & $\begin{array}{l}\text { Rescue medication } \\
\text { use, number of } \\
\text { puffs in } 24 \mathrm{~h}\end{array}$ & $\begin{array}{l}2 \text { RCTs }^{146,147} \\
(209)\end{array}$ & $\begin{array}{l}\text { Favors doxofylline } \\
\text { Rajanandh, } 2014^{146} \\
\text { MD } 0.30(-0.21 \text { to } 0.81) \\
\text { Rajanandh, } 2015^{147} \\
\text { MD } 1.21(0.89 \text { to } 1.53)\end{array}$ & $\begin{array}{l}\text { Low } \\
\text { (medium ROB, } \\
\text { inconsistent) }\end{array}$ \\
\hline
\end{tabular}

$\mathrm{CI}$ = confidence interval; FEV1 = forced expiratory volume in one second; MD = mean difference; $\mathrm{n}$ = patient sample size; RCT $=$ randomized controlled trial; $\mathrm{ROB}=$ risk of bias; $\mathrm{RR}=$ relative risk

\section{LAMA Versus LABA as Add-on to ICS}

\section{Overview of Studies}

Eight RCTs ${ }^{27,118-120,146-148}(n=3679)$ were included in the analysis of LAMA versus LABA as add-on to ICS, two of which were crossover in design. ${ }^{27,120}$ Two replicate trials were reported in a single publication and each trial results were considered unique except for the results that were only reported in a combined way. ${ }^{119}$ Four trials were multicenter, multinational trials reporting industry sponsorship. ${ }^{118-120}$ Two trials were conducted in Indiaa ${ }^{146,147}$ and 2 in the US, ${ }^{122,148}$ all of which were nonindustry sponsored. Trails ranged from $15 \mathrm{~d}$ to $18 \mathrm{~m}$ in duration. All trials required patients to be at least $18 y$ old for enrollment (mean age 36 to 47). One trial ${ }^{148}$ enrolled only African Americans while patients in the remaining trials reporting race $27,118,120$ were mostly Caucasian (54.8\% to 93.3\%). All trials randomized patients to LAMA versus LABA in addition to background ICS therapy. Seven trials ${ }^{27,118,119,146-148}$ studied tiotropium and one ${ }^{120}$ studied umeclidinium. Four trials ${ }^{27,118,119}$ studied salmeterol, one studied vilanterol, ${ }^{120}$ two studied formoterol, ${ }^{146,147}$ and one studied either salmeterol or formoterol based on pre-study use. ${ }^{148}$ Two trials allowed concurrent asthma therapy that were similar across arms. ${ }^{119}$ Risk of bias was low in 5 trials, ${ }^{27,118,119,148}$ medium in 1 trial (open-label), ${ }^{146}$ high in 1 trial (open-label and significant attrition), ${ }^{147}$ and unclear in 1 trial. ${ }^{120}$

\section{Results}

There was no difference in the risk of exacerbation requiring systemic corticosteroids (Figure 10) or in the risk of asthma worsening when LAMA was compared with LABA as add-on to ICS. One trial reported exacerbations requiring oral corticosteroid or an increase in ICS or other asthma medication use and the risk was no different with LAMA versus LABA. ${ }^{27}$ Of the four trials that reported death, events occurred in a single trial ${ }^{148}$ and the odds of all-cause mortality or of asthma-specific mortality was no different with LAMA versus LABA. 
Figure 10. Risk of exacerbation with LAMA versus LABA as add-on to ICS

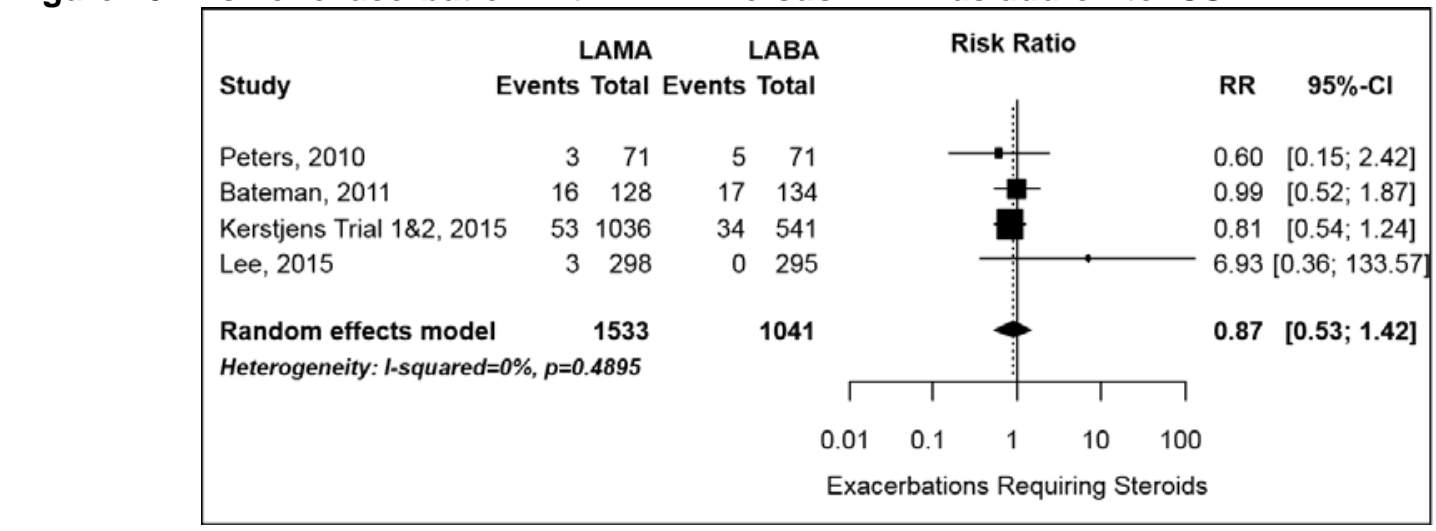

$\mathrm{CI}$ = confidence interval; LABA = long-acting beta- agonist; LAMA = long-acting muscarinic antagonists; RR = relative risk

The mean difference in ACQ-7 score or the chance of being a responder was no different with LAMA versus LABA. One trial ${ }^{27}$ reported mean difference in ACQ-6 score which was no different with LAMA versus LABA. All measures of spirometry including mean difference in FEV1 percent predicted or in peak, trough and AUC for both FEV1 and FVC were no different with LAMA versus LABA. Asthma-specific quality of life measured by the mean difference in AQLQ was no different with LAMA versus LABA. One trial evaluated the mean difference in AQLQ-mini which also found no difference with LAMA versus LABA. ${ }^{118}$ The only health care utilization outcome reported was rescue medication use, defined as the mean puffs per 24 hours. The mean change in rescue medication use was no different with LAMA versus LABA.

\section{Subgroup Data}

Disease duration, age, smoking status, FEV1 percent predicted, allergic status, BMI, bronchodilator reversibility: Three ${ }^{119,148}$ of the 8 included RCTs conducted subgroup analysis within the original trial. Kertjens et al., ${ }^{119}$ combined data from the two replicate trials and in a pre-planned subgroup analysis found the following did not influence outcomes of FEV1 peak and trough: disease duration, age, smoking history, FEV1 percent predicted at baseline, allergic status and BMI. Weschler et al., ${ }^{148}$ reported no difference in treatment effects based on BMI or smoking history but those with bronchodilator reversibility at 1 month had a higher likelihood of exacerbation with tiotropium versus LABA compared with those without reversibility at 1 month.

\section{LAMA Versus Other Controllers as Add-on to ICS}

\section{Results}

Two trials $(n=320)$ of the above 8 trials also compared LAMA versus other controllers, including montelukast 10mg daily and doxofylline 400mg daily. ${ }^{146,147}$ Mean difference in FEV1 percent predicted was reduced in one trial with LAMA versus montelukast [MD -2.14 (-2.93 to 1.35)] but no different in the second trial [MD -0.87 (-2.77 to 1.03)]. Mean difference in FEV1 percent predicted was reduced with LAMA versus doxofylline by -2.69 percent and -3.87 percent in two trials (moderate SOE). Mean difference in rescue medication use was inconsistent in the two trials comparing LAMA versus montelukast [MD 0.26 [-0.25 to 0.77) and [MD 1.19 (0.88 to 1.50$)$ ] as well as in the two trials comparing LAMA versus doxofylline [MD $0.30(-0.21$ to 0.81 ) and MD 1.21 (0.89 to 1.53)]. 
KQ2c: What is the comparative effectiveness of LAMA as add-on to ICS plus LABA compared to ICS plus LABA as controller therapy in patients 12 years of age and older with uncontrolled, persistent asthma?

\section{Key Points}

- LAMA added to ICS plus LABA versus ICS plus LABA does not significantly differ in effect on the risk of asthma exacerbations (low to moderate SOE) but does decrease the risk of asthma worsening (high SOE).

- LAMA added to ICS plus LABA versus ICS plus LABA improved the mean difference in FEV1 AUC and of peak, trough and AUC for FVC (all high SOE), the chance of being an ACQ responder (low to moderate SOE) and the chance of being an AQLQ responder (moderate SOE). There was no difference in asthma control composite scores (low to moderate SOE) or in rescue medication use (moderate SOE).

- In the single trial that compared LAMA added to ICS plus LABA versus increasing the ICS dose and continuing LABA found no significant difference in effect on the mean difference in ACT score.

Table 26. Evidence overview for KQ2c, LAMA added to ICS plus LABA versus ICS plus LABA

\begin{tabular}{|c|c|c|c|c|}
\hline Comparison & Outcome & $\begin{array}{c}\text { Quantity and } \\
\text { type of } \\
\text { evidence (n) }\end{array}$ & $\begin{array}{c}\text { Conclusion } \\
\text { Effect estimate }(95 \% \mathrm{Cl})\end{array}$ & $\begin{array}{l}\text { Strength of evidence } \\
\text { (rationale) }\end{array}$ \\
\hline \multirow[t]{3}{*}{ Exacerbations } & $\begin{array}{l}\text { Requiring systemic } \\
\text { corticosteroid }\end{array}$ & $\begin{array}{l}\text { 3 RCTs }{ }^{150,152} \\
(1299)\end{array}$ & $\begin{array}{l}\text { No Difference } \\
\text { RR } 0.84 \text { (0.57 to } 1.22)\end{array}$ & $\begin{array}{l}\text { Moderate } \\
\text { (imprecise) }\end{array}$ \\
\hline & $\begin{array}{l}\text { Requiring } \\
\text { hospitalization }\end{array}$ & $\begin{array}{l}2 \mathrm{RCTs}^{150} \\
(907)\end{array}$ & $\begin{array}{l}\text { No difference } \\
\text { Kerstjens Trial } 1,2012^{150} \\
\text { RR } 1.33 \text { (0.54 to } 3.32) \\
\text { Kerstjens Trial } 2,2012^{150} \\
\text { RR } 1.16(0.47 \text { to } 2.89)\end{array}$ & $\begin{array}{l}\text { Moderate } \\
\text { (imprecise) }\end{array}$ \\
\hline & Asthma worsening ${ }^{a}$ & $\begin{array}{l}3 \text { RCTs }{ }^{150,152} \\
(1299)\end{array}$ & $\begin{array}{l}\text { Lower with LAMA } \\
\text { RR } 0.78(0.72 \text { to } 0.86)\end{array}$ & High \\
\hline \multirow[t]{2}{*}{ Death } & All-cause & $\begin{array}{l}\text { 3 RCTs }{ }^{150,152} \\
(1299)\end{array}$ & No deaths occurred & $\begin{array}{l}\text { Insufficient } \\
\text { (no events occurred) }\end{array}$ \\
\hline & Asthma-specific & $\begin{array}{l}\text { 3 RCTss }{ }^{150,152} \\
(1299)\end{array}$ & No deaths occurred & $\begin{array}{l}\text { Insufficient } \\
\text { (no events occurred) }\end{array}$ \\
\hline \multirow{5}{*}{$\begin{array}{l}\text { Asthma } \\
\text { control } \\
\text { composite } \\
\text { scores }\end{array}$} & ACQ-5 responder ${ }^{b}$ & $\begin{array}{l}1 \mathrm{RCT}^{150} \\
(907)\end{array}$ & $\begin{array}{l}\text { Favors LAMA } \\
\text { Kerstjens Trial } 1 \& 2,2012^{150} \\
\text { OR } 1.42 \text { (1.08 to } 1.86)\end{array}$ & $\begin{array}{l}\text { Low } \\
\text { (unknown consistency, } \\
\text { imprecise) }\end{array}$ \\
\hline & ACQ-6 score & $\begin{array}{l}1 \mathrm{RCT}^{152} \\
(338)\end{array}$ & $\begin{array}{l}\text { No difference } \\
\text { Hamelmann, } 2016^{152} \\
\text { MD } 0.09(-0.08 \text { to } 0.25)\end{array}$ & $\begin{array}{l}\text { Low } \\
\text { (unknown consistency, } \\
\text { imprecise) }\end{array}$ \\
\hline & ACQ-6 responderb & $\begin{array}{l}2 \mathrm{RCTs}^{150,152} \\
(1299)\end{array}$ & $\begin{array}{l}\text { Favors LAMA } \\
\text { Hamelmann, } 2016^{152} \\
\text { RR } 1.00(0.88 \text { to } 1.12) \\
\text { Kerstjens Trial } 1 \& 2,2012^{150} \\
\text { OR } 1.49(1.14 \text { to } 1.90) \\
\end{array}$ & $\begin{array}{l}\text { Low } \\
\text { (inconsistent, } \\
\text { imprecise) }\end{array}$ \\
\hline & ACQ-7 score & $\begin{array}{l}3 \text { RCTs }{ }^{150,152} \\
(1301)\end{array}$ & $\begin{array}{l}\text { No Difference } \\
\text { MD }-0.07(-0.31 \text { to } 0.17)\end{array}$ & $\begin{array}{l}\text { Moderate } \\
\text { (inconsistent) }\end{array}$ \\
\hline & ACQ-7 responder ${ }^{b}$ & $\begin{array}{l}2 \mathrm{RCTs}^{150,152} \\
(1299)\end{array}$ & $\begin{array}{l}\text { Favors LAMA } \\
\text { Hamelmann, } 2016^{152} \\
\text { RR } 1.01(0.89 \text { to } 1.14) \\
\text { Kerstjens Trial } 1 \& 2,2012^{150} \\
\text { RR } 1.28(1.13 \text { to } 1.46)\end{array}$ & $\begin{array}{l}\text { Moderate } \\
\text { (inconsistent) }\end{array}$ \\
\hline
\end{tabular}




\begin{tabular}{|c|c|c|c|c|}
\hline Comparison & Outcome & $\begin{array}{c}\text { Quantity and } \\
\text { type of } \\
\text { evidence (n) }\end{array}$ & $\begin{array}{c}\text { Conclusion } \\
\text { Effect estimate }(95 \% \mathrm{Cl})\end{array}$ & $\begin{array}{l}\text { Strength of evidence } \\
\text { (rationale) }\end{array}$ \\
\hline \multirow[t]{6}{*}{ Spirometry } & FEV1 peak & $\begin{array}{l}3 \mathrm{RCTs}^{150,152} \\
\text { (1295) }\end{array}$ & $\begin{array}{l}\text { No difference } \\
\text { MD } 0.10 \text { (0.00 to } 0.22)\end{array}$ & $\begin{array}{l}\text { Moderate } \\
\text { (inconsistent) }\end{array}$ \\
\hline & FEV1 trough & $\begin{array}{l}\text { 3 RCTs } 150,152 \\
(1295)\end{array}$ & $\begin{array}{l}\text { No difference } \\
\text { MD } 0.07(0.00 \text { to } 0.14)\end{array}$ & $\begin{array}{l}\text { Moderate } \\
\text { (inconsistent) }\end{array}$ \\
\hline & FEV1 AUC & $\begin{array}{l}3 \mathrm{RCTs}^{150,152} \\
(1295)\end{array}$ & $\begin{array}{l}\text { Favors LAMA } \\
\text { MD } 0.10(0.01 \text { to } 0.19)\end{array}$ & High \\
\hline & FVC peak & $\begin{array}{l}\text { 3 RCTs } 150,152 \\
(1295)\end{array}$ & $\begin{array}{l}\text { Favors LAMA } \\
\text { MD } 0.11(0.05 \text { to } 0.17)\end{array}$ & High \\
\hline & FVC trough & $\begin{array}{l}\text { 3 RCTs } 150,152 \\
(1295)\end{array}$ & $\begin{array}{l}\text { Favors LAMA } \\
\text { MD } 0.09(0.03 \text { to } 0.15)\end{array}$ & High \\
\hline & FVC AUC & $\begin{array}{l}\text { 3 RCTs } 150,152 \\
(1295)\end{array}$ & $\begin{array}{l}\text { Favors LAMA } \\
\text { MD } 0.10(0.04 \text { to } 0.17)\end{array}$ & High \\
\hline \multirow[t]{2}{*}{ Quality of life } & AQLQ score & $\begin{array}{l}2 \mathrm{RCTs}^{150} \\
(907)\end{array}$ & $\begin{array}{l}\text { No difference } \\
\text { Kerstjens Trial } 1,2012^{150} \\
\text { MD 0.04 (-0.13 to } 0.20) \\
\text { Kerstjens Trial } 2,2012^{150} \\
\text { MD 0.14 (-0.03 to } 0.31)\end{array}$ & High \\
\hline & AQLQ responder ${ }^{C}$ & $\begin{array}{l}1 \mathrm{RCT}^{150} \\
(907)\end{array}$ & $\begin{array}{l}\text { Favors LAMA } \\
\text { Kerstjens Trial } 1 \& 2,2012^{150} \\
\text { RR } 1.62(1.34 \text { to } 1.96)\end{array}$ & $\begin{array}{l}\text { Moderate } \\
\text { (imprecise) }\end{array}$ \\
\hline $\begin{array}{l}\text { Health care } \\
\text { utilization }\end{array}$ & $\begin{array}{l}\text { Rescue medication } \\
\text { use, number of puffs } \\
\text { in } 24 \mathrm{~h}\end{array}$ & $\begin{array}{l}\text { 3 RCTs } 150,152 \\
(1302)\end{array}$ & $\begin{array}{l}\text { No difference } \\
\text { MD }-0.10(-0.37 \text { to } 0.18)\end{array}$ & $\begin{array}{l}\text { Moderate } \\
\text { (inconsistent) }\end{array}$ \\
\hline
\end{tabular}

ACQ = Asthma Control Questionnaire; AQLQ = Asthma Quality of Life Questionnaire; AUC = area under the curve; CI = confidence interval; $\mathrm{h}$ = hours; FEV1 = forced expiratory volume in one second; FVC = forced vital capacity; LAMA = longacting muscarinic antagonist; $\mathrm{MD}=$ mean difference; $\mathrm{n}$ = sample size; $\mathrm{OR}$ = odds ratio; $\mathrm{PEF}=$ peak expiratory flow; RCT = randomized controlled trial; $\mathrm{RR}$ = relative risk

a Defined as progressive increase in asthma symptoms compared to usual day-to-day symptoms or decrease in morning PEF greater than or equal to 30 percent for 2 or more days

${ }^{b}$ Defined as a decrease in score by 0.5 or more

'Defined as an increase in score of 0.5 or more

Table 27. Evidence overview for KQ2c, LAMA added to ICS plus LABA versus increasing ICS dose plus LABA

\begin{tabular}{|c|c|c|c|c|}
\hline Comparison & Outcome & $\begin{array}{l}\text { Quantity and } \\
\text { type of } \\
\text { evidence (n) }\end{array}$ & $\begin{array}{c}\text { Conclusion } \\
\text { Effect estimate }(95 \% \mathrm{Cl})\end{array}$ & $\begin{array}{l}\text { Strength of evidence } \\
\text { (rationale) }\end{array}$ \\
\hline $\begin{array}{l}\text { Asthma control } \\
\text { composite } \\
\text { scores }\end{array}$ & ACT score & $\begin{array}{l}1 \mathrm{RCT}^{151} \\
(63)\end{array}$ & $\begin{array}{l}\text { No difference } \\
\text { Wang, } 2012^{151} \\
\text { MD -0.61 (-4.82 to } 3.60)\end{array}$ & $\begin{array}{l}\text { Low } \\
\text { (unknown consistency, } \\
\text { imprecise) }\end{array}$ \\
\hline
\end{tabular}

ACT = Asthma Control Test; $\mathrm{CI}$ = confidence interval; $\mathrm{h}$ = hours; $\mathrm{MD}$ = mean difference; $\mathrm{n}$ = sample size; $\mathrm{RCT}=$ randomized controlled trial

\section{LAMA as Add-on to ICS Plus LABA Versus ICS Plus LABA}

\section{Overview of Studies}

Three trials ${ }^{150,152}(\mathrm{n}=1304)$ were included in the analysis of LAMA as add-on to ICS plus LABA versus ICS plus LABA. All trials were multicenter, multinational trials reporting industry sponsorship and had low risk of bias. Two trials ${ }^{150}$ required patients to be at least $18 \mathrm{y}$ for enrollment (mean age 51 to 53y) while the third trial ${ }^{152}$ focused on patients ages 12 to $17 \mathrm{y}$ (mean age 14y). Most patients were Caucasian (82.1\% to 94.6\%). Two replicate trials randomized patients taking ICS plus LABA to either tiotropium $5 \mu$ g daily or placebo for 48 weeks. ${ }^{150}$ Concurrent asthma therapies were allowed and use was similar in both arms. These two trials 
were reported in a single publication and each trial was considered unique in the analyses unless the results were only reported in the source documents in a combined fashion. ${ }^{150}$ The third trial included patients taking high-dose ICS plus one other controller or medium-dose ICS plus two other controllers and randomized patients to tiotropium $2.5 \mu \mathrm{g}$ daily, $5 \mu \mathrm{g}$ daily or placebo for 12 weeks. ${ }^{152}$ LABA was the most common additional controller (83.2\%) while use of other controllers was similar in both groups.

\section{Results}

There was no difference in the risk of exacerbation requiring systemic corticosteroids (Figure 11, Panel A) or in the risk of exacerbation requiring hospitalization when LAMA added to ICS plus LABA was compared with ICS plus LABA. The risk of asthma worsening was reduced by 22 percent with LAMA added to ICS plus LABA versus ICS plus LABA (high SOE) (Figure 11, Panel B). All three trials reported that no deaths occurred.

Figure 11. Risk of exacerbation and of asthma worsening with LAMA as add-on to ICS and LABA versus ICS and LABA

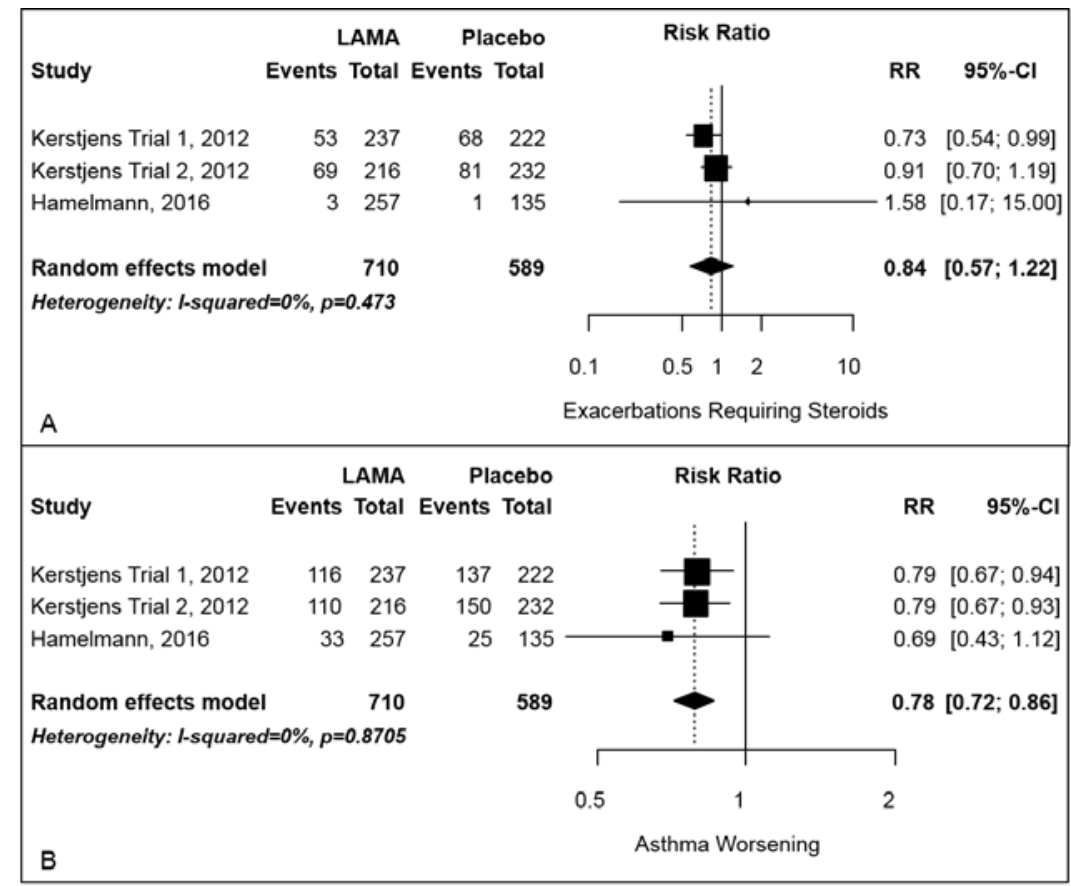

$\mathrm{CI}=$ confidence interval; LAMA = long-acting muscarinic antagonists; RR = relative risk

The MD in ACQ score (whether ACQ-6 or ACQ-7) was no different with LAMA added to ICS plus LABA versus ICS plus LABA. The chance of being an ACQ responder, regardless of the ACQ version, favored LAMA in the combined results of two replicate trials of 48 weeks duration but was no different with LAMA in the single trial of 12 weeks duration. ${ }^{142}$ Most measures of lung function obtained from spirometry were improved with LAMA added to ICS plus LABA versus ICS plus LABA including FEV1 AUC (MD 0.10 L), peak FVC (MD 0.11 L), trough FVC (MD 0.09 L) and FVC AUC (MD 0.10 L) (all with high SOE). Data suggest a trend towards improved peak and trough FEV1 with the lower limit of the confidence interval at zero. Mean difference in AQLQ was no different with LAMA added to ICS plus LABA versus ICS plus LABA although the chance of being an AQLQ responder was increased by 62 percent with LAMA added to ICS plus LABA versus ICS plus LABA. The only health care utilization 
outcome reported was rescue medication use, defined as the mean puffs per 24 hours. The mean change in rescue medication use was no different with LAMA added to ICS plus LABA versus ICS plus LABA.

\section{Subgroup Data}

We identified one post-hoc analysis ${ }^{173}$ by Kerstjens et al., that combined data from two previous replicate trials ${ }^{150}$ and found ACQ-7 responder rate at week 24 was influenced by smoking status and screening FEV1 percent predicted, favoring a response with tiotropium 5mcg versus placebo in ex-smokers and in those with lower FEV1 percent predicted at screening. ACQ-7 responder at 48 weeks was influenced by blood eosinophils favoring a response with tiotropium $5 \mathrm{mcg}$ versus placebo with lower blood counts. The following characteristics did not influence outcomes: age, race, ethnicity, disease duration, BMI, screening FEV1 percent predicted, FEV1 percent reversibility, clinician-determined allergic status and serum IgE.

\section{LAMA as Add-on to ICS Plus LABA Versus ICS Plus LABA With a Higher ICS Dose}

\section{Overview of Studies}

One trial (n=63) randomized participants taking salmeterol/fluticasone 50/250mcg twice daily to either add-on tiotropium $18 \mu \mathrm{g}$ daily or to increasing the salmeterol/fluticasone dose to 50/500mcg twice daily. ${ }^{151}$ The trial was conducted in China, funding was not reported, and the risk of bias was unclear. The population was referred to as "adults" and the mean age was 35 to 36.

\section{Results}

The only outcome reported was mean difference in ACT score which was no different LAMA added to ICS plus LABA versus increasing the ICS dose and continuing LABA. ${ }^{151}$ 


\section{Discussion}

\section{Overview and Applicability}

We conducted a systematic review with meta-analysis to assess the comparative effectiveness of pharmacologic management of asthma, specifically intermittent inhaled corticosteroid (ICS) dosing (with or without long-acting beta agonist (LABA)) and long-acting muscarinic antagonists (LAMA) in comparison to guideline recommended approaches to the treatment of persistent asthma, or recurrent wheezing in the case of patients 4 years (y) old or younger. A total of 54 randomized controlled trials (RCTs) and 2 observational studies comprised the evidence base of this review.

\section{Key Question 1a}

In this report, intermittent ICS was defined as the prescribed use of ICS that is not the same on a daily basis. We found several types of intermittent dosing within the evidence base. In patients 0 to 4y old (Key Question [KQ]1a) with recurrent wheezing, intermittent ICS was generally defined as an episode of ICS daily dosing initiated with onset of a respiratory tract infection (RTI) and continued for a defined period, generally 7 to 10 days. Otherwise, the patient was not taking ICS. Data from three trials of 324 patients found this practice, when used with asneeded short-acting $\beta_{2}$-agonist (SABA), reduces the risk of exacerbation requiring oral corticosteroid (moderate strength of evidence [SOE]) in comparison to as-needed SABA. However a difference in exacerbation risk was not detected between intermittent ICS use during RTI compared to ICS controller with as-needed SABA (low SOE), based on a single trial of 278 patients. Thus the strength of evidence was low for the current conclusion. Caregiver quality of life improved (low SOE) versus as-needed SABA although not reaching a minimally important difference and the tool applied has not been validated in this age. Overall, for this KQ the evidence base was limited by the number of trials per comparison and inability to evaluate consistency since several outcomes were based on a single trial, and as such domains of consistency and precision were most impacted for strength of evidence ratings. Evidence was insufficient to draw conclusions for the comparison of intermittent ICS versus no therapy and we found no evidence comparing intermittent ICS to nonpharmacologic therapy.

\section{Key Question 1b}

In patients 5y of age or older, intermittent ICS dosing was described in the evidence base in two ways (KQ1b). The first strategy was in patients regularly taking ICS controller therapy who would increase ICS dose temporarily in response to a specific trigger, most often doubling routine ICS dose upon deterioration of peak expiratory flow consistent with the "yellow zone". However, some studies allowed quadrupling of dose and due to limited studies in this analysis overall, we were unable to discern if a given strategy for providing intermittent ICS (i.e., doubling vs. quadrupling) resulted in differing effects. We found patients resembled a mixture of persistent asthma severity and levels of control as described by the studies. Evidence was limited to exacerbations, of which we found no difference in effect between intermittent ICS and ICS controller in patients 12 years of age and older. The largest analysis was for exacerbations leading to oral corticosteroid use which included three trials with 908 patients. However, the other analyses were mostly limited to a single study and thus imprecision and either inconsistency or lack of the ability to evaluate consistency led to low strength of evidence for all 
outcomes with this intermittent ICS strategy. The age of patients included in this evidence base reflects middle-aged adults with mean ages in the 30's to 50's. Although data was reported in a single trial for younger patients, evidence was insufficient to draw conclusions in patients 5 to $11 \mathrm{y}$ old.

The second strategy of intermittent ICS dosing described by the evidence base was in patients not otherwise on ICS therapy who would temporarily use ICS in comparison to ICS controller therapy. Most studies asked patients to use the ICS study inhaler when they would normally require as-needed SABA, in conjunction with a SABA inhaler. The majority of the population had mild persistent asthma, some of which were required to be at least partially controlled while others were symptomatic at baseline. In the group of studies included in that analysis of 12 years of age and older, the population reflected more of an adult population with the mean age being in the 30's. We did not detect a difference between intermittent ICS and ICS controller in patients 12 years of age and older on exacerbations, asthma control scores, spirometry, quality of life, rescue inhaler use or asthma-related urgent care visits. However, like the other dosing strategy described for KQ1b, the evidence base for this dosing strategy was scarce as well with most outcomes based on a single trial. Thus, strength of evidence was primarily low due to issues of precision and consistency. Evidence is insufficient to draw conclusions in patients 5 to $11 \mathrm{y}$ old.

\section{Key Question 1c}

Analysis of ICS and long-acting $\beta_{2}$-agonist (LABA) as both controller and quick relief therapy (KQ1c) in patients with persistent asthma was separated based on the comparator being either ICS or ICS and LABA and also in consideration of the comparative daily ICS dose in the intervention and comparator arms, using thresholds set by the Expert Panel Report-3. All but one trial evaluated a single ICS and LABA combination in the intervention arm (budesonide/formoterol) and the majority of control arms were of the same ICS and LABA combination. In the group of studies considered in the evidence base of 12 years of age and older, the age of patients was again more middle-aged with mean ages ranging from the 30's to 50's. The evidence comparing ICS and LABA controller and quick relief therapy to ICS controller was small relative to other groups in this KQ and primarily based on composite outcomes of asthma exacerbations with little to no evidence for asthma control, spirometry, quality of life, or health care utilization. Patients represented a mix of asthma severity (mild to severe) and were mostly symptomatic at baseline. Based on composite exacerbation outcomes, ICS and LABA controller and quick relief versus ICS controller at the same or higher comparative ICS dose reduced exacerbation risk, both in patients 12 years of age and older and in patients 4 to $11 \mathrm{y}$ old. Strength of evidence was low or moderate due to imprecision and unknown consistency in the event of single trial. Data for patients 4 to $11 \mathrm{y}$ was also downgraded for indirectness given the dosing used in the study was lower than approved doses and what would be considered "low dose" according to the EPR-3.

ICS and LABA controller and quick relief versus ICS and LABA controller at the same comparative ICS dose had the largest literature base in this report and most evidence was focused on asthma exacerbations and forced expiratory volume in 1 second (FEV1). Most patients were described as either symptomatic or not controlled, and not further described in terms of persistent asthma severity. In patients 12 years of age and older, not only was the risk of the composite exacerbation requiring systemic corticosteroids, hospitalization or emergency room (ER) visit reduced with ICS and LABA controller and quick relief therapy (high SOE), so 
were the individual components of the composite outcome (moderate or high SOE). There was no difference in FEV1 (low SOE) and 3 or fewer trials reported data for other outcomes including asthma control composite scores, spirometry (FEV1 \% predicted and forced vital capacity $[\mathrm{FVC}])$, and health care utilization. Thus SOE for these outcomes was low to moderate, mostly suggesting no difference in effect between comparison with exception of asthma control questionnaire (ACQ)-5 responder (moderate SOE) and rescue medication use (low SOE) which both favored ICS and LABA controller and quick relief therapy. Evidence in patients 4 to $11 \mathrm{y}$ old was limited to a single subgroup analysis of a larger trial and suggested benefit in reducing composite exacerbation outcomes with ICS and LABA controller and quick relief therapy (low SOE). However, these outcomes were downgraded for indirectness given the dosing used in the study was lower than approved doses and what would be considered "low dose" according to the EPR-3.

ICS and LABA controller and quick relief versus ICS and LABA controller at a higher comparative ICS dose reduces the risk of composite exacerbations (high SOE) in patients 12 years of age and older. This population was primarily either symptomatic or a mixture of patients with and without symptoms at baseline, without further specification of persistent asthma severity. No difference was found for death (moderate SOE), ACQ-5 score (high SOE), FEV1 (moderate SOE), Asthma Quality of Life Questionnaire (AQLQ)-(S) score (moderate SOE), or rescue medication use (high SOE). No evidence was found for patients 5 to 11y old. Finally ICS and LABA controller and quick relief therapy, when compared to physician adjusted asthma therapy reflecting standard of care controller options (at a minimum daily ICS), ICS and LABA controller and quick relief therapy reduces risk of composite exacerbation (moderate SOE) but not the risk of the individual components (low SOE). Patients in the ICS and LABA controller and quick relief group had a greater chance of achieving a minimally important difference in ACQ-5 score (moderate SOE) and used fewer rescue medication inhalations (moderate SOE) while no difference was found in FEV1 (low SOE), or FEV1 percent predicted (low SOE). SOE was reduced in this evidence base due to effect estimates that were imprecise and inconsistent, in addition to evidence with risk of bias given the open-label design being subject to performance and detection bias.

\section{Key Question 2}

The role of LAMA therapy in asthma management was addressed in KQ2a-c and specific to a population 12 years of age and older with uncontrolled, persistent asthma. Although the age requirement of included studies could have been as young as $12 \mathrm{y}$ old, almost all data were derived from trials requiring participants to be at least 18 years old. The mean ages ranged from the 30's to 50's. Most studies defined “uncontrolled” with use of the ACQ, requiring a score of 1.5 or greater for inclusion. Almost the entire evidence base reflects a single LAMA (tiotropium) delivered via a soft mist inhaler as opposed to dry powder inhaler. Many of the trials for KQ2a and KQ2b overlapped as they were three arm trials. We found LAMA to be more effective than placebo as add-on to ICS, supported by the reduction in risk of exacerbation requiring systemic corticosteroids (high SOE) and the peak, trough and area under the curve (AUC) of both FEV1 and FVC (all high SOE). No difference was found for asthma control composite scores, quality of life, or rescue medication use. Add-on LAMA to ICS versus doubling ICS dose did not significantly differ in effect on outcomes of exacerbation, asthma control scores, FEV1 trough, or AQLQ, all with low SOE. LAMA compared to LABA, as add-on to ICS, was no different in any evaluated outcomes including exacerbations, death, asthma control scores, spirometry, 
quality of life, or rescue medication use. SOE was high for more outcomes than not, and limitations downgrading SOE to low or moderate were due to precision and consistency. Few studies, limited to outcomes of FEV1 and rescue medication use, evaluated other controllers than LABA as a comparator to add-on LAMA. FEV1 and rescue medication use was improved with either montelukast or doxyfylline versus LAMA although SOE was low due to risk of bias and consistency. LAMA added to ICS and LABA in comparison to ICS and LABA did not result in a significant difference on effect of exacerbation risk although most measures of lung function, particularly FEV1 AUC and peak trough and AUC of FVC, were improved. The chance of a patient achieving a minimally important difference in ACQ-7 and AQLQ scores was also increased with LAMA added to ICS and LABA.

\section{Limitations}

This review sought to evaluate different ICS dosing strategies and LAMA therapy in persistent asthmatics of various ages, depending on the KQ. Comparisons were class-based and thus this review does not inform the impact of specific doses on outcomes, rather more globally addresses classes and broad dosing strategies (i.e. intermittent dosing of ICS). Although effectiveness is an important part of decision-making, this report did not include harms associated with drug therapies, which should also be taking in to consideration. The majority of patients included in trials, when race was reported, were Caucasian and thus application of data to other races is limited. KQ1 included young pediatric populations, and evidence overall was sparse in those under 5 years old making it difficult to draw conclusions, if at all. Even within the age category of 12 years of age and older, regardless of KQ, data centered around mean ages of 30 to 50y thus extremes of age are underrepresented in the evidence base. Lastly, review of LAMA in patients under 12 years of age was outside of the scope of this review although clinicians should recognize recent approval of tiotropium in the pediatric population as young as 6 years of age. Inclusion criteria of studies rarely provided enough information to determine persistent asthma severity thus we relied on study reported severity, which in the majority of trials was not present. In addition, control of asthma was infrequently reported. In the ICS evidence base, it was more common to find trials describing presence of symptoms during run-in than a clearer measure of asthma control. In the LAMA evidence base, we only included trials evaluating a population with uncontrolled asthma, which most often was defined using the ACQ score. However, this is only one of many criteria of impairment or risk that can be applied to determine asthma control.

Overall, most studies in this review were of low risk of bias. However, particularly in KQ1c, studies were found to have increased risk of bias do to their open-label design and risk of performance and detection bias.

Although we sought to evaluate any LAMA in KQ2a-c, regardless of Food and Drug Administration approval status, the evidence base is driven almost exclusively by tiotropium, administered as a soft mist inhaler. In addition, the evidence base comparing LAMA to other controllers, as add-on to ICS, was limited in number and size of trials and also to very few outcomes, making it challenging to draw conclusions comparing LAMA to other controllers outside of LABA when added to ICS.

Many studies reported exacerbations requiring systemic corticosteroids; however, other exacerbation types, such as those requiring ER visits or hospitalizations, which are important health outcomes, were far less frequently reported. In addition, the evidence base for some KQ relied on composite outcomes that grouped components that likely vary in importance, making 
results difficult to interpret. Outside of exacerbations and spirometry, measures of asthma control composite scores, quality of life and health care utilization other than rescue inhaler use were infrequently reported.

Little data exists regarding subgroups that are of interest in this field, not limited to but including asthma severity and control. Although we sought to collect and analyze such data when possible, we were only able to perform a subgroup analysis for the dose of tiotropium in in LAMA-related KQs. Additional data reported relevant to subgroups of interest came from analyses of original trials included in this review.

\section{Future Research Needs}

Additional research would be valuable in the area of intermittent ICS dosing, particularly that which was evaluated in KQ1a and 1b where currently the evidence base is limited in size, not only overall but also per comparator/outcome evaluated. In addition, there seems to be a relatively lower amount of published evidence related to intermittent ICS dosing in comparison to other KQ addressed in this report such as the use of ICS and LABA as quick relief and controller therapy or the role of LAMA therapy in asthma. This may unfortunately lead to misinterpretation of evidence suggesting lack of benefit to intermittent therapy when in fact there is a limited data set currently from which to draw conclusions. Given most outcomes were rated with low strength of evidence, future research could change the direction or magnitude of effect or the strength of evidence the consistency and precision in effect estimates improve. For KQ1b, there appears to be several trials evaluating yellow-zone triggered ICS therapy, although evidence of other "intermittent ICS" strategies is limited and may offer different effects. We are aware of at least two ongoing trials (NCT 02066129 and NCT 02298205) registered with www.clinicaltrials.gov that will provide some additional evidence to these research questions in the future.

Since there are several LAMAs other than tiotropium on the US market, it would be valuable to understand their efficacy in asthma management. We are aware of several ongoing clinical trials (NCT 02676089, NCT 02676076, NCT 02433834, NCT 02382510) related to other LAMAs (e.g. glycopyrronium and investigational LAMAs such as TRN-157) in asthma management which may provide future evidence in this area. The same holds true for other combinations of ICS/LABA. Future studies comparing LAMA to controllers other than LABAs would also be of value since currently the evidence base is largest for comparing LAMA to LABA.

Future studies would benefit from consistently defining the severity and control of asthma in the recruited population. There are many potential reasons a patient may be considered to have asthma that is not controlled and this may provide insight into preference for a particular treatment. Future studies should focus on these various causes of having "uncontrolled" asthma as part of investigation for alternative treatments. Knowing more about the severity and control of enrolled participants would also enhance applicability of evidence. Future trials should also consider other subgroups of interest, including racial and ethnic subgroups, and routinely report such results numerically to help decision makers make more individualized treatment decisions. Future studies would also benefit from analyzing and reporting individual components of exacerbation composite outcomes so that various end users can make decisions based on which outcome is most important to them. In addition, studies would benefit from more routine use of validated tools for quality of life and asthma control measurement in addition to incorporation of 
health resource utilization outcomes so the impact of therapy outside of exacerbation risk can be more thoroughly evaluated.

\section{Conclusions}

Compared to rescue SABA use, adding intermittent ICS use appears to benefit children less than 5 years old with recurrent wheezing in the setting of an RTI. In patients 12 years of age and older with persistent asthma, differences in intermittent ICS versus controller use of ICS were not detected, although few studies provided evidence for this KQ leading to primarily low strength of evidence ratings. Using ICS and LABA as both a controller and quick relief therapy showed benefits over use as a controller medication alone (ICS or ICS and LABA controller). In patients 12 years of age and older with uncontrolled, persistent asthma, adding LAMA to ICS controller or adding LAMA to ICS plus LABA controller compared to ICS or ICS plus LABA alone improves some outcomes. However, adding LAMA to ICS controller compared to adding LABA to ICS controller produced no difference in outcomes. 


\section{References}

1. Expert Panel Report 3: guidelines for the diagnosis and management of asthma. National Asthma Education and Prevention Program, Third Expert Panel on the Diagnosis and Management of Asthma. Bethesda (MD). Report No: 07-4051. Washington, DC: National Heart, Lung, and Blood Institute; 2007.

2. Most recent asthma data. Centers for Disease Control and Prevention. Available at: http://www.cdc.gov/asthma/most_recent_data.ht m [Accessed June 15, 2017].

3. The Global Asthma Report 2014. Auckland, New Zealand: Global Asthma Network, 2014.

4. Asthma national health statistics. Centers for Disease Control and Prevention. Available at: http://www.cdc.gov/nchs/fastats/asthma.htm [Accessed June 15, 2017].

5. National Heart, Lung and Blood Advisory Council Asthma Expert Working Group. Needs Assessment Report for Potential Update of the Expert Panel Report-3 (2007): Guidelines for the Diagnosis and Management of Asthma. 2015.

6. Herndon JB, Mattke S, Evans CA et al. Antiinflammatory medication adherence, healthcare utilization and expenditure among Medicaid children's health insurance program enrollees with asthma. Pharmacoeconomics. 2012;30:397412. PMID: 22268444

7. Williams LK, Peterson EL, Wells K. et al. Quantifying the proportion of severe asthma exacerbations attributable to inhaled corticosteroid nonadherence. J Allergy Clin Immunol. 2011;128:1185e2-1191.e2. PMID: 22019090

8. Morton RW, Everard ML, Elphick HE. Adherence in childhood asthma: the elephant in the room. Arch Dis Child. 2014;99:949-953. PMID: 24876303

9. Krishnan JA, Bender BG, Wamboldt FS et al. Adherence to inhaled corticosteroids: an ancillary study of the childhood athma management program clinical trial. J Allergy Clin Immunol. 2012;129:112-118. PMID: 22104610

10. Desai M, Oppenheimer JJ. Medication adherence in the asthmatic child and adolescent. Curr Allergy Asthma Rep. 2011;11:454-464. PMID: 21968618
11. Lasmar L, Camargos P, Champs NS et al. Adherence rate to inhaled corticosteroids and their impact on asthma control. Allergy. 2009;64:784-789. PMID: 19183166

12. Schatz M, Cook EF, Nakahiro R, Petitti D. Inhaled corticosteroids and allergy specialty care reduce emergency hospital use for asthma. $\mathrm{J}$ Allergy Clin Immunol.2003;111:503-508. PMID: 12642829

13. Sabate E. Adherence to longterm therapies: evidence for action. Geneva: World Health Organization; 2003.

14. Jackson DJ. Emerging issues in pediatric asthma: gaps in EPR-3 guidelines for infants and children. Curr Allergy Asthma Rep. 2014;14:477. PMID: 25269401.

15. Hoch HE, Szefler SJ. Intermittent steroid inhalation for the treatment of childhood asthma. Expert Rev Clin Immunol. 2016;12:183-194. PMID: 26561351.

16. Peters M. Single-inhaler combination therapy for maintenance and relief of asthma. Drugs 2009;69:137-150. PMID: 19228072.

17. Spiriva Respimat [package insert]. Boehringer Ingelheim Pharmaceuticals, Inc. Ridgefield, CT. 2016

18. Higgins JPT, Altman DG, Gotzsche PC, et al. The Cochrane Collaboration's tool for assessing risk of bias in randomised trials. BMJ. 2011;343:d5928. PMID: 22008217.

19. Wells GA, Shea B, O'Connell D, et al. The Newcastle-Ottawa Scale (NOS) for assessing the quality of nonrandomised studies in metaanalyses. Available from http://www.ohri.ca/programs/clinical_epidemiol ogy/oxford.asp. Accessed December 13, 2016.

20. Viswanathan M, Ansari MT, Berkman ND, et al. Assessing the Risk of Bias of Individual Studies in Systematic Reviews of Health Care Interventions; 2012. In: Methods Guide for Effectiveness and Comparative Effectiveness Reviews. AHRQ Publication No. 10(14)EHC063-EF. Rockville, MD: Agency for Healthcare Research and Quality; 2014. Chapters available at www.effectivehealthcare.ahrq.gov. 
21. Higgins JPT, Green S (editors). Cochrane Handbook for Systematic Reviews of Interventions Version 5.1.0 [updated March 2011]. The Cochrane Collaboration, 2011. Available from www.handbook.cochrane.org.

22. Hartung J, Knapp G. On tests of the overall treatment effect in meta-analysis with normally distributed responses. Stats Med. 2001 May;20;1771-82. PMID: 11406840.

23. Hartung J, Knapp G. A refined method for metaanalysis of controlled clinical trials with binary outcomes. Stats Med. 2001 Dec;20(24);3875-89. PMID: 11782040.

24. Bradburn MJ, Deeks JJ, Berlin JA, et al. Much ado about nothing: a comparison of the performance of meta-analytical methods with rare events. Stat Med 2007;26:53-77. PMID: 16596572

25. Higgins JP, Thomas SG, Deeks JJ, Altman DG. Measuring inconsistency in meta-analyses. BMJ. 2003;327:557-60. PMID: 12958120.

26. Egger M, Davey Smith G, Schneider M, Minder C. Bias in meta-analysis detected by a simple, graphical test. BMJ. 1997;315:629-34. PMID: 9310563.

27. Peters SP, Kunselman SJ, Icitovic N, et al. Tiotropium bromide step-up therapy for adults with uncontrolled asthma. N Engl J Med. 2010 Oct 28;363(18):1715-26. PMID: 20979471.

28. Berkman ND, Lohr KN, Ansari M, et al. Grading the Strength of a Body of Evidence When Assessing Health Care Interventions for the Effective Health Care Program of the Agency for Healthcare Research and Quality: An Update, 2013. In: Methods Guide for Effectiveness and Comparative Effectiveness Reviews. AHRQ Publication No. 10(14)-EHC063-EF. Rockville MD: Agency for Healthcare Research and Quality; 2014. Chapters available at www.effectivehealthcare.ahrq.gov.

29. Atkins D, Chang S, Gartlehner G, et al. Assessing the Applicability of Studies When Comparing Medical Interventions; 2010. In: Methods Guide for Effectiveness and Comparative Effectiveness Reviews. AHRQ Publication No. 10(14)-EHC063-EF. Rockville, MD: Agency for Healthcare Research and Quality; 2014. Chapters available at www.effectivehealthcare.ahrq.gov.
30. Lazarus SC, Chinchilli VM, Rollings NJ, et al. Smoking affects response to inhaled corticosteroids or leukotriene receptor antagonists in asthma. Am J Respir Crit Care Med. 2007;175:783-90. PMID:17204725

31. Berger WE, Bleecker ER, O-Dowd L, et al. Efficacy and safety of budesonide/formoterol pressurized metered-dose inhaler: randomized controlled trial comparing once- and twice-daily dosing in patients with asthma. Allergy Asthma Proc 2010;31:49-59. PMID:20167145

32. Methods Guide for Effectiveness and Comparative Effectiveness Reviews. AHRQ Publication No. 10(14)-EHC063-EF. Rockville, MD: Agency for Healthcare Research and Quality; January 2014. Chapters available at www.effectivehealthcare.ahrq.gov.

33. Schatz M, Kosinski M, Yarlas A, et al. The minimally important difference of the Asthma Control Test. J Allergy Clin Immunol. 2009;124:719-23. PMID: 19767070.

34. Juniper E, Svensson K, Mork AC, et al. Measurement properties and interpretation of three shortened versions of the asthma control questionnaire. Respir Med. 2005 May;99:553-8. PMID: 15823451.

35. Juniper EF, Gruffydd-Jones K, Ward S, et al. Asthma Control Questionnaire in children: validation, measurement properties, interpretation. Eur Respir J. 2010;36:1410-6. PMID: 20530041.

36. Juniper EF, Buist S, Cox FM, et al .Validation of a standardized version of the Asthma Quality of Life Questionnaire. Chest. 1999;115:1265-70. PMID: 10334138.

37. Juniper EF, Guyatt GH, Cox FM, et al. Development and validation of the Mini Asthma Quality of Life Questionnaire. Eur Respir .J 1999;14:32-8. PMID: 10489826.

38. Juniper EF, Guyatt GH, Willam A, et al. Determining a minimal important change in disease-specific quality of life questionnaire. J Clin Epidemiol. 1994;47(1):81-7. PMID: 8283197.

39. Juniper EF, Svensson K, Mork AC, et al. Modification of the asthma quality of life questionnaire (standardized) for patients 12 years and older. Health Qual Life Outcomes. 2005;3:58. PMID: 16168050. 
40. Wyrwich KW, Ireland AM, Navaratnam P, et al. Validation of the AQLQ12+ among adolescents and adults with persistent asthma. Qual Life Res. 2011;20:903-12. PMID: 21184185.

41. Juniper EF, Guyatt GH, Feeny DH, et al. Measuring quality of life in children with asthma. Qual Life Res 1996;5:35-46. PMID: 8901365.

42. Juniper EF, Guyatt GH, Feeny DH, et al. Measuring quality of life in the parents of children with asthma. Qual Life Res. 1996;5:2734. PMID: 8901364.

43. Santanello NC, Zhang J, Seidenberg B, et al. What are minimal important changes for asthma measures in a clinical trial? Eur Respir J. 1999,14:23-7. PMID: 10489824.

44. Bacharier LB1, Phillips BR, Zeiger RS, et al. Episodic use of an inhaled corticosteroid or leukotriene receptor antagonist in preschool children with moderate-to-severe intermittent wheezing. J Allergy Clin Immunol. 2008 Dec;122(6):1127-1135. PMID: 18973936.

45. Ducharme FM, Lemire C, Noya FJ, et al. Preemptive use of high-dose fluticasone for virus-induced wheezing in young children. $\mathrm{N}$ Engl J Med. 2009 Jan 22;360(4):339-53. PMID: 19164187.

46. Ghirga G, Ghirga P, Fagioli S, et al. Intermittent treatment with high dose nebulized beclomethasone for recurrent wheezing in infants due to upper respiratory tract infection. Minerva Pediatr. 2002 Jun;54(3):217-20. PMID: 12070480.

47. Papi A, Nicolini G, Baraldi E, et al. Regular vs prn nebulized treatment in wheeze preschool children. Allergy. 2009 Oct;64(10):1463-71. PMID: 19772514.

48. Svedmyr J, Nyberg E, Thunqvist P, et al. Prophylactic intermittent treatment with inhaled corticosteroids of asthma exacerbations due to airway infections in toddlers. Acta Paediatr. 1999 Jan;88(1):42-7. PMID: 10090546.

49. Zeiger RS, Mauger D, Bacharier LB, et al. Daily or intermittent budesonide in preschool children with recurrent wheezing. N Engl J Med. 2011 Nov 24;365(21):1990-2001. PMID: 22111718.
50. Milton S. Hershey Medical Center; National Heart, Lung, and Blood Institute (NHLBI). Childhood Asthma Research and Education (CARE) network trial - maintenance versus intermittent inhaled steroids in wheezing toddlers (MIST). In: ClinicalTrials.gov. Bethesda, MD: National Library of Medicine (US); 2000- [cited 2016 Dec 2]. https:/clinicaltrials.gov/ct2/show/NCT00675584 . NLM Identifier: NCT0067558.

51. Boushey HA, Sorkness CA, King TS, et al. Daily versus as-needed corticosteroids for mild persistent asthma. N Engl J Med. 2005 Apr 14;352(15):1519-28. PMID: 15829533.

52. Calhoun WJ, Ameredes BT, King TS, et al. Comparison of physician-, biomarker-, and symptom-based strategies for adjustment of inhaled corticosteroid therapy in adults with asthma: the BASALT randomized controlled trial. JAMA. 2012 Sep 12;308(10):987-97. PMID: 22968888.

53. Milton S. Hershey Medical Center; National Heart, Lung, and Blood Institute (NHLBI). Asthma Clinical Research Network (ACRN) trial- best adjustment strategy for asthma in long term (BASALT). In: ClinicalTrials.gov. Bethesda, MD: National Library of Medicine (US); 2000- [cited 2016 Dec 2]. https:/clinicaltrials.gov/ct2/show/NCT00495157 . NLM Identifier: NCT00495157.

54. Colland VT, van Essen-Zandvliet LE, Lans C, et al. Poor adherence to self-medication instructions in children with asthma and their parents. Patient Educ Couns. 2004 Dec;55(3):416-21. PMID: 15582348.

55. FitzGerald JM, Becker A, Sears MR, et al. Doubling the dose of budesonide versus maintenance treatment in asthma exacerbations. Thorax. 2004 Jul;59(7):550-6. PMID: 15223858.

56. Foresi A, Morelli MC, Catena E. Low-dose budesonide with the addition of an increased dose during exacerbations is effective in longterm asthma control. Chest. 2000 Feb;117(2):440-6. PMID: 10669688.

57. Gerald JK, Gerald LB, Vasquez MM, et al. Markers of differential response to inhaled corticosteroid treatment among children with mild persistent asthma. J Allergy Clin Immunol Pract. 2015 Jul-Aug;3(4):540-6. PMID: 25783161. 
58. Gerald JK, Gerald LB, Chinchilli VM, et al. Adherence to rescue inhaled corticosteroid use during the TREXA trial. Am J Respir Crit Care Med. 2012;185:A2200. DOI: http://dx.doi.org/10.1164/ajrccmconference.2012.185.1_MeetingAbstracts.A2200

59. Harrison TW, Oborne J, Newton S, et al. Doubling the dose of inhaled corticosteroid to prevent asthma exacerbations: randomised controlled trial. Lancet. 2004 Jan 24;363(9405):271-5. PMID: 14751699.

60. Martinez FD, Chinchilli VM, Morgan WJ, et al. Use of beclomethasone dipropionate as rescue treatment for children with mild persistent asthma (TREXA): a randomised, double-blind, placebo-controlled trial. Lancet. $2011 \mathrm{Feb}$ 19;377(9766):650-7. PMID: 21324520.

61. Milton S. Hershey Medical Center; National Heart, Lung, and Blood Institute (NHLBI). Childhood Asthma Research and Education (CARE) network trial - treating children to prevent exacerbations of asthma (TREXA). In: ClinicalTrials.gov. Bethesda, MD: National Library of Medicine (US); 2000- [cited 2016 Dec 2]. https://clinicaltrials.gov/ct2/show/NCT00394329 . NLM Identifier: NCT00394329.

62. Oborne J, Mortimer K, Hubbard RB, et al. Quadrupling the dose of inhaled corticosteroid to prevent asthma exacerbations: a randomized, double-blind, placebo-controlled, parallel-group clinical trial. Am J Respir Crit Care Med. 2009 Oct 1;180(7):598-602. PMID: 19590019.

63. Papi A, Canonica GW, Maestrelli P, et al. Rescue use of beclomethasone and albuterol in a single inhaler for mild asthma. N Engl J Med. 2007 May 17;356(20):2040-52. PMID: 17507703 .

64. Turpeinen M, Nikander K, Pelkonen AS, et al. Daily versus as-needed inhaled corticosteroid for mild persistent asthma (The Helsinki early intervention childhood asthma study). Arch Dis Child, 2008 Aug;93(8):654-9. PMID: 17634183.

65. Morelli MC, Bordonaro S, Chiesa M, et al. Clinical efficacy of a new treatment regimen with inhaled budesonide in moderate asthma. Eur Respir J. 1996;9;Suppl 12:79s.
66. Oborne J, Hubbard RB, Tattersfield AE, et al. Can acute exacerbations of asthma be prevented with a four-fold increase in inhaled corticosteroid dose? Am J Respir Crit Care Med. 2009;179:A2794. DOI: http://dx.doi.org/10.1164/ajrccmconference.2009.179.1_MeetingAbstracts.A2794

67. Lahdensuo A, Haahtela T, Herrala, et al. Randomised comparison of guided self management and traditional treatment of asthma over one year. BMJ. 1996 Mar;312(7033):74852. PMID: 8605463.

68. Lahdensuo, Haahtela T, Herrala J, et al. PEFguided use of an inhaled corticosteroid is successful. The FINNISH asthma-self management study. Eur Respir J. 1994;7;Suppl 18:142s.

69. Ambrose HJ, Lawrance RM, Cresswell CJ, et al. Effect of $\beta 2$-adrenergic receptor gene (ADRB2) 3 ' untranslated region polymorphisms on inhaled corticosteroid/long-acting $\beta 2$-adrenergic agonist response. Respir Res. 2012 May 4;13:37. PMID: 22559839.

70. Atienza T, Aquino T, Fernández M, et al. Budesonide/formoterol maintenance and reliever therapy via Turbuhaler versus fixed-dose budesonide/formoterol plus terbutaline in patients with asthma: phase III study results. Respirolog. 2013 Feb;18(2):354-63. PMID: 23126237.

71. AstraZeneca. Study to investigate the efficacy of Symbicort SMART (SAKURA). In: ClinicalTrials.gov. Bethesda, MD: National Library of Medicine (US); 2000- [cited 2016 Dec 2].

https://clinicaltrials.gov/ct2/show/NCT00839800 . NLM Identifier: NCT00839800.

72. Atienza T, Aquino T, Fernandez M, et al. Budesonide/formoterol maintenance and reliever therapy via turbuhaler vs fixed-dose budesonide/formoterol plus terbutaline in patients with asthma: phase iii study results. Am J Respir Crit Care Med. 2012;185:A3950. DOI: http://dx.doi.org/10.1164/ajrccmconference.2012.185.1_MeetingAbstracts.A3950

73. Bateman ED, Harrison TW, Quirce S, et al. Overall asthma control achieved with budesonide/formoterol maintenance and reliever therapy for patients on different treatment steps. Respir Res. 2011 Apr 4;12:38. PMID: 21463522. 
74. Bateman ED, Reddel HK, Eriksson G, et al. Overall asthma control: the relationship between current control and future risk. J Allergy Clin Immunol. 2010 Mar;125(3):600-8. PMID: 20153029.

75. Bisgaard H, Le Roux P, Bjåmer D, et al. Budesonide/formoterol maintenance plus reliever therapy: a new strategy in pediatric asthma. Chest. 2006 Dec;130(6):1733-43. PMID: 17166990.

76. Bousquet J, Boulet LP, Peters MJ, et al. Budesonide/formoterol for maintenance and relief in uncontrolled asthma vs. high-dose salmeterol/fluticasone. Respir Med. 2007 Dec;101(12):2437-46. PMID: 17905575.

77. Buhl R, Kuna P, Peters MJ, et al. The effect of budesonide/formoterol maintenance and reliever therapy on the risk of severe asthma exacerbations following episodes of high reliever use: an exploratory analysis of two randomised, controlled studies with comparisons to standard therapy. Respir Res. 2012 Jul 20;13:59. PMID: 22816878 .

78. Hozawa S, Terada M, Hozawa M. Comparison of the effects of budesonide/formoterol maintenance and reliever therapy with fluticasone/salmeterol fixed-dose treatment on airway inflammation and small airway impairment in patients who need to step-up from inhaled corticosteroid monotherapy. Pulm Pharmacol Ther. 2014 Apr;27(2):190-6. PMID: 24388868.

79. Kardos P. Budesonide/formoterol maintenance and reliever therapy versus free-combination therapy for asthma: a real-life study. Pneumologie. 2013 Aug;67(8):463-70. PMID: 23904191.

80. Kuna P. Treatment comparison of budesonide/formoterol with salmeterol/fluticasone propionate in adults aged $\geq 16$ years with asthma: post hoc analysis of a randomized, double-blind study. Clin Drug Investig. 2010;30(9):565-79. PMID: 20593912.

81. Kuna P, Peters MJ, Manjra AI, et al. Effect of budesonide/formoterol maintenance and reliever therapy on asthma exacerbations. Int J Clin Pract. 2007 May;61(5):725-36. PMID: 17362472.
82. Louis R, Joos G, Michils A, et al. A comparison of budesonide/formoterol maintenance and reliever therapy vs. conventional best practice in asthma management. Int J Clin Pract. 2009 Oct;63(10):1479-88. PMID: 19769705.

83. O'Byrne PM, Bisgaard H, Godard PP, et al. Budesonide/formoterol combination therapy as both maintenance and reliever medication in asthma. Am J Respir Crit Care Med. 2005 Jan 15;171(2):129-36. PMID: 15502112.

84. Papi A, Corradi M, Pigeon-Francisco C, et al. Beclometasone-formoterol as maintenance and reliever treatment in patients with asthma: a double-blind, randomised controlled trial. Lancet Respir Med. 2013 Mar;1(1):23-31. PMID: 24321801.

85. Patel M, Pilcher J, Hancox RJ, et al. The use of $\beta 2$-agonist therapy before hospital attendance for severe asthma exacerbations: a post-hoc analysis. NPJ Prim Care Respir Med. 2015 Jan 8;25:14099. PMID: 25569185.

86. Patel M, Pilcher J, Pritchard A, et al. Efficacy and safety of maintenance and reliever combination budesonide-formoterol inhaler in patients with asthma at risk of severe exacerbations: a randomised controlled trial. Lancet Respir Med. 2013 Mar;1(1):32-42. PMID: 24321802.

87. Patel M, Pilcher J, Reddel HK, et al. Predictors of severe exacerbations, poor asthma control, and $\beta$-agonist overuse for patients with asthma. J Allergy Clin Immunol Pract. 2014 NovDec;2(6):751-8. PMID: 25439367.

88. Patel M, Pilcher J, Shaw D, et al. A randomised controlled trial of single combination budesonide/formoterol inhaler as maintenance and reliever therapy in asthma patietns at risk of severe exacerbations. Thorax. 2013(68):A148. DOI: 10.1136/thoraxjnl-2013-204457.312.

89. Pavord ID, Jeffery PK, Qiu Y, et al. Airway inflammation in patients with asthma with highfixed or low-fixed plus as-needed budesonide/formoterol. J Allergy Clin Immunol. 2009 May;123(5):1083-9. PMID: 19368965.

90. Pilcher J, Patel M, Smith A, et al. Combination budesonide/formoterol inhaler as maintenance and reliever therapy in Māori with asthma. Respirology. 2014 Aug;19(6):842-51. PMID: 24889937. 
91. Quirce S, Barcina C, Plaza V, et al. A comparison of budesonide/formoterol maintenance and reliever therapy versus conventional best practice in asthma management in Spain. J Asthma. 2011 Oct;48(8):839-47. PMID: 21942354.

92. AstraZeneca. Symbicort single inhaler therapy vs conventional best practice for the treatment of persistent asthma in adults. In:

ClinicalTrials.gov. Bethesda, MD: National Library of Medicine (US); 2000- [cited 2016 Dec 2]. https://clinicaltrials.gov/ct2/show/NCT00385593 . NLM Identifier: NCT00385593.

93. Rabe KF, Atienza T, Magyar P, et al. Effect of budesonide in combination with formoterol for reliever therapy in asthma exacerbations: a randomised controlled, double-blind study. Lancet. 2006 Aug 26;368(9537):744-53. PMID: 16935685.

94. Rabe KF, Pizzichini E, Ställberg B, et al. Budesonide/formoterol in a single inhaler for maintenance and relief in mild-to-moderate asthma: a randomized, double-blind trial. Chest. 2006 Feb;129(2):246-56. PMID: 16478838.

95. Riemersma RA, Postma D, van der Molen T. Budesonide/formoterol maintenance and reliever therapy in primary care asthma management: effects on bronchial hyperresponsiveness and asthma control. Prim Care Respir J. 2012 Mar;21(1):50-6. PMID: 22015542.

96. Scicchitano R, Aalbers R, Ukena D, et al. Efficacy and safety of budesonide/formoterol single inhaler therapy versus a higher dose of budesonide in moderate to severe asthma. Curr Med Res Opin. 2004 Sep;20(9):1403-18. PMID: 15383189.

97. Sears MR, Boulet LP, Laviolette M, et al. Budesonide/formoterol maintenance and reliever therapy: impact on airway inflammation in asthma. Eur Respir J. 2008 May;31(5):982-9. PMID: 18216054.

98. Søes-Petersen U, Kava T, Dahle R, et al. Budesonide/formoterol maintenance and reliever therapy versus conventional best standard treatment in asthma in an attempted 'real life' setting. Clin Respir J. 2011 Jul;5(3):173-82. PMID: 21679353.
99. Sovani MP, Whale CI, Oborne J, et al. Poor adherence with inhaled corticosteroids for asthma: can using a single inhaler containing budesonide and formoterol help? Br J Gen Pract. 2008 Jan;58(546):37-43. PMID: 18186995.

100.Ställberg B, Ekström T, Neij F, et al. A real-life cost-effectiveness evaluation of budesonide/formoterol maintenance and reliever therapy in asthma. Respir Med. 2008 Oct;102(10):1360-70. PMID: 18723335.

101.Takeyama K, Kondo M, Tagaya E, et al. Budesonide/formoterol maintenance and reliever therapy in moderate-to-severe asthma: effects on eosinophilic airway inflammation. Allergy Asthma Proc. 2014 Mar-Apr;35(2):141-7. PMID: 24717791.

102.Takeyama K, Konodo M, Tagaya E, et al. Efficacy and tolerability of budesonide/formoterol maintenance and reliever therapy in Japanese patients with moderate to severe persistent asthma. Am J Respir Crit Care Med. 2013;187:A2730. Embase 71982190.

103.Vogelmeier C, D'Urzo A, Pauwels R, et al. Budesonide/formoterol maintenance and reliever therapy: an effective asthma treatment option? Eur Respir J. 2005 Nov;26(5):819-28. PMID: 16264042.

104. Vogelmeier C, Naya I, Ekelund J. Budesonide/formoterol maintenance and reliever therapy in Asian patients (aged $\geq 16$ years) with asthma: a sub-analysis of the COSMOS study. Clin Drug Investig. 2012 Jul 1;32(7):439-49. PMID: 22607479.

105. Weatherall M, Patel M, Pilcher J, et al. Predictors of severe asthma exacerbations, poor asthma control and beta-agonist overuse in adult asthma. Eur Respir J. 2013;42:P776. Embase 71842638.

106.Pilcher J, Patel M, Smith A, et al. Single budesonide/formoterol inhaler as maintenance and reliever therapy is beneficial in Maori asthma. Respirology. 2013;18;Suppl 2:44.

107.Kuna P, Peters M, Buhl R. Budesonide/formoterol for maintenance and relief vs. higher dose ICS/LABA therapy: outcomes in patients symptomatic on high-dose inhaled corticosteroids (HDICS). Eur Respir J. 2007;30;Suppl 51:357s. 
108. Bousquet J, Boulet LP, AHEAD Investigators. Budesonide/formoterol as maintenance and reliever therapy in uncontrolled asthma compared with high dose salmeterol/fluticasone: the AHEAD double-blind study. Eur Respir J. 2007;30;Suppl 51:358s.

109. Rabe KF, Pizzichini E, Stallberg B, et al. Single inhaler therapy with budesonide/formoterol provides superior asthma control compared with fixed dosing with budesonide plus terbutaline asneeded. J Allergy Clin Immunol. 2004 Feb;113;Suppl 2:S116.

110. Scicchitano R, Aalbers R, Ukena D, et al. Single inhaler therapy with budesonide/formoterol reduces the risk of severe exacerbations compared with budesonide plus terbutaline asneeded in patients with asthma. J Allergy Clin Immunol. 2004 Feb;113;Suppl 2:S116.

111.Pistolesi M, Godard P, Aalbers R, et al. Budesonide/formoterol single inhaler therapy (SiT) provides superior asthma control compared with fixed dose (FD) budesonide or budesonide/formoterol in patients with severe persistent asthma. Eur Respir J. 2004;24;Suppl 48:509s.

112.Sovani MP, Whale CI, Oborne J, et al. The effect of providing a single inhaler containing formoterol and budesonide to be used once daily and as required on inhaled budesonide use and asthma control in poorly compliant patients. Thorax. 2004;59;Suppl ii:ii11.

113.Lin JT, Chen P, Zhou X, et al. Budesonide/formoterol maintenance and reliever therapy in Chinese patients with asthma. Chin Med J. 2012 Sep;125(17):2994-3001. PMID: 22932169.

114.Loh LC, Lim BK, Raman S, et al. Budesonide/formoterol combination therapy as both maintenance and reliever medication in moderate-to-severe asthma: a real-life effectiveness study of Malaysian patients. Med J Malaysia. 2008 Aug;63(3):188-92. PMID: 19248687.

115.Lundborg M, Wille S, Bjermer L, et al. Maintenance plus reliever budesonide/formoterol compared with a higher maintenance dose of budesonide/formoterol plus formoterol as reliever therapy in asthma: an efficacy and costeffectiveness study. Curr Med Res Opin. 2006 May;22(5):809-21. PMID: 16709303.
116.Pilcher J, Patel M, reddel H et al. Effect of smoking status on the efficacy of SMART regimen in high risk asthma.

Respirology.2016;21:858-866. PMID: 26897389

117. Hozawa S, Terada M, Haruta Y, Hozawa M. Comparison of early effects of budesonide/formoterol maintenance and reliever therapy with fluticasone furoate/Vilanterol for asthma patients requiring step-up from inhaled corticosteroid monotherapy. Pulmonary Pharmacology \& Therapeutics.2016;37:15-23. PMID: 26850307

118. Bateman ED, Kornmann O, Schmidt P, et al. Tiotropium is noninferior to salmeterol in maintaining improved lung function in B16Arg/Arg patients with asthma. J Allergy Clin Immun. 2011 Aug;128(2):315-22. PMID: 21807250.

119.Kerstjens HA, Casale TB, Bleecker ER, et al. Tiotropium or salmeterol as add-on therapy to inhaled corticosteroids for patients with moderatesymptomatic asthma: two replicate, double-blind, placebo-controlled, parallel-group, active-comparator, randomised trials. Lancet Respir Med. 2015 May;3(5):367-76. PMID: 25682232.

120.Lee LA, Yang S, Kerwin E, et al. The effect of fluticasone furoate/umeclidinium in adult patients with asthma: a randomized, doseranging study. Respir Med. 2015 Jan;109(1):5462. PMID: 25452139.

121. Ohta K, Ichinose M, Tohda Y, et al. Long-term once-daily tiotropium respimat is well tolerated and maintains efficacy over 52 weeks in patients with symptomatic asthma in Japan: a randomized, placebo-controlled study. PLoS One. 2015 Apr 20;10(4):e0124109. PMID: 25894430.

122.Paggiaro P, Halpin DM, Buhl R, et al. The effect of tiotropium in symptomatic asthma despite low- to medium-dose inhaled corticosteroids: a randomized controlled trial. J Allergy Clin Immunol Pract. 2016 Jan-Feb;4(1):104-13. PMID: 26563670.

123.Hamelmann E, Bateman ED, Vogelberg C, et al. Tiotropium add-on therapy in adolescents with moderate asthma: A 1-year randomized controlled trial. J Allergy Clin Immunol. 2016 Aug;138(2):441-450. PMID: 26960245. 
124. Boehringer Ingelheim. Efficacy and safety of tiotropium and salmeterol in moderate persistent asthma patients homozygous for B16-Arg/Arg. In: ClinicalTrials.gov. Bethesda, MD: National Library of Medicine (US); 2000- [cited 2016 Nov 29]. https://clinicaltrials.gov/ct2/show/NCT00350207 . NLM Identifier: NCT00350207.

125.Boehringer Ingelheim. Evaluation of tiotropium 2.5 and 5 mcg once daily delivered via the Respimat ${ }^{\circledR}$ inhaler compared to placebo and salmeterol hydrofluoroalkane (HFA) metered dose inhaler (MDI) (50 mcg twice daily) in patient with moderate persistent asthma I. In: ClinicalTrials.gov. Bethesda, MD: National Library of Medicine (US); 2000- [cited 2016 Nov 29]. https://clinicaltrials.gov/ct2/show/NCT01172808 . NLM Identifier: NCT01172808.

126. Boehringer Ingelheim. Evaluation of tiotropium 2.5 and 5 mcg once daily delivered via the Respimat ${ }^{\circledR}$ inhaler compared to placebo and salmeterol hydrofluoroalkane (HFA) metered dose inhaler (MDI) (50 mcg twice daily) in patient with moderate persistent asthma II. In: ClinicalTrials.gov. Bethesda, MD: National Library of Medicine (US); 2000- [cited 2016 Nov 29]. https://clinicaltrials.gov/ct2/show/NCT01172821 . NLM Identifier: NCT01172821.

127. Boehringer Ingelheim. Evaluation of tiotropium 2.5 and $5 \mu \mathrm{g}$ once daily delivered via the respimat inhaler compared to placebo in patient with moderate to severe persistent asthma. In: ClinicalTrials.gov. Bethesda, MD: National Library of Medicine (US); 2000- [cited 2016 Nov 29]. https://clinicaltrials.gov/ct2/show/NCT01340209 . NLM Identifier: NCT01340209.

128. Boehringer Ingelheim. Efficacy and safety of 2 doses of tiotropium via respimat in adult patients with mild persistent asthma. In: ClinicalTrials.gov. Bethesda, MD: National Library of Medicine (US); 2000- [cited 2016 Nov 29]. https://clinicaltrials.gov/ct2/show/NCT01316380 . NLM Identifier: NCT01316380.
129. Boehringer Ingelheim. Efficacy and safety of 2 doses of tiotropium via respimat compared to placebo in adolescents with moderate persistent asthma. In: ClinicalTrials.gov. Bethesda, MD: National Library of Medicine (US); 2000- [cited 2016 Nov 29]. https://clinicaltrials.gov/ct2/show/NCT01275230 . NLM Identifier: NCT01275230.

130.Milton S. Hershey Medical Center. Asthma Clinical Research Network (ACRN) trial tiotropium bromide as an alternative to increased inhaled corticosteroid in patients inadequately controlled on a lower dose of inhaled corticosteroid (TALC). In: ClinicalTrials.gov. Bethesda, MD: National Library of Medicine (US); 2000- [cited 2016 Nov 29]. https://clinicaltrials.gov/ct2/show/NCT00565266 . NLM Identifier: NCT00565266.

131.Casale T, Bleecker E, Meltzer E, et al. Phase III trials to investigate tiotropium as add-on therapy to inhaled corticosteroids for patients with symptomatic asthma: trial design and planned statistical analysis. Allergy. 2013;68;Suppl 97:377.

132.Casale TB, Bateman ED, Dahl R, et al. Tiotropium respimat add-on therapy reduces airflow obstruction in patients with symptomatic moderate asthma, independent of $\mathrm{T}_{\mathrm{H}} 2$ inflammatory status. J Allergy Clin Immun. 2014 Feb;133(2);Suppl:AB5. DOI: http://dx.doi.org/10.1016/j.jaci.2013.12.040.

133.Kerstjens H, Bleecker E, Meltzer E, et al. Tiotropium as add-on to inhaled corticosteroids significantly improves asthma control as reflected by the ACQ responder rate. Respirology. 2014; 19;Suppl 2:78.

134.Kerstjens H, Bleecker E, Meltzer E, et al. Tiotropium as add-on therapy to inhaled corticosteroids for patients with symptomatic asthma: lung function and safety. Respirology. 2014;19 Suppl 2:78.

135.Kerstjens HAM, Bleecker E, Meltzer E, et al. Tiotropium as add-on to inhaled corticosteroids significantly improves asthma control as reflected by the ACQ responder rate. Eur Respir J. 2013;42;Suppl 57:P4130.

136.Kerstjens HAM, Bleecker E, Meltzer E, et al. Tiotropium as add-on to inhaled corticosteroids for patients with symptomatic asthma: lung function and safety. Eur Respir J. 2013;42;Suppl 57:P4629. 
137. Yang WH, Casale T, Bateman ED ,et al. Tiotropium respimat add-on therapy reduces airflow obstruction in patients with symptomatic moderate asthma, independent of $\mathrm{T}_{\mathrm{H}} 2$ inflammatory status. Allergy Asthma Clin Immunol. 2014;10; Suppl 2:A52. DOI: 10.1186/1710-1492-10-S2-A52.

138. Ohta K, Ichinose M, Tohda, et al. Once-daily tiotropium respimat is well tolerated and efficacious over 52 weeks in Japanese patients with symptomatic asthma receiving inhaled corticosteroids (ics) \pm long-acting $\beta 2$-agonist (laba): a randomized, double-blind, placebocontrolled study. Am J Respir Crit Care Med. 2014;189:A1311.

139.Paggiaro P, Engel M, Tudoric N, et al. Phase III trial of tiotropium as add-on therapy to low-dose inhaled corticosteroids for patients with symptomatic mild persistent asthma: design and planned analyses. Eur Respir J. 2013;42;Suppl 57:P4133.

140.Paggiaro P, Halpin DMG, Buhl R, et al. Tiotropium respmat add-on to inhaled corticosteroids improve lung function in patients with symptomatic mild asthma: results from a phase III trial. J Allergy Clin Immunol. 2014;133(2);Suppl:AB4. DOI: http://dx.doi.org/10.1016/j.jaci.2013.12.039.

141.Dahl R, Szefler SJ, Bernstein J, et al. Safety and tolerability of once-daily tiotropium respimat add-on to at least inhaled corticosteroid maintenance therapy in adolescent patients with moderate or severe symptomatic asthma. Allergy. 2015;70;Suppl 101:34-5.

142.Hamelmann E, Boner A, Bernstein J, et al. 1year efficacy and safety study of tiotropium respimat add-on to ICS in adolescent patients with symptomatic asthma. Eur Respir J. 2014;44;Suppl 58:1889.

143.Vandewalker M, Harper T, Moroni-Zentgraf P, et al. Once-daily tiotropium respimat add-on therapy improves lung function in adolescent patients with moderate symptomatic asthma, independent of $\mathrm{T}$ helper 2 inflammatory status. Ann Allergy Asthma Immunol. 2015;115:A54-5.

144.Peters SP, Bleecker ER, Kunselman SJ, et al. Predictors of response to tiotropium versus salmeterol in asthmatic adults. J Allergy Clin Immunol. 2013 Nov;132(5):1068-1074. PMID: 24084072.
145.Confirmatory trials: Spiriva respimat in adult and adolescent patients with asthma. Ridgefield, CT: Boehringer Ingelheim Pharmecuticals, Inc. 2016 Nov.

146.Rajanandh MG, Nageswari AD, Ilango K. Pulmonary function assessment in mild to moderate persistent asthma patients receiving montelukast, doxofylline, and tiotropium with budesonide: a randomized controlled study. Clin Ther. 2014 Apr 1;36(4):526-33. PMID: 24650447.

147.Rajanandh MG, Nageswari AD, Ilango K. Assessment of montelukast, doxofylline, and tiotropium with budesonide for the treatment of asthma: which is the best among the second-line treatment? A randomized trial. Clin Ther. 2015 Feb 1;37(2):418-26. PMID: 25577543.

148. Wechsler ME, Yawn BP, Fuhlbrigge AL, et al. Anticholinergic vs long-acting $\beta$-agonist in combination with inhaled corticosteroids in black adults with asthma: the BELT randomized clinical trial. JAMA. 2015 Oct 27;314(16):172030. PMID: 26505596.

149.Rajanandh MG, Nageswari AD, Ilango K. Assessment of various second-line medications in addition to inhaled corticosteroid in asthma patients: a randomized controlled trial. Clin Exp Pharmacol Physiol. 2014 Jul;41(7):509-13. PMID: 24738981.

150.Kerstjens HA, Engel M, Dahl, et al. Tiotropium in asthma poorly controlled with standard combination therapy. N Engl J Med. 2012 Sep 27;367(13):1198-207. PMID: 22938706.

151.Wang K, Tian P, Fan Y, et al. Assessment of second-line treatments for patients with uncontrolled moderate asthma. Int J Clin Exp Med. 2015 Oct 15;8(10):19476-80. PMID: 26770595.

152.Hamelmann E, Bernstein JA, Vandewalker M, et al. A randomised controlled trial of tiotropium in adolescents with severe symptomatic asthma. Eur Respir J. 2016 Nov 3;pii:ERJ-01100-2016. Epub 2016 Nov 3. PMID: 27811070.

153.Boehringer Ingelheim. Evaluation of tiotropium $5 \mu \mathrm{g} /$ day delivered via the respimat inhaler over 48 weeks in patients with severe persistent asthma (study I). In: ClinicalTrials.gov. Bethesda, MD: National Library of Medicine (US); 2000- [cited 2016 Nov 30]. https://clinicaltrials.gov/ct2/show/NCT00772538 . NLM Identifier: NCT00772538. 
154.Boehringer Ingelheim. Evaluation of tiotropium $5 \mu \mathrm{g} /$ day delivered via the respimat inhaler over 48 weeks in patients with severe persistent asthma (study II). In: ClinicalTrials.gov. Bethesda, MD: National Library of Medicine (US); 2000- [cited 2016 Nov 30]. https:/clinicaltrials.gov/ct2/show/NCT00776984 . NLM Identifier: NCT00776984.

155.Bernstein JA, Kerstjens HAM, Moroni-Zentgraf $\mathrm{P}$, et al. Once-daily tiotropium is well tolerated as add-on to standard treatment for patients with symptomatic asthma despite receiving inhaled corticosteroids and long-acting $\beta_{2}$-agonists. Chest. 2013;144(4_MeetingAbstracts):89A. DOI: $10.1378 /$ chest.1701649.

156. Casale TB, Halpin DM, Engel M, et al. 24-hour efficacy of tiotropium respimat in asthma. J Gen Intern Med. 2015;30;Suppl 2:S83.

157. Corren J, Frew A, Engel M, et al. Tiotropium as add-on therapy to ICS+LABA in patients with symptomatic severe asthma: spirometric assessment over 24 hours. Chest. 2013;144(4_MeetingAbstracts):91A. DOI: 10.1378/chest.1702134.

158.Corren J, Murphy KR, Bensch G, et al. Oncedaily tiotropium respimat decreases the risk of exacerbations, independent of baseline characteristics, in patients with symptomatic severe asthma without evidence of chronic obstructive pulmonary disease. J Gen Intern Med. 2014;29;Suppl 1:S157-8.

159.Dahl R, Doherty DE, Corren J, et al. Once-daily tiotropium respimat improves lung function in patietns with severe symptomatic asthma independent of leukotriene modifier use. Thorax. 2014;69;Suppl 2:A178. DOI: 10.1136/thoraxjnl2014-206260.358.

160.Dahl R, Paggiaro P, Engel M, et al. Once-daily tiotropium improves lung function and reduces risk of asthma exacerbation/worsening in patients with symptomatic asthma, regardless of allergic status. Allergy. 2013;68;Suppl 97:40.

161.Doherty DE, Tashkin DP, Harrison TW, et al. Improvements in lung function with tiotropium as add-on controller therapy to ICS+LABA for patients with severe symptomatic asthma. Chest. 2013;144(4_MeetingAbstracts):88A. DOI: 10.1378/chest.1702143.
162.Halpin DM, Bateman ED, Moroni-Zentgraf P, et al. Tiotropium is effective in patients with severe asthma without evidence of chronic obstructive pulmonary disease. Am J Respir Crit Care Med. 2013;187:A2731.

163. Halpin DMG, Bateman ED, Moroni-Zentgraf P, et al. Tiotropium is effective in patients with severe asthma without evidence of chronic obstructive pulmonary disease. Thorax. 2013;68;Suppl 3:A152. DOI: 10.1136/thoraxjnl2013-204457.320.

164.Halpin DMG, Bateman ED, Tashkin DP, et al. Tiotropium decreases the risk of exacerbations in patients with symptomatic asthma regardless of baseline characteristics including markers of allergic status. Thorax. 2013;68;Suppl 3:A14950. DOI: 10.1136/thoraxjnl-2013-204457.314.

165.Halpin DMG, Paggiaro P, Bateman ED, et al. Once-daily tiotropium respimat add-on to at least ICS maintenance therapy reduces exacerbation risk in patients with uncontrolled symptomatic asthma. Thorax. 2014;69;Suppl 2:A189. DOI: 10.1136/thoraxjnl-2014-206260.383.

166. Hayden M, Engel M, Schmidt H, et al. Efficacy of once-daily tiotropium respimat $5 \mu \mathrm{g}$ from phase III trials in adults with symptomatic asthma. J Am Pharm Assoc. 2015;55(2):e242-3.

167.Hoy H, Engel M, Schmidt H, et al. Once-daily tiotropium respimat: safety and tolerability results from phase III trials in adults with symptomatic asthma. J Am Pharm Assoc. 2015;55(2):e244.

168. Hozawa S, Kerstjens HAM, Tashkin DP, et al. Tiotropium decreases the risk of exacerbations in patients with symptomatic asthma regardless of baseline characteristics. Respirology. 2013;18;Suppl 4:175.

169. Kerstjens HAM, Tashkin DP, Engel M, et al. Tiotropium decreases the risk of exacerbations in patients with symptomatic asthma regardless of baseline characteristics. Am J Respir Crit Care Med. 2013;187(1_MeetingAbstracts):A4217. DOI: 10.1164/ajrccmconference.2013.187.1_Meeting Abstracts.A4217.

170.Murphy K, Berger W, Engel M, et al. Tiotropium respimat: control in symptomatic asthma. J Gen Intern Med. 2015;30;Suppl 2:S77. 
171.Murphy K, Dahl R, Paggiaro P, et al. Once-daily tiotropium respimat add-on to at least inhaled corticosteroid maintenance therapy reduces airflow obstruction in patients with symptomatic asthma, independent of allergic status. J Am Pharm Assoc. 2015;55(2):e243.

172.Tashkin DP, Moroni-Zentgraf P, Engel M, et al. Once-daily tiotropium reduces risk of exacerbations and asthma worsening in patients with symptomatic asthma despite treatment with inhaled corticosteroids and long-acting $\beta_{2}$ agonists. Chest. 2013;144(4_MeetingAbstracts):90A. DOI: 10.1378/chest.1701739.
173.Kerstjens HA, Moroni-Zentgraf P, Tashkin DP, et al. Tiotropium improves lung function, exacerbation rate, and asthma control, independent of baseline characteristics including age, degree of airway obstruction, and allergic status. Respir Med. 2016 Aug;117:198-206. PMID: 27492532.

174.Boner A, Hamelmann E, Bernstein J, et al. Oneyear efficacy and safety study of tiotropium respimat add-on to ICS in adolescent patients with symptomatic asthma. Orally presented at: $24^{\text {th }}$ Annual Congress of the European Respiratory Society. 2014 Sep 8; Munich, Germany. 


\section{Glossary}

Asthma control: The degree to which the manifestations of asthma (symptoms, functional impairments, exacerbations) are minimized. Asthma control is determined by assessing the domains of impairment (patient self-reported symptoms, nighttime awakenings, rescue SABA use, interference with normal activities; objective measures of lung function) and risk (exacerbations requiring oral systemic corticosteroids).

Asthma severity: The intrinsic intensity of the disease process. Asthma severity is assessed in a patient who is not currently receiving controller therapy using the domains of impairment (patient self-reported symptoms, nighttime awakenings, rescue SABA use, interference with normal activities; objective measures of lung function) and risk (exacerbations requiring oral systemic corticosteroids) or it is inferred from the least amount of treatment required to maintain control. Asthma severity is classified as “intermittent”, “mild persistent”, “moderate persistent”, or "severe persistent".

Controlled asthma: Minimal manifestations of asthma symptoms and functional impairments, as determined by assessment of the impairment and risk domains.

Controller therapy: Medications recommended to be taken daily on a long-term basis to achieve and maintain control of persistent asthma. Long-term controller medications include inhaled corticosteroids, inhaled long-acting bronchodilators, leukotriene modifiers, cromolyn, theophylline, immunomodulators, and oral systemic corticosteroids.

Intermittent dosing: The prescribed use of ICS that is not the same on a daily basis. As prescribed, intermittent ICS dosing may specify variations in the dose or frequency of administration of ICS. The determinant of ICS use with intermittent ICS dosing may be a patient decision (based on need), an index of worsening asthma, or some other pre-defined criteria.

Persistent asthma: A classification of asthma severity defined either by the assessment of the impairment (patient self-reported symptoms, nighttime awakenings, rescue SABA use, interference with normal activities; objective measures of lung function) and/or risk (exacerbations requiring oral systemic corticosteroids) domains in a patient not taking controller therapy or use of controller therapy to achieve and maintain asthma control. Persistent asthma is further sub-divided as “mild persistent”, “moderate persistent”, and "severe persistent”.

Quick-relief therapy: Medication to be used as-needed for acute symptom relief.

Uncontrolled asthma: A lack of asthma control, as determined by assessment of the impairment and/or risk domains. 
Abbreviations

$\begin{array}{ll}\text { Abbreviation } & \text { Definition } \\ \text { ACQ } & \text { Asthma Control Questionnaire } \\ \text { ACT } & \text { Asthma Control Test } \\ \text { AQLQ } & \text { Asthma Quality of Life Questionnaire } \\ \text { AQLQ(S) } & \text { Standardized Asthma Quality of Life Questionnaire } \\ \text { AUC } & \text { Area Under the Curve } \\ \text { CBP } & \text { Conventional Best Practice } \\ \text { CI } & \text { Confidence Intervals } \\ \text { EPC } & \text { Evidence-based Practice Centers } \\ \text { EPR } & \text { Expert Panel Report } \\ \text { ER } & \text { Emergency Room } \\ \text { FEV1 } & \text { Forced Expiratory Volume in 1 second } \\ \text { FVC } & \text { Forced Vital Capacity } \\ \text { HR } & \text { Hazard Ratio } \\ \text { ICS } & \text { Inhaled Corticosteroid } \\ \text { ICTRP } & \text { International Controlled Trials Registry Platform } \\ \text { KQ } & \text { Key Question } \\ \text { LABA } & \text { Long-acting ß2 Agonists } \\ \text { LAMA } & \text { Long-acting Muscarinic Antagonists } \\ \text { LTRA } & \text { Leukotriene Receptor Antagonist } \\ \text { mAPI } & \text { modified Asthma Prediction Index } \\ \text { MD } & \text { Mean Difference } \\ \text { NAEPP } & \text { National Asthma Education and Prevention Program } \\ \text { NHLBI } & \text { National Heart, Lung and Blood Institute } \\ \text { OR } & \text { Odds Ratio } \\ \text { PACQLQ } & \text { Pediatric Asthma Caregivers Asthma Quality of Life Questionnaire } \\ \text { PAQLQ } & \text { Pediatric Asthma Quality of Life Questionnaire } \\ \text { PEF } & \text { Peak Expiratory Flow } \\ \text { PICOTS } & \text { Population, Intervention, Comparison, Outcomes, Timing, Setting } \\ \text { RCT } & \text { Randomized Controlled Trial } \\ \text { RR } & \text { Relative Risk } \\ \text { RTI } & \text { Respiratory Tract Infection } \\ \text { SABA } & \text { Short-acting ß2 Agonists } \\ \text { SOE } & \text { Strength of Evidence } \\ \text { UK } & \text { United Kingdom } \\ \text { US } & \text { United States } \\ & \end{array}$




\section{Appendixes}

\section{Contents}

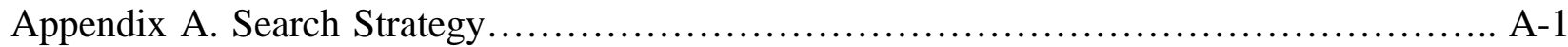

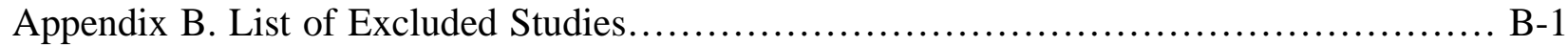

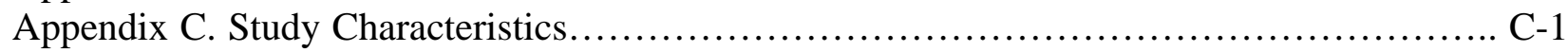

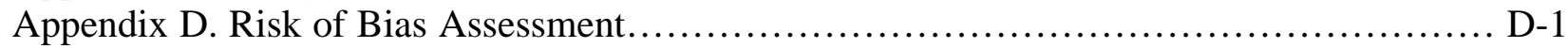

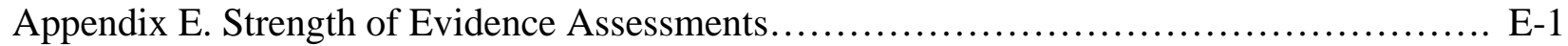

Appendix F. Forest Plots............................................................................................ F-1

\section{Tables}

Table C-1. Study and population characteristics for KQ 1c ...........................................................

Table C-2. Study level outcomes for KQ1a, intermittent ICS vs. no therapy ..............................-4

Table C-3. Study level outcomes for KQ1a, intermittent ICS with as-needed SABA vs. ICS

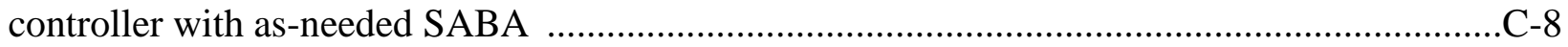
Table C-4. Study level outcomes for KQ1a, intermittent ICS with as-needed SABA vs. as-needed

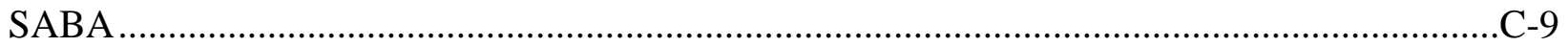

Table C-5. Study and population characteristics for KQ1b, intermittent ICS and ICS controller vs.

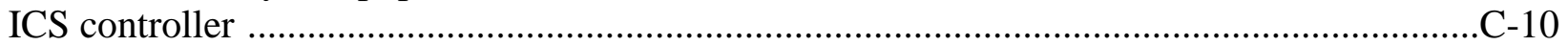
Table C-6. Study and population characteristics for KQ1b, intermittent ICS versus ICS controller .C-15

Table C-7. Study level outcomes for KQ1b, intermittent ICS and ICS controller vs. ICS controller ..C-18 Table C-8. Study level outcomes for KQ1b, intermittent ICS versus ICS controller .................-21 Table C-9. Study and population characteristics for KQ1c, ICS and LABA controller and quick relief vs. ICS controller (same dose).

Table C-10. Study and population characteristics for KQ1c, ICS and LABA controller and quick relief vs. ICS (higher dose) .C-26 Table C-11. Study and population characteristics for KQ1c, ICS and LABA controller and quick relief vs. ICS and LABA controller (same dose) Table C-12. Study and population characteristics for KQ1c, ICS and LABA controller and quick relief vs. ICS and LABA controller (higher dose) ) ..... Table C-13. Study and population characteristics for KQ1c, ICS and LABA controller and quick relief vs. ICS and LABA controller (lower dose) ) ... Table C-14. Study and population characteristics for KQ1c, ICS and LABA controller and quick relief vs. CBP) ....

Table C-15. Study level outcomes for KQ1c, ICS and LABA controller and quick relief vs. ICS controller (same dose).

Table C-16. Study level outcomes for KQ1c, ICS and LABA controller and quick relief vs. ICS controller (higher dose) )

Table C-17. Study level outcomes for KQ1c, ICS and LABA controller and quick relief vs. ICS

and LABA controller (same dose) ) ..... .C-41 Table C-18. Study level outcomes for KQ1c, ICS and LABA controller and quick relief vs. ICS and LABA (higher dose) ) 
Table C-19. Study level outcomes for KQ1c, ICS and LABA controller and quick relief vs. ICS

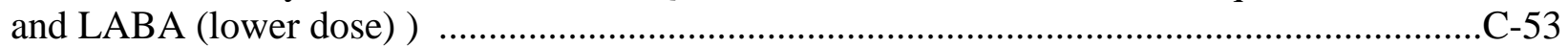
Table C-20. Study level outcomes for KQ1c, ICS and LABA controller and quick relief vs. CBP) .C-54

Table C-21. Study and population characteristics for KQ2a) ...............................................58

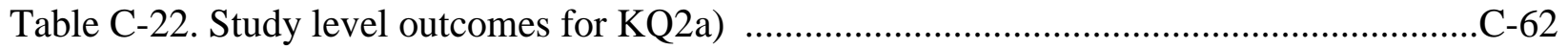

Table C-23. Subgroup analysis by tiotropium dose for KQ2a) .............................................65

Table C-24. Study and population characteristics for KQ2b) ..............................................6-66

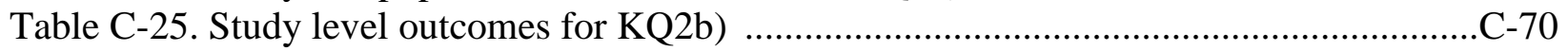

Table C-26. Study and population characteristics for KQ2c) ...............................................73

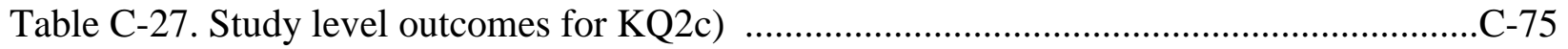

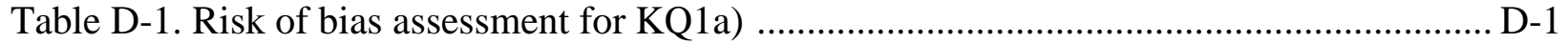

Table D-2. Risk of bias assessment for KQ1b ................................................................... D-2

Table D-3. Risk of bias assessment for KQ1c, ICS and LABA controller and quick relief vs. ICS controller (same dose) ........................................................................................... D-3 Table D-4. Risk of bias assessment for KQ1c, ICS and LABA controller and quick relief vs. ICS

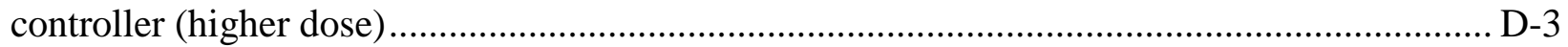
Table D-5. Risk of bias assessment for KQ1c, ICS and LABA controller and quick relief vs. ICS

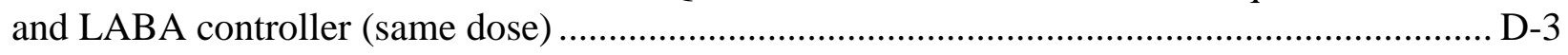
Table D-6. Risk of bias assessment for KQ1c, ICS and LABA controller and quick relief vs. ICS

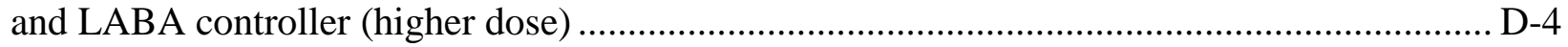
Table D-7. Risk of bias assessment for KQ1c, ICS and LABA controller and quick relief vs. ICS

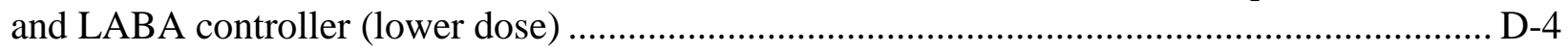
Table D-8. Risk of bias assessment for KQ1c, ICS and LABA controller and quick relief vs. CBP Table D-9. Risk of bias assessment for non-randomized studies, KQ1c ............................... D-5

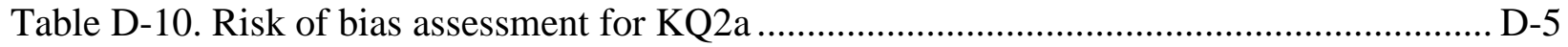
Table D-11. Risk of bias assessment for KQ2b ............................................................ D-6 Table D-12. Risk of bias assessment for KQ2c ............................................................. D-6 Table E-1. Strength of evidence KQ1a, intermittent ICS with as-needed SABA vs. as-needed

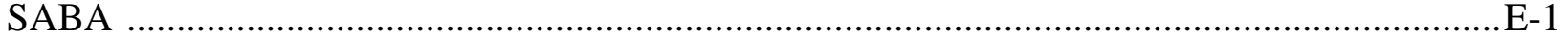
Table E-2. Strength of evidence KQ1a, intermittent ICS with as-needed SABA vs. ICS controller with as-needed SABA ...................................................................................................... Table E-3. Strength of evidence KQ1a, intermittent ICS vs. no therapy ................................... E-5 Table E-4. Strength of evidence KQ1b, intermittent ICS and ICS controller vs. ICS controller E-7 Table E-5. Strength of evidence KQ1b, intermittent ICS versus ICS controller .....................E-11 Table E-6. Strength of evidence KQ1c, ICS and LABA as controller and quick relief vs. ICS

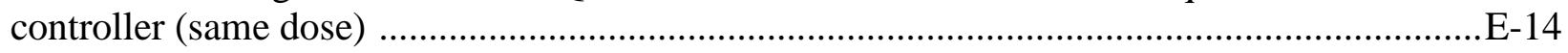
Table E-8. Strength of evidence rating KQ1c, ICS and LABA controller and quick relief vs. ICS

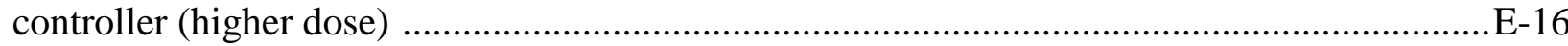
Table E-9. Strength of evidence rating KQ1c, ICS and LABA controller and quick relief vs. ICS and LABA controller (same dose) .................................................................................18 Table E-10. Strength of evidence rating KQ1c, ICS and LABA controller and quick relief vs. ICS

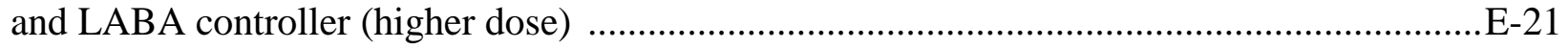
Table E-11. Strength of evidence rating KQ1c, ICS and LABA controller and quick relief vs. ICS and LABA controller (lower dose) 
Table E-12. Strength of evidence rating KQ1c, ICS and LABA controller and quick relief vs. CBP E-24

Table E-13. Strength of evidence rating KQ2a, LAMA as add-on to ICS vs. doubling ICS dose ...

E-26

Table E-14. Strength of evidence rating KQ2a, LAMA vs. placebo as add-on to ICS ............E-28

Table E-15. Strength of evidence rating KQ2b, LAMA vs. LABA as add-on to ....................E-30

Table E-16. Strength of evidence rating KQ2b, LAMA vs. controller other than LABA as add-on to ICS

Table E-17. Strength of evidence rating KQ2c

E-34

\section{Figures}

Figure F-1. Asthma-related acute care visit: intermittent ICS with as-needed SABA vs. as-needed SABA

Figure F-2. Hospital admissions due to asthma: intermittent ICS with as-needed SABA vs. asneeded SABA

Figure F-3. All-cause death: ICS and LABA controller and quick relief vs. ICS and LABA Controller (Same Dose)

Figure F-4. Change in ACQ-5 mean score from baseline: ICS and LABA controller and quick relief vs. ICS and LABA Controller (Same Dose)

Figure F-5. Change in on-treatment FEV1 from baseline: ICS and LABA controller and quick

relief vs. ICS and LABA Controller (Same Dose)

Figure F-6. Change in rescue medication use from baseline, mean inhalations per day: ICS and

LABA controller and quick relief vs. ICS and LABA Controller (Same Dose) F-2

Figure F-7. All-cause death: ICS and LABA controller and quick relief vs. ICS and LABA

Controller (Higher Dose)

Figure F-8. All-cause death: ICS and LABA controller and quick relief vs. CBP

Figure F-9. Change in ACQ-5 mean score from baseline: ICS and LABA controller and quick relief vs. CBP

Figure F-10. Change in ACQ-7 score from baseline: LAMA vs. placebo as add-on to ICS .....F-4

Figure F-11. ACQ-7 responder: LAMA vs. placebo as add-on to ICS ....................................F-4

Figure F-12. Change in FEV1 peak from baseline: LAMA vs. placebo as add-on to ICS .........F-4

Figure F-13. Change in FEV1 trough from baseline: LAMA vs. placebo as add-on to ICS ...... F-5

Figure F-14. Change in FEV1 AUC from baseline: LAMA vs. placebo as add-on to ICS .........F-5

Figure F-15. Change in FVC peak from baseline: LAMA vs. placebo as add-on to ICS ..........F-5

Figure F-16. Change in FVC trough from baseline: LAMA vs. placebo as add-on to ICS .......F-6

Figure F-17. Change in FVC AUC from baseline: LAMA vs. placebo as add-on to ICS .........F-6 Figure F-18. Difference in rescue medication mean puffs in 24 hours: LAMA vs. placebo as add-

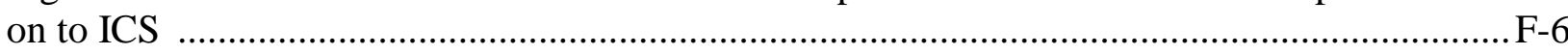

Figure F-19. All-Cause Death: LAMA vs. LABA as add-on to ICS .....................................F-7

Figure F-20. Asthma-specific death: LAMA vs. LABA as add-on to ICS .............................F-7

Figure F-21. Change in FEV1 trough from baseline: LAMA vs. LABA as add-on to ICS .......F-7

Figure F-22. Change in FEV1 \% predicted from baseline: LAMA vs. LABA as add-on to ICS F-8 Figure F-23. Change in FVC trough from baseline: LAMA vs. LABA as add-on to ICS ..........F-8 Figure F-24. Change in AQLQ score from baseline: LAMA vs. LABA as add-on to ICS .........F-8 
Figure F-25. Difference in rescue medication mean puffs in 24 hours: LAMA vs. LABA as add-on to ICS F-9

Figure F-26. Change in ACQ-7 score from baseline: LAMA and ICS and LABA vs. ICS and LABA

Figure F-27. Change in FEV1 peak from baseline: LAMA and ICS and LABA vs. ICS and LABA

Figure F-28. Change in FEV1 trough from baseline: LAMA and ICS and LABA vs. ICS and

LABA F-10

Figure F-29. Change in FEV1 AUC from baseline: LAMA and ICS and LABA vs. ICS and LABA F-10

Figure F-30. Change in FVC peak from baseline: LAMA and ICS and LABA vs. ICS and LABA

Figure F-31. Change in FVC trough from baseline: LAMA and ICS and LABA vs. ICS and LABA

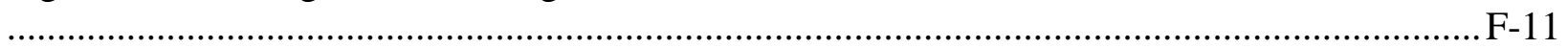
Figure F-32. Change in FVC AUC from baseline: LAMA and ICS and LABA vs. ICS and LABA . Figure F-33. Difference in rescue medication mean puffs in 24 hours: LAMA and ICS and LABA vs. ICS and LABA F-11 


\section{Appendix A. Search Strategy}

\section{Search for KQ 1- Medline, Cochrane Central and Cochrane Database of Systematic Reviews- via Ovid}

1. Asthma.mp or Asthma/

2. Wheez\$.mp.

3. Bronchial spasm/ or bronchospas $\$ . m p$.

4. Bronchoconstriction/ or bronchoconstrict\$.mp.

5. Bronchial hyperreactivity/

6. Reactive airway disease.mp.

7. 1 or 2 or 3 or 4 or 5 or 6

8. Inhaled corticosteroid.mp.

9. Inhal\$.mp.

10. Ciclesonide.mp.

11. Fluticasone/ or fluticasone.mp.

12. Flunisolide.mp.

13. Beclomethasone/ or beclomethasone.mp.

14. Budesonide/ or budesonide.mp.

15. Mometasone furoate/ or mometasone.mp.

16. Triamcinolone/ or triamcinolone.mp.

17. 9 AND (10 or 11 or 12 or 13 or 14 or 15 or 16 )

18. "Single inhaler".mp. OR "single maintenance and reliever therapy".mp. OR SMART

19. 8 or 17 or 18

20. 7 and 19

21. Limit 20 to humans

\section{Search for KQ 1- Embase}

1. 'asthma'/de OR asthma

2. 'wheezing'/de OR wheezing

3. 'wheeze'/de OR wheeze

4. 'bronchospasm'/de OR 'bronchospasm'

5. 'bronchoconstriction'/de OR 'bronchoconstriction'

6. 'bronchial hyperreactivity'/de OR

7. 'reactive airway disease'

8. \#1 OR \#2 OR \#3 OR \#4 OR \#5 OR \#6 OR \#7

9. 'ciclesonide'/exp/dd_ih

10. 'budesonide'/exp/dd_ih

11. 'fluticasone'/exp/dd_ih

12. 'flunisolide'/exp/dd_ih

13. 'beclomethasone'/exp/dd_ih

14. 'mometasone'/exp/dd_ih

15. 'triamcinolone'/exp/dd_ih

16. 'single maintenance and rescue therapy'

17. 'single inhaler therapy'

18. \#9 OR \#10 OR \#11 OR \#12 OR \#13 OR \#14 OR \#15 OR \#16 OR \#17

19. \#8 AND \#18 
Search for KQ 2- Medline, Cochrane Central and Cochrane Database of Systematic Reviews- via Ovid

1. Asthma.mp or Asthma/

2. Wheez\$.mp.

3. Bronchial spasm/ or bronchospas\$.mp.

4. Bronchoconstriction/ or bronchoconstrict\$.mp.

5. Bronchial hyperreactivity/

6. Reactive airway disease.mp.

7. 1 or 2 or 3 or 4 or 5 or 6

8. Long acting muscarinic antagonist.mp.

9. Tiotropium bromide/ or tiotropium.mp.

10. Aclidinium.mp.

11. Glycopyrronium.mp. or glycopyrrolate/ or glycopyrrolate.mp.

12. Umeclidinium.mp.

13. 9 or 10 or 11 or 12

14. 8 or 13

15. 7 and 14

16. Limit 15 to humans

\section{Search for KQ 2- Embase}

20. 'asthma'/de OR asthma

21. 'wheezing'/de OR wheezing

22. 'wheeze'/de OR wheeze

23. 'bronchospasm'/de OR 'bronchospasm'

24. 'bronchoconstriction'/de OR 'bronchoconstriction'

25. 'bronchial hyperreactivity'/de OR

26. 'reactive airway disease'

27. \#1 OR \#2 OR \#3 OR \#4 OR \#5 OR \#6 OR \#7

28. 'long acting muscarinic antagonist'

29. 'tiotropium'/exp/dd_ih

30. 'aclidinium'/exp/dd_ih

31. 'glycopyrronium'/exp/dd_ih

32. "glycopyrrolaye'/exp/dd_ih

33. 'umeclidinium'/exp/dd_ih

34. \#9 OR \#10 OR \#11 OR \#12 OR \#13 OR \#14

35. \#8 AND \#15 


\section{Appendix B. List of Excluded Studies}

\section{ICS Search}

1. 2nd WAO International Scientific Conference, WISC 2012, Abstracts. World Allergy Organ J. 2013;6;Suppl 1:1-67. [Not an intervention of interest]

2. A combination of fluticasone and salmeterol for asthma. Med Lett Drugs Ther. 2001 Apr 16;43(1102):31-3. PMID: 11309534. [Not a human study]

3. Aalbers R, Backer V, Kava TTK, et al. Adjustable maintenance dosing with budesonide/formoterol compared with fixeddose salmeterol/fluticasone in moderate to severe asthma. Curr Med Res Opin. 2004;20(2):225-40. PMID: 15006018. [Not an intervention of interest]

4. Aalbers R, Mensing M, Boorsma M, et al. Protective effect of budesonide /formoterol in a model of repeated exposure to inhaled adenosine 5'-monophosphate (AMP) in patients with asthma. Eur Respir J. 2007;30;Suppl 51:353s. [Not an intervention of interest]

5. Aalbers R. Fixed or adjustable maintenancedose budesonide/formoterol compared with fixed maintenance-dose salmeterol/fluticasone propionate in asthma patients aged $>$ or $=16$ years: Post hoc analysis of a randomized, double-blind/open-label extension, parallelgroup study. Clin Drug Invest. 2010;30(7):439-51. PMID: 20528000. [Not an intervention of interest]

6. Aalbers R. Single inhaler as maintenance and reliever therapy--is it SMART? Lancet Respir Med. 2013 Mar;1(1):2-3. PMID: 24321788. [Not a human study]

7. Abramson M, Sim MR. Occupational asthma. Thorax. 2006 Sep;61(9):741-2. [Not a human study]

8. Acun C, Tomac N, Sogut A, et al. A comparison of inhaled budesonide and oral prednisolone for children with acute asthma. 2003 Sep;22;Suppl 45:134s. [Not in the target population]
9. Adachi M, Ishihara K, Inoue H, et al. Safety and efficacy of inhaled ciclesonide in longterm administration to adult patients with bronchial asthma. Ther Res. 2008;29(5):82132. [Not an intervention of interest]

10. Adelroth E, Thompson S. Advantages of high-dose inhaled budesonide. Lancet. 1988 Feb 27;1(8583):476. PMID: 2893900. [Not an intervention of interest]

11. Adelsberg B. Combined budesonide and formoterol for maintenance and relief provided better asthma control than budesonide for maintenance and terbutaline for relief: commentary. Evid-Based Med. 2006 Oct;11(5):138. [Not a human study]

12. Adler LM, Clarke IC. Efficacy and safety of beclomethasone dipropionate (BDP) delivered via a novel dry powder inhaler (Clickhaler[TM]) in paediatric patients with asthma. Thorax. 1997;52;Suppl 6:A57 P106. [Not an intervention of interest]

13. Adolfsson LE, Lundgren M, Tilling B, et al. Short-term safety and tolerability of doubledose salmeterol/fluticasone propionate in adult asthmatic patients. Clin Drug Invest. 2005;25(4):231-41. DOI: 10.2165/00044011200525040-00002. [Not an intervention of interest]

14. Aelony Y. Inhaled fluticasone and zafirlukast in persistent asthma. Am J Med. 2002 Mar;112(4):333. PMID: 11893383. [Not a human study]

15. Affrime MB, Banfield C, Nolop K. Systemic bioavailability of inhaled corticosteriods: appropriate and comparable methodology. Eur Respir J. 2001;18(1):246. [Not a human study] 
16. Afilalo M, Guttman A, Colacone A, et al. Efficacy of inhaled steroids (beclomethasone dipropionate) for treatment of mild to moderately severe asthma in the emergency department: A randomized clinical trial. Ann Emerg Med. 1999 Mar;33(3):304-9. PMID: 10036345. [Not in the target population]

17. Agarwal SK, Arshad N. Utility of high dose inhaled fluticasone therapy for the early management of acute exacerbations of asthma [Abstract]. European Respiratory Society; 2009 Sep 12-16; Vienna, Austra. E4352. [Not in the target population]

18. Agarwal SK, Sharma S. Effect of fluticasone/formoterol pressurized metereddose inhaler (pMDI) in early management o facute exacerbations of asthma. Am J Respir Crit Care Med. 2010;181:A5659. [Not in the target population]

19. Agarwal SK, Sharma S. Utility of inhaled corticosteroids (fluticasone/formoterol) by pressurized metered-dse inhaler for the early management of acute exacerbations of asthma [Abstarct]. European Respiratory Society; 2010 Ssep 18-22; Barcelona, Spain. E5476. [Not in the target population]

20. Agerroft L, Pedersen S. Comparison of lower leg growth rate in prepubertal children with mild asthma treated with inhaled placebo, ciclesonide, or fluticasone propionate. Allergy. 2007;62:131. [Not an intervention of interest]

21. Agerroft L, Pedersen S. Inhaled ciclesonide does not effect lower leg growth rate or HPAaxis function in children with mild asthma. Eur Respir J. 2004;24;Suppl 48:377s. [Not an intervention of interest]

22. Agerroft L, Pedersen S. Lower-leg growth rate and APA-axis function in children with asthma during treatment with inhaled ciclesonide. J Allergy Clin Immunol. 2004;113;Suppl 2:S119. [Not an intervention of interest]
23. Agertoft L, Pedersen S. Bone mineral density in children with asthma receiving long-term treatment with inhaled budesonide. Am J Respir Crit Care Med. 1998 Jan;157(1):178-83. PMID: 9445297. [Excluded study design]

24. Agertoft L, Pedersen S. Effects of long-term treatment with an inhaled corticosteroid on growth and pulmonary function in asthmatic children. Respir Med. 1994 May;88(5):37381. PMID: 8036306. [Not an intervention of interest]

25. Agertoft L, Pedersen S. Influence of inspiratory flow rate on plasma levels and lung deposition of fluticasone propionate inhaled from diskus dry powder inhaler. European Respiratory Society; 1999 Oct 913; Madrid, Spain. 1264p. [Irretrievable]

26. Agertoft L, Pederson S. Long term growth in children with inhaled budesonide or nedocromil. Eur Respir J. 2000;16;Suppl 31:553s. [Irretrievable]

27. Akhtaruzzaman M, Ahmed SU, Hoque MA, et al. Effects of nebulized budesonide as an adjunct to standard treatment of asthma exacerbations: A randomized, double-blind, placebo-controlled trial. Mymensingh Med J. 2014 Jul;23(3):418-25. PMID: 25178590. [Not in the target population]

28. Akkoca O, Mungan D, Karabiyikoglu G, et al. Inhaled and systemic corticosteroid therapies: Do they contribute to inspiratory muscle weakness in asthma?. Respiration. 1999;66(4):332-7. PMID: 10461081. [Not an intervention of interest]

29. Alangari AA, Malhis N, Mubasher M, et al. Budesonide nebulization added to systemic prednisolone in the treatment of acute asthma in children: A double-blind, randomized, controlled trial. Chest. 2014 Apr;145(4):7728. PMID: 24384609. [Not in the target population] 
30. Aldridge RE, Hancox RJ, Cowan JO, et al. Eosinophils and eosinophilic cationic protein in induced sputum and blood: Effects of budesonide and terbutaline treatment. Ann Allergy Asthma Immunol. 2002 Nov;89(5):492-7. [Not an intervention of interest]

31. Allen DB, Bronsky EA, LaForce CF, et al. Growth in asthmatic children treated with fluticasone propionate. J Pediatr. 1998 Mar;132(3 Pt 1):472-7. PMID: 9544904. [Not an intervention of interest]

32. Allen DB. Effect of inhaled corticosteroids on growth. Pediatrics. 2001

Nov;108(5):1234-5. PMID: 11694712. [Not a human study]

33. Allen DB. Sense and sensitivity: assessing inhaled corticosteroid effects on the hypothalamic-pituitary-adrenal axis. Ann Allergy Asthma Immunol. 2002 Dec;89(6):537-9. [Not a human study]

34. Allen HD, Thong IG, Clifton-Bligh P, et al. Effects of high-dose inhaled corticosteroids on bone metabolism in prepubertal children with asthma. Pediatr Pulmonol. 2000 Mar;29(3):188-93. PMID: 10686039. [Not an intervention of interest]

35. Al-Samri MT, Benedetti A, Prefontaine D, et al. Variability of sputum inflammatory cells in asthmatic patients receiving corticosteroid therapy: A prospective study using multiple samples. J Allergy Clin Immunol. 2010 May;125(5):1161,1163.e4. PMID: 20392486. [Not an intervention of interest]

36. Altintas DU, Karakoc GB, Can S, et al. The effects of long term use of inhaled corticosteroids on linear growth, adrenal function and bone mineral density in children. Allergol Immunopathol (Madr). 2005 Jul-Aug;33(4):204-9. PMID: 16045858. [Not an intervention of interest]

37. Amar NJ, Shekar T, Varnell T, et al. Mometasone furoate (MF) improves lung function in pediatric asthma: a dose-ranging study of MF metered-dose inhaler (MDI). J Allergy Clin Immunol. 2016;137;2 Suppl 1:AB214. Embase 72197450. [Not an intervention of interest]
38. Amirav I, Newhouse MT. Treatment failures in children with asthma due to inappropriate use of turbuhaler. J Pediatr. 2002;140(4):483. [Excluded study design]

39. Anaev E, Chuchalin A. The efficiency of inhaled budesonide for patients with bronchila asthma. Eur Respir J. 2000;16;Suppl 31:279s. [Excluded study design]

40. Anderson W, McFarlane L, Lipworth B. Prospective follow-up of novel bone turnover markers in asthmatics exposed to low or high doses of inhaled ciclesonide over 1 year. Eur Respir J. 2012 Sep 5;40; Suppl 56:P2100. Embase 71926472. [Not an intervention of interest]

41. Anderson WJ, McFarlane LC, Lipworth BJ. Prospective follow-up of novel markers of bone turnover in persistent asthmatics exposed to low and high doses of inhaled ciclesonide over 12 months. J Clin Endocrinol Metab. 2012 Jun;97(6):1929-36. PMID: 22438232. [Not an intervention of interest]

42. Anderson WJ, Short PM, Williamson PA, et al. The FENOtype trial: inhaled corticosteroid dose-response using domiciliary exhaled nitric oxide in persistent asthma. Thorax. 2012;67; Suppl 2:A5. [Not an intervention of interest]

43. Angus R, Reagon R, Cheesbrough A. Shortacting beta 2-agonist and oral corticosteroid use in asthma patients prescribed either concurrent beclomethasone and long-acting beta 2-agonist or salmeterol/fluticasone propionate combination. Int J Clin Pract. 2005 Feb;59(2):156-62. PMID: 15854190. [Not an intervention of interest]

44. Ankerst J, Malolepszy J, Eliraz A. Budesonide/formoterol in a single inhaler is more effective than a higher dose of inhaled corticosteroids in patients with persistent asthma. Eur Respir J. 2002;20; Suppl 38:387s. [Not an intervention of interest] 
45. Ankerst J, Persson G, Weibull E. A high dose of budesonide/formoterol in a single inhaler was well tolerated by asthmatic patients. Eur Respir J. 2000;16;Suppl 31:33s. [Not an intervention of interest]

46. Ankerst J, Persson G, Weibull E. Cardiovascular effects of a high dose of the budesonide/formoterol single inhaler in asthmatic patients. Eur Respir J. 2001;18;Suppl 33:54s. [Not an intervention of interest]

47. Ankerst J, Persson G, Weibull E.

Tolerability of a high dose of budesonide/formoterol in a single inhaler in patients with asthma. Pulm Pharmacol Ther. 2003;16(3):147-51. PMID: 12749830. [Not an intervention of interest]

48. Anthonisen NR. Step-down therapy in a asthma. Can Respir J. 2006 Apr;13(3):123-4. [Irretrievable]

49. Anthracopoulos MB, Papadimitriou A, Panagiotakos DB, et al. Growth deceleration of children on inhaled corticosteroids is compensated for after the first 12 months of treatment. Pediatr Pulmonol. 2007 May;42(5):465-70. PMID: 17394256. [Not an intervention of interest]

50. Antonicelli L, Micucci C, Bonifazi F. Bronchospasm induced by inhalant corticosteroids: The role of ethanol. Allergy. 2006 Jan;61(1):146-7. PMID: 16364174. [Excluded study design]

51. Apold J, Djoseland O. Inhaled beclomethasone dipropionate in the treatment of childhood asthma. Postgrad Med J. 1975;51(Suppl 4):104-5. PMID: 1105511. [Not an intervention of interest]

52. Apold J, Djoseland O. Inhaled beclomethasone dipropionate in the treatment of childhood asthma. Postgrad Med J. 1975;51;Suppl 4:104-5. [Duplicate]

53. Appel DW. Effect of aminophylline when added to metaproterenol sulfate and beclomethasone dipropionate aerosol. J Allergy Clin Immunol. 1984 Feb;73(2):2917. PMID: 6699312. [Not an intervention of interest]
54. Archer H, Creese K, Doull I, et al. Higher dose inhaled steroids in childhood asthma. $\mathrm{Br}$ Med J. 2001 Jun 06;322(7301):1546. [Not a human study]

55. Arend EE, Fischer GB, Debiasi M, et al. Inhaled corticosteroid treatment and growth of asthmatic children seen at outpatient clinics. J Pediatr (Rio J). 2006 MayJun;82(3):197-203. PMID: 16773175. [Not an intervention of interest]

56. Arshad H, Holgate ST. Effect of low doses of mometasone furoate (MF) dry powder inhaler (DPI) on adenosine monophosphate (AMP)-induced bronchoconstriction in asthma. European Respiratory Society; 1999 Oct 9-13; Madrid, Spain. 2239p.

[Irretrievable]

57. Arvidsson P, Larsson S, Lofdahl CG, et al. Inhaled formoterol during one year in asthma: A comparison with salbutamol. Eur Respir J. 1991 Nov;4(10):1168-73. PMID: 1687129. [Excluded study design]

58. Aubier M, Buhl R, Ekstrom T, et al. Comparison of two twice-daily doses of budesonide/formoterol maintenance and reliever therapy. Eur Respir J. 2010 Sep;36(3):524-30. PMID: 20595145. [Not an intervention of interest]

59. Aubier M, Buhl R, Haughney J, et al. Predictive factors for asthma control according to ACQ5 in asthma patients treated with budesonide/ formoterol maintenance and reliever therapy. results from the

EuroSMART study. Irish J Med Sci. 2010

Nov 6;179;Suppl 12:S474. DOI: 10.1007/s11845-010-0593-0. [Not an intervention of interest]

60. Aubier M, Haughney J, Selroos O, et al. Is the patient's baseline inhaled steroid dose a factor for choosing the budesonide/formoterol maintenance and reliever therapy regimen? Therap adv respir dis. 2011 Oct;5(5):289-98. PMID: 21586508. [Not an intervention of interest] 
61. Ayres JG, Campbell LM. A controlled assessment of an asthma self-management plan involving a budesonide dose regimen. OPTIONS research group. Eur Respir J. 1996 May;9(5):886-92. PMID: 8793447. [Not an intervention of interest]

62. Baba K, Hattori T, Koishikawa I, et al. Serum eosinophil cationic protein for predicting the prognosis of a step-down in inhaled corticosteroid therapy in adult chronic asthmatics. J Asthma. 2000 Aug;37(5):399-408. PMID: 10983617. [Excluded study design]

63. Baba K, Sakakibara A, Yagi T, et al. Longterm observations of the clinical course after step down of corticosteroid inhalation therapy in adult chronic asthmatics: Correlation with serum levels of eosinophil cationic protein. Respirology. 2002 Sep;7(3):255-66. PMID: 12153692. [Not an intervention of interest]

64. Bacci E, Novelli F, Bartoli ML, et al. Patients with moderate asthma symptoms may benefit from short term inhaled corticosteroid monotherapy. Eur Respir J. 2007;30;Suppl 51:615s. [Not an intervention of interest]

65. Bacharier LB. "Step-down" therapy for asthma: why, when, and how? J Allergy Clin Immunol. 2002;109(6):916-9. [Not a human study]

66. Bahçeciler NN, Barlan IB, Nuhoglu Y, et al. Risk factors for the persistence of respiratory symptoms in childhood asthma. Ann Allergy Asthma Immunol. 2001;86(4):449-55. [Not an intervention of interest]

67. Bahna SL. Is it time to reduce our phobia of inhaled corticosteroids? Pediatrics. 2004 Jun;113(6):1813-4. PMID: 15173513. [Not a human study]

68. Bajraktarevic A, Maglajlija S, Penava S, et al. Effectiveness of fluticasone propionate and rare adverse effects in preschoolers with asthma. Allergy. 2011;66;S94:584. [Not an intervention of interest]
69. Balanag VM, Yunus F, Yang P, et al. Budesonide/formoterol in a single inhaler is as effective and well tolerated as salbutamol in relieving aacute asthma in adults and adolescents. Eur Respir J. 2003122;Suppl 45:Abstract P2836. [Not in the target population]

70. Balanag VM, Yunus F, Yang P, et al. Efficacy and safety of budesonide/formoterol compared with salbutamol in the treatment of acute asthma. Pulm Pharmacol Ther. 2006;19(2):139-47. PMID: 16009588. [Not in the target population]

71. Balanzat A, Centanni S, Palmqvst M, et al. Budesonide/formterol single inhaler therapy reduces overreliance on rapid-acting reliever medication. Eur Respir J. 2004;24;Suppl 48:344s. [Excluded study design]

72. Balter MS, Bell AD, Kaplan AG, et al. Management of asthma in adults. CMAJ. 2009 Dec;181(12):915-22. [Not a human study]

73. Baraldi E, Rossi GA, Boner AL. Budesonide in preschool-age children with recurrent wheezing. N Engl J Med. 2012 Feb;366(6):570-1. [Not a human study]

74. Barnes N, Laviolette M, Allen D, et al. Effects of montelukast compared to double dose budesonide on airway inflammation and asthma control. Respir Med. 2007 Aug;101(8):1652-8. PMID: 17481879. [Not an intervention of interest]

75. Barnes N, Price D, Colice G, et al. Asthma control with extrafine-particle hydrofluoroalkane-beclometasone vs. largeparticle chlorofluorocarbon-beclometasone: A real-world observational study. Clin Exp Allergy. 2011 Nov;41(11):1521-32. PMID: 21752116. [Not an intervention of interest]

76. Barnes PJ, O'Byrne PM, Rodriguez Roisin $\mathrm{R}$, et al. Treatment of mild persisitent asthma with low doses of inhaled budesonide alone or in combination with formoterol. Thorax. 2000;55; Suppl 3:A4. [Not an intervention of interest] 
77. Barnes PJ. A single inhaler for asthma? Am J Respir Crit Care Med. 2005 Jan;171(2):956. [Not a human study]

78. Barnes PJ. Using a combination inhaler (budesonide plus formoterol) as rescue therapy improves asthma control. BMJ. 2007 Sep 8;335(7618):513. PMID: 17823193. [Not a human study]

79. Barrueto L, Mallol J, Figueroa L. Beclomethasone dipropionate and salbutamol by metered dose inhaler in infants and small children with recurrent wheezing. Pediatr Pulmonol. 2002 Jul;34(1):52-7. PMID: 12112798. [Not an intervention of interest]

80. Bateman ED, Bantje TA, Joao Gomes M, et al. Budesonide/formoterol in a single inhaler improves asthma control more effectively than a higher dose of fluticasone. Eur Respir J. 2001;18;Suppl 33:21s. [Not an intervention of interest]

81. Bateman ED, Bantje TA, Joao Gomes M, et al. Early and sustained benefits of budesonide and formoterol in a single inhaler vs fluticasone in moderate asthma. Eur Respir J. 2001;18;Suppl 33:157s. [Not an intervention of interest]

82. Bateman ED, Bousquet J, Keech ML, et al. The correlation between asthma control and health status: The GOAL study. Eur Respir J. 2007 Jan;29(1):56-62. PMID: 17050557.

[Not an intervention of interest]

83. Bateman ED, Buhl R, O'Byrne PM, et al. Development and validation of a novel risk score for asthma exacerbations: the risk score for exacerbations. J Allergy Clin Immunol. 2015 Jun;135(6):1457,64.e4. PMID: 25258144. [Excluded study design]

84. Bateman ED, Palmqvist M, Juniper EF, et al. Single inhaler therapy with budesonside/formoterol has superior efficacy to fixed-dose budesonide/formoterol or a higher dose of budesonide alone [Abstract]. American Thoracic Society International Conference; 2004 May 21-26; Orlando, FL. J75p. [Irretrievable]
85. Bauer K, Bantje TA, Sips AP, et al. The effect of inhaled fluticasone propionate FP, a new potent corticosteroid in severe asthma. Eur Respir J. 1988;1;Suppl 2:201s. [Not an intervention of interest]

86. Baxter-Jones AD, Helms PJ, Russell G, et al. Early asthma prophylaxis, natural history, skeletal development and economy (EASE): A pilot randomised controlled trial. Health Technol Assess. 2000;4(28):1-89. PMID: 11074396. [Not an intervention of interest]

87. Baxter-Jones AD, Helms PJ. Early introduction of inhaled steroids in wheezing children presenting in primary care. A pilot study. EASE study group. Clin Exp Allergy. 2000 Nov;30(11):1618-26. PMID: 11069572. [Not an intervention of interest]

88. Bayiz H, Ozkaya S, Dirican A, et al. The rapid effects of budesonide plus formoterol in patients with obstructive airway diseases. Drug Des Devel Ther. 2015;9:5287-90. PMID: 26451084. [Excluded study design]

89. Beasley R, Cushley M, Holgate ST. A self management plan in the treatment of adult asthma. Thorax. 1989 Mar;44(3):200-4. PMID: 2705150. [Excluded study design]

90. Beasley R, Pavord I, Papi A, et al. Description of a randomised controlled trial of inhaled corticosteroid/fast-onset LABA reliever therapy in mild asthma. Eur Respir J. 20162016 Mar;47(3):981-4. [Not a human study]

91. Beasley R, Sterk PJ, Kerstjens HAM, et al. Comparative studies of inhaled corticosteroids in asthma. Eur Respir J. 2001;17(4):579-80. [Not a human study]

92. Becker AB, Paré PD. Wheezing in young children: WAITing for pharmacogenomics? Lancet Respir Med. 2014 Oct;2(10):776-7. [Not a human study]

93. Becker AB. Asthma in the preschool child: still a rose by any other name? J Allergy Clin Immunol. 2008 Dec;122(6):1136-7. PMID: 19084109. [Not a human study] 
94. Beigelman A, King TS, Mauger D, et al. Do oral corticosteroids reduce the severity of acute lower respiratory tract illnesses in preschool children with recurrent wheezing?. J Allergy Clin Immunol. 2013;131(6):15181525.e14. DOI: 10.1016/j.jaci.2013.01.034. [Not an intervention of interest]

95. Beigelman A, Zeiger RS, Mauger D, et al. The association between vitamin $\mathrm{D}$ status and the rate of exacerbations requiring oral corticosteroids in preschool children with recurrent wheezing. J Allergy Clin Immunol. 2013;133(5):1489-92.e3. [No outcomes of interest]

96. Bell A, McIvor RA. SMART therapy. CMAJ. 2006 Aug 1;175(3):276-7. PMID: 16880449. [Not a human study]

97. Ben-Aryeh H, Berdicevsky I, Zinmann P, et al. Salivary composition and oral candida in asthmatic children and the effect of inhaled drugs. J Oral Med. 1985 Jul-Sep;40(3):123-6. PMID: 3928845. [Not an intervention of interest]

98. Benbow AG, Naya IP. Patient compliance with inhaled medication: does combining beta-agonists with corticosteroids improve compliance?. Eur Respir J. 1994 Aug;7(8):1554. PMID: 7957846. [Not a human study]

99. Bennati D, Piacentini GL, Peroni DG, et al. Changes in bronchial reactivity in asthmatic children after treatment with beclomethasone alone or in association with salbutamol. $\mathrm{J}$ Asthma. 1989;26(6):359-64. PMID: 2702243. [Not an intervention of interest] 100. Berger WE, Ford LB, Mahr T, et al. Efficacy and safety of fluticasone propionate 250 microg administered once daily in patients with persistent asthma treated with or without inhaled corticosteroids. Ann Allergy Asthma Immunol. 2002 Oct;89(4):393-9. PMID: 12392384. [Not an intervention of interest]
101. Berger WE, Leflein JG, Uryniak T, et al. Long term efficacy and resource utilization after treatment with budesonide and formoterol administered via one pressurized metered dose inhaler (pMDI) compared with budesonide dry powder inhaler (DPI) alone in children with asthma. J Allergy Clin Immunol. 2008;21;2 Suppl 1:S8. [Not an intervention of interest]

102. Berger WE, Noonan M, Weinstein SF, et al. Effect of inhaled mometasone furoate on the use of rescue medication in children aged 4-11 years with mild to moderate persistent asthma. J Allergy Clin Immunol. 2009;123;2 Suppl 1:S7. [Not an intervention of interest] 103. Berger WE, Qaqundah PY, Blake K, et al. Safety of budesonide inhalation suspension in infants aged six to twelve months with mild to moderate persistent asthma or recurrent wheeze. J Pediatr. 2005 Jan;146(1):91-5. PMID: 15644830. [Not an intervention of interest]

104. Berglund E, Lofdahl CG, Svedmyr N. Dosing of inhaled corticosteroids and therapeutic goals in asthmatic patients. Eur J Respir Dis. 1984 Jul;65(5):319-20. PMID: 6745334. [Not a human study]

105. Bernstein D, Nathan R, Ledford D, et al. Ciclesonide, a new inhaled corticosteroid, significantly improves asthma-related quality of life in patients with severe, persistent asthma. J Allergy Clin Immunol. 2005;115;2 Suppl:S210. [Not an intervention of interest]

106. Bernstein DI, Hebert J, Cheema A, et al. Efficacy and onset of action of mometasone furoate/formoterol and fluticasone propionate/salmeterol combination treatment in subjects with persistent asthma. Allergy Asthma Clin Immunol. 2011;7(1):21. [Not an intervention of interest] 
107. Bernstein DI, Rachelfsky G, Chrvinsky P, et al. Mometasone furoate dry powder inhaler improves pulmonary function in patients with persistent asthma previously using inhaled corticosteroids: efficacy analysis based on baseline FEV1 [Abstract]. Chest; 2002; San Diego, CA. P424p. [Not an intervention of interest]

108. Bielory L, Piccone F, Rabinowitz P, et al. Multicentre, randomised, parallel-group study of the efficacy and tolerability of flunisolide administered once daily via AeroChamber in the treatment of mild to moderate asthma. Clin Drug Investig. 2000;19(2):93-101. Embase 2000093460.

[Not an intervention of interest]

109. Bilderback A, Krishnan JA, Riekert KA, et al. Patterns of use for oral montelukast and inhaled fluticasone in a clinical trial [Abstract]. American Thoracic Society International Conference; 2004 May 21-26; Orlando, Florida. C18p. [Irretrievable]

110. Bisgaard H, Gillies J, Groenewald M, et al. Efficacy of inhaled fluticasone propionate in the treatment of young children with asthmatic symptoms: a dose comparison study. Am J Respir Crit Care Med. 1998;157;Suppl 3:A711. [Not an intervention of interest]

111. Bisgaard H, Hermansen MN, Loland L, et al. Intermittent inhaled corticosteroids in infants with episodic wheezing. N Engl J Med. 2006 May 11;354(19):1998-2005. PMID: 16687712. [Not in the target population]

112. Bisgaard H, Munck S, Nielsen JP, et al. Recurrent wheezing in children below 3 years treated with inhaled budesonide. Eur Respir J. 1990;3;Suppl 10:298S. [Not an intervention of interest]

113. Bisgaard H, Munck SL, Nielsen JP, et al. Inhaled budesonide for treatment of recurrent wheezing in early childhood. Lancet (London, England). 1990 Sep 15;336(8716):649-51. PMID: 1975851. [Not an intervention of interest]
114. Bisgaard H. Systemic activity of inhaled topical steroid in toddlers studied by knemometry. Acta Paediatr. 1993 Dec;82(12):1066-71. PMID: 8155929. [Not an intervention of interest]

115. Black P. Inhaled steroid maintenance treatment of severe asthma. Lancet. 1993 Feb 13;341(8842):445-6. PMID: 8094218. [Not a human study]

116. Bleecker ER, Bateman ED, Busse W, et al. Fluticasone furoate (FF), an inhaled corticosteroid (ICS), is efficacious in asthma patients symptomatic on low doses of ICS therapy [Abstract]. European Respiratory Society Annual Congress; 2010 Sep 18-22; Barcelona, Spain. P1167. [Not an intervention of interest]

117. Bloom J, Calhoun W, Koenig S, et al. Fluticasone propionate/salmeterol $100 / 50 \mathrm{mcg}$ is inhaled steroid sparing in patients who require fluticasone propionate 250mcg for asthma stability [Abstract]. American Thoracic Society 99th International conference; 2003; D034 Poster C33p. [Not an intervention of interest]

118. Bodzenta-Lukaszyk A, Buhl R, Balint B, et al. Fluticasone/formoterol combined in a single aerosol inhaler vs budesonide/formoterol for the treatment of asthma: A non-inferiority trial [Abstract]. European Respiratory Society Annual Congress; 2011 Sep 24-28; Amsterdam, The Netherlands. P894. [Not an intervention of interest]

119. Boskovska MI, Dokic D, Busletic Bozinovska K, et al. Concomitant use of low-dose inhaled corticosteroids and a longacting bronchodilatator visavi doubling the dose of inhaled corticosteroid in asthma patients. Eur Respir J. 2001;18;Suppl 33:98s. [Not an intervention of interest]

120. Bosman H G, van Uffelen R. Different effects of inhaled beclomethasone dipropionate and oral prednisone on bronchial hyperresponsiveness in asthma. Eur Respir J. 1990;3;Suppl 10:134S. [Not an intervention of interest] 
121. Boushey HA. Daily inhaled corticosteroid treatment should not be prescribed for mild persistent asthma. Am J Respir Crit Care Med. 2005 discusion 414-5; Aug 15;172(4):412-4. PMID: 16081554. [Not a human study]

122. Bousquet J, Miravitlles M, Wiren A. Budesonide/formoterol provides better efficacy at a lower or similar cost as compared to high-dose salmeterol/fluticasone treatment. Eur Respir J. 2007;30;Suppl 51:193s. [Excluded study design]

123. Boyter AC, Ford NH, Zlotos L. Audit of budesonide/formoterol prescribing for asthma in community pharmacy in the U.K. Respir Med. 2011 Jun;105(6):864-8. PMID: 21227673. [Not an intervention of interest]

124. Breath-actuated inhaler improves asthma control. Pharm J. 2001 Oct ;267(7169):497. [Not a human study]

125. Brenner BE, Chavda KK, Camargo CAJ. Randomized trial of inhaled flunisolide versus placebo among asthmatic patients discharged from the emergency department. Ann Emerg Med. 2000 Nov;36(5):417-26. PMID: 11054193. [Not in the target population]

126. Bright P. High dose nebulized steroid in the treatment of chronic steroid dependent asthma. Respir Med. 1992 Nov;86(6):528-9. PMID: 1470714. [Not a human study]

127. British Thoracic and Tuberculosis Association (BTTA), British Thoracic and Tuberculosis Association. Inhaled corticosteroids compared with oral prednisone in patients starting long-term corticosteroid therapy for asthma. Lancet. 1975;2(7933):469-73. [Not an intervention of interest]

128. Broder I, Tarlo SM, Davies GM, et al. Safety and efficacy of long-term treatment with inhaled beclomethasone dipropionate in steroid-dependent asthma. CMAJ. 1987 Jan 15;136(2):129-35. PMID: 3098400.

[Excluded study design]
129. Brodlie M, Gupta A, Rodriguez-Martinez $\mathrm{CE}$, et al. Leukotriene receptor antagonists as maintenance or intermittent treatment in pre-school children with episodic viral wheeze. Paediatr Respir Rev. 20162016 Jan;17:57-9. [Not a human study]

130. Bruce SA, Scherer YK. Maintenance and symptom relief with budesonide plus formoterol reduced severe asthma exacerbations. Evid Based Nurs. 2005;8:78. DOI: 10.1136/ebn.8.3.78. [Not a human study]

131. Bruggenjurgen B, Selim D, Kardos P, et al. Economic assessment of adjustable maintenance treatment with budesonide/formoterol in a single inhaler versus fixed treatment in asthma. Pharmacoeconomics. 2005;23(7):723-31. PMID: 15987228. [Excluded study design]

132. Budesonide hydrofluoroalkane inhalation Chiesi. Drugs R D. 2003;4(1):37-8. [Not a human study]

133. Budesonide turbuhaler for asthma. Med Lett Drugs Ther. 1998 Jan 16;40(1018):156. PMID: 9457158. [Not a human study]

134. Budesonide/formoterol (symbicort) for asthma. Med Lett Drugs Ther. 2008 Feb;50(1279):9-11. [Not a human study]

135. Budesonide/formoterol improves asthma control. Can Respir J. 2001. 8:5;357-74. [Irretrievable]

136. Buhl R, Creemers JP, Vondra V, et al. Once daily symbicort (budesonide/eformoterol in a single inhaler) is effective in moderate-persistent asthma. Thorax. 2011;56;Suppl 3:iii62. [Not an intervention of interest]

137. Buhl R, Creemers JP, Vondra V, et al. Once-daily budesonide/formoterol via a single inhaler is effective in mild-tomoderate persistent asthma. Eur Respir J. 2001;18;Suppl 33:21s. [Not an intervention of interest] 
138. Buhl R, Haughney J, van Schayck OCP, et al. Switching asthma patients using highdose inhaled steroids to budesonide/formoterol maintenance and reliever therapy [Abstract]. European Respiratory Society Annual Congress; 2010 Sep 18-22; Barcelona, Spain. P4565. [Not an intervention of interest]

139. Buhl R, Kardos P, Richter K, et al. The effect of adjustable dosing with budesonide/formoterol on health-related quality of life and asthma control compared with fixed dosing. Curr Med Res Opin. 2004 Aug;20(8):1209-20. PMID: 15324523. [Not an intervention of interest]

140. Buhl R, Soler M, Matz J, et al. Omalizumab provides long-term control in patients with moderate-to-severe allergic asthma. Eur Respir J. 2002 Jul;20(1):73-8. PMID: 12166585. [Not an intervention of interest]

141. Buhl R, Van Schayck O, Aubier M, et al. Impact of age, age at diagnosis and duration of asthma on the risk of exacerbations in the EuroSMART study. Eur Respir J. 2012 Sep;P2163. Embase 71926516. [Not an intervention of interest]

142. Buhl R, Vinkler I, Magyar P, et al. Comparable efficacy of ciclesonide once daily versus fluticasone propionate twice daily in asthma. Pulm Pharmacol Ther. 2006;19(6):404-12. PMID: 16310388. [Not an intervention of interest]

143. Buhl R, Zetterstrom O, Mellem H, et al. Improved asthma control with budesonide/formoterol via a single inhaler compared with budesonide alone, in moderate persistent asthma. Eur Respir J. 2001;18;Suppl 33:48s. [Not an intervention of interest]

144. Bukstein DA, Luskin AT, Bernstein A. "Real-world" effectiveness of daily controller medicine in children with mild persistent asthma. Ann Allergy Asthma Immunol. 2003 May;90(5):543-9. PMID: 12775136. [Excluded study design]
145. Bulac S, Cimrin A, Ellidokuz H. The effect of beclometasone dipropionate/formoterol extra-fine fixed combination on the peripheral airway inflammation in controlled asthma. J Aerosol Med Pulm Drug Deliv. 2015 Apr;28(2):82-7. PMID: 25050594. [Not an intervention of interest]

146. Bulow KB, Kalen N. Local and systemic effects of beclomethasone inhalation in steroid-dependent asthmatic patients. Curr Ther Res Clin Exp. 1974 Oct;16(10):1110-8. PMID: 4215621. [Excluded study design]

147. Bulow KB, Kalen N. Local and systemic effects of beclomethasone inhalation in steroid-dependent asthmatic patients. Curr Ther Res Clin Exp. 1974 Oct;16(10):1110-8. PMID: 4215621. [Duplicate]

148. Bush A, Grigg J, Saglani S. Managing wheeze in preschool children. BMJ (Online). 2014 Feb;348:Article Number g15. [Not a human study]

149. Bush A. Inhaled corticosteroid and children's growth. Arch Dis Child. 2014 Mar;99(3):191-2. PMID: 24162008. [Not a human study]

150. Bush A. Practice imperfect--treatment for wheezing in preschoolers. N Engl J Med. 2009 Jan 22;360(4):409-10. PMID: 19164192. [Not a human study]

151. Busse W, Bleecker ER, Bateman ED, et al. Fluticasone furoate (FF), an inhaled corticosteroid (ICS), demonstrates efficacy in asthma patients symptomatic on moderate doses of ICS therapy [Abstract]. European Respiratory Society Annual Congress; 2010 Sep 18-22; Barcelona, Spain. P1168. [Not an intervention of interest]

152. Busse W, Kaliner M, Bernstein D, et al. The novel inhaled corticosteroid ciclesonide is effacious and has a favourable safety profile in adults and adolescents with severe persistent asthma. J Allergy Clin Immunol. 2005;115;Suppl 2:S213. [Not an intervention of interest] 
153. Busse WW, Shah SR, Somerville L, et al. Comparison of adjustable- and fixed-dose budesonide/formoterol pressurized metereddose inhaler and fixed-dose fluticasone propionate/salmeterol dry powder inhaler in asthma patients. J Allergy Clin Immunol. 2008 Jun;121(6):1407-14. PMID: 18455221. [Not an intervention of interest]

154. Busse WW, Shah SR, Somerville L, et al. Comparison of asthma exacerbations and lung function with adjustable-dose budesonide/formoterol pressurized metereddose inhaler (BUD/FM pMDI), fixed dose BUD/FM pMDI and fixed-dose fluticasone/salmeterol dry powder inhaler (FP/SM DPI)[Abstract]. American Thoracic Society International Conference; 2007 May 18-23; San Francisco, California. K2p. [Irretrievable]

155. Busse WW, Uryniak T. Efficacy of inhaled budesonide (Pulicort Tubuhaler(R)) in recent-onset moderate to severe persistent asthma. J Allergy Clin Immunol. 2004;113;Suppl 2:S119. [Not an intervention of interest]

156. Caballero-Fonseca F, Sanchez-Borges M. Adrenal suppression related to inhaled corticosteroids revisited. Chest. 2002 Sep;122(3):1103-4. PMID: 12226066. [Not a human study]

157. Calhoun WJ. Physician-, biomarker-, and symptombased djustment of inhaled corticosteroids for asthma had similar effects. Ann Intern Med. 2013;158(2):JC6. [Not a human study]

158. Callén Blecua M, Aizpurua Galdeano P, Ozcoidi Erro I, et al. Inhaled corticosteroids and wheezing post-bronchiolitis. An Esp Pediatr. 2000;52(4):351-5. [Not an intervention of interest]

159. Campusano L, Pastenes M, Fontecilla C, et al. Response to budesonide among atopic and non-atopic infants/preschoolers with recurrent wheezing. Allergol Immunopathol (Madr). 2010 Jan-Feb;38(1):31-6. PMID: 19875223. [Not an intervention of interest]
160. Canonica GW, Castellani P, Cazzola M, et al. Adjustable maintenance dosing with budesonide/formoterol in a single inhaler provides effective asthma symptom control at a lower dose than fixed maintenance dosing. Pulm Pharmacol Ther. 2004;17(4):239-47. PMID: 15219269. [Not an intervention of interest]

161. Cao EH, Tong MR, Tang XM, et al. Effects of inhaled budesonide on asthmatic patients. Journal Nanjin University. 1998;34(2):2236. [No English language abstract]

162. Caramez MPR, Grunauer MA, Boueri FMV, et al. Effect of continuous inhaled beclomethasone for asthmatic pregnant patients on asthma control and perinatal outcome: a randomized controlled study. Am J Respir Crit Care Med. 1998;157;Suppl 3:A621. [Not an intervention of interest]

163. Carlsen K-, Gerritsen J. Inhaled steroids in children: adrenal suppression and growth impairment. Eur Respir J. 2002;19(6):985-8. [Not a human study]

164. Carra S, Gagliardi L, Zanconato S, et al. Budesonide but not nedocromil sodium reduces exhaled nitric oxide levels in asthmatic children. Respir Med. 2001 Sep;95(9):734-9. PMID: 11575894. [Not an intervention of interest]

165. Casale TB, Nelson HS, Corren J, et al. Long-term safety of flunisolide hydrofluoroalkane metered-dose inhaler in adults and adolescents with asthma. Clin Drug Invest. 2001;21(11):755-64. [Not an intervention of interest]

166. Castiller F, Trow TK. "Fine tuning" the use of inhaled steroids. Clin Pulm Med. 2005 Sep;12(5):324-6. [Not a human study]

167. Castro HP, Espino SR, Rodríguez Orozco AR. Budesonide (inhaled steroid) to children to control intermittent asthma. Rev Alerg Mex. 2009;56(1):9-12. [Not an intervention of interest]

168. Cates C. Chronic asthma. BMJ. 2001 Oct 27;323(7319):976-9. PMID: 11679388. [Not a human study] 
169. Cazzola M, Curradi G. How to prevent relapse after acute exacerbation of asthma? Pol Arch Med Wewn. 2007;117(11-12):48790. [Not a human study]

170. Cazzola M, Matera MG. Lung blood flow must be considered when prescribing a longacting beta2-agonist/inhaled corticosteroid combination. Chest. 2012 May;141(5):11346. PMID: 22553257. [Not a human study]

171. Chalmers GW, MacLeod KJ, Little SA, et al. Cigarette smoking impairs the efficacy of inhaled corticosteroid in mild asthma. Annual Thoracic Society 97th International conference; 2001 May 18-23; San Francisco, CA. [Not an intervention of interest]

172. Chandra S. Health outcomes, education, healthcare delivery and quality-3057: randomized, double blind comparative study to assess safety, efficacy with mometasone $\&$ formoterol versus fluticasone \& formoterol dry powder inhaler (DPI) in the treatment of mild to moderate persistent asthma. World Allergy Organ J. 2013;6; Suppl 2:P255. Embase 71252441. [Not an intervention of interest]

173. Chandra S. Randomized, double blind comparative study to assess safety, efficacy with mometasone \& formoterol versus fluticasone \& formoterol dry powder inhaler (DPI) in the treatment of mild to moderate persistent asthma. World Allergy Organ J. 2013;6;Suppl 2:P225. [Not an intervention of interest]

174. Chanez P, Karlstrom R, Godard P. High or standard initial dose of budesonide to control mild-to-moderate asthma?. Eur Respir J. 2001 May;17(5):856-62. PMID: 11488316. [Not an intervention of interest]

175. Chao L-, Lin Y-, Wu W-, et al. Efficacy of nebulized budesonide in hospitalized infants and children younger than 24 months with bronchiolitis. Acta Paediatr Taiwan. 2003;44(6):332-5. [Not in the target population]

176. Chapman KR, McIvor A. Asthma that is unresponsive to usual care. CMAJ. 2010;182(1):45-52. [Not a human study]
177. Chapman KR. SMART isn't. J Allergy Clin Immunol. 2010 Mar;125(3):609-10. PMID: 20226296. [Not a human study]

178. Chatzimichail A, Pietrobelli A, Boner AL. Growth and adrenal suppression due to moderate- to high-dose inhaled fluticasone. J Paediatr Child Health. 2002 Dec;38(6):623. PMID: 12410884. [Excluded study design]

179. Chavasse R, Bastian Lee Y, et al. Wheezing in infants with an atopic tendency responds to inhaled fluticasone. Thorax. 1999;54;Suppl 3:A7 S27. [Not an intervention of interest]

180. Chavasse R, Bastian Lee Y, Richter H, et al. Wheezing in infants responds to inhaled fluticasone. Am J Respir Crit Care Med. 2000;161;Suppl 3:A38. [Irretrievable]

181. Chay OM, Goh A, Lim WH, et al. Effects of inhaled corticosteroid on bone turnover in children with bronchial asthma.

Respirology. 1999 Mar;4(1):63-7. PMID: 10339732. [Not an intervention of interest]

182. Chen XH, Xia Y, Dong CC, et al. Therapeutic effect of salmeterol xinafoate and fluticasone propionate powder for inhalation in treatment of 50 moderate and severe asthma children. Zhongguo Xinyao yu Linchuang Zazhi. 2004;23(9):575-8. [Not an intervention of interest]

183. Cheng QJ, Huang SG, Chen YZ, et al. Formoterol as reliever medication in asthma: A post-hoc analysis of the subgroup of the RELIEF study in East Asia. BMC pulmonary medicine. 2016;Jan;16(1).8. PMID: 26758377. [duplicate]

184. Cheng QJ, Huang SG, Chen YZ, et al. Formoterol as reliever medication in asthma: a post-hoc analysis of the subgroup of the RELIEF study in East Asia. BMC Pulmonary Medicine. 2016;Jan;16:8. PMID: 26758377 [not an intervention of interest] 
185. Chervinsky P, Baker J, Bensch G, et al. Improvement in health-related quality of life (HRQL) after use of budesonide (BUD) and formoterol (FM) in one pressurized metereddose inhaler (pMDI) in adults with moderate to severe asthma [Abstract]. American Thoracic Society International Conference; 2007 May 18-23; San Francisco, California. 617p. [Irretrievable]

186. Chetty A, Roy S, Sunderam KR.

Beclomethasone dipropionate aerosol therapy in childhood asthma. Indian Pediatr. 1987 Jul;24(7):537-41. PMID: 3692582.

[Excluded study design]

187. Chhabra SK. A comparison of inhaled salbutamol with a combination of salbutamol and beclomethasone dipropionate in moderately severe asthma. Indian J Chest Dis Allied Sci. 1994;36(3):119-24. [Not an intervention of interest]

188. Chipps B. Effect of inhaled glucocorticoids in childhood on adult height. Pediatrics. 2013;132;Suppl 1:S45. DOI: 10.1542/peds.2013-2294WWW. [Not a human study]

189. Chipps BE, Bacharier LB, Harder JM. Phenotypic expressions of childhood wheezing and asthma: implications for therapy. J Pediatr. 2011;158(6):878-884.e1. [Not a human study]

190. Chkhaidze I, Kherkheulidze M, Kavlashvili $\mathrm{N}$, et al. Non-viral wheezing in preschool children: The effect of inhaled fluticasone on symptoms and lung function. Georgian Med News. 2006PMID: 16575135. [Not an intervention of interest]

191. Chlumský J, Striz I, Terl M, et al. Strategy aimed at reduction of sputum eosinophils decreases exacerbation rate in patients with asthma. J Int Med Res. 2006;34(2):129-39. [Not an intervention of interest]

192. Chong SL, Hsu AA. Not all that wheezes is asthma. Ann Acad Med Singapore. 2014 Oct;43(10):519-20. [Excluded study design]
193. Chowdhury BA. Ciclesonide inhalation aerosol for persistent asthma. J Allergy Clin Immunol. 2006 May;117(5):1194-5. PMID: 16675356. [Not a human study]

194. Chronic asthma. MeReC Brief. 2002;18:15. [Irretrievable]

195. Chuchalin AG, Molostova TN. Efficacy of budesonide in bronchial asthma patients assessed by a double-blind crossover placebo-controlled method. Klin Farmakologiia Terapiia. 1999: 23-6p. [Irretrievable]

196. Ciclesonide (alvesco)-a new inhaled corticosteroid for asthma. Med Lett Drugs Ther. 2008 Sep 22;50(1295):75-6. PMID: 18800024. [Not a human study]

197. Ciclesonide. Aust Prescr. 2005 Aug;28(4):106. [Not a human study]

198. Ciclesonide. Drugs R D. 2002;3(6):407-10. [Not a human study]

199. Ciclesonide: Novel asthma treatment. WHO Drug Inf. 2004;18(3):225. [Not a human study]

200. Cimrin AH, Sevinc C, Ellidokuz H, et al. Is withdrawal of inhaled corticosteroid therapy possible in stable mild-moderate persistent bronchial asthma cases? A randomised controlled study. Eur Respir J. 2000;16;Suppl 31:93s. [Irretrievable]

201. Cisneros C, Quiralte J, Capel M, et al. Cost-effectiveness analysis of budesonide/formoterol in the maintenance treatment and as-needed (Symbicort SMART) versus salmeterol/fluticasone plus terbutaline in the treatment of persistent asthma in Spain. Pharmacoeconomics. 2010;7(4):163-75. [Excluded study design]

202. Clark TJ. Inhaled steroid aerosols and alternate-day prednisone. Lancet. 1979 May 5;1(8123):970-1. PMID: 87630. [Not a human study]

203. Clarke GW, Greenaway SD, James WY, et al. The acute effect of inhaled steroids on airway mucosal flow in asthma [Abstract]. American Thoracic Society International Conference; 2007 May 18-23; San Francisco, California. B60p. [Irretrievable] 
204. Clavenna A, Sequi M, Cartabia M, et al. Effectiveness of nebulized beclomethasone in preventing viral wheezing: An RCT. Pediatrics. 2014 Mar;133(3):e505-12. PMID: 24534400. [Not in the target population]

205. Cochran D. Diagnosing and treating chesty infants. A short trial of inhaled corticosteroid is probably the best approach. BMJ. 1998 May 23;316(7144):1546-7. PMID: 9596586. [Not a human study]

206. Cockcroft DW, Davis BE, Swystun VA. Salmeterol, inhaled corticosteroids, and tolerance to allergen bronchoprotection. Chest. 1999 Nov;116(5):1497-8. PMID: 10559129. [Not a human study]

207. Combined oral, inhaled steroids prevent relapse in acute asthma. Healthc Demand Dis Manag. 1999 Aug;5(8):123-5. PMID: 10557952. [Not a human study]

208. Connett G, Lenney W. Prevention of viral induced asthma attacks using inhaled budesonide. Arch Dis Child. 1993 Jan;68(1):85-7. PMID: 8435016. [No outcomes of interest]

209. Convery RP, Leitch DN, Bromly C, et al. Effect of inhaled fluticasone propionate on airway responsiveness in treatment-naive individuals--a lesser benefit in females. Eur Respir J. 2000 Jan;15(1):19-24. PMID: 10678615. [Not in the target population] 210. Corren J, Korenblat PE, Miller CJ, et al. Comparative assessment of asthma control with budesonide and formoterol in one pressurized metered dose inhaled (pMDI) versus budesonide and formoterol in individual inhalers and placebo. J Allergy Clin Immunol. 2007;119;Suppl 1:S248. [Not an intervention of interest]

211. Cortese S, Gatta A, Della Valle L, et al. Fluticasone/formoterol association favors long-lasting decrease in bronchial reactivity to methacholine and weekly PEF variability. International Journal of Immunopathology \& Pharmacology. 2016;Dec;29(4):769-774. PMID: 27272161 [no outcomes of interest]
212. Corticosteroid therapy for wheezy infants. Indian Pediatr. 2006 Jul;43(7):662. [Not a human study]

213. Cote J, Cartier A, Robichaud P, et al. Influence on asthma morbidity of asthma education programs based on selfmanagement plans following treatment optimization. Am J Respir Crit Care Med. 1997 May;155(5):1509-14. PMID: 9154850.

[Not an intervention of interest]

214. Crim C, Scott CA, Maden CJ, et al. Fluticasone propionate administered via metered-dose inhaler with valved holding chamber and attached face-mask is effective in improving asthma control by producing at least a 2-step improvement in asthma staging in preschool age children with asthma. J Allergy Clin Immunol. 2004;113;Suppl 2:S118. [Not an intervention of interest]

215. Crimi N, Polosa R, Prosperini G, et al. Inhaled beclomethasone attenuates bronchial reactivity to neurokinin a (NKA) and histamine in asthma. Eur Respir J. 1996;9;Suppl 23:33s. [Not an intervention of interest]

216. Csonka P, Mertsola J, Klaukka T, et al. Corticosteroid therapy and need for hospital care in wheezing preschool children. Eur J Clin Pharmacol. 2000 Nov;56(8):591-6. PMID: 11151750. [Not in the target population]

217. Currie GP, Douglas JG, Heaney LG. Difficult to treat asthma in adults. BMJ (Online). 2009 Mar;338(7694):593-7. [Not a human study]

218. Currie GP, Small I, Douglas G. Long acting $\beta 2$ agonists in adult asthma. BMJ (Online). 2013 Oct;347(7927):Article Number f4662. [Not a human study]

219. Currie GP. Why SMART about second-line treatment when first-line treatment is being ignored?. Chest. 2006 Sep;130(3):929. PMID: 16963701. [Not a human study] 220. Curtiss FR. Asthma disease management evidence-based medicine must be dynamic. J Managed Care Pharm. 2006;12(1):80-2. [Not a human study] 
221. Curtiss FR. More evolution of the evidence in asthma disease management--SMART versus GOAL clinical trials debate the costbenefit of LABA while the value of leukotriene modifiers, particularly montelukast, is uncertain. J Manage Care Pharm. 2006 May;12(4):343-6. PMID: 16792441. [Not a human study]

222. Dahl R, Johansson SA. Effect on lung function of budesonide by inhalation, terbutaline s.c. and placebo given simultaneously or as single treatments. Eur J Respir Dis Suppl. 1982;122:132-7. PMID: 6958477. [Not an intervention of interest]

223. Dahl R, Pedersen B, Hagglof B. Nocturnal asthma: effect of treatment with oral sustained-release terbutaline, inhaled budesonide and the two in combination. Eur Respir J. 1988;1;Suppl 2:339s. [Not an intervention of interest]

224. Dal Negro R, Micheletto C, Ciani F, et al. Efficacy and safety of inhaled beclomethasone dipropionate dry powder in the treatment of chronic asthma: a controlled study vs. budesonide. Eur Respir J. 1998;12;Suppl 28:351S. [Not an intervention of interest]

225. Danov Z, Guilbert T. Regular use of inhaled corticosteroids controls symptoms of mild persistent asthma, but with growth effect. J Pediatr. 2009 Jan;154(1):150. [Not a human study]

226. Daugbjerg P, Brenoe E, Forchhammer H, et al. A comparison between nebulized terbutaline, nebulized corticosteroid and systemic corticosteroid for acute wheezing in children up to 18 months of age. Acta Paediatr. 1993 Jun-Jul;82(6-7):547-51. PMID: 8338988. [Not in the target population]

227. Davies G, Thomas P, Broder I, et al. Steroid-dependent asthma treated with inhaled beclomethasone dipropionate. A long-term study. Ann Intern Med. 1977 May;86(5):549-53. PMID: 322562. [Not an intervention of interest]
228. De Benedictis FM, Boner A, Cavagni G, et al. Treating asthma in children with beclomethasone dipropionate: Pulvinal versus diskhaler. J Aerosol Med. 2000;13(1):35-41. PMID: 10947322. [Not an intervention of interest]

229. De Benedictis FM, Del Giudice MM, Vetrella M, et al. Nebulized fluticasone propionate vs. budesonide as adjunctive treatment in children with asthma exacerbation. J Asthma. 2005 Jun;42(5):331-6. PMID: 16116682. [Not an intervention of interest]

230. de Blic J, Delacourt C, Le Bourgeois M, et al. Efficacy of nebulized budesonide in treatment of severe infantile asthma: A double-blind study. J Allergy Clin Immunol. 1996 Jul;98(1):14-20. PMID: 8765813. [Not an intervention of interest]

231. de Jongste JC, Carraro S, Hop WC, et al. Daily telemonitoring of exhaled nitric oxide and symptoms in the treatment of childhood asthma. Am J Respir Crit Care Med. 2009 Jan 15;179(2):93-7. PMID: 18931330. [Not an intervention of interest]

232. De Marzo N, Maestrelli P, Saetta M, et al. Management of occupational asthma induced by toluene diisocyanate (TDI) effect of removal from exposure and long term treatment with inhaled beclomethasone dipropionate (BPD). Eur Respir J. 1992;5;Suppl 15:111s. [Not an intervention of interest]

233. De Vries MP, Van den Bemt L, Aretz K, et al. House dust mite allergen avoidance and self-management in allergic patients with asthma: randomised controlled trial. $\mathrm{Br} \mathrm{J}$ Gen Pract. 2007;57(536):184-90. [Not an intervention of interest]

234. de Vries MP, van den Bemt L, Thoonen BPA, et al. Relationship between house dust mite (HDM) allergen exposure level and inhaled corticosteroid dosage in HDMsensitive asthma patients on a self management program. Prim Care Respir J. 2006 Apr;15(2):110-5. PMID: 16701770. [Not an intervention of interest] 
235. Decimo F, Maiello N, Miraglia Del Giudice $M$, et al. High-dose inhaled flunisolide versus budesonide in the treatment of acute asthma exacerbations in preschool-age children. Int J Immunopathol Pharmacol. 2009 Apr-Jun;22(2):363-70. PMID: 19505390. [Not in the target population]

236. Del Donno M, Foresi A, Chetta A, et al. Effect of six week treatment with low dose of inhaled fluticasone propionate on airway inflammation in mild asthma. Eur Respir J. 1995;8;Suppl 19:302S. [Not an intervention of interest]

237. del-Rio-Navarro BE, Corona-Hernandez L, Fragoso-Rios R, et al. Effect of salmeterol and salmeterol plus beclomethasone on saliva flow and IgA in patients with moderate-persistent chronic asthma. Ann Allergy Asthma Immunol. 2001 Nov;87(5):420-3. PMID: 11730186. [Not an intervention of interest]

238. Demay MCR, Magny JP, Idrès N, et al. Use of the low-dose corticotropin stimulation test for the monitoring of children with asthma treated with inhaled corticosteroids. Horm Res. 2006;66(2):5160 . [Not an intervention of interest] 239. Derom E, Louis R, Tiesler C, et al. Comparison of systemic and clinical effects of inhaled ciclesonide and fluticasone propionate in moderate to severe asthma [Abstract]. Americna Thoracic Society International Conference; 2008 May 16-21; Toronto, Canada. A50p. [Not an intervention of interest]

240. Deslandes B, Lim J, Staudinger H. Efficacy and safety of azmacort MDI and flovent diskhaler. J Allergy Clin Immunol. 1998 Jul;102(1):154-5. PMID: 9679864. [Not a human study]

241. Devoy M. Use of inhaled corticosteroids in children. Arch Dis Child. 2003 May;88(5):461. PMID: 12716732. [Not a human study]
242. Di Franco A, Bacci E, Bartoli ML, et al. Inhaled fluticasone propionate is effective as well as oral prednisone in reducing sputum eosinophilia during exacerbations of asthma which do not require hospitalization. Pulm Pharmacol Ther. 2006;19(5):353-60. PMID: 16289980. [Not an intervention of interest]

243. DiSantostefano RL, Boudiaf N, Stempel DA, Barnes NC, Greening AP. The frequency of, and adherence to, single maintenance and reliever therapy instructions in asthma: a descriptive analysis. NPJ Primary Care Respiratory Medicine. 2016;July;26:16038. PMID: 27442488 [no outcomes of interest]

244. Dixit R, Dixit K, Sharma S, et al. Adrenal suppression and its pattern with high dose inhaled budesonide and fluticasone propionate in adult asthmatic patients. Chest. 2007;132(4):505a. [Not an intervention of interest]

245. Djordjevic DD, Stankovic IJ, Rancic MH, et al. Inhaled corticosteroids in treatment of patients with intermittent bronchial asthmla, yes or no? Eur Respir J. 2005;26; Suppl 49: Abstract No 3288. [Not in the target population]

246. Dogra P, Kajal NC, Bhushan B, et al. To study the effect of inhaled fluticasone verses montelukast as treatment of persistent asthma. Chest. 2006;130(4):109s. [Not an intervention of interest]

247. Dombrowski MP, Schatz M, Wise R, et al. Inhaled beclomethasone and oral theophylline were similarly effective in pregnant women with moderate asthma. Evid -based Obstet Gynecol. 2005 Mar;7(1):11-2. [Not a human study]

248. Domingo C. Ultra-LAMA, ultra-LABA, ultra-inhaled steroids? the future has landed. Arch Bronconeumol. 2013 Apr;49(4):131-4. PMID: 23415574. [Not a human study] 
249. Dorinsky P, Yancey S, Reilly D, et al. Long-term effectiveness of the fluticasone propionate/salmeterol (FSC) 100/50mcg combination product as an inhaled corticosteroid sparing. J Allergy Clin Immunol. 2003;11(2):S125. [Not an intervention of interest]

250. Dorow P, Thalhofer S. Inhaled beclomethasone (BDP) versus oral theophylline: a 12 month study in patients with bronchial asthma. Eur Respir J. 1990;3;Suppl 10:91S. [Not an intervention of interest]

251. Dos Santos LZM, Soares CG, Filho WR. Oral montelukast versus inhaled beclomethasone in the prophylactic treatment of post acute viral bronchiolitis wheezing. World Allergy Organ J. 2014;8;Suppl 1:A128. DOI: 10.1186/19394551-8-S1-A128. [Not an intervention of interest]

252. Dose-effect of inhaled corticosteroid on growth rates of children. Drug Ther Bull. 2014;52(10):111. [Not a human study]

253. Doubling the dose of inhaeled corticosteroid ineffective when asthma control is detiorating. AJP. 2004;85(1011):457. [Not a human study] 254. Drake AJ, Howells RJ, Shield JPH, et al. Symptomatic adrenal insufficiency presenting with hypoglycaemia in children with asthma receiving high dose inhaled fluticasone propionate. BMJ. 2002 May 4;324(7345):1081-2. PMID: 11991916. [Excluded study design]

255. Dreyer EB. Inhaled steroid use and glaucoma. N Engl J Med. 1993 Dec 9;329(24):1822. PMID: 8232507. [Excluded study design].

256. Drollman A, Langdon C, Engelst A, et al. Ciclesonide is effective in the treatment of bronchial asthma. Eur Respir J. 2001;18;Suppl 33:95s. [Not an intervention of interest]
257. du Toit JI, Salome CM, Woolcock AJ. Short term effects of inhaled corticosteroids on bronchial hyperresponsiveness. Aust NZ J Med Suppl. 1986;16(4):627. [Not an intervention of interest]

258. Dubus J, Mely L, Huiart L, et al. Cough after inhalation of corticosteroids delivered from spacer devices in children with asthma. Fundam Clin Pharmacol. 2003 Oct;17(5):627-31. PMID: 14703724.

[Excluded study design]

259. Ducharme FM. Continuous versus intermittent inhaled corticosteroids for mild persistent asthma in children: Not too much, not too little. Thorax. 2012 Feb;67(2):102-5. [Not a human study]

260. Dukes EM, Kemp J, Tinkelman D, et al. The impact of budesonide inhalation suspension BIS on the health status of young children with asthma. Ann Allergy Asthma Immunol. 1999:82;124. [Irretrievable]

261. Duong-Quy S, Hua-Huy T, Doan-Quynh $\mathrm{N}$, et al. A study of exhaled NO (FENO) measurement used to determine asthma control, dose of inhaled corticosteroid and cost in a developing country. Eur Respir J. 2015;46:PA5013. DOI: 10.1183/13993003.congress2015.PA5013. [Not an intervention of interest]

262. Durmaz C, Asilsoy S, Usta Guc B. Efficacy of nebulised budesonide in infants with viral wheezing. Allergy. 2011;6;Suppl 94:563-4. DOI: 10.1111/j.1398-9995.2011.02608.x. [Abstract without full-text]

263. Durzo A, Hebrt JR, Kunkel G, et al. Mometasone furoate (MF) therapy improves plmonary function in patients previously maintained on high doses of inhaled corticosteroids (ICS). Eur Respir J. 2000;16;Suppl 31:338s. [Irretrievable]

264. Dutu S, Stoicescu P, Bistriceanu G, et al. Clinical management of bronchial asthma with inhaled high-dose beclomethasone dipropionate (beclomet 250--orion). Pneumoftiziologia. 1991 Jul-Sep;40(3):46-7. PMID: 1841740. [Excluded study design] 
265. Dykewicz MS. Asthma treatment with inhaled corticosteroids versus antileukotrienes: What exhaled nitric oxide studies do and do not tell us. Ann Allergy Asthma Immunol. 2001 Oct;87(4):257-60. PMID: 11686416. [Not a human study] 266. Edelman JM, Ghannam A, Bird S et al. Onset of action of montelukast and inhaled beclomethasone in achieving asthma control. Am J Respir Crit Care Med. 2000;161;Suppl 3:A202. [Irretrievable]

267. Edelman JM. Rescue-free days in patients with mild persistent asthma receiving montelukast sodium or an inhaled corticosteroid [abstract]. European Respiratory Society Annual Congress; 2002; Stockholm, Sweden. 771.

[Irretrievable]

268. Edin HM, Payne E, Herrle MR, et al. Salmeterol/Fluticasone Propionate combination via HFA MDI improves quality of life in asthma patients. J Allergy Clin Immunol. 2001;107(2):S246. [Not an intervention of interest]

269. Edmonds ML, Rowe BH. Treatment with inhaled flunisolide. Chest. 2004 May;125(5):1961-2. PMID: 15136418. [Not a human study]

270. Edsbacker S, Thorsson L. Fluticasone and asthma. Lancet. 2001 Mar 10;357(9258):804. PMID: 11253999. [Not a human study]

271. Eigen H. Differential diagnosis and treatment of wheezing and asthma in young children. Clin Pediatr. 2008 Oct;47(8):73543. [Not a human study]

272. Ekroos H, Lindqvist A, Saarinen A, et al. Significant association with the decrease of bronchial hyperresponsiveness and the decrease of exhaled nitric oxide after starting inhaled fluticasone in mild asthma. European Respiratory Society; 1999 Oct 913; Madrid, Spain. 1213p. [Irretrievable]
273. Eliraz A, Fritscher CC, Perez CMR, et al. Budesonide and formoterol in a single inhaler quickly gains asthma control compared with fluticasone propionate in mild asthma. Eur Respir J. 2001;18;Suppl 33:48s. [Not an intervention of interest]

274. Emin O, Fatih M, Mustafa O, et al. Evaluation impact of long-term usage of inhaled fluticasone propionate on ocular functions in children with asthma. Steroids. 2011 May;76(6):548-52. PMID: 21335020. [Excluded study design]

275. Ermers MJJ, Rovers MM, van Woensel JB, et al. The effect of high dose inhaled corticosteroids on wheeze in infants after respiratory syncytial virus infection:

Randomised double blind placebo controlled trial. BMJ. 2009;338:b897. PMID: 19336497. [Not in the target population]

276. Estelle F, Simons R. The benefits of longterm inhaled glucocorticosteroid treatment in children with asthma outweigh the risks. Pediatr Res. 2001;49(3):315-6. [Not a human study]

277. Fabbri LM. Does mild persistent asthma require regular treatment?. N Engl J Med. 2005 Apr 14;352(15):1589-91. PMID: 15829540. [Not a human study]

278. Farah CS, King GG, Brown NJ, et al. Ventilation heterogeneity predicts asthma control in adults following inhaled corticosteroid dose titration. J Allergy Clin Immunol. 2012 Jul;130(1):61-8. PMID: 22460065. [Excluded study design]

279. FitzGerald JM, Boulet L, Follows RMA. The CONCEPT trial: A 1-year, multicenter, randomized,double-blind, double-dummy comparison of a stable dosing regimen of salmeterol/fluticasone propionate with an adjustable maintenance dosing regimen of formoterol/budesonide in adults with persistent asthma. Clin Ther. 2005 Apr;27(4):393-406. PMID: 15922813. [Not an intervention of interest] 
280. FitzGerald JM, Sears MR, Boulet L, et al. Adjustable maintenance dosing with budesonide/formoterol reduces asthma exacerbations compared with traditional fixed dosing: A five-month multicentre canadian study. Can Respir J. 2003 NovDec;10(8):427-34. PMID: 14679407. [Not an intervention of interest]

281. FitzGerald JM, Shragge D, Haddon J, et al. A randomized, controlled trial of high dose, inhaled budesonide versus oral prednisone in patients discharged from the emergency department following an acute asthma exacerbation. Can Respir J. 2000 JanFeb;7(1):61-7. PMID: 10700672. [Not in the target population]

282. FitzGerald JM. Effect of inhaled formoterol and budesonide on exacerbations of asthma. N Engl J Med. 1998 Apr 9;338(15):1071-2. PMID: 9537879. [Not a human study]

283. Fitzpatrick AM, Jackson DJ, Mauger DT, Boehmer SJ. Individualized therapy for persistent asthma in young children. Journal of Allergy \& Clinical Immunology. 2016;Dec 138(6):1608-1618.e12. PMID: 27777180 [no outcomes of interest]

284. Fleming L, Wilson N, Regamey N, et al. Use of sputum eosinophil counts to guide management in children with severe asthma. Thorax. 2012 Mar;67(3):193-8. PMID: 21825081. [Not an intervention of interest]

285. Fluticason furoate (arnuity ellipta) for asthma. Med Lett Drugs Ther. 2015 May 25;57(1469):76-9. PMID: 25989197. [Not a human study]

286. Fluticasone linked to adrenal crisis. Pharm J. 2002 2002/11;269(7226):770. [Not a human study]

287. Fluticasone/salmeterol: New indications not justified. Prescrire Int. 2008;17(98):229. [Not a human study]

288. Foresi A, Pelucchi A, Dorini S, et al. Effect of low and high dose inhaled fluticasone propionate fp in symptomatic asthma. Annual Thoracic Society 97th International Conference; 2001 May 18-23; San Francisco, CA. A519. [Not an intervention of interest]
289. Fox GF, Everard ML, Marsh MJ, et al. Randomised controlled trial of budesonide for the prevention of post-bronchiolitis wheezing. Arch Dis Child. 1999 Apr;80(4):343-7. PMID: 10086941. [Not in the target population]

290. Francis RS, McEnery G. Disodium cromoglycate compared with beclomethasone dipropionate in juvenile asthma. Clin Allergy. 1984 Nov;14(6):53740. PMID: 6439430. [Not an intervention of interest]

291. Francis RS, McEnery G. Disodium cromoglycate compared with beclomethasone dipropionate in juvenile asthma. Clin Allergy. 1984;14(6):537-40. [Not an intervention of interest]

292. Freed-Martens R, Anderson SD, Brannan JD. Effect of treatment on recovery of FEV1 to baseline after a mannitol challenge: a phase 3 study. Respirology. 2005;10;Suppl;A1. [Not an intervention of interest]

293. Fritsch M, Uxa S, Horak F, et al. Exhaled nitric oxide in the management of childhood asthma: a prospective 6-months study. Pediatr Pulmonol. 2006 Sep;41(9):855-62. PMID: 16850457. [Not an intervention of interest]

294. Fukuoka J. Different responses of morning dipping and nocturnal dipping to inhaled and/or oral steroids in chronic asthmatics. Nihon Kyobu Shikkan Gakkai Zasshi. 1994 Aug;32(8):731-8. [Not an intervention of interest]

295. Gajanan SG. Inhaled corticosteroids in childhood bronchial asthma. Natl Med J India. 1993 Mar-Apr;6(2):76-7. PMID: 8477214. [Not a human study]

296. Galant S, Gode Sellers S, Kalberg C, et al. Low dose inhaled fluticasone propionate provides greater improvement in pulmonary function as compared to montelukast in patients with persistent asthma. J Allergy Clin Immunol. 2001;107(2):S106. [Not an intervention of interest] 
297. Galant S, Miller CJ, Mezzanotte WS, et al. Efficacy of budesonide inhalation suspension (pulmicort respules) in children with asthma previously treated with inhaled corticosteroids or other daily medications. J Allergy Clin Immunol. 2002;109;Suppl 1:S241. [Not an intervention of interest]

298. Garay SM, Bensch GW, Lockey RF. Rapid reduction of nocturnal awakenings with inhaled mometasone furoate in adults with mild to moderate persistent asthma [Abstract]. American Thoracic Society International Conference; 2008 May 16-21; Toronto, Canada. A52p. [Not an intervention of interest]

299. Garrett J, Williams S, Wong C, et al. Treatment of acute asthmatic exacerbations with an increased dose of inhaled steroid. Arch Dis Child. 1998 Jul;79(1):12-7. PMID: 9771245. [No outcomes of interest]

300. Geddes DM. Inhaled budesonide for mild asthma. N Engl J Med. 1995 Mar 9;332(10):683-4. PMID: 7845439. [Not a human study]

301. Gelfand EW, Gallegos CM, Silveira LJ, et al. Effect of the Inhaled Corticosteroid Mometasone Furoate on Small Airway Patency in Patients with Asthma. J Allergy Clin Immunol. 2009;123;2 Suppl 1:S77. [Not an intervention of interest]

302. Gerald JK, Gerald LB, Chinchilli VM, et al. Adherence to rescue inhaled corticosteroid use during the TREXA trial. Am J Respir Crit Care Med. 2012;185; Meeting Abstracts:A2200. Embase 71986726. [Duplicate]

303. Ghosh CS, Joseraj R, Kumari A, et al. A randomized controlled clinical trial comparing the effects of inhaled budesonide vs. inhaled ipratropium bromide in patients with bronchiectasis. Indian J Allergy Asthma Immunol. 2002;16(1):67. [Not in the target population]
304. Giannini D, Di Franco A, Bacci E, et al. Different doses of inhaled fluticasone propionate fp in the management of moderate asthmatic subjects. Annual Thoracic Society 97th International Conference; 2001 May 13-23; San Francisco CA. A517. [Not an intervention of interest]

305. Glassroth J. Use of long-acting $\beta$-agonists and inhaled corticosteroids [7]. Ann Intern Med. 2006 Nov;145(9):710. [Not a human study]

306. Gleeson JG, Price JF. Controlled trial of budesonide given by the nebuhaler in preschool children with asthma. BMJ. 1988 Jul 16;297(6642):163-6. PMID: 3044506. [Not an intervention of interest]

307. Godfrey S, Avital A, Rosler A, et al. Nebulised budesonide in severe infantile asthma. Lancet. 1987 Oct 10;2(8563):851-2. PMID: 2889046. [Excluded study design]

308. Gogtay JA, Balki A, Dalal S, et al. Efficacy and tolerability of a new HFA-propelled fluticasone/formoterol combination inhaler compared to budesonide/formoterol combination in subjects with moderate to persistent asthma. Chest. 2010;138(4):161A. [Not an intervention of interest]

309. Gold DR, Fuhlbrigge AL. Inhaled corticosteroids for young children with wheezing. N Engl J Med. 2006 May 11;354(19):2058-60. PMID: 16687719. [Not a human study]

310. Gomez Tejada RA, Finkelstein CN, Gene RJ. Inhaled corticosteroids and asthma education. Medicina. 1998;58(6):692-8. [Not an intervention of interest]

311. Gonzalez PYE, Ruiz BA, Garate AJ, et al. A multicenter randomized, open, parallel group study comparing different treatments for hospitalized infants with acute wheezy bronchitis. An Esp Pediatr. 1994;41(5):3159. [Not an intervention of interest]

312. Goodman DC. When an asthma drug has an inferiority complex: a noninferiority trial. Pediatrics. 2005 Aug;116(2):493-5. PMID: 16061609. [Not a human study] 
313. Goossens LMA, Riemersma RA, Postma DS, et al. An economic evaluation of budesonide/formoterol for maintenance and reliever treatment in asthma in general practice. Adv Ther. 2009 Sep;26(9):872-85. PMID: 19768640. [Excluded study design]

314. Gotz M. The safety and efficacy of inhaled fluticasone propionate (FP) in childhood asthma. Eur Respir J. 1994;4;Suppl 14:S804. [Not an intervention of interest]

315. Gould W, Peterson EL, Karungi G, et al. Factors predicting inhaled corticosteroid responsiveness in african american patients with asthma. J Allergy Clin Immunol. 2010 Dec;126(6):1131-8. PMID: 20864153. [Excluded study design]

316. Gradman J, Wolthers OD. One year height growth in children with asthma treated with inhaled budesonide delivered from a new dry powder inhaler [Abstract]. European Respiratory Society Annual Congress; 2008 Oct 4-8; Berlin, Germany. P3942. [Not an intervention of interest]

317. Green RH, Brightling CE, McKenna S, et al. Asthma exacerbations and sputum eosinophil counts: A randomised controlled trial. Lancet. 2002 Nov 30;360(9347):171521. PMID: 12480423. [Not an intervention of interest]

318. Green RH, Pavord ID. Use of long-acting beta2 agonists in arginine-16 homozygous patients with asthma. Thorax. 2008 Jun;63(6):568-9. PMID: 18511645. [Not a human study]

319. Greenough A, Pool J, Gleeson JG, et al. Effect of budesonide on pulmonary hyperinflation in young asthmatic children. Thorax. 1988 Nov;43(11):937-8. PMID: 3065976. [Not an intervention of interest]

320. Greos L, Corren J, Ruiz N, et al. Efficacy of flunisolide HFA (aerospan) in adult and adolescent patients 12 years and older with asthma by baseline inhaled steroid. Ann Allergy Asthma Immunol. 2014;113;5 Suppl 1:A42. Embase 71679240. [Not an intervention of interest]
321. Gross G, Woodring A, Prillaman B, et al. Efficacy and safety of the salmeterol/fluticasone propionate (50/100 $\mu \mathrm{g})$ dry powder combination inhaler in patients with asthma. Eur Respir J. 1998;12;Suppl:156s. [Not an intervention of interest]

322. Growth retardation in asthmatic children treated with inhaled beclomethasone dipropionate. Lancet. 1988 Feb 27;1(8583):475-6. PMID: 2893899. [Not a human study]

323. Grunberg K, Sharon RF, Sont JK, et al. Rhinovirus-induced airway inflammation in asthma: Effect of treatment with inhaled corticosteroids before and during experimental infection. Am J Respir Crit Care Med. 2001 Nov 15;164(10 Pt 1):181622. PMID: 11734429. [Not an intervention of interest]

324. Guleria R, Singh TR, Sinha S, et al. Effect of inhalation of Salbutamol, Beclomethasone dipropionate and Ipratropium bromide on mucociliary clearance in chronic stable bronchial asthma. Indian J Tuberc. 2004;51:54-7. [Not an intervention of interest]

325. Guo XD, Xu SL, Zhao P, et al. Efficiency of inhalation of budesonide aerosol in the treatment of asthma in infants and young children. Guangxi Medical Journal. 2002;24(1):14-6. [No English language abstract]

326. Haahtela T. Lung function decline in asthma and early intervention with inhaled corticosteroids. Chest. 2006 Jun;129(6):1405-6. PMID: 16778255. [Not a human study]

327. Hacena M, Ingard A, Guenot A, et al. A prospective outcome study in patients with asthma on inhaled corticosteroid treatment. Ann Allergy Asthma Immunol. 2001;86:103. [Not an intervention of interest] 
328. Hahn DL. Bronchodilator therapy with or without inhaled corticosteroid therapy for obstructive airway disease. N Engl J Med. 1993 Apr 8;328(14):1044-5. PMID: 8450868. [Not a human study]

329. Hamada K, Yasuba H, Tanimura K, et al. How can we stop ICS? -Risk control therapy by as-needed inhaled fluticasone after stepping down. J Allergy Clin Immunol. 2008;121(2):S219. [Excluded study design]

330. Hamalainen KM, Laurikainen K, Leionen $\mathrm{M}$, et al. Comparison of two multidose powder inhalers (MDP) in the treatment of asthma with inhaled corticosteroids. Eur Respir J. 1998;12;Suppl 28:61S. [Not an intervention of interest]

331. Hampel Jr FC, Martin P, Mazzanotte WS. Early bronchodilatory effects of budesonide formoterol pressurized metered dose inhaler (pMDI) compared with fluticasone propionate salmeterol dry powder inhaler (DPI) and albuterol pMDI in adults with asthma. J Allergy Clin Immunol. 2008;21;2 Suppl 1:S220. [Not an intervention of interest]

332. Hancox RJ, Cowan JO, Flannery EM, et al. Randomised trial of an inhaled beta2 agonist, inhaled corticosteroid and their combination in the treatment of asthma. Thorax. 1999 Jun;54:482-7. PMID: 10335000. [Not an intervention of interest]

333. Handforth J, Friedland JS, Sharland M. Inhaled corticosteroids after respiratory syncytial virus infection. BMJ (Online). 2009 Apr;338(7701):963. [Not a human study]

334. Harding S, Herje N, Hamedani A, et al. Long term effects of inhaled fluticasone propionate in subjects with asthma. Eur Respir J. 1997;10;Suppl 25:173S. [Not an intervention of interest]

335. Harding SM, Herje NE, Hamedani AG. Comparison of the long-term effects of inhaled fluticasone propionate FP on the HPA axis in patients with asthma. Ann Allergy Asthma Immunol. 1997;78:156. [Not an intervention of interest]
336. Hart L, Sim S, Adcock I, et al. Effects of inhaled corticosteroid on expression and activation of nuclear factor -kB (NFkB) in asthma. Eur Respir J. 1998;12;Suppl 28:115S. [Not an intervention of interest]

337. Haughney J, Aubier M, Jorgensen L, et al. Comparing asthma treatment in elderly versus younger patients. Respir Med. 2011 Jun;105(6):838-45. PMID: 21435854. [Not an intervention of interest]

338. Hebert JR, Kunkel G, Neffen H, et al. Mometasone furoate (MF) therapy improves asthma symptoms in addition to pulmonary function in patients previously maintained on high doses of inhaled corticosteroids (ICS). Am J Respir Crit Care Med. 2000;161;Suppl 3:A187. [Irretrievable]

339. Hedlin G, Svedmyr J, Ryden AC. Systemic effects of a short course of betamethasone compared with high-dose inhaled budesonide in early childhood asthma. Acta Paediatr. 1999 Jan;88(1):48-51. PMID: 10090547. [No outcomes of interest]

340. Henriksen JM. Effect of inhalation of corticosteroids on exercise induced asthma: Randomised double blind crossover study of budesonide in asthmatic children. Br Med J (Clin Res Ed). 1985 Jul 27;291(6490):248-9. PMID: 3926141. [Not an intervention of interest]

341. Hesselmar B, Adolfsson S. Inhalation of corticosteroids after hospital care for respiratory syncytial virus infection diminishes development of asthma in infants. Acta Paediatr. 2001 Mar;90(3):2603. PMID: 11332164. [Not in the target population]

342. Hofhuis W, van der Wiel EC, Nieuwhof EM, et al. Efficacy of fluticasone propionate on lung function and symptoms in wheezy infants. Am J Respir Crit Care Med. 2005 Feb 15;171(4):328-33. PMID: 15531753. [Not an intervention of interest]

343. Holt S, Patel M, Montgomery B, et al. Cohort study of a simple 'step-up' regimen with the asthma control test. Respirology. 2015 Apr;20(3):504-6. PMID: 25572675. [Excluded study design] 
344. Hozawa S, Terada M, Haruta Y, et al. Comparison of early effects of budesonide/formoterol maintenance and reliever therapy with fluticasone furoate/vilanterol for asthma patients requiring step-up from inhaled corticosteroid monotherapy. Pulm Pharmacol Ther. 2016;37:15-23. DOI: 10.1016/j.pupt.2016.01.005. [Duplicate]

345. Huang J-L, Hung I-J, Hsieh K-H. Effect of inhaled beclomethasone dipropionate in the treatment of recurrent wheezing in infancy and early childhood. J Formos Med Assoc. 1993;92(12):1066-9. [Not an intervention of interest]

346. Huang JL, Hung IJ, Hsieh KH. Effect of inhaled beclomethasone dipropionate in the treatment of recurrent wheezing in infancy and early childhood. J Formos Med Assoc. 1993 Dec;92(12):1066-9. PMID: 7911355. [Not an intervention of interest]

347. Huang SG, Cheng QJ, Sears MR. Asneeded formoterol (F) in asthma: an analysis of the East-Asian subgroup of the RELIEF study. Eur Respir J. 2014;44:P2425. Embase 71850114. [Not an intervention of interest]

348. Hughes GL, Edelman JM, Turpin JA. Randomized, open-label pilot study comparing the effects of montelukast sodium tablets, fluticasone aerosol inhaler and budesonide dry powder inhaler on asthma control in mild asthmatics. Am J Respir Crit Care Med. 1999;159(3 (Pt 2)):A641. [Not an intervention of interest]

349. Hypertrichosis in children treated with steroids. Prescrire Int. 2008;17(97):204. [Excluded study design]

350. Ige OM, Ohaju-Obodo JO, Chukwu C, et al. Effectiveness and safety of adjustable maintenance dosing with budesonide/formoterol turbuhaler compared with traditional fixed doses in bronchial asthma: A multi-centre nigerian study. Afr J Med Med Sci. 2010 Sep;39(3):165-72. PMID: 21416785. [Irretrievable]
351. Implementing key therapeutic topics: 1 NSAIDs; antibiotics; and inhaled corticosteroids in asthma. MeReC Bull. 2012;22(3):1-8. [Irretrievable]

352. Ind P, Haughney J, Price D, et al. 4-month adjustable or fixed maintenance treatment with budesonide/formoterol in a single inhaler reduces symptoms severity. Eur Respir J. 2002;20;Suppl 38:41s. [Not an intervention of interest]

353. Ind P, Haughney J, Price D, et al. Four months adjustable or fixed BD dosing with budesonide/formoterol in a single inhaler reduces symptom severity. Thorax. 2002;57;Suppl III:iii88. [Not an intervention of interest]

354. Ind PW, Dal Negro R, Colman N, et al. Inhaled fluticasone propionate and salmeterol in moderate adult asthma II: exacerbations. Am J Respir Crit Care Med. 1998;157;Suppl 3:A415. [Not an intervention of interest]

355. Ind PW, Dal Negro R, Colman N, et al. Inhaled fluticasone propionate and salmeterol in moderate adult asthma I: lung function and symptoms. Am J Respir Crit Care Med. 1998;157;Suppl 3:A416. [Not an intervention of interest]

356. Ind PW, dal Negro R, Fletcher CP, et al. Inhaled salmeterol and fluticasone propionate therapy in moderate adult asthma. Eur Respir J. 1997;10; Suppl 25:1S. [Not an intervention of interest]

357. Ind PW, Haughney J, Price D, et al. Adjustable and fixed dosing with budesonide/ formoterol via a single inhaler in asthma patients: The ASSURE study. Respir Med. 2004 May;98(5):464-75. PMID: 15139576. [Not an intervention of interest]

358. Ind PW, Price D, Haughney J, et al. Adjustable dosing with budesonide/formoterol in a single inhaler (symbicortA(R)) provides similarly effective treatment of asthma compared with fixed dosing but at a lower overall dose [abstract]. American Thoracic Society International Conference; 2003. 38p. [Irretrievable] 
359. Inhaled corticosteroids for mild asthma. Med Today. 2002;3(1):9. [Not a human study]

360. Inhaled corticosteroids may cause only temporary slowing of growth in children, studies suggest. Am J Health-Syst Pharm. 2000 Dec2;57(23):2142-9. [Not a human study]

361. Inhaled corticosteroids: Are higher doses better? Drug Ther Bull. 1986 Jan 13;24(1):1-2. PMID: 3516617. [Not a human study]

362. Inhaled corticosteroids: Children are at risk from high doses. MeReC Extra. 2007:27. [Irretrievable]

363. Inhaled corticosteroids: Do they inhibit growth? Med Today. 2002;3(5):10. [Not a human study]

364. Inhaled glucocorticoids found to cause dose-related bone density loss. Pharm J. 2001 Oct;267(7168):454. [Not a human study]

365. Inhaled glucocorticoids more effective than leukotriene receptor antagonists for treating asthma. Formulary. 2003 May;38(5):271. [Not a human study]

366. Inhaled steroids switch can destabilise asthma. Pharm J. 2002 May;268(7199):710. [Not a human study]

367. Inman MD, Watson RM, Rerecich T, et al. Dose-dependent protection against allergeninduced asthmatic responses by inhaled mometasone furoate. European Respiratory Society; 1999 Oct 9-13; Madrid, Spain. 1989p. [Irretrievable]

368. Inman MD, Watson RM, Rerecich T, et al. Effect of low doses of mometasone furoate (MF) dry powder inhaler (DPI) on allergen induced asthmatic responses. Am J Respir Crit Care Med. 2000;161;Suppl 3:A187. [Irretrievable]

369. Intelligent inhalers for pulmonary delivery. Manuf Chem. 2001;72(4):23-5. [Irretrievable]

370. Intermittent therapy effective for mild persistent asthma. J Fam Pract. 2005;54(7):578. Embase 2005312735. [Not a human study]
371. Irani AM, Berger W, Qaquandah P, et al. Effect of budesonide inhalation suspension (BIS) on HPA axis function in infants stratified by age [Abstract]. American Thoracic Society 100th International Conference; 2004 May 21-26; Orlando, FL. A37 Poster J106p. [Not an intervention of interest]

372. Irani AM, Fitzpatrick S, Smith J, et al. Budesonide inhalation suspension compared with cromolyn sodium: effects on asthma outcomes in young children. Pediatr Res. 2001;49(4):130A. [Not an intervention of interest]

373. Jackson C, Lipworth B. Benefits of combination therapy on exacerbations in nonsmoking patients with asthma. J Allergy Clin Immunol. 2008;121(3):780. [Not a human study]

374. Jarjour NN, Kelly EAB, Rodriguez RR, et al. Inhaled budesonide (BUD) via turbohaler decreases late asthmatic reaction (LAR) to antigen and down regulates airway lymphocyte function in atopic asthma. Am J Respir Crit Care Med. 1998;157;Suppl 3:A873. [Not an intervention of interest] 375. Jayaram L, Pizzichini MM, Cook RJ, et al. Determining asthma treatment by monitoring sputum cell counts: effect on exacerbations. Eur Respir J. 2006 Mar;27(3):483-94. PMID: 16507847. [Not an intervention of interest]

376. Jenkins C, Belousova E, Marks G, et al. Intermittent or continuous inhaled corticosteroids for mild asthma? Respirology. 2006;11;Suppl 2:A70. [Abstract without full-text]

377. Jenkins C, Eriksson G, Bateman ED, et al. Efficacy of budesonide/formoterol maintenance and reliever therapy in mild asthma. Eur Respir J. 2013 Sep 11;42:P4125. Embase 71842582. [Abstract without full-text]

378. Jenkins C, Goldberg H, Ryder E, et al. The effect of inhaled budesonide on bronchial responsiveness to histamine in patients with asthma. Aust Nz J Med. 1991;21:662. [Not an intervention of interest] 
379. Jonasson G, Edvardsen E, Carlsen KH. Clinical efficacy of a low dose inhaled budesonide in children with mild asthma previously not treated with steroids. Eur Respir J. 1997;10;Suppl 25:221S. [Not an intervention of interest]

380. Jung J, Lee J, Kim J. Treatment of inhaled corticosteroid and leukotriene receptor antagonist in Korean young cough variant asthma children. J Allergy Clin Immunol. 2006;117;2 Suppl 1:S93. [Not an intervention of interest]

381. Kaiser HB, Miller CJ, O'Dowd L. Measured onset of bronchodilation with budesonide and formoterol administered via one pressurized metered dose inhaler (pMDI) in patients with asthma previously receiving inhaled corticosteroids. J Allergy Clin Immunol. 2007;119;Suppl 1:S249. [Not an intervention of interest]

382. Kajosaari M, Syvanen P, Forars M, et al. Inhaled corticosteroids during and after respiratory syncytial virus-bronchiolitis may decrease subsequent asthma. Pediatr Allergy Immunol. 2000 Aug;11(3):198-202. PMID: 10981531. [Not in the target population]

383. Kalister H. Treating children with asthma. West J Med. 2001;174(6):415-20. [Not a human study]

384. Kaplan A. Inadequately controlled asthma. patients do not understand their treatment plans. Can Fam Phys. 2002 Aug;48:1280-2. [Not a human study]

385. Kardos P, Brueggenjuergen B, Baare A, et al. The ATACO study: adjustable maintenance therapy with budesonide and formoterol in a single inhaler. Eur Respir J. 2002;20;Suppl 38:41s. [Not an intervention of interest]

386. Kardos P, Bruggenjurgen B, Martin A, et al. The treatment of asthma: A study (TACO asthma control lan) introducing a new adjustable combination-treatment plan. Pneumologie. 2001;55(5):253-7. [Duplicate]
387. Kardos P, Brüggenjürgen B, Martin A, et al. The treatment of asthma: a study (TACO asthma control plan) introducing a new adjustable combination-treatment plan. Pneumologie. 2001;55(5):253-7. [Not an intervention of interest]

388. Kardos P, Bruggenjurgen B, Martin A, et al. Treatment of bronchial asthma using a new adjustable combination treatment plan: Asthma Control Plan (ATACO).

Pneumologie. 2001 May;55(5):253-7. [Duplicate]

389. Kardos P, Richter K, Vogelmeier C, et al. Adjustable dosing with budesonide/formoterol in a single inhaler maintains improvement in health-related quality of life at a lower drug load than fixed dosing - the ATACO study. Eur Respir J. 2003;22;Suppl 45:Abstract P1696. [Not an intervention of interest]

390. Kari O. Helsinki early intervention childhood asthma (HEICA) study: inhaled budesonide halved the number of asthma exacerbations compared with inhaled disodium cromogylcate during 18 months of treatment. Eur Respir J. 2000;16;Suppl 31:311s. [Irretrievable]

391. Karkinski D, Arsovski Z, Nikolau M, et al. Inhalation of fluticasone propionate spray compared with theophilline as primary treatment for chronic mild to moderate asthma. Eur Respir J. 2006;28;Suppl 50:500s. [Not an intervention of interest] 392. Karpel JP, Fish JE, Craig TJ, et al. Mometasone furoate (MF) administered by metered dose inhaler (MDI) reduces oral prednisone requirements and improves pulmonary function of patients with severe persistent asthma. Eur Respir J. 2000116;Suppl 31:93s. [Not an intervention of interest]

393. Karpel JP, Nayak A, Lumry W, et al. Mometasone furoate reduces oral corticosteroid requirements in patients with severe persisitent asthma previously using other inhaled corticosteroids. Chest. 2002;122(4):65S. [Not an intervention of interest] 
394. Kasayama S, Otsuki M, Tanemura M, et al. Association of subclinical hypothalamicpituitary-adrenal axis suppression with bone loss in patients with asthma taking inhaled corticosteroids. Ann Allergy Asthma Immunol. 2013;111(3):229-31. [Not an intervention of interest]

395. Kassutto S, Daily JP. Footprints. N Engl J Med. 2004 Sep;351(14):1438-43 and 1475. [Excluded study design]

396. Kawayama T, Gauveau GM, Watson RM, et al. Effects of inhaled ciclesonide on circulating Th1/Th2 cells in atopic asthmatics after allergen challenge. American Thoracic Society International Conference; 2005 May 20-25; San Diego, CA. A351. [Not an intervention of interest]

397. Keeley D. Higher dose inhaled corticosteroids in childhood asthma. Br Med J. 2001 Mar;322(7285):504-5. [Not a human study]

398. Kellerman D, Stricker W, Howland W, et al. Effects of inhaled fluticasone propionate (FP) on the HPA axis of patients with asthma. Eur Respir J. 1996;9;Suppl 23:162s. [Not an intervention of interest]

399. Kelly M, O' Connor T, Leigh R, et al. Inhaled budesonide /formoterol combination therapy significantly attenuates allergen induced increases in airway myfibroblasts. Eur Respir J. 2007;30;Suppl 51:137s. [Not an intervention of interest]

400. Kelso JM. Daily versus as-needed inhaled corticosteroid for mild persistent asthma (the helsinki early intervention childhood asthma study). Pediatrics. 2009;124;suppl 2:S148-9. [Not a human study]

401. Kerigan AT, Pugsley SO, Cockcroft DW, et al. Subsittution of inhaled beclomethasone dipropionate for ingested prednisone in steroid-dependent asthmatics. Can Med Assoc J. 1977 Apr 23;116(8):867-71. PMID: 851928. [Not an intervention of interest]
402. Kerwin EM, Gillespie M, Song S, et al. Dose-ranging study of a fluticasone propionate multidose dry powder inhaler in adolescents and adults with asthma uncontrolled by noncorticosteroid asthma medications. Am J Respir Crit Care Med. 2015;191:A4232. Embase 72052107. [Not an intervention of interest]

403. Kerwin EM, Gillespie M, Song S, et al. Randomized, dose-ranging study of a fluticasone propionate multidose dry powder inhaler in adolescents and adults with uncontrolled asthma not previously treated with inhaled corticosteroids. J Asthma. 2016 Jun. Epub 2016 Jun 10. PMID: 27285965. [Not an intervention of interest]

404. Ketchell RI, Jensen MW, Montgomery AA, et al. Inhaled fluticasone propionate rapidly attentuates airway responsiveness to adenosine 5'-monophosophate and decreases exhaled nitric oxide in mild asthma. Eur Respir J. 2000;16;Suppl 31:340s. [Irretrievable]

405. Kim KT, Lanier BQ, Goldman M, et al. Effect of adjustable-dose (AD) budesonide/formoterol pressurized metereddose inhaler (pMDI), fixed-dose (FD) budesonide/formoterol pMDI, and FD fluticasone/salmeterol dry powder inhaler (DPI) on predose FEF25-75\% [Abstract]. American Thoracic Society International Conference; 2009 May 15-20; San Diego, CA. A2788 Poster \#J57. [Not an intervention of interest]

406. Kim S, Ye Y, Hur G, et al. Effect of beta2adrenergic receptor polymorphism in asthma control of patients receiving combination treatment. Yonsei Med J. 2009 Apr 30;50(2):182-8. PMID: 19430548. [Not an intervention of interest]

407. Kim SR, Lim KH, Kim MJ, et al. The efficacy and safey of inhaled steroid therapy for prevention of recurrent wheezing after bronchiolitis. Pediatr Allergy Respir Dis. 2004;14(4):392-401. [Not in the target population] 
408. King V, Nettleton W. Intermittent Inhaled Corticosteroid Therapy for Mild Persistent Asthma in Children and Adults. American Family Physician. 2016; July;94(1):21-2. PMID: 27386720 [not a human study]

409. Kini SH, Jain K, Nabar ST, et al. Three modes of delivery of steroids in asthma: a comparison. Eur Respir J. 2001;18;Suppl 33:99s. [Not an intervention of interest]

410. Klaassen EMM, van de Kant,K D G., Jobsis Q, et al. Symptoms, but not a biomarker response to inhaled corticosteroids, predict asthma in preschool children with recurrent wheeze. Mediators Inflamm. 2012;2012:162571. PMID: 23304059. [Not an intervention of interest]

411. Knox AJ, Deacon K, Clifford R. Blanching the airways: Steroid effects in asthma. Thorax. 2007;62(4):283-5. [Not a human study]

412. Ko FWS, Wang HY, Wong GWK, et al. Wheezing in chinese schoolchildren: Disease severity distribution and management practices, a community-based study in hong kong and guangzhou. Clin Exp Allergy. 2005 Nov;35(11):1449-56. PMID: 16297141. [Excluded study design]

413. Koenig SM, Murray JJ, Wolfe J, et al. Does measuring BHR add to guideline derived clinical measures in determining treatment for patients with persistent asthma?. Respir Med. 2008 May;102(5):665-73. PMID: 18328683. [Not an intervention of interest] 414. Konig P, Ford L, Galant S, et al. A 1-year comparison of the effects of inhaled fluticasone propionate (FP) and placebo on growth in pre-pubescent children with asthma. Eur Respir J. 1996;9;Suppll S294. [Not an intervention of interest]

415. Kotaniemi-Syrjanen A, Reijonen TM, Korhonen K, et al. Sodium cromoglycate therapy in wheezing infants: Preliminary evidence of beneficial outcome at early school age. Pediatr Int. 2005 Dec;47(6):62734. PMID: 16354214. [Not an intervention of interest]
416. Kovesi T, Schuh S, Spier S, et al. Achieving control of asthma in preschoolers. CMAJ. 2010 Mar;182(4):E172-183. [Not a human study]

417. Kovesi T. In children and adolescents with mild persistent asthma, daily beclomethasone reduces treatment failure compared with rescue beclomethasone plus albuterol. Evidence-based medicine. 2011;16(6):183-4. DOI: 10.1136/ebm1411. [Not a human study]

418. Kraemer R, Graf Bigler U, Casaulta Aebischer $\mathrm{C}$, et al. Clinical and physiological improvement after inhalation of low-dose beclomethasone dipropionate and salbutamol in wheezy infants. Respiration. 1997;64(5):342-9. PMID: 9311050. [Not an intervention of interest]

419. Kraemer R, Graf Bigler U, Casaulta Aebischer C. Clinical and functional improvement after inhalations of low-dose beclomethasone dipropionate (BDP) and salbutamol in wheezy infants. Eur Respir J. 1995;8;Suppl 19:468S. [Not an intervention of interest]

420. Kraemer R, Sennhauser F. Inhaled beclometasone and cromoglycate on bronchial hyperreactivity in asthmatic children. Atemwegs-Lungenkrankh. 1986;12(3):110-3. [Not an intervention of interest]

421. Kraft M, Israel E, O'Connor GT. Treatment of mild persistent asthma. N Engl J Med. 2007 May;356(20):2096-100. [Not a human study]

422. Krishnan JA, Nowak R, Davis SQ, et al. Anti-inflammatory treatment after discharge home from the emergency department in adults with acute asthma. J Emerg Med. 2009 Aug;37;2 Suppl:S35-41. [Not a human study]

423. Krishnan JA, Nowak R, Davis SQ, et al. Anti-inflammatory treatment after discharge home from the emergency department in adults with acute asthma. J Allergy Clin Immunol. 2009 Aug;124;Suppl 2:S29-34. [Not a human study] 
424. Krishnan JA, Nowak R, Davis SQ, et al. Anti-inflammatory treatment after discharge home from the emergency department in adults with acute asthma. Proc Am Thorac Soc. 2009 Aug;6(4):380-5. [Not a human study]

425. Kuna P, Chuchalin A, Ringdal N, et al. Low-dose single-inhaler budesonide/formoterol administered once daily is effective in mild-persistent asthma. Eur Respir J. 2001;18;Suppl 33:158s. [Not an intervention of interest]

426. Kuna P, Gath I, ThyroffFriesinger U, et al. Equivalence of an innovative multidose salmeterol/fluticasone dry powder inhaler vs comparator in paediatric asthma. Eur Respir J. 2013;42;Suppl 57:918s. Embase 71843005. [Not an intervention of interest]

427. Kuna P, Gath I, ThyroffFriesinger U, et al. Equivalence of fluticasone propionate/salmeterol delivered via new multi-dose dry powder inhaler and accuhalerTM in adolescent and adult asthma. Am J Respir Crit Care Med. 2013;187:A2611. [Not an intervention of interest]

428. Kuna P, Lalloo U, Bateman ED, et al. Budesonide/formoterol in a single inhaler rapidly improves lung function in adult patients with mild or moderate asthma. European Respiratory Society Annual Congress; 2002. Abstract P2400. [Not an intervention of interest]

429. Kuo HP, Uy TR. The relationship of hypodense eosinophil with clinical severity and its response to inhaled corticosteroid in patients with bronchial asthma. Eur Respir J. 1993;6;Suppl 17:584S. [Not an intervention of interest]

430. Kuzik BA. Inhaled corticosteroids in children with persistent asthma: Effects on growth. Paediatr Child Health. 2015 Jun;20(5):248-50. [Not a human study]
431. La Rosa M, Francesco G, Musarra I, et al. Double-blind comparative study of inhaled flunisolide and flunisolide plus salbutamol in bronchial asthma in children. Curr Ther Res Clin Exp. 1991;50(1):56-61. [Not an intervention of interest]

432. LaForce CF, Baker JW, Amin D, et al. Ciclesonide a novel inhaled steroid has no effect on hypothalamic pituitary adrenal (HPA) - axis function in mild to moderate asthmatics. J Allergy Clin Immunol. 2003;111;Suppl 2:S218. [Not an intervention of interest]

433. Lahzami S, King GG. Targeting small airways in asthma: The new challenge of inhaled corticosteroid treatment. Eur Respir J. 2008 Jun;31(6):1145-7. PMID: 18515551. [Not a human study]

434. Lai S-T, Hua Y-M, Lai Y-S, et al. Comparison of nebulized budesonide with intravenous dexamethasone in the treatment of young children hospitalized with acute asthma. J Med Sci. 2005 Oct;25(5):223-8. [Not in the target population]

435. Lalloo UG, Malolepsky J, Kozma D, et al. Budesonide and formoterol in a single inhaler controls exacerbations more effectively than a higher dose of inhaled corticosteroids alone, in mild-moderate persistent asthma. Eur Resp J. 2001;18;Suppl 33:43s. [Not an intervention of interest]

436. Lalloo UG, Malolepsky J, Kozma D, et al. Budesonide and formoterol in a single inhaler is more effective than a higher dose of inhaled corticosteroid in mild-moderate persistent asthma. Eur Resp J. 2001;18;Suppl 33:159s. [Not an intervention of interest]

437. Lalloo UG, Malolepszy J, Kozma D, et al. Symbicort(R) (budesonide and formoterol in a single inhaler) is more effective than increasing the dose of inhaled corticosteroids in mild asthma. Annual Thoracic Society 97th International Conference; 2001; San Francisco, CA. D31p. [Not an intervention of interest] 
438. Lalloo UG, Malolepszy J, Kozma D, et al. Symbicort(R) (budesonide and formoterol in a single inhaler) is more effective than increasing the dose of inhaled corticosteroids in mild asthma. Am J Respir Crit Care Med. 2001;163;Suppl 5:A863. [Irretrievable]

439. Lan WP, Wang J, Dai C, et al. Efficacy of fluticasone proprioante aerosol versus budesonide suspention in treatment of recurrent wheezing caused by bronchiolitis. Chin J Contemp Pediatr. 2016 Apr; 18(4):316-9. [Excluded study design]

440. Langdon CG, Thompson J. A multicentre study to compare the efficacy and safety of inhaled fluticasone propionate and budesonide via metered-dose inhalers in adults with mild-to-moderate asthma. British Journal of Clinical Research. 1994;5:73-84. [Not an intervention of interest]

441. Lara-Perez EA. Improvement of the asthma in children using salmeterol and fluticasone (Seretide) in inhaled combination [abstract]. XIX World Allergy Organization Congress; 2005. 816p. [Irretrievable]

442. Laurikainen K, Toivanen P, Silvasti M, et al. Comparison of two beclomethasone dipropionate (BDO) powder inhalers in the treatment of asthma. Eur Resp J. 1997;10;Suppl 25:235S. [Not an intervention of interest]

443. Laursen LC, Taudorf E, Weeke B, et al. High-dose inhaled budesonide in treatment of severe steroid-dependent asthmatics. Lancet. 1983 Dec 3;2(8362):1305. PMID: 6139644. [Excluded study design]

444. Laviolette M, Barnes N, Lindsay C, et al. Absence of sputum eosinophils in subjects with symptomatic asthma on inhaled budesonide [Abstract]. European Respiratory Society Annual Congress; 2002. P1753. [Not an intervention of interest] 445. Laviolette M, Ferland C, Trepanier L, et al. Effects of inhaled steroids on blood eosinophils in moderate asthma. Ann N Y Acad Sci. 1994 May 28;725:288-97. PMID: 8031001. [Not an intervention of interest]
446. Lawrance R, Ambrose H, Goldman M. Effect of gly16arg beta2-adrenergic receptor variation on the long-term safety of formoterol (FM) in combination with budesonide (BUD) and of BUD alone, delivered via one pressurized metered-dose inhaler (pMDI) in patients with moderate to severe asthma [Abstract]. American Thoracic Society International Conference; 2007 May 18-23; San Francisco, California. 420p. [Irretrievable]

447. Le Bourgeois M, Cormier C, Kindermans $\mathrm{C}$, et al. Inhaled beclomethasone and bone metabolism in young asthmatic children: A six month study. J Allergy Clin Immunol. 1995 Oct;96(4):565-7. PMID: 7560673. [Excluded study design]

448. Lee DKC, Currie GP, Cockburn WJ, et al. Budesonide/formoterol and fluticasone/salmeterol combination inhalers delay immediate albuterol recovery following acute bronchoconstriction. J Allergy Clin Immunol. 2003;111;Suppl 2:S202. [Not an intervention of interest]

449. Lee DKC, Currie GP, Cockburtn WJ, et al. Comparison of budesonide/formoterol versus fluticasone/salmeterol combination inhalers in moderate persistent asthma [abstract]. American Thoracic Society International Conference; 2003. 613p. [Irretrievable]

450. Lee-Wong M, Dayrit FM, Kohli AR, et al. Comparison of high-dose inhaled flunisolide to systemic corticosteroids in severe adult asthma. Chest. 2002 Oct;122(4):1208-13. PMID: 12377843. [Not in the target population]

451. Leflein JG, Berger WE, Uryniak T, et al. Long term safety and systemic effects of budesonide and formoterol administered via one pressurized metered dose inhaler (pMDI) in children with asthma. J Allergy Clin Immunol. 2008;21;2 Suppl 1:S155. [Not an intervention of interest] 
452. Leflein JG, Gawchick SM, Galant SP, et al. Safety of budesonide inhalation suspension (Pulmicort Respules) after up to 52 weeks of treatment in infants and young children with persistent asthma. Allergy Asthma Proc. 2001;22(6):359-66. [Not an intervention of interest]

453. Leidy NK, Gutierrez B, Lampl K, et al. Can patients with asthma feel inhaler therapy working right away? two clinical trials testing the effect of timing of assessment on patient perception. J Asthma. 2009 Dec;46(10):1006-12. PMID: 19995138. [Not an intervention of interest]

454. Leidy NK, Patrick DL, Boggs R, et al. Perceived onset of effect of budesonide and formoterol administered via one pressurized metered dose inhaler in patients with asthma previously receiving inhaled corticosteroids. J Allergy Clin Immunol. 2007;119;Suppl 1:S246. [Not an intervention of interest]

455. Lemanske RF, Lockey RF, Murphy KR. Effects of one year of treatment with mometasone furoate metered dose inhaler (MF-MDI) on growth in children with asthma. Eur Respir J. 2004;24;Suppl 48:379s. [Not an intervention of interest]

456. Leuppi JD, Salzberg M, Meyer L, et al. An individualized, adjustable maintenance regimen of budesonide/formoterol provides effective asthma symptom control at a lower overall dose than fixed dosing. Swiss Med Wkly. 2003 May 31;133(21-22):302-9. PMID: 12861468. [Not an intervention of interest]

457. Levy ML, Stevenson C, Maslen T. Comparison of short courses of oral prednisolone and fluticasone propionate in the treatment of adults with acute exacerbations of asthma in primary care. Thorax. 1996 Nov;51(11):1087-92. PMID: 8958890. [Not in the target population]
458. Li LW, Huang Y, Luo R, et al. Efficacy of regular or intermittent inhalation of corticosteroids in treatment of asthma and its effects on growth and development in children. Zhongguo Dangdai Erke Zazhi. 2015 Mar;17(3):237-40. [Not an intervention of interest]

459. Li Y, Liu D, Yi H-L. Clinical significance of bronchial reversibility test in the treatment of childhood asthma. Chin J Contemp Pediatr. 2013;15(2):105-8. [Not an intervention of interest]

460. Li YQ, Xue HY, Chen W, et al. Application of asthma predictive indexbased group therapy in wheezing children under 5 years of age. Zhongguo Dangdai Erke Zazhi. 2014 Aug;16(8):795-9. [Not an intervention of interest]

461. Liam C, Pang Y, Chua K. Satisfaction level and asthma control among malaysian asthma patients on symbicort maintenance and reliever therapy (SMART) in the primary care setting (SMARTEST study). Asian Pac J Allergy Immunol. 2014 Jun;32(2):145-52. PMID: 25003728. [Excluded study design]

462. Lim DH, Kim JH, Son BK. New regimen of inhaled corticosteroid in preschool children with asthma. J Korean Med Assoc. 2012 Dec;55(12):1201-6. DOI:

http://dx.doi.org/10.5124/jkma.2012.55.12.1 201. [Not a human study]

463. Lin C, Hsu J, Hsiao Y, et al. Budesonide/formoterol maintenance and reliever therapy in asthma control: Acute, dose-related effects and real-life effectiveness. Respirology. 2015 Feb;20(2):264-72. PMID: 25366969. [Not an intervention of interest]

464. Lin J, Tang Y, Xiu Q. Real-life effectiveness of budesonide/formoterol therapy in asthma: A subanalysis of the SMARTASIA study. Allergy \& Asthma Proceedings. 2016;Feb;37(1):27-34. PMID: 26831844 [not an intervention of interest] 
465. Lindgren S, Eriksson NE, Lindholm N. Experience of local inhalation of beclomethasone dipropionate (becotide) in the treatment of adult steroid-dependent asthmatic patients. Scand J Respir Dis Suppl. 1977;101:163-72. PMID: 343237. [Not an intervention of interest] 466. Lindgren S, Eriksson NE, Lindholm N. Experience of local inhalation of beclomethasone dipropionate becotide in the treatment of adult steroid-dependent asthmatic patients. Scand J Respir Dis Suppl. 1977;101:163-72. [Not an intervention of interest]

467. Lipworth BJ, Short PM, Williamson PA, et al. A randomized primary care trial of steroid titration against mannitol in persistent asthma: STAMINA trial. Chest. 2012 Mar;141(3):607-15. PMID: 21998259. [Not an intervention of interest]

468. Liu CT, Wang YM, Wang G, et al. A clinical study on the significance of airway hyperresponsiveness monitoring in the adjustment of combined therapy for asthmatic patients. Chin J Tuberc Respir Dis. 2007 Jul;30(7):498-503. [Not an intervention of interest]

469. Lockey RF, Abreu P, Kimel M, et al. Health related quality of life effects of mometasone furoate dry-powder inhaler corticosteroids. Eur Respir J. 2003;22;Suppl 45:P1834. [Not an intervention of interest]

470. Lodrup Carlsen KC, Carlsen KH, Nikander K, et al. Nebulized budesonide after hospitalization for recurrent bronchial obstruction in children younger than 18 months. Pediatr Allergy Immunol. 2001 Jun;12(3):159-65. PMID: 11473681. [Not an intervention of interest]

471. Look for adrenal insufficiency caused by inhaled corticosteroids. Pharm J. 2001 Oct;267(7168):454. [Not a human study]

472. Loukides S, Papageorgiou M, Karokis A, et al. Single inhaler therapy (SiT) with budesonide/formoterol (BUD/FUM) is effective in asthma control. Eur Respir J. 2005;26;Suppl 49:A848. [Abstract without full-text]
473. Low-dose steroids and asthma mortality. Hosp Pract. 2000;35(10):25. [Not a human study]

474. Lowhagen O, Wever AM, Lusuardi M, et al. The inflammatory marker serum eosinophil cationic protein (ECP) compared with PEF as a tool to decide inhaled corticosteroid dose in asthmatic patients. Respir Med. 2002 Feb;96(2):95-101. PMID: 11862965. [Not an intervention of interest]

475. Lyutzkanova T, Klinkanova M. The effect of drugs on inhalatory provocation tests in children with bronchial asthma. Folia Med (Plovdiv). 1980;22(4):33-5. PMID: 6790377. [Not an intervention of interest] 476. Maayan C, Itzhaki T, Bar-Yishay E, et al. The functional response of infants with persistent wheezing to nebulized beclomethasone dipropionate. Pediatr Pulmonol. 1986 Jan-Feb;2(1):9-14. PMID: 3513105. [Not an intervention of interest]

477. Macias CG, Felner EI, Gan V. Inhaled corticosteroids may be superior to systemic corticosteroids in children with moderate-tosevere acute asthma. Pediatr Asthma Alelrgy Immunol. 2003;16(3):121-8. Embase 2003322769. [Not in the target population]

478. Maintenance treatment. J Invest Allergol Clin Immunol. 2010;20;Suppl 1:19-26. [Not a human study]

479. Mallol J, Aguirre V, Barrueto L, et al. Effect of inhaled fluticasone on lung function in infants with recurrent wheezing: A randomised controlled trial. Allergol Immunopathol (Madr). 2009 MarApr;37(2):57-62. PMID: 19445860. [Not an intervention of interest]

480. Malo JL, Cartier A, Laviolette M, et al. Skin bruising adrenal function and bone metabolism in asthmatic subjects on inhaled beclomethasone and fluticasone. Am J Resp Crit Care Med. 1998;157;Suppl 3:A406. [Not an intervention of interest] 
481. Malur A, Rambasek T, Isabella T, et al. Therapy for asthma with long acting betaagonist and a lower dose of an inhaled corticosteroid (ICS) does not activate proinflammatory genes when compared with higher dose ICS alone [Abstract]. American Thoracic Society 100th International Conference; 2004 May 21-26; Orlando, FL. C8p. [Not an intervention of interest]

482. Managing asthma and allergy medications during pregnancy. J Respir Dis. 2000;21(12):744-6. [Not a human study]

483. Manolitsas N, Wang J, Trigg C, et al. Long-term inhaled beclomethasone dipropionate BDP and bronchial inflammation in mild asthma. Aust NZ J Med. 1994;24:460. [Not an intervention of interest]

484. Marcus P. Dosing inhaled steroids in asthma: is once-a-day administration effective?. Chest. 2003 Oct;124(4):1196-8. PMID: 14555546. [Not a human study]

485. Maritotti F, Poli G, Acerbi D, et al. Pharmacokinetics and pharmacodynamics of beclomethasone dipropionate and formoterol combination after inhalation using dry powder inhaler. Eur Respir J. 2007;20;Suppl 51:350s. [Not an intervention of interest] 486. Mark Fitzgerald J. A randomized, controlled trial of high dose, inhaled budesonide versus oral prednisone in patients discharged from the emergency department following an acute asthma exacerbation. Can Respir J. 2000;7(1):61-7. [Not in the target population]

487. Maspero J, Cherrez I, Nolte H. Long-term safety and tolerability of two doses of mometasone furoate/formoterol (MF/F) combination, administered via a metereddose inhaler, for the treatment of moderateto-severe persistent asthma. J Allergy Clin Immunol. 2009;123;2S Suppl 1:S159. [Not an intervention of interest]
488. Maspero JF, Cherrez I, Nolte H. Mometasone furoate and formoterol (MF/F) combination administered via a metereddose inhaler (MDI) for the treatment of asthma: results from a 1-yr safety study. American Thoracic Society International Conference; 2009 May 15-20; San Diego, CA. A2768 Poster \#J37. [Not an intervention of interest]

489. McCarthy T P, Edin H M, House K, et al. Low dose salmeterol/fluticasone propionate combination (SFC) via metered dose inhaler (MDI) improves asthma control and quality of life in patients not well controlled on inhaled steroids (ICS). Eur Respir J. 2002. 20;Suppl 38:47s. [Irretrievable]

490. McCarthy T P, Edin H M, House K, et al. Salmeterol/fluticasone 50/100 (SFC) dry powder (DPI) provides improved control and quality of life in patients symptomatic on inhaled corticosteroids (ICS). Eur Respir J. 2002;20;Suppl 38:47s. [Not an intervention of interest]

491. McCarthy TP, Edin HM, House K, et al. Quality of life and asthma control assessment in patients previously on inhaled corticosteroids (ICS) treated with salmeterol/fluticasone combination (SFC) metered dose inhaler (MDI). Thorax. 2001;56;Suppl 3:iii64. [Not an intervention of interest]

492. McCarthy TP, Edin HM, House K, et al. The effects of salmeterol/fluticasone combination (SFC) dry powder inhaler (DPI) on asthma control and quality of life in patients previously treated with inhaled corticosteroids (ICS). Thorax. 2001;56;Suppl 3:iii63. [Not an intervention of interest]

493. McCarthy TP, Greening AP, Holgate SK, et al. The efficacy of salmeterol/fluticasone propionate combination (SFC) metered dose inhaler compared with beclomethasone dipropionate (BDP) in patients not well controlled at step 1 of the British guidelines on asthma management (BGAM). Thorax. 2001;56;Suppl 3:iii62. [Not an intervention of interest] 
494. McCarthy TP, Russell D, Baxter LE, et al. A comparison of the efficacy of salmeterol/fluticasone propionate combination (SF) with beclometasone dipropionate (BDP) delivered via metered dose inhaler (MDI) in patients mot well controlled on bronchodilators alone. Eur Respir J. 2001;18;Suppl 33:53s. [Not an intervention of interest]

495. McKinlay L, Williamson PA, Short PM, et al. Proof of concept study to evaluate stepdown therapy with inhaled corticosteroid alone or additive therapy on surrogate inflammatory markers in asthma. Br J Clin Pharmacol. 2011 Jan;71(1):128-31. PMID: 21143509. [Not an intervention of interest]

496. Mehta PN. Asthma and the school going child. Indian Pediatr. 2002 Aug;39(8):731-8. [Not a human study]

497. Melamed J, Beaucher W. A prospective evaluation of the adequacy of peak inspiratory flow rates and validation of the turbutester score in asthmatic individuals with "low" peak expiratory flow rates: Implications for dry powder inhalers. J Allergy Clin Immunol. 2003 Mar;111(3):648-50. [Not an intervention of interest]

498. Mellon M, Dukes E, Ollendorf D, et al. Budesonide inhalation suspension improves symptom-free days and use of asthmarelated services in infants and young children. Ann Allergy Asthma Immunol. 2000;84:161. [Not an intervention of interest]

499. Meltzer EO, Uryniak T, Trudo F, et al. Efficacy and safety of budesonide (BUD) administered by pressurized metered-dose inhaler (pMDI) in children aged 6 to $<12$ years with asthma: a phase II study. Am J Resp Crit Care Med. 2014;189:A1811. [Not an intervention of interest]

500. Mendelson L, Welch M, Murphy K, et al. Greater efficacy of budesonide inhalation suspension compared to cromolyn sodium over 52 weeks in young children with persistent asthma. Am J Respir Crit Care Med. 2000;161;Suppl 3:A36. [Irretrievable]
501. Merkus PJFM, De Jongste JC. Inhaled corticosteroids and long term outcome in adults with asthma. Thorax. 2006 Nov;61(11):1011. [Not a human study]

502. Mezzanotte WS, Miller CJ, Senn S. Comparative bronchodilatory effects of formoterol dry powder inhaler (DPI) versus the combination of formoterol and budesonide pressurized metered dose inhaler (pMDI). J Allergy Clin Immunol. 2007;119;Suppl 1:S248. [Not an intervention of interest]

503. Micheletto C, Mauroner L, Burti E, et al. Inhaled beclomethasone dipropionate and budesonide dry powder in chronic asthma: lung function-serum ECP relationship. Eur Respir J. 1998;12;Suppl 28:351S. [Not an intervention of interest]

504. Mild asthma may not require daily corticosteroid use. Pharm J. 2005 Apr;274(7345):442. [Not a human study]

505. Milenkovic B, Bosnjak-Petroic V. Selfmanagement program in treatment of asthma. Srpski Arhiv Za Celokupno Lekarstvo. 2007 Mar-Apr;135:147-52. [Not an intervention of interest]

506. Mileva S, Galeva I, Kufardzhieva A, et al. Inhaled corticosteroids in wheezing infants with clinical diagnosis asthma [Abstract]. XIX World Allergy Organization Congress; 2005:853p. [Excluded study design]

507. Milgrom H, Berger W, Noonan M, et al. Rapid onset of significant improvements in peak expiratory flow among children with asthma treated with mometasone furoate administered via a dry powder inhaler. Chest. 2008;134(4):51003s. [Not an intervention of interest]

508. Miller DS, Yiu G, Hellriegel ET, et al. Dose-ranging study of salmeterol using a novel fluticasone propionate/salmeterol multidose dry powder inhaler in patients with persistent asthma. Allergy Asthma Proc. 2016;37:291-301. PMID: 27216137. [Not an intervention of interest] 
509. Mitra A, Sims EJ, Mukhopadhyay S, et al. Low-dose inhaled corticosteroid (ICS) confers optimal anti-inflammatory effects while additional bronchodilator activity is afforded by salmeterol in mild persistent asthmatic children. J Allergy Clin Immunol. 2003;111;Suppl 2:S145. [Not an intervention of interest]

510. Mitsui S, Yoshida T, Kobayashi S, et al. Double-blind study on the clinical effect of beclomethasone dipropionate inhaler and its placebo in the treatment of steroidindependent bronchial asthma. Rinsho Hyoka. 1977;5(2):213-30. [Not an intervention of interest]

511. Miyamoto T, Takishima T, Makino S, et al. Clinical Examination of Fluticasone Propionate Dry Powder: Comparison between Beclomethasone Dipropionate Inhaler in Bronchial Asthma. Rinsho Iyaku. 1994;10(2):321-45. [Not an intervention of interest]

512. Moeller A, Franklin P, Hall GL, et al. Inhaled fluticasone dipropionate decreases levels of nitric oxide in recurrenty wheezy infants. Pediatr Pulmonol. 2004 Sep;38(3):250-5. PMID: 15274106. [Not an intervention of interest]

513. Moeller A, Franklin PJ, Straub D, et al. Inhaled fluticasone diproprionate decreases levels of nitric oxide in recurrently wheezy infants. Eur Respir J. 2003;22;Suppl 45:388s. [Not an intervention of interest] 514. Mohan G, MacLusky KA, Godley CC, et al. A comparison of a budesonide-based and a beclomethasone/prednisolone-based management strategy for the treatment of severe asthma in general practice. Dis Manage Health Out. 1999;5(2):83-91. DOI: 10.2165/00115677-199905020-00003. [Not an intervention of interest]

515. Mometasone (asmanex twisthaler) for asthma. Med Lett Drugs Ther. 2005 Dec 519;47(1223-1224):98-9. PMID: 16331243. [Not a human study]
516. Mometasone/Formoterol (dulera) for asthma. Med Lett Drugs Ther. 2010 Oct 18;52(1349):83-4. PMID: 21045758. [Not a human study]

517. Montelukast for persistent asthma. Med Lett Drugs Ther. 1998 Jul 17;40(1031):71-3. PMID: 9698701. [Not a human study]

518. More support for single maintenance and reliever therapy regimens for asthma. Drug Ther Bull. 2013;51(5):51-2. [Not a human study]

519. Morgul M, Cerrahoglu K, Ilvan A, et al. The effect of inhaled budesonide on pulmonary function (FEV1) of asthmatic patients. Eur Respir J. 1998;12;Suppl 29:73s. [Not an intervention of interest]

520. Morimoto Y, Yagura T, Yamamura Y. The effect of prolonged administration of beclomethasone dipropionate inhaler on adrenocortical functions in bronchial asthma. J Med. 1977;8(1):1-26. PMID: 194990. [Not an intervention of interest]

521. Moss MH. Long-term effect of budesonide on hypothalamic-pituitary-adrenal axis function in children with mild to moderate asthma. Pediatrics. 2005;116(2):567. [Not a human study]

522. Murphy K, Fitzpatrick S, Cruz Rivera M, et al. Greater caregiver satisfaction and compliance with budesonide inhalation suspension vs cromolyn sodium. Am J Respir Crit Care Med. 2002;165;Suppl 8:A742. [Not an intervention of interest]

523. Murphy K, Nelson H, Parasuraman B, et al. Patient satisfaction with budesonide and formoterol in one pressurized metered-dose inhaler in adults with mild to moderate persistent asthma [Abstract]. American Thoracic Society International Conference; 2007 May 18-23; San Francisco, California. 928p. [Irretrievable]

524. Murphy KR, Meltzer EO, Nolte H, et al. Quality of life is improved in persistent asthma subjects treated with mometasone furoate/formoterol: a new inhaled corticosteroid/long-acting beta2-agonist combination. Chest. 2010;138(4):159A. [Not an intervention of interest] 
525. Murphy KR, Parasuraman B, Pethick N, et al. Greater improvement in functional health status with budesonide inhalation suspension (pulmicort respules) versus conventional therapy in children with persistent asthma. Pediatr Res. 2002;51(4):177A. [Not an intervention of interest]

526. Murphy KR, Pearlman DS, Uryniak T, et al. Efficacy of budesonide/formoterol pressurized metered dose inhaler (BUD/FM pMDI) in children with asthma previously treated with inhaled corticosteroids (ICSs)

[Abstract]. American Thoracic Society International Conference; 2008 May 16-21;

Toronto, Canada. A710. [Not an intervention of interest]

527. Murphy VE, Jensen ME, Mattes J, et al. The breathing for life trial: a randomised controlled trial of fractional exhaled nitric oxide (FENO)-based management of asthma during pregnancy and its impact on perinatal outcomes and infant and childhood respiratory health. BMC Pregnancy and Childbirth. 2016;16:111. DOI: 10.1186/s12884-016-0890-3. [Not a human study]

528. Murphy VE, Powell H, Gibson P. Exacerbations following step down and step up inhaled corticosteroid therapy in the managing asthma in pregnancy (MAP) study. Am J Respir Crit Care Med. 2015;191:A4275. [Not an intervention of interest]

529. Murphy VE, Powell H, Gibson PG. Exacerbations of asthma following changes in inhaled corticosteroid (ICS) and long acting beta agonist (LABA) therapy in the managing asthma in pregnancy (MAP) study. J Paediatr Child Health. 2015;62:64. [Not an intervention of interest]

530. Murphy VK, Ververeli K. Antibody response after varicella vaccination similar in children treated with budesonide inhalation suspension (BIS) or nonsteroidal conventional asthma therapy (NSCAT). Eur Respir J. 2006;28;Suppl 50;711s. [Excluded study design]
531. Murray C, Martin L, Deas J, et al. Early intervention with inhaled fluticasone propionate (FP) in wheezy children under 2 years of age [abstract]. American Thoracic Society International Conference; 2003. 617p. [Irretrievable]

532. Murray CS, Gore C, Kerry G, Custovic A, et al. Inhaled fluticasone propionate in young wheezy children- does early use alter the course of disease? [Abstract]. American Thoracic Society International Conference; 2006 May 19-24; San Diego, California: Proceedings of the American Thoracic Society; 2006:A54p. [Irretrievable]

533. Murray CS, Woodcock A, Langley SJ, et al. Secondary prevention of asthma by the use of inhaled fluticasone propionate in wheezy INfants (IFWIN): Double-blind, randomised, controlled study. Lancet. 2006 Aug 26;368(9537):754-62. PMID:

16935686. [Not an intervention of interest]

534. Murray JJ, Busse W, Dockhorn R, et al. Long-term safety of mometasone furoate (MF) administered by dry powder inhaler (DPI) in patients with moderate persistent asthma. Eur Respir J. 2000;16;Suppl 31:280. [Irretrievable]

535. Naji N, O'Byrne PM. Asthma maintenance and reliever therapy. Ann Allergy Asthma Immunol. 2012 Dec;109(6):388-91. [Not a human study]

536. Nakanishi AK, Klasner AK, Rubin BK. A randomized controlled trial of inhaled flunisolide in the management of acute asthma in children. Chest. 2003

Sep;124(3):790-4. PMID: 12969999. [Not in the target population]

537. Nana A, Youngchaiyud P, Charoenratanakul S, et al. High-dose inhaled budesonide may substitute for oral therapy after an acute asthma attack. J Asthma. 1998;35(8):647-55. PMID: 9860085. [Not in the target population] 
538. Nathan R, Pearlman D, Nayak A, et al. Safety and tolerability of medium-dose mometasone furoate/formoterol treatment versus mometasone furoate or formoterol monotherapies in persistent asthmatics who previously used medium-dose inhaled corticosteroids (alone or with long-acting beta2-agonist). Chest. 2009;136(4):8S. [Not an intervention of interest]

539. Nayak A, Charous BL, Finn A, et al. A novel inhaled corticosteroid ciclesonide significantly improves quality of life in patients with mild-to-moderate asthma. J Allergy Clin Immunol. 2005;115;Suppl 2:S210. [Not an intervention of interest]

540. Nebulized budesonide for asthma in children. Med Lett Drugs Ther. 2001 Jan;43(1096):6-7. [Not a human study]

541. Nebulized budesonide for asthma in children. Med Lett Drugs Ther. 2001 Jan 22;43(1096):6-7. PMID: 11177221. [Not a human study]

542. Nelson H, Murphy K, Parasuraman B, et al. Budesonide and formoterol in one metered dose inhaled improves health related quality of life in adults with mild to moderate persistent asthma previously treated with inhaled corticosteroids. J Allergy Clin Immunol. 2007;119;Suppl 1:S246. [Not an intervention of interest]

543. Nelson HS, Baitinger L, Scott C, et al. Salmeterol/fluticasone propionate $(50 / 100 \mu \mathrm{g}$ dose) non-CFC metered dose inhaler is safe and effective in patients with asthma using short-acting $\beta 2$-agonists alone. Eur Respir J. 2000;16;Suppl 31:53s. [Not an intervention of interest]

544. New data from asthma and COPD inhaler studies. Pharm J. 2000 Sep;265(7113):355. [Not a human study]

545. Newman K, Corren J, Nelson H. Improves pulmonary function in patients with mild-tomoderate asthma treated with inhaled HFA Flunisolide for 12 weeks. J Allergy Clin Immunol. 2001;107(2):S104. [Not an intervention of interest]
546. NICE endorses costly inhaler devices for children if asthma better controlled. Pharm J. 2002 Apr;268(7194):524. [Not a human study]

547. Nielson K, Mather DC, Clements D, et al. Inhaled fluticasone propionate inproves asthma-related quality of life in oral steroiddependent asthmatic subjects undergoing reduction or elimination of oral steroid use. $\mathrm{J}$ Allergy Clin Immunol. 2001;107(2):S100. [Not an intervention of interest]

548. Nielson KG, Bisgard H. Effect of inhaled budesonide on symptoms, lung functions and bronchial hyperresponsiveness to cold, dry air challenge in preschool children. Eur Respir J. 2000;16;Suppl 31:306s. [Not an intervention of interest]

549. Niphadkar P, Joshi J, Mahesh PA, et al. Randomized double blind comparison of ciclesonide formoterol combination inhale rand ciclesonide alone in persistent asthma [Abstract]. European Respiratory Society Annual Congress; 2008 Oct 4-8; Berlin, Germany. E4278. [Not an intervention of interest]

550. Niu CK, Huang SC, Huang CB. Effect of short-course budesonide on the bone turnover of asthmatic children. Pediatr Pulmonol. 1998 Oct;26(4):290-2. PMID: 9811081. [Not an intervention of interest]

551. Noble V, Ruggins NR, Everard ML, et al. Inhaled budesonide for chronic wheezing under 18 months of age. Arch Dis Child. 1992 Mar;67(3):285-8. PMID: 1575550. [Not an intervention of interest] 552. Noonan M, Berger W, Thomas R, et al. Inhaled fluticasone propionate dry powder administered via the diskus or diskhaler is safe and effective in pediatric patients with chronic asthma. Eur Respir J. 1997;10;Suppl 25:221s. [Not an intervention of interest] 
553. Noonan M, Corren J, Leflein J. Safety of mometasone furoate dry powder inhaler and comparison with beclomethasone dipropionate in children with asthma previously maintained on inhaled corticosteroids (ICS). Chest. 2004;126;Suppl 4:912S. [Not an intervention of interest]

554. Noonan MJ, Rosenwasser LJ, Martin P, et al. Effect of budesonide and formoterol administered via one pressurized metered dose inhaler on lung function in adults and adolescents with moderate to severe persistent asthma. J Allergy Clin Immunol. 2007;119;Suppl 1:S2. [Not an intervention of interest]

555. Novotna B, Teturova J, Kolman P, et al. A multi-centre, double-blind, double-dummy, randomised, parallel group study to assess efficacy and safety of beclometasone dipropionate and ease of handling of a breath operated aerosol inhaler in adults with reversible airways obstruction. Eur Respir J. 2001;18;Suppl 33:101s. [Not an intervention of interest]

556. Nuhoglu Y, Bahceciler NN, Barlan IB, et al. The effectiveness of high-dose inhaled budesonide therapy in the treatment of acute asthma exacerbations in children. Ann Allergy Asthma Immunol. 2001 Mar;86(3):318-22. PMID: 11289332. [Not an intervention of interest]

557. O' Byrne P, Pedersen S, Lamm C-J, et al. Severe exacerbations, decline in lung function and inhaled budesonide in asthma. Eur Respir J. 2007;30;Suppl 51:619s. [Not an intervention of interest]

558. O' Connor RD, Patrick DL, Parasuraman MB, et al. Patient satisfaction during treatment with adjustable dose budesonide/formoterol pressurized metered dose inhaler (BUD/FM pMDI) fixed dose BUD/FM pMDI and fixed dose fluticasone/salmeterol dry powder inhaler (FP/SM DPI) [Abstract]. American Thoracic Society International Conference; 2008 May 16-21; Toronto, Canada. A609. [Not an intervention of interest]
559. O' Connor TM, Kelley MM, Leigh R, et al. Additional anti-inflammatory effects of inhaled budesonide in subjects with atopic asthma. Eur Respir J. 2006;28;Suppl 20:441s. [Not an intervention of interest] 560. O' Dowd L, Berger WE, Leflein JG, et al. Health related quality of life (HRQL) and asthma control after long term treatment with budesonide and formoterol administered via one pressurized meter dose inhaler (pMDI) compared with budesonide dry powder inhaler (DPI) alone in children with asthma. J Allergy Clin Immunol. 2008;21;2 Suppl 1:S152. [Not an intervention of interest]

561. Obodo O, Ige O, Chukwu C. Scientific rationale for using a single inhaler for asthma control by comparison of the effectiveness and safety of formoterol/budesonide turbuhaler as physician-guided adjustable maintenance dosing regimen versus formoterol/budesonide given as fixed dose of twice daily therapy in the management of bronchial asthma [Abstract]. European Respiratory Society Annual congress; 2009 Sep 12-16; Vienna, Austria. 1968. [Not an intervention of interest]

562. O'Brien CD, Peters SP, Prenner BM, et al. Long-term safety of budesonide/formoterol pressurized metered-dose inhaler (BUD/FM pMDI) in asthma patients: adverse events and asthma exacerbations [Abstract]. American Thoracic Society International Conference; 2007 May 18-23; San Francisco, California. L57p. [Irretrievable] 563. O'Brien CD, Peters SP, Prenner BM, et al. Resource use with budesonide/formoterol pressurized metered-dose inhaler (BUD/FM pMDI) versus BUD pMDI in asthma patients [Abstract]. American Thoracic Society International Conference; 2007 May 18-23; San Francisco, California. L58p. [Irretrievable] 
564. O'Byrne P, Barnes P, Rodriguez-Roisin R, et al. Low dose inhaled budesonide with and without formoterol in steroid free patients with mild persistent asthma [abstract]. Am J Respir Crit Care Med. 2001;163;Suppl 5:A862. [Irretrievable]

565. O'Byrne PM, Godard P, Pistolesi M, et al. Single inhaler therapy with budesonide/formoterol improves asthma control compared with fixed dosing with budesonide/formoterol or a higher dose of budesonide alone [Abstract]. American Thoracic Society International Conference; 2004 May 21-26; Orlando, FL. J93p. [Irretrievable]

566. O'Callaghan C, Milner AD. Inhaled steroids and recurrent wheeze after bronchiolitis. Lancet. 1989 Jun 24;1(8652):1458. PMID: 2567473. [Not a human study]

567. O'Connor TM, Kelly MM, Leigh R, et al. Anti-inflammatory effects of inhaled budesonide combined with formoterol after allergen challenge in subjects with atopic asthma [Abstract]. American Thoracic Society International Conference; 2006 May 19-24; San Diego, California. A75. [Not an intervention of interest]

568. Oliver AJ, Covar RA, Goldfrad CH, et al. Randomised trial of once-daily vilanterol in children with asthma on inhaled corticosteroid therapy. Respir Res. 2016;17(1):37. PMID: 27044326. [Not an intervention of interest]

569. Oliver AJ, Covar RA, Goldfrad CH, et al. Randomised trial of once-daily vilanterol in children with asthma on inhaled corticosteroid therapy. Respir Res. 2016;17(1):37. DOI: 10.1186/s12931-0160353-4. [Not an intervention of interest] 570. Olsson P, Stallberg B, Ekstrom T, et al. Adjustable maintenance treatment of asthma with budesonide and formoterol in a single inhaler [abstract]. European Respiratory Society Annual Congress; 2002. P2451. [Not an intervention of interest]
571. Olsson, Karlsson G, Ekstrom T, et al. Adjustable dosing with budesonide/formeterol in a single inhaler reduces costs compared with a conventional fixed dosing regimen. Eur Respir J. 2003;22;Suppl 45:P2643. [Not an intervention of interest]

572. Orr LC, Fowler SJ, Lipworth BJ. Relationship between changes in quality of life and measures of lung function and bronchial hyper-responsiveness during highdose inhaled corticosteroid treatment in uncontrolled asthma. Am J Respir Med. 2003;2(5):433-8. PMID: 14719994. [Excluded study design]

573. Ortega-Cisneros M, Maldonado-Alaniz ML, RosasVargas MA, et al. Salmeterol and inhaled beclomethasone versus high dose inhaled beclomethasone in the control of pediatric patients with moderate asthma. Ann Allergy Asthma Immunol. 1998;80:131. [Not an intervention of interest]

574. Osur S, Chervinsky P, Herie N, et al. Long term effects of fluticasone propionate (FP) inhalation aerosol in subjects with asthma. Am J Respir Crit Care Med. 1998;157;Suppl 3:A405. [Not an intervention of interest]

575. Paggiaro P, Nicolini G, Papi A. Extrafine beclomethasone dipropionate/formoterol hydrofluoroalkane-propelled inhaler in asthma. Expert Rev Resp Med. 2008;2(2):161-6. DOI: 10.1586/17476348.2.2.161. [Not a human study]

576. Palmer KP, Green TD, Williams LW. Effects of inhaled fluticasone propionate in children less than 2 years old with recurrent wheezing. Pediatrics. 2005;116(2):565-6. [Not a human study]

577. Palumbo R, Groth ML. The CAMP asthma study. Clin Pulm Med. 2001;8(3):192-3. [Not a human study] 
578. Pao CS, McKenzie SA. Randomized controlled trial of fluticasone in preschool children with intermittent wheeze. Am J Respir Crit Care Med. 2002 Oct 1;166(7):945-9. PMID: 12359651. [Not an intervention of interest]

579. Papi A, Marku B, Scichilone N, et al. Regular versus as-needed budesonide and formoterol combination treatment for moderate asthma: A non-inferiority, randomised, double-blind clinical trial. Lancet Respir Med. 2015 Feb;3(2):109-19. PMID: 25481378. [Not an intervention of interest]

580. Papi A, Nicolini G, Boner AL, et al. Short term efficacy of nebulized beclomethasone in mild-to-moderate wheezing episodes in pre-school children. Ital J Pediatr. 2011;37:39. PMID: 21859484. [Not an intervention of interest]

581. Parakh U, Gupta K, Sharma S, et al. A comparative evaluation of the efficacy of inhaled beclomethasone dipropionate, budesonide and fluticasone propionate in the management of bronchial asthma. Indian J Allergy Asthma Immunol. 2004;18(1):33-8. [Not an intervention of interest]

582. Parasuraman B, Murphy KR, Pethick N, et al. Budesonide inhalation suspension improves the functional health status of pediatric asthmatic patients. Eur Respir J. 2001;18;Suppl 33:121s. [Not an intervention of interest]

583. Parasuraman B, Pethick N, Juniper E, et al. Budesonide inhalation suspension improves quality of life in families of childrem with asthma. J Allergy Clin Immunol. 2001;107(2):S102. [Not an intervention of interest]

584. Park J, Lee J, Whang K, et al. The effect of salbutamol and budesonide inhalation therapy in infants with bronchiolitis. J Korean Pediatr Soc. 1997140(1):45-54. [Not in the target population]
585. Patel M, Pilcher J, Beasley R. Combination ICS/fast-onset LABA inhaler as maintenance and reliever therapy: The future for uncontrolled adult asthma?. Expert Rev Respir Med. 2013 Oct;7(5):4514. PMID: 24138688. [Not a human study]

586. Patel M, Pilcher J, Reddel HK, et al. Metrics of salbutamol use as predictors of future adverse outcomes in asthma. Clin Exp Allergy. 2013 Oct;43(10):1144-51. PMID: 24074332. [Not an intervention of interest]

587. Patel YA, Patel P, Bavadia H, et al. A randomized, open labeled, comparative study to assess the efficacy and safety of controller medications as add on to inhaled corticosteroid and long-acting beta2 agonist in the treatment of moderate-to-severe persistent asthma. J Postgrad Med. 2010 Oct-Dec;56(4):270-4. PMID: 20935397. [Not an intervention of interest]

588. Pauli G, Aubert B. A comparison of inhaled fluticasone propionate with nedocromil in the treatment of moderate adult asthma. A French Study Group. European Journal of Clinical Researach. 1995;7:45-56. [No English language abstract]

589. Pearlman D, Kerwin E, Kim K, et al. Fluticasone prorionate HFA-134 A significantly improves asthma control in inhaled corticosteroid dependent asthmatics. Am J Respir Crit Care Med. 2002;165;Suppl 8:A770. [Not an intervention of interest] 590. Pearlman DS, Murphy KR, Uryniak T, et al. Safety of budesonide/formoterol pressurized metered dose inhaler (BUD/FM pMDI) in children with asthma previously treated with inhaled corticosteroids (ICSs) [Abstract]. American Thoracic Society International Conference; 2008 May 16-21; Toronto, Canada. A710. [Not an intervention of interest] 
591. Pearlman DS, Uryniak T, O'Brien CD, et al. Predose forced expiratory flow between $25 \%$ and $75 \%$ (FEF25-75\%) in inhaled corticosteroid (ICS)-dependent patients with mild to moderate or moderate to severe persistent asthma receiving budesonide/formoterol pressurized metereddose inhaler (BUD/FM pMDI). J Allergy Clin Immunol. 2009;123;2 Suppl 1:S158. [Not an intervention of interest]

592. Pedersen S. Budesonide plus formoterol for reliever therapy in asthma. Lancet. 2006 Aug;368(9537):707-8. [Not a human study]

593. Pelkonen AS, Hakulinen AL, Hallman M, et al. Effect of inhaled budesonide therapy on lung function in schoolchildren born preterm. Respir Med. 2001 Jul;95(7):56570. PMID: 11453312. [Not in the target population]

594. Pelkonen AS, Malmstrom K, Malmberg LP, et al. Budesonide improves decreased airway conductance in infants with respiratory symptoms. Arch Dis Child. 2009 Jul;94(7):536-41. PMID: 19254906. [Not an intervention of interest]

595. Pepys J. Effects of inhaled beclomethasone dipropionate on bronchial provocation test reactions. Postgrad Med J. 1975;51; Suppl 4:42-8. PMID: 812074. [Not a human study]

596. Perera BJ. Efficacy and cost effectiveness of inhaled steroids in asthma in a developing country. Arch Dis Child. 1995 discussion 315-6; Apr;72(4):312-5. PMID: 7763062.

[Not an intervention of interest]

597. Perlman DS, Kent E, Lanz MJ, et al. Fluticasone propionate/salmeterol HFA MDI has a rapid onset of effect in asthmatics treated with short or long-acting beta2agonists (BA) or inhaled corticosteroids (ICS). Annual Thoracic Society 97th International Conference; 2001 May 18-23; San Francisco CA. A865. [Not an intervention of interest]

598. Pescollderungg L, Radetti G, Gottardi E, et al. Inhaled fluticasone in asthmatic children. Ann Allergy Asthma Immunol. 2002 author reply 329; Sep;89(3):328-9. PMID: 12269658. [Not an intervention of interest]
599. Peters SP, Prenner BM, Martin P, et al. Bronchodilation with budesonide/formoterol pressurized metered-dose inhaler (BUD/FM pMDI) vs BUD pMDI in asthma patients [Abstract]. American Thoracic Society International Conference; 2007 May 18-23; San Francisco, California. K6p. [Irretrievable]

600. Peters SP, Prenner BM, Martin P, et al. Long-term effects on lung function of budesonide (BUD) and formoterol (FM) in one pressurized metered-dose inhaler (BUD/FM pMDI) and BUD pMDI in patients with asthma [Abstract]. American Thoracic Society International Conference; 2007 May 18-23; San Francisco, California. K5p. [Irretrievable]

601. Peters SP, Bleecker ER, Canonica GW, et al. Serious Asthma Events with Budesonide plus Formoterol vs. Budesonide Alone. New England Journal of Medicine. 2016;Sept;375(9):850-60. PMID: 27579635 [not an intervention of interest]

602. Petitto J, Jones SM. Adherence to inhaled corticosteroids: An ancillary study of the childhood asthma management program clinical trial. Pediatrics. 2012;130;Suppl 1:S37-8. DOI 10.1542/peds.2012-2183JJJ. [Not a human study]

603. Pharmacotherapy - treatment of intermittent asthma with ICSs. Can Med Assoc J. 2005;173;Suppl 6:S33-6. [Not a human study]

604. Pieters W, Ringdal N, Aubier M, et al. A new inhaler combination containing salmeterol and fluticasone propionate is well-tolerated in longterm use. Eur Respir J. 1998;12;Suppl 29:20s. [Not an intervention of interest]

605. Pizzichini MM, Stirbulov R, Fristcher CC, et al. Efficacy and safety of a combination of budesonide/formoterol in a single capsule in uncontrolled asthma. Am J Respir Crit Care Med. 185:A3970. [Not an intervention of interest] 
606. Pohl WR, Vetter N, Zwick H, et al. Adjustable maintenance dosing with budesonide/formoterol or budesonide: Double-blind study. Respir Med. 2006 Mar;100(3):551-60. PMID: 16005623. [Not an intervention of interest]

607. Ponce $\mathrm{CH}$, Rodrigquez ES, Rodriguez OAR. Administration of budesonide (inhaled steroid) to children to control intermittent asthma. Rev Alerg Mex. 2009;56(1):9-12. [Not in the target population]

608. Poulton A, Liu A, Nanan R. Budesonide in preschool-age children with recurrent wheezing. N Engl J Med. 2012 Feb;366(6):570. [Not a human study]

609. Prasad R, Bandhu M, Kant S, et al. A comparative study on efficacy of inhaled fluticasone propionate and beclomethasone dipropionate in patients of bronchial asthma. Indian J Allergy Asthma Immunol. 2004;18(2):73-7. [Not an intervention of interest]

610. Prenner B, Berkowitz R, Bensch GW, et al. Onset of improvements of lung function with mometasone furoate dry powder inhaler (MF-DPI) in ICS-naive patients with asthma. J Allergy Clin Immunol. 2005;115;Suppl 2:S5. [Not an intervention of interest]

611. Prenner BM, Peters SP, Martin P, et al. Long-term control of asthma symptoms with budesonide/formoterol pressurized metereddose inhaler (BUD/FM pMDI) versus BUD pMDI [Abstract]. American Thoracic Society International Conference; 2007 May 18-23; San Francisco, California. L67p. [Irretrievable]

612. Price D, Haughney J, Duerden M. The effect of switching to beclomethasone extrafine aerosol on symptom-free days. Eur Respir J. 2001;18;Suppl 33:69s. [Not an intervention of interest]
613. Price MJ, Mahajan P, Maden C, et al. Impact of inhaled fluticasone propionate on parental sleep disturbance and perception of asthma symptoms in pre-school children. $\mathrm{J}$ Allergy Clin Immunol. 1998;101(1(Pt 2)):S151. [Not an intervention of interest]

614. Priftis KN, Papadimitriou A, Nicolaidou P, et al. Testing for hypothalamic-pituitaryadrenal axis suppression in asthmatic children. Pediatr Allergy Immunol. 2008;19(5):466-7. [Not a human study]

615. Pro-drug improves lung function. Pharm J. 2003 Oct;271(7270):487. [Not a human study]

616. Prosperini G, Spicuzza L, Piccillo G, et al. Rapid protective of effect of inhaled fluticasone on airway hyperresponsiveness to AMP in patients with fixed airway obstruction due to asthma but not COPD. Eur Respir J. 2006;28;Suppl 50:670s. [Not an intervention of interest]

617. Purello-D'Ambrosio F, Gangemi S, Merendino RA, et al. Fluticasone propionate reduces serum interleukin-8 levels in asthmatic patients. Respiration. 2000;67(3):348. PMID: 10867611. [Not an intervention of interest]

618. Pyke SD, Frith L, Pritchard J, et al. Synergy with salmeterol and fluticasone proprionate after administration from a single inhaler (Seretide). Eur Respir J. 2001;18;Suppl 33:176s. [Not a human study]

619. Raissy HH, Blake K. As needed use of inhaled corticosteroids for management of mild persistent asthma in children. Pediatr Allergy Immunol Pulmonol. 2011 Dec;24(4):231-3. [Not a human study]

620. Rakes G, Gaston B. Inhaled budesonide in acute asthma? J Pediatr. 2001 Sep;139(3):346-8. PMID: 11562611. [Not a human study]

621. Ramirez I, Lumeng CN. Daily and intermittent corticosteroids have similar impact on recurrent wheezing in young children. J Pediatr. 2012;160(5):881. [Not a human study] 
622. Randolph C. Poor adherence with inhaled corticosteroids for asthma: Can using a single inhaler containing budesonide and formoterol help? J Asthma. 2008;45(4):349. [Not a human study]

623. Reddel HK, Jenkins C, Quirce S, et al. Effect of different asthma treatments on risk of cold-related exacerbations. Eur Respir J. 2011 Sep;38(3):584-93. PMID: 21406510.

[No outcomes of interest]

624. Reddel HK, Peyters MJ, Wark PA, et al. Comparison of the efficacy of Seretide and Flixotide when down-titrating the inhaled corticosteroid dose. Respirology. 2007;12;Suppl 1:A40. [Not an intervention of interest]

625. Reddel HK, Ware SI, Marks GB, et al. Effect of starting dose of inhaled budesonide on airway hyperresponsiveness in poorly controlled asthma. European Respiratory Society; 1999 Oct 9-13; Madrid, Spain. 105p. [Irretrievable]

626. Reddel HK, Ware SI, Marks GB, et al. Long-term back-titration of inhaled corticosteroids - the effect of starting dose. European Respiratory Society; 1999 Oct 913; Madrid, Spain. 106p. [Irretrievable]

627. Reddel HK, Yan KY. Single maintenance and reliever therapy (SMART) of asthma. Thorax. 2011 Jan;66(1):86-7. PMID: 21097538. [Not a human study]

628. Reddel HK. Increasing the dose of inhaled corticosteroid when asthma deteriorates-does it prevent severe exacerbations?.Pol Arch Med Wewn. 2010 Mar;120(3):64-7. PMID: 20332710. [Not a human study]

629. Reijonen T, Korppi M, Kuikka L, et al. Anti-inflammatory therapy reduces wheezing after bronchiolitis. Arch Pediatr Adolesc Med. 1996 May;150(5):512-7. PMID: 8620234. [Not an intervention of interest]
630. Reijonen TM, Korppi M. One-year followup of young children hospitalized for wheezing: The influence of early antiinflammatory therapy and risk factors for subsequent wheezing and asthma. Pediatr Pulmonol. 1998 Aug;26(2):113-9. PMID: 9727762. [Not an intervention of interest]

631. Reijonen TM, Kotaniemi-Syrjanen A, Korhonen K, et al. Predictors of asthma three years after hospital admission for wheezing in infancy. Pediatrics. 2000 Dec;106(6):1406-12. PMID: 11099596. [Not an intervention of interest]

632. Riccioni G, D'Orazio N, Castronuovo M, et al. Dosage tapering of inhalatory budesonide in subjects with mild to moderate persistent asthma treated with montelukast. Eur Respir J. 2003;22;Suppl 45:P713. [Not an intervention of interest]

633. Rice-McDonald G, Bowler S, Staines G, et al. Doubling daily inhaled corticosteroid dose is ineffective in mild to moderately severe attacks of asthma in adults. Intern Med J. 2005 Dec;35(12):693-8. PMID: 16313543. [No outcomes of interest]

634. Riedler J, Huttegger I. Long-term effect of inhaled corticosteroid and cromoglycate on the bronchial responsiveness in children with asthma. Eur Respir J. 1992;5;Suppl 15:309s. [Not an intervention of interest]

635. Robinson WS, Blaiss MS. Randomized trial to evaluate efficacy and safety of combination budesonide and formoterol and new FDA mandate regarding LABAs. Hosp Pract (Minneap). 2010 Jun;38(3):79-81. PMID: 20499777. [Not a human study]

636. Robinson WS, Blaiss MS. Randomized trial to evaluate efficacy and safety of combination budesonide and formoterol and new FDA mandate regarding LABAs. Hosp Pract (Minneap). 2010;38(3):79-81. [Not a human study]

637. Roche N, Postma DS, Colice G, et al. Differential effects of inhaled corticosteroids in smokers/ex-smokers and nonsmokers with asthma. Am J Respir Crit Care Med. 2015 Apr 15;191(8):960-4. PMID: 25876207. [Not an intervention of interest] 
638. Rodriguez Santos O, Celio Murillo R. Quality of life in asthmatic children in Cuba and Mexico that use inhaled steroids. Acta Pediatr Esp. 2010;68(3):124-7. [Not an intervention of interest]

639. Rogala B, Majak P, Gluck J, et al. Asthma control in adult patients treated with a combination of inhaled corticosteroids and long-acting beta2agonists: a prospective observational study. Polish Archives Of Internal Medicine. 2017;127(2):100-106. PMID: 28220767 [not an intervention of interest]

640. Rogers AJ, Tantisira KG, Fuhlbrigge AL, et al. Phenotypic predictors of poor response to inhaled corticosteroids in asthmatic children over four years [Abstract]. American Thoracic Society International Conference; 2007 May 18-23; San Francisco, California. 617p. [Irretrievable]

641. Roorda RJ, Mezei G, Bisgaard H, et al. Response of preschool children with asthma symptoms to fluticasone propionate. J Allergy Clin Immunol. 2001 Oct;108(4):540-6. PMID: 11590379. [Not an intervention of interest]

642. Rosenhall L, Heinig JH, Lindqvist A, et al. Budesonide and formoterol in a single inhaler is safe and effective in the treatment of asthma. Eur Respir J. 2001;18;Suppl 33:159s. [Not an intervention of interest]

643. Rosenhall L, Heinig JH, Lindqvist A, et al. Symbicort (budesonide/formoterol in a single inhaler) is safe and effective in the treatment of asthma. Thorax. 2011;56;Suppl 3:iii63. [Not an intervention of interest]

644. Rosenhall L, Lundqvist G, Adelroth E, et al. Comparison between inhaled and oral corticosteroids in patients with chronic asthma. Eur J Respir Dis Suppl. 1982;122;Suppl 122:154-62. PMID: 6958480. [Not an intervention of interest]
645. Rosenhall L, Stahl E, Heinig JH, et al. Health-related quality of life and asthma control in patients using symbicort(R) (budesonide and formoterol in a single inhaler). Annual Thoracic Society 97th International Conference; 2001; San Francisco CA. D31p. [Not an intervention of interest]

646. Rosenhall L, Stahl E, Heinig JH, et al. Health-related quality of life and asthma control in patients treated with budesonide and formoterol in a single inhaler. Eur Respir J. 2001;18;Suppl 33:46s. [Not an intervention of interest]

647. Rosenwasser LJ, Noonan MJ, Martin P, et al. Safety of budesonide and formoterol administered via one pressurized metered dose inhaler (budesonide/formoterol pMDI) in patients ( $>12$ years) with moderate to severe persistent asthma. J Allergy Clin Immunol. 2007;119;Suppl 1:S5. [Not an intervention of interest]

648. Rowe BH, Bota GW, Fabris L, et al. Inhaled budesonide in addition to oral corticosteroids to prevent asthma relapse following discharge from the emergency department: A randomized controlled trial. JAMA. 1999 Jun 9;281(22):2119-26. PMID: 10367823. [Not in the target population]

649. Rowe BH, Wong E, Blitz S, et al. Adding long-acting beta-agonists to inhaled corticosteroids after discharge from the emergency department for acute asthma: A randomized controlled trial. Acad Emerg Med. 2007 Oct;14(10):833-40. PMID: 17898245. [Not in the target population] 650. Rutkowski R, Rutkowski K, Bilbin M, et al. Childhood asthma - effect of regular and on demand formoterol with budesonide treatment twice a day. Int Rev Allergol Clin Immunol. 2009;15(3-4):52-8. [Not an intervention of interest]

651. Rytila P, Lisa G, Varghese S, et al. Inhaled mometasone benefits adult patients with asthma like symptoms but not fulfilling functional asthma criteria. Eur Respir J. 2007;30;Suppl 51:351s. [Not in the target population] 
652. Sacks H, Gates D, Kuo WL, et al. Assessment of the defined daily dose for mometasone furoate dry powder inhaler in persistent asthma. Eur Respir J. 2003;22;Suppl 45:P335. [Not an intervention of interest]

653. Sahu GN, Mania RN, Panigrahi MK, et al. Comparison of inhaled salmeterol and budesonide with salmeterol and fluticasone propionate in patients with moderate to severe asthma. Indian J Allergy Asthma Immunol. 2004;18(2):100-1. [Not an intervention of interest]

654. Saito M, Kikuchi Y, Hoshina M. Inhaled high dose budesonide is as effective as systemic corticosteroids for children under three with mild asthma exacerbations. J Allergy Clin Immunol. 2016;137;2 Suppl 1:AB212. Embase 72197446. [Not in the target population]

655. Saito T, Hasunuma T. Safety and tolerability of high-dose budesonide/formoterol via turbuhaler in japanese patients with asthma: A randomized, double-blind, crossover, active comparator-controlled, phase III study. Clin Drug Invest. 2012 Jan 1;32(1):51-61. PMID: 22024920. [Not an intervention of interest]

656. Saito T, Hasunuma T. Safety and tolerability of high-dose budesonide/formoterol via turbuhaler in Japanese patients with asthma: phase III study results. Am J Respir Crit Care Med. 2011;183;1MeetingAbstracts. [Not an intervention of interest]

657. Salvi S. Effect of inhaled formoterol and budesonide on exacerbations of asthma. $\mathrm{N}$ Engl J Med. 1998 Apr 9;338(15):1072. PMID: 9537880. [Not a human study] 658. Sawicki GS, Strunk RC, Schuemann B, et al. Patterns of inhaled corticosteroid use and asthma control in the childhood asthma management program continuation study. Ann Allergy Asthma Immunol. 2010 Jan;104(1):30-5. PMID: 20143642. [Not an intervention of interest]
659. Schokker S, Kooi EMW, de Vries TW, et al. Inhaled corticosteroids for recurrent respiratory symptoms in preschool children in general practice: Randomized controlled trial. Pulm Pharmacol Ther. 2008;21(1):8897. PMID: 17350868. [Not an intervention of interest]

660. Sears MR, Taylor DR, Print CG, et al. Increased inhaled bronchodilator vs increased inhaled corticosteroid in the control of moderate asthma. Chest. 1992 Dec;102(6):1709-15. PMID: 1446477. [Not an intervention of interest]

661. See S, Rubin S. Tapering inhaled steroids effective for chronic asthma. J Fam Pract. 2003 Oct;52(10):748-51. PMID: 14529591. [Not a human study]

662. Sehmi R, Wood LJ, Gauvreau GM, et al. Allergen-induced phenotypic changes in bone marrow progenitors from asthmatic subjects: effect of inhaled budesonide. Am J Respir Crit Care Med. 1998;157;Suppl 3:A871. [Not an intervention of interest] 663. Sekerel BE, Sackesen C, Tuncer A, et al. The effect of nebulized budesonide treatment in children with mild to moderate exacerbations of asthma. Acta Paediatr. 2005 Oct;94(10):1372-7. PMID: 16299866. [Not in the target population]

664. Selroos O, Löfroos A-, Pietinalho A, et al. Asthma control and steroid doses 5 years after early or delayed introduction of inhaled corticosteroids in asthma: a real-life study. Respir Med. 2004;98(3):254-62. [Not an intervention of interest]

665. Shah A, Solanki R, Shah K. Effect of add on therapy compared with doubling steroid inhalation in bronchial asthma. Thorax;59;Suppl II:ii70. [Not an intervention of interest]

666. Shah S. Asthma \& COPD - SMi's sixth annual conference. IDrugs. 2010;13(6):37678. [Irretrievable] 
667. Shah SR, Busse WW, McElhattan J, et al. Efficacy and tolerability of fixed-dose (FD) and adjustable-dose (AD) budesonide/formoterol pressurized metereddose inhaler (BUD/FM pMDI) and FD fluticasone propionate/salmeterol dry powder inhaler (FP/SAL DPI) within racial groups. J Allergy Clin Immunol. 2009;123;2 Suppl 1:S80. [Not an intervention of interest]

668. Shah SR, Busse WW, Somerville L, et al. Asthma control with adjustable-and fixeddose budesonide/formoterol pressurized metered-dose inhaler (BUD/FM pMDI) and fixed-dose fluticasone/salmeterol dry powder inhaler (FP/SM DPI) [Abstract]. American Thoracic Society International Conference; 2007 May 18-23; San Francisco, California. K4p. [Irretrievable]

669. Shamsul AI, Hadzri HM, Noradina AT, et al. Step-down approach in chronic stable asthma; a comparison of reducing dose inhaled formoterol/budesonide with maintaining inhaled budesonide. Respirology. 2007;12;Suppl 4:A141. [Not an intervention of interest]

670. Shimoda T, Obase Y, Kishikawa R, et al. Impact of inhaled corticosteroid treatment on 15-year longitudinal respiratory function changes in adult patients with bronchial asthma. Int Arch Allergy Immunol. 2013;162(4):323-9. PMID: 24193229. [Not an intervention of interest]

671. Shiraishi S, Hirata K, Ohtani K, et al. Inhaled corticosteroid improved the perception of dyspnea during methacholine induced bronchoconstriction and changed the hypoxic ventilatory response in patients with asthma. Eur Respir J. 2002;20;Suppl 38:49s. [Not an intervention of interest]

672. Shokker S, Kooi EM, Duiverman EJ, et al. Effectiveness of inhaled corticosteroids in preschool children with recurrent respiratory symptoms in general practice: Asterisk study. Prim Care Respir J. 2006;15(3):186. [Not an intervention of interest]
673. Simon RA. Clinical implications of combination therapy on the future of asthma management. Allergy Asthma Proc. 2003;24(2):91-3. [Irretrievable]

674. Skoner D, Dunn M, Lee T. Effects of mometasone furoate dry powder inhaler on growth velocity and HPA axis function in children with asthma [abstract]. American Thoracic Society International Conference; 2003. A117p. [Irretrievable]

675. Smart BA. Daily or intermittent budesonide in preschool children with recurrent wheezing. Pediatrics. 2012;130;Suppl 1:S39-40. [Not a human study]

676. Smith AD, Cowan J, Taylor R. Optimising inhaled corticosteroid (ICS) dose using exhaled nitric oxide (eNO) measurements. Eur Respir J. 2003;22;Suppl 45:P342. [Not an intervention of interest]

677. Smith AD, Cowan JO, Brassett KP, et al. Use of exhaled nitric oxide measurements to guide treatment in chronic asthma. $\mathrm{N}$ Engl $\mathrm{J}$ Med. 2005 May 26;352(21):2163-73. PMID: 15914548. [Not an intervention of interest]

678. Sole D. Inhaled steroids for young children with recurrent wheezing: Friend or foe? Allergol Immunopathol (Madr). 2009 MarApr;37(2):55-6. PMID: 19445859. [Not a human study]

679. Somerville L, Busse WW, Shah SR, et al. Safety of adjustable-dose budesonide (BUD)/formoterol (FM) pressurized metered-dose inhaler (pMDI), fixed-dose (BUD/FM pMDI and fixed-dose fluticasone (FP)/salmeterol (SM) dry powder inhaler (DPI) in asthma patients [Abstract]. American Thoracic Society International Conference; 2007 May 18-23; San Francisco, California. K3p. [Irretrievable]

680. Sovijarvi ARA, Haahtela T, Ekroos HJ, et al. Sustained reduction of bronchial hyperresponsiveness with inhaled fluticasone propionate in mild asthma within three days [Abstract]. European Respiratory Soociety Annual Congress; 2002. P1244. [Not an intervention of interest] 
681. Special circumstances. J Invest Allergol Clin Immunol. 2010;20;Suppl 1:43-9. [Not a human study]

682. Spector S, Backer V, Pavord I, et al. Dosedependent anti-inflammatory effect of inhaled mometasone furoate/formoterol in subjects with asthma and high baseline exhaled nitric oxide and sputum eosinophils. J Allergy Clin Immunol. 2011;127;2 Suppl 1:AB161. [Not an intervention of interest]

683. Spector SL, O' Brien CD, Uryniak T, et al. Safety and tolerability of a budesonide/formoterol (BUD/FM) pressurized metered-dose inhaler (pMDI) in black adolescents and adults with moderate to severe persistent asthma. Chest. 2010;138(4):705A. [Not an intervention of interest]

684. Spencer DA, Gleeson JG, Price JF. Inhaled budesonide for acute wheeze in infants. Lancet. 1989 Mar 25;1(8639):665. PMID: 2564474. [Not a human study]

685. Spicuzza L, Scuderi V, Prosperini G, et al. Acute effect of inhaled fluticasone on airway hyperresponsiveness to adenosine 5'monophosphate in asthma and in COPD [Abstract]. American Thoracic Society International Conference; 2004 May 21-26; Orlando, FL. K33p. [Irretrievable]

686. Spicuzza L, Scuderi V, Prosperini G, et al. Rapid protective effect of inhaled fluticasone on airway hyperresponsiveness to AMP in asthma but not in COPD. J Allergy Clin Immunol. 2004l113;Suppl 2:S266. [Not an intervention of interest] 687. Stahl E, Baker J, Pearlman D, et al. QVARA(R)-BAI (HFA-propelled beclomethasone dipropionate in a breath actuated inhaler) reduced the number of asthma exacerbations in moderate asthmatic adolescents and adults [Abstract]. American Thoracic Society International Conference; 2007 May 18-23; San Francisco, California. F78p. [Irretrievable]
688. Stallberg B, Naya I, Ekelund J, et al. Reallife use of budesonide/formoterol in clinical practice: a 12-month follow-up assessment in a multi-national study of asthma patients established on single-inhaler maintenance and reliever therapy. Int J Clin Pharmacol Ther. 2015 Jun;53(6):447-55. PMID: 25907171. [Not an intervention of interest] 689. Stallberg B, Olsson P, Ekstrom T, et al. Fewer asthma patients experience exacerbations with budesonide/formoterol in a single inhaler using adjustable versus fixed dosing. Eur Respir J. 2003;22;Suppl 45:P2798. [Not an intervention of interest]

690. Stallberg B, Olsson P, Jorgensen LA, et al. Budesonide/formoterol adjustable maintenance dosing reduces asthma exacerbations versus fixed dosing. Int J Clin Pract. 2003 Oct;57(8):656-61. PMID: 14627173. [Not an intervention of interest]

691. Stanbrook MB. Is daily inhaled steroid use necessary in the treatment of mild persistent asthma? Can Med Assoc J. 2005 May;172(11):1439. [Not a human study]

692. Stempel DA. Montelukast added to inhaled beclomethasone in treatment of asthma. Am J Respir Crit Care Med. 2000 Jul;162(1):331-2. PMID: 10903264. [Not a human study]

693. Sterk PJ. Is there a need for higher doses of steroids in moderate asthma? Clin Exp Allergy Suppl Rev. 2001;1(1):39-44. [Not a human study]

694. Steroids show benifits in mild asthma. Pharm J. 2003 Mar;270(7242):429. [Not a human study]

695. Stockmann C, Reilly CA, Fassl B, et al. Effect of CYP3A5*3 on asthma control among children treated with inhaled beclomethasone. J Allergy Clin Immunol. 2015 Aug;136(2):505-7. PMID: 25825214. [Not an intervention of interest]

696. Storms W, Glaet V, Banerji D, et al. RPR 106541 - an effective inhaled corticosteroid asthma therapy with minimal side-effects on the HPA axis. Eur Respir J. 1997;10;Suppl 25:175S. [Not an intervention of interest] 
697. Sudarshan S. Monotherapy vs. combination therapy for the management of mild asthma. Am Fam Phys. 2012;85(6):652. [Not a human study]

698. Suissa S, Ernst P. Comparison of inhaled beclomethasone and budesonide. studies of potencies of asthma drugs have methodological limitations. BMJ. 1999 Jul 10;319(7202):126. PMID: 10465595. [Not a human study]

699. Sullivan SD, Buxton M, Andersson LF, et al. Budesonide increased symptom free days in patients with recent onset mild asthma at an additional cost of US\$0.42/day. Evid Based Med. 2004 May;9(3):90. [Not a human study]

700. Svedmyr J, Nyberg E, Asbrink-Nilsson E, et al. Intermittent treatment with inhaled steroids for deterioration of asthma due to upper respiratory tract infections. Acta Paediatr. 1995 Aug;84(8):884-8. PMID: 7488811. [Not in the target population]

701. Syk J, Malinovschi A, Borres M, et al. Reduction of IgE by intensified antiinflammatory treatment in patients with atopic asthma. Allergy. 2014;69;Suppl 99:61. [Not an intervention of interest]

702. Syk J, Malinovschi A, Johansson G, et al. Anti-inflammatory treatment of atopic asthma guided by exhaled nitric oxide: A randomized, controlled trial. J Allergy Clin Immunol Pract. 2013 Nov-

Dec;1(6):639,48.e1-8. PMID: 24565712. [Not an intervention of interest]

703. Syk J, Malinovschi A, Johansson G, et al. Lower incidence of asthma exacerbations with FENO-guided anti-inflammatory treatment: a randomised controlled trial. Eur Respir J. 2012;40:4341. [Not an intervention of interest]

704. Syk J, Unden A, Alving K. Relationship between exhaled nitric oxide and IgE sensitisation in patients with asthma: Influence of steroid treatment. Clin Respir J. 2009 Jul;3(3):143-51. PMID: 20298397. [Excluded study design]
705. Szefler SJ, Baker JW, Uryniak T, et al. Comparative study of budesonide inhalation suspension and montelukast in young children with mild persistent asthma. J Allergy Clin Immunol. 2007 Nov;120(5):1043-50. PMID: 17983871. [Not an intervention of interest]

706. Szefler SJ, Carlsson L, Uryniak T, et al. Budesonide inhalation suspension versus montelukast in children aged 2 to 4 years with mild persistent asthma. J Allergy Clin Immunol Pract. 2013 Jan;1(1):58-64. PMID: 24229823. [Not an intervention of interest] 707. Szefler SJ, Mitchell H, Sorkness CA, et al. Management of asthma based on exhaled nitric oxide in addition to guideline-based treatment for inner-city adolescents and young adults: A randomised controlled trial. Lancet. 2008 Sep 20;372(9643):1065-72. PMID: 18805335. [Not an intervention of interest]

708. Tabachnik E, Zadik Z. Diurnal cortisol secretion during therapy with inhaled beclomethasone dipropionate in children with asthma. J Pediatr. 1991 Feb;118(2):294-7. PMID: 1993964. [Excluded study design]

709. Tagaya E, Tamaoki J, Isono K, et al. Role of regular treatment with inhaled corticosteroid or leukotriene receptor antagonist in mild intermittent (step 1) asthma [Abstract]. American Thoracic Society International conference; 2008 May 16-21; Toronto. A70. [Not in the target population]

710. Takahashi K, Kotoh N, Soda R, et al. Usefulness of inhaled steroids in steroiddependent intractable asthma--equivalent dose of oral steroid to inhaled steroid. Arerugi. 1994;43(9):1163-71. [Not an intervention of interest]

711. Tal A, Simon G, Vermeulen JH, et al. Symbicort (budesonide and formoterol in a single inhaler) is more effective that budesonide alone in children with asthma. International Paediatric Respiratory and Allergy Congress; 2001. 84-5p. [Not an intervention of interest] 
712. Tal A, Simon G, Vermeulen JH, et al. The benefit of the new single inhaler product containing both budesonide and formeterol in asthmatic children. Eur Respir J. 2000;16;Suppl 31:384s. [Not an intervention of interest]

713. Tal A, Simon G, Vermeulen JH. Symbicort (budesonide and formoterol in a single inhaler) is effective and well tolerated in children with asthma. Annual Thoracic Society 97th International Conference; 2001 May 18-23; San Francisco CA. D29p. [Not an intervention of interest]

714. Tashkin D, Chipps B, Brown R, et al. Responder analysis evaluating the long-term treatment of budesonide/formoterol pressurized metered-dose inhaler (BUD/FM pmdi) in patients with moderate to severe asthma with versus without fixed airflow obstruction (FAO). Chest. 2013;144;4 Meeting Abstracts:79A. [Not an intervention of interest]

715. Tashkin DP, Chipps BE, Uryniak T, et al. Responder analysis evaluating the effect of budesonide/formoterol pressurized metereddose inhaler (BUD/FM pMDI) in patients with moderate to severe asthma with versus without fixed airflow obstruction (FAO). J Allergy Clin Immunol. 2013;131(2):AB5. Embase 70984076. [Not an intervention of interest]

716. Telenga ED, Kerstjens HAM, ten Hacken NHT, et al. Inflammation and corticosteroid responsiveness in ex-, current- and neversmoking asthmatics. BMC Pulm Med. 2013 Sep;13(1):58. [Not an intervention of interest]

717. Teper A, Murphy KR, Meltzer EO, et al. Reduction of relief medication use in children receiving inhaled mometasone fuorate for control of mild persistent asthma. J Allergy Clin Immunol. 2010;125;2 Suppl 1:AB195. [Not an intervention of interest]
718. Tereshchenko S, Bychkovskaya S, Nicolay S. "Stepping down" in mild-to-moderate asthmatic children being well controlled while receiving low doses of inhaled corticosteroids (ICS): daily vs. cyclical ICS administration (prospective, randomized, multicentre, open-label trial). Eur Respir J. 2013;42:P4300. [Abstract without full-text]

719. Terracciano L, Fiocchi A, Bouygue GR. Beclomethasone and albuterol in mild asthma. N Engl J Med. 2007 Aug 2;357(5):506-7. PMID: 17674456. [Not a human study]

720. The use of newer asthma and allergy medications during pregnancy. the American College of Obstetricians and Gynecologists (ACOG) and the American College of Allergy, Asthma and Immunology (ACAAI). Ann Allergy Asthma Immunol. 2000 May;84(5):475-80. PMID: 10830999. [Not a human study]

721. Thomas M, Pavord I. Single inhaler maintenance and reliever therapy (SMART) in general practice asthma management: where are we?. Prim Care Respir J. 2012 Mar;21(1):8-10. PMID: 22367253. [Not a human study]

722. Thomas M, Prince D. High-dose inhaled corticosteroid versus long-acting betaagonist addition in asthma. Chest. 2009 May;135(5):1404-5. PMID: 19420216. [Not a human study]

723. Thomas M. Long-acting $\beta$-agonist step-up therapy is more likely to provide best response, compared to inhaled corticosteroid or leukotriene-receptor antagonist step-up in children with uncontrolled asthma receiving inhaled corticosteroids. Evid -Based Med. 2010;15(6):167-8. [Not a human study]

724. Tivenius L, Kiviloog J, Glennow C. Effect of budesonide inhalation on airway obstruction at bronchial allergen provocation after varying lengths of pre-treatment. Allergy. 1984 Nov;39(8):639-40. PMID: 6528960. [Excluded study design] 
725. Tobin MJ. Asthma, airway biology, and allergic rhinitis in AJRCCM 2000. Am J Respir Crit Care Med. 2001 Nov;164(9):1559-80. [Not a human study]

726. Tobin MJ. Asthma, airway biology, and nasal disorders in AJRCCM 2002. Am J Respir Crit Care Med. 2003 Feb;167(3):31932. [Not a human study]

727. Tobin MJ. Asthma, airway biology, and nasal disorders in AJRCCM 2001. Am J Respir Crit Care Med. 2002 Mar;165(5):598-618. [Not a human study]

728. Tobin MJ. Pediatrics, surfactant, and cystic fibrosis in AJRCCM 2003. Am J Respir Crit Care Med. 2004 Jan;169(2):277-87. [Not a human study]

729. Tobin MJ. Pediatrics, surfactant, and cystic fibrosis in AJRCCM 2002. Am J Respir Crit Care Med. 20032003 Feb;167(3):333-44.

[Not a human study]

730. Todd GR. Side-effects of high-dose fluticasone propionate in children. Eur Respir J. 1999 Mar;13(3):707-9. PMID: 10232453. [Not a human study]

731. Tofts RPH. Steroids do not improve RSVrelated wheeze in children. Thorax. 2009;64(9):769. [Not a human study]

732. Toth PP. Montelukast and fluticasone therapy in patients with mild persistent asthma. J Appl Res. 2005;5(3):ii. [Not a human study]

733. Trautmann M, Banik N, Jorres RA, et al. Acheivment of total control of asthma in clinical practice using the combination of inhaled salmeterol and fluticasone propionate. Eur Respir J. 2006;28;Suppl 50:616s. [Not an intervention of interest] 734. Trautmann M, Banik N, Tews JT, et al. Efficacy of the combination of fluticasone propionate and salmeterol in patients with moderate persistent asthma within a "reallife" setting. Eur J Med Res. 2007 Jun 27;12(6):255-63. PMID: 17666315. [Not an intervention of interest]

735. Treatment of asthma in children. J Invest Allergol Clin Immunol. 2010;20; Suppl 1:326. [Not a human study]
736. Treatment of persistent asthma: Novopulmon ${ }^{\circledR} 200$ novolizer ${ }^{\circledR}$, conceived to improve compliance with treatment. Eur Ann Allergy Clinical Immunol. 2005 Apr;37(4):152. [Not a human study]

737. Triamcinolone acetonide hydrofluoroalkane inhalation--aventis. Drugs R D. 2002;3(2):141-2. PMID: 12001820. [Not a human study]

738. Turcotte H, Boulet LP, Prince FP, et al. Influence of inhaled fluticasone in asthma and asymptomatic airway hyperresponsiveness [Abstract]. American Thoracic Society International Conference; 2007 May 18-23; San Francisco, California. F77p. [Irretrievable]

739. Turkas H, Levent E, Ouzulgen IK, et al. Effects of inhaler budesonide and nedocromil sodium on exhaled nitric oxide levels in mild asthmatic patients. Eur Respir J. 1998;12;Suppl 29:63s. [Not an intervention of interest]

740. Turpeinen M, Pelkonen AS, Nikander K, et al. Bone mineral density in children treated with daily or periodical inhaled budesonide: The helsinki early intervention childhood asthma study. Pediatr Res. 2010 Aug;68(2):169-73. PMID: 20485203. [Not an intervention of interest]

741. Turpeinen M, Pelkonen AS, Selroos O, et al. Continuous versus intermittent inhaled corticosteroid (budesonide) for mild persistent asthma in children--not too much, not too little. Thorax. 2012 Feb;67(2):100-2. PMID: 22038795. [Not a human study]

742. Turpeinen M, Raitio H, Pelkonen AS, et al. Skin thickness in children treated with daily or periodical inhaled budesonide for mild persistent asthma. the helsinki early intervention childhood asthma study. Pediatr Res. 2010 Feb;67(2):221-5. PMID: 19858777. [Not an intervention of interest]

743. Turpeinen M, Sorva R, Metso T, et al. Inhaled budesonide in adults with asthma net formation of type I collagen is not decreased. Eur Respir J. 1994; 7; Suppl 18:382s. [Not an intervention of interest] 
744. Turpeinen M, Sorva R. Inhaled beclomethasone dipropionate and growth in children with mild asthma. Am J Respir Crit Care Med. 1996 May;153(5):1726. PMID: 8630627. [Not a human study]

745. Turpeinen M. Helsinki early intervention childhood asthma (HEICA) astudy: inhaled budesonide halved the number of asthma exacerbatoins compared with inhaled disodium cromoglycate during 18 months of treatment. Eur Respir J. 2000;16;Suppl 31:311s. [Irretrievable]

746. Turton JA, Glasgow NJ, Brannan JD. Feasibility and acceptability of using bronchial hyperresponsiveness to manage asthma in primary care: A pilot study. Prim care respir j. 2012 Mar;21(1):28-34. PMID: 21938353. [Excluded study design]

747. Udwadia ZF, Pinto LM. LABAs and asthma: From the SMART study to the SMART approach. Indian J Chest Dis Allied Sci. 2010 Oct-Dec;52(4):191-3. PMID: 21302593. [Not a human study]

748. Utiger RD. Differences between inhaled and oral glucocorticoid therapy. N Engl J Med. 1993 Dec 2;329(23):1731-3. PMID: 8232464. [Not a human study]

749. Vaessen-Verberne A, Van den Berg N, Brackel H, et al. Salmeterol/fluticasone propionate combination (SFC) versus doubling dose of fluticasone propionate (FP) in children with asthma insufficiently controlled on moderate doses of inhaled corticosteroids [Abstract]. European Respiratory Society Annual Congress; 2010 Sep 18-22; Barcelona, Spain. P2644. [Not an intervention of interest]

750. van den Berge M, Luijk B, Bareille P, et al. Fluticasone furoate, a novel inhaled corticosteroid (ICS) provides sustained protection against amp airway hyperresponsiveness (AHR) in mild asthma [Abstract]. European Respiratory Society Annual Congress; 2009 Sep 12-16; Vienna, Austria. 1804. [Not an intervention of interest]
751. van der Meer V, van Stel HF, Bakker MJ, et al. Weekly self-monitoring and treatment adjustment benefit patients with partly controlled and uncontrolled asthma: An analysis of the SMASHING study. Respir Res. 2010;11:74. PMID: 20537124. [Not an intervention of interest]

752. van der Molen T, Foster JM, Mueller T. The effect of ciclesonide or fluticasone propionate on the perception of treatmentrelated side effects using the self-administered inhaled corticosteroid questionnaire (ICQ) [Abstract]. American Thoracic Society International Conference; 2007 May 18-23; San Francisco, California. L60p. [Irretrievable]

753. van Essen-Zandvliet EEM, Hughes MD, Waalkens HJ, et al. The effect of 30 months treatment with an inhaled corticosteroid and an inhaled beta2-agonist on airway

responsiveness, airway calibre, bronchodilator response, symtoms and stage of remission in children with asthma. Eur Respir J. 1992;5;Suppl 15:180s. [Not an intervention of interest]

754. van Schayck OCP, Haughney J, Aubier M, et al. Do asthmatic smokers benefit as much as non-smokers on budesonide/formoterol maintenance and reliever therapy? results of an open label study. Respir Med. 2012 Feb;106(2):189-96. PMID: 22119455. [Not an intervention of interest]

755. Van Schoor J, Joos GF, Pauwels RA. The effects of inhaled fluticasone propionate on metacholine- and Neurokinin A-induced bronchoconstriction in asthmatics. European Respiratory Society; 1999 Oct 9-13; Madrid, Spain. 513s. [Irretrievable]

756. Vandenberg R, Tovey E, Love I, et al. Beclomethasone dipropionate. trial of a new inhalational steroid preparation in the treatment of steroid-dependent chronic asthmatics. Med J Aust. 1975 Feb 15;1(7):189-93. PMID: 1128399. [Excluded study design] 
757. Vandenberg R, Tovey E, Love I, et al. Beclomethasone dipropionate. trial of a new inhalational steroid preparation in the treatment of steroid-dependent chronic asthmatics. Med J Aust. 1975;1(7):189-93. [Excluded study design]

758. Vander Leek TK. GOAL: What have we learned? Allergy Asthma Clin Immunol. 2005;1(3):117-9. [Not a human study]

759. Varon J. Oral vs inhaled corticosteroids following emergency department discharge of patients with acute asthma. Chest. 2002;121(6):1735-6. [Not a human study]

760. Vaz R, Senior B, Morris M, et al. Adrenal effects of beclomethasone inhalation therapy in asthmatic children. J Pediatr. 1982 Apr;100(4):660-2. PMID: 7062222. [Excluded study design]

761. Ventura A, Strinati R, Longo G. Systemic effects and inhaled beclomethasone dipropionate. Lancet. 1986 Jun 14;1(8494):1393. PMID: 2872512. [Not a human study]

762. Vermeulen JH, Simon G, Tal A, et al. Improved lung function and rapid control achieved with the new single inhaler product containing both budesonide and formeterol in asthmatic children aged 4-17 years. Eur Respir J. 2000;16;Suppl 31:384s. [Not an intervention of interest]

763. Vidaurreta SM. Wheezing in infants: Can we separate the wheat from the chaff? Arch Argent Pediatr. 2013;111(3):188-9. [Not a human study]

764. Virchow JC. Salmeterol powder provides significantly better benefit than montelukast in asthmatic patients receiving concomitant inhaled corticosteroid therapy. Chest. 2002 Jun;121(6):2083-4. PMID: 12065391. [Not a human study]

765. Visser MJ, Brand PLP, Kamps AWA, et al. One year treatment with different schedules of inhaled fluticasone propionate in childhood asthma: effects on lung function and immunological parameters. Annual Thoracic Society 97th International Conference; 2001; San Francisco CA. D29p A846. [Not an intervention of interest]
766. Visser MJ, Postma DS, Arends LR, et al. One-year treatment with different dosing schedules of fluticasone propionate in childhood asthma. effects on hyperresponsiveness, lung function, and height. Am J Respir Crit Care Med. 2001 Dec 1;164(11):2073-7. PMID: 11739137. [Not an intervention of interest]

767. Visser MJ, Postma DS, Brand PLP, et al. Influence of different dosage schedules of inhaled fluticasone propionate on peripheral blood cytokine concentrations in childhood asthma. Clin Exp Allergy. 2002 Oct;32(10):1497-503. PMID: 12372131.

[Not an intervention of interest]

768. Visser MJ, van der Veer E, Postma DS, et al. Side-effects of fluticasone in asthmatic children: no effects after dose reduction. Eur Respir J. 2004 Sep;24(3):420-5. [Not an intervention of interest]

769. Volovitz B, Bentur L, Finkelstein Y, et al. Effectiveness and safety of inhaled corticosteroids in controlling acute asthma attacks in children who were treated in the emergency department: A controlled comparative study with oral prednisolone. J Allergy Clin Immunol. 1998 Oct;102(4 Pt 1):605-9. PMID: 9802368. [Not in the target population]

770. Volovitz B, Bilavsky E, Nussinovitch M. Effectiveness of high repeated doses of inhaled budesonide or fluticasone in controlling acute asthma exacerbations in young children. J Asthma. 2008

Sep;45(7):561-7. PMID: 18773327. [Excluded study design]

771. Volovitz B, Nussinovitch M, Finkelstein Y, et al. Effectiveness of inhaled corticosteroids in controlling acute asthma exacerbations in children at home. Clin Pediatr (Phila). 2001 Feb;40(2):79-86. PMID: 11261454. [Excluded study design] 
772. Volovitz B, Nussinovitch M. Effect of high starting dose of budesonide inhalation suspension on serum cortisol concentration in young children with recurrent wheezing episodes. J Asthma. 2003 Sep;40(6):625-9. PMID: 14579993. [Not an intervention of interest]

773. Volovitz B, Nussinovitch M. Inhaled beta2agonists and corticosteroids and the treatment of children with acute asthma attack. Isr Med Assoc J. 2002 Nov;4;SUPPL 11:891-2. [Irretrievable]

774. Volovitz B, Soferman R, Blau H, et al. Rapid induction of clinical response with a short-term high-dose starting schedule of budesonide nebulizing suspension in young children with recurrent wheezing episodes. J Allergy Clin Immunol. 1998 Apr;101(4 Pt 1):464-9. PMID: 9564798. [Not an intervention of interest]

775. Von Mutius E, Drazen JM. Choosing asthma step-up care. N Engl J Med. 2010 Mar;362(11):1042-3. [Not a human study]

776. Voorend-van Bergen S, Vaessen-Verberne AA, Brackel HJ, et al. Monitoring strategies in children with asthma: A randomised controlled trial. Thorax. 2015 Jun;70(6):54350. PMID: 25825006. [Not an intervention of interest]

777. Vortkamp M, Ederle K, Hader S. Hydrofluoroalkane beclomethasone dipropionate extrafine aerosol efficacy response at reduced dose compared to other inhaled corticosteroids treatment regimens. Eur Respir J. 2001;18;Suppl 33:70s. [Not an intervention of interest]

778. Wales JK, Barnes ND, Swift PG. Growth retardation in children on steroids for asthma. Lancet. 1991 Dec 14;338(8781):1535. PMID: 1683962. [Excluded study design]

779. Wang CZ, Wang Y, Lin KX, et al. Comparison of inhaled corticosteroid combined with theophylline and double dose inhaled corticosteroid in moderate-severe persistent asthma. Eur Respir J. 2004;24;Suppl 48:127s. [Not an intervention of interest]
780. Wang JH, Trigg CJ, Manolitsas N, et al. Long-term inhaled beclomethasone dipropionate (BDP) and bronchial inflammation in mild asthma. Eur Respir J. 1993;6;Suppl 17:601s. [Not an intervention of interest]

781. Wanich NH, Kaplan. Management of asthma based on exhaled nitric oxide in addition to guideline-based treatment for inner-city adolescents and young adults: a randomised controlled trial. Pediatrics. 2009;124;Suppl 2:S147. DOI: 10.1542/peds.2009-18700OO. [Not a human study]

782. Wanner A, Kumar SD, Brieva JL, et al. Adrenergic-glucocorticoid interactions in the regulation of airway blood flow. Arch Physiol Biochem. 2003;111(4):319-21. [Excluded study design]

783. Ward C, Pais M, Reid DW, et al. The effect of 12 months treatment with inhaled fluticasone (FP) on diffuse sub-epitherlial collagen I and III in symptomatic steroid naïve asthmatics. Eur Respir J. 2000;16;Suppl 31:341s. [Excluded study design]

784. Ward C, Pais M, Reid DW. The effect of 12 months treatment with inhaled fluticasone propionate (FP) on diffuse subepitherlial collagen I and III in symptomatic steroid naïve asthmatics. Eur Respir J. 2000;16;Suppl 31:341s. [Not in the target population]

785. Webb J. High-dose beclomethasone inhaler in the treatment of asthma. Lancet. $1983 \mathrm{Apr}$ 16;1(8329):872. PMID: 6132194. [Not a human study]

786. Webb MS, Milner AD, Hiller EJ, et al. Nebulised beclomethasone dipropionate suspension. Arch Dis Child. 1986 Nov;61(11):1108-10. PMID: 3539031. [Not an intervention of interest]

787. Weersink EJM, Meijer RJ, Kerstjens HAM, et al. Inhaled fluticasone. Thorax. 2000;55(7):628-9. [Not a human study] 
788. Weinberger M, Sherman B. Inhaled steroid aerosols and alternate-day prednisone. Lancet. 1979 Apr 21;1(8121):871-2. PMID: 86111. [Not a human study]

789. Weinberger M. Inhaled corticosteroids for infants. J Pediatr. 2006 Feb;148(2):284-5. PMID: 16492448. [Not a human study]

790. Weinberger M. Inhaled steroid aerosols and alternate-day prednisone. Lancet. 1979 Jul 7;2(8132):48-9. PMID: 87931. [Not a human study]

791. Weinstein S, Murphy K, White M, et al. Treatment of severe asthma with a new mometasone furoate and formoterol (MF/F) combination administered with a pressurized metered-dose inhaler device. Am J Respir Crit Care Med. 2010;181; Meeting Abstracts:A5411. [Not an intervention of interest]

792. Weinstein SF, Berger WE, Noonan M, et al. Prevention of asthma worsening with inhaled mometasone furoate therapy in children. J Allergy Clin Immunol. 2009;123;2 Suppl 1:S66. [Not an intervention of interest]

793. Wennergren G, Nordvall SL, Hedlin G, et al. Nebulized budesonide for the treatment of moderate to severe asthma in infants and toddlers. Acta Paediatr. 1996 Feb;85(2):1839. PMID: 8640047. [Not an intervention of interest]

794. Wenzel SE. Efficacy versus effectiveness: Leukotriene receptor antagonists or inhaled corticosteroids. Eur Respir Rev. 2001;11(79):38-40. [Not a human study] 795. Westbroek J, Pasma HR, James MH, et al. Inhaled fluticasone propionate and oral zafirlukast in moderate asthma: a clinical and cost comparison. Am J Respir Crit Care Med. 1998;157;3 Suppl:A416. [Not an intervention of interest]
796. White M, Scott C, Herrle MR, et al. Salmeterol/fluticasone propionate $42 / 88 \mathrm{mcg}$ hfa-mdi improves asthma control in asthmatics previously treated with short- or long-acting beta2-agonists or inhaled corticosteroids.Ann Allergy Asthma Immunol. 2001;86:81. [Not an intervention of interest]

797. Wignarajah D, Zheng L, Reid D, et al. Fluticasone priopionate decreases airway vascularity in asthma. Respirology. 2004;9;Suppl 2:A24. [Not an intervention of interest]

798. Wilcox JB, Avery GS. Beclomethasone dipropionate corticosteroid inhaler: A preliminary report of its pharmacological properties and therapeutic efficacy in asthma. Drugs. 1973;6(2):84-93. PMID: 4753325. [Not a human study]

799. Wildhaber JH, Möller A, Hall GL, et al. Levels of exhaled nitric oxide in recurrently wheezy infants are decreased following inhaled steroid therapy. Schweiz Med Wochenschr. 2000 Apr;130(15):529-34. [Not an intervention of interest]

800. Wilken-Jensen K. The effect of inhalations of beclomethasone dipropionate on plasma cortisol levels and growth hormone production. Postgrad Med J. 1975;51(Suppl 4):31-2. PMID: 1105515. [Excluded study design]

801. Wilken-Jensen K. The effect of inhalations of beclomethasone dipropionate on plasma cortisol levels and growth hormone production. Postgrad Med J. 1975;51(Suppl 4):31-2. PMID: 1105515. [Not an intervention of interest]

802. Williams C. Potency of inhaled corticosteroid fails to predict reduced emergency department visits. Arch Intern Med. 2003 Jan 27;163(2):247-8. PMID: 12546628. [Not a human study]

803. Williams DM. What does potency actually mean for inhaled corticosteroids? J Asthma. 2005;42(6):409-17. [Not a human study] 
804. Wilson AM, Duong M, Pratt B, et al. An assessment of the anti-inflammatory properties of low dose inhaled ciclesonide in asthmatic patients [Abstract]. American Thoracic Society International Conference; 2005 May 20-25; San Diego, CA. C33 Poster: F64. [Not an intervention of interest] 805. Wilson E, McKeever T, Hargadon B, et al. Exhaled nitric oxide and inhaled corticosteroid dose reduction in asthma: A cohort study. Eur Respir J. 2014 Dec;44(6):1705-7. PMID: 25142486. [Not an intervention of interest]

806. Wilson JW, Robertson CF. Inhaled steroids - too much of a good thing?. Med J Aust. 2002 Sep 16;177(6):288-9. PMID: 12225273. [Not a human study]

807. Wilson N, Sloper K, Silverman M. Effect of continuous treatment with topical corticosteroid on episodic viral wheeze in preschool children. Arch Dis Child. 1995 Apr;72(4):317-20. PMID: 7763063. [Not an intervention of interest]

808. Wilson NM, Silverman M. Treatment of acute, episodic asthma in preschool children using intermittent high dose inhaled steroids at home. Arch Dis Child. 1990 Apr;65(4):407-10. PMID: 2189367. [No outcomes of interest]

809. Wisniewski J, Nowak-Wegrzyn A. Comparative study of budesonide inhalation suspension and montelukast in young children with mild persistent asthma. Pediatrics. 2008;122;Suppl 4:S219-20. [Not a human study]

810. Wohl ME, Majzoub JA. Asthma, steroids, and growth. N Engl J Med. 2000 Oct 12;343(15):1113-4. PMID: 11027747. [Not a human study]

811. Wolthers OD, Allen DB. Inhaled corticosteroids, growth, and compliance. $\mathrm{N}$ Engl J Med. 2002 Oct 10;347(15):1210-1. PMID: 12374890. [Not a human study]

812. Wolthers OD, Juul Riis B, Pedersen S. Bone turnover in asthmatic children treated with inhaled budesonide. Eur Respir J. 1992;5;Suppl 15:311s. [Not an intervention of interest]
813. Wolthers OD, Pedersen S. Linear growth in asthmatic school children treated with inhaled budesonide. Eur Respir J. 1992;5;Suppl 15:311s. [Not an intervention of interest]

814. Wolthers OD, Pedersen S. Short term linear growth in children with asthma during treatment with inhaled flutiscasone propionate and beclomethasone dipropionate. Eur Respir J. 1992;5;Suppl 15:181s. [Not an intervention of interest]

815. Wolthers OD. It is still an open question whether inhaled glucocorticoid-induced effects may reduce adult height. Evid Based Med. 2013 Oct;18(5):195-6. PMID: 23335270. [Not a human study]

816. Wolthers OD. Short term growth and hypopituity-adrenal axis function in asthmatic children treated with inhaled beclomethasone dipropionate. Eur Respir J. 2005;26;Suppl 49:A1059. [Not an intervention of interest]

817. Wood LJ, Gauvreau GM, Watson RM, et al. Effect of inhaled budesonide on allergeninduced bone marrow eosinophil progenitors in asthmatic subjects. Am J Respir Crit Care Med. 1998;157;Suppl 3:A871. [Not an intervention of interest]

818. Wu AC, Li L, Miroshnik I, et al. Outcomes after periodic use of inhaled corticosteroids in children. J Asthma. 2009 Jun;46(5):51722. PMID: 19544175. [Not an intervention of interest]

819. Yan XQ, Dai YR, Ong HX, et al. Observation of the efficacy of budesonide dry-powder inhalant in treatment of bronchial asthma. Chinese Journal of New Drugs. 2002;11(7):557-9. [Not an intervention of interest]

820. Yanagida N, Tomikawa M, Shukuya A, et al. Budesonide inhalation suspension versus methylprednisolone for treatment of moderate bronchial asthma attacks. World Allergy Organ J. 2015 2015;8(1). [Not in the target population] 
821. Yoshihara S, Kanno N, Fukuda H, et al. Caregiver treatment satisfaction is improved together with children's asthma control: Prospective study for budesonide monotherapy in school-aged children with uncontrolled asthma symptoms. Allergol intern. 2015 Oct;64(4):371-6. PMID: 26433534. [Excluded study design]

822. Youkou A, Hasegawa T, Suzuki K, et al. Influence of obesity on control in asthmatic japanese patients defined by the japanese definition of obesity. Intern Med. 2011;50(18):1911-6. PMID: 21921368. [Excluded study design]

823. Yousef E, Hossain J, Mannan S, et al. Early intervention with high-dose inhaled corticosteroids for control of acute asthma exacerbations at home and improved outcomes: A randomized controlled trial. Allergy Asthma Proc. 2012 NovDec;33(6):508-13. PMID: 23394509. [Not an intervention of interest]

824. Yu H, Lin H, Zhang X. Budesonide with terbutaline inhalation treatment of asthma care and nursing effect analysis. Chest. 2016;149;4 Suppl 1:A11. [Not an intervention of interest]

825. Yuksel B, Greenough A. Preterm infants with recurrent symptoms at follow up and prophlaxis with inhaled beclomethasone. Eur Resp J. 1992;5;Suppl 15:181s. [Not an intervention of interest]

826. Zeiger RS, Mauger D, Bacharier LB. The authors reply. N Engl J Med. 2012 Feb;366(6):571. [Not a human study] 827. Zetterstrom O, Buhl R, Mellem H, et al. Efficacy and safety of a new single inhaler product containing both budesonide and formoterol in adult asthma. Eur Respir J. 2000;16;Suppl 31:455s. [Not an intervention of interest]

828. Zetterstrom O, Buhl R, Mellem H, et al. The new single inhaler product containing both budesonide/formoterol improves asthma control in adults. Eur Respir J. 2000;16;Suppl 31:455s. [Not an intervention of interest]
829. Zetterstrom O, Buhl R, Mellem H. Efficacy and safety of symbicort(R) budesonide and formoterol in a single inhaler in adults with asthma. Annual Thoracic Society 97th International Conference; 2001 May 18-23; San Francisco, CA. A863. [Not an intervention of interest]

830. Zhang J, Yu C, Holgate ST, et al. Variability and lack of predictive ability of asthma end-points in clinical trials. Eur Respir J. 2002 Nov;20(5):1102-9. PMID: 12449161. [Not an intervention of interest]

831. Zhang L, Prietsch SOM. Effect of inhaled corticosteroids on linear growth in children with persistent asthma. Paediatr Respir Rev. 2014 2014/12;15(4):322-4. [Not a human study]

832. Zhong N, Lin J, Mehta P, et al. Real-life effectiveness of budesonide/formoterol maintenance and reliever therapy in asthma patients across asia: SMARTASIA study. BMC Pulm Med. 2013;13:22. PMID: 23557023. [Excluded study design]

833. Zhou X, Hong J, Cheng $\mathrm{H}$, et al.

Budesonide suspension nebulization treatment in chinese pediatric patients with cough variant asthma: A multi-center observational study. J Asthma. 2016 May;53(5):532-7. [Not in the target population]

834. Zielen S, Christmann M, Kloska M, et al. Predicting short term response to antiinflammatory therapy in young children with asthma. Curr Med Res Opin. 2010 Feb;26(2):483-92. PMID: 20001651. [Not an intervention of interest]

835. Zielen S, Rose MA, Bez C, et al. Effectiveness of budesonide nebulising suspension compared to disodium cromoglycate in early childhood asthma. Curr Med Res Opin. 2006 Feb;22(2):367-73. PMID: 16466609. [Not an intervention of interest] 
836. Zimmerman B, Tsui F. Can the measurement of serum ECP be used to monitor treatment of childhood asthma with inhaled steroid?. Allergy. 1993 discussion 143-5;48(17 Suppl):129-32. PMID: 8109704. [Excluded study design]

837. Zomer-Kooijker K, van der Ent CK, Ermers MJJ, et al. Lack of long-term effects of high-dose inhaled beclomethasone for respiratory syncytial virus bronchiolitis: A randomized placebo-controlled trial. Pediatr Infect Dis J. 2014 Jan;33(1):19-23. PMID: 24346594. [Not an intervention of interest]

\section{LAMA Search}

1.Afonso A, Schmiedl S, Becker C, et al. A methodological comparison of two European primary care databases and replication in a US claims database: inhaled long-acting beta-2-agonists and the risk of acute myocardial infarction. Eur J Clin Pharmacol. 2016 Sep;72(9):1105-16. PMID: 27216032. [Not an intervention of interest]

2.Afonso ASM, Schmiedl S, Becker C, et al. Association between inhaled long-acting beta-2-agonists and the risk of acute myocardial infarction: a methodological comparison of two databases.

Pharmacoepidemiol Drug Saf. 2014 Oct;23:390-1. DOI: 10.1002/pds.3701. [Not an intervention of interest]

3.Antoniu SA. Aclidinium bromide in experimental asthma. Expert Opin Investig Drugs. 2011 Jun;20(6):871-3. PMID: 21417951. [Not a human study]

4.Barnes PJ. Triple inhalers for obstructive airways disease: will they be useful? Expert Rev Respir Med. 2011 Jun;5(3):297-300. PMID: 21702649. [Not a human study]
838. Zomer-Kooijker K, van der Ent K, Ermers

$\mathrm{M}$, et al. Effect of high dose inhaled beclomethasone for respiratory syncytial virus bronchiolitis during infancy on lung function and asthma at age 6 - A randomised placebo-controlled trial [Abstract]. European Respiratory Society Annual Congress; 2013 Sept 7-11; Barcelona, Spain. A61. [Not an intervention of interest]

839. Zomer-Kooijker K, Van Der Ent K, Ermers M, et al. Lack of long-term effects of high-dose inhaled beclomethasone for respiratory syncytial virus bronchiolitis: a randomized placebo-controlled trial. Pediatr Infect Dis J. 2014 Jan;33(1):19-23. [Not an intervention of interest]

5.Beeh K, Ablinger O, Moroni-Zentgraf P, et al. Tiotropium in asthma: a dose-finding study in adult patients with moderate persistent asthma. Am J Respir Crit Care Med.2013;187:A1283. Embase 71980652. [No outcomes of interest]

6.Beeh KM, Ablinger O, MoroniZentgraf P, et al. Once-daily add-on tiotropium: A dose-finding trial in adult patients with moderate persistent asthma. Allergy. 2013;68;Suppl 97:376-7. DOI: 10.1111/all.12251. [No outcomes of interest]

7. Beeh K, Moroni-Zentgraf P, Ablinger O, et al. Tiotropium respimat in asthma: a double-blind, randomised, dose-ranging study in adult patients with moderate asthma. Respir Res. 2014 Jun 3;15:61. PMID: 24890738. [No outcomes of interest] 
8.Beeh KM, Kirsten AM, Dusser D, et al. Pharmacodynamics and Pharmacokinetics Following Once-Daily and Twice-Daily Dosing of Tiotropium Respimat( $\left({ }^{\circledR}\right)$ in Asthma Using Standardized Sample-Contamination Avoidance. Journal of Aerosol Medicine and Pulmonary Drug Delivery. 2016;Oct;29(5):406-415. PMID: 26859538 [not an intervention of interest]

9.Bel EH. Tiotropium for asthma-promise and caution. N Engl J Med. 2012 Sep 27;367(13):1257-9. PMID: 22938707. [Not a human study]

10.Buhl R, Moroni-Zentgraf P, Cornelissen $\mathrm{P}$, et al. Tiotropium respimat in asthma: evaluation of dosing regimens by comparing once-daily $5 \mu \mathrm{g}$ with twicedaily $2.5 \mu \mathrm{g}$. Am J Respir Crit Care Med. 2014;189:A1309. Embase 72043759. [No outcomes of interest]

11.Cates CJ. Safety of tiotropium. BMJ. 2011;342:d2970. DOI: http://dx.doi.org/10.1136/bmj.d2970. [Not a human study]

12.Cazzola M, Matera MG, O'Donnell KM. Association of $\beta 2$-adrenergic agonists and tiotropium: is the combination justified? Arch Bronconeumol. 2005;41;suppl 2:2431. [Not a human study]

13.Chung KF. Tiotropium as an add-on therapy in patients with symptomatic asthma. Lancet Respir Med. 2015 May;3(5):331-3. PMID: 25682231. [Not a human study]

14.Colice GL. Getting back to the basics: administering inhaled bronchodilators. Respir Care. 2009;54(4):455-7. PMID: 19327178. [Not a human study]

15.Curfman GD, Morrissey S, Drazen JM. Products at risk. N Engl J Med. 2010 Oct 28;363(18):1763. PMID: 20979478. [Not a human study]
16.Cydulka RK, Emerman CL. Effects of combined treatment with glycopyrrolate and albuterol in acute exacerbation of asthma. Ann Emerg Med. 1994 Feb;23(2):270-4. PMID: 8304607. [Not in the target population]

17.Derom E, Van Durme Y, Salhi B, et al. Assessments of protective effects of tiotropium bromide against methacholineand neurokinin A-induced bronchoconstriction in patients with asthma. Eur Respir J. 2011;38;Suppl 55:p872. [No outcomes of interest]

18.Derom E, Van Durme Y, Salhi B, et al. Tiotropium bromide protects against methacholine-, but not against neurokinin A-induced bronchoconstriction in patients with asthma: a randomized, double-blind, placebo-controlled, crossover study. Am J Respir Crit Care Med. 2011;183:A4500. Embase 70848807. [No outcomes of interest]

19.Domingo C. Ultra-LAMA, ultra-LABA, ultra-inhaled steroids? The future has landed. Arch Bronconeumol. 2013 Apr;49(4):131-4. PMID: 23415574. [Not a human study]

20.Emerman CL, Cydulka RK. Changes in serum catecholamine levels during acute bronchospasm. Ann Emerg Med. 1993 Dec;22(12):1836-41. PMID: 8239104. [Not in the target population]

21.Fardon T, Haggart K, Lee DKC, et al. A proof of concept study to evaluate stepping down the dose of fluticasone in combination with salmeterol and tiotropium in severe persistent asthma. Respir Med. 2007 Jun;101(6):1218-28. PMID: 17178217. [No outcomes of interest]

22.Feshchenko Y, Iashyna L, Moskalenko S, et al. Clinical-functional effectiveness of different regimens of basic treatment in severe bronchial asthma patients. Allergy. 2014;69:517. DOI: 10.1111/all.12478. [Abstract without full-text] 
23.Gilman MJ, Meyer L, Carter J, et al. Comparison of aerosolized glycopyrrolate and metaproterenol in acute asthma. Chest. 1990 Nov;98(5):1095-8. PMID: 2225951. [Not in the target population]

24.Haggart K, Fardon TC, Lee DKC, et al. Stepping down inhaled steroids in severe asthma with long acting bronchodilators: utilising effort dependent and independent measures of pulmonary function. Thorax. 2004 Dec;59;Suppl II:ii72-3. [No outcomes of interest]

25.Hansel TT, Neighbour H, Erin EM, et al. Glycopyrrolate causes prolonged bronchoprotection and bronchodilatation in patients with asthma. Chest. 2005 Oct;128(4):1974-9. PMID: 16236844. [Not an intervention of interest]

26.Higashi A, Zhu S, Stafford RS, et al. National trends in ambulatory asthma treatment, 1997-2009. J Gen Intern Med. 2011 Dec;26(12):1465-70. PMID: 21769507. [Excluded study design]

27.Hoshino M, Ohtawa J, Akitsu K. Effects of the addition of tiotropium on airway dimensions in symptomatic asthma. Allergy and asthma proceedings. 2016;37(6):e147-e153. PMID: 27931291 [no outcomes of interest]

28.Huang J, Chen Y, Long Z, et al. Clinical efficacy of tiotropium in children with asthma. Pak J Med Sci. 2016;32(2):4625. PMID: 27182262. [Not in the target population]

29.Iwamoto H, Yokoyama A, Shiota N, et al. Tiotropium bromide is effective for severe asthma with noneosinophilic phenotype. Eur Respir J. 2008 Jun;31(6):1379-80. PMID: 18515562. [Excluded study design]

30.Izco-Basurko I. Novelties in the treatment and management of thoracic disorders. Drug News Perspect. 2008 Sep;21(7):391-402. PMID: 19259552. [Not a human study]
31.Jara M, Wentworth III C, Lanes S. A new user cohort study comparing the safety of long-acting inhaled bronchodilators in COPD. BMJ Open. 2012 May 22;2(3):pii:e000841. PMID: 22619266. [Not in the target population]

32.Jara M, Lanes SF, Wentworth C3, et al. Comparative safety of long-acting inhaled bronchodilators: a cohort study using the UK THIN primary care database. Drug Saf. 2007;30(12):115160. PMID: 18035867. [Not in the target population]

33.Johnson BE, Suratt PM, Gal TJ, et al. Effect of inhaled glycopyrrolate and atropine in asthma precipitated by exercise and cold air inhalation. Chest. 1984 Mar;85(3):325-8. PMID: 6697786. [Not in the target population]

34.Kerstjens HA. Tiotropium improved lung function and delayed exacerbations in poorly controlled asthma. Ann Intern Med. 2012;157(12):J6-3. Embase 2012743126. [Not a human study]

35.Kerstjens HAM, Disse B, SchroderBabo W, et al. Tiotropium improves lung function in patients with severe uncontrolled asthma: a randomized controlled trial. J Allergy Clin Immunol. 2011 Aug;128(2):308-14. PMID: 21636120. [No outcomes of interest]

36.Kerstjens HAM, Moroni-Zentgraf P. Bronchodilator reversibility and cardiac considerations with use of tiotropium. Lancet Respir Med. 2015 Aug;3(8):e256. PMID: 26282477. [Not a human study]

37.Kerstjens HAM, Moroni-Zentgraf P, Bateman ED. Tiotropium in asthma authors' reply. Lancet Respir Med. 2015 May;3(5):e17. PMID: 25969363. [Not a human study]

38.Korelitz JJ, Zito JM, Gavin NI, et al. Asthma-related medication use among children in the United States. Ann Allergy Asthma Immunol. 2008 Mar;100(3):222-9. PMID: 18426141. [Excluded study design] 
39.Kuziemski K. Which dry powder inhaler should be chosen? Respiration. 2009;78(3):356. PMID: 19602872. [Not a human study]

40.Lane M. Tiotropium bromide in asthma patients: an alternative to inhaled longacting beta-agonists? J R Coll Physicians Edinb. 2010 Dec;40(4):321-2. PMID: 21132141. [Not a human study]

41.Lee LA, Briggs A, Edwards LD, et al. A randomized, three-period crossover study of umeclidinium as monotherapy in adult patients with asthma. Respir Med. 2015 Jan;109(1):63-73. PMID: 25464907. [Not an intervention of interest]

42.Limaye S, Kodgule R, Raskar S, et al. Single dose of of tiotropium bromide (18 mcg) produces a similar bronchodilator response as two doses of formoterol fumarate (12 mcg) over 24 hours in subjects with moderate-to-severe asthma [P1193]. Presented at: European Respiratory Society Annual Congress. 2010 Sep 19; Barcelona, Spain. [Not an intervention of interest]

43.Lipworth B. Tiotropium in asthma. Lancet Respir Med. 2015 May;3(5):e167. PMID: 25969362. [Not a human study]

44.Lommatzsch M, Julius P, Virchow JC. Tiotropium step-up therapy in asthma. $\mathrm{N}$ Engl J Med. 2011 Feb 10;364(6):578-9. PMID: 21306255. [Not a human study] 45.Magnussen H, Bugnas B, van Noord J, et al. Improvements with tiotropium in COPD patients with concomitant asthma. Respir Med. 2008 Jan;102(1):50-6. PMID: 17920256. [Not in the target population]
46. Mariotti F, Ciurlia G, Spaccapelo L, et al. A two-period open-label, single-dose crossover study in healthy volunteers to evaluate the drug-drug interaction between cimetidine and inhaled extrafine CHF 5993. Eur J Drug Metab Pharmacokinet. 2016 May 21. Epub 2016 May 21. PMID: 27209586. [Not in the target population]

47.Miller DR, Chetty M, Currie GP. Tiotropium step-up therapy in asthma. N Engl J Med. 2011 Feb 10;364(6):578-9. PMID: 21306256. [Not a human study]

48.Mundy C, Kirkpatrick P. Tiotropium bromide. Nat Rev Drug Discov. 2004 Aug;3(8):643-4. PMID: 15317149. [Not a human study]

49.Nair GB, Spiegler P. Role of anticholinergics in the treatment of asthma. Clin Pulm Med. 2011;18(2):956. DOI: 0.1097/CPM.0b013e31820e2a70. [Not a human study]

50.Norris AA. 15th Annual Congress of European Respiratory Society. Expert Opin Invest Drugs. 2006;15(2):185-8. DOI: $10.1517 / 13543784.15 .2 .185$. [Not a human study]

51.O'Connor BJ, Towse LJ, Barnes PJ. Prolonged effect of tiotropium bromide on methacholine-induced bronchoconstriction in asthma. Am J Respir Crit Care Med. 1996 Oct;154(4 Pt 1):876-80. PMID: 8887578. [Not in the target population]

52.Park H, Yang M, Park C, et al. Additive role of tiotropium in severe asthmatics and Arg16Gly in ADRB2 as a potential marker to predict response. Allergy. 2009 May;64(5):778-83. PMID: 19183167. [Not an intervention of interest]

53.Peters SP. Tiotropium plus beclomethasone was more effective than doubling beclomethasone for asthma. Ann Intern Med. 2011;154(4):J2-4. Embase 2011097331. [Not a human study] 
54.Peters SP. Tiotropium bromide triple combination therapy improves lung function and decreases asthma exacerbations. Evid Based Med. 2013 Oct;18(5):179. PMID: 23349214. [Not a human study]

55.Peters SP, Kunselman SJ, Icitovic N, et al. Tiotropium bromide step-up therapy for adults with uncontrolled asthma. N Engl J Med. 2010 Oct 28;363(18):171526. PMID: 20979471. [Duplicate]

56.Prescott LM, Prescott SL. 101st International Conference of the American Thoracic Society. P\&T. 2005 Aug;30(8):467-70. [Not a human study]

57.Price D, Kaplan A, Jones R, et al. Longacting muscarinic antagonist use in adults with asthma: real-life prescribing and outcomes of add-on therapy with tiotropium bromide. J Asthma Allergy. 2015;8:1-13. PMID: 25609985. [Not in the target population]

58.Price D, West D, Brusselle G, et al. Management of COPD in the UK primary-care setting: An analysis of reallife prescribing patterns. Int J Chron Obstruct Pulmon Dis. 2014;9:889-904. PMID: 25210450. [Not in the target population]

59. Quijada C, Venegas M, Bernardine $\mathrm{H}$. How long should tiotropium bromide be suspended before methacholine challenge? Eur Respir J. 2006;28;Suppl 50:218s. [No outcomes of interest]

60.Ranaweera A. The 102nd Annual Conference of the American Thoracic Society. Int J Pharm Med. 2006;20(4):263-8. [Not a human study]

61.Sayal P, Adhikari T, Vijayan VK. The effects of inhaled tiotropium bromide on lung inflammation in bronchial asthma. Chest. 2007;132(4_MeetingAbstracts):509a. DOI: 10.1378/chest.132.4_MeetingAbstracts.5 09a. [Abstract without full-text]
62.Schelfhout V, Joos G, Garcia Gil E, et al. Bronchodilator/bronchoprotective effects of aclidinium bromide a novel long acting anticholinergic a phase 1 study. Eur Respir J. 2007;30;Suppl 51:356s. [Not in the target population] 63.Schroeckenstein DC, Bush RK, Chervinsky P, et al. Twelve-hour bronchodilation in asthma with a single aerosol dose of the anticholinergic compound glycopyrrolate. J Allergy Clin Immunol. 1988 Jul;82(1):115-9. PMID: 3392363. [Not an intervention of interest]

64.Self T, Joe R, Kellerman A. Glycopyrrolate for asthma. Am J Emerg Med. 1992 Jul;10(4):395-6. PMID: 1616535. [Not a human study]

65.Sen IM, Ahuja V. Theophylline: A drug of caution. J Anaesthesiol Clin Pharmacol. 2007;23(4):433-4. [Excluded study design]

66.Shah S. Asthma \& COPD - SMi's Sixth Annual Conference. IDrugs. 201;13(6):376-8. [Not a human study] 67.Slats AM, Janssen K, de Jeu R, et al. The effect of tiotropium bromide on deep inspiration-induced bronchodilation and airway responsiveness in asthma. Am J Respir Crit Care Med. 2009;179:A2427. DOI: http://dx.doi.org/10.1164/ajrccmconference.2009.179.1_MeetingAbstract s.A2427. [No outcomes of interest]

68.Sposato B, Bruno S, Barzan R, et al. Comparison of the protective effect amongst anticholinergic drugs on methacholine-induced bronchoconstriction in asthma. $\mathrm{J}$ Asthma. 2008 Jun;45(5):397-401. PMID: 18569233. [Not an intervention of interest] 
69.Sridevi K, MohanaRao V, Vijaya N, et al. Safety and efficacy of tiotropium bromide in bronchial asthma and COPD patients, cross over studies by placebo. Int J Life Sci Biotechnol Pharma Res. 2012;1(4):250-62. Embase 2013173434. [Not in the target population]

70.Storms WW. Exercise-induced bronchospasm. Curr Sports Med Rep. 2009;8(2):45-6. PMID: 19276902. [Not a human study]

71.Suffredini AF, Masur H, Lynch JP. Update in pulmonary and critical care medicine. Ann Intern Med. 2010 May 4;152(9):601-8. PMID: 20410448. [Not a human study]

72.Terzano C, Petroianni A, Ricci A, et al. Early protective effects of tiotropium bromide in patients with airways hyperresponsiveness. Eur Rev Med Pharmacol Sci. 2004 Nov-Dec;8(6):25964. PMID: 15745385. [Not an intervention of interest]

73.Timmer W, Moroni-Zentgraf P, Cornelissen P, et al. Once-daily tiotropium respimat $5 \mu \mathrm{g}$ is an efficacious 24-h bronchodilator in adults with symptomatic asthma. Respir Med. 2015 Mar;109(3):329-38. PMID: 25661281. [No outcomes of interest]

74. Tochino Y, Kanazawa H, Ichimaru Y, et al. Ne-(carboxymethyl)lysine, a major advanced glycation end product in exhaled breath condensate as a biomarker of small airway involvement in asthma. J Asthma. 2007 Dec;44(10):861-6. PMID: 18097864. [Not an intervention of interest] 75.Vogelberg C, Engel M, MoroniZentgraf $\mathrm{P}$, et al. O05-once-daily tiotropium in adolescents with symptomatic asthma despite inhaled corticosteroid treatment: a dose-ranging study. Clin Transl Allergy. 2014;4;Suppl 1:O5. DOI: 10.1186/2045-7022-4-S1-O5. [No outcomes of interest]
76.Vogelberg C, Engel M, Moroni-Zentgraf $\mathrm{P}$, et al. Tiotropium in asthmatic adolescents symptomatic despite inhaled corticosteroids: A randomised doseranging study. Respir Med. 2014 Sep;108(9):1268-76. PMID: 25081651. [No outcomes of interest]

77. Vogelberg C, LeonaviciuteKlimantaviciene M, Vevere $\mathrm{V}$, et al. Dose-ranging study of tiotropium as treatment for moderate persistent asthma in adolescents. Allergo J. 2013 Sep 7;22 (6):389. Embase 71405612. [No outcomes of interest]

78.Vogelberg C, LeonaviciuteKlimantaviciene $\mathrm{M}$, Vevere $\mathrm{V}$, et al. Dose-ranging study of tiotropium as treatment for moderate persistent asthma in adolescents. Am J Respir crit Care Med. 2012;185:A4069. Embase 71988705. [No outcomes of interest]

79. Vogelberg C, Moroni-Zentgraf P, Leonaviciute-Klimantaviciene $\mathrm{M}$, et al. A randomised dose-ranging study of tiotropium respimat in children with symptomatic asthma despite inhaled corticosteroids. Respir Res. 2015 Feb 4;16:20. PMID: 25851298. [Not in the target population]

80.Walker FB4, Kaiser DL, Kowal MB, et al. Prolonged effect of inhaled glycopyrrolate in asthma. Chest. 1987 Jan;91(1):49-51. PMID: 3792086. [Not an intervention of interest]

81.Wark P. ACP journal club. Tiotropium reduced exacerbations more than salmeterol in moderate-to-very severe COPD. Ann Intern Med. 2011 Jul 19;155(2):JC1-3. PMID: 21768569. [Not a human study]

82.Wenzel SE. Tiotropium for severe asthma: a step forward or more of the same? Pol Arch Med Wewn. 2012;122(11):525-6. PMID: 23207413. [Not a human study] 
83.Yaqub F. 2013 American Thoracic Society International Conference. Lancet Respir Med. 2013 Jul;1(5):359. PMID: 24429194. [Not a human study]

84. Yoshida M, Inoue H, Iwanaga T. Effects of tiotropium on lung function in severe asthmatics with or without emphysematous changes. Am J Respir Crit Care Med. 2012;185:A3962. DOI: http://dx.doi.org/10.1164/ajrccmconference.2012.185.1_MeetingAbstract s.A3962. [Not an intervention of interest]

85. Yoshida M, Nakano T, Fukuyama S, et al. Effects of tiotropium on lung function in severe asthmatics with or without emphysematous changes. Pulm Pharmacol Ther. 2013 Apr;26(2):159-66. PMID: 23073336. [Not an intervention of interest]
86.Glycopyrronium bromide for chronic obstructive pulmonary disease. Aust Prescr 2014;37:64-71. DOI: 10.18773/austprescr.2014.027. [Not a human study]

87.Spiriva: A new drug treatment for asthma? Tiotropium (spiriva), a drug prescribed for chronic obstructive pulmonary disease (COPD), may provide effective preventive care for individuals with moderate to severe asthma. Johns Hopkins Med Lett Health After 50. 2011 Jul;23(5):3. PMID: 27024143. [Not a human study]

88.Asian Pacific Society of Respirology 19th Congress. Respirology. 2014 Nov;19;Suppl S3:1-270. Embase 71678388. [Abstract without full-text] 


\section{Appendix C. Study Characteristics}

Table C-1. Study and population characteristics for KQ1a

\begin{tabular}{|c|c|c|c|c|c|c|c|c|c|c|}
\hline $\begin{array}{l}\text { Study, } \\
\text { Year, } \\
\text { Acronym } \\
\text { n, } \\
\text { Study } \\
\text { design, } \\
\text { Duration, } \\
\text { Risk of } \\
\text { bias }\end{array}$ & Study population & $\begin{array}{l}\text { Intervention } \\
\text { Comparisons }\end{array}$ & $\begin{array}{l}\text { Age } \\
\text { [mean } \\
\text { (SD)] }\end{array}$ & $\begin{array}{l}\text { Males } \\
\text { (\%) }\end{array}$ & $\begin{array}{l}\text { Parent } \\
\text { wl } \\
\text { asthma } \\
\text { (\%) }\end{array}$ & $\begin{array}{l}\text { Atopy } \\
\text { (\%) }\end{array}$ & $\begin{array}{l}2^{\text {nd }} \\
\text { hand } \\
\text { smoke } \\
(\%)\end{array}$ & $\begin{array}{l}\text { Systemic } \\
\text { corti- } \\
\text { costeroid } \\
\text { in last } \\
12 \mathrm{~m}(\%)\end{array}$ & $\begin{array}{l}\text { Hospital- } \\
\text { ized in } \\
\text { last } 12 \mathrm{~m} \\
(\%)\end{array}$ & $\begin{array}{l}\text { ICS } \\
\text { dose } \\
\text { during } \\
\text { study } \\
\text { ( } \mu \text { g/d) } \\
\text { [mean } \\
(\mathrm{SD})]\end{array}$ \\
\hline \multirow[t]{2}{*}{$\begin{array}{l}\text { Svedmyr, } \\
1999^{48} \\
n=55 \\
\text { RCT,12m } \\
\text { or } 6 \\
\text { treatments }\end{array}$} & \multirow{2}{*}{$\begin{array}{l}\text { 1-3 years of age w/ } \geq 3 \text { episodes of } \\
\text { wheezing w/URTI, asthma } \\
\text { symptoms during last } 2 \text { airway } \\
\text { infections and no symptoms in- } \\
\text { between URTI; physician's } \\
\text { diagnosis of wheezy bronchitis or } \\
\text { asthma } \\
\text { SABA and theophylline use } \\
\text { allowed when needed; fixed dose } \\
\text { cromoglycate was allowed }\end{array}$} & $\begin{array}{l}\text { Budesonide } 400 \mu \mathrm{g} \\
\text { QID } \times 3 \mathrm{~d} \text { then } 400 \mu \mathrm{g} \\
\text { BID } \times 7 \mathrm{~d}(\mathrm{MDI}), \\
\text { initiated by the parent } \\
\text { at first sign of URTI } \\
\mathrm{n}=28\end{array}$ & $\begin{array}{l}25 \mathrm{~m} \\
(12 \text { to } \\
47)^{\mathrm{b}}\end{array}$ & 60.7 & NR & $25.0^{c}$ & $7.1^{\mathrm{d}}$ & NR & $\begin{array}{l}1.2 \\
(0 \text { to } 4)^{\mathrm{b}, \mathrm{e}}\end{array}$ & NR \\
\hline & & $\begin{array}{l}\text { Placebo MDI } \times 10 d \\
\text { initiated by the parent } \\
\text { at first sign of URTI } \\
n=27\end{array}$ & $\begin{array}{l}26 \mathrm{~m} \\
(13 \text { to } \\
47)^{\mathrm{b}}\end{array}$ & 77.8 & NR & $22.2^{c}$ & $7.4^{\mathrm{d}}$ & NR & $\begin{array}{l}1.1 \\
(0 \text { to } 3)^{\mathrm{b}, \mathrm{e}}\end{array}$ & NR \\
\hline \multirow[t]{2}{*}{$\begin{array}{l}\text { Ghirga, } \\
2002^{46} \\
\text { n=26 } \\
\text { RCT, until } 4 \\
\text { URTIs }^{f}\end{array}$} & \multirow[t]{2}{*}{$\begin{array}{l}\text { 7-12 months old, history of } \\
\text { recurrent wheezing during URTI } \\
\text { w/at least } 2-3 \text { airway infections } \\
\text { causing wheezing }\end{array}$} & $\begin{array}{l}\text { Beclomethasone } \\
400 \mu g \text { TID (neb) x5d } \\
\text { initiated by parent } \\
\text { w/very early phase of } \\
\text { URTI before any sign } \\
\text { of wheezing } \\
n=13\end{array}$ & \multirow[t]{2}{*}{$\begin{array}{l}8.2 \mathrm{~m} \\
(1.6)\end{array}$} & \multirow[t]{2}{*}{69.2} & NR & NR & NR & NR & NR & NR \\
\hline & & $\begin{array}{l}\text { No preventative } \\
\text { treatment w/URTI } \\
n=13\end{array}$ & & & NR & NR & NR & NR & NR & NR \\
\hline $\begin{array}{l}\text { Bacharier, } \\
2008^{44} \\
\text { AIMS } \\
n=143 \\
\text { RCT, } 12 \mathrm{~m} \\
\end{array}$ & $\begin{array}{l}12-59 \text { months old w/ } \geq 2 \text { episodes } \\
\text { of wheezing in context of RTI } \\
\text { within past yearh, } 1 \text { in the past } 6 \\
\text { months and } 1 \text { documented by a } \\
\text { healthcare provider }\end{array}$ & $\begin{array}{l}\text { Budesonide 1mg BID } \\
\text { (neb) x7d initiated by } \\
\text { parent at the first sign } \\
\text { of RTI } \\
n=96\end{array}$ & $\begin{array}{l}36.7 m \\
(13.5)\end{array}$ & 72.9 & 41.7 & $44.8^{j}$ & $4.2^{k}$ & $\begin{array}{l}1=21.9 \\
2=26.0 \\
3=8.3 \\
4+=3.1\end{array}$ & 8 & NR \\
\hline
\end{tabular}




\begin{tabular}{|c|c|c|c|c|c|c|c|c|c|c|}
\hline $\begin{array}{l}\text { Study, } \\
\text { Year, } \\
\text { Acronym } \\
\text { n, } \\
\text { Study } \\
\text { design, } \\
\text { Duration, } \\
\text { Risk of } \\
\text { bias }\end{array}$ & Study population & $\begin{array}{l}\text { Intervention } \\
\text { Comparisons }\end{array}$ & $\begin{array}{l}\text { Age } \\
\text { [mean } \\
\text { (SD)] }\end{array}$ & $\begin{array}{l}\text { Males } \\
(\%)\end{array}$ & $\begin{array}{l}\text { Parent } \\
\text { wl } \\
\text { asthma } \\
\text { (\%) }\end{array}$ & $\begin{array}{l}\text { Atopy } \\
\text { (\%) }\end{array}$ & $\begin{array}{l}2^{\text {nd }} \\
\text { hand } \\
\text { smoke } \\
(\%)\end{array}$ & $\begin{array}{l}\text { Systemic } \\
\text { corti- } \\
\text { costeroid } \\
\text { in last } \\
12 \mathrm{~m}(\%)\end{array}$ & $\begin{array}{l}\text { Hospital- } \\
\text { ized in } \\
\text { last } 12 \mathrm{~m} \\
(\%)\end{array}$ & $\begin{array}{l}\text { ICS } \\
\text { dose } \\
\text { during } \\
\text { study } \\
\text { ( } \mu \text { g/d) } \\
\text { [mean } \\
\text { (SD)] }\end{array}$ \\
\hline Low & $\begin{array}{l}\text { All patients received albuterol } \\
\text { QID while awake + PRN for } 48 \mathrm{~h} \\
\text { then PRN; oral corticosteroids } \\
\text { were available at home }\end{array}$ & $\begin{array}{l}\text { Placebo } \times 7 d \text { initiated } \\
\text { at the first sign of } R T I \\
n=47\end{array}$ & $\begin{array}{l}35.7 m \\
(13.7)\end{array}$ & 48.9 & 53.2 & $44.7^{j}$ & $1.7^{\mathrm{k}}$ & $\begin{array}{l}1=27.7 \\
2=17.0 \\
3=4.3 \\
4+=4.3\end{array}$ & & NR \\
\hline $\begin{array}{l}\text { Ducharme, } \\
2009^{45} \\
n=129 \\
\text { RCT, } 12 \mathrm{~m}\end{array}$ & $\begin{array}{l}\text { 1-6 years old w/ } \geq 3 \text { wheezing } \\
\text { episodes in lifetime seemingly } \\
\text { triggered exclusively by URTI with } \\
\text { no symptoms in between, with at } \\
\text { least } 1 \text { course of rescue systemic } \\
\text { corticosteroid in prior } 6 \mathrm{~m} \text { or } 2 \text { in } \\
\text { prior } 12 \mathrm{~m}\end{array}$ & $\begin{array}{l}\text { Fluticasone } 750 \mu g \\
\text { BID (MDI) initiated by } \\
\text { parent at first sign of } \\
\text { URTI until } 48 \text { h without } \\
\text { cough or wheeze } \\
n=62\end{array}$ & $\begin{array}{l}2.60 y \\
(1.09)\end{array}$ & 52 & $19^{l}$ & $10^{\mathrm{m}}$ & $\begin{array}{l}\text { In } \\
\text { utero: } \\
18 \\
\text { In } \\
\text { home: } \\
23\end{array}$ & $\begin{array}{l}2.3 \\
(1.1)^{n}\end{array}$ & 47 & $\begin{array}{l}50(39 \\
\text { to } 91)^{\circ}\end{array}$ \\
\hline Low & $\begin{array}{l}\text { All patients received albuterol } \\
200-400 \mu \mathrm{g} \text { q4h PRN for cough, } \\
\text { wheeze and dyspnea }\end{array}$ & $\begin{array}{l}\text { Placebo initiated by } \\
\text { parent at first sign of } \\
\text { URTI until } 48 \text { h without } \\
\text { cough or wheeze } \\
n=67\end{array}$ & $\begin{array}{l}2.86 y \\
(1.20)\end{array}$ & 69 & $18^{\prime}$ & $12^{\mathrm{m}}$ & $\begin{array}{l}\text { In } \\
\text { utero: } \\
13 \\
\text { In } \\
\text { home: } \\
21\end{array}$ & $\begin{array}{l}2.4 \\
(1.4)^{n}\end{array}$ & 52 & NR \\
\hline \multirow[t]{2}{*}{$\begin{array}{l}\text { Papi, } \\
200947 \\
\text { BEST- } \\
\text { children } \\
\text { n=276 } \\
\text { RCT, 12w }\end{array}$} & \multirow[t]{2}{*}{$\begin{array}{l}\text { 1-4 years old with frequent } \\
\text { wheeze ( } \geq 3 \text { episodes requiring } \\
\text { medical attention) referred to } \\
\text { specialist centers because of } \\
\text { further episode of wheezing in } \\
\text { addition to the } 3 \text { required }\end{array}$} & $\begin{array}{l}\text { Beclomethasone/ } \\
\text { salbutamol } \\
800 / 1600 \mu g \text { PRN } \\
\text { (neb) for symptom } \\
\text { relief } \\
n=110\end{array}$ & $\begin{array}{l}2.26 y \\
(0.79)\end{array}$ & 61.8 & NR & NR & NR & NR & NR & $\begin{array}{l}15.1 \\
(21.5)\end{array}$ \\
\hline & & $\begin{array}{l}\text { Beclomethasone } \\
400 \mu g \text { BID (neb) }+ \\
\text { salbutamol } 2500 \mu g \\
\text { PRN (neb) for } \\
\text { symptom relief } \\
n=110\end{array}$ & $\begin{array}{l}2.35 y \\
(0.81)\end{array}$ & 58.2 & NR & NR & NR & NR & NR & $\begin{array}{l}66.8 \\
(6.8)^{p}\end{array}$ \\
\hline
\end{tabular}




\begin{tabular}{|c|c|c|c|c|c|c|c|c|c|c|}
\hline \multirow[t]{2}{*}{$\begin{array}{l}\text { Study, } \\
\text { Year, } \\
\text { Acronym } \\
\text { n, } \\
\text { Study } \\
\text { design, } \\
\text { Duration, } \\
\text { Risk of } \\
\text { bias } \\
\end{array}$} & Study population & $\begin{array}{l}\text { Intervention } \\
\text { Comparisons }\end{array}$ & $\begin{array}{l}\text { Age } \\
\text { [mean } \\
\text { (SD)] }\end{array}$ & $\begin{array}{l}\text { Males } \\
(\%)\end{array}$ & $\begin{array}{l}\text { Parent } \\
\text { wl } \\
\text { asthma } \\
(\%)\end{array}$ & $\begin{array}{l}\text { Atopy } \\
\text { (\%) }\end{array}$ & $\begin{array}{l}2^{\text {nd }} \\
\text { hand } \\
\text { smoke } \\
(\%)\end{array}$ & $\begin{array}{l}\text { Systemic } \\
\text { corti- } \\
\text { costeroid } \\
\text { in last } \\
12 \mathrm{~m}(\%)\end{array}$ & $\begin{array}{l}\text { Hospital- } \\
\text { ized in } \\
\text { last } 12 \mathrm{~m} \\
(\%)\end{array}$ & $\begin{array}{l}\text { ICS } \\
\text { dose } \\
\text { during } \\
\text { study } \\
\text { ( } \mu \text { g/d) } \\
\text { [mean } \\
(\mathrm{SD})]\end{array}$ \\
\hline & & $\begin{array}{l}\text { Salbutamol } 2500 \mu \mathrm{g} \\
\text { PRN (neb) for } \\
\text { symptom relief } \\
n=56\end{array}$ & $\begin{array}{l}2.29 y \\
(0.78)\end{array}$ & 60.7 & NR & NR & NR & NR & NR & NR \\
\hline \multirow[t]{2}{*}{$\begin{array}{l}\text { Zeiger, } \\
2011^{49} \\
\text { MIST } \\
n=278 \\
\text { RCT, 52w } \\
\text { Low }\end{array}$} & \multirow{2}{*}{$\begin{array}{l}12-53 \text { months old w/positive } \\
\text { mAPI and history of } \geq 4 \text { wheezing } \\
\text { episodes in the prior year with } \geq 1 \\
\text { physician diagnosed or } \geq 3 \\
\text { wheezing episodes in the prior } \\
\text { year with } \geq 3 \text { months of asthma } \\
\text { controller therapy in the prior year } \\
\text { All patients received albuterol } \\
\text { QID while awake for the first } 48 \mathrm{~h} \\
+ \text { PRN }\end{array}$} & $\begin{array}{l}\text { Placebo once daily } \\
\text { (neb) + budesonide } \\
\text { 1mg BID (neb) x7d at } \\
\text { RTI onset } \\
n=139\end{array}$ & $\begin{array}{l}2.9 y \\
(0.9)\end{array}$ & 73.4 & 64.9 & $59.9^{q}$ & $39.6^{r}$ & 79.1 & 18.7 & $\begin{array}{l}45.7 \\
(38.9 \\
\text { to } \\
52.8)\end{array}$ \\
\hline & & $\begin{array}{l}\text { Budesonide } 500 \mu \mathrm{g} \\
\text { (neb) once daily }+ \\
\text { placebo neb for RTI } \\
n=139\end{array}$ & $\begin{array}{l}2.9 y \\
(0.9)\end{array}$ & 64.7 & 63.7 & $56.8^{q}$ & $42.4^{r}$ & 71.9 & 19.4 & $\begin{array}{l}149.9 \\
(140.1 \\
\text { to } \\
159.6)\end{array}$ \\
\hline
\end{tabular}

Abbreviations: BID=twice daily; $\mathrm{CI}=$ confidence interval; $\mathrm{d}=$ day; h=hour; ICS=inhaled corticosteroid; $\mathrm{m}=$ month; IQR=interquartile range; $\mathrm{mAPI}=$ modified Asthma Predictive Index; MDI=metered dose inhaler; mg=milligram; $n=$ patient sample size; neb=nebulized; NR=not reported; PRN=pro re nata (i.e., as needed); Q=every; QID=four times daily; RCT=randomized controlled trial; RTI=respiratory tract infection; SABA=short-acting $\beta_{2}$-agonist; SD=standard deviation; TID=three times daily; URTI=upper respiratory tract infection; $\mu \mathrm{g}=$ microgram; $\mathrm{y}=\mathrm{year}$

${ }^{a}$ Treatment with cromoglycate was $17.9 \%$ in the budesonide arm and $22.2 \%$ in the placebo arm

bData reported as mean (range)

${ }^{\mathrm{C}}$ Represents positive skin prick test

${ }^{\mathrm{d}}$ Represents parents smoking indoors

eRepresents number of hospital admissions due to asthma

fPatients were not enrolled for a finite time period, but completed the study after 4 URTIs

gAt least 2 of 3 URTI signs were to be present before starting medication (nasal discharge, coughing and fever). Treatment was stopped if all signs of URTI disappeared within 24h

hIn an effort to include children with prior moderate-to-severe wheezing episodes, children were required to have experienced either 2 urgent care visits for acute wheezing within

the past year, 2 wheezing episodes for which oral corticosteroids were prescribed, or 1 episode requiring urgent care and 1 episode requiring oral corticosteroids

iA course of prednisolone was considered if at any point the child had symptoms that did not improve after 3 SABA treatments administered every 15 minutes, if the child needed

SABA more than 6 neb treatments or more than 12 puffs/d for $>24 \mathrm{~h}$, moderate-severe cough or wheeze for at least 5 of the preceding 7 days was present or at physician discretion.

The prednisolone course was $2 \mathrm{mg} / \mathrm{kg} / \mathrm{d}$ (maximum 60mg/d) x2d followed by $1 \mathrm{mg} / \mathrm{kg} / \mathrm{d}$ (maximum 30mg/d) x2 d

${ }_{\mathrm{j}}^{\mathrm{j}}$ epresents positive aeroallergen skin test 
kepresents exposure at home or daycare

${ }^{\mathrm{l}}$ Represents maternal asthma

mepresents food or drug allergy, allergies to aeroallergens documented by positive skin test or IgE were excluded

${ }^{n}$ Represents courses of systemic corticosteroids in the past year, data reported as mean (SD)

${ }^{\circ}$ Represents cumulative dose of fluticasone used (mg) per patient-month of observation, data reported as median (IQR)

pBeclomethasone dipropionate equivalent dose in $\mathrm{mg}$

${ }^{\mathrm{q}}$ Represents sensitivity to any aeroallergen

rRepresents smoke exposure from birth

sRepresents cumulative dose (mg) over study course, data reported as mean (95\% CI)

Table C-2. Study level outcomes for KQ1a, intermittent ICS with as-needed SABA vs. ICS controller with as-needed SABA

\begin{tabular}{|c|c|c|c|c|c|c|}
\hline $\begin{array}{l}\text { Study, } \\
\text { Year, n, } \\
\text { Study } \\
\text { design, } \\
\text { Duration }\end{array}$ & Population $^{a}$ & Exacerbations $^{\mathbf{b}}$ & Mortality & Asthma Control & Quality of Life & Healthcare Utilization \\
\hline $\begin{array}{l}\text { Svedmyr, } \\
1999^{48} \\
n=55 \\
\text { RCT, } 12 \mathrm{~m} \text { or } \\
6 \text { treatments }\end{array}$ & 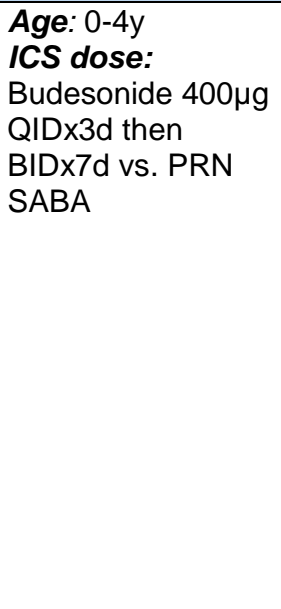 & $\begin{array}{l}\text { Required oral corticosteroid } \\
\text { course: } \\
\text { RR } 0.90 \text { (0.44 to } 1.85) \\
\text { Asthma-related ER visit: } \\
\text { RR } 0.83 \text { (0.44 to } 1.58) \\
\text { Hospital admission due to } \\
\text { asthma: } \\
\text { RR } 2.50 \text { (0.53 to } 11.74) \\
\text { Number of ER admissions for } \\
\text { asthma: } \\
16 \text { vs. } 23 \\
\text { Number of hospital } \\
\text { admissions for asthma: } \\
6 \text { vs. } 2 \\
\text { Total number of oral } \\
\text { corticosteroid courses: } \\
14 \text { vs. } 17\end{array}$ & NR & $\begin{array}{l}\text { Composite } \\
\text { measures: } \\
\text { NR } \\
\text { Spirometry: } \\
\text { NR }\end{array}$ & NR & NR \\
\hline
\end{tabular}




\begin{tabular}{|c|c|c|c|c|c|c|}
\hline $\begin{array}{l}\text { Study, } \\
\text { Year, n, } \\
\text { Study } \\
\text { design, } \\
\text { Duration }\end{array}$ & Population $^{a}$ & Exacerbations $^{b}$ & Mortality & Asthma Control & Quality of Life & Healthcare Utilization \\
\hline $\begin{array}{l}\text { Bacharier, } \\
2008^{44} \\
n=143 \\
\text { RCT, } 12 \mathrm{~m}\end{array}$ & $\begin{array}{l}\text { Age: } 0-4 y \\
\text { ICS dose: } \\
\text { Budesonide 1.0mg } \\
\text { BID (high) x7d vs. } \\
\text { PRN SABA }\end{array}$ & $\begin{array}{l}\text { Required oral corticosteroid } \\
\text { course: } \\
\text { RR } 0.70 \text { (0.49 to } 1.00) \\
\text { Asthma-related urgent/ER } \\
\text { visit: } \\
\text { RR } 0.98 \text { (0.71 to } 1.34) \\
\text { Number of urgent care/ER } \\
\text { visits per patient: } \\
-0.5 \text { (-1.16 to } 0.16) \\
\text { Hospital admission due to } \\
\text { asthma: } \\
\text { RR } 0.24 \text { (0.05 to } 1.29) \\
\text { Average courses of oral } \\
\text { corticosteroid/participant: } \\
\text { MD -0.2 (0.6 to 0.26) } \\
\text { Days of oral corticosteroid } \\
\text { use/participant: } \\
\text { MD -0.1 (-1.87 to } 1.67)\end{array}$ & NR & $\begin{array}{l}\text { Composite } \\
\text { measures: } \\
\text { NR } \\
\text { Spirometry: } \\
\text { NR }\end{array}$ & $\begin{array}{l}\text { PACQLQ score: } \\
\text { MD }-0.1(-0.36 \text { to } 0.34)\end{array}$ & NR \\
\hline
\end{tabular}




\begin{tabular}{|c|c|c|c|c|c|c|}
\hline $\begin{array}{l}\text { Study, } \\
\text { Year, n, } \\
\text { Study } \\
\text { design, } \\
\text { Duration }\end{array}$ & Population $^{a}$ & Exacerbations $^{b}$ & Mortality & Asthma Control & Quality of Life & Healthcare Utilization \\
\hline $\begin{array}{l}\text { Ducharme, } \\
2009^{45} \\
n=129 \\
\text { RCT, } 12 \mathrm{~m}\end{array}$ & 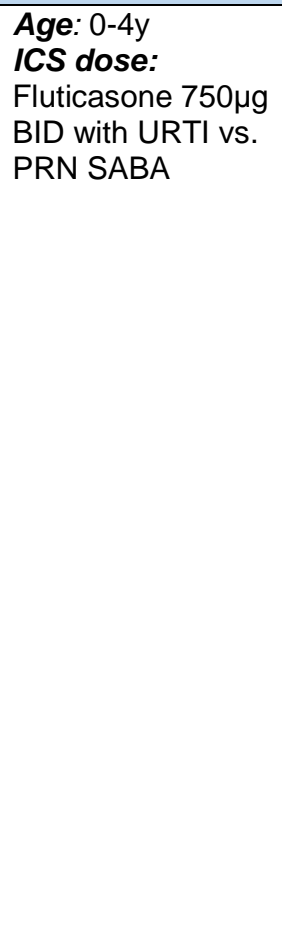 & $\begin{array}{l}\text { Required a course of oral } \\
\text { corticosteroid: } \\
\text { RR } 0.60 \text { ( } 0.42 \text { to } 0.87) \\
\text { URTI w/asthma symptoms: } \\
\text { OR } 0.64 \text { ( } 0.36 \text { to } 1.13) \\
\text { URTI requiring systemic } \\
\text { corticosteroid: } \\
\text { OR } 0.49 \text { (0.3 to } 0.83) \\
\text { Asthma-related acute care } \\
\text { visit: } \\
\text { RR } 0.88 \text { ( } 0.72 \text { to } 1.07) \\
\text { Hospital admission due to } \\
\text { asthma: } \\
\text { RR } 0.72 \text { (0.35 to } 1.48) \\
\text { URTI requiring } \\
\text { hospitalization: } \\
\text { OR } 0.67 \text { (0.29 to } 1.38) \\
\text { URTI requiring acute care } \\
\text { visit: } \\
\text { OR } 0.79 \text { (0.53 to 1.19) } \\
\text { Number of asthma-related } \\
\text { acute care visits: } \\
107 \text { vs. } 146 \\
\text { Number of asthma-related } \\
\text { hospitalizations: } \\
11 \text { vs. } 18\end{array}$ & NR & $\begin{array}{l}\text { Composite } \\
\text { measures: } \\
\text { NR } \\
\text { Spirometry: } \\
\text { NR }\end{array}$ & $\begin{array}{l}\text { PACQLQ score during } \\
\text { URTI: } \\
\text { MD } 0.49 \text { (0.1 to } 0.86)\end{array}$ & $\begin{array}{l}\text { Total number of SABA } \\
\text { puffs per URTI [median } \\
\text { (IQR)]: } \\
36(23 \text { to } 61 \text { ) vs. } 44 \text { ( } 25 \text { to } \\
78) \\
\text { Total number of days per } \\
\text { URTI SABA used [median } \\
\text { (IQR)]: } \\
5 \text { (3 to } 8 \text { ) vs. } 6 \text { ( } 4 \text { to } 10) \\
\text { Duration of SABA use: } \\
\text { Rate ratio: } 0.85 \text { (0.74 to } \\
0.98) \\
\text { Cumulative number of } \\
\text { SABA inhalations: } \\
\text { Rate ratio } 0.80 \text { (0.68 to } \\
\text { 0.94) }\end{array}$ \\
\hline
\end{tabular}




\begin{tabular}{|c|c|c|c|c|c|c|}
\hline $\begin{array}{l}\text { Study, } \\
\text { Year, n, } \\
\text { Study } \\
\text { design, } \\
\text { Duration }\end{array}$ & Population $^{a}$ & Exacerbations $^{b}$ & Mortality & Asthma Control & Quality of Life & Healthcare Utilization \\
\hline $\begin{array}{l}\text { Papi, } 2009^{47} \\
\mathrm{n}=166 \\
\text { RCT, } 12 \mathrm{w}\end{array}$ & 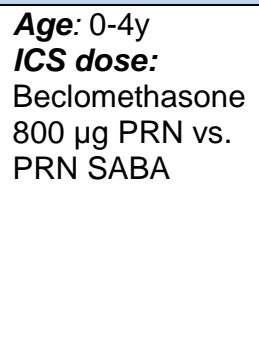 & $\begin{array}{l}\text { Progressive increase in SOB, } \\
\text { cough or wheeze: } \\
23 \text { total exacerbations, } 14 \\
\text { required oral corticosteroid }\end{array}$ & NR & $\begin{array}{l}\text { Composite } \\
\text { measures: } \\
\text { NR } \\
\text { Spirometry: } \\
\text { NR }\end{array}$ & NR & $\begin{array}{l}\text { Cumulative salbutamol } \\
\text { dose (mg): } \\
30.1(43.0) \text { vs. } 56.3 \text { (84.2), } \\
\text { p<0.001 } \\
\text { Daytime rescue } \\
\text { medication use: } \\
\text { MD -0.08 (-0.21 to } 0.05) \\
\text { Nighttime rescue } \\
\text { medication use: } \\
\text { MD - } 0.04(-0.11 \text { to } 0.03)\end{array}$ \\
\hline
\end{tabular}

Abbreviations: BID=twice daily; EPR=Expert Panel Review (Guidelines for Diagnosis and Management of Asthma); ER=emergency room; HR=hazard ratio; ICS=inhaled

corticosteroid; IQR=interquartile range; IRR= incident rate ratio; $m=$ months; $M D=$ mean difference; $m g=$ milligram; $n=$ patient sample size; $N R=$ not reported; $O R=$ odds ratio;

PACQLQ=Pediatric Asthma Caregiver's Quality of Life Questionnaire; PRN=pro re nata (i.e., as-needed); RCT=randomized controlled trial; RR=relative risk; SABA=shortacting $\beta_{2}$-agonist; $\mathrm{SOB}=$ short of breath; $\mu \mathrm{g}=$ microgram; $\mathrm{QID}=$ four times daily; URTI=upper respiratory tract infection; $w=$ weeks

${ }^{a}$ Age is categorized using study inclusion criteria and the age categories used in EPR-3 of $0-4 y, 5-11 y$ and $12 y+$. ICS dose is categorized, when possible, using the study's required

ICS dose and the EPR-3 categories of low, medium and high

${ }^{b}$ Relative measures are presented first and include, when reported by the study, RR, HR for time to the event, and IRR for count data allowing multiple events over the period of follow-up. Count data is presented, when reported by the study, for number of hospitalizations, hospital days, and ER visits in association with exacerbations. Number of

hospitalizations, hospital days, and ER visits not specified to be due to exacerbation are listed in the healthcare utilization column 
Table C-3. Study level outcomes for KQ1a, intermittent ICS with as-needed SABA vs. ICS controller with as-needed SABA

\begin{tabular}{|c|c|c|c|c|c|c|}
\hline $\begin{array}{l}\text { Study, } \\
\text { Year, n, } \\
\text { Study } \\
\text { design, } \\
\text { Duration }\end{array}$ & Population $^{a}$ & Exacerbations $^{b}$ & Mortality & Asthma Control & $\begin{array}{l}\text { Quality of } \\
\text { Life }\end{array}$ & Healthcare Utilization \\
\hline $\begin{array}{l}\text { Papi, } 2009^{47} \\
n=220 \\
\text { RCT, } 12 \mathrm{w}\end{array}$ & $\begin{array}{l}\text { Age: 0-4y } \\
\text { ICS dose: } \\
\text { Beclomethasone } \\
800 \mu \mathrm{g} \text { PRN vs. } \\
400 \mu \mathrm{B} \text { BID }\end{array}$ & $\begin{array}{l}\text { Progressive increase in SOB, } \\
\text { cough or wheeze: } \\
23 \text { total exacerbations, } 14 \\
\text { required oral corticosteroid }\end{array}$ & NR & $\begin{array}{l}\text { Composite } \\
\text { measures: } \\
\text { NR } \\
\text { Spirometry: } \\
\text { NR }\end{array}$ & NR & $\begin{array}{l}\text { Cumulative salbutamol dose } \\
\text { (mg): } \\
30.1(43.0) \text { vs. } 34.2(42.3) \\
\text { Daytime rescue medication } \\
\text { use: } \\
\text { MD } 0.07 \text { (-0.4 to } 1.8) \\
\text { Nighttime rescue medication } \\
\text { use: } \\
\text { MD }-0.02 \text { (-0.7 to } 0.3)\end{array}$ \\
\hline $\begin{array}{l}\text { Zeiger, } \\
2011^{49} \\
n=278 \\
\text { RCT, 52w }\end{array}$ & $\begin{array}{l}\text { Age: } 0-4 y \\
\text { ICS dose: } \\
\text { Budesonide 1.0mg } \\
\text { BID (high)x7d vs. } \\
0.5 \mathrm{mg} \text { (low) daily }\end{array}$ & $\begin{array}{l}\text { Exacerbation requiring } \\
\text { prednisolone: } \\
\text { HR } 0.97 \text { (0.76 to } 1.22) \\
\text { IRR } 0.99 \text { (0.71 to } 1.35) \\
\text { Second exacerbation } \\
\text { requiring prednisolone: } \\
\text { HR } 0.79 \text { (0.49 to } 1.32) \\
\text { Exacerbation occurring during } \\
\text { RTI: } \\
\text { RR } 0.99 \text { (0.92 to } 1.08) \\
\text { Proportion of RTI in which } \\
\text { prednisolone was } \\
\text { administered: } \\
\text { MD } 0.02 \text { (-0.05 to } 0.09) \\
\text { Asthma related } \\
\text { hospitalization: } \\
\text { RR } 1.25 \text { (0.34 to } 4.56) \\
\text { Asthma related urgent care } \\
\text { visit: } \\
\text { IRR } 0.99 \text { (0.72 to } 1.35)\end{array}$ & $\begin{array}{l}\text { All-cause: No } \\
\text { events occurred }\end{array}$ & $\begin{array}{l}\text { Composite } \\
\text { measures: } \\
\text { NR } \\
\text { Spirometry: } \\
\text { NR }\end{array}$ & NR & $\begin{array}{l}\text { \% days w/albuterol use: } \\
\text { MD } 0.4(-1.00 \text { to } 2.00)\end{array}$ \\
\hline
\end{tabular}

Abbreviations: BID=twice a day; d=day; EPR=Expert Panel Review (Guidelines for Diagnosis and Management of Asthma); ER=emergency room; HR=hazard ratio; ICS=inhaled corticosteroid; IRR=incident rate ratio; $\mathrm{MD}=$ mean difference; $\mathrm{mg}=$ milligram; $\mathrm{n}=$ =patient sample size; $\mathrm{NR=not} \mathrm{reported;} \mathrm{RCT=randomized} \mathrm{controlled} \mathrm{trial;} \mathrm{RR=relative} \mathrm{risk;}$

RTI=respiratory tract infection; SOB=short of breath; $\mu \mathrm{g}=$ microgram; $w=$ week; $y=y e a r$

${ }^{a}$ Age is categorized using study inclusion criteria and the age categories used in EPR-3 of 0-4y, 5-11y and 12y+. ICS dose is categorized, when possible, using the study's required ICS dose and the EPR-3 categories of low, medium and high 
belative measures are presented first and include, when reported by the study, RR, HR for time to the event, and IRR for count data allowing multiple events over the period of follow-up. Count data is presented, when reported by the study, for number of hospitalizations, hospital days, and ER visits in association with exacerbations. Number of hospitalizations, hospital days, and ER visits not specified to be due to exacerbation are listed in the healthcare utilization column

Table C-4. Study level outcomes for KQ1a, intermittent ICS versus no therapy

\begin{tabular}{|c|c|c|c|c|c|c|}
\hline $\begin{array}{l}\text { Study, } \\
\text { Year, n, } \\
\text { Study } \\
\text { design, } \\
\text { Duration }\end{array}$ & Population $^{\mathrm{a}}$ & Exacerbations $^{b}$ & Mortality & Asthma Control & Quality of Life & $\begin{array}{l}\text { Healthcare } \\
\text { Utilization }\end{array}$ \\
\hline $\begin{array}{l}\text { Ghirga, } \\
2002^{46} \\
N=26 \\
\text { RCT, NR }\end{array}$ & $\begin{array}{l}\text { Age: } 0-4 y \\
\text { ICS dose: } \\
\text { Beclomethasone } \\
400 \mu g \text { TIDx5d vs. } \\
\text { no preventative } \\
\text { therapy }\end{array}$ & $\begin{array}{l}\text { Received oral corticosteroid: } \\
\text { RR } 0.54(0.12 \text { to } 2.44) \\
\text { Asthma-related } \\
\text { hospitalizations: } \\
\text { No events occurred } \\
\text { Asthma-related ER visits: } \\
\text { RR } 0.27(0.04 \text { to } 2.10)\end{array}$ & NR & $\begin{array}{l}\text { Composite measures: } \\
\text { NR } \\
\text { Spirometry: } \\
\text { NR }\end{array}$ & NR & NR \\
\hline
\end{tabular}

Abbreviations: d=day; EPR=Expert Panel Review (Guidelines for Diagnosis and Management of Asthma); ER=emergency room; HR=hazard ratio; ICS=inhaled corticosteroid;

IRR=incident rate ratio; $n=$ patient sample size; $N R=$ not reported; RCT=randomized controlled trial; $R R=$ relative risk; TID=three times a day; $\mu g=$ microgram; $y=y e a r$

${ }^{a}$ Age is categorized using study inclusion criteria and the age categories used in EPR-3 of 0-4y, 5-11y and 12y+. ICS dose is categorized, when possible, using the study's required ICS dose and the EPR-3 categories of low, medium and high

${ }^{b}$ Relative measures are presented first and include, when reported by the study, RR, HR for time to the event, and IRR for count data allowing multiple events over the period of follow-up. Count data is presented, when reported by the study, for number of hospitalizations, hospital days, and ER visits in association with exacerbations. Number of hospitalizations, hospital days, and ER visits not specified to be due to exacerbation are listed in the healthcare utilization column 
Table C-5. Study and population characteristics for KQ1b, intermittent ICS and ICS controller vs. ICS controller

\begin{tabular}{|c|c|c|c|c|c|c|c|c|c|}
\hline $\begin{array}{l}\text { Study, Year, } \\
\text { N, } \\
\text { Acronym, } \\
\text { Study } \\
\text { design, } \\
\text { Duration, } \\
\text { Risk of bias }\end{array}$ & Study population & $\begin{array}{l}\text { Intervention } \\
\text { Comparisons }\end{array}$ & $\begin{array}{l}\text { Age } \\
\text { (y) } \\
\text { [mean } \\
\text { (SD)] }\end{array}$ & $\begin{array}{l}\text { Males } \\
\text { (\%) }\end{array}$ & $\begin{array}{l}\text { Duration } \\
\text { of } \\
\text { asthma } \\
\text { (y) [mean } \\
\text { (SD)] }\end{array}$ & $\begin{array}{l}\text { FEV1 } \\
\text { (L) } \\
\text { [mean } \\
\text { (SD)] }\end{array}$ & $\begin{array}{l}\text { FEV1 \% } \\
\text { predicted } \\
\text { (L) } \\
\text { [mean } \\
\text { (SD)] }\end{array}$ & $\begin{array}{l}\text { Rescue } \\
\text { inhaler } \\
\text { use } \\
\text { (puffs/d) } \\
\text { [mean } \\
\text { (SD)] }\end{array}$ & $\begin{array}{l}\text { ICS } \\
\text { dose } \\
\text { during } \\
\text { study } \\
\text { ( } \mu \text { g/d) } \\
\text { [mean } \\
\text { (SD)] }\end{array}$ \\
\hline \multirow[t]{2}{*}{$\begin{array}{l}\text { Lahdensuo, } \\
1996^{67} \\
\mathrm{n}=115 \\
\mathrm{RCT}, 12 \mathrm{~m} \\
\text { Medium }\end{array}$} & $\begin{array}{l}\geq 18 \mathrm{y} \text { with mild to moderately } \\
\text { severe asthma on budesonide } \\
(400-1600 \mu \mathrm{g} / \mathrm{d}) \text { or } \\
\text { beclomethasone }(500-2000 \mu \mathrm{g} / \mathrm{d}) \\
\text { during the prior } 6 \mathrm{~m}\end{array}$ & $\begin{array}{l}\text { Budesonide } 200 \mu \mathrm{g} / \mathrm{dose} \\
\text { (DPI) self-adjusted: PEF } \\
<85 \% \text { double ICS dose } x \\
2 \mathrm{w} \text {; PEF<70\% initiate } \\
\text { oral prednisolone } 40 \mathrm{mg} / \mathrm{d} \\
\mathrm{x} 7 \mathrm{~d} \text {; otherwise maintain } \\
\text { stable dose } \\
\mathrm{n}=56\end{array}$ & $\begin{array}{l}40.6 \\
(14.2)\end{array}$ & 26.8 & $8.2(8.4)$ & $\begin{array}{l}2.84 \\
(0.74)\end{array}$ & $\begin{array}{l}82.4 \\
(15.8)\end{array}$ & NR & $\begin{array}{l}979 \\
(375)\end{array}$ \\
\hline & $\begin{array}{l}\text { All patients used SABA as rescue } \\
\text { PRN. Other concomitant asthma } \\
\text { therapies were continued }\end{array}$ & $\begin{array}{l}\text { Budesonide (DPI/MDI) or } \\
\text { beclomethasone (MDI) } \\
\text { traditional treatment with } \\
\text { usual evaluation by } \\
\text { physician for adjustments } \\
\mathrm{n}=59\end{array}$ & $\begin{array}{l}42.8 \\
(15.2)\end{array}$ & 47.5 & $6.8(7.6)$ & $\begin{array}{l}2.96 \\
(0.89)\end{array}$ & $\begin{array}{l}81.7 \\
(16.6)\end{array}$ & NR & $\begin{array}{l}962 \\
(392) \\
1167 \\
(408)^{b}\end{array}$ \\
\hline \multirow[t]{2}{*}{$\begin{array}{l}\text { Foresi, } \\
2000^{56} \\
\mathrm{n}=134 \\
\mathrm{RCT}, 6 \mathrm{~m} \\
\text { Unclear }\end{array}$} & \multirow{2}{*}{$\begin{array}{l}\text { 18-65 years old with moderate } \\
\text { perennial asthma, treated with } \\
\text { beclomethasone } 500-1000 \mu \mathrm{g} / \mathrm{d} \text { for } \\
\text { at least } 4 \mathrm{w} \text {, daily requirement of } \\
\text { inhaled } \beta_{2} \text {-agoniost, wheeze, } \\
\text { cough, chest tightness, SOB at } \\
\text { rest that interfered with normal } \\
\text { activities during } 2 \mathrm{w} \text { pre-study } \\
\text { period } \\
\text { Inhaled } \beta_{2} \text {-agoniost was allowed } \\
\text { PRN and treatment with LABA } \\
\text { and theophylline were kept } \\
\text { constant }\end{array}$} & $\begin{array}{l}\text { Budesonide } 100 \mu \mathrm{g} \text { BID + } \\
200 \mu \mathrm{g} \text { QID x 7d if PEF } \\
<70 \% \text {. If PEF remained } \\
<70 \% \text { after } 2 \text { days then } \\
\text { prednisolone PO } 30 \mathrm{mg} \\
\text { x3-10d added by } \\
\text { investigator } \\
n=67\end{array}$ & $\begin{array}{l}39.0 \\
(13.5)\end{array}$ & 41.8 & $\begin{array}{l}<5 y=28.4 \\
5-10 y= \\
19.4 \\
>10 y=52.2\end{array}$ & NR & $75.6(9.9)$ & NR & NR \\
\hline & & $\begin{array}{l}\text { Budesonide } 400 \mu \mathrm{g} \text { BID+ } \\
\text { placebo if } \mathrm{PEF}<70 \% \text {. If } \\
\text { PEF remained }<70 \% \\
\text { prednisolone initiated as } \\
\text { above } \\
\mathrm{n}=67\end{array}$ & $\begin{array}{l}36.6 \\
(13.1)\end{array}$ & 46.3 & $\begin{array}{l}<5 y=25.4 \\
5 \text { to } 10 y= \\
28.4 \\
>10 y=46.3\end{array}$ & NR & $\begin{array}{l}73.2 \\
(11.0)\end{array}$ & NR & NR \\
\hline
\end{tabular}




\begin{tabular}{|c|c|c|c|c|c|c|c|c|c|}
\hline $\begin{array}{l}\text { Study, Year, } \\
\text { N, } \\
\text { Acronym, } \\
\text { Study } \\
\text { design, } \\
\text { Duration, } \\
\text { Risk of bias }\end{array}$ & Study population & $\begin{array}{l}\text { Intervention } \\
\text { Comparisons }\end{array}$ & $\begin{array}{l}\text { Age } \\
\text { (y) } \\
\text { [mean } \\
\text { (SD)] }\end{array}$ & $\begin{array}{l}\text { Males } \\
(\%)\end{array}$ & $\begin{array}{l}\text { Duration } \\
\text { of } \\
\text { asthma } \\
\text { (y) [mean } \\
\text { (SD)] }\end{array}$ & $\begin{array}{l}\text { FEV1 } \\
\text { (L) } \\
\text { [mean } \\
\text { (SD)] }\end{array}$ & $\begin{array}{l}\text { FEV1 \% } \\
\text { predicted } \\
\text { (L) } \\
\text { [mean } \\
\text { (SD)] }\end{array}$ & $\begin{array}{l}\text { Rescue } \\
\text { inhaler } \\
\text { use } \\
\text { (puffs/d) } \\
\text { [mean } \\
\text { (SD)] }\end{array}$ & $\begin{array}{l}\text { ICS } \\
\text { dose } \\
\text { during } \\
\text { study } \\
(\mu g / d) \\
{[\text { mean }} \\
\text { (SD)] }\end{array}$ \\
\hline $\begin{array}{l}\text { Colland, } \\
2004^{54} \\
\mathrm{n}=29 \\
\mathrm{RCT}, 1 \mathrm{y}\end{array}$ & $\begin{array}{l}4 \text { to } 11 \text { years old with moderate } \\
\text { asthma, ICS naïve with an } \\
\text { indication to begin ICS } \\
\text { maintenance treatment }\end{array}$ & $\begin{array}{l}\text { Self-initiated doubling of } \\
\text { daily ICS dose } x 1 w \text { with } \\
\text { occurrence of prodromal } \\
\text { signs } \\
n=14\end{array}$ & $\begin{array}{l}6 \\
(4-10)^{d}\end{array}$ & 71.4 & NR & NR & $100(13)$ & NR & NR \\
\hline Unclear & $\begin{array}{l}\text { All patients received } \\
\text { beclomethasone or budesonide } \\
400 \mu \mathrm{g} \text {, or fluticasone } 200-250 \mu \mathrm{g} \\
\text { divided over } 2 \text { doses (spacer/DPI) }\end{array}$ & $\begin{array}{l}\text { Daily maintenance } \\
\text { medications with no } \\
\text { adjustments } \\
\mathrm{n}=15\end{array}$ & $\begin{array}{l}7 \\
(4-11)^{d}\end{array}$ & 60 & NR & NR & $105(17)$ & NR & NR \\
\hline \multirow[t]{2}{*}{$\begin{array}{l}\text { FitzGerald, } \\
2004^{55} \\
n=98 \\
\text { RCT, } 6 \mathrm{~m}\end{array}$} & \multirow[t]{2}{*}{$\begin{array}{l}\geq 13 \text { years old with asthma on a } \\
\text { stable dose of } \leq 1200 \mu \mathrm{g} \\
\text { beclomethasone or equivalent } \\
\text { daily for } 1 \mathrm{~m} \text { prior to study, } \geq 1 \\
\text { exacerbation in prior } 12 \mathrm{~m} \\
\text { All patients received budesonide } \\
100-400 \mu \mathrm{g} \text { BID depending on } \\
\text { their prior maintenance therapy+ } \\
\text { terbutaline PRN. Mean } \\
\text { budesonide at baseline was } 634.7 \\
\mu \mathrm{g} / \mathrm{d} \text {. Theophylline was allowed } \\
\text { during the studye }\end{array}$} & $\begin{array}{l}\text { Add study inhaler which } \\
\text { provided doubling of } \\
\text { daily ICS dose } x 14 d \text { if } \\
\text { prompted by MiniDoc } \\
\text { (PEF<80\% + additional } \\
\text { required symptoms } \\
\text { present); PEF<60\% } \\
\text { prompted by MiniDoc to } \\
\text { take oral } \\
\text { methylprednisolone } \\
32 \mathrm{mg} / \mathrm{d} \times 7 \mathrm{~d}^{f} \\
\mathrm{n}=46\end{array}$ & $\begin{array}{l}31.6 \\
(14.6)\end{array}$ & 30 & $>1 y=93$ & $\begin{array}{l}2.9 \\
(0.8)\end{array}$ & NR & NR & NR \\
\hline & & $\begin{array}{l}\text { Add placebo inhaler } x 14 d \\
\text { if prompted by MiniDoc } \\
\text { (PEF<80\% + additional } \\
\text { required symptoms } \\
\text { present); PEF<60\% } \\
\text { prompted by MiniDoc to } \\
\text { take oral } \\
\text { methylprednisolone as } \\
\text { above } \\
n=52\end{array}$ & $\begin{array}{l}32.7 \\
(11.9)\end{array}$ & 25 & $>1 y r=90$ & $\begin{array}{l}2.8 \\
(0.6)\end{array}$ & NR & NR & NR \\
\hline
\end{tabular}




\begin{tabular}{|c|c|c|c|c|c|c|c|c|c|}
\hline $\begin{array}{l}\text { Study, Year, } \\
\text { N, } \\
\text { Acronym, } \\
\text { Study } \\
\text { design, } \\
\text { Duration, } \\
\text { Risk of bias }\end{array}$ & Study population & $\begin{array}{l}\text { Intervention } \\
\text { Comparisons }\end{array}$ & $\begin{array}{l}\text { Age } \\
\text { (y) } \\
\text { [mean } \\
\text { (SD)] }\end{array}$ & $\begin{array}{l}\text { Males } \\
\text { (\%) }\end{array}$ & $\begin{array}{l}\text { Duration } \\
\text { of } \\
\text { asthma } \\
\text { (y) [mean } \\
\text { (SD)] }\end{array}$ & $\begin{array}{l}\text { FEV1 } \\
\text { (L) } \\
\text { [mean } \\
\text { (SD)] }\end{array}$ & $\begin{array}{l}\text { FEV1 \% } \\
\text { predicted } \\
\text { (L) } \\
\text { [mean } \\
\text { (SD)] }\end{array}$ & $\begin{array}{l}\text { Rescue } \\
\text { inhaler } \\
\text { use } \\
\text { (puffs/d) } \\
\text { [mean } \\
\text { (SD)] }\end{array}$ & $\begin{array}{l}\text { ICS } \\
\text { dose } \\
\text { during } \\
\text { study } \\
\text { ( } \mu \mathrm{g} / \mathrm{d}) \\
\text { [mean } \\
\text { (SD)] }\end{array}$ \\
\hline \multirow[t]{2}{*}{$\begin{array}{l}\text { Harrison, } \\
2004^{59} \\
n=390 \\
\text { RCT, } 12 \mathrm{~m} \\
\text { Low }\end{array}$} & \multirow[t]{2}{*}{$\begin{array}{l}\geq 16 \text { years old with asthma taking } \\
\text { ICS }(100-2000 \mu \mathrm{g} / \mathrm{d}) \text { regularly, } \\
\text { taken oral corticosteroids or } \\
\text { temporarily doubled dose in prior } \\
12 \mathrm{~m} \text { due to an exacerbation, } \\
\text { stable during run-in based on PEF } \\
\text { and symptoms } \\
\text { All patients continued usual } \\
\text { treatment throughout the study. } \\
\text { Mean ICS dose } 708-711 \mu \mathrm{d} / \mathrm{d} \\
34.3-37.5 \% \text { on LABA at baseline }\end{array}$} & $\begin{array}{l}\text { Add study inhaler which } \\
\text { provided doubling of } \\
\text { daily ICS dose x14d if } \\
\text { AM PEF } \leq 85 \% \text { or daytime } \\
\text { symptom score } \\
\text { increased by } 1 \text { point from } \\
\text { run-in value; if PEF } \leq 60 \% \\
\text { or asthma control } \\
\text { deteriorated to point of } \\
\text { usual corticosteroid } \\
\text { therapy then oral } \\
\text { prednisolone } 30 \mathrm{mg} \text { daily } \\
\mathrm{x} 10 \mathrm{~d} \text { was started } \\
\mathrm{n}=192\end{array}$ & $50(13)$ & 36 & NR & $\begin{array}{l}2.4 \\
(0.8)\end{array}$ & 79 (19.6) & NR & NR \\
\hline & & $\begin{array}{l}\text { Add placebo inhaler } \times 14 d \\
\text { for } P E F \leq 85 \% \text { or } \\
\text { symptom score increase. } \\
\text { If PEF } \leq 60 \% \text { or asthma } \\
\text { control deteriorated to } \\
\text { point of usual } \\
\text { corticosteroid therapy } \\
\text { then oral prednisolone as } \\
\text { above } \\
n=198\end{array}$ & $48(14)$ & 29 & NR & $\begin{array}{l}2.4 \\
(0.8)\end{array}$ & 81 (21.1) & NR & NR \\
\hline $\begin{array}{l}\text { Oborne, } \\
2009^{66} \\
n=403 \\
\text { RCT, } 12 m\end{array}$ & $\begin{array}{l}\geq 16 y \text { old with asthma, taking } 200- \\
1000 \mu \mathrm{g} / \mathrm{d} \text { beclomethasone or } \\
\text { equivalent, have taken oral } \\
\text { corticosteroids or doubled ICS } \\
\text { dose in prior } 12 \mathrm{~m} \text { for exacerbation }\end{array}$ & $\begin{array}{l}\text { Add study inhaler x7-14d } \\
\text { which provided a } \\
\text { quadrupling of daily ICS } \\
\text { dose, otherwise usual } \\
\text { ICS dose daily } \\
n=197\end{array}$ & $53(14)$ & 41 & NR & $\begin{array}{l}2.4 \\
(0.7)\end{array}$ & 83.7 (19) & NR & NR \\
\hline
\end{tabular}




\begin{tabular}{|c|c|c|c|c|c|c|c|c|c|}
\hline $\begin{array}{l}\text { Study, Year, } \\
\text { N, } \\
\text { Acronym, } \\
\text { Study } \\
\text { design, } \\
\text { Duration, } \\
\text { Risk of bias }\end{array}$ & Study population & $\begin{array}{l}\text { Intervention } \\
\text { Comparisons }\end{array}$ & $\begin{array}{l}\text { Age } \\
\text { (y) } \\
\text { [mean } \\
\text { (SD)] }\end{array}$ & $\begin{array}{l}\text { Males } \\
(\%)\end{array}$ & $\begin{array}{l}\text { Duration } \\
\text { of } \\
\text { asthma } \\
\text { (y) [mean } \\
\text { (SD)] }\end{array}$ & $\begin{array}{l}\text { FEV1 } \\
\text { (L) } \\
\text { [mean } \\
\text { (SD)] }\end{array}$ & $\begin{array}{l}\text { FEV1 \% } \\
\text { predicted } \\
\text { (L) } \\
\text { [mean } \\
\text { (SD)] }\end{array}$ & $\begin{array}{l}\text { Rescue } \\
\text { inhaler } \\
\text { use } \\
\text { (puffs/d) } \\
\text { [mean } \\
\text { (SD)] }\end{array}$ & $\begin{array}{l}\text { ICS } \\
\text { dose } \\
\text { during } \\
\text { study } \\
\text { ( } \mu \text { g/d) } \\
\text { [mean } \\
\text { (SD)] }\end{array}$ \\
\hline Low & $\begin{array}{l}\text { Patients self-adjusted therapy } \\
\text { according to action plan- } \\
\text { AM PEF } \leq 70 \% \text { for } 1 \text { day or } \leq 85 \% \\
\text { for two or more days, in } \\
\text { presences of symptom worsening } \\
\text { or URTI: start study inhaler for } 7 d \\
\text { in addition to normal asthma } \\
\text { treatment }{ }^{9} \text {, continue for another } \\
7 d \text { if PEF did not return to } \\
\text { baseline AM PEF } \leq 40 \% \text {, general } \\
\text { practitioner advised so, or asthma } \\
\text { was at the point of usually starting } \\
\text { systemic corticosteroids: start } \\
\text { prednisone } 30 \mathrm{mg} \text { PO daily }\end{array}$ & $\begin{array}{l}\text { Add placebo inhaler } x 7- \\
14 d+\text { usual daily ICS } \\
\text { dose otherwise } \\
n=206\end{array}$ & $55(13)$ & 37 & NR & $\begin{array}{l}2.4 \\
(0.7)\end{array}$ & $83.2(18)$ & NR & NR \\
\hline $\begin{array}{l}\text { Martinez, } \\
2011^{60} \\
\text { TREXA } \\
n=143 \\
\text { RCT, } 44 w \\
\text { Low }\end{array}$ & 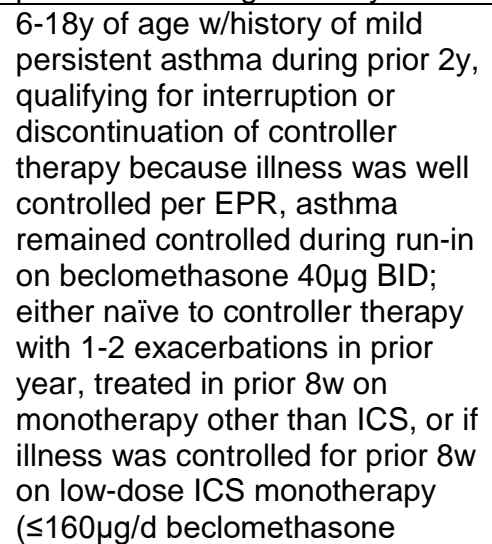 & $\begin{array}{l}\text { Beclomethasone } 40 \mu \mathrm{g} \\
\text { BID (MDI) with PRN use } \\
\text { of beclomethasone } 40 \mu \mathrm{g} \\
\text { (MDI) + albuterol } 90 \mu \mathrm{g} \\
\text { (MDI) PRN } \\
\mathrm{n}=71\end{array}$ & $\begin{array}{l}11.4 \\
(3.1)\end{array}$ & 55 & NR & NR & $\begin{array}{l}101.5 \\
(11.7)\end{array}$ & NR & NR \\
\hline
\end{tabular}




\begin{tabular}{|c|c|c|c|c|c|c|c|c|c|}
\hline $\begin{array}{l}\text { Study, Year, } \\
\text { N, } \\
\text { Acronym, } \\
\text { Study } \\
\text { design, } \\
\text { Duration, } \\
\text { Risk of bias }\end{array}$ & Study population & $\begin{array}{l}\text { Intervention } \\
\text { Comparisons }\end{array}$ & $\begin{array}{l}\begin{array}{l}\text { Age } \\
\text { (y) }\end{array} \\
\text { [mean } \\
\text { (SD)] }\end{array}$ & $\begin{array}{l}\text { Males } \\
(\%)\end{array}$ & $\begin{array}{l}\text { Duration } \\
\text { of } \\
\text { asthma } \\
\text { (y) [mean } \\
\text { (SD)] }\end{array}$ & $\begin{array}{l}\text { FEV1 } \\
\text { (L) } \\
{[\text { mean }} \\
\text { (SD)] }\end{array}$ & $\begin{array}{l}\text { FEV1 \% } \\
\text { predicted } \\
\text { (L) } \\
\text { [mean } \\
\text { (SD)] }\end{array}$ & $\begin{array}{l}\text { Rescue } \\
\text { inhaler } \\
\text { use } \\
\text { (puffs/d) } \\
\text { [mean } \\
\text { (SD)] }\end{array}$ & $\begin{array}{l}\text { ICS } \\
\text { dose } \\
\text { during } \\
\text { study } \\
\text { ( } \mu \text { g/d) } \\
\text { [mean } \\
\text { (SD)] }\end{array}$ \\
\hline & $\begin{array}{l}\text { equivalent) }^{\mathrm{h}} \\
\text { All patients used PRN inhalers } \\
\text { every time they would have used } \\
\text { albuterol for symptom relief or to } \\
\text { treat decreased in PEF, number of } \\
\text { puffs was self-determined. All } \\
\text { patients received prednisone x4d } \\
\text { for asthma exacerbation }\end{array}$ & $\begin{array}{l}\text { Beclomethasone } 40 \mu \mathrm{g} \\
\text { BID (MDI) with PRN use } \\
\text { of placebo inhaler }+ \\
\text { albuterol } 90 \mu \mathrm{g}(\mathrm{MDI}) \\
\mathrm{n}=72\end{array}$ & $\begin{array}{l}10.8 \\
(3.5)\end{array}$ & 58 & NR & NR & $\begin{array}{l}100.1 \\
(10.8)\end{array}$ & NR & NR \\
\hline
\end{tabular}

Abbreviations: AM=morning; BID=twice daily; d=day; DPI=dry powder inhaler; EPR=Expert Panel Review (Guidelines for Diagnosis and Management of Asthma);

$\mathrm{FEV}_{1}=$ forced expiratory volume in one second; $\mathrm{GP}=$ general practitioner; ICS=inhaled corticosteroid; $\mathrm{L}=$ liter; LABA=long-acting $\beta_{2}$-agonist; $\mathrm{m}=$ month; $\mathrm{MDI}=$ metered dose

inhaler; $\mathrm{n}=$ patient sample size; $\mathrm{NR}=$ not reported; $\mathrm{PO}=$ by mouth; $\mathrm{PRN}=$ pro re nata (i.e., as-needed); $\mathrm{PEF}=$ peak expiratory flow; $\mathrm{QID=four}$ times daily; RCT=randomized controlled trial; SABA=short-acting $\beta_{2}$-agonist; $\mathrm{SD}=$ standard deviation; $w=$ weeks; $y=$ years

${ }^{a}$ Concurrent therapies during the trial in the self-adjusted arm included inhaled anticholinergics (5.4\%), methylxanthines (16.1\%) and nedocromil (3.6\%). Concurrent therapies during the trial in the traditional treatment arm included inhaled anticholinergics (3.6\%), methylxanthines (18.6\%) and nedocromil (3.4\%)

bFirst and second set of values represent budesonide and beclomethasone, respectively

'LABA and theophylline use during the trial in the budesonide $100 \mu \mathrm{g}$ BID + additional use arm were $37.3 \%$ and $11.9 \%$, respectively. LABA and theophylline use during the trial in the budesonide $100 \mu \mathrm{g}$ BID + placebo arm were $49.3 \%$ and $26.9 \%$, respectively, and in the $400 \mu \mathrm{g}$ BID + placebo arm were $41.8 \%$ and $13.4 \%$, respectively

${ }^{\mathrm{d}}$ Data reported as mean (range)

eTheophylline use in the doubled dose and maintenance dose arms were $0 \%$ and $3.8 \%$, respectively

${ }^{\mathrm{f}}$ MinDoc programmed with alert asthma symptom score (three ordinal values above the mean baseline total symptom score on 2 consecutive days) and alerted the patient in the event of an asthma exacerbation. Patient reported exacerbation to study personnel and given instructions to take additional inhaler

${ }^{g} \mathrm{LABA}$ use in the quadrupled dose and maintenance dose arms were $38 \%$ and $39 \%$, respectively

hInhaled corticosteroid and leukotriene receptor inhibitor/antagonist use in the previous year in the rescue arm was $72 \%$ and $20 \%$, respectively. Previous year use of inhaled ICS and leukotriene receptor inhibitor/antagonist in the combined arm were $76 \%$ and $16 \%$, respectively, and in the daily arm were $82 \%$ and $10 \%$ 
Table C-6. Study and population characteristics for KQ1b, intermittent ICS vs. ICS controller

\begin{tabular}{|c|c|c|c|c|c|c|c|c|c|}
\hline $\begin{array}{l}\text { Study, Year, } \\
\text { N, } \\
\text { Acronym, } \\
\text { Study } \\
\text { design, } \\
\text { Duration } \\
\text { Risk of Bias }\end{array}$ & Study population & $\begin{array}{l}\text { Intervention } \\
\text { Comparisons }\end{array}$ & $\begin{array}{l}\text { Age } \\
\text { (y) } \\
\text { [mean, } \\
\text { (SD)] }\end{array}$ & $\begin{array}{l}\text { Males } \\
(\%)\end{array}$ & $\begin{array}{l}\text { Duration } \\
\text { of } \\
\text { asthma } \\
\text { (y) [mean } \\
\text { (SD)] }\end{array}$ & $\begin{array}{l}\text { FEV1 } \\
\text { (L) } \\
\text { [mean } \\
\text { (SD)] }\end{array}$ & $\begin{array}{l}\text { FEV1 \% } \\
\text { predicted } \\
\text { (L) } \\
\text { [mean } \\
\text { (SD)] }\end{array}$ & $\begin{array}{l}\text { Rescue } \\
\text { inhaler } \\
\text { use } \\
\text { (puffs/d) } \\
\text { [mean } \\
\text { (SD)] }\end{array}$ & $\begin{array}{l}\text { ICS } \\
\text { dose } \\
\text { during } \\
\text { study } \\
\text { ( } \mu \text { g/d) } \\
\text { [mean } \\
(\mathrm{SD})] \\
\end{array}$ \\
\hline \multirow[t]{2}{*}{$\begin{array}{l}\text { Boushey, } \\
2005^{51} \\
\text { IMPACT } \\
n=149 \\
\text { RCT, 52w }\end{array}$} & \multirow{2}{*}{$\begin{array}{l}\text { 18-65 years of age w/mild } \\
\text { persistent asthma (self-treatment } \\
\text { with } \beta_{2} \text {-agonist }>2 d \text { per week, } \\
\text { nighttime awakenings related to } \\
\text { asthma }>2 d \text { per month, or } \\
\text { variability in the PEF of } 20-30 \% \text { ). } \\
\text { All patients self-adjusted } \\
\text { according to action plan }{ }^{2} \text { - } \\
\text { Green zone: Continue as usual, } \\
\text { albuterol PRN } \\
\text { Yellow zone: Start budesonide } \\
800 \mu \text { BID x10d } \\
\text { Red zone: Start prednisone } \\
0.5 m g / k g \text { PO x5d } \\
\text { Extra red zone: albuterol, } \\
\text { prednisone and go to ER or call } \\
911\end{array}$} & $\begin{array}{l}\text { Placebo inhaler BID + } \\
\text { placebo tablets BID } \\
n=76\end{array}$ & $\begin{array}{l}32.0 \\
(10.5)\end{array}$ & 43 & $\begin{array}{l}19.5 \\
(11.8)\end{array}$ & $\begin{array}{l}3.2 \\
(0.7)\end{array}$ & $\begin{array}{l}87.8 \\
(12.7)\end{array}$ & NR & NR \\
\hline & & $\begin{array}{l}\text { Budesonide } 200 \mu \mathrm{g} \text { BID } \\
\text { (DPI)+ placebo tablets } \\
\text { BID } \\
n=73\end{array}$ & $\begin{array}{l}33.2 \\
(9.5)\end{array}$ & 38 & $\begin{array}{l}17.1 \\
(11.0)\end{array}$ & $\begin{array}{l}3.2 \\
(0.8)\end{array}$ & $\begin{array}{l}90.5 \\
(12.6)\end{array}$ & NR & NR \\
\hline \multirow{3}{*}{$\begin{array}{l}\text { Papi, } 2007^{63} \\
\text { BEST-adult } \\
n=337 \\
\text { RCT, 6m } \\
\text { Low }\end{array}$} & \multirow{3}{*}{$\begin{array}{l}\text { 18-65 years old with mild } \\
\text { persistent asthma according to } \\
\text { EPR2 for at least } 6 \mathrm{~m} \text {, adequately } \\
\text { controlled at the end of run-in on } \\
\text { beclomethasone } 250 \mu \mathrm{g} \text { BID. } \\
\text { No written action plan, orally } \\
\text { instructed to use PRN inhaler for } \\
\text { symptom relief. }\end{array}$} & $\begin{array}{l}\text { Placebo inhaler BID + } \\
\text { Beclomethasone/ } \\
\text { albuterol } 250 / 100 \mu \mathrm{g} \text { PRN } \\
\mathrm{n}=122\end{array}$ & $\begin{array}{l}36.8 \\
(13.1)\end{array}$ & 41.0 & NR & $\begin{array}{l}3.0 \\
(0.8)\end{array}$ & $\begin{array}{l}88.5 \\
(11.3)\end{array}$ & $0.4(0.7)$ & $\begin{array}{l}18,480 \\
(25250) \\
b\end{array}$ \\
\hline & & $\begin{array}{l}\text { Beclomethasone/ } \\
\text { albuterol } 250 / 100 \mu \mathrm{g} \mathrm{BID} \\
+ \text { albuterol } 100 \mu \mathrm{g} \text { PRN } \\
\mathrm{n}=109\end{array}$ & $\begin{array}{l}39.9 \\
(14.4)\end{array}$ & 39.4 & NR & $\begin{array}{l}2.9 \\
(0.7)\end{array}$ & $\begin{array}{l}87.2 \\
(10.7)\end{array}$ & $0.5(0.7)$ & $\begin{array}{l}77,070 \\
(17550) \\
b\end{array}$ \\
\hline & & $\begin{array}{l}\text { Beclomethasone } 250 \mu \mathrm{g} \\
\text { BID + albuterol } 100 \mu \mathrm{g} \\
\text { PRN } \\
\mathrm{n}=106\end{array}$ & $\begin{array}{l}37.9 \\
(13.5)\end{array}$ & 42.5 & NR & $\begin{array}{l}3.0 \\
(0.7)\end{array}$ & $\begin{array}{l}88.8 \\
(11.1)\end{array}$ & $0.4(0.7)$ & $\begin{array}{l}76,970 \\
(17350) \\
b\end{array}$ \\
\hline
\end{tabular}




\begin{tabular}{|c|c|c|c|c|c|c|c|c|c|}
\hline $\begin{array}{l}\text { Study, Year, } \\
\mathrm{N}, \\
\text { Acronym, } \\
\text { Study } \\
\text { design, } \\
\text { Duration } \\
\text { Risk of Bias }\end{array}$ & Study population & $\begin{array}{l}\text { Intervention } \\
\text { Comparisons }\end{array}$ & $\begin{array}{l}\text { Age } \\
\text { (y) } \\
\text { [mean, } \\
\text { (SD)] }\end{array}$ & $\begin{array}{l}\text { Males } \\
(\%)\end{array}$ & $\begin{array}{l}\text { Duration } \\
\text { of } \\
\text { asthma } \\
\text { (y) [mean } \\
\text { (SD)] }\end{array}$ & $\begin{array}{l}\text { FEV1 } \\
\text { (L) } \\
{[\text { mean }} \\
\text { (SD)] }\end{array}$ & $\begin{array}{l}\text { FEV1 \% } \\
\text { predicted } \\
\text { (L) } \\
\text { [mean } \\
\text { (SD)] }\end{array}$ & $\begin{array}{l}\text { Rescue } \\
\text { inhaler } \\
\text { use } \\
\text { (puffs/d) } \\
\text { [mean } \\
\text { (SD)] }\end{array}$ & $\begin{array}{l}\text { ICS } \\
\text { dose } \\
\text { during } \\
\text { study } \\
\text { ( } \mu \text { g/d) } \\
\text { [mean } \\
\text { (SD)] }\end{array}$ \\
\hline \multirow[t]{2}{*}{$\begin{array}{l}\text { Turpeinen, } \\
2007^{64} \\
\text { HELSINKI } \\
\mathrm{n}=116 \\
\text { RCT, } 18 \mathrm{~m} \\
\text { Low }\end{array}$} & $\begin{array}{l}5-10 \text { years old with symptoms } \\
\text { such as wheezing, prolonged } \\
\text { cough or SOB suggesting asthma } \\
\text { for at least } 1 \mathrm{~m} \text {. According to } \\
\text { symptoms and lung function } \\
\text { majority of children could be } \\
\text { categorized as mild persistent } \\
\text { asthma. }\end{array}$ & $\begin{array}{l}\text { Budesonide } 400 \mu \mathrm{g} \text { BID } \\
\text { x1m, } 200 \mu \mathrm{g} \text { BID } \times 5 \mathrm{~m} \text {, } \\
\text { placebo } \times 12 \mathrm{~m} \\
\mathrm{n}=58\end{array}$ & $\begin{array}{l}6.7 \\
(5-10)^{d}\end{array}$ & 66 & $\begin{array}{l}11.3 \\
(2.0 \text { to } \\
76.4)^{\mathrm{d}, \mathrm{e}}\end{array}$ & $\begin{array}{l}1.32 \\
(0.72 \\
\text { to } \\
2.36)^{d}\end{array}$ & $\begin{array}{l}82 \\
(52-107)^{d}\end{array}$ & $\begin{array}{l}0.55 \\
(0-3.7)^{d}\end{array}$ & NR \\
\hline & $\begin{array}{l}\text { All patients received terbutaline } \\
\text { PRN and physician determined } \\
\text { replacement of study medication } \\
\text { with budesonide } 400 \mu \mathrm{g} \text { BID } \times 2 \mathrm{w} \\
\text { during exacerbations. }{ }^{\mathrm{c}}\end{array}$ & $\begin{array}{l}\text { Budesonide } 400 \mu \mathrm{g} \text { BID } \\
\text { x1m, } 200 \mu \mathrm{g} \text { BID x5m, } \\
100 \mu \mathrm{g} \text { BID x12m } \\
\mathrm{n}=58\end{array}$ & $\begin{array}{l}7.0 \\
(5 \text { to } \\
10)^{d}\end{array}$ & 59 & $\begin{array}{l}12.8 \\
(1.1 \text { to } \\
70.5)^{\mathrm{d}, \mathrm{e}}\end{array}$ & $\begin{array}{l}1.43 \\
(0.89 \\
\text { to } \\
2.15)^{d}\end{array}$ & $\begin{array}{l}87 \\
(57-111)^{d}\end{array}$ & $\begin{array}{l}0.47 \\
(0-4.0)^{d}\end{array}$ & NR \\
\hline $\begin{array}{l}\text { Martinez, } \\
2011^{60} \\
\text { TREXA } \\
\mathrm{n}=143 \\
\text { RCT, } 44 \mathrm{w} \\
\text { Low }\end{array}$ & 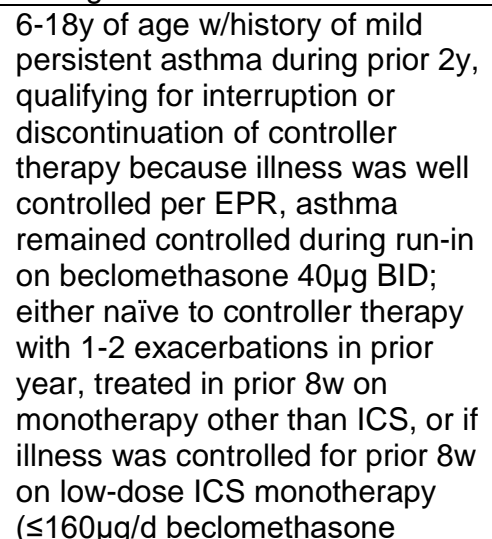 & $\begin{array}{l}\text { Placebo inhaler BID with } \\
\text { PRN use of } \\
\text { beclomethasone } 40 \mu \mathrm{g} \\
(\mathrm{MDI})+\text { albuterol } 90 \mu \mathrm{g} \\
(\mathrm{MDI}) \\
\mathrm{n}=71\end{array}$ & $\begin{array}{l}10.4 \\
(2.8)\end{array}$ & 52 & NR & NR & $\begin{array}{l}101.4 \\
(12.1)\end{array}$ & NR & NR \\
\hline
\end{tabular}




\begin{tabular}{|c|c|c|c|c|c|c|c|c|c|}
\hline \multirow[t]{2}{*}{$\begin{array}{l}\text { Study, Year, } \\
\text { N, } \\
\text { Acronym, } \\
\text { Study } \\
\text { design, } \\
\text { Duration } \\
\text { Risk of Bias }\end{array}$} & Study population & $\begin{array}{l}\text { Intervention } \\
\text { Comparisons }\end{array}$ & $\begin{array}{l}\text { Age } \\
\text { (y) } \\
\text { [mean, } \\
\text { (SD)] }\end{array}$ & $\begin{array}{l}\text { Males } \\
(\%)\end{array}$ & $\begin{array}{l}\text { Duration } \\
\text { of } \\
\text { asthma } \\
\text { (y) [mean } \\
\text { (SD)] }\end{array}$ & $\begin{array}{l}\text { FEV1 } \\
\text { (L) } \\
\text { [mean } \\
\text { (SD)] }\end{array}$ & $\begin{array}{l}\text { FEV1 \% } \\
\text { predicted } \\
\text { (L) } \\
\text { [mean } \\
\text { (SD)] }\end{array}$ & $\begin{array}{l}\text { Rescue } \\
\text { inhaler } \\
\text { use } \\
\text { (puffs/d) } \\
\text { [mean } \\
\text { (SD)] }\end{array}$ & $\begin{array}{l}\text { ICS } \\
\text { dose } \\
\text { during } \\
\text { study } \\
\text { ( } \mu \text { g/d) } \\
\text { [mean } \\
\text { (SD)] }\end{array}$ \\
\hline & $\begin{array}{l}\text { equivalent). }{ }^{f} \\
\text { All patients used PRN inhalers } \\
\text { every time they would have used } \\
\text { albuterol for symptom relief or to } \\
\text { treat decreased in PEF, number of } \\
\text { puffs was self-determined. All } \\
\text { patients received prednisone x4d } \\
\text { for asthma exacerbation }\end{array}$ & $\begin{array}{l}\text { Beclomethasone } 40 \mu \mathrm{g} \\
\text { BID (MDI) with PRN use } \\
\text { of placebo inhaler }+ \\
\text { albuterol } 90 \mu \mathrm{g} \text { (MDI) } \\
\mathrm{n}=72\end{array}$ & $\begin{array}{l}10.8 \\
(3.5)\end{array}$ & 58 & NR & NR & $\begin{array}{l}100.1 \\
(10.8)\end{array}$ & NR & NR \\
\hline \multirow[t]{2}{*}{$\begin{array}{l}\text { Calhoun, } \\
2012^{52} \\
\text { BASALT } \\
n=227 \\
\text { RCT, 9m }\end{array}$} & \multirow{2}{*}{$\begin{array}{l}\geq 18 y \text { and older with mild to } \\
\text { moderate asthma, need for daily } \\
\text { controller therapy based on } \\
\text { receiving prescription in prior } 12 \mathrm{~m} \\
\text { or symptoms more than twice/w } \\
\text { and not on controller, if on ICS } \\
\leq 1000 \mu \text { fluticasone or equivalent } \\
\text { stable for at least } 2 \mathrm{w} \text {, completely } \\
\text { controlled asthma during run-in on } \\
\text { beclomethasone } 80 \mu \mathrm{B} \text { BID, based } \\
\text { on asthma evaluation } \\
\text { questionnaire and FEV>70\% } \\
\text { predicted. } \\
\text { All patients received unrestricted } \\
\text { albuterol (MDI). Investigators were } \\
\text { allowed to add open-label } \\
\text { budesonide } 80 \mu \mathrm{Bg} \text { BID x14d if } \\
\text { needed. }\end{array}$} & $\begin{array}{l}\text { Budesonide } 40 \mu \mathrm{g}(\mathrm{MDI}) \\
\text { used on a puff-per-puff } \\
\text { basis every time the } \\
\text { patient uses albuterol } \\
(\mathrm{MDI}) \\
\mathrm{n}=113\end{array}$ & $\begin{array}{l}36.0 \\
(12.2)\end{array}$ & 26.5 & $\begin{array}{l}21.3 \\
(12.1)\end{array}$ & $\begin{array}{l}2.90 \\
(0.69)\end{array}$ & $\begin{array}{l}85.6 \\
(11.0)\end{array}$ & $\begin{array}{l}0 \\
(0-0.31)^{g}\end{array}$ & $\begin{array}{l}832 \\
(N R)^{h}\end{array}$ \\
\hline & & $\begin{array}{l}\text { Budesonide } 80 \mu \mathrm{g} \text { BID } \\
\text { (MDI) adjusted by } \\
\text { physician every } 6 \mathrm{w} \\
\text { based on NHLBI } \\
\text { guidelines } \\
\mathrm{n}=114\end{array}$ & $\begin{array}{l}34.2 \\
(11.9)\end{array}$ & 36.8 & $\begin{array}{l}20.4 \\
(10.4)\end{array}$ & $\begin{array}{l}3.03 \\
(0.72)\end{array}$ & $\begin{array}{l}87.7 \\
(12.1)\end{array}$ & $\begin{array}{l}0.04(0- \\
0.29)^{\mathrm{g}}\end{array}$ & $\begin{array}{l}1610 \\
(N R)^{h}\end{array}$ \\
\hline
\end{tabular}

Abbreviations: BID=twice daily; d=day; DPI=dry powder inhaler; EPR=Expert Panel Review (Guidelines for Diagnosis and Management of Asthma); ER=emergency room;

$\mathrm{FEV}_{1}=$ forced expiratory volume in one second; ICS=inhaled corticosteroid; L=liter; LABA=long-acting $\beta_{2}$-agonist; $m=$ months; MDI=metered dose inhaler; $n=$ patient sample size; NHLBI=National Heart, Lung and Blood Institute; NR=not reported; PO=by mouth; PRN=pro re nata (i.e., as-needed); PEF=peak expiratory flow; QID=four times daily;

$\mathrm{RCT}=$ randomized controlled trial; $\mathrm{SD}=$ standard deviation; $\mathrm{SOB}=$ shortness of breath; $\mathrm{w}=$ weeks; $\mathrm{y}=\mathrm{years}$

${ }^{a}$ Green zone: symptoms and albuterol use stable; Yellow zone: Awakening from asthma 3+ times in a 2-week period or on 2 consecutive nights, or using albuterol for relief of symptoms 4+ times/day for 2 or more consecutive days, or albuterol has been relieving symptoms for less than 4h each treatment over a 12-hour period, or using albuterol for relief of symptoms daily for 7 days, and this use exceeds 2 times the weekly use of albuterol in the baseline period, or exercise induces unusual breathlessness; Red zone: For the

$$
\text { C-17 }
$$


previous 24 hours, daily life activities cause SOB or breathlessness is present at rest, or albuterol has been relieving symptoms for $<2 \mathrm{~h}$ after each treatment over an $8 \mathrm{~h}$ period; Extra red zone: Severe SOB at rest, or difficulty talking because of SOB, or albuterol has been relieving symptoms for less than $1 \mathrm{~h}$ after each treatment over a $4 \mathrm{~h}$ period, or does not relieve symptoms after 2 treatments repeated within a single hour

${ }^{\mathrm{b}}$ Cumulative doses of beclomethasone inhaled during the entire 6-month treatment period

'Exacerbations defined as an increase in symptoms not controlled by 6 doses/24h of terbutaline that caused the parent to contact the clinic

dData reported as mean (range)

'Data reported in months

fInhaled ICS and leukotriene receptor inhibitor/antagonist use in the previous year in the rescue arm was $72 \%$ and $20 \%$, respectively. Previous year use of inhaled corticosteroids and leukotriene receptor inhibitor/antagonist in the combined arm were $76 \%$ and $16 \%$, respectively, and in the daily arm were $82 \%$ and $10 \%$

gData reported as median (interquartile range)

hepresents mean monthly dose

Table C-7. Study level outcomes for KQ1b, intermittent ICS and ICS controller vs. ICS controller

\begin{tabular}{|c|c|c|c|c|c|c|}
\hline $\begin{array}{l}\text { Study, } \\
\text { Year, n, } \\
\text { Study } \\
\text { design, } \\
\text { Duration }\end{array}$ & Population $^{a}$ & Exacerbations $^{b}$ & Mortality & Asthma control & Quality of life & $\begin{array}{l}\text { Healthcare } \\
\text { utilization }\end{array}$ \\
\hline $\begin{array}{l}\text { Lahdensuo, } \\
1996^{67} \\
n=115 \\
\text { RCT, } 12 \mathrm{~m}\end{array}$ & $\begin{array}{l}\text { Age: } 12 y+ \\
\text { Severity/control: } \\
\text { Mild to moderately } \\
\text { severe asthma } \\
\text { Intermittent ICS: } \\
\text { Doubling regular } \\
\text { dose }\end{array}$ & $\begin{array}{l}\text { Relative measures } \\
\text { Requiring oral corticosteroid: } \\
\text { RR } 0.51 \text { ( } 0.29 \text { to } 0.88) \\
\text { Exacerbation (undefined): } \\
\text { RR } 0.48 \text { ( } 0.33 \text { to } 0.71) \\
\text { Asthma-related } \\
\text { hospitalization: } \\
\text { RR } 0.70 \text { (0.12 to } 4.05) \\
\text { Unscheduled outpatient visit: } \\
\text { RR } 0.53 \text { ( } 0.29 \text { to } 0.96) \\
\text { Count data } \\
\text { Number of hospitalizations: } \\
2 \text { vs. } 3\end{array}$ & NR & $\begin{array}{l}\text { Composite measures: } \\
\text { NR } \\
\text { Spirometry: } \\
\text { NR }\end{array}$ & NR & NR \\
\hline $\begin{array}{l}\text { Foresi, } \\
2000^{56} \\
\mathrm{n}=134 \\
\mathrm{RCT}, 6 \mathrm{~m}\end{array}$ & $\begin{array}{l}\text { Age: } 12 \mathrm{y}+ \\
\text { Severity/control: } \\
\text { Moderate } \\
\text { persistent asthma/ } \\
\text { symptomatic } \\
\text { Intermittent ICS: } \\
\text { Quadrupling } \\
\text { regular dose }\end{array}$ & $\begin{array}{l}\text { Relative measures } \\
\text { Fall in PEF <70\% from } \\
\text { baseline: RR } 1.09 \text { ( } 0.52 \text { to } \\
2.30) \\
\text { Count data } \\
\text { Total number of oral } \\
\text { corticosteroid days: } \\
37 \text { vs. } 47\end{array}$ & NR & $\begin{array}{l}\text { Composite measures: } \\
\text { NR } \\
\text { Spirometry: } \\
\text { NR }\end{array}$ & NR & NR \\
\hline
\end{tabular}




\begin{tabular}{|c|c|c|c|c|c|c|}
\hline $\begin{array}{l}\text { Study, } \\
\text { Year, n, } \\
\text { Study } \\
\text { design, } \\
\text { Duration }\end{array}$ & Population $^{a}$ & Exacerbations $^{b}$ & Mortality & Asthma control & Quality of life & $\begin{array}{l}\text { Healthcare } \\
\text { utilization }\end{array}$ \\
\hline $\begin{array}{l}\text { Colland, } \\
2004^{54} \\
n=29 \\
\text { RCT, } 12 m\end{array}$ & $\begin{array}{l}\text { Age: 5-11y } \\
\text { Severity/control: } \\
\text { Moderate } \\
\text { persistent asthma/ } \\
\text { symptomatic } \\
\text { Intermittent ICS: } \\
\text { Doubling regular } \\
\text { dose }\end{array}$ & $\begin{array}{l}\text { Relative measures } \\
\text { Requiring hospitalization: } \\
\text { Peto's OR } 0.14 \text { (0.003 to } \\
7.31) \\
\text { Count data } \\
\text { NR }\end{array}$ & $\mathrm{NR}$ & $\begin{array}{l}\text { Composite measures: } \\
\text { NR } \\
\text { Spirometry: } \\
\text { FEV1 \% predicted: } \\
\text { MD } 5 \text { (-6.01 to 16.01) }\end{array}$ & NR & NR \\
\hline $\begin{array}{l}\text { Fitzgerald, } \\
2004^{55} \\
n=98 \\
\text { RCT, } 6 \mathrm{~m}\end{array}$ & $\begin{array}{l}\text { Age: } 12 \mathrm{y}+ \\
\text { Severity/control: } \\
\text { Persistent asthma } \\
\text { Intermittent ICS: } \\
\text { Doubling regular } \\
\text { dose }\end{array}$ & $\begin{array}{l}\text { Relative measures } \\
\text { Requiring oral corticosteroid } \\
\text { (of those who initiated study } \\
\text { inhaler) } \\
\text { RR: } 0.85 \text { (0.39 to } 1.83 \text { ) } \\
\text { Requiring oral corticosteroid, } \\
\text { unscheduled doctors visit, } \\
\text { ER, or unstable asthma: } \\
\text { RR } 1.03 \text { (0.63 to } 1.65) \\
\text { Unstable asthmac: } \\
\text { RR } 0.57 \text { (0.23 to } 1.38) \\
\text { Count data } \\
\text { NR }\end{array}$ & NR & $\begin{array}{l}\text { Composite measures: } \\
\text { NR } \\
\text { Spirometry: } \\
\text { NR }\end{array}$ & NR & NR \\
\hline $\begin{array}{l}\text { Harrison, } \\
2004^{59} \\
n=390 \\
\text { RCT, } 12 \mathrm{~m}\end{array}$ & $\begin{array}{l}\text { Age: } 12 \mathrm{y}+ \\
\text { Severity/control: } \\
\text { Persistent asthma/ } \\
\text { stable during run-in } \\
\text { Intermittent ICS: } \\
\text { Doubling regular } \\
\text { dose }\end{array}$ & $\begin{array}{l}\text { Relative measures } \\
\text { Requiring oral corticosteroid } \\
\text { (full population): } \\
\text { RR } 0.95 \text { (0.55 to } 1.63 \text { ) } \\
\text { Requiring oral corticosteroid } \\
\text { (of those who initiated study } \\
\text { inhaler) } \\
\text { RR: } 0.76 \text { (0.44 to 1.32) } \\
\text { Count data } \\
\text { NR }\end{array}$ & NR & $\begin{array}{l}\text { Composite measures: } \\
\text { NR } \\
\text { Spirometry: } \\
\text { NR }\end{array}$ & NR & $\begin{array}{l}\text { Asthma-related } \\
\text { general practitioner } \\
\text { visits: } \\
\text { RR 1.14 (0.71 to } \\
1.83)\end{array}$ \\
\hline
\end{tabular}




\begin{tabular}{|c|c|c|c|c|c|c|}
\hline $\begin{array}{l}\text { Study, } \\
\text { Year, n, } \\
\text { Study } \\
\text { design, } \\
\text { Duration }\end{array}$ & Population $^{a}$ & Exacerbations $^{b}$ & Mortality & Asthma control & Quality of life & $\begin{array}{l}\text { Healthcare } \\
\text { utilization }\end{array}$ \\
\hline $\begin{array}{l}\text { Oborne, } \\
2009^{66} \\
n=403 \\
\text { RCT, } 12 m\end{array}$ & $\begin{array}{l}\text { Age: } 12 \mathrm{y}+ \\
\text { Severity/control: } \\
\text { Persistent asthma } \\
\text { Intermittent ICS: } \\
\text { Quadrupling } \\
\text { regular dose }\end{array}$ & $\begin{array}{l}\text { Relative measures } \\
\text { Requiring oral corticosteroid } \\
\text { (full population): } \\
\text { RR } 0.64(0.37 \text { to } 1.11 \text { ) } \\
\text { Requiring oral corticosteroid } \\
\text { (of those who initiated study } \\
\text { inhaler) } \\
\text { RR: } 0.43 \text { ( } 0.24 \text { to } 0.78 \text { ) } \\
2 \text { to } 3 \text { exacerbations requiring } \\
\text { oral corticosteroid (full } \\
\text { population): } \\
\text { RR } 0.63 \text { (0.15 to } 2.59 \text { ) } \\
2 \text { to } 3 \text { exacerbations requiring } \\
\text { oral corticosteroid (of those } \\
\text { who initiated study inhaler): } \\
\text { RR } 0.34 \text { ( } 0.07 \text { to } 1.76 \text { ) } \\
\text { Count data } \\
\text { NR }\end{array}$ & NR & $\begin{array}{l}\text { Composite measures: } \\
\text { NR } \\
\text { Spirometry: } \\
\text { NR }\end{array}$ & NR & NR \\
\hline $\begin{array}{l}\text { Martinez, } \\
2011^{60} \\
n=143 \\
\text { RCT, } 12 m\end{array}$ & $\begin{array}{l}\text { Age: Mixed, (5-11y } \\
\text { and 12y+) } \\
\text { Severity/control: } \\
\text { Mild persistent } \\
\text { asthma/well } \\
\text { controlled } \\
\text { Intermittent ICS: } \\
\text { ICS used with } \\
\text { albuterol } \\
\end{array}$ & $\begin{array}{l}\text { Relative measures } \\
\text { Requiring oral corticosteroid: } \\
\text { RR } 1.12 \text { (0.67 to } 1.86) \\
\text { Treatment failure }{ }^{\text {d: }} \\
\text { RR } 2.03 \text { (0.39 to } 10.72)\end{array}$ & NR & $\begin{array}{l}\text { Composite measures: } \\
\text { NR } \\
\text { Spirometry: } \\
\text { FEV1 \% predicted: } \\
\text { MD } 0.57 \text { (-2.24 to } 3.38)\end{array}$ & $\begin{array}{l}\text { PAQLQ score: } \\
\text { MD -0.003 (- } \\
0.25 \text { to } 0.25)\end{array}$ & $\begin{array}{l}\text { Albuterol puffs/day: } \\
\text { MD } 0.04 \text { (-0.33 to } \\
0.40)\end{array}$ \\
\hline
\end{tabular}

Abbreviations: d=days; ER=emergency room; EPR-3=Expert Panel Review-3; FEV1=forced expiratory volume in one second; HR=hazard ratio; ICS=inhaled corticosteroid; IRR= incident rate ratio; $\mathrm{m}=$ months; $\mathrm{MD}=$ mean difference; $\mathrm{n}=$ patient sample size; $\mathrm{NR}=$ not reported; $\mathrm{OR}=$ odds ratio; $\mathrm{PAQLQ}=$ Pediatric Asthma Quality of Life Questionnaire;

$\mathrm{RCT}=$ randomized controlled trial; $\mathrm{RR}=$ relative risk; $\mathrm{y}=$ year

${ }^{a}$ Categorized using study inclusion criteria and the age categories used in EPR-3 of 0-4y, 5-11y and 12y+. Severity is as reported per the study. Control was usually not specified and rather details about patients being symptomatic or not at entry were given and reported here. Intermittent ICS indicates how the usual ICS dose was altered in the intervention arm

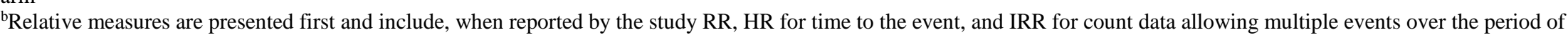
follow-up. Count data is presented, when reported by the study, for number of hospitalizations, hospital days, and ER visits in association with exacerbations. 
'Defined as the absence of stability, where stability is defined as morning peak expiratory flow $90 \%$ or more of mean baseline value on either of the two previous days, $<4$

inhalations of inhaled corticosteroid per day over the past 2 days, no nocturnal awakenings in the prior 2 nights and a total symptom score not exceeding mean baseline value more than 2 ordinal values over the previous 2 days

${ }^{\mathrm{d}}$ Defined as any of following: (1) Hospitalization due to asthma; (2) Hypoxic seizure due to asthma; (3) Intubation due to asthma; (4) Requirement for a second burst of prednisone within any 6 months period; (5) Significant adverse event related to the use of a study medication. The only criterion for assignment of treatment failure during the trial was the requirement for a second burst of prednisone within any six-month period

\section{Table C-8. Study level outcomes for KQ1b, intermittent ICS vs. ICS controller}

\begin{tabular}{|c|c|c|c|c|c|c|}
\hline $\begin{array}{l}\text { Study, } \\
\text { Year, n, } \\
\text { Study } \\
\text { design, } \\
\text { Duration }\end{array}$ & Population $^{a}$ & Exacerbations $^{b}$ & Mortality & Asthma Control & Quality of Life & $\begin{array}{l}\text { Healthcare } \\
\text { Utilization }\end{array}$ \\
\hline $\begin{array}{l}\text { Boushey, } \\
2005^{51} \\
n=149 \\
\text { RCT, 52w }\end{array}$ & $\begin{array}{l}\text { Age: } 12 \mathrm{y}+ \\
\text { Severity/control: } \\
\text { Mild persistent } \\
\text { Intermittent ICS: } \\
\text { Yellow zone } \\
\text { budesonide } 800 \mu \mathrm{g} \\
\text { BIDx10d }\end{array}$ & $\begin{array}{l}\text { Requiring oral } \\
\text { corticosteroid: } \\
\text { RR } 0.70 \text { (0.30 to } 1.64) \\
\text { Requiring hospitalization: } \\
\text { No events occurred }\end{array}$ & NR & $\begin{array}{l}\text { Composite measures: } \\
\text { ACQ-7 score: } \\
\text { MD 0.1 (-0.12 to } 0.32) \\
\text { Spirometry: } \\
\text { FEV1 pre-albuterol ( } \% \\
\text { change): } \\
\text { MD -3.3 (-6.51 to }-0.09) \\
\text { FEV1 post-albuterol ( } \% \\
\text { change): } \\
\text { MD -0.7 (-2.1 to } 0.7)\end{array}$ & $\begin{array}{l}\text { AQLQ(S) score: } \\
\text { MD }-0.2(-0.48 \text { to } \\
0.08)\end{array}$ & NR \\
\hline $\begin{array}{l}\text { Papi, } 2007^{63} \\
\mathrm{n}=337 \\
\mathrm{RCT}, 6 \mathrm{~m}\end{array}$ & 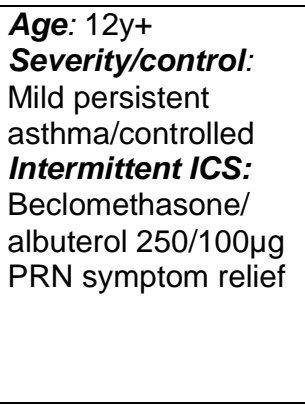 & $\begin{array}{l}\text { Mildc or severed }^{d} \\
\text { exacerbation: } \\
\text { RR } 0.87 \text { ( } 0.29 \text { to } 2.61) \\
\text { Severe exacerbation: } \\
\text { Peto's OR } 0.11 \text { ( } 0.01 \text { to } \\
1.11)\end{array}$ & NR & $\begin{array}{l}\text { Composite measures: } \\
\text { NR } \\
\text { Spirometry: } \\
\text { FEV1, trough } \\
\text { MD 0.09 (-0.01 to } 0.18) \\
\text { FEV1 \% predicted: } \\
\text { MD } 2.04 \text { (-0.71 to } 4.79) \\
\text { FVC, trough } \\
\text { MD } 0.07 \text { (-0.03 to } 0.18) \\
\text { FVC \% predicted } \\
\text { MD } 1.72 \text { (-1.04 to } 4.48)\end{array}$ & NR & $\begin{array}{l}\text { Rescue albuterol use, } \\
\text { inhalations/d } \\
\text { MD } 0.07(-0.13 \text { to } \\
0.26)\end{array}$ \\
\hline
\end{tabular}




\begin{tabular}{|c|c|c|c|c|c|c|}
\hline $\begin{array}{l}\text { Study, } \\
\text { Year, n, } \\
\text { Study } \\
\text { design, } \\
\text { Duration }\end{array}$ & Population $^{a}$ & Exacerbations $^{b}$ & Mortality & Asthma Control & Quality of Life & $\begin{array}{l}\text { Healthcare } \\
\text { Utilization }\end{array}$ \\
\hline $\begin{array}{l}\text { Turpeinen, } \\
2007^{64} \\
n=116 \\
\text { RCT, } 18 m\end{array}$ & $\begin{array}{l}\text { Age: 5-11y } \\
\text { Severity/control: } \\
\text { Majority mild } \\
\text { persistent/ } \\
\text { symptomatic } \\
\text { Intermittent ICS: } \\
\text { Budesonide 400mg } \\
\text { BIDx14d upon } \\
\text { symptoms } \\
\text { determined by } \\
\text { pediatrician to be } \\
\text { exacerbation }\end{array}$ & $\begin{array}{l}\text { Exacerbation rate } \\
\text { MD }-0.72(-1.27 \text { to }-0.17)\end{array}$ & NR & NR & NR & NR \\
\hline $\begin{array}{l}\text { Martinez, } \\
2011^{60} \\
\mathrm{n}=143 \\
\text { RCT, 44w }\end{array}$ & $\begin{array}{l}\text { Age: Mixed (5-11, } \\
12 \mathrm{y}+) \\
\text { Severity/control: } \\
\text { Mild persistent/ } \\
\text { well controlled } \\
\text { Intermittent ICS: } \\
\text { Beclomethasone } \\
40 \mu \mathrm{g}+\text { albuterol } 90 \mu \mathrm{g} \\
\text { PRN symptom relief } \\
\text { prompting albuterol } \\
\text { use or to treat } \\
\text { decrease PEF }\end{array}$ & $\begin{array}{l}\text { Requiring oral } \\
\text { corticosteroid: } \\
\text { RR } 1.27 \text { (0.78 to } 2.07) \\
\text { Treatment failure } \\
\text { RR } 3.04 \text { (0.64 to } 14.57 \text { ) }\end{array}$ & NR & $\begin{array}{l}\text { Composite measures: } \\
\text { NR } \\
\text { Spirometry: } \\
\text { FEV1 \% predicted: } \\
\text { MD }-1.30 \text { (-4.24 to } 1.64)\end{array}$ & $\begin{array}{l}\text { PAQLQ score: } \\
\text { MD } 0.04(-0.25 \text { to } \\
0.33)\end{array}$ & $\begin{array}{l}\text { Rescue albuterol use, } \\
\text { inhalations/d: } \\
\text { MD } 0.003(-0.24 \text { to } \\
0.25)\end{array}$ \\
\hline
\end{tabular}




\begin{tabular}{|c|c|c|c|c|c|c|}
\hline $\begin{array}{l}\text { Study, } \\
\text { Year, n, } \\
\text { Study } \\
\text { design, } \\
\text { Duration }\end{array}$ & Population $^{a}$ & Exacerbations $^{b}$ & Mortality & Asthma Control & Quality of Life & $\begin{array}{l}\text { Healthcare } \\
\text { Utilization }\end{array}$ \\
\hline $\begin{array}{l}\text { Calhoun, } \\
2012^{52,9} \\
n=227 \\
\text { RCT, 9m }\end{array}$ & $\begin{array}{l}\text { Age: } 12 \mathrm{y}+ \\
\text { Severity/control: } \\
\text { Mild to moderate } \\
\text { persistent/ } \\
\text { well or partially well } \\
\text { controlled } \\
\text { Intermittent ICS: } \\
\text { Beclomethasone } \\
\text { 80ug PRN symptom } \\
\text { relief prompting } \\
\text { albuterol use }\end{array}$ & $\begin{array}{l}\text { Exacerbation }{ }^{\mathrm{h}}: \\
\text { IRR } 2.0(0.87 \text { to } 4.61) \\
\text { Urgent care visit for } \\
\text { asthma: } \\
\text { RR } 0.25 \text { (0.05 to } 1.16) \\
\text { Treatment failure } \\
\text { HR } 1.6(0.86 \text { to } 2.98) \\
\text { IRR } 1.7(0.96 \text { to } 3.00)\end{array}$ & NR & $\begin{array}{l}\text { Composite measures: } \\
\text { ACQ-5 } \\
\text { MD -0.01 (-0.17 to } 0.15) \\
\text { Spirometry: } \\
\text { FEV1 trough pre } \\
\text { albuterol: } \\
\text { MD } 0.01 \text { (-0.13 to } 0.15) \\
\text { FEV1 trough post } \\
\text { albuterol: } \\
\text { MD -0.01 (-0.06 to } 0.04) \\
\text { FEV1 \% predicted pre } \\
\text { albuterol: } \\
\text { MD } 0.01 \text { (-1.89 to } 1.91) \\
\text { FEV1 \% predicted post } \\
\text { albuterol: } \\
\text { MD }-0.48 \text { (-1.97 to } 1.01)\end{array}$ & $\begin{array}{l}\text { AQLQ(S) score: } \\
\text { MD } 0.01 \text { (-0.19 to } \\
0.21)\end{array}$ & $\begin{array}{l}\text { Rescue albuterol use, } \\
\text { inhalations/d: } \\
\text { MD }-0.04(-0.11 \text { to } \\
0.03)\end{array}$ \\
\hline
\end{tabular}
daily; $d=$ days; ER=emergency room; FEV1=forced expiratory volume in one second; FVC=forced vital capacity; HR=hazard ratio; ICS=inhaled corticosteroid; IRR= incident rate ratio; $\mathrm{m}=$ months; $\mathrm{MD}=$ mean difference; $\mathrm{mg}=$ =milligrams; $\mathrm{n}=$ patient sample size; $\mathrm{NR}=$ not reported; $\mathrm{OR}=$ odds ratio; $\mathrm{PAQLQ=Pediatric} \mathrm{Asthma} \mathrm{Quality} \mathrm{of} \mathrm{Life} \mathrm{Questionnaire;}$ $\mathrm{PEF}=$ peak expiratory flow; $\mathrm{PRN}=$ pro re nata (i.e., as-needed); RCT=randomized controlled trial; $\mathrm{RR}=$ relative risk; $\mu \mathrm{g}=$ micrograms; $\mathrm{w}=$ weeks; $\mathrm{y}=\mathrm{year}$

${ }^{a}$ Age is categorized using study inclusion criteria and the age categories used in Expert Panel Review-3 (EPR-3) of 0-4y, 5-11y and $12 \mathrm{y}+$. Severity is as reported per the study. Control was usually not specified and rather details about patients being symptomatic or not at entry were given and reported here. Intermittent ICS indicates how the usual ICS dose was altered in the intervention arm

${ }^{b}$ Relative measures are presented first and include, when reported by the study, relative risk (RR), hazard ratio (HR) for time to the event, and incident rate ratio (IRR) for count data allowing multiple events over the period of follow-up. Count data is presented, when reported by the study, for number of hospitalizations, hospital days, and ER visits in association with exacerbations

'Defined as awakening at night owing to asthma or as a decrease in the morning peak expiratory flow rate to more than $20 \%$ below the baseline value, the use of more than three additional puffs per day of rescue medication (either albuterol or beclomethasone and albuterol) as compared with during the baseline for 2 or more consecutive days, or both. Single, isolated days on which mild exacerbation occurred were not counted

${ }^{\mathrm{d} D e f i n e d ~ a s ~ a ~ d e c r e a s e ~ i n ~ t h e ~ m o r n i n g ~ p e a k ~ e x p i r a t o r y ~ f l o w ~ r a t e ~ t o ~ m o r e ~ t h a n ~} 30 \%$ below the baseline value on 2 consecutive days or more than eight puffs per day of rescue medication for 3 consecutive days or the need for treatment with oral corticosteroids, as judged by the investigator

eDefined as the mean number of exacerbations divided by the number of patients in the group. An asthma exacerbation was defined as an increase in symptoms that were not controlled with six doses of rescue terbutaline per $24 \mathrm{~h}$ that caused the parent to contact the clinic. At clinic pediatrician determined if exacerbation occurred and prescribed budesonide inhaler

${ }^{\mathrm{f}}$ Defined as any of following: (1) Hospitalization due to asthma; (2) Hypoxic seizure due to asthma; (3) Intubation due to asthma; (4) Requirement for a second burst of prednisone 
within any 6 months period; (5) Significant adverse event related to the use of a study medication. The only criterion for assignment of treatment failure during the trial was the requirement for a second burst of prednisone within any six-month period

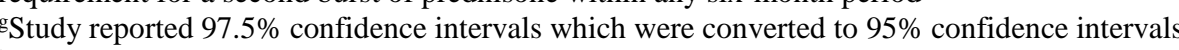

hefined as unscheduled medical contact for increased asthma symptoms that results in use of oral corticosteroids, increased inhaled corticosteroids, or additional medications for asthma

iDefined as any of the following: (1) Asthma exacerbation; (2) An at-home measurement of prebronchodilator AM PEF $<65 \%$ of baseline on 2 consecutive mornings,

postbronchodilator PEF $<80 \%$ of baseline despite 60 minutes of rescue treatment, or an increase in albuterol use of more than 8 puffs per 24 hours over baseline use for 48 hours or

more than 16 puffs per 24 hours for more than 48 hours; (3) In-clinic measurements of prebronchodilator FEV1 on 2 consecutive sets of spirometric determinations measured 24 to 72 hours apart that are less than $80 \%$ of baseline, physician judgement for patient safety, patient dissatisfaction with asthma control achieved by study regimen or requirement for open-label ICS or another new asthma medication without the addition of systemic corticosteroids 
Table C-9. Study and population characteristics for KQ1c, ICS and LABA controller and quick relief vs. ICS controller (same dose)

\begin{tabular}{|c|c|c|c|c|c|c|c|c|c|}
\hline $\begin{array}{l}\text { Study, Year, } \\
\text { n, } \\
\text { Acronym, } \\
\text { Study design, } \\
\text { Duration, } \\
\text { Risk of bias }\end{array}$ & Study population & $\begin{array}{l}\text { Intervention } \\
\text { Comparisons }\end{array}$ & $\begin{array}{l}\text { Age (y) } \\
\text { [mean } \\
(\mathrm{SD})]\end{array}$ & $\begin{array}{l}\text { Males } \\
(\%)\end{array}$ & $\begin{array}{l}\text { Duration } \\
\text { of } \\
\text { asthma } \\
\text { (y) } \\
\text { [mean } \\
\text { (SD)] }\end{array}$ & $\begin{array}{l}\text { FEV1 } \\
\text { (L) } \\
\text { [mean } \\
\text { (SD)] }\end{array}$ & $\begin{array}{l}\text { FEV1 \% } \\
\text { predict- } \\
\text { ed (L) } \\
\text { [mean } \\
\text { (SD)] }\end{array}$ & $\begin{array}{l}\text { Rescue } \\
\text { inhaler } \\
\text { use } \\
\text { (puffs/d) } \\
\text { [mean } \\
\text { (SD)] }\end{array}$ & $\begin{array}{l}\text { ICS dose } \\
\text { during } \\
\text { study } \\
(\mu \mathrm{g} / \mathrm{d}) \\
\text { [mean } \\
(\mathrm{SD})]\end{array}$ \\
\hline \multirow[t]{2}{*}{$\begin{array}{l}\text { Scicchitano, } \\
2004^{96} \\
n=1890 \\
\text { RCT, } 12 \mathrm{~m}\end{array}$} & \multirow{2}{*}{$\begin{array}{l}12-80 \text { years of age with moderate } \\
\text { to severe ( } 83 \% \text { with severe } \\
\text { according to GINA guidelines), } \\
\text { symptomatic asthma on ICS } 400 \text { - } \\
1600 \mu g / d, \text { FEV1 } 50-90 \% \\
\text { predicted, history of at least } 1 \\
\text { exacerbation in prior year } \\
\text { ICS dose at entry: } 744-748 \mu \mathrm{g} / \mathrm{d} \\
\text { Taking LABA at entry: } 35 \%\end{array}$} & $\begin{array}{l}\text { Budesonide/formoterol } \\
320 / 9 \mu \mathrm{g} \text { in the evening } \\
+160 / 4.5 \mu \mathrm{g} \text { PRN (DPI) } \\
\mathrm{n}=947\end{array}$ & $\begin{array}{l}43 \\
(12 \text { to } \\
79)^{a}\end{array}$ & 41 & $\begin{array}{l}12(1 \text { to } \\
65)^{\mathrm{a}}\end{array}$ & NR & $\begin{array}{l}70 \\
(46 \text { to } \\
102)^{a}\end{array}$ & $\begin{array}{l}1.9 \\
(0 \text { to } \\
15.6)^{\mathrm{a}}\end{array}$ & 466 (NR) \\
\hline & & $\begin{array}{l}\text { Budesonide } 160 \mu \mathrm{g} \text { BID } \\
\text { (DPI) + terbutaline PRN } \\
\text { (DPI) } \\
n=943\end{array}$ & $\begin{array}{l}43 \\
(11 \text { to } \\
80)^{a}\end{array}$ & 43 & $\begin{array}{l}12 \text { (1 to } \\
71)^{a}\end{array}$ & NR & $\begin{array}{l}70 \\
(37 \text { to } \\
95)^{a}\end{array}$ & $\begin{array}{l}2.0(0 \text { to } \\
9.2)^{\mathrm{a}}\end{array}$ & 640 (NR) \\
\hline \multirow[t]{2}{*}{$\begin{array}{l}\text { Rabe, } 2006^{94} \\
\mathrm{n}=697 \\
\text { RCT, } 6 \mathrm{~m} \\
\text { Low }\end{array}$} & \multirow{2}{*}{$\begin{array}{l}12-80 \text { years of age with mild to } \\
\text { moderate asthma on ICS } 200- \\
500 \mu \mathrm{g} / \mathrm{d}, \mathrm{FEV} 160-100 \% \\
\text { predicted, symptomatic with } \geq 7 \\
\text { SABA inhalations during last } 10 \\
\text { run-in days } \\
\text { ICS dose at entry: } 343-353 \mu \mathrm{g} / \mathrm{d} \\
\text { LABA at entry: } 10-13 \%\end{array}$} & $\begin{array}{l}\text { Budesonide/formoterol } \\
160 / 9 \mu \mathrm{g} \text { in the evening } \\
+80 / 4.5 \mathrm{mcg} \text { PRN (DPI) } \\
\mathrm{n}=355\end{array}$ & $\begin{array}{l}38 \\
(12 \text { to } \\
79)^{a}\end{array}$ & 41 & $\begin{array}{l}10 \text { (1 to } \\
70)^{b}\end{array}$ & NR & $\begin{array}{l}75 \\
(51 \text { to } \\
123)^{a}\end{array}$ & NR & 240 (NR) \\
\hline & & $\begin{array}{l}\text { Budesonide } 160 \mu \mathrm{g} \text { in } \\
\text { the evening }(\mathrm{DPI})+ \\
\text { terbutaline PRN (DPI) } \\
\mathrm{n}=342\end{array}$ & $\begin{array}{l}38 \\
(11 \text { to } \\
78)^{a}\end{array}$ & 36 & $\begin{array}{l}10(1 \text { to } \\
61)^{b}\end{array}$ & NR & $\begin{array}{l}75 \\
(52 \text { to } \\
109)^{a}\end{array}$ & NR & 320 (NR) \\
\hline \multirow[t]{2}{*}{$\begin{array}{l}\text { Sovani, } 2008^{99} \\
\mathrm{n}=71 \\
\mathrm{RCT}, 6 \mathrm{~m} \\
\text { High }\end{array}$} & \multirow[t]{2}{*}{$\begin{array}{l}\text { 18-70 years of age with asthma } \\
\text { on ICS } 400-1000 \mu \mathrm{g} / \mathrm{d} \text { of } \\
\text { beclomethasone or equivalent, } \\
\text { with evidence of poor asthma } \\
\text { control (in prior year } \geq 2 \text { courses } \\
\text { of prednisolone or } 10 \text { SABA } \\
\text { canisters, and taking } \geq 4 \text { SABA } \\
\text { puffs in } \geq 4 \mathrm{~d} / \text { week in prior month } \\
\text { ICS dose at entry:565-611 } \mu \mathrm{g} / \mathrm{d}\end{array}$} & $\begin{array}{l}\text { Budesonide/formoterol } \\
\text { 160/4.5 } \mu \mathrm{g} \text { BID + PRN } \\
\text { (DPI) } \\
n=36\end{array}$ & $\begin{array}{l}40.3 \\
(12.8)\end{array}$ & 47.2 & $23.1(12)$ & $\begin{array}{l}2.9 \\
(0.84)\end{array}$ & $\begin{array}{l}88.1 \\
(19.3)\end{array}$ & NR & 448 (NR) \\
\hline & & $\begin{array}{l}\text { Budesonide } 160 \mu \mathrm{g} \text { BID } \\
\text { (DPI) + SABA PRN } \\
\mathrm{n}=35\end{array}$ & $\begin{array}{l}40.3 \\
(12.3)\end{array}$ & 42.9 & $22.6(14)$ & $\begin{array}{l}2.65 \\
(0.82)\end{array}$ & $\begin{array}{l}82.3 \\
(18.7)\end{array}$ & NR & 252 (NR) \\
\hline
\end{tabular}

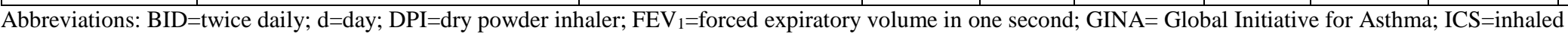
corticosteroid; $\mathrm{L}=$ liter; LABA=long-acting $\beta_{2}$-agonist; $\mathrm{m}=$ =months; $\mathrm{n}=$ =patient sample size; $\mathrm{NR}=$ not reported; $\mathrm{PRN}=$ pro re nata (i.e., as-needed); RCT=randomized controlled trial; $\mathrm{SABA}=$ short-acting $\beta 2$-agonist; $\mathrm{SD}=$ standard deviation; $\mu \mathrm{g}=$ microgram; $\mathrm{w}=\mathrm{week}$; $\mathrm{y}=\mathrm{year}$

a Data reported as mean (range)

bData reported as median (range) 
Table C-10. Study and population characteristics for KQ1C, ICS and LABA controller and quick relief vs. ICS controller (higher dose)

\begin{tabular}{|c|c|c|c|c|c|c|c|c|c|}
\hline $\begin{array}{l}\text { Study, Year, } \\
\text { n, } \\
\text { Acronym, } \\
\text { Study design, } \\
\text { Duration, } \\
\text { Risk of bias }\end{array}$ & Study population & $\begin{array}{l}\text { Intervention } \\
\text { Comparisons }\end{array}$ & $\begin{array}{l}\text { Age (y) } \\
{[\text { mean }} \\
\text { (SD)] }\end{array}$ & $\begin{array}{l}\text { Males } \\
(\%)\end{array}$ & $\begin{array}{l}\text { Duration } \\
\text { of } \\
\text { asthma } \\
\text { (y) } \\
\text { [mean } \\
\text { (SD)] }\end{array}$ & $\begin{array}{l}\text { FEV1 } \\
\text { (L) } \\
\text { [mean } \\
\text { (SD)] }\end{array}$ & $\begin{array}{l}\text { FEV1 \% } \\
\text { predict- } \\
\text { ed (L) } \\
\text { [mean } \\
\text { (SD)] }\end{array}$ & $\begin{array}{l}\text { Rescue } \\
\text { inhaler } \\
\text { use } \\
\text { (puffs/d) } \\
\text { [mean } \\
\text { (SD)] }\end{array}$ & $\begin{array}{l}\text { ICS dose } \\
\text { during } \\
\text { study } \\
\text { ( } \mu \mathrm{g} / \mathrm{d} \text { ) } \\
\text { [mean } \\
\text { (SD)] }\end{array}$ \\
\hline \multirow[t]{4}{*}{$\begin{array}{l}\text { O'Byrne, } 2005^{83} \\
\text { n=1851 } \\
\text { STAY } \\
\text { RCT, } 12 \mathrm{~m}\end{array}$} & \multirow{2}{*}{$\begin{array}{l}\text { 4-80 years of age with asthma } \\
\text { treated with } 400-1000 \mu \mathrm{g} / \mathrm{d} \text { of ICS } \\
(200-500 \mu \mathrm{g} / \mathrm{d} \text { if } 4-11 \text { years old), } \\
\text { history of } 1 \text { or more exacerbation } \\
\text { in prior year, FEV1 } 60-100 \% \\
\text { predicted, } 12+(8+\text { if } 4-11 \mathrm{y}) \text { SABA } \\
\text { inhalations during last } 10 \mathrm{~d} \text { of run- } \\
\text { in. } \\
\text { ICS dose at entry: } 598-620 \mu \mathrm{g} / \mathrm{d} \\
\text { Taking LABA at entry: } 27-29 \%\end{array}$} & $\begin{array}{l}\text { Budesonide/formoterol } \\
80 / 4.5 \mu \mathrm{g} \text { BID + PRN } \\
\text { (DPI) } \\
n=925\end{array}$ & $\begin{array}{l}35 \\
(4 \text { to } \\
77)^{\mathrm{a}}\end{array}$ & 45.5 & $\begin{array}{l}9(0 \text { to } \\
63)^{b}\end{array}$ & $\begin{array}{l}2.13 \\
(0.65 \\
\text { to } \\
4.28)^{a}\end{array}$ & $\begin{array}{l}73 \\
(43 \text { to } \\
108)^{a}\end{array}$ & $\begin{array}{l}1.74 \\
(0 \text { to } \\
8.0)^{\mathrm{a}, \mathrm{c}}\end{array}$ & $\begin{array}{l}235.5 \\
(N R)^{d}\end{array}$ \\
\hline & & $\begin{array}{l}\text { Budesonide } 320 \mu g \text { BID } \\
\text { (DPI) + terbutaline } \\
0.4 \mathrm{mg} \text { PRN (DPI) } \\
\mathrm{n}=926\end{array}$ & $\begin{array}{l}36 \\
(4 \text { to } \\
79)^{a}\end{array}$ & 44.9 & $\begin{array}{l}9(0 \text { to } \\
96)^{b}\end{array}$ & $\begin{array}{l}2.14 \\
(0.64 \\
\text { to } \\
4.02)^{a}\end{array}$ & $\begin{array}{l}73 \\
(49 \text { to } \\
100)^{a}\end{array}$ & $\begin{array}{l}1.69 \\
(0 \text { to } 7)^{a, c}\end{array}$ & $\begin{array}{l}641.5 \\
(N R)^{d}\end{array}$ \\
\hline & \multirow[t]{2}{*}{$\begin{array}{l}\text { 4-11 year old subgroup with } \\
\text { asthma treated with } 200-500 \mu \mathrm{g} / \mathrm{d} \\
\text { of ICS, history of } 1 \text { or more } \\
\text { exacerbation in prior year, FEV1 } \\
60-100 \% \text { predicted, } 8+\text { SABA } \\
\text { inhalations during last } 10 \mathrm{~d} \text { of run- } \\
\text { in. } \\
\text { ICS dose at entry:319-321 } \mu \mathrm{g} / \mathrm{d}\end{array}$} & 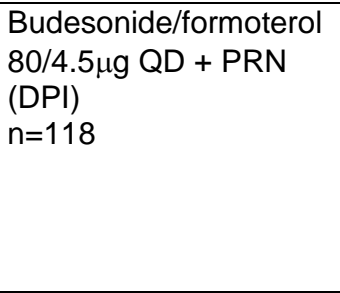 & $\begin{array}{l}8(4 \text { to } \\
11)^{\mathrm{a}}\end{array}$ & 72.0 & $\begin{array}{l}3(1 \text { to } \\
10)^{b}\end{array}$ & $\begin{array}{l}1.6 \\
(0.9 \text { to } \\
2.7)^{\mathrm{a}}\end{array}$ & $\begin{array}{l}76(57 \\
\text { to } 108)^{a}\end{array}$ & $\begin{array}{l}1.7(0.7 \\
\text { to } 5.9)^{\mathrm{a}}\end{array}$ & $\begin{array}{l}125.6 \\
(N R)\end{array}$ \\
\hline & & $\begin{array}{l}\text { Budesonide } 320 \mu g \text { QD } \\
\text { (DPI) + terbutaline } \\
0.4 \mathrm{mg} \text { PRN (DPI) } \\
\mathrm{n}=106\end{array}$ & $\begin{array}{l}8(4 \text { to } \\
11)^{\mathrm{a}}\end{array}$ & 66.4 & $\begin{array}{l}3(0 \text { to } \\
10)^{b}\end{array}$ & $\begin{array}{l}1.6 \\
(0.7 \text { to } \\
3.1)^{\mathrm{a}}\end{array}$ & $\begin{array}{l}76(60 \\
\text { to } 100)^{a}\end{array}$ & $\begin{array}{l}1.6(0.1 \\
\text { to } 4.0)^{\mathrm{a}}\end{array}$ & $\begin{array}{l}320.1 \\
(N R)\end{array}$ \\
\hline
\end{tabular}

Abbreviations: BID=twice daily; d=day; DPI=dry powder inhaler; FEV1=forced expiratory volume in one second; ICS=inhaled corticosteroid; L=liter; LABA=long-acting $\beta_{2}$ agonist; $m=$ months; $n=$ patient sample size; $N R=$ not reported; $P R N=$ pro re nata (i.e., as-needed); $Q D=$ daily; $R C T=$ randomized controlled trial; $S A B A=$ short-acting $\beta_{2}$-agonist; $\mathrm{SD}=$ standard deviation; $\mu \mathrm{g}=$ microgram; $\mathrm{y}=$ years

aData reported as mean (range)

bData reported as median (range)

'Represents inhalations/d (vs. night)

${ }^{\mathrm{d}}$ Represents patients $12 \mathrm{y}^{+}$ 
Table C-11. Study and population characteristics for KQ1c, ICS and LABA controller and quick relief vs. ICS and LABA controller (same dose)

\begin{tabular}{|c|c|c|c|c|c|c|c|c|c|}
\hline $\begin{array}{l}\text { Study, Year, } \\
\text { n, } \\
\text { Acronym, } \\
\text { Study design, } \\
\text { Duration, } \\
\text { Risk of bias }\end{array}$ & Study population & $\begin{array}{l}\text { Intervention } \\
\text { Comparisons }\end{array}$ & $\begin{array}{l}\text { Age } \\
\text { (y) } \\
\text { [mean } \\
\text { (SD)] }\end{array}$ & $\begin{array}{l}\text { Males } \\
(\%)\end{array}$ & $\begin{array}{l}\text { Duration } \\
\text { of } \\
\text { asthma } \\
\text { (y) } \\
\text { [mean } \\
\text { (SD)] }\end{array}$ & $\begin{array}{l}\text { FEV1 } \\
\text { (L) } \\
\text { [mean } \\
\text { (SD)] }\end{array}$ & $\begin{array}{l}\text { FEV1 \% } \\
\text { predicted } \\
\text { (L) } \\
\text { [mean } \\
\text { (SD)] }\end{array}$ & $\begin{array}{l}\text { Rescue } \\
\text { inhaler } \\
\text { use } \\
\text { (puffs/d) } \\
\text { [mean } \\
\text { (SD)] }\end{array}$ & $\begin{array}{l}\text { ICS dose } \\
\text { during } \\
\text { study } \\
\text { ( } \mu \text { g/d) } \\
\text { [mean } \\
\text { (SD)] }\end{array}$ \\
\hline \multirow[t]{4}{*}{$\begin{array}{l}\text { O'Byrne, } \\
2005^{75,83,} \\
\text { STAY } \\
\text { n=1834 } \\
\text { RCT, } 12 \mathrm{~m}\end{array}$} & \multirow{2}{*}{$\begin{array}{l}\text { 4-80 years of age with asthma } \\
\text { treated with } 400-1000 \mu \mathrm{g} / \mathrm{d} \text { of ICS } \\
(200-500 \mu \mathrm{g} / \mathrm{d} \text { if } 4-11 \text { years old), } \\
\text { history of } 1 \text { or more exacerbation } \\
\text { in prior year, FEV1 } 60-100 \% \\
\text { predicted, } 12+(8+\text { if } 4-11 \mathrm{y}) \text { SABA } \\
\text { inhalations during last } 10 \mathrm{~d} \text { of run- } \\
\text { in } \\
\text { ICS dose at entry: } 598-620 \mu \mathrm{g} / \mathrm{d} \\
\text { Taking LABA at entry: } 27-29 \%\end{array}$} & $\begin{array}{l}\text { Budesonide/formoterol } \\
80 / 4.5 \mu \mathrm{g} \text { BID + PRN } \\
\text { (DPI) } \\
n=925\end{array}$ & $\begin{array}{l}35 \\
(4 \text { to } \\
77)^{a}\end{array}$ & 45.5 & $\begin{array}{l}9(0 \text { to } \\
63)^{b}\end{array}$ & $\begin{array}{l}2.13 \\
(0.65 \\
\text { to } \\
4.28)^{\mathrm{a}}\end{array}$ & $\begin{array}{l}73(43 \text { to } \\
108)^{\mathrm{a}}\end{array}$ & $\begin{array}{l}1.74 \\
(0 \text { to } \\
8.0)^{a, c}\end{array}$ & $\begin{array}{l}235.5 \\
(N R)^{d}\end{array}$ \\
\hline & & $\begin{array}{l}\text { Budesonide/formoterol } \\
80 / 4.5 \mu \mathrm{g} \text { BID (DPI) + } \\
\text { terbutaline 0.4mg PRN } \\
(\mathrm{DPI}) \\
\mathrm{n}=909\end{array}$ & $\begin{array}{l}36 \\
(4 \text { to } \\
79)^{a}\end{array}$ & 43.3 & $\begin{array}{l}9(0 \text { to } \\
65)^{b}\end{array}$ & $\begin{array}{l}2.10 \\
(0.62 \\
\text { to } \\
4.50)^{\mathrm{a}}\end{array}$ & $\begin{array}{l}73 \\
(46 \text { to } \\
108)^{a}\end{array}$ & $\begin{array}{l}1.69 \\
(0 \text { to } \\
9.4)^{a, c}\end{array}$ & $\begin{array}{l}165.5 \\
(N R)^{d}\end{array}$ \\
\hline & \multirow[t]{2}{*}{$\begin{array}{l}\text { 4-11 year old subgroup with } \\
\text { asthma treated with } 200-500 \mu \mathrm{g} / \mathrm{d} \\
\text { of ICS, history of } 1 \text { or more } \\
\text { exacerbation in prior year, FEV1 } \\
60-100 \% \text { predicted, } 8+\text { SABA } \\
\text { inhalations during last } 10 \mathrm{~d} \text { of run- } \\
\text { in } \\
\text { ICS dose at entry: } 302-319 \mu \mathrm{g} / \mathrm{d}\end{array}$} & $\begin{array}{l}\text { Budesonide/formoterol } \\
\text { 80/4.5 } \mu \mathrm{g} \text { QD + PRN } \\
\text { (DPI) } \\
\mathrm{n}=118\end{array}$ & $\begin{array}{l}8(4 \text { to } \\
11)^{\mathrm{a}}\end{array}$ & 72.0 & $\begin{array}{l}3(1 \text { to } \\
10)^{b}\end{array}$ & $\begin{array}{l}1.6 \\
(0.9 \text { to } \\
2.7)^{\mathrm{a}}\end{array}$ & $\begin{array}{l}76(57 \text { to } \\
108)^{\mathrm{a}}\end{array}$ & $\begin{array}{l}1.7(0.7 \\
\text { to } 5.9)^{\mathrm{a}}\end{array}$ & $\begin{array}{l}125.6 \\
(N R)\end{array}$ \\
\hline & & $\begin{array}{l}\text { Budesonide/formoterol } \\
\text { 80/4.5 } \mu \mathrm{g} \text { QD (DPI) + } \\
\text { terbutaline 0.4mg PRN } \\
(\mathrm{DPI}) \\
\mathrm{n}=117\end{array}$ & $\begin{array}{l}8(4 \text { to } \\
11)^{\mathrm{a}}\end{array}$ & 70.1 & $\begin{array}{l}3(0 \text { to } \\
11)^{b}\end{array}$ & $\begin{array}{l}1.5 \\
(0.7 \text { to } \\
2.9)^{a}\end{array}$ & $\begin{array}{l}76 \text { (54 to } \\
99)^{\mathrm{a}}\end{array}$ & $\begin{array}{l}1.6(0.3 \\
\text { to } 5.6)^{\mathrm{a}}\end{array}$ & 81.8 (NR) \\
\hline $\begin{array}{l}\text { Vogelmeier, } \\
2005^{104} \\
\text { COSMOS } \\
\mathrm{n}=2143 \\
\text { RCT, } 12 \mathrm{~m} \\
\text { Medium }\end{array}$ & $\begin{array}{l}\geq 12 \text { years of age with asthma, } \\
\text { taking } \geq 500 \mu \mathrm{g} / \mathrm{d} \text { of budesonide or } \\
\text { fluticasone (or } \geq 1000 \mu \mathrm{g} / \mathrm{d} \text { for } \\
\text { other ICS), FEV } 140-90 \% \\
\text { predicted, at least } 1 \text { severe } \\
\text { exacerbation in prior year, rescue } \\
\text { medication use } \geq 4 \text { of } 7 \text { days in } \\
\text { run-in }\end{array}$ & $\begin{array}{l}\text { Budesonide/formoterol } \\
320 / 9 \mu \mathrm{g} \mathrm{BID} \mathrm{+} \\
160 / 4.5 \mu \mathrm{g} / \mathrm{d} \text { PRN } \\
\text { (DPI) } \\
\mathrm{n}=1067\end{array}$ & $\begin{array}{l}45 \\
(12 \text { to } \\
80)^{a}\end{array}$ & 42.3 & $\begin{array}{l}13(1 \text { to } \\
75)^{\mathrm{a}}\end{array}$ & NR & $\begin{array}{l}73 \\
(39 \text { to } \\
115)^{a}\end{array}$ & $\begin{array}{l}2.6 \\
(0.2 \text { to } \\
10.7)^{a}\end{array}$ & $\begin{array}{l}1019 \\
(N R)^{e}\end{array}$ \\
\hline
\end{tabular}




\begin{tabular}{|c|c|c|c|c|c|c|c|c|c|}
\hline \multirow[t]{2}{*}{$\begin{array}{l}\text { Study, Year, } \\
\text { n, } \\
\text { Acronym, } \\
\text { Study design, } \\
\text { Duration, } \\
\text { Risk of bias } \\
\end{array}$} & Study population & $\begin{array}{l}\text { Intervention } \\
\text { Comparisons }\end{array}$ & $\begin{array}{l}\text { Age } \\
\text { (y) } \\
\text { [mean } \\
\text { (SD)] }\end{array}$ & $\begin{array}{l}\text { Males } \\
(\%)\end{array}$ & $\begin{array}{l}\text { Duration } \\
\text { of } \\
\text { asthma } \\
\text { (y) } \\
\text { [mean } \\
\text { (SD)] }\end{array}$ & $\begin{array}{l}\text { FEV1 } \\
\text { (L) } \\
\text { [mean } \\
\text { (SD)] }\end{array}$ & $\begin{array}{l}\text { FEV1 \% } \\
\text { predicted } \\
\text { (L) } \\
\text { [mean } \\
\text { (SD)] }\end{array}$ & $\begin{array}{l}\text { Rescue } \\
\text { inhaler } \\
\text { use } \\
\text { (puffs/d) } \\
\text { [mean } \\
\text { (SD)] }\end{array}$ & $\begin{array}{l}\text { ICS dose } \\
\text { during } \\
\text { study } \\
\text { ( } \mu \text { g/d) } \\
\text { [mean } \\
\text { (SD)] }\end{array}$ \\
\hline & $\begin{array}{l}\text { ICS dose at entry: } 881-888 \mu \mathrm{g} / \mathrm{d} \\
\text { LABA use at entry: } 38 \% \\
\text { Doses of randomized therapies } \\
\text { could be titrated and additional } \\
\text { controllers added during trial if } \\
\text { needed }^{f}\end{array}$ & $\begin{array}{l}\text { Fluticasone/salmeterol } \\
\text { 250/50 } \mu \mathrm{g} \text { BID (DPI) + } \\
\text { salbutamol PRN } \\
\text { (DPI/MDI) } \\
n=1076\end{array}$ & $\begin{array}{l}45 \\
(12 \text { to } \\
84)^{\mathrm{a}}\end{array}$ & 39.9 & $\begin{array}{l}12(0 \text { to } \\
74)^{\mathrm{a}}\end{array}$ & NR & $\begin{array}{l}73 \\
(28 \text { to } \\
100)^{a}\end{array}$ & $\begin{array}{l}2.7 \\
(0.3 \text { to } \\
33.7)^{\mathrm{a}}\end{array}$ & $\begin{array}{l}1166 \\
(\mathrm{NR})^{\mathrm{e}}\end{array}$ \\
\hline \multirow[t]{3}{*}{$\begin{array}{l}\text { Rabe, } 2006^{93} \\
\mathrm{n}=3394 \\
\mathrm{RCT}, 12 \mathrm{~m}\end{array}$} & \multirow{3}{*}{$\begin{array}{l}\geq 12 \text { years of age with asthma on } \\
\text { ICS, FEV1 } 50-100 \% \text { predicted, at } \\
\text { least } 1 \text { severe asthma } \\
\text { exacerbation in prior year, } \\
\text { symptomatic during run-in } \\
\text { ICs dose at entry: } 751-758 \mu \mathrm{g} / \mathrm{d} \\
\text { LABA use at entry: } 59 \%\end{array}$} & $\begin{array}{l}\text { Budesonide/formoterol } \\
160 / 4.5 \mu \mathrm{g} \text { BID + PRN } \\
\text { (DPI) } \\
n=1113\end{array}$ & $\begin{array}{l}42 \\
(12 \text { to } \\
89)^{a}\end{array}$ & 39 & $\begin{array}{l}9 \\
(0 \text { to } 64)^{b}\end{array}$ & $\begin{array}{l}2.21 \\
(0.61 \\
\text { to } \\
4.68)^{a}\end{array}$ & $\begin{array}{l}72 \\
(30 \text { to } \\
110)^{a}\end{array}$ & $\begin{array}{l}1.8 \\
(0 \text { to } \\
8.9)^{\mathrm{a}}\end{array}$ & NR \\
\hline & & $\begin{array}{l}\text { Budesonide/formoterol } \\
160 / 4.5 \mu \mathrm{g} \text { BID (DPI) + } \\
\text { formoterol 4.5 } \mu \mathrm{g}(\mathrm{DPI}) \\
\text { PRN } \\
\mathrm{n}=1140\end{array}$ & $\begin{array}{l}42 \\
(12 \text { to } \\
81)^{\mathrm{a}}\end{array}$ & 40 & $\begin{array}{l}10(1 \text { to } \\
77)^{\mathrm{b}}\end{array}$ & $\begin{array}{l}2.20 \\
(0.74 \\
\text { to } \\
4.58)^{\mathrm{a}}\end{array}$ & $\begin{array}{l}72 \\
(38 \text { to } \\
115)^{a}\end{array}$ & $\begin{array}{l}1.9 \\
(0 \text { to } \\
9.1)^{\mathrm{a}}\end{array}$ & NR \\
\hline & & $\begin{array}{l}\text { Budesonide/formoterol } \\
160 / 4.5 \mu \mathrm{g} \text { BID (DPI) + } \\
\text { terbutaline } 0.4 \mathrm{mg} \\
\mathrm{n}=1141\end{array}$ & $\begin{array}{l}43 \\
(12 \text { to } \\
83)^{a}\end{array}$ & 39 & $\begin{array}{l}10(1 \text { to } \\
69)^{b}\end{array}$ & $\begin{array}{l}2.16 \\
(0.68 \\
\text { to } \\
4.58)^{a}\end{array}$ & $\begin{array}{l}72 \\
(39 \text { to } \\
100)^{a}\end{array}$ & $\begin{array}{l}1.9 \\
(0.3 \text { to } \\
9.7)^{\mathrm{a}}\end{array}$ & NR \\
\hline \multirow[t]{2}{*}{$\begin{array}{l}\text { Atienza, } 2013^{70} \\
n=2091 \\
\text { RCT, } 12 \mathrm{~m} \\
\text { Low }\end{array}$} & \multirow{2}{*}{$\begin{array}{l}\geq 16 \text { years of age with persistent } \\
\text { asthma, FEV } 1 \geq 50 \% \text { predicted, } \\
\text { not adequately controlled despite } \\
\text { maintenance ICS, at least } 1 \\
\text { exacerbation in prior year, SABA } \\
\text { use } \geq 5 \text { of last } 7 \text { run-in days } \\
\text { ICs dose at entry: } 659-662 \mu \mathrm{g} / \mathrm{d} \\
\text { LABA use at entry: } 61-62 \%\end{array}$} & $\begin{array}{l}\text { Budesonide/formoterol } \\
160 / 4.5 \mu \mathrm{g} \text { BID + PRN } \\
\text { (DPI) } \\
n=1049\end{array}$ & $\begin{array}{l}45.7 \\
(14.5)\end{array}$ & 31.2 & $\begin{array}{l}12(1 \text { to } \\
67)^{b}\end{array}$ & $\begin{array}{l}1.93 \\
(0.64)\end{array}$ & $\begin{array}{l}70.18 \\
(14.65)\end{array}$ & $\begin{array}{l}2.41 \\
(1.55)\end{array}$ & 514 (NR) \\
\hline & & $\begin{array}{l}\text { Budesonide/formoterol } \\
160 / 4.5 \mu \mathrm{BID}(\mathrm{DPI})+ \\
\text { terbutaline 0.4mg PRN } \\
\text { (DPI) } \\
\mathrm{n}=1042\end{array}$ & $\begin{array}{l}45.6 \\
(14.5)\end{array}$ & 33.6 & $\begin{array}{l}12 \text { (1 to } \\
74)^{b}\end{array}$ & $\begin{array}{l}1.93 \\
(0.65)\end{array}$ & $\begin{array}{l}69.64 \\
(13.75)\end{array}$ & $\begin{array}{l}2.43 \\
(1.58)\end{array}$ & 320 (NR) \\
\hline
\end{tabular}




\begin{tabular}{|c|c|c|c|c|c|c|c|c|c|}
\hline $\begin{array}{l}\text { Study, Year, } \\
\text { n, } \\
\text { Acronym, } \\
\text { Study design, } \\
\text { Duration, } \\
\text { Risk of bias }\end{array}$ & Study population & $\begin{array}{l}\text { Intervention } \\
\text { Comparisons }\end{array}$ & $\begin{array}{l}\text { Age } \\
\text { (y) } \\
\text { [mean } \\
\text { (SD)] }\end{array}$ & $\begin{array}{l}\text { Males } \\
(\%)\end{array}$ & $\begin{array}{l}\text { Duration } \\
\text { of } \\
\text { asthma } \\
\text { (y) } \\
\text { [mean } \\
\text { (SD)] }\end{array}$ & $\begin{array}{l}\text { FEV1 } \\
\text { (L) } \\
\text { [mean } \\
\text { (SD)] }\end{array}$ & $\begin{array}{l}\text { FEV1 \% } \\
\text { predicted } \\
\text { (L) } \\
\text { [mean } \\
\text { (SD)] }\end{array}$ & $\begin{array}{l}\text { Rescue } \\
\text { inhaler } \\
\text { use } \\
\text { (puffs/d) } \\
\text { [mean } \\
\text { (SD)] }\end{array}$ & $\begin{array}{l}\text { ICS dose } \\
\text { during } \\
\text { study } \\
\text { ( } \mu \text { g/d) } \\
\text { [mean } \\
\text { (SD)] }\end{array}$ \\
\hline \multirow[t]{2}{*}{$\begin{array}{l}\text { Papi, } 2013^{84} \\
\mathrm{n}=1701 \\
\mathrm{RCT}, 48 \mathrm{w}\end{array}$} & \multirow{2}{*}{$\begin{array}{l}\geq 18 \text { years of age with asthma not } \\
\text { fully controlled on ICS alone } \\
\text { ( } \geq 1000 \mu \mathrm{g} / \mathrm{d} \text { beclomethasone } \\
\text { equivalents) or ICS ( } \geq 500 \mu \mathrm{g} / \mathrm{d} \\
\text { beclomethasone equivalents) } \\
+ \text { LABA, FEV } 1 \geq 60 \% \text { predicted, at } \\
\text { least } 1 \text { severe exacerbation in } \\
\text { prior year } \\
\text { ICS dose at entry: } 1128-1139 \\
\text { beclomethasone equivalents } \\
\text { LABA use at entry: } 79-83 \%\end{array}$} & $\begin{array}{l}\text { Beclomethasone/ } \\
\text { formoterol } 84.6 / 5 \mu \mathrm{g} \\
\text { BID + PRN (MDI) } \\
n=852\end{array}$ & $\begin{array}{l}49 \\
(18 \text { to } \\
83)^{\mathrm{a}}\end{array}$ & 39 & $\begin{array}{l}9 \\
(0.5 \text { to } \\
62.0)^{9}\end{array}$ & $\begin{array}{l}2.21 \\
(0.88 \\
\text { to } \\
5.04)^{a}\end{array}$ & $\begin{array}{l}74 \\
(29 \text { to } \\
127)\end{array}$ & $\begin{array}{l}0.98 \\
(0.00 \text { to } \\
8.71)\end{array}$ & $701(293)^{\mathrm{e}}$ \\
\hline & & $\begin{array}{l}\text { Beclomethasone/ } \\
\text { formoterol } 84.6 / 5 \mu \mathrm{g} \\
\text { BID (MDI) }+ \\
\text { salbutamol 100 } \mu \mathrm{g} \\
\text { PRN (MDI) } \\
\mathrm{n}=849\end{array}$ & $\begin{array}{l}47 \\
(18 \text { to } \\
77)^{\mathrm{a}}\end{array}$ & 38 & $\begin{array}{l}9 \\
(0.5 \text { to } \\
61.0)^{9}\end{array}$ & $\begin{array}{l}2.27 \\
(1.00- \\
4.74)^{\mathrm{a}}\end{array}$ & $\begin{array}{l}75 \\
(50 \text { to } \\
127)\end{array}$ & $\begin{array}{l}0.97 \\
(0.00 \text { to } \\
9.43)\end{array}$ & $489(48)^{\mathrm{e}}$ \\
\hline \multirow[t]{2}{*}{$\begin{array}{l}\text { Patel, } 2013^{86} \\
\text { SMART } \\
\mathrm{n}=303 \\
\text { RCT, 24w }\end{array}$} & \multirow{2}{*}{$\begin{array}{l}16-65 \text { years of age with asthma } \\
\text { on ICS, at least } 1 \text { exacerbation } \\
\text { requiring steroids in prior year } \\
\text { ICS dose at entry: } 804-812 \mu \mathrm{g} / \mathrm{d} \\
\text { LABA use at entry: } 61-68 \%\end{array}$} & $\begin{array}{l}\text { Budesonide/formoterol } \\
320 / 9 \mu \mathrm{g} \text { BID + PRN } \\
\text { (MDI) } \\
n=151\end{array}$ & $\begin{array}{l}41.3 \\
(13.7)\end{array}$ & 32 & $\begin{array}{l}26.7 \\
(14.5)\end{array}$ & $\begin{array}{l}2.62 \\
(0.91)^{h}\end{array}$ & $\begin{array}{l}81.6 \\
(18.9)^{h}\end{array}$ & NR & $\begin{array}{l}943.5 \\
(1502.5)\end{array}$ \\
\hline & & $\begin{array}{l}\text { Budesonide/formoterol } \\
320 / 9 \mu \mathrm{g} \text { BID (MDI) }+ \\
\text { salbutamol 100-200 } \mu \mathrm{g} \\
\text { PRN } \\
\mathrm{n}=152\end{array}$ & $\begin{array}{l}42.6 \\
(14.5)\end{array}$ & 30 & $\begin{array}{l}26.2 \\
(14.6)\end{array}$ & $\begin{array}{l}2.50 \\
(0.78)^{h}\end{array}$ & $\begin{array}{l}80.4 \\
(20.5)^{h}\end{array}$ & NR & $\begin{array}{l}684.3 \\
(390.5)\end{array}$ \\
\hline \multirow[t]{2}{*}{$\begin{array}{l}\text { Hozawa, } \\
2014^{78} \\
\mathrm{n}=30 \\
\text { RCT, } 8 \mathrm{w} \\
\text { Medium }\end{array}$} & \multirow[t]{2}{*}{$\begin{array}{l}\geq 20 \text { years of age with asthma not } \\
\text { well controlled (ACQ }>0.75 \text { ) on } \\
\text { medium dose ICS (budesonide } \\
800 \mu \mathrm{g} / \mathrm{d} \text {, fluticasone or } \\
\text { mometasone } 400 \mu \mathrm{g} / \mathrm{d} \text { ) without } \\
\text { another controller, SABA use } 2-6 \\
\text { times/w }\end{array}$} & $\begin{array}{l}\text { Budesonide/formoterol } \\
320 / 9 \mu \mathrm{g} \text { BID + } \\
160 / 4.5 \mu \mathrm{g} \text { PRN (DPI) } \\
\mathrm{n}=15\end{array}$ & $\begin{array}{l}41.9 \\
(8.7)\end{array}$ & 33.3 & $6.9(3.6)$ & NR & NR & NR & NR \\
\hline & & $\begin{array}{l}\text { Fluticasone/salmeterol } \\
250 / 50 \mu \mathrm{g} \text { BID (DPI) + } \\
\text { procaterol } 20 \mu \mathrm{g} \text { PRN } \\
\mathrm{n}=15\end{array}$ & $\begin{array}{l}41.3 \\
(9.9)\end{array}$ & 33.3 & $6.7(3.1)$ & NR & NR & NR & NR \\
\hline
\end{tabular}




\begin{tabular}{|c|c|c|c|c|c|c|c|c|c|}
\hline $\begin{array}{l}\text { Study, Year, } \\
\text { n, } \\
\text { Acronym, } \\
\text { Study design, } \\
\text { Duration, } \\
\text { Risk of bias }\end{array}$ & Study population & $\begin{array}{l}\text { Intervention } \\
\text { Comparisons }\end{array}$ & $\begin{array}{l}\text { Age } \\
\text { (y) } \\
\text { [mean } \\
\text { (SD)] }\end{array}$ & $\begin{array}{l}\text { Males } \\
(\%)\end{array}$ & $\begin{array}{l}\text { Duration } \\
\text { of } \\
\text { asthma } \\
\text { (y) } \\
\text { [mean } \\
\text { (SD)] }\end{array}$ & $\begin{array}{l}\text { FEV1 } \\
\text { (L) } \\
\text { [mean } \\
\text { (SD)] }\end{array}$ & $\begin{array}{l}\text { FEV1 \% } \\
\text { predicted } \\
\text { (L) } \\
\text { [mean } \\
\text { (SD)] }\end{array}$ & $\begin{array}{l}\text { Rescue } \\
\text { inhaler } \\
\text { use } \\
\text { (puffs/d) } \\
\text { [mean } \\
\text { (SD)] }\end{array}$ & $\begin{array}{l}\text { ICS dose } \\
\text { during } \\
\text { study } \\
\text { ( } \mu \mathrm{g} / \mathrm{d} \text { ) } \\
\text { [mean } \\
\text { (SD)] }\end{array}$ \\
\hline \multirow[t]{2}{*}{$\begin{array}{l}\text { Takeyma, } \\
2014^{101} \\
\mathrm{n}=63 \\
\mathrm{RCT}, 1 \mathrm{y} \\
\text { Unclear }\end{array}$} & \multirow[t]{2}{*}{$\begin{array}{l}\text { 16-80 years of age with moderate } \\
\text { to severe persistent asthma, on } \\
\text { ICS (budesonide } 320-640 \mu \mathrm{g} / \mathrm{d} \text { or } \\
\text { fluticasone } 200-500 \mu \mathrm{g} / \mathrm{d} \text { ) }+\mathrm{LABA} \text {, } \\
\text { at least } 1 \text { exacerbation in prior } \\
\text { year, ACT score<20, reliever use } \\
\geq 5 \text { times per week, FEV1 } 60 \text { - } \\
100 \% \text { predicted } \\
\text { ICS dose at entry: } 574-610 \mu \mathrm{g} / \mathrm{d}\end{array}$} & $\begin{array}{l}\text { Budesonide/formoterol } \\
320 / 9 \mu \mathrm{g} \text { BID }+ \\
160 / 4.5 \mu \mathrm{g} \text { PRN } \\
\mathrm{n}=32\end{array}$ & $\begin{array}{l}41 \\
(N R)\end{array}$ & 40.6 & NR & $\begin{array}{l}1.86 \\
(0.33)\end{array}$ & $68.3(8.7)$ & NR & NR \\
\hline & & $\begin{array}{l}\text { Budesonide/formoterol } \\
320 / 9 \mu \mathrm{g} \text { BID }+ \\
\text { salbutamol } 100 \mu \mathrm{g} \\
\text { PRN } \\
\mathrm{n}=31\end{array}$ & $\begin{array}{l}39 \\
(N R)\end{array}$ & 32.3 & NR & $\begin{array}{l}1.89 \\
(0.40)\end{array}$ & $\begin{array}{l}70.4 \\
(10.2)\end{array}$ & NR & NR \\
\hline \multirow[t]{2}{*}{$\begin{array}{l}\text { Stallberg, } \\
2008^{100} \\
\text { SHARE } \\
n=1343 \\
\text { RCT, } 12 \mathrm{~m} \\
\text { Medium }\end{array}$} & \multirow{2}{*}{$\begin{array}{l}\geq 12 \text { years of age with persistent } \\
\text { asthma on free combination } \\
\text { ICS+LABA or symptomatic } \\
\text { despite ICS alone, on ICS } \\
\geq 400 \mu \mathrm{g} / \mathrm{d} \\
\text { ICS dose at entry: } 636-650 \mu \mathrm{g} / \mathrm{d} \\
\text { LABA use at entry: } 51-52 \% \\
\text { Randomized therapy stratified by } \\
\text { baseline ICS dose }\end{array}$} & $\begin{array}{l}\text { Budesonide/formoterol } \\
160 / 9 \mu \mathrm{g} \text { or } 320 / 9 \mu \mathrm{g} \\
\text { QD + PRN OR } \\
80 / 4.5 \mu \mathrm{g} \text { or } 160 / 4.5 \mu \mathrm{g} \\
\text { BID + PRN } \\
\mathrm{n}=887\end{array}$ & $\begin{array}{l}43 \\
(\mathrm{NR})\end{array}$ & 40 & NR & NR & NR & NR & 291 (NR) \\
\hline & & $\begin{array}{l}\text { Budesonide/formoterol } \\
160 / 9 \mu \mathrm{g} \text { or } 320 / 9 \mu \mathrm{g} \\
\text { BID + terbutaline PRN } \\
n=456\end{array}$ & $\begin{array}{l}45 \\
(\mathrm{NR})\end{array}$ & 44 & NR & NR & NR & NR & 368 (NR) \\
\hline
\end{tabular}

Abbreviations: ACQ=Asthma Control Questionnaire; ACT=Asthma Control Test; BID=twice daily; CI=confidence interval; d=day; DPI=dry powder inhaler; FEV1=forced expiratory volume in one second; ICS=inhaled corticosteroid; L=liter; LABA=long-acting $\beta_{2}$-agonist; $m=$ =month; MDI=metered dose inhaler; $n=$ =patient sample size; NR=not reported; PRN=pro re nata (i.e., as-needed); $\mathrm{QD}=$ daily; $\mathrm{RCT}=$ randomized controlled trial; $\mathrm{SABA}=$ short-acting $\beta_{2}$-agonist; $\mathrm{SD}=$ standard deviation; $\mu \mathrm{g}=\mathrm{microg}$ (am; $\mathrm{w}=$ week;

y=year

${ }^{\text {aData }}$ reported as mean (range)

bData reported as median (range)

Represents inhalations/d (vs. night)

${ }^{\mathrm{d}}$ Represents patients $12 \mathrm{y}^{+}$

eBeclomethasone dipropionate equivalent dose in $\mu \mathrm{g}$

fIn the control group (fluticasone/salmeterol BID + salbutamol PRN), 27\% and 14\% of patients completed the study on the maximum 1000/100 $\mu \mathrm{g} / \mathrm{d}$ dose and lowest dose of fluticasone/salmeterol, respectively

'Data reported as median (95\% CI)

hepresents values on treatment

iPatients previously treated with ICS $400-500 \mu \mathrm{g} / \mathrm{d}$ received budesonide/formoterol $80 / 4.5 \mu \mathrm{g}$ dose and those previously treated with ICS $>500 \mu \mathrm{g} / \mathrm{d}$ received budesonide/formoterol $160 / 4.5 \mu \mathrm{g}$ dose 
Table C-12. Study and population characteristics for KQ1c, ICS and LABA controller and quick relief vs. ICS and LABA controller (higher dose)

\begin{tabular}{|c|c|c|c|c|c|c|c|c|c|}
\hline $\begin{array}{l}\text { Study, Year, } \\
\text { N, } \\
\text { Acronym, } \\
\text { Study design, } \\
\text { Duration, } \\
\text { Risk of bias }\end{array}$ & Study population & $\begin{array}{l}\text { Intervention } \\
\text { Comparisons }\end{array}$ & $\begin{array}{l}\text { Age (y) } \\
\text { [mean } \\
(\mathrm{SD})]\end{array}$ & $\begin{array}{l}\text { Males } \\
(\%)\end{array}$ & $\begin{array}{l}\text { Duration } \\
\text { of } \\
\text { asthma } \\
\text { (y) } \\
\text { [mean } \\
\text { (SD)] }\end{array}$ & $\begin{array}{l}\text { FEV1 } \\
\text { (L) } \\
\text { [mean } \\
\text { (SD)] }\end{array}$ & $\begin{array}{l}\text { FEV1 \% } \\
\text { predict } \\
\text { ed (L) } \\
\text { [mean } \\
\text { (SD)] }\end{array}$ & $\begin{array}{l}\text { Rescue } \\
\text { inhaler } \\
\text { use } \\
\text { (puffs/d) } \\
\text { [mean } \\
\text { (SD)] }\end{array}$ & $\begin{array}{l}\text { ICS dose } \\
\text { during } \\
\text { study } \\
\text { ( } \mu \text { g/d) } \\
\text { [mean } \\
\text { (SD)] }\end{array}$ \\
\hline \multirow[t]{2}{*}{$\begin{array}{l}\text { Bousquet, } \\
2007^{76} \\
\text { AHEAD } \\
n=2309 \\
\text { RCT, } 6 \mathrm{~m} \\
\text { Low }\end{array}$} & \multirow{2}{*}{$\begin{array}{l}\geq 12 \text { years of age with persistent } \\
\text { asthma on ICS alone }(800- \\
1600 \mu \mathrm{g} / \mathrm{d}) \text { or ICS }(400-1000 \mu \mathrm{g} / \mathrm{d}) \\
+\mathrm{LABA} \text {, symptomatic with use of } \\
\text { SABA during run-in } \geq 5 \text { of } 7 \text { days, } \\
\text { FEV } 1 \geq 50 \% \text { predicted } \\
\text { ICs dose at entry: } 705-720 \mu \mathrm{g} / \mathrm{d} \\
\text { LABA use at entry: } 54-56 \%\end{array}$} & $\begin{array}{l}\text { Budesonide/formoterol } \\
320 / 9 \mu \mathrm{g} \text { BID + PRN } \\
\text { (DPI) } \\
n=1154\end{array}$ & $\begin{array}{l}40(12 \\
\text { to } 80)^{\mathrm{a}}\end{array}$ & 38 & $\begin{array}{l}14(1 \text { to } \\
67)^{b}\end{array}$ & $\begin{array}{l}2.08 \\
(0.60 \\
\text { to } \\
4.65)^{a}\end{array}$ & $\begin{array}{l}70.2(45 \\
\text { to } 114)^{\mathrm{a}}\end{array}$ & NR & $\begin{array}{l}792(\mathrm{NR}), \\
1238 \\
(\mathrm{NR})^{\mathrm{C}}\end{array}$ \\
\hline & & $\begin{array}{l}\text { Fluticasone/salmeterol } \\
500 / 50 \mu \mathrm{g} \text { BID (DPI) + } \\
\text { terbutaline 0.4mg PRN } \\
(\mathrm{DPI}) \\
\mathrm{n}=1155\end{array}$ & $\begin{array}{l}39(12 \\
\text { to } 80)^{\mathrm{a}}\end{array}$ & 38 & $\begin{array}{l}13 \text { (1 to } \\
77)^{\mathrm{b}}\end{array}$ & $\begin{array}{l}2.10 \\
(0.72 \\
\text { to } \\
4.89)^{a}\end{array}$ & $\begin{array}{l}71.0(45 \\
\text { to } 222)^{a}\end{array}$ & NR & $\begin{array}{l}1000 \\
(N R) \\
2000 \\
(N R)^{c}\end{array}$ \\
\hline \multirow[t]{3}{*}{$\begin{array}{l}\text { Kuna, } 2007^{81} \\
\text { COMPASS } \\
n=3335 \\
\text { RCT, } 6 \mathrm{~m} \\
\text { Low }\end{array}$} & \multirow{3}{*}{$\begin{array}{l}\geq 12 \text { years of age with asthma on } \\
\text { ICS } \geq 500 \mu \mathrm{g} / \mathrm{d} \text { fluticasone or } \\
\text { budesonide (or } \geq 1000 \mu \mathrm{g} / \mathrm{d} \text { of } \\
\text { other ICS), FEV } 1 \geq 50 \% \\
\text { predicted, at least } 1 \text { exacerbation } \\
\text { in prior year, SABA used } \geq 5 \text { of } \\
\text { last } 7 \text { run-in days } \\
\text { ICS dose at entry: } 740-750 \mu \mathrm{g} / \mathrm{d} \\
\text { LABA use at entry: } 46-47 \%\end{array}$} & $\begin{array}{l}\text { Budesonide/formoterol } \\
\text { 160/4.5 } \mu \mathrm{g} \text { BID + PRN } \\
\text { (DPI) } \\
n=1107\end{array}$ & 38 (17) & 43 & NR & NR & $72(14)$ & NR & $\begin{array}{l}483(\mathrm{NR}) \\
755(\mathrm{NR}) \mathrm{C}\end{array}$ \\
\hline & & $\begin{array}{l}\text { Budesonide/formoterol } \\
320 / 9 \mu \mathrm{g} \text { BID + } \\
\text { terbutaline PRN (DPI) } \\
n=1105\end{array}$ & $38(17)$ & 41 & NR & NR & $73(14)$ & NR & $\begin{array}{l}640(\mathrm{NR}), \\
1000 \\
(\mathrm{NR})^{\mathrm{c}}\end{array}$ \\
\hline & & $\begin{array}{l}\text { Fluticasone/salmeterol } \\
250 / 50 \mu \mathrm{g} \text { BID (MDI) + } \\
\text { terbutaline PRN (DPI) } \\
n=1123\end{array}$ & $38(17)$ & 43 & NR & NR & $73(14)$ & NR & $\begin{array}{l}500(\mathrm{NR}), \\
1000 \\
(\mathrm{NR}) \mathrm{c}\end{array}$ \\
\hline $\begin{array}{l}\text { Pavord, } 2009^{89} \\
\mathrm{n}=127 \\
\text { RCT, } 1 \mathrm{yr} \\
\text { Low }\end{array}$ & $\begin{array}{l}\text { 18-65 years of age with asthma } \\
\text { on ICS alone } 800-1600 \mu \mathrm{g} / \mathrm{d} \text { or } \\
\text { ICS } 400-1000 \mu \mathrm{g} / \mathrm{d}+\mathrm{LABA} \text {, } \\
\text { FEV } 1 \geq 60 \% \text { predicted. SABA or } \\
\text { symptoms } \geq 4 \text { of last } 7 \text { run-in days } \\
\text { with mean morning PEF } 50-85 \%\end{array}$ & $\begin{array}{l}\text { Budesonide/formoterol } \\
\text { 160/4.5 } \mu \mathrm{g} \text { BID + PRN } \\
\text { (DPI) } \\
n=64\end{array}$ & $\begin{array}{l}39(19 \\
\text { to } 63)^{\mathrm{a}}\end{array}$ & 55 & $\begin{array}{l}20(1 \text { to } \\
62)^{b}\end{array}$ & $\begin{array}{l}2.9 \\
(1.2 \text { to } \\
4.7)^{\mathrm{a}}\end{array}$ & $\begin{array}{l}81.4(58 \\
\text { to } 121)^{\mathrm{a}}\end{array}$ & $\begin{array}{l}1.5 \\
(0-6.0)^{a}\end{array}$ & NR \\
\hline
\end{tabular}




\begin{tabular}{|c|c|c|c|c|c|c|c|c|c|}
\hline $\begin{array}{l}\text { Study, Year, } \\
\text { N, } \\
\text { Acronym, } \\
\text { Study design, } \\
\text { Duration, } \\
\text { Risk of bias }\end{array}$ & Study population & $\begin{array}{l}\text { Intervention } \\
\text { Comparisons }\end{array}$ & $\begin{array}{l}\text { Age (y) } \\
\text { [mean } \\
\text { (SD)] }\end{array}$ & $\begin{array}{l}\text { Males } \\
(\%)\end{array}$ & $\begin{array}{l}\text { Duration } \\
\text { of } \\
\text { asthma } \\
\text { (y) } \\
\text { [mean } \\
\text { (SD)] }\end{array}$ & $\begin{array}{l}\text { FEV1 } \\
\text { (L) } \\
\text { [mean } \\
\text { (SD)] }\end{array}$ & $\begin{array}{l}\text { FEV1 \% } \\
\text { predict } \\
\text { ed (L) } \\
\text { [mean } \\
\text { (SD)] }\end{array}$ & $\begin{array}{l}\text { Rescue } \\
\text { inhaler } \\
\text { use } \\
\text { (puffs/d) } \\
\text { [mean } \\
\text { (SD)] }\end{array}$ & $\begin{array}{l}\text { ICS dose } \\
\text { during } \\
\text { study } \\
\text { ( } \mu \mathrm{g} / \mathrm{d} \text { ) } \\
\text { [mean } \\
\text { (SD)] }\end{array}$ \\
\hline & $\begin{array}{l}\text { ICS dose at entry: } 741-867 \mu \mathrm{g} / \mathrm{d} \\
\text { LABA use at entry: } 81-84 \%\end{array}$ & $\begin{array}{l}\text { Budesonide/formoterol } \\
320 / 9 \mu \mathrm{g} \text { BID (MDI) + } \\
\text { budesonide } 400 \mu \mathrm{g} \text { BID } \\
\text { (DPI) + terbutaline } \\
0.5 \mathrm{mg} \text { PRN (DPI) } \\
\mathrm{n}=63\end{array}$ & $\begin{array}{l}41(20- \\
65)^{a}\end{array}$ & 54 & $\begin{array}{l}21(1 \text { to } \\
54)^{b}\end{array}$ & $\begin{array}{l}2.8 \\
(1.4 \text { to } \\
4.3)^{\mathrm{a}}\end{array}$ & $\begin{array}{l}80.6(60 \\
\text { to } 110)^{\mathrm{a}}\end{array}$ & $\begin{array}{l}1.2 \\
(0 \text { to } \\
7.4)^{\mathrm{a}}\end{array}$ & NR \\
\hline $\begin{array}{l}\text { Lundborg, } \\
2006^{115} \\
N=491 \\
\text { RCT, 26w }\end{array}$ & \multirow{3}{*}{$\begin{array}{l}\geq 6 \text { years of age with asthma not } \\
\text { well controlled on ICS alone (25- } \\
36 \%) \text { or well controlled on } \\
\text { ICS+LABA }(64-75 \%) \text {, treated with } \\
\text { ICS } 500-1200 \mu \mathrm{g} / \mathrm{d}(250-600 \mu \mathrm{g} / \mathrm{d} \\
\text { for } 6-11 \mathrm{y}) \text {, FEV1 } \geq 60 \% \text { predicted } \\
\text { ICS dose at entry: } 4-11 \mathrm{y} 419- \\
435 \mu \mathrm{g} / \mathrm{d} ; 12 \mathrm{y}+708-721 \mu \mathrm{g} / \mathrm{d} \text {; } \\
\text { Allowed to continue disodium } \\
\text { cromoglycate and montelukast at } \\
\text { stable pre-study dose }\end{array}$} & $\begin{array}{l}\text { Budesonide/formoterol } \\
160 / 4.5 \mu \mathrm{g} Q \mathrm{QD}+\mathrm{PRN} \\
\text { (DPI) (80/4.5 } \mu \mathrm{g} / \mathrm{d} \text { used } \\
\text { for 4-11y) } \\
\mathrm{n}=162\end{array}$ & $\begin{array}{l}39.7 \\
(19.6)\end{array}$ & 43 & NR & $\begin{array}{l}3.0 \\
(0.9)^{d}\end{array}$ & $\begin{array}{l}95.7 \\
(13.7)^{d}\end{array}$ & NR & $\begin{array}{l}339.0 \\
(N R)^{f} \\
129.0 \\
(N R)^{g}\end{array}$ \\
\hline \multirow[t]{2}{*}{ Medium } & & $\begin{array}{l}\text { Budesonide/formoterol } \\
160 / 4.5 \mu \mathrm{g} \text { BID + PRN } \\
(\mathrm{DPI})(80 / 4.5 \mu \mathrm{g} / \mathrm{d} \text { used } \\
\text { for } 4-11 \mathrm{y}) \\
n=165\end{array}$ & $\begin{array}{l}38.2 \\
(20.6)\end{array}$ & 49 & NR & $\begin{array}{l}3.0 \\
(0.9)\end{array}$ & $\begin{array}{l}96.2 \\
(14.7)\end{array}$ & NR & $\begin{array}{l}405.2 \\
(N R)^{f} \\
194.1 \\
(N R)^{g}\end{array}$ \\
\hline & & $\begin{array}{l}\text { Budesonide/formoterol } \\
320 / 9 \mu \mathrm{g} \text { BID + } \\
\text { formoterol } 4.5 \mu \mathrm{g} \text { PRN } \\
n=164\end{array}$ & $\begin{array}{l}40.8 \\
(19.9)\end{array}$ & 49 & NR & $\begin{array}{l}3.0 \\
(0.9)\end{array}$ & $\begin{array}{l}96.5 \\
(15.2)\end{array}$ & NR & $\begin{array}{l}637.5 \\
(\mathrm{NR}) / \\
325.8 \\
(\mathrm{NR})\end{array}$ \\
\hline \multirow[t]{2}{*}{$\begin{array}{l}\text { Stallberg, } \\
2008^{100} \\
\text { SHARE } \\
\mathrm{N}=1343 \\
\mathrm{RCT}, 12 \mathrm{~m} \\
\\
\text { Medium }\end{array}$} & \multirow{2}{*}{$\begin{array}{l}\geq 12 \text { years of age with persistent } \\
\text { asthma on free combination } \\
\text { ICS+LABA or symptomatic } \\
\text { despite ICS alone, on ICS } \\
\geq 400 \mu \mathrm{g} / \mathrm{d} \\
\text { ICS dose at entry: } 636-650 \mu \mathrm{g} / \mathrm{d} \\
\text { LABA use at entry: } 51-52 \% \\
\text { Randomized therapy stratified by } \\
\text { baseline ICS dose }\end{array}$} & $\begin{array}{l}\text { Budesonide/formoterol } \\
160 / 9 \mu \mathrm{g} \text { or } 320 / 9 \mu \mathrm{g} \text { QD } \\
\text { + PRN OR } \\
80 / 4.5 \mu \mathrm{g} \text { or } 160 / 4.5 \mu \mathrm{g} \\
\text { BID + PRN } \\
\mathrm{n}=887\end{array}$ & 43 (NR) & 40 & NR & NR & NR & NR & 291 (NR) \\
\hline & & $\begin{array}{l}\text { Budesonide/formoterol } \\
160 / 9 \mu \mathrm{g} \text { or } 320 / 9 \mu \mathrm{g} \text { BID } \\
+ \text { terbutaline PRN } \\
\mathrm{n}=456\end{array}$ & 45 (NR) & 44 & NR & NR & NR & NR & 368 (NR) \\
\hline
\end{tabular}

Abbreviations: BID=twice daily; d=day; DPI=dry powder inhaler; FEV1=forced expiratory volume in one second; ICS=inhaled corticosteroid; L=liter; LABA=long-acting $\beta_{2}-$ agonist; $\mathrm{m}=$ month; MDI-metered dose inhaler; n=patient sample size; NR=not reported; PEF=peak expiratory flow; PRN=pro re nata (i.e., as-needed); QD=daily;

RCT=randomized controlled trial; SABA=short-acting $\beta_{2}$-agonist; $\mathrm{SD}=$ standard deviation; $\mu \mathrm{g}=$ microgram; $\mathrm{w}=$ week; $\mathrm{y}=\mathrm{year}$

ata reported as mean (range)

bData reported as median (range)

'Beclomethasone dipropionate equivalent dose in $\mu \mathrm{g}$

${ }^{\mathrm{d}}$ Represents values post-bronchodilator 
ePercentage of patients continued on concurrent disodium cromoglycate and montelukast not reported

${ }^{\mathrm{f}}$ Represents values from adults $(\geq 12 \mathrm{y})$

${ }^{g}$ Represents values from children $(6-11 \mathrm{y})$

hPatients previously treated with ICS $400-500 \mu \mathrm{g} / \mathrm{d}$ received budesonide/formoterol $80 / 4.5 \mu \mathrm{g}$ dose and those previously treated with ICS $>500 \mu \mathrm{g} / \mathrm{d}$ received budesonide/formoterol $160 / 4.5 \mu \mathrm{g}$ dose

Table C-13. Study and population characteristics for KQ1C, ICS and LABA controller and quick relief vs. ICS and LABA controller (Iower dose)

\begin{tabular}{|c|c|c|c|c|c|c|c|c|c|}
\hline $\begin{array}{l}\text { Study, Year, } \\
\text { N, } \\
\text { Study design, } \\
\text { Duration, } \\
\text { Risk of bias }\end{array}$ & Study population & $\begin{array}{l}\text { Intervention } \\
\text { Comparisons }\end{array}$ & $\begin{array}{l}\text { Age (y) } \\
\text { [mean } \\
\text { (SD)] }\end{array}$ & $\begin{array}{l}\text { Males } \\
(\%)\end{array}$ & $\begin{array}{l}\text { Duration } \\
\text { of } \\
\text { asthma } \\
\text { (y) } \\
\text { [mean } \\
\text { (SD)] }\end{array}$ & $\begin{array}{l}\text { FEV1 } \\
\text { (L) } \\
\text { [mean } \\
\text { (SD)] }\end{array}$ & $\begin{array}{l}\text { FEV1 \% } \\
\text { predict } \\
\text { ed (L) } \\
\text { [mean } \\
\text { (SD)] }\end{array}$ & $\begin{array}{l}\text { Rescue } \\
\text { inhaler } \\
\text { use } \\
\text { (puffs/d) } \\
\text { [mean } \\
\text { (SD)] }\end{array}$ & $\begin{array}{l}\text { ICS dose } \\
\text { during } \\
\text { study } \\
\text { ( } \mu \mathrm{g} / \mathrm{d}) \\
\text { [mean } \\
\text { (SD)] }\end{array}$ \\
\hline $\begin{array}{l}\text { Hozawa, } \\
2016^{117} \\
n=30 \\
\text { RCT, } 4 w\end{array}$ & $\begin{array}{l}\geq 20 \text { years of age with persistent } \\
\text { asthma on ICS alone (BUD } \\
800 \mathrm{mcg} / \mathrm{d}, \mathrm{FP} \text { or MF } 400 \mathrm{mg} / \mathrm{d} \text { ), } \\
\text { symptomatic with use of SABA } 2 \\
\text { to } 6 \text { times/w and ACQ } \geq 1.5\end{array}$ & $\begin{array}{l}\text { Budesonide/formoterol } \\
320 / 9 \mu \mathrm{g} \text { BID + PRN } \\
\text { (DPI) } \\
n=15\end{array}$ & $\begin{array}{l}41.7 \\
(5.9)\end{array}$ & 46.7 & $8.7(3.2)$ & NR & $\begin{array}{l}88.5 \\
(5.6)\end{array}$ & NR & $\begin{array}{l}688.8 \mathrm{mcg} \\
\text { (NR) }\end{array}$ \\
\hline Medium & ICS dose at entry: $705-720 \mu \mathrm{g} / \mathrm{d}$ & $\begin{array}{l}\text { Fluticasone/vilanterol } \\
100 / 25 \mu \mathrm{g} \text { QD (DPI) + } \\
\text { procaterol 20mcg PRN } \\
n=15\end{array}$ & $\begin{array}{l}40.4 \\
(7.6)\end{array}$ & 40.0 & $8.0(2.7)$ & NR & $\begin{array}{l}90.2 \\
(6.4)\end{array}$ & NR & NR \\
\hline
\end{tabular}

Abbreviations: BID=twice daily; d=day; DPI=dry powder inhaler; FEV1=forced expiratory volume in one second; ICS=inhaled corticosteroid; L=liter; $\mathrm{n}=$ patient sample size; $\mathrm{NR}=$ not reported; $\mathrm{PRN}=$ pro re nata (i.e., as-needed); $\mathrm{QD}=$ daily; $\mathrm{RCT}=$ randomized controlled trial; $\mathrm{SABA}=$ short-acting $\beta_{2}$-agonist; $\mathrm{SD}=$ standard deviation; $\mu \mathrm{g}=$ microgram; $\mathrm{w}=$ week; $\mathrm{y}=\mathrm{year}$ 
Table C-14. Study and population characteristics for KQ1C, ICS and LABA controller and quick relief vs. CBP

\begin{tabular}{|c|c|c|c|c|c|c|c|c|c|}
\hline $\begin{array}{l}\text { Study, Year, } \\
\text { n, } \\
\text { Acronym, } \\
\text { Study design, } \\
\text { Duration, } \\
\text { Risk of bias }\end{array}$ & Study population & $\begin{array}{l}\text { Intervention } \\
\text { Comparisons }\end{array}$ & $\begin{array}{l}\text { Age (y) } \\
\text { [mean } \\
\text { (SD)] }\end{array}$ & $\begin{array}{l}\text { Males } \\
(\%)\end{array}$ & $\begin{array}{l}\text { Duration } \\
\text { of } \\
\text { asthma } \\
\text { (y) } \\
\text { [mean } \\
\text { (SD)] }\end{array}$ & $\begin{array}{l}\text { FEV1 } \\
\text { (L) } \\
\text { [mean } \\
\text { (SD)] }\end{array}$ & $\begin{array}{l}\text { FEV1\% } \\
\text { predict- } \\
\text { ed (L) } \\
\text { [mean } \\
\text { (SD)] }\end{array}$ & $\begin{array}{l}\text { Rescue } \\
\text { inhaler } \\
\text { use } \\
\text { (puffs/d) } \\
\text { [mean } \\
\text { (SD)] }\end{array}$ & $\begin{array}{l}\text { ICS dose } \\
\text { during } \\
\text { study } \\
\text { ( } \mu \text { g/d) } \\
\text { [mean } \\
\text { (SD)] }\end{array}$ \\
\hline \multirow[t]{2}{*}{$\begin{array}{l}\text { Loh, } 2008^{114} \\
\mathrm{n}=38 \\
\text { Retrospective } \\
\text { observational } \\
\text { cohort study, } \\
3 \mathrm{~m}\end{array}$} & \multirow{2}{*}{$\begin{array}{l}\geq 14 \text { years of age with moderate } \\
\text { to severe asthma and } \\
\text { inadequately controlled despite } \\
\text { step } 3 \text { or } 4 \text { ( } 52.6 \% \text { step } 3,47.4 \% \\
\text { step } 4 \text {, per GINA guidelines) } \\
\text { treatment } \\
\text { ICS dose at entry: } 400-1200 \mu \mathrm{g} / \mathrm{d} \\
\text { LABA at entry: } 100 \%\end{array}$} & $\begin{array}{l}\text { Budesonide/formoterol } \\
\text { maintenance + PRN } \\
\text { (DPI) } \\
n=22\end{array}$ & $\begin{array}{l}49(36 \\
\text { to } 65)^{\mathrm{a}}\end{array}$ & 13.6 & NR & $\begin{array}{l}1.16 \\
(0.71 \\
\text { to } \\
2.35)^{\mathrm{a}}\end{array}$ & $\begin{array}{l}41(21 \\
\text { to } 74)^{a}\end{array}$ & NR & $\begin{array}{l}1200 \\
(200- \\
1400)^{a}\end{array}$ \\
\hline & & $\begin{array}{l}\text { Budesonide/formoterol } \\
\text { maintenance (DPI) }+ \\
\text { SABA PRN (MDI/DPI) } \\
\mathrm{n}=16\end{array}$ & $\begin{array}{l}50(14 \\
\text { to } 66)^{a}\end{array}$ & 43.8 & NR & $\begin{array}{l}1.41 \\
(0.52 \\
\text { to } \\
2.79)^{a}\end{array}$ & $\begin{array}{l}48(20 \\
\text { to } 91)^{a}\end{array}$ & NR & NR \\
\hline \multirow[t]{2}{*}{$\begin{array}{l}\text { Sears, } 2008^{97} \\
\mathrm{n}=1538 \\
\mathrm{RCT}, 6 \mathrm{~m} \\
\text { Medium }\end{array}$} & \multirow{2}{*}{$\begin{array}{l}\geq 12 \text { years of age with mild-severe } \\
\text { persistent asthma ( } 18 \% \text { mild, } \\
43 \% \text { moderate, } 39 \% \text { severe per } \\
\text { GINA guidelines) on ICS } \\
\geq 400 \mu \text { g/d and sub-optimal control } \\
\text { or on daily maintenance } \\
\text { ICS+LABA } \\
\text { ICS dose at entry: } 566-572 \mu \mathrm{g} / \mathrm{d} \\
\text { LABA use at entry: } 73-75 \%\end{array}$} & $\begin{array}{l}\text { Budesonide/formoterol } \\
\text { 160/4.5 } \mu \mathrm{g} \text { BID + PRN } \\
\text { (DPI) } \\
n=772\end{array}$ & $\begin{array}{l}42.1 \\
(16.4)\end{array}$ & 42.2 & NR & NR & NR & $\begin{array}{l}1.25 \\
(1.67)\end{array}$ & $\begin{array}{l}748 \text { with } \\
(0 \text { to } \\
2710)^{\text {b,c }}\end{array}$ \\
\hline & & $\begin{array}{l}\text { Conventional best } \\
\text { practice }^{d} \\
n=766\end{array}$ & $\begin{array}{l}43.1 \\
(16.0)\end{array}$ & 37.5 & NR & NR & NR & $\begin{array}{l}1.22 \\
(1.69)\end{array}$ & $\begin{array}{l}1015(30 \\
\text { to } 4000)^{\mathrm{b}, \mathrm{c}}\end{array}$ \\
\hline $\begin{array}{l}\text { Stallberg, } \\
2008^{100} \\
\text { SHARE } \\
n=1776 \\
\text { RCT, } 12 \mathrm{~m}\end{array}$ & $\begin{array}{l}\geq 12 \text { years of age with persistent } \\
\text { asthma on free combination } \\
\text { ICS+LABA or symptomatic } \\
\text { despite ICS alone, on ICS } \\
\geq 400 \mu \mathrm{g} / \mathrm{d}\end{array}$ & $\begin{array}{l}\text { Budesonide/formoterol } \\
160 / 9 \mu \mathrm{g} \text { or } 320 / 9 \mu \mathrm{g} \text { QD } \\
+ \text { PRN OR } \\
80 / 4.5 \mu \mathrm{g} \text { or } 160 / 4.5 \mu \mathrm{g} \\
\text { BID + PRN } \\
\mathrm{n}=887\end{array}$ & $43(\mathrm{NR})$ & 40 & NR & NR & NR & NR & 291 (NR) \\
\hline Medium & $\begin{array}{l}\text { ICS dose at entry: } 636-650 \mu \mathrm{g} / \mathrm{d} \\
\text { LABA use at entry: } 51-52 \% \\
\text { Randomized therapy stratified by } \\
\text { baseline ICS dose }\end{array}$ & $\begin{array}{l}\text { Budesonide } 100-400 \mu \mathrm{g} \\
(\mathrm{DPI})+\text { formoterol } 4.5 \\
\text { or } 9 \mu \mathrm{g}(\mathrm{DPI}) \text { at a dose } \\
\text { judged by investigator }+ \\
\text { terbutaline PRN } \\
\mathrm{n}=433\end{array}$ & 43 (NR) & 41 & NR & NR & NR & NR & 550 (NR) \\
\hline
\end{tabular}




\begin{tabular}{|c|c|c|c|c|c|c|c|c|c|}
\hline $\begin{array}{l}\text { Study, Year, } \\
\text { n, } \\
\text { Acronym, } \\
\text { Study design, } \\
\text { Duration, } \\
\text { Risk of bias }\end{array}$ & Study population & $\begin{array}{l}\text { Intervention } \\
\text { Comparisons }\end{array}$ & $\begin{array}{l}\text { Age (y) } \\
\text { [mean } \\
(\mathrm{SD})]\end{array}$ & $\begin{array}{l}\text { Males } \\
(\%)\end{array}$ & $\begin{array}{l}\text { Duration } \\
\text { of } \\
\text { asthma } \\
\text { (y) } \\
\text { [mean } \\
\text { (SD)] }\end{array}$ & $\begin{array}{l}\text { FEV1 } \\
\text { (L) } \\
\text { [mean } \\
\text { (SD)] }\end{array}$ & $\begin{array}{l}\text { FEV1\% } \\
\text { predict- } \\
\text { ed (L) } \\
\text { [mean } \\
\text { (SD)] }\end{array}$ & $\begin{array}{l}\text { Rescue } \\
\text { inhaler } \\
\text { use } \\
\text { (puffs/d) } \\
\text { [mean } \\
\text { (SD)] }\end{array}$ & $\begin{array}{l}\text { ICS dose } \\
\text { during } \\
\text { study } \\
\text { ( } \mu \text { g/d) } \\
\text { [mean } \\
\text { (SD)] }\end{array}$ \\
\hline \multirow[t]{2}{*}{$\begin{array}{l}\text { Louis, } 2009^{82} \\
\text { SALTO } \\
\mathrm{n}=908 \\
\text { RCT, } 26 \mathrm{w} \\
\text { Medium }\end{array}$} & \multirow[t]{2}{*}{$\begin{array}{l}\geq 12 \text { years of age with persistent } \\
\text { asthma, symptomatic on ICS } \\
\text { alone } \geq 500 \mu \mathrm{g} / \mathrm{d} \text { beclomethasone } \\
\text { equivalents or without regard to } \\
\text { symptoms on ICS+ another } \\
\text { controller therapy } \\
\text { ICS dose at entry:570-589 } \mu \mathrm{g} / \mathrm{d}\end{array}$} & $\begin{array}{l}\text { Budesonide/formoterol } \\
\text { 160/4.5 } \mu \mathrm{g} \text { BID + PRN } \\
\text { (DPI) } \\
n=450\end{array}$ & $\begin{array}{l}43.4 \\
(\mathrm{NR})\end{array}$ & 44.0 & $\begin{array}{l}21.0 \\
(0 \text { to } 86)^{a}\end{array}$ & NR & NR & $\begin{array}{l}1.09 \\
(0-15)^{b}\end{array}$ & $749(N R)^{c}$ \\
\hline & & $\begin{array}{l}\text { Conventional best } \\
\text { practice }^{\mathrm{g}} \\
\mathrm{n}=458\end{array}$ & $\begin{array}{l}42.9 \\
(\mathrm{NR})\end{array}$ & 41.0 & $\begin{array}{l}20.2 \\
(0 \text { to } 78)^{a}\end{array}$ & NR & NR & $\begin{array}{l}1.02 \\
(0-11)^{b}\end{array}$ & $\begin{array}{l}1059 \\
(N R)^{c}\end{array}$ \\
\hline \multirow[t]{2}{*}{$\begin{array}{l}\text { Quirce, } 2011^{91} \\
\mathrm{n}=654 \\
\mathrm{RCT}, 26 \mathrm{w} \\
\text { Medium }\end{array}$} & \multirow{2}{*}{$\begin{array}{l}\geq 18 \text { years of age with persistent } \\
\text { asthma (mild } 26 \% \text {, moderate } \\
32 \% \text {, severe } 42 \% \text { ) on ICS } \pm \text { LABA, } \\
\text { ICS } \geq 400 \mu \text { g/d budesonide or } \\
\text { equivalent, history of suboptimal } \\
\text { control per investigator, SABA } \\
\text { use } \geq 3 \text { occasion in prior week } \\
\text { ICS dose at entry: } 1028- \\
1040 \mu \text { g/d beclomethasone } \\
\text { equivalents } \\
\text { LABA use at entry: } 80-81 \%\end{array}$} & $\begin{array}{l}\text { Budesonide/formoterol } \\
160 / 4.5 \mu \mathrm{g} \text { BID + PRN } \\
\text { (DPI) } \\
n=328\end{array}$ & $\begin{array}{l}43.7 \\
(18-89)^{b}\end{array}$ & 33.5 & $\begin{array}{l}9.7 \\
(0.3 \text { to } \\
57.4)^{\mathrm{a}}\end{array}$ & NR & NR & $1.6(1.2)$ & $799(N R)^{c}$ \\
\hline & & $\begin{array}{l}\text { Conventional best } \\
\text { practice }^{\mathrm{h}} \\
\mathrm{n}=326\end{array}$ & $\begin{array}{l}44.3 \\
(8-82)^{b}\end{array}$ & 38 & $\begin{array}{l}11.2 \\
(0.3 \text { to } \\
60.6)^{a}\end{array}$ & NR & NR & $1.6(1.2)$ & $\begin{array}{l}1184 \\
(N R)^{c}\end{array}$ \\
\hline \multirow[t]{2}{*}{$\begin{array}{l}\text { Soes-Peterson, } \\
2011^{98} \\
\text { MONO } \\
n=1854 \\
\text { RCT, } 26 \mathrm{w} \\
\text { Medium }\end{array}$} & \multirow[t]{2}{*}{$\begin{array}{l}\geq 12 \text { years of age with persistent } \\
\text { asthma on ICS } \geq 320 \mu \mathrm{g} / \mathrm{d} \pm \mathrm{LABA} \text {, } \\
\text { including patients on ICS alone } \\
\text { with history of suboptimal asthma } \\
\text { control indicating need for } \\
\text { additional treatment } \\
\text { ICS dose at entry: } 1018- \\
1051 \mu \mathrm{g} / \mathrm{d} \text { beclomethasone } \\
\text { equivalents } \\
\text { LABA use at entry: } 74-75 \%\end{array}$} & $\begin{array}{l}\text { Budesonide/formoterol } \\
\text { 160/4.5 } \mu \text { B BID + PRN } \\
\text { (DPI) } \\
n=921\end{array}$ & $\begin{array}{l}43.0 \\
(15.9)\end{array}$ & 39.3 & NR & NR & NR & $1.1(1.4)$ & $\begin{array}{l}753(0 \text { to } \\
2500)^{b, c}\end{array}$ \\
\hline & & $\begin{array}{l}\text { Conventional best } \\
\text { standardi } \\
n=914\end{array}$ & $\begin{array}{l}42.0 \\
(15.9)\end{array}$ & 41.4 & NR & NR & NR & $1.1(1.5)$ & $\begin{array}{l}1092(42 \\
\text { to } 6000)^{\mathrm{b}, \mathrm{c}}\end{array}$ \\
\hline $\begin{array}{l}\text { Riemersma, } \\
2012^{95} \\
n=102 \\
\text { RCT, } 12 \mathrm{~m}\end{array}$ & $\begin{array}{l}\geq 18 \text { years of age with mild to } \\
\text { moderate persistent, stable } \\
\text { asthma on daily ICS, FEV } 1 \geq 60 \% \\
\text { predicted, } 36 \% \text { well-controlled } \\
(A C Q \leq 0.75)\end{array}$ & $\begin{array}{l}\text { Budesonide/formoterol } \\
80 / 4.5 \mu \mathrm{g} \text { QD + PRN } \\
n=54\end{array}$ & $\begin{array}{l}44.7 \\
(13.2)\end{array}$ & 41 & NR & NR & $\begin{array}{l}96.0 \\
(16.0)\end{array}$ & $0.6(1.3)$ & $326(N R)^{c}$ \\
\hline
\end{tabular}




\begin{tabular}{|c|c|c|c|c|c|c|c|c|c|}
\hline $\begin{array}{l}\text { Study, Year, } \\
\text { n, } \\
\text { Acronym, } \\
\text { Study design, } \\
\text { Duration, } \\
\text { Risk of bias }\end{array}$ & Study population & $\begin{array}{l}\text { Intervention } \\
\text { Comparisons }\end{array}$ & $\begin{array}{l}\text { Age (y) } \\
\text { [mean } \\
\text { (SD)] }\end{array}$ & $\begin{array}{l}\text { Males } \\
(\%)\end{array}$ & $\begin{array}{l}\text { Duration } \\
\text { of } \\
\text { asthma } \\
\text { (y) } \\
\text { [mean } \\
\text { (SD)] }\end{array}$ & $\begin{array}{l}\text { FEV1 } \\
\text { (L) } \\
\text { [mean } \\
\text { (SD)] }\end{array}$ & $\begin{array}{l}\text { FEV1 \% } \\
\text { predict- } \\
\text { ed (L) } \\
\text { [mean } \\
\text { (SD)] }\end{array}$ & $\begin{array}{l}\text { Rescue } \\
\text { inhaler } \\
\text { use } \\
\text { (puffs/d) } \\
\text { [mean } \\
\text { (SD)] }\end{array}$ & $\begin{array}{l}\text { ICS dose } \\
\text { during } \\
\text { study } \\
\text { ( } \mu \mathrm{g} / \mathrm{d} \text { ) } \\
\text { [mean } \\
\text { (SD)] }\end{array}$ \\
\hline Medium & $\begin{array}{l}\text { ICS dose at entry: } 757-851 \mu \mathrm{g} / \mathrm{d} \\
\text { beclomethasone equivalents }\end{array}$ & $\begin{array}{l}\text { Usual care } \\
\mathrm{n}=48\end{array}$ & $\begin{array}{l}40.6 \\
(12.0)\end{array}$ & 35 & NR & NR & $\begin{array}{l}101.5 \\
(17.5)\end{array}$ & $0.4(0.7)$ & $798(N R)^{c}$ \\
\hline \multirow{2}{*}{$\begin{array}{l}\text { Kardos, } 2013^{79} \\
\mathrm{n}=482 \\
\text { Prospective } \\
\text { observational } \\
\text { cohort study, } \\
6 \mathrm{~m} \\
\text { Low }\end{array}$} & $\begin{array}{l}\geq 18 \text { years of age requiring step } 3 \\
\text { or } 4 \text { (78\% step } 3,22 \% \text { step } 4 \text {, per } \\
\text { GINA guidelines) treatment and } \\
\text { with history of at least } 1 \text { severe } \\
\text { exacerbation in prior } 24 \text { months } \\
\text { (but not in the previous month) }\end{array}$ & $\begin{array}{l}\text { Budesonide/formoterol } \\
\text { maintenance }+ \text { PRN at } \\
\text { a dose judged by } \\
\text { investigatork } \\
n=310\end{array}$ & $\begin{array}{l}49.1 \\
(15.2)\end{array}$ & 38.4 & NR & $\begin{array}{l}2.64 \\
(0.87)\end{array}$ & NR & NR & $615(318)^{\prime}$ \\
\hline & LABA at entry: $100 \%$ & $\begin{array}{l}\text { ICS + LABA } \\
\text { maintenance + SABA } \\
\text { PRN at a dose judged } \\
\text { by the investigatorm } \\
n=172\end{array}$ & $\begin{array}{l}51.4 \\
(15.4)\end{array}$ & 34.3 & NR & $\begin{array}{l}2.45 \\
(0.73)\end{array}$ & NR & NR & $678(380)^{\prime}$ \\
\hline
\end{tabular}

Abbreviations: ACQ=Asthma Control Questionnaire; BID=twice daily; d=day; DPI=dry powder inhaler; FEV1=forced expiratory volume in one second; GEMA=Guía Española para el Manejo del Asma; GINA= Global Initiative for Asthma; ICS=inhaled corticosteroid; L=liter; LABA=long-acting $\beta_{2}$-agonist; LAMA=long-acting muscarinic antagonist; LTRA=leukotriene receptor antagonist; $m=$ months; $\mathrm{MDI}=$ =meter-dose inhaler; $\mathrm{n}=$ patient sample size; NR=not reported; PRN=pro re nata (i.e., as-needed); $\mathrm{QD}=$ daily;

RCT=randomized controlled trial; SABA=short-acting $\beta_{2}$-agonist; SD=standard deviation; $w=w e e k ; y=y e a r$

aData reported as median (range)

${ }^{b}$ Data reported as mean (range)

'Beclomethasone dipropionate equivalent dose in $\mu \mathrm{g}$

dTherapy managed by investigator following Canadian Asthma Consensus Guidelines and could involve ICS+LABA combination products but not combination products used as single maintenance and reliever therapy. During the trial, $18 \%$ of patients were on ICS alone and $82 \%$ of patients were on ICS+LABA

ePatients previously treated with ICS $400-500 \mu \mathrm{g} / \mathrm{d}$ received budesonide/formoterol $80 / 4.5 \mu \mathrm{g}$ dose and those previously treated with ICS $>500 \mu \mathrm{g} / \mathrm{d}$ received budesonide/formoterol $160 / 4.5 \mu \mathrm{g}$ dose

fTherapy used at appropriate dose according to asthma severity as judged by the investigator. Doses could be adjusted up or down within the range but budesonide could not be completely withdrawn

'Physician's choice of stepwise maintenance therapy with multiple controller therapies allowed. However, an ICS+LABA combination single maintenance and reliever therapy and oral steroids were not allowed. Investigators were encouraged to use the GINA guidelines. Prescribed maintenance medications included ICS+LABA combination inhaler (86\%), LTRA (27\%), separate ICS inhaler (7\%), separate LABA inhaler (7\%), inhaled LAMA (4\%), xanthines (3\%) and mucolytics (1\%)

${ }^{\text {h}}$ Active stepped and individualized treatment in accordance with GINA and GEMA guidelines. Patients had to be treated with at least ICS as maintenance treatment and could be treated with any asthma medication except ICS+LABA combination single maintenance and reliever therapy and oral steroids. During the trial, 91\% of patients were treated with ICS+LABA either in single or separate inhalers, 27\% with LTRAs, $2 \%$ with inhaled anticholinergics and 2.5\% with mucolytics

${ }^{1}$ Any guideline-defined treatment was allowed, except ICS+LABA combination single maintenance and reliever therapy. During the trial, $81 \%$ of patients were treated with LABA in addition to their ICS, $11 \%$ used LTRAs and $88 \%$ used SABAs for rescue

jContinued medication as before randomization and treated as usual by general practitioner 
${ }^{k}$ Investigators were provided with the package insert for budesonide/formoterol including dosage and Symbicort maintenance and reliever therapy treatment principles. No other restrictions were applied. No concomitant therapies were disallowed (with the exception of systemic corticosteroids and $\beta$-blockers), but investigators were asked to take into account relevant information from the budesonide /formoterol summary of product characteristics

${ }^{\mathrm{l}}$ Represents prescribed inhaled corticosteroid dose

${ }^{\mathrm{m}}$ Only directions given to investigators regarding the comparator group was that these patients had to be treated with inhaled corticosteroids plus long-acting $\beta_{2}$-agonist and asneeded short-acting $\beta_{2}$-agonist via separate inhalers and should be treated according to the relevant information in the product package inserts

Table C-15. Study level outcomes for KQ1c, ICS and LABA controller and quick relief vs. ICS and LABA controller and quick relief vs.

ICS controller (same dose)

\begin{tabular}{|c|c|c|c|c|c|c|}
\hline $\begin{array}{l}\text { Study, } \\
\text { Year, n, } \\
\text { Study } \\
\text { design, } \\
\text { Duration }\end{array}$ & Population $^{a}$ & Exacerbations $^{b}$ & Mortality & Asthma control & Quality of life & $\begin{array}{l}\text { Healthcare } \\
\text { utilization }\end{array}$ \\
\hline $\begin{array}{l}\text { Scicchitano, } \\
2004^{86} \\
n=1890 \\
\text { RCT, } 12 \mathrm{~m}\end{array}$ & $\begin{array}{l}\text { Age: } 12 y+ \\
\text { Severity/control: } \\
\text { Moderate to severe } \\
\text { persistent asthma/ } \\
\text { symptomatic } \\
\text { ICS daily dose: } \\
\text { Low vs. low }\end{array}$ & $\begin{array}{l}\text { Relative measures } \\
\text { Requiring systemic } \\
\text { corticosteroids, } \\
\text { hospitalization, or ER visit: } \\
\text { RR } 0.64 \text { ( } 0.53 \text { to } 0.78) \\
\text { HR } 0.61 \text { ( } 0.49 \text { to } 0.75) \\
\text { IRR } 0.55 \text { ( } 0.46 \text { to } 0.66) \\
\text { Requiring systemic } \\
\text { corticosteroids, } \\
\text { hospitalization, ER visit, or } \\
\text { PEF < } 70 \% \text { : } \\
\text { RR } 0.65 \text { ( } 0.55 \text { to } 0.78) \\
\text { HR } 0.61 \text { ( } 0.50 \text { to } 0.74) \\
\text { Mild exacerbation: } \\
\text { HR } 0.68 \text { ( } 0.61 \text { to } 0.75) \\
\text { Count data } \\
\text { Hospitalization or ER visit: } \\
15 \text { vs. } 25 \\
\text { Total number of oral } \\
\text { corticosteroid days: } \\
1776 \text { vs. } 3177\end{array}$ & $\begin{array}{l}\text { All-cause: } \\
\text { Peto's OR } 0.51 \\
\text { (0.05 to 4.92) } \\
\text { Asthma-specific: } \\
\text { No events } \\
\text { occurred }\end{array}$ & $\begin{array}{l}\text { Composite measures: } \\
\text { NR } \\
\text { Spirometry: } \\
\text { FEV1 } \\
\text { MD } 0.1 \text { (0.07 to } 0.13)\end{array}$ & NR & $\begin{array}{l}\text { Rescue medication, } \\
\text { inhalations/d: } \\
0.9 \text { vs. } 1.42, p<0.001\end{array}$ \\
\hline
\end{tabular}




\begin{tabular}{|c|c|c|c|c|c|c|}
\hline $\begin{array}{l}\text { Study, } \\
\text { Year, n, } \\
\text { Study } \\
\text { design, } \\
\text { Duration }\end{array}$ & Population $^{a}$ & Exacerbations $^{b}$ & Mortality & Asthma control & Quality of life & $\begin{array}{l}\text { Healthcare } \\
\text { utilization }\end{array}$ \\
\hline $\begin{array}{l}\text { Rabe, } \\
2006^{94} \\
\mathrm{n}=697 \\
\text { RCT, } 6 \mathrm{~m}\end{array}$ & $\begin{array}{l}\text { Age: } 12 y+ \\
\text { Severity/control: } \\
\text { Mild to moderate } \\
\text { persistent asthma/ } \\
\text { symptomatic } \\
\text { ICS daily dose: } \\
\text { Low vs. low }\end{array}$ & $\begin{array}{l}\text { Relative measures } \\
\text { Requiring systemic } \\
\text { corticosteroids, } \\
\text { hospitalization, ER visit, or } \\
\text { PEF < } 70 \% \text { : } \\
\text { RR } 0.49 \text { (0.32 to } 0.76) \\
\text { Count data } \\
\text { Total number of oral } \\
\text { corticosteroid days: } \\
114 \text { vs. } 498\end{array}$ & NR & $\begin{array}{l}\text { Composite measures: } \\
\text { NR } \\
\text { Spirometry: } \\
\text { FEV1, change from } \\
\text { baseline } \\
0.21 \text { vs. } 0.06, p<0.001\end{array}$ & NR & $\begin{array}{l}\text { Rescue medication, } \\
\text { inhalations/d: } \\
\text { MD }-0.34(-0.51 \text { to }- \\
0.17)\end{array}$ \\
\hline $\begin{array}{l}\text { Sovani, } \\
2008^{99} \\
n=71 \\
\text { RCT, } 6 \mathrm{~m}\end{array}$ & $\begin{array}{l}\text { Age: } 12 \mathrm{y}+ \\
\text { Severity/control: } \\
\text { Persistent asthma/ } \\
\text { poor asthma } \\
\text { control } \\
\text { ICS daily dose: } \\
\text { Low vs. low }\end{array}$ & $\begin{array}{l}\text { Relative Measures } \\
\text { NR } \\
\text { Count data } \\
\text { Number of oral corticosteroid } \\
\text { courses: } \\
6 \text { vs. } 6\end{array}$ & NR & $\begin{array}{l}\text { Composite measures: } \\
\text { ACQ-7 score: } \\
\text { MD } 0.15 \text { (-0.5 to } 0.7) \\
\text { Spirometry: } \\
\text { FEV1 } \\
\text { MD } 0.01 \text { (-0.2 to } 2.00)\end{array}$ & $\begin{array}{l}\text { AQLQ-mini } \\
\text { score: } \\
\text { MD } 0.35 \text { (-0.3 to } \\
1.00)\end{array}$ & NR \\
\hline
\end{tabular}

Management of Asthma); ER=emergency room; FEV1=forced expiratory volume in one second; HR=hazard ratio; ICS=inhaled corticosteroid; IRR= incident rate ratio; m=month;

$\mathrm{MD}=$ mean difference; $\mathrm{n}=$ patient sample size; $\mathrm{NR}=$ not reported; $\mathrm{OR}=$ odds ratio; $\mathrm{PEF}=$ peak expiratory flow; RCT=randomized controlled trial; RR=relative risk; $\mathrm{y}=\mathrm{year}$

${ }^{a}$ Age is categorized using study inclusion criteria and the age categories used in EPR-3 of 0-4y, 5-11y and 12y+. Severity is as reported per the study. Control was usually not specified and rather details about patients being symptomatic or not at entry were given and reported here. ICS daily dose is categorized using the study's required ICS dose and the EPR-3 categories of low, medium and high

${ }^{b}$ Relative measures are presented first and include, when reported by the study, RR, HR for time to the event, and IRR for count data allowing multiple events over the period of follow-up. Count data is presented, when reported by the study, for number of hospitalizations, hospital days, and ER visits in association with exacerbations 
Table C-16. Study level outcomes for KQ1C, ICS and LABA controller and quick relief vs. ICS controller (higher dose)

\begin{tabular}{|c|c|c|c|c|c|c|}
\hline $\begin{array}{l}\text { Study, } \\
\text { Year, n, } \\
\text { Study } \\
\text { design, } \\
\text { Duration }\end{array}$ & Population $^{a}$ & Exacerbations $^{b}$ & Mortality & Asthma control & Quality of life & $\begin{array}{l}\text { Healthcare } \\
\text { utilization }\end{array}$ \\
\hline $\begin{array}{l}\text { O'Byrne, } \\
2005^{75,83} \\
n=1851 \\
\text { RCT, } 12 \mathrm{~m}\end{array}$ & $\begin{array}{l}\text { Age: Mixed (5-11y } \\
\text { and } 12+y) \\
\text { Severity/control: } \\
\text { Persistent asthma/ } \\
\text { symptomatic during } \\
\text { run-inc } \\
\text { ICS daily dose: } \\
\text { Low vs. high }\end{array}$ & $\begin{array}{l}\text { Full population } \\
\text { Relative measures } \\
\text { Composite systemic } \\
\text { corticosteroids, } \\
\text { hospitalization, ER visit, or } \\
\text { increase in ICS or other } \\
\text { medication for } 4-11 y \text { : } \\
\text { RR } 0.58 \text { ( } 0.46 \text { to } 0.72) \\
\text { HR } 0.55 \text { (0.43 to } 0.70) \\
\text { IRR } 0.54 \text { (0.44 to } 0.66) \\
\text { Composite systemic } \\
\text { corticosteroids, } \\
\text { hospitalization, ER visit, or } \\
\text { increase in ICS or other } \\
\text { medication for } 4-11 y, \\
\text { PEF<70\%: } \\
\text { RR } 0.57 \text { (0.48 to } 0.69) \\
\text { HR } 0.53 \text { (0.43 to } 0.65) \\
\text { IRR } 0.53 \text { (0.44 to } 0.64) \\
\text { Mild exacerbation: } \\
\text { IRR } 0.64 \text { (0.57 to } 0.73 \text { ) } \\
\text { Count data } \\
\text { Requiring hospitalization or } \\
\text { ER visit: } \\
25 \text { vs. } 29 \\
\text { Average courses of } \\
\text { corticosteroid/y: } \\
0.19 \text { vs. } 0.38\end{array}$ & NR & $\begin{array}{l}\text { Composite measures: } \\
\text { NR } \\
\text { Spirometry: } \\
\text { NR }\end{array}$ & NR & NR \\
\hline
\end{tabular}




\begin{tabular}{|c|c|c|c|c|c|c|}
\hline $\begin{array}{l}\text { Study, } \\
\text { Year, n, } \\
\text { Study } \\
\text { design, } \\
\text { Duration }\end{array}$ & Population $^{a}$ & Exacerbations $^{b}$ & Mortality & Asthma control & Quality of life & $\begin{array}{l}\text { Healthcare } \\
\text { utilization }\end{array}$ \\
\hline & & 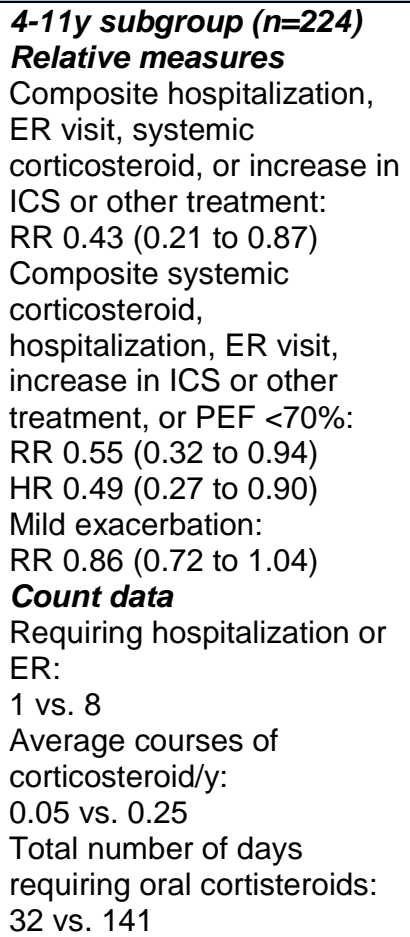 & NR & $\begin{array}{l}\text { Composite measures: } \\
\text { NR } \\
\text { Spirometry: } \\
\text { NR }\end{array}$ & NR & NR \\
\hline
\end{tabular}

Abbreviations: EPR=Expert Panel Review (Guidelines for the Diagnosis and Management of Asthma); ER=emergency room; HR=hazard ratio; ICS=inhaled corticosteroid; IRR= incident rate ratio; $m=$ month; $n=$ patient sample size; $N R=$ not reported; $P E F=$ peak expiratory flow; $R C T=$ randomized controlled trial; $R R=$ relative risk; $y=y e a r$

${ }^{a}$ Age is categorized using study inclusion criteria and the age categories used in EPR-3 of 0-4y, 5-11y and $12 y+$. Severity is as reported per the study. Control was usually not specified and rather details about patients being symptomatic or not at entry were given and reported here. ICS daily dose is categorized using the study's required ICS dose and the EPR-3 categories of low, medium and high

${ }^{b}$ Relative measures are presented first and include, when reported by the study, RR, HR for time to the event, and IRR for count data allowing multiple events over the period of follow-up. Count data is presented, when reported by the study, for number of hospitalizations, hospital days, and ER visits in association with exacerbations

'Defined as $12+$ short-acting $\beta_{2}$-agonist inhalations during last 10 days of the run-in or $8+$ short-acting $\beta_{2}$-agonist inhalations during last 10 days of the run-in for $4-11 y$ olds 
Table C-17. Study level outcomes for KQ1c, ICS and LABA controller and quick relief vs. ICS and LABA controller (same dose)

\begin{tabular}{|c|c|c|c|c|c|c|}
\hline $\begin{array}{l}\text { Study, } \\
\text { Year, n, } \\
\text { Study } \\
\text { design, } \\
\text { Duration }\end{array}$ & Population $^{\mathrm{a}}$ & Exacerbations $^{b}$ & Mortality & Asthma control & $\begin{array}{l}\text { Quality of } \\
\text { life }\end{array}$ & Healthcare utilization \\
\hline $\begin{array}{l}\text { O'Byrne, } \\
2005^{75,83} \\
n=1834 \\
\text { RCT, } 12 \mathrm{~m}\end{array}$ & $\begin{array}{l}\text { Age: Mixed (5-11y } \\
\text { and 12y+) } \\
\text { Severity/control: } \\
\text { Persistent asthma/ } \\
\text { symptomatic during } \\
\text { run-inc } \\
\text { ICS daily dose: } \\
\text { Low vs. low }\end{array}$ & $\begin{array}{l}\text { Full population } \\
\text { Relative measures } \\
\text { Composite systemic } \\
\text { corticosteroid, hospitalization, ER } \\
\text { visit, or increase in ICS or other } \\
\text { medication for } 4-11 y: \\
\text { RR } 0.52 \text { ( } 0.42 \text { to } 0.65) \\
\text { HR } 0.50(0.40 \text { to } 0.63) \\
\text { IRR } 0.47(0.39 \text { to } 0.57) \\
\text { Composite systemic } \\
\text { corticosteroid, hospitalization, ER } \\
\text { visit, increase in ICS or other } \\
\text { medication for } 4-11 y, \text { PEF }<70 \% \text { : } \\
\text { RR } 0.59 \text { (0.49 to } 0.71) \\
\text { HR } 0.55 \text { (0.44 to } 0.67) \\
\text { IRR } 0.53 \text { (0.44 to } 0.65) \\
\text { Mild exacerbation: } \\
\text { IRR } 0.70 \text { (0.62 to } 0.80) \\
\text { Count data } \\
\text { Requiring hospitalization or ER } \\
\text { visit: } \\
25 \text { vs. } 32 \\
\text { Average courses of } \\
\text { corticosteroid/yr: } \\
0.19 \text { vs. } 0.42\end{array}$ & $\mathrm{NR}$ & $\begin{array}{l}\text { Composite measures: } \\
\text { NR } \\
\text { Spirometry: } \\
\text { NR }\end{array}$ & NR & NR \\
\hline
\end{tabular}




\begin{tabular}{|c|c|c|c|c|c|c|}
\hline $\begin{array}{l}\text { Study, } \\
\text { Year, n, } \\
\text { Study } \\
\text { design, } \\
\text { Duration }\end{array}$ & Population $^{\mathrm{a}}$ & Exacerbations $^{\text {b }}$ & Mortality & Asthma control & $\begin{array}{l}\text { Quality of } \\
\text { life }\end{array}$ & Healthcare utilization \\
\hline & & $\begin{array}{l}\text { 4-11y subgroup ( } \boldsymbol{n}=235 \text { ) } \\
\text { Relative measures } \\
\text { Composite hospitalization, ER } \\
\text { visit, systemic corticosteroid, or } \\
\text { increase in ICS or other } \\
\text { treatment: } \\
\text { RR } 0.28 \text { ( } 0.14 \text { to } 0.53 \text { ) } \\
\text { Composite systemic } \\
\text { corticosteroid, hospitalization, ER } \\
\text { visit, increase in ICS or other } \\
\text { treatment, or PEF <70\%: } \\
\text { RR } 0.38 \text { ( } 0.23 \text { to } 0.63) \\
\text { HR } 0.34 \text { (0.19 to } 0.60) \\
\text { Mild exacerbation: } \\
\text { RR } 0.75 \text { ( } 0.64 \text { to } 0.88) \\
\text { Count data } \\
\text { Requiring hospitalization or ER } \\
\text { visit: } \\
1 \text { vs. } 8 \\
\text { Average courses of } \\
\text { corticosteroid/y: } \\
0.05 \text { vs. } 0.30 \\
\text { Total number of days requiring } \\
\text { oral corticosteroid: } \\
32 \text { vs. } 230\end{array}$ & NR & $\begin{array}{l}\text { Composite measures: } \\
\text { NR } \\
\text { Spirometry: } \\
\text { NR }\end{array}$ & NR & NR \\
\hline
\end{tabular}




\begin{tabular}{|c|c|c|c|c|c|c|}
\hline $\begin{array}{l}\text { Study, } \\
\text { Year, n, } \\
\text { Study } \\
\text { design, } \\
\text { Duration }\end{array}$ & Population $^{a}$ & Exacerbations $^{b}$ & Mortality & Asthma control & $\begin{array}{l}\text { Quality of } \\
\text { life }\end{array}$ & Healthcare utilization \\
\hline $\begin{array}{l}\text { Vogelmeier, } \\
2005^{104} \\
\mathrm{n}=2143 \\
\text { RCT, } 12 \mathrm{~m}\end{array}$ & $\begin{array}{l}\text { Age: } 12 \mathrm{y}+ \\
\text { Severity/control: } \\
\text { Persistent asthma/ } \\
\text { symptomatic during } \\
\text { run-in }{ }^{\mathrm{d}} \\
\text { ICS daily dose: } \\
\text { Medium vs. } \\
\text { medium }\end{array}$ & $\begin{array}{l}\text { Relative Measures } \\
\text { Composite systemic cortisteroid, } \\
\text { hospitalization, or ER visit: } \\
\text { RR } 0.80 \text { ( } 0.64 \text { to } 0.99) \\
\text { HR } 0.77 \text { (0.61 to } 0.97) \\
\text { Composite hospitalization, ER, } \\
\text { systemic corticosteroid, or } \\
\text { unscheduled visit: } \\
\text { RR } 0.79 \text { (0.65 to } 0.95) \\
\text { HR } 0.75 \text { (0.61 to } 0.93) \\
\text { IRR } 0.88 \text { (0.56 to } 0.91) \\
\text { Requiring hospitalization or ER } \\
\text { visit: } \\
\text { RR } 0.68 \text { (0.43 to } 1.06) \\
\text { Count data: } \\
\text { Hospitalization or ER visit: } \\
44 \text { vs. } 50 \\
\text { Unscheduled visit: } \\
39 \text { vs. } 62 \\
\text { Asthma-related hospital day: } \\
59 \text { vs. } 94 \\
\text { Asthma-related ER visit: } \\
38 \text { vs. } 45 \\
\text { Unscheduled visit: } \\
117 \text { vs. } 154 \\
\text { Total number of oral } \\
\text { corticosteroid day: } \\
1980 \text { vs. } 2978\end{array}$ & $\begin{array}{l}\text { All-cause: } \\
\text { Peto's OR } 0.14 \\
\text { (0.01 to 2.18) } \\
\text { Asthma- } \\
\text { specific: } \\
\text { No events } \\
\text { occurred }\end{array}$ & $\begin{array}{l}\text { Composite measures: } \\
\text { NR } \\
\text { Spirometry: } \\
\text { NR }\end{array}$ & NR & NR \\
\hline
\end{tabular}




\begin{tabular}{|c|c|c|c|c|c|c|}
\hline $\begin{array}{l}\text { Study, } \\
\text { Year, n, } \\
\text { Study } \\
\text { design, } \\
\text { Duration }\end{array}$ & Population $^{a}$ & Exacerbations $^{b}$ & Mortality & Asthma control & $\begin{array}{l}\text { Quality of } \\
\text { life }\end{array}$ & Healthcare utilization \\
\hline $\begin{array}{l}\text { Rabe, } \\
2006^{93} \\
n=3394 \\
\text { RCT, } 12 \mathrm{~m}\end{array}$ & $\begin{array}{l}\text { Age: } 12 \mathrm{y}+ \\
\text { Severity/control: } \\
\text { Persistent asthma/ } \\
\text { symptomatic during } \\
\text { run-in } \\
\text { ICS daily dose: } \\
\text { Low vs. low }\end{array}$ & $\begin{array}{l}\text { Relative Measures } \\
\text { Composite systemic } \\
\text { corticosteroid, hospitalization, or } \\
\text { ER visit: } \\
\text { RR } 0.60 \text { (0.50 to } 0.72) \\
\text { HR } 0.55 \text { (0.45 to } 0.68) \\
\text { IRR } 0.52 \text { (0.44 to } 0.62) \\
\text { Requiring hospitalization or ER } \\
\text { visit: } \\
\text { RR } 0.61 \text { (0.44 to } 0.85) \\
\text { HR } 0.57 \text { (0.41 to } 0.81) \\
\text { IRR } 0.61 \text { (0.45 to } 0.82) \\
\text { Mild exacerbation: } \\
\text { RR } 0.94 \text { (0.90 to } 0.99) \\
\text { HR } 0.88 \text { (0.80 to } 0.97) \\
\text { IRR } 0.82(0.74 \text { to } 0.91) \\
\text { Count Data } \\
\text { Hospitalization or ER visit: } \\
\text { 70 vs. } 115\end{array}$ & $\begin{array}{l}\text { All-cause: } \\
\text { Peto's OR } 0.53 \\
\text { (0.05 to 5.08) } \\
\text { Asthma- } \\
\text { specific: } \\
\text { No events } \\
\text { occurred }\end{array}$ & $\begin{array}{l}\text { Composite measures: } \\
\text { ACQ-5 score: } \\
\text { MD -0.15 (-0.21 to - } \\
\text { 0.08) } \\
\text { Spirometry: } \\
\text { FEV1: } \\
\text { MD } 0.08(0.05 \text { to } 0.10)\end{array}$ & NR & $\begin{array}{l}\text { Rescue medication use, } \\
\text { inhalations/d: } \\
\text { MD }-0.20 \text { (-0.28 to - } \\
0.12)\end{array}$ \\
\hline
\end{tabular}




\begin{tabular}{|c|c|c|c|c|c|c|}
\hline $\begin{array}{l}\text { Study, } \\
\text { Year, n, } \\
\text { Study } \\
\text { design, } \\
\text { Duration }\end{array}$ & Population $^{a}$ & Exacerbations $^{b}$ & Mortality & Asthma control & $\begin{array}{l}\text { Quality of } \\
\text { life }\end{array}$ & Healthcare utilization \\
\hline $\begin{array}{l}\text { Atienza, } \\
2013^{70} \\
n=2091 \\
\text { RCT, 12m }\end{array}$ & $\begin{array}{l}\text { Age: } 12 \mathrm{y}+ \\
\text { Severity/control: } \\
\text { Persistent asthma/ } \\
\text { not adequately } \\
\text { controlled, } \\
\text { symptomatic during } \\
\text { run-ine } \\
\text { ICS daily dose: } \\
\text { Low vs. low }\end{array}$ & 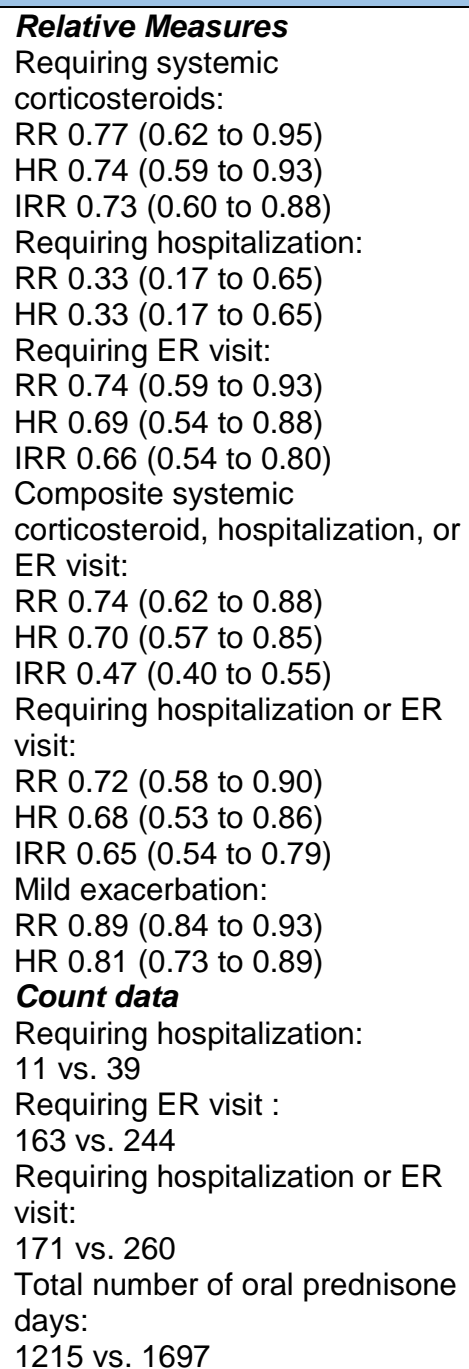 & $\begin{array}{l}\text { All-cause: } \\
\text { Peto's OR } 0.99 \\
\text { (0.06 to 15.89) } \\
\text { Asthma- } \\
\text { specific: } \\
\text { No events } \\
\text { occurred }\end{array}$ & $\begin{array}{l}\text { Composite measures: } \\
\text { ACQ-5 score: } \\
\text { MD -0.124 (-0.179 to - } \\
0.069) \\
\text { ACQ-5 responder: } \\
\text { RR 1.14 (1.05 to } 1.24) \\
\text { Spirometry: } \\
\text { FEV1: } \\
\text { MD 0.04 (0.015 to } \\
0.064)\end{array}$ & NR & $\begin{array}{l}\text { Rescue medication use, } \\
\text { inhalations/d: } \\
\text { MD }-0.25(-0.35 \text { to - } \\
0.15)\end{array}$ \\
\hline
\end{tabular}




\begin{tabular}{|c|c|c|c|c|c|c|}
\hline $\begin{array}{l}\text { Study, } \\
\text { Year, n, } \\
\text { Study } \\
\text { design, } \\
\text { Duration }\end{array}$ & Population $^{\mathrm{a}}$ & Exacerbations $^{\text {b }}$ & Mortality & Asthma control & $\begin{array}{l}\text { Quality of } \\
\text { life }\end{array}$ & Healthcare utilization \\
\hline $\begin{array}{l}\text { Papi, } 2013^{84} \\
n=1701 \\
\text { RCT, 48w }\end{array}$ & $\begin{array}{l}\text { Age: } 12 \mathrm{y}+ \\
\text { Severity/control: } \\
\text { Persistent asthma/ } \\
\text { not fully controlled } \\
\text { ICS daily dose: } \\
\text { Low vs. low }\end{array}$ & $\begin{array}{l}\text { Relative Measures } \\
\text { Requiring systemic } \\
\text { corticosteroid: } \\
\text { RR } 0.62 \text { (0.49 to } 0.79) \\
\text { IRR } 0.65 \text { (0.54 to } 0.80) \\
\text { Composite systemic } \\
\text { corticosteroid, hospitalization, or } \\
\text { ER visit: } \\
\text { RR } 0.65 \text { (0.51 to } 0.82) \\
\text { HR } 0.64 \text { (0.49 to } 0.83) \\
\text { IRR } 0.66 \text { (0.55 to } 0.80) \\
\text { Requiring hospitalization or ER } \\
\text { visit: } \\
\text { RR } 0.69 \text { (0.49 to } 0.96) \\
\text { IRR } 0.67 \text { (0.54 to } 0.84) \\
\text { Requiring hospitalization: } \\
\text { RR } 1.18 \text { (0.2 to } 2.2) \\
\text { Mild exacerbation: } \\
\text { RR } 1.00 \text { (0.94 to } 1.06) \\
\text { HR } 0.97 \text { (0.87 to } 1.09) \\
\text { IRR } 0.86 \text { (0.76 to } 0.98) \\
\text { Count Data } \\
\text { Requiring hospitalization or ER } \\
\text { visit: } \\
67 \text { vs. } 99 \\
\text { Hospitalization: } \\
5 \text { vs. } 17 \\
\text { Intubation: } \\
\text { No events occurred }\end{array}$ & NR & $\begin{array}{l}\text { Composite measures: } \\
\text { ACQ-7 score: } \\
\text { MD -0.06 (-0.13 to } 0.02) \\
\text { Spirometry: } \\
\text { FEV1: } \\
\text { MD } 0.001 \text { ( }-0.04 \text { to } \\
0.04) \\
\text { FVC: } \\
\text { MD }-0.01(-0.07 \text { to } 0.04)\end{array}$ & NR & $\begin{array}{l}\text { Rescue medication use, } \\
\text { inhalations/d: } \\
\text { MD }-0.02 \text { (-0.13 to } 0.09)\end{array}$ \\
\hline
\end{tabular}




\begin{tabular}{|c|c|c|c|c|c|c|}
\hline $\begin{array}{l}\text { Study, } \\
\text { Year, n, } \\
\text { Study } \\
\text { design, } \\
\text { Duration }\end{array}$ & Population $^{a}$ & Exacerbations $^{b}$ & Mortality & Asthma control & $\begin{array}{l}\text { Quality of } \\
\text { life }\end{array}$ & Healthcare utilization \\
\hline $\begin{array}{l}\text { Patel, } \\
2013^{86} \\
n=303 \\
\text { RCT, 24w }\end{array}$ & $\begin{array}{l}\text { Age: } 12 y+ \\
\text { Severity/control: } \\
\text { Persistent asthma } \\
\text { ICS daily dose: } \\
\text { Medium vs. } \\
\text { medium }\end{array}$ & $\begin{array}{l}\text { Relative Measures } \\
\text { Composite systemic } \\
\text { corticosteroid, hospitalization, or } \\
\text { ER visit: } \\
\text { RR } 0.56 \text { (0.38 to } 0.84) \\
\text { HR } 0.53 \text { (0.33 to } 0.85) \\
\text { IRR } 0.54 \text { (0.36 to } 0.81) \\
\text { Hospital or ER admission for } \\
\text { asthma: } \\
\text { RR } 0.78 \text { (0.30 to } 2.05) \\
\text { HR } 0.85 \text { (0.37 to } 2.00) \\
\text { Hospital admission for asthma: } \\
\text { RR } 1.01 \text { (0.14 to } 7.05) \\
\text { HR } 1.54(0.26 \text { to } 9.09) \\
\text { Oral corticosteroid dose (mg } \\
\text { prednisone): } \\
\text { MD -49.1 (-121.34 to } 23.14) \\
\text { Rate of prednisone courses per } \\
\text { year: } \\
\text { HR } 0.58 \text { (0.41 to } 0.84) \\
\text { Count data } \\
\text { NR }\end{array}$ & $\begin{array}{l}\text { All-cause: } \\
\text { No events } \\
\text { occurred } \\
\text { Asthma- } \\
\text { specific: } \\
\text { No events } \\
\text { occurred }\end{array}$ & $\begin{array}{l}\text { Composite measures: } \\
\text { ACQ-7 score: } \\
\text { MD }-0.23(-0.47 \text { to } 0.01) \\
\text { Spirometry: } \\
\text { FEV1: } \\
\text { MD } 0.15(-0.06 \text { to } 0.36) \\
\text { FEV1 \% predicted: } \\
\text { MD } 1.8 \text { (-2.8 to } 6.4)\end{array}$ & NR & NR \\
\hline $\begin{array}{l}\text { Hozawa, } \\
2014^{78} \\
n=30 \\
\text { RCT, 8w }\end{array}$ & $\begin{array}{l}\text { Age: } 12 \mathrm{y}+ \\
\text { Severity/control: } \\
\text { Persistent asthma/ } \\
\text { not well controlled } \\
\text { and symptomatic } \\
\text { ICS daily dose: } \\
\text { Medium vs. } \\
\text { medium }\end{array}$ & NR & NR & $\begin{array}{l}\text { Composite measures: } \\
\text { ACQ-5 score: } \\
\text { MD -0.37 (-0.58 to - } \\
0.16) \\
\text { Spirometry: } \\
\text { FEV1 \% predicted: } \\
\text { MD } 1.9 \text { (-4.27 to } 8.07)\end{array}$ & NR & $\begin{array}{l}\text { Rescue medication use, } \\
\text { inhalations/w: } \\
\text { MD }-0.73(-1.42 \text { to - } \\
0.04)\end{array}$ \\
\hline
\end{tabular}




\begin{tabular}{|c|c|c|c|c|c|c|}
\hline $\begin{array}{l}\text { Study, } \\
\text { Year, n, } \\
\text { Study } \\
\text { design, } \\
\text { Duration }\end{array}$ & Population $^{\mathrm{a}}$ & Exacerbations $^{b}$ & Mortality & Asthma control & $\begin{array}{l}\text { Quality of } \\
\text { life }\end{array}$ & Healthcare utilization \\
\hline $\begin{array}{l}\text { Takeyama, } \\
2014^{101,102} \\
\mathrm{n}=63 \\
\text { RCT, 1y }\end{array}$ & $\begin{array}{l}\text { Age: } 12 \mathrm{y}+ \\
\text { Severity/control: } \\
\text { Moderate to severe } \\
\text { persistent asthma/ } \\
\text { not well controlled } \\
\text { and symptomatic } \\
\text { ICS daily dose: } \\
\text { Low vs. low }\end{array}$ & $\begin{array}{l}\text { Relative Measures } \\
\text { Any exacerbation: } \\
\text { HR } 0.34 \text { ( } 0.11 \text { to } 0.92) \\
\text { Count data } \\
\text { NR }\end{array}$ & NR & $\begin{array}{l}\text { Composite measures: } \\
\text { ACT: } \\
\text { MD } 6.3 \text { (5.15 to } 7.45) \\
\text { Spirometry: } \\
\text { FEV1: } \\
\text { MD } 0.04(0.02 \text { to } 0.06)\end{array}$ & NR & $\begin{array}{l}\text { Rescue medication use, } \\
\text { inhalations/w: } \\
\text { MD }-2.2(-3.92 \text { to }-0.48)\end{array}$ \\
\hline $\begin{array}{l}\text { Stallberg, } \\
2008^{100} \\
n=1343 \\
\text { RCT, } 12 \mathrm{~m}\end{array}$ & $\begin{array}{l}\text { Age: } 12 \mathrm{y}+ \\
\text { Severity/control: } \\
\text { Persistent asthma/ } \\
\text { symptomatic or } \\
\text { without symptoms } \\
\text { ICS daily dose: } \\
\text { Low vs. low to } \\
\text { medium }\end{array}$ & $\begin{array}{l}\text { Relative Measures: } \\
\text { Composite systemic } \\
\text { corticosteroid, hospitalization, or } \\
\text { ER visit: } \\
\text { RR } 0.77(0.53 \text { to } 1.12) \\
\text { IRR } 0.81 \text { (0.61 to } 1.09) \\
\text { Count Data: } \\
\text { Hospitalizations/pt/y: } \\
0.007 \text { vs. } 0.000 \\
\text { Unplanned or ER visits/pt/y: } \\
0.448 \text { vs. } 0.346\end{array}$ & NR & $\begin{array}{l}\text { Composite measures: } \\
\text { NR } \\
\text { Spirometry:: } \\
\text { NR }\end{array}$ & NR & \\
\hline
\end{tabular}

Abbreviations: ACQ=Asthma Control Questionnaire; ACT=Asthma Control Test; d=day; EPR=Expert Panel Review (Guidelines for the Diagnosis and Management of Asthma); $\mathrm{ER}=$ =mergency room; FEV1=forced expiratory volume in one second; FVC=forced vital capacity; HR=hazard ratio; ICS=inhaled corticosteroid; IRR= incident rate ratio;

$\mathrm{m}=$ month; $\mathrm{mg}=$ =milligram; $\mathrm{MD}=$ mean difference; $\mathrm{n}=$ patient sample size; $\mathrm{NR}=$ not reported; $\mathrm{PEF}=$ peak expiratory flow; $\mathrm{p}=$ =patient; $\mathrm{RCT}=$ randomized controlled trial; $\mathrm{RR}=$ relative risk; $w=$ week; $y=$ year

${ }^{a}$ Age is categorized using study inclusion criteria and the age categories used in EPR-3 of $0-4 y, 5-11 y$ and $12 y+$. Severity is as reported per the study. Control was usually not specified and rather details about patients being symptomatic or not at entry were given and reported here. ICS daily dose is categorized using the study's required ICS dose and the EPR-3 categories of low, medium and high

belative measures are presented first and include, when reported by the study, RR, HR for time to the event, and IRR for count data allowing multiple events over the period of follow-up. Count data is presented, when reported by the study, for number of hospitalizations, hospital days, and ER visits in association with exacerbations

'Defined as $12+$ short-acting $\beta_{2}$-agonist inhalations during last 10 days of the run-in or $8+$ short-acting $\beta_{2}$-agonist inhalations during last 10 days of the run-in for 4 - 11 y olds

${ }^{\mathrm{d}}$ Defined as rescue medication use 4 or more of the last 7 days in the run-in period

eDefined as rescue medication use 5 or more of the last 7 days in the run-in period

${ }^{\mathrm{f}}$ Defined as Asthma Control Questionnaire $>0.75$ and short-acting $\beta_{2}$-agonist use 2-6 times per week

gDefined as Asthma Control Test $<20$ and reliever use at least 5 times per week 
Table C-18. Study level outcomes for KQ1C, ICS and LABA controller and quick relief vs. ICS and LABA controller (higher dose)

\begin{tabular}{|c|c|c|c|c|c|c|}
\hline $\begin{array}{l}\text { Study, } \\
\text { Year, n, } \\
\text { Study } \\
\text { design, } \\
\text { Duration }\end{array}$ & Population $^{a}$ & Exacerbations & Mortality & Asthma control & Quality of life & $\begin{array}{l}\text { Healthcare } \\
\text { utilization }\end{array}$ \\
\hline $\begin{array}{l}\text { Bousquet, } \\
2007^{76} \\
n=2309 \\
\text { RCT, } 6 m\end{array}$ & $\begin{array}{l}\text { Age: } 12 \mathrm{y}+ \\
\text { Severity/control: } \\
\text { Persistent asthma/ } \\
\text { symptomatic } \\
\text { ICS daily dose: } \\
\text { Medium vs. high }\end{array}$ & $\begin{array}{l}\text { Relative measures: } \\
\text { Requiring systemic } \\
\text { corticosteroid: } \\
\text { RR } 0.82 \text { (0.62 to } 1.07) \\
\text { Composite systemic } \\
\text { corticosteroid, hospitalization, } \\
\text { or ER visit: } \\
\text { RR } 0.83 \text { (0.65 to } 1.06) \\
\text { HR } 0.82 \text { (0.63 to } 1.05) \\
\text { IRR: } 0.79 \text { (0.63 to } 0.99) \\
\text { Requiring hospitalization or } \\
\text { ER visit: } \\
\text { RR } 0.66 \text { (0.44 to } 0.98) \\
\text { HR } 0.64(0.43 \text { to } 0.96) \\
\text { IRR: } 0.69 \text { (0.49 to } 0.99) \\
\text { Count data: } \\
\text { Total number of oral } \\
\text { corticosteroid days: } \\
764 \text { vs. } 990\end{array}$ & $\begin{array}{l}\text { All-cause: } \\
\text { OR } 7.39 \text { (0.15 to } \\
372.38) \\
\text { Asthma-specific: } \\
\text { No events } \\
\text { occurred }\end{array}$ & $\begin{array}{l}\text { Composite measures: } \\
\text { ACQ-5: } \\
\text { MD -0.02 (-0.07 to } 0.04) \\
\text { Spirometry:: } \\
\text { NR }\end{array}$ & NR & $\begin{array}{l}\text { PRN inhalations/d: } \\
\text { MD }-0.04(-0.12 \text { to } \\
0.04)\end{array}$ \\
\hline
\end{tabular}




\begin{tabular}{|c|c|c|c|c|c|c|}
\hline $\begin{array}{l}\text { Study, } \\
\text { Year, n, } \\
\text { Study } \\
\text { design, } \\
\text { Duration }\end{array}$ & Population $^{a}$ & Exacerbations & Mortality & Asthma control & Quality of life & $\begin{array}{l}\text { Healthcare } \\
\text { utilization }\end{array}$ \\
\hline \multirow[t]{2}{*}{$\begin{array}{l}\text { Kuna, } \\
2007^{81} \\
n=3335 \\
\text { RCT, } 6 \mathrm{~m}\end{array}$} & $\begin{array}{l}\text { Age: } 12 \mathrm{y}+ \\
\text { Severity/control: } \\
\text { Persistent asthma/ } \\
\text { symptomatic during } \\
\text { run-inc } \\
\text { ICS daily dose: } \\
\text { Low vs. medium }\end{array}$ & $\begin{array}{l}\text { Relative Measures vs. } \\
\text { budesonide/formoterol: } \\
\text { Composite systemic } \\
\text { corticosteroid, hospitalization, } \\
\text { or ER visit: } \\
\text { RR } 0.75 \text { (0.58 to } 0.96) \\
\text { HR } 0.74 \text { (0.56 to } 0.96) \\
\text { IRR } 0.72 \text { (0.57 to } 0.90) \\
\text { Requiring hospitalization or } \\
\text { ER visit: } \\
\text { RR } 0.96 \text { (0.65 to } 1.41) \\
\text { HR } 0.97(0.65 \text { to } 1.44) \\
\text { IRR } 0.88 \text { (0.63 to } 1.24) \\
\text { Mild exacerbation: } \\
\text { RR } 0.97 \text { (0.91 to } 1.04) \\
\text { Count data: } \\
\text { Total number of oral } \\
\text { corticosteroid days: } \\
\text { 619d vs. } 1044 d\end{array}$ & $\begin{array}{l}\text { All-cause: } \\
\text { OR } 7.39 \text { (0.15 to } \\
372.38) \\
\text { Asthma-specific: } \\
\text { No events } \\
\text { occurred }\end{array}$ & $\begin{array}{l}\text { Composite measures: } \\
\text { ACQ-5: } \\
\text { MD -0.02 (-0.08 to } 0.05) \\
\text { Spirometry:: } \\
\text { FEV1 } \\
\text { MD } 0.01 \text { (-0.03 to } 0.04)\end{array}$ & $\begin{array}{l}\text { AQLQ(S): } \\
\text { MD } 0.01(-0.07 \\
\text { to } 0.08)\end{array}$ & $\begin{array}{l}\text { PRN inhalations/d: } \\
\text { MD }-0.03(-0.12 \text { to } \\
0.06)\end{array}$ \\
\hline & & $\begin{array}{l}\text { Relative Measures vs. } \\
\text { salmeterol/fluticasone: } \\
\text { Composite systemic } \\
\text { corticosteroid, hospitalization } \\
\text { or ER visit: } \\
\text { RR } 0.68 \text { ( } 0.53 \text { to } 0.87) \\
\text { HR } 0.67 \text { (0.52 to } 0.87) \\
\text { IRR } 0.61 \text { (0.49 to } 0.76) \\
\text { Requiring hospitalization or } \\
\text { ER visit: } \\
\text { RR } 0.69 \text { (0.48 to } 0.98) \\
\text { HR } 0.69(0.48 \text { to } 0.99) \\
\text { IRR } 0.61 \text { (0.44 to } 0.83) \\
\text { Mild exacerbation: } \\
\text { RR } 1.04 \text { (0.97 to } 1.11) \\
\text { Count data: } \\
\text { Total number of oral } \\
\text { corticosteroid days: } \\
619 d \text { vs. } 1132 \text { d }\end{array}$ & $\begin{array}{l}\text { All-cause: } \\
\text { OR } 1.00 \text { (0.06 to } \\
16.00) \\
\text { Asthma-specific: } \\
\text { No events } \\
\text { occurred }\end{array}$ & $\begin{array}{l}\text { Composite measures: } \\
\text { ACQ-5: } \\
\text { MD } 0.03 \text { (-0.03 to } 0.09) \\
\text { Spirometry:: } \\
\text { FEV1 } \\
\text { MD } 0.01 \text { (-0.03 to } 0.04)\end{array}$ & $\begin{array}{l}\text { AQLQ(S): } \\
\text { MD }-0.02(-0.09 \\
\text { to } 0.06)\end{array}$ & $\begin{array}{l}\text { PRN inhalations/d: } \\
0.07(-0.02 \text { to } 0.16) \\
\text { Total number of oral } \\
\text { corticosteroid days: } \\
619 d \text { vs. } 1132 d\end{array}$ \\
\hline
\end{tabular}




\begin{tabular}{|c|c|c|c|c|c|c|}
\hline $\begin{array}{l}\text { Study, } \\
\text { Year, n, } \\
\text { Study } \\
\text { design, } \\
\text { Duration }\end{array}$ & Population $^{a}$ & Exacerbations & Mortality & Asthma control & Quality of life & $\begin{array}{l}\text { Healthcare } \\
\text { utilization }\end{array}$ \\
\hline $\begin{array}{l}\text { Pavord, } \\
2009^{89} \\
\mathrm{n}=127 \\
\text { RCT, 1yr }\end{array}$ & $\begin{array}{l}\text { Age: } 12 \mathrm{y}+ \\
\text { Severity/control: } \\
\text { Persistent asthma/ } \\
\text { symptomatic } \\
\text { ICS daily dose: } \\
\text { Low vs. medium }\end{array}$ & $\begin{array}{l}\text { Relative Measures } \\
\text { Rate of composite systemic } \\
\text { steroids, hospitalization, ER } \\
\text { visit: } \\
\text { IRR } 1.02 \text { (0.52 to } 2.02) \\
\text { Count data: } \\
\text { NR }\end{array}$ & $\begin{array}{l}\text { All-cause: } \\
\text { No events } \\
\text { occurred } \\
\text { Asthma-specific: } \\
\text { No events } \\
\text { occurred }\end{array}$ & $\begin{array}{l}\text { Composite measures: } \\
\text { NR } \\
\text { Spirometry:: } \\
\text { NR }\end{array}$ & NR & NR \\
\hline \multirow[t]{2}{*}{$\begin{array}{l}\text { Lundborg, } \\
2006^{115} \\
n=491 \\
\text { RCT, 26w }\end{array}$} & $\begin{array}{l}\text { Age: Mixed (5-11y } \\
\text { and 12+) } \\
\text { Severity/control: } \\
\text { Persistent asthma/ } \\
\text { well controlled and } \\
\text { not well controlled } \\
\text { ICS daily dose: } \\
\text { Low vs. medium }\end{array}$ & $\begin{array}{l}\text { Bud/for daily+PRN } \\
\text { Relative measures: } \\
\text { NR } \\
\text { Count data: } \\
\text { Number of hospital nights: } \\
0 \text { vs. } 0 \\
\text { Number of ER visits: } \\
9 \text { vs. } 11 \\
\text { Number of unscheduled MD } \\
\text { visits: } \\
11 \text { vs. } 17\end{array}$ & NR & $\begin{array}{l}\text { Composite measures: } \\
\text { ACQ-5: } \\
\text { MD -0.07 (-0.24 to } 0.10) \\
\text { Spirometry:: } \\
\text { NR }\end{array}$ & NR & NR \\
\hline & & $\begin{array}{l}\text { Bud/for twice daily+PRN } \\
\text { Relative measures: } \\
\text { NR } \\
\text { Count data: } \\
\text { Number of hospital nights: } \\
3 \text { vs. } 0 \\
\text { Number of ER visits: } \\
17 \text { vs. } 11 \\
\text { Number of unscheduled MD } \\
\text { visits: } \\
20 \text { vs. } 17\end{array}$ & NR & $\begin{array}{l}\text { Composite measures: } \\
\text { ACQ-5: } \\
\text { MD -0.10 (-0.26 to } 0.07) \\
\text { Spirometry:: } \\
\text { NR }\end{array}$ & NR & NR \\
\hline
\end{tabular}




\begin{tabular}{|c|c|c|c|c|c|c|}
\hline $\begin{array}{l}\text { Study, } \\
\text { Year, n, } \\
\text { Study } \\
\text { design, } \\
\text { Duration }\end{array}$ & Population $^{a}$ & Exacerbations & Mortality & Asthma control & Quality of life & $\begin{array}{l}\text { Healthcare } \\
\text { utilization }\end{array}$ \\
\hline $\begin{array}{l}\text { Stallberg, } \\
2008^{100} \\
n=1343 \\
\text { RCT, } 12 \mathrm{~m}\end{array}$ & $\begin{array}{l}\text { Age: } 12 \mathrm{y}+ \\
\text { Severity/control: } \\
\text { Persistent asthma/ } \\
\text { symptomatic or } \\
\text { without symptoms } \\
\text { ICS daily dose: } \\
\text { Low vs. low to } \\
\text { medium }\end{array}$ & $\begin{array}{l}\text { Relative Measures: } \\
\text { Composite systemic } \\
\text { corticosteroid, hospitalization, } \\
\text { or ER visit: } \\
\text { RR } 0.77 \text { (0.53 to } 1.12) \\
\text { IRR } 0.81(0.61 \text { to } 1.09) \\
\text { Count Data: } \\
\text { Hospitalization/pt/y: } \\
0.007 \text { vs. } 0.000 \\
\text { Unplanned ER visit/ pt/y: } \\
0.448 \text { vs. } 0.346\end{array}$ & NR & $\begin{array}{l}\text { Composite measures: } \\
\text { NR } \\
\text { Spirometry:: } \\
\text { NR }\end{array}$ & NR & NR \\
\hline
\end{tabular}

Abbreviations: ACQ=Asthma Control Questionnaire; Bud/for=budesonide/formoterol; d=day; EPR=Expert Panel Review (Guidelines for the Diagnosis and Management of

Asthma); ER=emergency room; FEV1=forced expiratory volume in one second; HR=hazard ratio; ICS=inhaled corticosteroid; IRR= incident rate ratio; m=months; MD=mean difference; n=patient sample size; $\mathrm{NR}=$ not reported; $\mathrm{OR}=$ odds ratio; $\mathrm{PRN}=$ pro re nata (i.e., as-needed); pt=patient; RCT=randomized controlled trial; RR=relative risk; w=week; $\mathrm{y}=$ year

${ }^{a}$ Age is categorized using study inclusion criteria and the age categories used in EPR-3 of $0-4 y, 5-11 y$ and $12 y+$. Severity is as reported per the study. Control was usually not specified and rather details about patients being symptomatic or not at entry were given and reported here. ICS daily dose is categorized using the study's required ICS dose and the EPR-3 categories of low, medium and high

${ }^{b}$ Relative measures are presented first and include, when reported by the study, RR, HR for time to the event, and IRR for count data allowing multiple events over the period of

follow-up. Count data is presented, when reported by the study, for number of hospitalizations, hospital days, and ER visits in association with exacerbations

${ }^{c}$ Defined as symptomatic as short-acting $\beta_{2}$-agonist use was required at least 5 of 7 days 
Table C-19. Study level outcomes for KQ1c, ICS and LABA controller and quick relief vs. ICS and LABA controller and quick relief vs. ICS controller (same dose)

\begin{tabular}{|c|c|c|c|c|c|c|}
\hline $\begin{array}{l}\text { Study, } \\
\text { Year, n, } \\
\text { Study } \\
\text { design, } \\
\text { Duration }\end{array}$ & Population $^{\mathrm{a}}$ & Exacerbations & Mortality & Asthma control & Quality of life & $\begin{array}{l}\text { Healthcare } \\
\text { utilization }\end{array}$ \\
\hline $\begin{array}{l}\text { Hozawa, } \\
2016^{117} \\
n=30 \\
\text { RCT, 4w }\end{array}$ & $\begin{array}{l}\text { Age: } 12 \mathrm{y}+ \\
\text { Severity/control: } \\
\text { Persistent asthma/ } \\
\text { symptomatic } \\
\text { ICS daily dose: } \\
\text { Medium vs. low }\end{array}$ & NR & NR & $\begin{array}{l}\text { Composite measures: } \\
\text { ACQ-5: } \\
\text { MD }-0.40 \text { (-0.53 to - } \\
0.27) \\
\text { Spirometry:: } \\
\text { FEV1 \% predicted: } \\
\text { MD } 3.10 \text { (-1.36 to } 7.56)\end{array}$ & NR & $\begin{array}{l}\text { PRN inhalations/w: } \\
\text { MD }-0.9 \text { (-1.48 to - } \\
0.32)\end{array}$ \\
\hline
\end{tabular}

Abbreviations: ACQ=Asthma Control Questionnaire; d=day; FEV1=forced expiratory volume in one second; ICS=inhaled corticosteroid; MD=mean difference; $\mathrm{n}=$ patient sample size; $\mathrm{NR}=$ not reported; $\mathrm{PRN}=$ =pro re nata (i.e., as-needed); $\mathrm{pt}=$ patient; $\mathrm{RCT}=$ randomized controlled trial; $\mathrm{w}=$ week

${ }^{a}$ Age is categorized using study inclusion criteria and the age categories used in EPR-3 of 0-4y, 5-11y and $12 y+$. Severity is as reported per the study. Control was usually not specified and rather details about patients being symptomatic or not at entry were given and reported here. ICS daily dose is categorized using the study's required ICS dose and the EPR-3 categories of low, medium and high 
Table C-20. Study level outcomes for KQ1c, ICS and LABA controller and quick relief vs. CBP

\begin{tabular}{|c|c|c|c|c|c|c|}
\hline $\begin{array}{l}\text { Study, } \\
\text { Year, n, } \\
\text { Study } \\
\text { design, } \\
\text { Duration }\end{array}$ & Population $^{a}$ & Exacerbations & Mortality & Asthma control & $\begin{array}{l}\text { Quality of } \\
\text { life }\end{array}$ & Healthcare utilization \\
\hline $\begin{array}{l}\text { Sears, } \\
2008^{97} \\
n=1538 \\
\text { RCT, } 6 \mathrm{~m}\end{array}$ & $\begin{array}{l}\text { Age: } 12 y+ \\
\text { Severity/control: } \\
\text { Mild to severe } \\
\text { persistent asthma/ } \\
\text { with or without } \\
\text { suboptimal control } \\
\text { ICS daily dose: } \\
\text { Low vs. mixed }\end{array}$ & $\begin{array}{l}\text { Relative Measures: } \\
\text { Systemic corticosteroid: } \\
\text { RR } 1.03 \text { (0.72 to } 1.47) \\
\text { Hospitalization: } \\
\text { OR } 0.13 \text { (0.00 to } 6.77) \\
\text { ER visit: } \\
\text { RR } 0.69 \text { (0.37 to } 1.30) \\
\text { Composite systemic } \\
\text { corticosteroid, hospitalization, } \\
\text { or ER visit: } \\
\text { RR } 0.96 \text { (0.69 to } 1.35) \\
\text { HR } 0.99(0.85 \text { to } 1.15) \\
\text { IRR } 0.92 \text { (0.80 to } 1.06) \\
\text { Count data: } \\
\text { Hospitalization: } \\
0 \text { vs. } 1 \\
\text { Hospital day: } \\
0 \text { vs. } 5 \\
\text { ER visit: } \\
16 \text { vs. } 28 \\
\text { Total number of oral } \\
\text { corticosteroid days: } \\
590 \text { vs. } 709 \text {, p=NR }\end{array}$ & $\begin{array}{l}\text { All-cause: } \\
\text { OR } 0.51 \text { (0.05 to } \\
4.90) \\
\text { Asthma-specific: } \\
\text { No deaths } \\
\text { occurred }\end{array}$ & $\begin{array}{l}\text { Composite measures: } \\
\text { ACQ-5: } \\
\text { MD -0.02 (-0.10 to 0.06) } \\
\text { ACQ-5 responder: } \\
\text { RR } 1.22 \text { ( } 1.03 \text { to } 1.44) \\
\text { Spirometry:: } \\
\text { NR }\end{array}$ & NR & $\begin{array}{l}\text { PRN inhalations/d: } \\
\text { MD }-0.16(-0.26 \text { to }-0.05)\end{array}$ \\
\hline $\begin{array}{l}\text { Stallberg, } \\
2008^{100} \\
n=1776 \\
\text { RCT, } 12 \mathrm{~m}\end{array}$ & $\begin{array}{l}\text { Age: } 12 y+ \\
\text { Severity/control: } \\
\text { Persistent asthma/ } \\
\text { symptomatic and } \\
\text { without symptoms } \\
\text { ICS daily dose: } \\
\text { Low vs. mixed }\end{array}$ & $\begin{array}{l}\text { Relative Measures: } \\
\text { Composite systemic } \\
\text { corticosteroid, hospitalization, } \\
\text { or ER visit: } \\
\text { RR } 0.72(0.51 \text { to } 1.03) \\
\text { IRR } 0.89(0.78 \text { to } 1.01) \\
\text { Count Data: } \\
\text { Hospitalization/pt/y: } \\
0.007 \text { vs. } 0.010 \\
\text { Unplanned ER visit/pt/y: } \\
0.448 \text { vs. } 0.295\end{array}$ & NR & $\begin{array}{l}\text { Composite measures: } \\
\text { NR } \\
\text { Spirometry:: } \\
\text { NR }\end{array}$ & NR & NR \\
\hline
\end{tabular}




\begin{tabular}{|c|c|c|c|c|c|c|}
\hline $\begin{array}{l}\text { Study, } \\
\text { Year, n, } \\
\text { Study } \\
\text { design, } \\
\text { Duration }\end{array}$ & Population $^{a}$ & Exacerbations & Mortality & Asthma control & $\begin{array}{l}\text { Quality of } \\
\text { life }\end{array}$ & Healthcare utilization \\
\hline $\begin{array}{l}\text { Louis, } \\
2009^{82} \\
n=908 \\
\text { RCT, 26w }\end{array}$ & $\begin{array}{l}\text { Age: } 12 \mathrm{y}+ \\
\text { Severity/control: } \\
\text { Persistent asthma/ } \\
\text { symptomatic and } \\
\text { without symptoms } \\
\text { ICS daily dose: } \\
\text { Low vs. mixed }\end{array}$ & $\begin{array}{l}\text { Relative measures: } \\
\text { Systemic corticosteroid: } \\
\text { RR } 0.70 \text { (0.33 to } 1.49) \\
\text { Hospitalization: } \\
\text { OR } 1.99 \text { (0.21 to } 19.14) \\
\text { ER visit: } \\
\text { RR } 0.25 \text { (0.03 to } 2.27) \\
\text { Composite systemic } \\
\text { corticosteroid, hospitalization, } \\
\text { or ER visit: } \\
\text { RR } 0.64 \text { ( } 0.32 \text { to } 1.31) \\
\text { Count data: } \\
\text { Hospitalization: } \\
2 \text { vs. } 1 \\
\text { Number of hospital days: } \\
10 \text { vs. } 15 \\
\text { ER visit: } \\
1 \text { vs. } 4 \\
\text { Total number of oral } \\
\text { corticosteroid days: } \\
132 \text { vs. } 244\end{array}$ & $\begin{array}{l}\text { All-cause: } \\
\text { OR } 7.54 \text { (0.47 to } \\
120.72) \\
\text { Asthma-specific: } \\
\text { No deaths } \\
\text { occurred }\end{array}$ & $\begin{array}{l}\text { Composite measures: } \\
\text { ACQ-5: } \\
\text { MD }-0.12(-0.20 \text { to }-0.04) \\
\text { Spirometry:: } \\
\text { FEV1: } \\
\text { MD }-0.03(-0.12 \text { to } 0.06)\end{array}$ & NR & $\begin{array}{l}\text { PRN inhalations/d: } \\
\text { MD }-0.10 \text { ( }-0.24 \text { to } 0.03) \\
\geq 1 \text { day with PRN } \\
\text { inhalation: } \\
\text { RR } 2.96 \text { ( } 2.42 \text { to } 3.61)\end{array}$ \\
\hline
\end{tabular}




\begin{tabular}{|c|c|c|c|c|c|c|}
\hline $\begin{array}{l}\text { Study, } \\
\text { Year, n, } \\
\text { Study } \\
\text { design, } \\
\text { Duration }\end{array}$ & Population $^{a}$ & Exacerbations & Mortality & Asthma control & $\begin{array}{l}\text { Quality of } \\
\text { life }\end{array}$ & Healthcare utilization \\
\hline $\begin{array}{l}\text { Quirce, } \\
2011^{91} \\
\mathrm{n}=654 \\
\text { RCT, 26w }\end{array}$ & $\begin{array}{l}\text { Age: } 12 \mathrm{y}+ \\
\text { Severity/control: } \\
\text { Mild to severe } \\
\text { persistent asthma/ } \\
\text { history of } \\
\text { suboptimal control } \\
\text { ICS daily dose: } \\
\text { Low vs. mixed }\end{array}$ & $\begin{array}{l}\text { Relative measures: } \\
\text { Systemic corticosteroid: } \\
\text { RR } 0.62 \text { (0.33 to } 1.16) \\
\text { Hospitalization: } \\
\text { OR } 7.34 \text { ( } 0.15 \text { to } 370.13) \\
\text { ER visit: } \\
\text { RR } 0.99 \text { ( } 0.47 \text { to } 2.11) \\
\text { Composite systemic } \\
\text { corticosteroid, hospitalization, } \\
\text { or ER visit: } \\
\text { RR } 0.71 \text { ( } 0.42 \text { to } 1.19) \\
\text { HR } 0.75(0.59 \text { to } 0.95) \\
\text { IRR } 0.75 \text { (0.60 to } 0.95) \\
\text { Count data: } \\
\text { Hospitalization: } \\
1 \text { vs. } 0 \\
\text { ER visit: } \\
14 \text { vs. } 15 \\
\text { Total number of oral } \\
\text { corticosteroid days: } \\
177 \text { vs. } 229, p<0.001\end{array}$ & $\begin{array}{l}\text { All-cause: } \\
\text { No deaths } \\
\text { occurred } \\
\text { Asthma-specific: } \\
\text { No deaths } \\
\text { occurred }\end{array}$ & $\begin{array}{l}\text { Composite measures: } \\
\text { ACQ-5: } \\
\text { MD -0.12 (-0.23 to }-0.01) \\
\text { ACQ-5 responder: } \\
\text { RR } 1.09(0.92 \text { to } 1.30) \\
\text { Spirometry:: } \\
\text { NR }\end{array}$ & NR & $\begin{array}{l}\geq 1 \text { day with PRN } \\
\text { inhalation: } \\
\text { RR } 2.96 \text { ( } 2.42 \text { to } 3.61) \\
\text { Total number of oral } \\
\text { corticosteroid days: } \\
177 \text { vs. } 229, p<0.001\end{array}$ \\
\hline
\end{tabular}




\begin{tabular}{|c|c|c|c|c|c|c|}
\hline $\begin{array}{l}\text { Study, } \\
\text { Year, n, } \\
\text { Study } \\
\text { design, } \\
\text { Duration }\end{array}$ & Population $^{a}$ & Exacerbations & Mortality & Asthma control & $\begin{array}{l}\text { Quality of } \\
\text { life }\end{array}$ & Healthcare utilization \\
\hline $\begin{array}{l}\text { Soes- } \\
\text { Peterson, } \\
2011^{98} \\
n=1854 \\
\text { RCT, 26w }\end{array}$ & $\begin{array}{l}\text { Age: } 12 \mathrm{y}+ \\
\text { Severity/control: } \\
\text { Persistent asthma/ } \\
\text { with and without } \\
\text { history of } \\
\text { suboptimal control } \\
\text { ICS daily dose: } \\
\text { Low vs. mixed }\end{array}$ & $\begin{array}{l}\text { Relative Measures: } \\
\text { Systemic corticosteroid: } \\
\text { RR } 0.79 \text { (0.55 to } 1.13) \\
\text { Hospitalization: } \\
\text { OR: } 0.71 \text { (0.23 to } 2.21) \\
\text { ER visit: } \\
\text { RR } 0.80 \text { (0.43 to } 1.51) \\
\text { Composite systemic } \\
\text { corticosteroid, hospitalization, } \\
\text { or ER visit: } \\
\text { RR } 0.79 \text { (0.57 to } 1.10) \\
\text { HR } 0.79 \text { (0.68 to } 0.92) \\
\text { IRR } 0.74 \text { (0.65 to } 0.85) \\
\text { Count data: } \\
\text { Hospitalization: } \\
5 \text { vs. } 8 \\
\text { Hospital day: } \\
29 \text { vs. } 33 \\
\text { ER visit: } \\
18 \text { vs. } 22\end{array}$ & $\begin{array}{l}\text { All-cause: } \\
\text { OR } 7.33 \text { (0.15 to } \\
369.58) \\
\text { Asthma-specific: } \\
\text { No deaths } \\
\text { occurred }\end{array}$ & $\begin{array}{l}\text { Composite measures: } \\
\text { ACQ-5: } \\
\text { MD -0.09 (-0.15 to }-0.03) \\
\text { Spirometry:: } \\
\text { NR }\end{array}$ & NR & NR \\
\hline $\begin{array}{l}\text { Riemersma, } \\
2012^{95} \\
n=102 \\
\text { RCT, } 12 \mathrm{~m}\end{array}$ & $\begin{array}{l}\text { Age: } 12 \mathrm{y}+ \\
\text { Severity/control: } \\
\text { Mild to moderate } \\
\text { persistent asthma/ } \\
\text { history of } \\
\text { suboptimal control } \\
\text { ICS daily dose: } \\
\text { Low vs. mixed }\end{array}$ & $\begin{array}{l}\text { Relative Measures: } \\
\text { Composite systemic } \\
\text { corticosteroid, hospitalization, } \\
\text { or ER visit: } \\
\text { RR } 0.30 \text { (0.06 to } 1.40) \\
\text { Requiring ER or } \\
\text { hospitalization: } \\
\text { No events occurred } \\
\text { Count data: } \\
\text { Hospitalization: } \\
\text { No events occurred } \\
\text { ER visit: } \\
\text { No events occurred }\end{array}$ & NR & $\begin{array}{l}\text { Composite measures: } \\
\text { ACQ-5: } \\
\text { MD -0.06 (-0.31 to 0.19) } \\
\text { Spirometry:: } \\
\text { FEV1 \% predicted: } \\
\text { MD } 0.70 \text { (-1.80 to } 3.20)\end{array}$ & NR & NR \\
\hline
\end{tabular}

Abbreviations: ACQ=Asthma Control Questionnaire; d=day; EPR=Expert Panel Review (Guidelines for the Diagnosis and Management of Asthma); ER=emergency room;

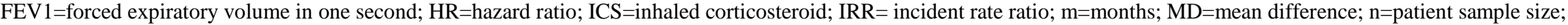

$\mathrm{NR}=$ not reported; $\mathrm{OR}=$ odds ratio; $\mathrm{PRN}=$ pro re nata (as-needed); $\mathrm{pt=patient;} \mathrm{RCT}=$ randomized controlled trial; $\mathrm{RR}=$ relative risk; $\mathrm{w}=\mathrm{week}$; $\mathrm{y}=\mathrm{year}$

${ }^{a}$ Age is categorized using study inclusion criteria and the age categories used in EPR-3 of 0-4y, 5-11y and $12 \mathrm{y}+$. Severity is as reported per the study. Control was usually not specified and rather details about patients being symptomatic or not at entry were given and reported here. ICS daily dose is categorized using the study's required ICS dose and the EPR-3 categories of low, medium and high 
${ }^{b}$ Relative measures are presented first and include, when reported by the study, RR, HR for time to the event, and IRR for count data allowing multiple events over the period of follow-up. Count data is presented, when reported by the study, for number of hospitalizations, hospital days, and ER visits in association with exacerbations

\begin{tabular}{|c|c|c|c|c|c|c|c|c|c|}
\hline $\begin{array}{l}\text { Study, Year, } \\
\text { n, } \\
\text { Acronym, } \\
\text { Study design, } \\
\text { Duration } \\
\text { Risk of bias }\end{array}$ & Study population & $\begin{array}{l}\text { Intervention } \\
\text { Comparisons }\end{array}$ & $\begin{array}{l}\text { Age } \\
\text { (y) } \\
\text { [mean } \\
\text { (SD)] }\end{array}$ & $\begin{array}{l}\text { Males } \\
(\%)\end{array}$ & $\begin{array}{l}\text { Duration } \\
\text { of } \\
\text { asthma } \\
\text { (y) [mean } \\
\text { (SD)] }\end{array}$ & $\begin{array}{l}\text { FEV1 } \\
\text { (L) } \\
\text { [mean } \\
\text { (SD)] }\end{array}$ & $\begin{array}{l}\text { FEV1 \% } \\
\text { predicted } \\
\text { (L) } \\
\text { [mean } \\
\text { (SD)] }\end{array}$ & $\begin{array}{l}\text { Rescue } \\
\text { inhaler } \\
\text { use } \\
\text { (puffs/d) } \\
\text { [mean } \\
\text { (SD)] }\end{array}$ & $\begin{array}{l}\text { ICS dose } \\
\text { during } \\
\text { study } \\
\text { ( } \mu \text { g/d) } \\
\text { [mean } \\
\text { (SD)] }\end{array}$ \\
\hline \multirow[t]{2}{*}{$\begin{array}{l}\text { Peters, } 2010^{27} \\
\mathrm{n}=210 \\
\text { TALC } \\
\text { RCT- crossover, } \\
14 \mathrm{w}\end{array}$} & $\begin{array}{l}\geq 18 \text { years of age with } \\
\text { moderately severe } \\
\text { asthma not well } \\
\text { controlled on a ICS alone }\end{array}$ & $\begin{array}{l}\text { Tiotropium } 18 \mu \text { g daily } \\
\text { (Handihaler) } \\
n=210\end{array}$ & \multirow[t]{2}{*}{$\begin{array}{l}42.2 \\
(12.3)\end{array}$} & \multirow[t]{2}{*}{32.9} & \multirow[t]{2}{*}{$26.1(14.1)$} & \multirow[t]{2}{*}{$\begin{array}{l}2.31 \\
(0.77)\end{array}$} & \multirow[t]{2}{*}{$\begin{array}{l}71.5 \\
(14.9)\end{array}$} & \multirow[t]{2}{*}{$\begin{array}{l}1.71 \\
(2.09)\end{array}$} & NR \\
\hline & $\begin{array}{l}\text { Tiotropium or salmeterol } \\
\text { were added on to run-in } \\
\text { dose of beclomethasone } \\
80 \mu g \text { BID }\end{array}$ & $\begin{array}{l}\text { Doubling ICS dose to } \\
160 \mu \mathrm{g} \text { BID (MDI) } \\
n=210\end{array}$ & & & & & & & NR \\
\hline \multirow[t]{2}{*}{$\begin{array}{l}\text { Bateman, } 2011^{118} \\
n=254 \\
\text { RCT, 16w }\end{array}$} & \multirow{2}{*}{$\begin{array}{l}\text { 18-65 years of age with } \\
\text { moderate persistent } \\
\text { asthma (GINA step } 3 \text { ) not } \\
\text { controlled on ICS alone } \\
\text { ( } 400-1000 \mu \mathrm{g} / \mathrm{d} \\
\text { budesonide or } \\
\text { equivalent) } \\
\text { Randomized therapy } \\
\text { added on to ICS } \\
\text { continued at prestudy } \\
\text { dose }\end{array}$} & $\begin{array}{l}\text { Tiotropium } 5 \mu \mathrm{g} \text { daily } \\
\text { (Respimat) } \\
n=128\end{array}$ & $\begin{array}{l}43.5 \\
(12.6)\end{array}$ & 35.9 & $18.1(12.1)$ & $\begin{array}{l}2.3 \\
(0.77)\end{array}$ & $\begin{array}{l}74.1 \\
(16.1)\end{array}$ & NR & NR \\
\hline & & $\begin{array}{l}\text { Placebo } \\
n=126\end{array}$ & $\begin{array}{l}44.0 \\
(11.9)\end{array}$ & 40.5 & $17.3(12.2)$ & $\begin{array}{l}2.4 \\
(0.8)\end{array}$ & $\begin{array}{l}75.3 \\
(19.0)\end{array}$ & NR & NR \\
\hline \multirow[t]{2}{*}{$\begin{array}{l}\text { Kerstjens, } 2015^{119} \\
\text { Study } 1 \\
\text { MezzoTinA-asthma } \\
1 \\
\mathrm{n}=795 \\
\text { RCT, 24w } \\
\text { Low }\end{array}$} & \multirow{2}{*}{$\begin{array}{l}\text { 18-75 year of age with } \\
\text { moderate persistent } \\
\text { asthma according to } \\
\text { GINA guidelines despite } \\
\text { treatment with stable } \\
\text { medium dose ICS ( } 400 \text { - } \\
800 \mu \mathrm{g} / \mathrm{d} \text { budesonide or } \\
\text { equivalent) alone or in } \\
\text { fixed combination with } \\
\text { LABA, symptomatic with } \\
\text { ACQ-7 } \geq 1.5 \\
\text { Randomized therapy was } \\
\text { added to prestudy stable } \\
\text { maintenance ICS dose }\end{array}$} & $\begin{array}{l}\text { Tiotropium } 5 \mu \mathrm{g} \text { daily } \\
\text { (Respimat) } \\
n=264\end{array}$ & $\begin{array}{l}44.4 \\
(12.6)\end{array}$ & 41.7 & $22.9(14.7)$ & $\begin{array}{l}2.2 \\
(0.6)\end{array}$ & $72.2(8.2)$ & NR & $\begin{array}{l}666.4 \\
(216.2)^{b}\end{array}$ \\
\hline & & $\begin{array}{l}\text { Tiotropium } 2.5 \mu \mathrm{g} \text { daily } \\
\text { (Respimat) } \\
\mathrm{n}=262\end{array}$ & $\begin{array}{l}43.7 \\
(13.1)\end{array}$ & 40.5 & $22.2(14.1)$ & $\begin{array}{l}2.2 \\
(0.7)\end{array}$ & $73.1(8.6)$ & NR & $\begin{array}{l}649.8 \\
(196.2)^{b}\end{array}$ \\
\hline
\end{tabular}




\begin{tabular}{|c|c|c|c|c|c|c|c|c|c|}
\hline $\begin{array}{l}\text { Study, Year, } \\
\text { n, } \\
\text { Acronym, } \\
\text { Study design, } \\
\text { Duration } \\
\text { Risk of bias }\end{array}$ & Study population & $\begin{array}{l}\text { Intervention } \\
\text { Comparisons }\end{array}$ & $\begin{array}{l}\text { Age } \\
\text { (y) } \\
{[\text { mean }} \\
\text { (SD)] }\end{array}$ & $\begin{array}{l}\text { Males } \\
(\%)\end{array}$ & $\begin{array}{l}\text { Duration } \\
\text { of } \\
\text { asthma } \\
\text { (y) [mean } \\
\text { (SD)] }\end{array}$ & $\begin{array}{l}\text { FEV1 } \\
\text { (L) } \\
\text { [mean } \\
\text { (SD)] }\end{array}$ & $\begin{array}{l}\text { FEV1 \% } \\
\text { predicted } \\
\text { (L) } \\
\text { [mean } \\
\text { (SD)] }\end{array}$ & $\begin{array}{l}\text { Rescue } \\
\text { inhaler } \\
\text { use } \\
\text { (puffs/d) } \\
\text { [mean } \\
\text { (SD)] }\end{array}$ & $\begin{array}{l}\text { ICS dose } \\
\text { during } \\
\text { study } \\
\text { ( } \mu \mathrm{g} / \mathrm{d}) \\
\text { [mean } \\
\text { (SD)] }\end{array}$ \\
\hline & & $\begin{array}{l}\text { Placebo } \\
\mathrm{n}=269\end{array}$ & $\begin{array}{l}42.5 \\
(13.1)\end{array}$ & 38.3 & $20.2(13.4)$ & $\begin{array}{l}2.3 \\
(0.7)\end{array}$ & $73.0(8.2)$ & NR & $\begin{array}{l}661.5 \\
(209.5)^{b}\end{array}$ \\
\hline \multirow[t]{3}{*}{$\begin{array}{l}\text { Kerstjens, } 2015^{119} \\
\text { Study } 2 \\
\text { MezzoTinA-asthma } \\
2 \\
\mathrm{n}=764 \\
\text { RCT, } 24 \mathrm{w} \\
\text { Low }\end{array}$} & \multirow{3}{*}{$\begin{array}{l}\text { 18-75 year of age with } \\
\text { moderate persistent } \\
\text { asthma according to } \\
\text { GINA guidelines despite } \\
\text { treatment with stable } \\
\text { medium dose ICS (400- } \\
800 \mu \mathrm{g} / \mathrm{d} \text { budesonide or } \\
\text { equivalent) alone or in } \\
\text { fixed combination with } \\
\text { LABA, symptomatic with } \\
\text { ACQ-7 } 1.5 \\
\text { Randomized therapy was } \\
\text { added to prestudy stable } \\
\text { maintenance ICS dose }\end{array}$} & $\begin{array}{l}\text { Tiotropium } 5 \mu \mathrm{g} \text { daily } \\
\text { (Respimat) } \\
n=253\end{array}$ & $\begin{array}{l}44.3 \\
(12.7)\end{array}$ & 42.3 & $23.1(15.3)$ & $\begin{array}{l}2.3 \\
(0.6)\end{array}$ & $72.2(8.3)$ & NR & $\begin{array}{l}661.3 \\
(216.1)^{b}\end{array}$ \\
\hline & & $\begin{array}{l}\text { Tiotropium } 2.5 \mu \mathrm{g} \text { daily } \\
\text { (Respimat) } \\
\mathrm{n}=257\end{array}$ & $\begin{array}{l}43.0 \\
(12.6)\end{array}$ & 37.7 & $21.9(14.5)$ & $\begin{array}{l}2.3 \\
(0.7)\end{array}$ & $72.5(8.0)$ & NR & $\begin{array}{l}662.1 \\
(229.5)^{b}\end{array}$ \\
\hline & & $\begin{array}{l}\text { Placebo } \\
\mathrm{n}=254\end{array}$ & $\begin{array}{l}43.0 \\
(13.0)\end{array}$ & 42.9 & $22.0(13.9)$ & $\begin{array}{l}2.3 \\
(0.7) \\
\end{array}$ & $73.0(8.4)$ & NR & $\begin{array}{l}675.6 \\
(225.4)^{b}\end{array}$ \\
\hline \multirow[t]{5}{*}{$\begin{array}{l}\text { Lee, } 2015^{120} \\
n=362 \\
\text { RCT- crossover, } \\
15 d\end{array}$} & \multirow[t]{5}{*}{$\begin{array}{l}18 \text { years of age and older } \\
\text { with symptomatic asthma } \\
\text { despite ICS treatment, } \\
\text { alone or in combination } \\
\text { with LABA or leukotriene } \\
\text { modifier }\end{array}$} & $\begin{array}{l}\text { Umeclidinium/fluticasone } \\
15.6 / 100 \mu \mathrm{g} \text { daily (DPI) } \\
\mathrm{n}=62\end{array}$ & \multirow[t]{5}{*}{$\begin{array}{l}47.5 \\
(13.8)\end{array}$} & \multirow[t]{5}{*}{31} & \multirow[t]{5}{*}{$\begin{array}{l}<1 y=2 \% \\
1-4 y=13 \% \\
5-9 y=17 \% \\
\geq 10=69 \%\end{array}$} & \multirow[t]{5}{*}{$\begin{array}{l}1.85 \\
(0.53)\end{array}$} & \multirow[t]{5}{*}{$\begin{array}{l}62.3 \\
(10.3)\end{array}$} & \multirow[t]{5}{*}{ NR } & \multirow[t]{5}{*}{ NR } \\
\hline & & $\begin{array}{l}\text { Umeclidinium/fluticasone } \\
31.25 / 100 \mu \mathrm{g} \text { daily (DPI) } \\
\mathrm{n}=60\end{array}$ & & & & & & & \\
\hline & & $\begin{array}{l}\text { Umeclidinium/fluticasone } \\
62.5 / 100 \mu \mathrm{g} \text { daily (DPI) } \\
\mathrm{n}=63\end{array}$ & & & & & & & \\
\hline & & $\begin{array}{l}\text { Umeclidinium/fluticasone } \\
125 / 100 \mu g \text { daily (DPI) } \\
n=58\end{array}$ & & & & & & & \\
\hline & & $\begin{array}{l}\text { Umeclidinium/fluticasone } \\
250 / 100 \mu g \text { daily (DPI) } \\
n=55\end{array}$ & & & & & & & \\
\hline
\end{tabular}




\begin{tabular}{|c|c|c|c|c|c|c|c|c|c|}
\hline $\begin{array}{l}\text { Study, Year, } \\
\text { n, } \\
\text { Acronym, } \\
\text { Study design, } \\
\text { Duration } \\
\text { Risk of bias }\end{array}$ & Study population & $\begin{array}{l}\text { Intervention } \\
\text { Comparisons }\end{array}$ & $\begin{array}{l}\text { Age } \\
\text { (y) } \\
\text { [mean } \\
\text { (SD)] }\end{array}$ & $\begin{array}{l}\text { Males } \\
(\%)\end{array}$ & $\begin{array}{l}\text { Duration } \\
\text { of } \\
\text { asthma } \\
\text { (y) [mean } \\
\text { (SD)] }\end{array}$ & $\begin{array}{l}\text { FEV1 } \\
\text { (L) } \\
\text { [mean } \\
\text { (SD)] }\end{array}$ & $\begin{array}{l}\text { FEV1 \% } \\
\text { predicted } \\
\text { (L) } \\
\text { [mean } \\
\text { (SD)] }\end{array}$ & $\begin{array}{l}\text { Rescue } \\
\text { inhaler } \\
\text { use } \\
\text { (puffs/d) } \\
\text { [mean } \\
\text { (SD)] }\end{array}$ & $\begin{array}{l}\text { ICS dose } \\
\text { during } \\
\text { study } \\
\text { ( } \mu \text { g/d) } \\
\text { [mean } \\
\text { (SD)] }\end{array}$ \\
\hline & & $\begin{array}{l}\text { Fluticasone } 100 \mu \text { g daily } \\
\text { (DPI) } \\
n=64\end{array}$ & & & & & & & \\
\hline \multirow[t]{3}{*}{$\begin{array}{l}\text { Ohta, } 2015^{121} \\
n=285 \\
\text { RCT, } 52 w\end{array}$} & \multirow{3}{*}{$\begin{array}{l}\text { 18-75 years of age with } \\
\text { moderate-severe asthma } \\
\text { according to GINA } \\
\text { guidelines despite } \\
\text { receiving stable medium- } \\
\text { dose ICS ( } 400-800 \mu \mathrm{g} / \mathrm{d} \\
\text { of budesonide or } \\
\text { equivalent) alone or fixed } \\
\text { combination with LABA, } \\
\text { symptomatic with ACQ-7 } \\
\geq 1.5 \\
\text { Randomized therapy was } \\
\text { added to continued } \\
\text { background ICS dose } \\
\text { with or without LABA }\end{array}$} & $\begin{array}{l}\text { Tiotropium } 2.5 \mu \mathrm{g} \text { daily } \\
\text { (Respimat) } \\
\mathrm{n}=114\end{array}$ & $\begin{array}{l}44.7 \\
(12.1)\end{array}$ & 36.8 & $\begin{array}{l}21.0(0.8 \\
\text { to } 57.8)^{\mathrm{e}}\end{array}$ & NR & NR & NR & $\begin{array}{l}673.2 \\
(247.4)^{\mathrm{b}, f}\end{array}$ \\
\hline & & $\begin{array}{l}\text { Tiotropium } 5 \mu \mathrm{g} \text { daily } \\
\text { (Respimat) } \\
n=114\end{array}$ & $\begin{array}{l}42.6 \\
(12.8)\end{array}$ & 42.1 & $\begin{array}{l}21.0(0.3 \\
\text { to } 54.0)^{\mathrm{e}}\end{array}$ & NR & NR & NR & $\begin{array}{l}658.9 \\
(220.5)^{\mathrm{b}, \mathrm{f}}\end{array}$ \\
\hline & & $\begin{array}{l}\text { Placebo } \\
\mathrm{N}=57\end{array}$ & $\begin{array}{l}47.8 \\
(13.0)\end{array}$ & 33.3 & $\begin{array}{l}26.8(0.8 \\
\text { to } 63.0)^{\mathrm{e}}\end{array}$ & NR & NR & NR & $\begin{array}{l}644.2 \\
(220.9)^{\mathrm{b}, \mathrm{f}}\end{array}$ \\
\hline \multirow[t]{3}{*}{$\begin{array}{l}\text { Hammelmann, } \\
2016^{123} \\
\text { RubaTinA-asthma } \\
\mathrm{n}=397 \\
\text { RCT, } 48 \mathrm{w} \\
\text { Low }\end{array}$} & $\begin{array}{l}\text { 12-17 years of age with } \\
\text { moderate symptomatic } \\
\text { asthma with an } A C Q \geq 1.5 \\
\text { receiving maintenance } \\
\text { therapy with ICS with or } \\
\text { without LABA or LTRA }\end{array}$ & $\begin{array}{l}\text { Tiotropium } 5 \mu \mathrm{g} \text { daily } \\
\text { (Respimat) } \\
n=134\end{array}$ & $\begin{array}{l}14.5 \\
(1.6)\end{array}$ & 66.4 & $8.2(4.2)$ & $\begin{array}{l}2.6 \\
(0.6)\end{array}$ & $77.3(8.6)$ & NR & $536(256)^{b, f}$ \\
\hline & \multirow[t]{2}{*}{$\begin{array}{l}\text { Randomized therapy was } \\
\text { added on to maintenance } \\
\text { ICS dose with or without } \\
\text { LTRA }^{\text {g }}\end{array}$} & $\begin{array}{l}\text { Tiotropium } 2.5 \mu \mathrm{g} \text { daily } \\
\text { (Respimat) } \\
n=125\end{array}$ & $\begin{array}{l}14.2 \\
(1.8)\end{array}$ & 64.8 & $7.7(4.0)$ & $\begin{array}{l}2.5 \\
(0.6)\end{array}$ & $78.1(7.9)$ & NR & $557(346)^{b, f}$ \\
\hline & & $\begin{array}{l}\text { Placebo } \\
\mathrm{n}=138\end{array}$ & $\begin{array}{l}14.2 \\
(1.7)\end{array}$ & 63.8 & $7.7(4.2)$ & $\begin{array}{l}2.6 \\
(0.6)\end{array}$ & $77.6(7.5)$ & NR & $527(275)^{b, f}$ \\
\hline
\end{tabular}




\begin{tabular}{|c|c|c|c|c|c|c|c|c|c|}
\hline $\begin{array}{l}\text { Study, Year, } \\
\text { n, } \\
\text { Acronym, } \\
\text { Study design, } \\
\text { Duration } \\
\text { Risk of bias }\end{array}$ & Study population & $\begin{array}{l}\text { Intervention } \\
\text { Comparisons }\end{array}$ & $\begin{array}{l}\text { Age } \\
\text { (y) } \\
\text { [mean } \\
\text { (SD)] }\end{array}$ & $\begin{array}{l}\text { Males } \\
(\%)\end{array}$ & $\begin{array}{l}\text { Duration } \\
\text { of } \\
\text { asthma } \\
\text { (y) [mean } \\
\text { (SD)] }\end{array}$ & $\begin{array}{l}\text { FEV1 } \\
\text { (L) } \\
\text { [mean } \\
\text { (SD)] }\end{array}$ & $\begin{array}{l}\text { FEV1 \% } \\
\text { predicted } \\
\text { (L) } \\
\text { [mean } \\
\text { (SD)] }\end{array}$ & $\begin{array}{l}\text { Rescue } \\
\text { inhaler } \\
\text { use } \\
\text { (puffs/d) } \\
\text { [mean } \\
\text { (SD)] }\end{array}$ & $\begin{array}{l}\text { ICS dose } \\
\text { during } \\
\text { study } \\
\text { ( } \mu \text { g/d) } \\
\text { [mean } \\
\text { (SD)] }\end{array}$ \\
\hline \multirow[t]{3}{*}{$\begin{array}{l}\text { Paggiaro, 2016 } \\
\text { GraziaTinA-asthma } \\
\text { n=464 } \\
\text { RCT, 12w } \\
\text { Low }\end{array}$} & \multirow{3}{*}{$\begin{array}{l}18-75 \text { years of age with } \\
\text { mild symptomatic asthma } \\
\text { with an } A C Q \geq 1.5 \text { despite } \\
\text { receiving maintenance } \\
\text { therapy with low- } \\
\text { moderate ICS (200- } \\
400 \mu \text { g/d budesonide or } \\
\text { equivalent) that is GINA } \\
\text { step } 2 \\
\text { Randomized therapy was } \\
\text { added on to continued } \\
\text { low-medium ICS dose }\end{array}$} & $\begin{array}{l}\text { Tiotropium } 5 \mu \mathrm{g} \text { daily } \\
\text { (Respimat) } \\
n=155\end{array}$ & $\begin{array}{l}41.9 \\
(13.0)\end{array}$ & 38.1 & $15.2(10.2)$ & $\begin{array}{l}2.3 \\
(0.6)\end{array}$ & $74.9(8.1)$ & NR & $\begin{array}{l}376.9 \\
(59.7)^{b, f}\end{array}$ \\
\hline & & $\begin{array}{l}\text { Tiotropium } 2.5 \mu \text { g daily } \\
\text { (Respimat) } \\
n=154\end{array}$ & $\begin{array}{l}43.8 \\
(14.0)\end{array}$ & 46.8 & $17.1(13.0)$ & $\begin{array}{l}2.3 \\
(0.7)\end{array}$ & $73.2(8.6)$ & NR & $\begin{array}{l}384.4 \\
(93.4)^{b, f}\end{array}$ \\
\hline & & $\begin{array}{l}\text { Placebo } \\
\mathrm{n}=155\end{array}$ & $\begin{array}{l}42.8 \\
(12.1)\end{array}$ & 33.5 & $16.2(12.3)$ & $\begin{array}{l}2.2 \\
(0.6)\end{array}$ & $73.7(8.5)$ & NR & $\begin{array}{l}383.0 \\
(77.1)^{b, f}\end{array}$ \\
\hline
\end{tabular}

ACQ=Asthma Control Questionnaire; BID=twice daily; d=day(s); DPI=dry powder inhaler; FEV1=forced expiratory volume in one second; GINA=Global Initiative for Asthma; ICS=inhaled corticosteroid; L=liter; LABA=long-acting ß-agonist; LTRA=leukotriene receptor antagonist; MDI=metered dose inhaler; n=patient sample size; NR=not reported; RCT=randomized controlled trial; $\mathrm{SD}=$ standard deviation; $w=$ weeks; $y=$ years

${ }^{a}$ Concurrent therapy during the study with leukotriene modifiers was $11.7 \%$ in the tiotropium $5 \mu$ g daily arm, $8.8 \%$ in the tiotropium $2.5 \mu \mathrm{g}$ daily arm, $10.9 \%$ in the salmeterol $50 \mu \mathrm{g}$ BID arm and $10.8 \%$ in the placebo arm

bData at baseline, randomized treatments were add-on to continued use of ICS

${ }^{c}$ Concurrent therapy during the study with leukotriene modifiers was $7.1 \%$ in the tiotropium $5 \mu \mathrm{g}$ daily arm, $9.7 \%$ in the tiotropium $2.5 \mu \mathrm{g}$ daily arm, $8.3 \%$ in the salmeterol $50 \mu \mathrm{g}$ BID arm and $7.5 \%$ in the placebo arm

${ }^{\mathrm{d} C}$ Concurrent therapies during the study in the tiotropium $2.5 \mu \mathrm{g}$ daily arm included LABAs (54.4\%), leukotriene modifiers (31.6\%) and methylxanthines (22.8\%). Concurrent therapies during the study in the tiotropium $5 \mu$ g daily arm included LABAs (57.0\%), leukotriene modifiers (25.4\%) and methylxanthines (16.7\%). Concurrent therapies during the study in the placebo arm included LABAs (61.4\%), leukotriene modifiers (24.6\%) and methylxanthines (17.5\%).

eData reported as median (range)

${ }^{\mathrm{f} B u d e s o n i d e ~ e q u i p o t e n t ~ d o s e ~ i n ~} \mu \mathrm{g}$

${ }^{g}$ Concurrent therapy during the study with leukotriene modifiers was $11.2 \%$ in the tiotropium $5 \mu$ g daily arm, $6.4 \%$ in the tiotropium $2.5 \mu$ g daily arm and $10.1 \%$ in the placebo arm 
Table C-22. Study level outcomes for KQ2a

\begin{tabular}{|c|c|c|c|c|c|c|}
\hline $\begin{array}{l}\text { Study, } \\
\text { Year, n, } \\
\text { Study } \\
\text { design, } \\
\text { Duration }\end{array}$ & Population $^{\mathrm{a}}$ & Exacerbations & Mortality & Asthma control & Quality of life & Healthcare utilization \\
\hline $\begin{array}{l}\text { Peters, } \\
2010^{27} \\
\mathrm{n}=210 \\
\text { RCT- } \\
\text { crossover, } \\
14 \mathrm{w}\end{array}$ & $\begin{array}{l}\text { Age: } 12 \mathrm{y}+ \\
\text { Severity/control: } \\
\text { Moderately severe/ } \\
\text { not well controlled } \\
\text { ICS daily dose: Low } \\
\text { vs. medium }\end{array}$ & $\begin{array}{l}\text { Systemic corticosteroids: } \\
\text { RR } 0.48 \text { (0.12 to } 1.84) \\
\text { Oral corticosteroids or } \\
\text { increase in ICS or other } \\
\text { asthma medications: } \\
\text { RR } 0.32 \text { (0.09 to } 1.13)\end{array}$ & NR & $\begin{array}{l}\text { Composite measures: } \\
\text { ACQ-6: } \\
\text { MD -0.15 (-0.45 to } 0.15) \\
\text { Spirometry:: } \\
\text { FEV1 trough: } \\
\text { MD } 0.09(-0.20 \text { to } 0.38)\end{array}$ & $\begin{array}{l}\text { AQLQ: } \\
\text { MD } 0.04(-0.32 \text { to } \\
0.40)\end{array}$ & NR \\
\hline $\begin{array}{l}\text { Bateman, } \\
2011^{118} \\
n=388 \\
\text { RCT, } 16 \mathrm{w}\end{array}$ & $\begin{array}{l}\text { Age: } 12 \mathrm{y}+ \\
\text { Severity/control: } \\
\text { Moderate persistent/ } \\
\text { not controlled } \\
\text { ICS daily dose: Low } \\
\text { to medium }\end{array}$ & $\begin{array}{l}\text { Systemic corticosteroids: } \\
\text { RR } 0.93 \text { (0.49 to } 1.75)\end{array}$ & NR & $\begin{array}{l}\text { Composite measures: } \\
\text { NR } \\
\text { Spirometry:: } \\
\text { FEV1 trough: } \\
\text { MD } 0.15(0.07 \text { to } 0.23) \\
\text { FVC trough: } \\
\text { MD } 0.14(0.04 \text { to } 0.23)\end{array}$ & $\begin{array}{l}\text { AQLQ-mini: } \\
\text { MD }-0.091(- \\
0.265 \text { to } 0.082)\end{array}$ & $\begin{array}{l}\text { Rescue medication use: } \\
\text { MD }-0.37 \text { (-0.90 to } 0.16)\end{array}$ \\
\hline $\begin{array}{l}\text { Kerstjens, } \\
2015^{119} \\
\text { Study } 1 \\
n=1071 \\
\text { RCT, 24w }\end{array}$ & $\begin{array}{l}\text { Age: } 12 \mathrm{y}+ \\
\text { Severity/control: } \\
\text { Moderate persistent/ } \\
\text { uncontrolled }^{\mathrm{d}} \\
\text { ICS daily dose: Low } \\
\text { to medium }\end{array}$ & $\begin{array}{l}\text { Systemic corticosteroids: } \\
\text { RR } 0.62(0.42 \text { to } 0.92)^{\mathrm{e}} \\
\text { Asthma worsening: RR } \\
0.79(0.67 \text { to } 0.94)^{\mathrm{e}}\end{array}$ & $\begin{array}{l}\text { All-cause: } \\
\text { No deaths } \\
\text { occurred }\end{array}$ & $\begin{array}{l}\text { Composite measures: } \\
\text { ACQ-7 score: } \\
\text { MD -0.21 (-0.30 to }-0.12) \\
\text { ACQ-7 responder: } \\
\text { RR } 1.21(1.07 \text { to } 1.38) \\
\text { Spirometry:: } \\
\text { FEV1 peak: } \\
\text { MD } 0.22 \text { (0.17 to } 0.27) \\
\text { FEV1 trough: } \\
\text { MD } 0.17(0.11 \text { to } 0.22) \\
\text { FEV1 AUC: } \\
\text { MD } 0.21(0.16 \text { to } 0.26) \\
\text { FVC peak: } \\
\text { MD } 0.14(0.09 \text { to } 0.19) \\
\text { FVC trough: } \\
\text { MD } 0.10(0.04 \text { to } 0.16) \\
\text { FVC AUC: } \\
\text { MD } 0.13(0.08 \text { to } 0.19)\end{array}$ & $\begin{array}{l}\text { AQLQ: } \\
\text { MD } 0.07(-0.06 \text { to } \\
0.2)\end{array}$ & $\begin{array}{l}\text { Rescue medication use: } \\
\text { MD }-0.01 \text { ( }-0.26 \text { to } 0.23)\end{array}$ \\
\hline
\end{tabular}




\begin{tabular}{|c|c|c|c|c|c|c|}
\hline $\begin{array}{l}\text { Study, } \\
\text { Year, n, } \\
\text { Study } \\
\text { design, } \\
\text { Duration }\end{array}$ & Population $^{a}$ & Exacerbations & Mortality & Asthma control & Quality of life & Healthcare utilization \\
\hline $\begin{array}{l}\text { Kerstjens, } \\
2015^{119} \\
\text { Study } 2 \\
n=1032 \\
\text { RCT, } 24 \mathrm{w}\end{array}$ & $\begin{array}{l}\text { Age: } 12 \mathrm{y}+ \\
\text { Severity/ control: } \\
\text { Moderate persistent/ } \\
\text { uncontrolled } \\
\text { ICS daily dose: Low } \\
\text { to medium }\end{array}$ & $\begin{array}{l}\text { Systemic corticosteroids: } \\
\text { RR } 0.62(0.42 \text { to } 0.92)^{\mathrm{e}} \\
\text { Asthma worsening: } \\
\text { RR } 0.79(0.67 \text { to } 0.94)^{\mathrm{e}}\end{array}$ & $\begin{array}{l}\text { All-cause: } \\
\text { No deaths } \\
\text { occurred }\end{array}$ & $\begin{array}{l}\text { Composite measures: } \\
\text { ACQ-7 score: } \\
\text { MD -0.07 (-0.16 to } 0.02) \\
\text { ACQ-7 responder: } \\
\text { RR } 1.03 \text { (0.92 to } 1.15) \\
\text { Spirometry:: } \\
\text { FEV1 peak: } \\
\text { MD } 0.19 \text { (0.15 to } 0.24) \\
\text { FEV1 trough: } \\
\text { MD } 0.16(0.10 \text { to } 0.21) \\
\text { FEV1 AUC: } \\
\text { MD 0.18 (0.14 to } 0.23) \\
\text { FVC peak: } \\
\text { MD 0.10 (0.05 to } 0.15) \\
\text { FVC trough: } \\
\text { MD } 0.08(0.02 \text { to } 0.15) \\
\text { FVC AUC: } \\
\text { MD } 0.10 \text { (0.04 to } 0.16)\end{array}$ & $\begin{array}{l}\text { AQLQ: } \\
\text { MD } 0.11(-0.03 \text { to } \\
0.25)\end{array}$ & $\begin{array}{l}\text { Rescue medication use: } \\
\text { MD }-0.03 \text { (-0.25 to } 0.19)\end{array}$ \\
\hline $\begin{array}{l}\text { Lee, } \\
2015^{120} \\
\mathrm{n}=421 \\
\text { RCT- } \\
\text { crossover, } \\
15 d\end{array}$ & $\begin{array}{l}\text { Age: } 12 y+ \\
\text { Severity/control: } \\
\text { Not reported/ } \\
\text { uncontrolled } \\
\text { ICS daily dose: Low }\end{array}$ & $\begin{array}{l}\text { Systemic corticosteroids: } \\
\text { RR } 0.64 \text { (0.07 to } 6.09)\end{array}$ & $\begin{array}{l}\text { All-cause: } \\
\text { No deaths } \\
\text { occurred }\end{array}$ & $\begin{array}{l}\text { Composite measures: } \\
\text { NR } \\
\text { Spirometry:: } \\
\text { FEV1 trough: } \\
\text { MD } 0.11 \text { (0.01 TO 0.21) }\end{array}$ & NR & $\begin{array}{l}\text { Rescue medication use: } \\
\text { MD }-0.29 \text { (-0.69 to } 0.10)\end{array}$ \\
\hline $\begin{array}{l}\text { Ohta, } \\
2015^{121} \\
n=285 \\
\text { RCT, 52w }\end{array}$ & $\begin{array}{l}\text { Age: } 12 \mathrm{y}+ \\
\text { Severity/ control: } \\
\text { Moderate-severe/ } \\
\text { uncontrolled } \\
\text { ICS daily dose: Low } \\
\text { to medium }\end{array}$ & NR & $\begin{array}{l}\text { All-cause: } \\
\text { No deaths } \\
\text { occurred }\end{array}$ & $\begin{array}{l}\text { Composite measures: } \\
\text { ACQ-7 responder: } \\
\text { RR } 0.98 \text { (0.83 to } 1.16) \\
\text { Spirometry:: } \\
\text { FEV1 trough: } \\
\text { MD } 0.06 \text { (-0.02 to } 0.15) \\
\text { FVC trough: } \\
\text { MD } 0.02(-0.07 \text { to } 0.12)\end{array}$ & NR & $\begin{array}{l}\text { Rescue medication use: } \\
\text { MD }-0.01 \text { (-0.26 to } 0.25)\end{array}$ \\
\hline
\end{tabular}




\begin{tabular}{|c|c|c|c|c|c|c|}
\hline $\begin{array}{l}\text { Study, } \\
\text { Year, n, } \\
\text { Study } \\
\text { design, } \\
\text { Duration }\end{array}$ & Population $^{a}$ & Exacerbations & Mortality & Asthma control & Quality of life & Healthcare utilization \\
\hline $\begin{array}{l}\text { Hammel- } \\
\text { mann, } \\
2016^{123} \\
n=398 \\
\text { RCT, } 48 w\end{array}$ & $\begin{array}{l}\text { Age: } 12 \mathrm{y}+ \\
\text { Severity/ control: } \\
\text { Moderate/ } \\
\text { uncontrolled } \\
\text { ICS daily dose: Low } \\
\text { to medium }\end{array}$ & $\begin{array}{l}\text { Systemic corticosteroids: } \\
\text { RR } 0.41 \text { (0.16 to } 1.09) \\
\text { Asthma worsening: } \\
\text { RR } 0.92 \text { (0.65 to } 1.31)\end{array}$ & $\begin{array}{l}\text { All-cause: } \\
\text { No deaths } \\
\text { occurred }\end{array}$ & $\begin{array}{l}\text { Composite measures: } \\
\text { ACQ-7: } \\
\text { MD -0.17 (-0.30 to }-0.04) \\
\text { ACQ-7 responder: } \\
\text { RR } 1.16(1.02 \text { to } 1.31) \\
\text { Spirometry:: } \\
\text { FEV1 peak: } \\
\text { MD } 0.16(0.06 \text { to } 0.25) \\
\text { FEV1 trough: } \\
\text { MD } 0.10(0.00 \text { to } 0.20) \\
\text { FEV1 AUC: } \\
\text { MD 0.16 (0.07 to } 0.24) \\
\text { FVC peak: } \\
\text { MD } 0.08(-0.02 \text { to } 0.18) \\
\text { FVC trough: } \\
\text { MD } 0.05(-0.06 \text { to } 0.16) \\
\text { FVC AUC: } \\
\text { MD } 0.08(-0.02 \text { to } 0.18)\end{array}$ & $\begin{array}{l}\text { AQLQ(S) 12+ } \\
\text { responder: } \\
\text { RR } 1.12(0.92 \text { to } \\
1.37)\end{array}$ & $\begin{array}{l}\text { Rescue medication use: } \\
\text { MD }-0.29(-0.53 \text { to }-0.05)\end{array}$ \\
\hline $\begin{array}{l}\text { Paggiaro, } \\
2016^{122} \\
n=465 \\
\text { RCT, 12w }\end{array}$ & $\begin{array}{l}\text { Age: } 12 \mathrm{y}+ \\
\text { Severity/ control: } \\
\text { Mild/uncontrolled } \\
\text { ICS daily dose: Low }\end{array}$ & $\begin{array}{l}\text { Systemic corticosteroid: } \\
\text { RR } 0.88 \text { (0.26 to } 2.95) \\
\text { Asthma worsening: RR } \\
0.78(0.47 \text { to } 1.28)\end{array}$ & $\begin{array}{l}\text { All-cause: } \\
\text { No deaths } \\
\text { occurred }\end{array}$ & $\begin{array}{l}\text { Composite measures: } \\
\text { ACQ-7: } \\
\text { MD } 0.03 \text { (-0.07 to } 0.14) \\
\text { ACQ-7 responder: } \\
\text { RR } 1.00 \text { (0.86 to } 1.18) \\
\text { Spirometry:: } \\
\text { FEV1 peak: } \\
\text { MD } 0.14(0.08 \text { to } 0.21) \\
\text { FEV1 trough: } \\
\text { MD } 0.12 \text { (0.05 to } 0.18) \\
\text { FEV1 AUC: } \\
\text { MD } 0.14(0.08 \text { to } 0.20) \\
\text { FEV1 \% predicted: } \\
\text { MD } 3.5 \text { (1.58 to } 5.42)\end{array}$ & NR & $\begin{array}{l}\text { Rescue medication use: } \\
\text { MD } 0.09 \text { (-0.13 to } 0.32)\end{array}$ \\
\hline
\end{tabular}

Abbreviations: ACQ=Asthma Control Questionnaire; AQLQ=Asthma Quality of Life Questionnaire; AUC=area under the curve; d=days; FEV1=forced expiratory volume in one second; FVC=forced vital capacity; EPR-3=Expert Panel Review-3 (guidelines for the diagnosis and management of asthma); ICS=inhaled corticosteroid; MD=mean difference; $\mathrm{n}=$ patient sample size; $\mathrm{NR}=$ not reported; $\mathrm{RCT}=$ randomized controlled trial; RR=relative risk; $\mathrm{w}=$ weeks

${ }^{a}$ Age is categorized using study inclusion criteria and the age categories used in EPR-3 of 0-4y, 5-11y and 12y+. Severity is as reported per the study. Control was not always explicitly stated thus study criteria were applied to EPR-3 categories of control to determine asthma control status. ICS daily dose is categorized using the study's required ICS dose and the EPR-3 categories of low, medium and high

${ }^{b}$ Defined as reported in the study, FEV1\% predicted $70 \%$ or less or during final 2 week run-in symptoms 6 or more days per week or rescue inhaler used 6 or more days per week or were awakened by symptoms of asthma 2 nights or more per week. 
'Defined as reported in the study, symptoms not well controlled on ICS alone

${ }^{\mathrm{d}}$ Required ACQ $\geq 1.5$ for enrollment

e Outcome was not reported for study 1 and 2 separately, value reflects data from study 1 and 2 combined

fPatients were required to be symptomatic on ICS with FEV1\% predicted $40-80 \%$ after run-in

Table C-23. Subgroup analysis by tiotropium dose for KQ2a

\begin{tabular}{|c|c|c|c|c|}
\hline & $\begin{array}{l}\text { Tiotropium vs. placebo } \\
\text { RR or MD (95\% } \mathrm{Cl}) \\
\text { (base case analysis) }\end{array}$ & $\begin{array}{l}\text { Tiotropium } 2.5 \mu \mathrm{g} \text { vs. placebo } \\
\text { RR or MD }(95 \% \mathrm{CI})\end{array}$ & $\begin{array}{l}\text { Tiotropium } 5 \mu \mathrm{g} \text { vs. placebo } \\
\text { RR or MD }(95 \% \mathrm{Cl})\end{array}$ & $\begin{array}{l}\text { Tiotropium } 2.5 \mu \mathrm{g} \text { vs. } 5 \mu \mathrm{g} \\
\text { RR or MD }(95 \% \mathrm{Cl})\end{array}$ \\
\hline $\begin{array}{l}\text { Exacerbation requiring } \\
\text { systemic corticosteroid }\end{array}$ & RR 0.67 (0.48 to 0.92) & RR 0.63 (0.20 to 2.04) & RR 0.69 (0.32 to 1.47) & RR 1.70 (0.11 to 25.55) \\
\hline Asthma worsening & RR 0.81 (0.68 to 0.97) & RR 0.82 (0.49 to 1.38 ) & RR 0.85 (0.63 to 1.15) & RR 1.08 (0.45 to 2.57 ) \\
\hline ACQ-7 score & MD $-0.10(-0.28$ to 0.07$)$ & MD $-0.12(-0.35$ to 0.11$)$ & MD $-0.09(-0.23$ to 0.06$)$ & MD $-0.03(-0.16$ to 0.10$)$ \\
\hline ACQ-7 responder & RR 1.08 (0.96 to 1.21$)$ & RR 1.08 (0.98 to 1.20$)$ & RR 1.08 (0.95 to 1.24$)$ & RR 0.99 (0.92 to 1.07) \\
\hline FEV1 peak & MD 0.18 (0.13 to 0.24$)$ & MD 0.20 (0.13 to 0.27$)$ & MD 0.17 (0.13 to 0.21$)$ & MD $0.03(-0.01$ to 0.07$)$ \\
\hline FEV1 trough & MD 0.13 (0.10 to 0.17$)$ & MD 0.12 (0.03 to 0.21$)$ & MD 0.13 (0.12 to 0.15$)$ & MD $-0.01(-0.08$ to 0.06$)$ \\
\hline FEV1 AUC & MD 0.18 (0.13 to 0.23$)$ & MD $0.19(0.12$ to 0.25$)$ & MD 0.17 (0.12 to 0.21$)$ & MD $0.02(-0.02$ to 0.07$)$ \\
\hline FVC peak & MD 0.11 (0.05 to 0.18$)$ & MD 0.13 (0.03 to 0.24$)$ & MD 0.09 (0.06 to 0.12$)$ & MD $0.04(-0.04$ to 0.12$)$ \\
\hline FVC trough & MD 0.08 (0.04 to 0.13$)$ & MD $0.07(-0.04$ to 0.18$)$ & MD 0.08 (0.05 to 0.12$)$ & MD $-0.01(-0.13$ to 0.11$)$ \\
\hline FVC AUC & MD 0.11 (0.05 to 0.17$)$ & MD 0.13 (0.04 to 0.21$)$ & MD 0.09 (0.05 to 0.13$)$ & MD $0.03(-0.02$ to 0.08$)$ \\
\hline $\begin{array}{l}\text { Rescue medication use, } \\
\text { puffs/24 hours }\end{array}$ & MD $-0.08(-0.23$ to 0.07$)$ & MD $-0.09(-0.34$ to 0.16$)$ & MD $-0.03(-0.22$ to 0.16$)$ & MD $-0.08(-0.37$ to 0.20$)$ \\
\hline
\end{tabular}

Abbreviations: ACQ=Asthma Control Questionnaire; AUC=area under curve; CI=confidence interval; FVC=forced vital capacity; FEV1=forced expiratory volume in one second; $\mathrm{MD}=$ mean difference; $\mathrm{RR}=$ relative risk 
Table C-24. Study and population characteristics for KQ2b

\begin{tabular}{|c|c|c|c|c|c|c|c|c|c|}
\hline $\begin{array}{l}\text { Study, Year, } \\
\text { n, } \\
\text { Acronym, } \\
\text { Study design, } \\
\text { Duration, } \\
\text { Risk of bias }\end{array}$ & Study population & $\begin{array}{l}\text { Intervention } \\
\text { Comparisons }\end{array}$ & $\begin{array}{l}\text { Age } \\
\text { (y) } \\
\text { [mean } \\
\text { (SD)] }\end{array}$ & $\begin{array}{l}\text { Males } \\
(\%)\end{array}$ & $\begin{array}{l}\text { Duration } \\
\text { of } \\
\text { asthma } \\
\text { (yr) [mean } \\
\text { (SD)] }\end{array}$ & $\begin{array}{l}\text { FEV } 1 \\
(\mathrm{~L}) \\
\text { [mean } \\
\text { (SD)] }\end{array}$ & $\begin{array}{l}\mathrm{FEV}_{1} \% \\
\text { predicted } \\
\text { (L) } \\
\text { [mean } \\
\text { (SD)] }\end{array}$ & $\begin{array}{l}\text { Rescue } \\
\text { inhaler } \\
\text { use } \\
\text { (puffs/d) } \\
\text { [mean } \\
\text { (SD)] }\end{array}$ & $\begin{array}{l}\text { ICS dose } \\
\text { during } \\
\text { study } \\
\text { ( } \mu \mathrm{g} / \mathrm{d} \text { ) } \\
\text { [mean } \\
\text { (SD)] }\end{array}$ \\
\hline \multirow[t]{2}{*}{$\begin{array}{l}\text { Peters, } 2010^{27} \\
\text { TALC } \\
n=210 \\
\text { RCT- crossover, } \\
14 \mathrm{w}\end{array}$} & \multirow{2}{*}{$\begin{array}{l}\geq 18 \text { years of age with } \\
\text { moderately severe } \\
\text { asthma not well } \\
\text { controlled on ICS alone } \\
\text { Tiotropium or salmeterol } \\
\text { were added on to run-in } \\
\text { dose of beclomethasone } \\
80 \mu \mathrm{g} \text { BID }\end{array}$} & $\begin{array}{l}\text { Tiotropium } 18 \mu \mathrm{g} \text { daily } \\
\text { (Handihaler) } \\
n=210\end{array}$ & \multirow[t]{2}{*}{$\begin{array}{l}42.2 \\
(12.3)\end{array}$} & \multirow[t]{2}{*}{32.9} & \multirow[t]{2}{*}{$26.1(14.1)$} & \multirow[t]{2}{*}{$\begin{array}{l}2.31 \\
(0.77)\end{array}$} & \multirow[t]{2}{*}{$\begin{array}{l}71.5 \\
(14.9)\end{array}$} & \multirow[t]{2}{*}{$\begin{array}{l}1.71 \\
(2.09)\end{array}$} & NR \\
\hline & & $\begin{array}{l}\text { Salmeterol 50 } \mu \mathrm{g} \text { BID } \\
\text { (DPI) } \\
n=210\end{array}$ & & & & & & & NR \\
\hline \multirow[t]{2}{*}{$\begin{array}{l}\text { Bateman, } 2011^{118} \\
n=262 \\
\text { RCT, 16w }\end{array}$} & \multirow{2}{*}{$\begin{array}{l}\text { 18-65 years of age with } \\
\text { moderate persistent } \\
\text { asthma (GINA step } 3 \text { ) not } \\
\text { controlled on ICS alone } \\
\text { (400-1000 } \mu \text { g/d } \\
\text { budesonide or } \\
\text { equivalent) } \\
\text { Randomized therapy } \\
\text { added on to ICS } \\
\text { continued at prestudy } \\
\text { dose }\end{array}$} & $\begin{array}{l}\text { Tiotropium } 5 \mu \text { daily } \\
\text { (Respimat) } \\
n=128\end{array}$ & $\begin{array}{l}43.5 \\
(12.6)\end{array}$ & 35.9 & $18.1(12.1)$ & $\begin{array}{l}2.3 \\
(0.77)\end{array}$ & $\begin{array}{l}74.1 \\
(16.1)\end{array}$ & NR & NR \\
\hline & & $\begin{array}{l}\text { Salmeterol 50 } \mu \mathrm{g} \text { BID } \\
(\mathrm{MDI}) \\
n=134\end{array}$ & $\begin{array}{l}42.3 \\
(13.4)\end{array}$ & 38.1 & $15.4(10.7)$ & $\begin{array}{l}2.4 \\
(0.8)\end{array}$ & $\begin{array}{l}75.6 \\
(17.6)\end{array}$ & NR & NR \\
\hline \multirow[t]{3}{*}{$\begin{array}{l}\text { Rajanandh, } \\
2014^{146} \\
n=123 \\
\text { RCT, 90d }\end{array}$} & \multirow[t]{3}{*}{$\begin{array}{l}\text { 18-60 years of age with } \\
\text { uncontrolled, mild to } \\
\text { moderate persistent } \\
\text { asthma according to the } \\
\text { GINA guidelines }^{\text {a }}\end{array}$} & $\begin{array}{l}\text { Tiotropium } 18 \mu \text { g daily } \\
\text { (HandiHaler) }+ \\
\text { budesonide } 400 \mu \text { g daily } \\
n=31\end{array}$ & $\begin{array}{l}40.4 \\
(13.6)\end{array}$ & 64.5 & $5.4(2.7)$ & NR & $66.9(1.7)$ & NR & NR \\
\hline & & $\begin{array}{l}\text { Formoterol } 6 \mu \mathrm{g} \text { BID }+ \\
\text { budesonide } 400 \mu \mathrm{g} \text { daily } \\
\mathrm{n}=32\end{array}$ & $\begin{array}{l}37.2 \\
(14.9)\end{array}$ & 56.3 & $5.6(2.7)$ & NR & $66.6(2.0)$ & NR & NR \\
\hline & & $\begin{array}{l}\text { Doxofylline } 400 \mathrm{mg} \text { daily } \\
\text { + budesonide } 400 \mu \mathrm{g} \\
\text { daily } \\
\mathrm{n}=30\end{array}$ & $\begin{array}{l}37.1 \\
(18.8)\end{array}$ & 36.7 & $5.2(2.7)$ & NR & $66.8(1.5)$ & NR & NR \\
\hline
\end{tabular}




\begin{tabular}{|c|c|c|c|c|c|c|c|c|c|}
\hline $\begin{array}{l}\text { Study, Year, } \\
\text { n, } \\
\text { Acronym, } \\
\text { Study design, } \\
\text { Duration, } \\
\text { Risk of bias }\end{array}$ & Study population & $\begin{array}{l}\text { Intervention } \\
\text { Comparisons }\end{array}$ & $\begin{array}{l}\text { Age } \\
\text { (y) } \\
\text { [mean } \\
\text { (SD)] }\end{array}$ & $\begin{array}{l}\text { Males } \\
(\%)\end{array}$ & $\begin{array}{l}\text { Duration } \\
\text { of } \\
\text { asthma } \\
\text { (yr) [mean } \\
\text { (SD)] }\end{array}$ & $\begin{array}{l}\text { FEV1 } \\
\text { (L) } \\
\text { [mean } \\
\text { (SD)] }\end{array}$ & $\begin{array}{l}\text { FEV }_{1} \% \\
\text { predicted } \\
\text { (L) } \\
\text { [mean } \\
\text { (SD)] }\end{array}$ & $\begin{array}{l}\text { Rescue } \\
\text { inhaler } \\
\text { use } \\
\text { (puffs/d) } \\
\text { [mean } \\
\text { (SD)] }\end{array}$ & $\begin{array}{l}\text { ICS dose } \\
\text { during } \\
\text { study } \\
\text { ( } \mu \mathrm{g} / \mathrm{d}) \\
\text { [mean } \\
\text { (SD)] }\end{array}$ \\
\hline & & $\begin{array}{l}\text { Montelukast } 10 \mathrm{mg} \text { daily } \\
\text { + budesonide } 400 \mu \mathrm{g} \\
\text { daily } \\
\mathrm{n}=30\end{array}$ & $\begin{array}{l}39.3 \\
(17.0)\end{array}$ & 40.0 & $5.6(3.0)$ & NR & $67.2(1.4)$ & NR & NR \\
\hline \multirow[t]{3}{*}{$\begin{array}{l}\text { Kerstjens, } 2015^{119} \\
\text { Study } 1 \\
\text { MezzoTinA-asthma } \\
1 \\
\mathrm{n}=801 \\
\text { RCT, } 24 \mathrm{w} \\
\text { Low }\end{array}$} & \multirow{3}{*}{$\begin{array}{l}\text { 18-75 year of age with } \\
\text { moderate persistent } \\
\text { asthma according to } \\
\text { GINA guidelines despite } \\
\text { treatment with stable } \\
\text { medium dose ICS (400- } \\
800 \mu \mathrm{g} / \mathrm{d} \text { budesonide or } \\
\text { equivalent) alone or in } \\
\text { fixed combination with } \\
\text { LABA, symptomatic with } \\
\text { ACQ-7 } 1.5 \text {. } \\
\text { Randomized therapy was } \\
\text { added to prestudy stable } \\
\text { maintenance ICS dose }\end{array}$} & $\begin{array}{l}\text { Tiotropium } 5 \mu \mathrm{g} \text { daily } \\
\text { (Respimat) } \\
n=264\end{array}$ & $\begin{array}{l}44.4 \\
(12.6)\end{array}$ & 41.7 & $22.9(14.7)$ & $\begin{array}{l}2.2 \\
(0.6)\end{array}$ & $72.2(8.2)$ & NR & $\begin{array}{l}666.4 \\
(216.2)^{c}\end{array}$ \\
\hline & & $\begin{array}{l}\text { Tiotropium } 2.5 \mu \mathrm{g} \text { daily } \\
\text { (Respimat) } \\
\mathrm{n}=262\end{array}$ & $\begin{array}{l}43.7 \\
(13.1)\end{array}$ & 40.5 & $22.2(14.1)$ & $\begin{array}{l}2.2 \\
(0.7)\end{array}$ & $73.1(8.6)$ & NR & $\begin{array}{l}649.8 \\
(196.2)^{c}\end{array}$ \\
\hline & & $\begin{array}{l}\text { Salmeterol } 50 \mu \mathrm{g} \text { BID } \\
\text { (MDI) } \\
n=275\end{array}$ & $\begin{array}{l}42.6 \\
(12.6)\end{array}$ & 42.2 & $21.4(14.5)$ & $\begin{array}{l}2.3 \\
(0.6)\end{array}$ & $72.8(8.5)$ & NR & $\begin{array}{l}656.7 \\
(193.1)^{c}\end{array}$ \\
\hline \multirow[t]{3}{*}{$\begin{array}{l}\text { Kerstjens, } 2015^{119} \\
\text { Study } 2 \\
\text { MezzoTinA-asthma } \\
2 \\
\mathrm{n}=776 \\
\text { RCT, 24w } \\
\text { Low }\end{array}$} & \multirow{3}{*}{$\begin{array}{l}\text { 18-75 year of age with } \\
\text { moderate persistent } \\
\text { asthma according to } \\
\text { GINA guidelines despite } \\
\text { treatment with stable } \\
\text { medium dose ICS (400- } \\
800 \mu \text { g/d budesonide or } \\
\text { equivalent) alone or in } \\
\text { fixed combination with } \\
\text { LABA, symptomatic with } \\
\text { ACQ-7 } 1.5 \\
\text { Randomized therapy was } \\
\text { added to prestudy stable } \\
\text { maintenance ICS dose }\end{array}$} & $\begin{array}{l}\text { Tiotropium } 5 \mu \text { daily } \\
\text { (Respimat) } \\
n=253\end{array}$ & $\begin{array}{l}44.3 \\
(12.7)\end{array}$ & 42.3 & $23.1(15.3)$ & $\begin{array}{l}2.3 \\
(0.6)\end{array}$ & $72.2(8.3)$ & NR & $\begin{array}{l}661.3 \\
(216.1)^{c}\end{array}$ \\
\hline & & $\begin{array}{l}\text { Tiotropium } 2.5 \mu \text { daily } \\
\text { (Respimat) } \\
n=257\end{array}$ & $\begin{array}{l}43.0 \\
(12.6)\end{array}$ & 37.7 & $21.9(14.5)$ & $\begin{array}{l}2.3 \\
(0.7)\end{array}$ & $72.5(8.0)$ & NR & $\begin{array}{l}662.1 \\
(229.5)^{c}\end{array}$ \\
\hline & & $\begin{array}{l}\text { Salmeterol } 50 \mu \mathrm{g} \text { BID } \\
\text { (MDI) } \\
n=266\end{array}$ & $\begin{array}{l}41.5 \\
(13.1)\end{array}$ & 42.5 & $20.4(14.1)$ & $\begin{array}{l}2.4 \\
(0.7)\end{array}$ & $73.1(8.1)$ & NR & $\begin{array}{l}644.7 \\
(217.2)^{c}\end{array}$ \\
\hline
\end{tabular}




\begin{tabular}{|c|c|c|c|c|c|c|c|c|c|}
\hline $\begin{array}{l}\text { Study, Year, } \\
\text { n, } \\
\text { Acronym, } \\
\text { Study design, } \\
\text { Duration, } \\
\text { Risk of bias }\end{array}$ & Study population & $\begin{array}{l}\text { Intervention } \\
\text { Comparisons }\end{array}$ & $\begin{array}{l}\text { Age } \\
(y) \\
{[\text { mean }} \\
\text { (SD)] }\end{array}$ & $\begin{array}{l}\text { Males } \\
(\%)\end{array}$ & $\begin{array}{l}\text { Duration } \\
\text { of } \\
\text { asthma } \\
\text { (yr) [mean } \\
\text { (SD)] }\end{array}$ & $\begin{array}{l}\text { FEV1 } \\
\text { (L) } \\
\text { [mean } \\
\text { (SD)] }\end{array}$ & $\begin{array}{l}\text { FEV } 1 \% \\
\text { predicted } \\
\text { (L) } \\
\text { [mean } \\
\text { (SD)] }\end{array}$ & $\begin{array}{l}\text { Rescue } \\
\text { inhaler } \\
\text { use } \\
\text { (puffs/d) } \\
\text { [mean } \\
\text { (SD)] }\end{array}$ & $\begin{array}{l}\text { ICS dose } \\
\text { during } \\
\text { study } \\
\text { ( } \mu \mathrm{g} / \mathrm{d} \text { ) } \\
\text { [mean } \\
\text { (SD)] }\end{array}$ \\
\hline $\begin{array}{l}\text { Lee, } 2015^{120} \\
n=357 \\
\text { RCT- crossover, } \\
15 d\end{array}$ & \multirow[t]{6}{*}{$\begin{array}{l}18 \text { years of age and older } \\
\text { with symptomatic asthma } \\
\text { despite ICS treatment, } \\
\text { alone or in combination } \\
\text { with LABA or leukotriene } \\
\text { modifier }\end{array}$} & $\begin{array}{l}\text { Umeclidinium/fluticasone } \\
15.6 / 100 \mu \mathrm{g} \text { daily (DPI) } \\
\mathrm{n}=62\end{array}$ & $\begin{array}{l}47.5 \\
(13.8)\end{array}$ & 31 & $\begin{array}{l}<1 y=2 \% \\
1-4 y=13 \% \\
5-9 y=17 \% \\
\geq 10=69 \%\end{array}$ & $\begin{array}{l}1.85 \\
(0.53)\end{array}$ & $\begin{array}{l}62.3 \\
(10.3)\end{array}$ & NR & NR \\
\hline \multirow[t]{5}{*}{ Unclear } & & $\begin{array}{l}\text { Umeclidinium/fluticasone } \\
31.25 / 100 \mu g \text { daily (DPI) } \\
n=60\end{array}$ & & & & & & & \\
\hline & & $\begin{array}{l}\text { Umeclidinium/fluticasone } \\
62.5 / 100 \mu \mathrm{g} \text { daily (DPI) } \\
\mathrm{n}=63\end{array}$ & & & & & & & \\
\hline & & $\begin{array}{l}\text { Umeclidinium/fluticasone } \\
125 / 100 \mu g \text { daily (DPI) } \\
n=58\end{array}$ & & & & & & & \\
\hline & & $\begin{array}{l}\text { Umeclidinium/fluticasone } \\
\text { 250/100 } \mu \text { g daily (DPI) } \\
n=55\end{array}$ & & & & & & & \\
\hline & & $\begin{array}{l}\text { Vilanterol/fluticasone } \\
125 / 100 \mu g \text { daily (DPI) } \\
n=59\end{array}$ & & & & & & & \\
\hline \multirow{4}{*}{$\begin{array}{l}\text { Rajanandh, } \\
2015^{147} \\
\mathrm{n}=297 \\
\text { RCT, 180d } \\
\text { Medium }\end{array}$} & \multirow[t]{4}{*}{$\begin{array}{l}\text { 18-60 years of age with } \\
\text { uncontrolled, mild- } \\
\text { moderate persistent } \\
\text { asthma according to } \\
\text { GINA guidelines }^{\mathrm{a}}\end{array}$} & $\begin{array}{l}\text { Tiotropium } 18 \mu \text { g daily } \\
\text { (Handihaler) }+ \\
\text { budesonide } 400 \mu \text { g daily } \\
n=72\end{array}$ & $\begin{array}{l}37.4 \\
(13.6)\end{array}$ & 52.8 & $5.8(8.7)$ & NR & $66.1(6.4)$ & $4.4(1.1)$ & NR \\
\hline & & $\begin{array}{l}\text { Formoterol } 6 \mu \mathrm{g} \text { BID }+ \\
\text { budesonide } 400 \mu \mathrm{g} \text { daily } \\
n=68\end{array}$ & $\begin{array}{l}38.4 \\
(14.9)\end{array}$ & 55.4 & $6.6(6.7)$ & NR & $66.2(8.3)$ & $4.4(1.1)$ & NR \\
\hline & & $\begin{array}{l}\text { Montelukast } 10 \mathrm{mg} \text { daily } \\
+ \text { budesonide } 400 \mu \mathrm{g} \\
\text { daily } \\
\mathrm{n}=81\end{array}$ & $\begin{array}{l}36.3 \\
(17.0)\end{array}$ & 44.4 & $5.9(8.0)$ & NR & $67.2(6.5)$ & $4.5(1.2)$ & NR \\
\hline & & $\begin{array}{l}\text { Doxofylline } 400 \mathrm{mg} \text { daily } \\
+ \text { budesonide } 400 \mu \mathrm{g} \\
\text { daily } \\
\mathrm{n}=76\end{array}$ & $\begin{array}{l}38.3 \\
(18.8)\end{array}$ & 53.9 & $6.2(9.7)$ & NR & $66.3(7.0)$ & $4.5(1.1)$ & NR \\
\hline
\end{tabular}




\begin{tabular}{|c|c|c|c|c|c|c|c|c|c|}
\hline $\begin{array}{l}\text { Study, Year, } \\
\text { n, } \\
\text { Acronym, } \\
\text { Study design, } \\
\text { Duration, } \\
\text { Risk of bias }\end{array}$ & Study population & $\begin{array}{l}\text { Intervention } \\
\text { Comparisons }\end{array}$ & $\begin{array}{l}\text { Age } \\
\text { (y) } \\
\text { [mean } \\
\text { (SD)] }\end{array}$ & $\begin{array}{l}\text { Males } \\
(\%)\end{array}$ & $\begin{array}{l}\text { Duration } \\
\text { of } \\
\text { asthma } \\
\text { (yr) [mean } \\
\text { (SD)] }\end{array}$ & $\begin{array}{l}\text { FEV } 1 \\
\text { (L) } \\
{[\text { mean }} \\
\text { (SD)] }\end{array}$ & $\begin{array}{l}\text { FEV }_{1} \% \\
\text { predicted } \\
\text { (L) } \\
\text { [mean } \\
\text { (SD)] }\end{array}$ & $\begin{array}{l}\text { Rescue } \\
\text { inhaler } \\
\text { use } \\
\text { (puffs/d) } \\
\text { [mean } \\
\text { (SD)] }\end{array}$ & $\begin{array}{l}\text { ICS dose } \\
\text { during } \\
\text { study } \\
\text { ( } \mu \text { g/d) } \\
\text { [mean } \\
\text { (SD)] }\end{array}$ \\
\hline \multirow[t]{2}{*}{$\begin{array}{l}\text { Wechsler, } 2015^{148} \\
\text { BELT } \\
\mathrm{n}=1070 \\
\text { RCT, } 18 \mathrm{~m} \\
\text { Low }\end{array}$} & \multirow{2}{*}{$\begin{array}{l}\text { 18-75 years of age with } \\
\text { asthma currently on or } \\
\text { eligible for step } 3 \text { or } 4 \\
\text { combination ICS/LABA } \\
\text { according to the NHLBI } \\
\text { guidelines } \\
\text { Randomized therapy was } \\
\text { added to continued } \\
\text { baseline ICS dose }\end{array}$} & $\begin{array}{l}\text { Tiotropium } 18 \mu \mathrm{g} \text { daily } \\
\text { (HandiHaler) } \\
n=532\end{array}$ & $\begin{array}{l}45.2 \\
(12.6)\end{array}$ & 23.9 & $23.3(15.8)$ & $\begin{array}{l}2.1 \\
(0.7)\end{array}$ & $\begin{array}{l}78.6 \\
(17.6)\end{array}$ & $3.4(3.5)$ & $N R^{f}$ \\
\hline & & $\begin{array}{l}\text { LABA BID }^{\mathrm{e}} \\
\mathrm{n}=538\end{array}$ & $\begin{array}{l}45.1 \\
(12.6)\end{array}$ & 24.2 & $25.6(16.0)$ & $\begin{array}{l}2.1 \\
(0.6)\end{array}$ & $\begin{array}{l}78.7 \\
(18.6)\end{array}$ & $3.5(3.7)$ & $\mathrm{NR}^{f}$ \\
\hline
\end{tabular}

Abbreviations: ACQ=Asthma Control Questionnaire; BID=twice daily; d=day; DPI=dry powder inhaler; FEV1=forced expiratory volume in one second; GINA=Global Initiative for Asthma; ICS=inhaled corticosteroid; L=liter; LABA=long-acting $\beta_{2}$-agonist; =months; MDI=metered dose inhaler; $n=$ patient sample size; NHLBI=National Heart, Lung, and Blood Institute; NR=not reported; RCT=randomized controlled trial; SD=standard deviation; $\mu g=$ microgram; $w=$ week; $y=y e a r$

${ }^{\mathrm{a} C o n f i r m e d ~ t h r o u g h ~ a u t h o r ~ c o r r e s p o n d e n c e ~}$

${ }^{b}$ Concurrent therapy during the study with leukotriene modifiers was $11.7 \%$ in the tiotropium $5 \mu$ g daily arm, $8.8 \%$ in the tiotropium $2.5 \mu$ g daily arm, $10.9 \%$ in the salmeterol $50 \mu$ g BID arm and $10.8 \%$ in the placebo arm

'Data at baseline, randomized treatments were add-on to continued use of ICS

${ }^{\mathrm{d} C}$ Concurrent therapy during the study with leukotriene modifiers was $7.1 \%$ in the tiotropium $5 \mu \mathrm{g}$ daily arm, $9.7 \%$ in the tiotropium $2.5 \mu \mathrm{g}$ daily arm, $8.3 \%$ in the salmeterol $50 \mu \mathrm{g}$ BID arm and $7.5 \%$ in the placebo arm

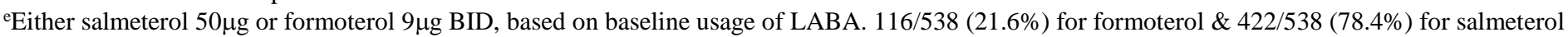

${ }_{\mathrm{f}}^{\mathrm{f}} \mathrm{Mean} / \mathrm{median}$ ICS dose was not reported, although patients continued baseline ICS dose. Of those taking an ICS without LABA at baseline (28\%), 88\% were taking low-dose ICS

$<500 \mu \mathrm{g}$. Of those taking ICS+LABA, $70 \%$ were using a single inhaler to delivery both medications. Approximately half were taking fluticasone/salmeterol $250 / 50 \mu g$ 
Table C-25. Study level outcomes for KQ2b

\begin{tabular}{|c|c|c|c|c|c|c|}
\hline $\begin{array}{l}\text { Study, } \\
\text { Year, n, } \\
\text { Study } \\
\text { design, } \\
\text { Duration }\end{array}$ & Population $^{a}$ & Exacerbations & Mortality & Asthma control & Quality of life & Healthcare utilization \\
\hline $\begin{array}{l}\text { Peters, } \\
2010^{27} \\
n=210 \\
\text { RCT- } \\
\text { crossover, } \\
14 \mathrm{w}\end{array}$ & $\begin{array}{l}\text { Age: } 12 \mathrm{y}+ \\
\text { Severity/control: } \\
\text { Moderately severe/ } \\
\text { not well controlled } \\
\text { ICS daily dose: Low } \\
\text { vs. medium }\end{array}$ & $\begin{array}{l}\text { Systemic corticosteroid: } \\
\text { RR } 0.60 \text { (0.15 to } 2.42) \\
\text { Oral corticosteroid or } \\
\text { increase in ICS or other } \\
\text { asthma medication: } \\
\text { RR } 0.60 \text { (0.15 to } 2.42)\end{array}$ & NR & $\begin{array}{l}\text { Composite measures: } \\
\text { ACQ-6: } \\
\text { MD } 0.30(0.00 \text { to } 0.60) \\
\text { Spirometry:: } \\
\text { FEV1 trough: } \\
\text { MD } 0.12(-0.15 \text { to } 0.39)\end{array}$ & $\begin{array}{l}\text { AQLQ: } \\
\text { MD }-0.22(-0.60 \\
\text { to } 0.16)\end{array}$ & NR \\
\hline $\begin{array}{l}\text { Bateman, } \\
2011^{118} \\
n=388 \\
\text { RCT, 16w }\end{array}$ & $\begin{array}{l}\text { Age: } 12 \mathrm{y}+ \\
\text { Severity/control: } \\
\text { Moderate persistent/ } \\
\text { not controlled } \\
\text { ICS daily dose: Low } \\
\text { to medium }\end{array}$ & $\begin{array}{l}\text { Systemic corticosteroid: } \\
\text { RR } 0.99 \text { (0.52 to } 1.87)\end{array}$ & NR & $\begin{array}{l}\text { Composite measures: } \\
\text { NR } \\
\text { Spirometry:: } \\
\text { FEV1 trough: } \\
\text { MD }-0.02(-0.10 \text { to } 0.06) \\
\text { FVC trough: } \\
\text { MD } 0.01(-0.08 \text { to } 0.11) \\
\end{array}$ & $\begin{array}{l}\text { AQLQ-mini: } \\
\text { MD -0.149 } \\
(-0.320 \text { to } 0.222)\end{array}$ & $\begin{array}{l}\text { Rescue medication use: } \\
\text { MD } 0.20(-0.32 \text { to } 0.72)\end{array}$ \\
\hline $\begin{array}{l}\text { Rajanandh, } \\
2014^{146} \\
n=167 \\
\text { RCT, 90d }\end{array}$ & $\begin{array}{l}\text { Age: } 12 \mathrm{y}+ \\
\text { Severity/control: } \\
\text { Mild to moderate } \\
\text { persistent/ } \\
\text { uncontrolled } \\
\text { ICS daily dose: Low } \\
\text { to medium }\end{array}$ & NR & NR & $\begin{array}{l}\text { Composite measures: } \\
\text { NR } \\
\text { Spirometry:: } \\
\text { FEV1 \% predicted: } \\
\text { LAMA vs. LABA: } \\
\text { MD -7.34 (-8.30 to }-6.38) \\
\text { LAMA vs. montelukast: } \\
\text { MD -2.14 (-2.93 to }-1.35) \\
\text { LAMA vs. doxofylline: } \\
\text { MD -3.87 (-4.6 to -3.14) } \\
\end{array}$ & NR & $\begin{array}{l}\text { Rescue medication use: } \\
\text { LAMA vs. LABA: } \\
\text { MD } 1.38 \text { (0.89 to } 1.87) \\
\text { LAMA vs. montelukast: } \\
\text { MD } 0.26 \text { (-0.25 to } 0.77) \\
\text { LAMA vs. doxofylline: } \\
\text { MD } 1.21 \text { (0.89 to } 1.53)\end{array}$ \\
\hline
\end{tabular}




\begin{tabular}{|c|c|c|c|c|c|c|}
\hline $\begin{array}{l}\text { Study, } \\
\text { Year, n, } \\
\text { Study } \\
\text { design, } \\
\text { Duration } \\
\end{array}$ & Population $^{\mathrm{a}}$ & Exacerbations & Mortality & Asthma control & Quality of life & Healthcare utilization \\
\hline $\begin{array}{l}\text { Kerstjens, } \\
2015^{119} \\
\text { Study } 1 \\
n=1071 \\
\text { RCT, 24w }\end{array}$ & $\begin{array}{l}\text { Age: } 12 \mathrm{y}+ \\
\text { Severity/control: } \\
\text { Moderate persistent/ } \\
\text { uncontrolled } \\
\text { ICS daily dose: Low } \\
\text { to medium }\end{array}$ & $\begin{array}{l}\text { Systemic corticosteroid: } \\
\text { RR } 0.81(0.54 \text { to } 1.24)^{f} \\
\text { Asthma worsening: } \\
\text { RR } 1(0.84 \text { to } 1.12)^{\dagger}\end{array}$ & $\begin{array}{l}\text { All-cause: No } \\
\text { deaths occurred }\end{array}$ & $\begin{array}{l}\text { Composite measures: } \\
\text { ACQ-7 score: } \\
\text { MD 0.04 (-0.05 to 0.13) } \\
\text { ACQ-7 responder: } \\
\text { RR 1.06 (0.96 to } 1.18) \\
\text { Spirometry:: } \\
\text { FEV1 peak: } \\
\text { MD } 0.004 \text { (-0.05 to 0.05) } \\
\text { FEV1 trough: } \\
\text { MD 0.05 (-0.01 to } 0.10) \\
\text { FEV1 AUC: } \\
\text { MD -0.004 (-0.05 to } 0.04) \\
\text { FVC peak: } \\
\text { MD 0.016 (-0.04 to 0.07) } \\
\text { FVC trough: } \\
\text { MD 0.03 (-0.03 to } 0.10) \\
\text { FVC AUC: } \\
\text { MD 0.005 (-0.05 to } 0.06)\end{array}$ & $\begin{array}{l}\text { AQLQ: } \\
\text { MD -0.07 (-0.20 } \\
\text { to } 0.06)\end{array}$ & $\begin{array}{l}\text { Rescue medication use: } \\
\text { MD } 0.44 \text { ( } 0.20 \text { to } 0.68)\end{array}$ \\
\hline $\begin{array}{l}\text { Kerstjens, } \\
2015^{119} \\
\text { Study } 2 \\
n=1032 \\
\text { RCT, 24w }\end{array}$ & $\begin{array}{l}\text { Age: } 12 \mathrm{y}+ \\
\text { Severity/ control: } \\
\text { Moderate persistent/ } \\
\text { uncontrolled } \\
\text { ICS daily dose: Low } \\
\text { to medium }\end{array}$ & $\begin{array}{l}\text { Systemic corticosteroid: } \\
\text { RR } 0.81(0.54 \text { to } 1.24)^{f} \\
\text { Asthma worsening: } \\
\text { RR } 1.00(0.84 \text { to } 1.12)^{f}\end{array}$ & $\begin{array}{l}\text { All-cause: No } \\
\text { deaths occurred }\end{array}$ & $\begin{array}{l}\text { Composite measures: } \\
\text { ACQ-7 score: } \\
\text { MD 0 (-0.09 to 0.09) } \\
\text { ACQ-7 responder: } \\
\text { RR 1.00 (0.90 to } 1.12) \\
\text { Spirometry:: } \\
\text { FEV1 peak: } \\
\text { MD } 0.014(-0.03 \text { to } 0.06) \\
\text { FEV1 trough: } \\
\text { MD } 0.05 \text { (0.00 to 0.10) } \\
\text { FEV1 AUC: } \\
\text { MD 0.004 (-0.04 to 0.05) } \\
\text { FVC peak: } \\
\text { MD -0.017 (-0.07 to } 0.03) \\
\text { FVC trough: } \\
\text { MD } 0.02(-0.05 \text { to } 0.08) \\
\text { FVC AUC: } \\
\text { MD -0.032 (-0.09 to } 0.03)\end{array}$ & $\begin{array}{l}\text { AQLQ: } \\
\text { MD -0.05 (0.18 to } \\
0.08)\end{array}$ & $\begin{array}{l}\text { Rescue medication use: } \\
\text { MD } 0.09 \text { ( }-0.13 \text { to } 0.31)\end{array}$ \\
\hline
\end{tabular}




\begin{tabular}{|c|c|c|c|c|c|c|}
\hline $\begin{array}{l}\text { Study, } \\
\text { Year, n, } \\
\text { Study } \\
\text { design, } \\
\text { Duration }\end{array}$ & Population $^{\mathrm{a}}$ & Exacerbations & Mortality & Asthma control & Quality of life & Healthcare utilization \\
\hline $\begin{array}{l}\text { Lee, } \\
2015^{120} \\
n=421 \\
\text { RCT- } \\
\text { crossover, } \\
15 d\end{array}$ & $\begin{array}{l}\text { Age: } 12 \mathrm{y}+ \\
\text { Severity/control: } \\
\text { Not reported/ } \\
\text { uncontrolled } \\
\text { ICS daily dose: Low }\end{array}$ & $\begin{array}{l}\text { Systemic corticosteroid: } \\
\text { RR } 6.93 \text { (0.36 to } 133.57)\end{array}$ & $\begin{array}{l}\text { All-cause: No } \\
\text { deaths occurred }\end{array}$ & $\begin{array}{l}\text { Composite measures: } \\
\text { NR } \\
\text { Spirometry: } \\
\text { FEV1 trough: } \\
\text { MD }-0.05(-0.15 \text { to } 0.06)\end{array}$ & NR & $\begin{array}{l}\text { Rescue medication use: } \\
\text { MD } 0.14(-0.25 \text { to } 0.53)\end{array}$ \\
\hline $\begin{array}{l}\text { Rajanandh, } \\
2015^{147} \\
n=362 \\
\text { RCT, 180d }\end{array}$ & $\begin{array}{l}\text { Age:12y+ } \\
\text { Severity/control: } \\
\text { Mild to moderate } \\
\text { persistent/ } \\
\text { uncontrolled } \\
\text { ICS daily dose: Low } \\
\text { to medium }\end{array}$ & $\begin{array}{l}\text { Requiring hospitalization: } \\
\text { No events occurred }\end{array}$ & NR & $\begin{array}{l}\text { Composite measures: } \\
\text { NR } \\
\text { Spirometry: } \\
\text { FEV1 \% predicted: } \\
\text { LAMA vs. LABA: } \\
\text { MD -4.46 (-6.71 to }-2.21) \\
\text { LAMA vs. montelukast: } \\
\text { MD -0.87 (-2.77 to }-1.03) \\
\text { LAMA vs. doxofylline: } \\
\text { MD -2.69 (-4.79 to }-0.59)\end{array}$ & NR & $\begin{array}{l}\text { Rescue medication use: } \\
\text { LAMA vs LABA: MD } \\
2.03 \text { ( } 1.72 \text { to } 2.34) \\
\text { LAMA vs. monteluklast: } \\
1.19 \text { (0.88 to } 1.5) \\
\text { LAMA vs. doxofylline: } \\
\text { MD } 1.21 \text { (0.89 to } 1.53)\end{array}$ \\
\hline $\begin{array}{l}\text { Wechsler, } \\
2015^{148} \\
n=1070 \\
\text { RCT, } 18 \mathrm{~m}\end{array}$ & $\begin{array}{l}\text { Age: } 12 \mathrm{y}+ \\
\text { Severity/control: } \\
\text { Step } 3 \text { or } 4 \\
\text { according to NHLBI } \\
\text { guidelines/ } \\
\text { uncontrolled } \\
\text { ICS daily dose: Low } \\
\text { to high }\end{array}$ & $\begin{array}{l}\text { Systemic corticosteroid } \\
\text { or hospitalization: } \\
\text { RR } 1.09 \text { (0.87 to } 1.36) \\
\text { Requiring hospitalization: } \\
\text { RR } 0.52(0.24 \text { to } 1.11)\end{array}$ & $\begin{array}{l}\text { All-cause: } \\
0.6 \% \text { vs. } 0 \% \\
p=0.12 \\
\text { Asthma-specific: } \\
0.4 \% \text { vs. } 0 \% \\
p=0.25\end{array}$ & $\begin{array}{l}\text { Composite measures: } \\
\text { ACQ-7: } \\
\text { MD 0.04 (-0.18 to 0.27) } \\
\text { Spirometry:: } \\
\text { FEV1 trough: } \\
\text { MD -0.02 (-0.09 to } 0.04) \\
\text { FEV1 \% predicted: } \\
\text { MD -0.63 (-4.41 to } 3.15)\end{array}$ & $\begin{array}{l}\text { AQLQ: } \\
\text { MD 0.05 (-0.23, } \\
0.33)\end{array}$ & $\begin{array}{l}\text { Rescue medication use: } \\
\text { MD }-0.05 \text { (-0.71 to } 0.61)\end{array}$ \\
\hline
\end{tabular}

Abbreviations: ACQ=Asthma Control Questionnaire; AQLQ=Asthma Quality of Life Questionnaire; AUC=area under the curve; $d=$ day; FEV1=forced expiratory volume in one second; FVC=forced vital capacity; EPR=Expert Panel Review (Guidelines for the Diagnosis and Management of Asthma); ICS=inhaled corticosteroid; LABA=long-acting betaagonist; LAMA=long-acting muscarinic antagonist; $m=$ =month; $M D=$ mean difference; $n=$ patient sample size; NHLBI=National Heart, Lung and Blood Institute; NR=not reported; $\mathrm{RCT}=$ randomized controlled trial; $\mathrm{RR}=$ relative risk; $\mathrm{w}=$ week

${ }^{a}$ Age is categorized using study inclusion criteria and the age categories used in EPR-3 of 0-4y, 5-11y and $12 y+$. Severity is as reported per the study. Control was not always explicitly stated thus study criteria were applied to EPR-3 categories of control to determine asthma control status. ICS daily dose is categorized using the study's required ICS dose and the EPR-3 categories of low, medium and high

${ }^{b}$ As reported in the study, FEV1 \% predicted $70 \%$ or less or during final 2 week run-in symptoms 6 or more days per week or rescue inhaler used 6 or more days per week or were awakened by symptoms of asthma 2 nights or more per week.

'As reported in the study, symptoms not well controlled on ICS alone

${ }^{\mathrm{d} C o n f i r m e d ~ t h r o u g h ~ e m a i l ~ c o r r e s p o n d e n c e ~ w i t h ~ a u t h o r ~ a l t h o u g h ~ f u r t h e r ~ d e t a i l s ~ w e r e ~ n o t ~ p r o v i d e d ~}$

${ }^{\mathrm{e} R e q u i r e d} \mathrm{ACQ} \geq 1.5$ for enrollment

${ }^{\mathrm{f}}$ Outcome was not reported for study 1 and 2 separately, value reflects data from study 1 and 2 combined

gPatients were required to be symptomatic on ICS with FEV1 \% predicted 40-80\% after run-in 


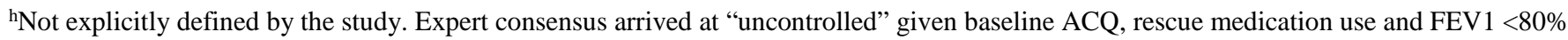

\begin{tabular}{|c|c|c|c|c|c|c|c|c|c|}
\hline $\begin{array}{l}\text { Study, Year, } \\
\text { n, } \\
\text { Acronym, } \\
\text { Study design, } \\
\text { Duration } \\
\text { Risk of bias }\end{array}$ & Study population & $\begin{array}{l}\text { Intervention } \\
\text { Comparisons }\end{array}$ & $\begin{array}{l}\text { Age } \\
\text { (y) } \\
\text { [mean } \\
\text { (SD)] }\end{array}$ & $\begin{array}{l}\text { Males } \\
\text { (\%) }\end{array}$ & $\begin{array}{l}\text { Duration } \\
\text { of } \\
\text { asthma } \\
\text { (y) [mean } \\
\text { (SD)] }\end{array}$ & $\begin{array}{l}\text { FEV1 (L) } \\
\text { [mean } \\
\text { (SD)] }\end{array}$ & $\begin{array}{l}\text { FEV1 \% } \\
\text { predicted } \\
\text { (L) } \\
\text { [mean } \\
\text { (SD)] }\end{array}$ & $\begin{array}{l}\text { Rescue } \\
\text { inhaler } \\
\text { use } \\
\text { (puffs/d) } \\
\text { [mean } \\
\text { (SD)] }\end{array}$ & $\begin{array}{l}\text { ICS dose } \\
\text { during } \\
\text { study } \\
\text { ( } \mu \mathrm{g} / \mathrm{d}) \\
\text { [mean } \\
\text { (SD)] }\end{array}$ \\
\hline \multirow[t]{2}{*}{$\begin{array}{l}\text { Kerstjens, } \\
2012^{141} \\
\text { Study } 1 \\
\text { PrimoTinA- } \\
\text { asthma } 1 \\
\mathrm{n}=459 \\
\text { RCT, } 48 \mathrm{w}\end{array}$} & $\begin{array}{l}\text { 18-75 years of age with severe } \\
\text { persistent, symptomatic asthma } \\
\& A C Q-7 \geq 1.5 \text { despite daily ICS } \\
\text { ( } \geq 800 \mu \mathrm{g} \text { budesonide or } \\
\text { equivalent per day) and LABA } \\
\text { therapy }\end{array}$ & $\begin{array}{l}\text { Tiotropium } 5 \mu \mathrm{g} \\
\text { daily (Respimat) } \\
n=237\end{array}$ & $\begin{array}{l}52.9 \\
(12.4)\end{array}$ & 38.4 & $\begin{array}{l}31 \text { (6 to } \\
70)^{b}\end{array}$ & $\begin{array}{l}1.60 \\
(0.55)\end{array}$ & $\begin{array}{l}54.6 \\
(12.2)\end{array}$ & $2.8(\mathrm{NR})$ & \multirow[t]{2}{*}{$\begin{array}{l}800(800- \\
1600)^{\mathrm{c}, \mathrm{d}, \mathrm{e}}\end{array}$} \\
\hline & $\begin{array}{l}\text { Randomized therapy added on to } \\
\text { pretrial maintenance high-dose } \\
\text { ICS and LABA. Other } \\
\text { maintenance medications } \\
\text { allowed to continue at stable } \\
\text { doses }^{\text {a }}\end{array}$ & $\begin{array}{l}\text { Placebo } \\
n=222\end{array}$ & $\begin{array}{l}53.9 \\
(12.8)\end{array}$ & 35.6 & $\begin{array}{l}28(6 \text { to } \\
68)^{b}\end{array}$ & $\begin{array}{l}1.56 \\
(0.54)\end{array}$ & $\begin{array}{l}54.6 \\
(12.2)\end{array}$ & $3.3(\mathrm{NR})$ & \\
\hline \multirow[t]{2}{*}{$\begin{array}{l}\text { Kerstjens, } \\
2012^{141} \\
\text { Study } 2 \\
\text { PrimoTinA- } \\
\text { asthma } 2 \\
\mathrm{n}=453 \\
\text { RCT, } 48 \mathrm{w}\end{array}$} & $\begin{array}{l}\text { 18-75 years of age with severe } \\
\text { persistent, symptomatic asthma } \\
\& \text { ACQ-7 } \geq 1.5 \text { despite daily ICS } \\
\text { ( } \geq 800 \mu \mathrm{g} \text { budesonide or } \\
\text { equivalent per day) and LABA } \\
\text { therapy }\end{array}$ & $\begin{array}{l}\text { Tiotropium } 5 \mu \mathrm{g} \\
\text { daily (Respimat) } \\
n=219\end{array}$ & $\begin{array}{l}51.4 \\
(12.5)\end{array}$ & 42.0 & $\begin{array}{l}26(5 \text { to } \\
72)^{b}\end{array}$ & $\begin{array}{l}1.66 \\
(0.57)\end{array}$ & $\begin{array}{l}55.1 \\
(12.8)\end{array}$ & $3.4(\mathrm{NR})$ & \multirow[t]{2}{*}{$\begin{array}{l}800(800- \\
1600)^{c, d, e}\end{array}$} \\
\hline & $\begin{array}{l}\text { Randomized therapy added on to } \\
\text { pretrial maintenance high-dose } \\
\text { ICS and LABA; Other } \\
\text { maintenance medications } \\
\text { allowed to continue at stable } \\
\text { doses. }^{f}\end{array}$ & $\begin{array}{l}\text { Placebo } \\
n=234\end{array}$ & $\begin{array}{l}53.6 \\
(11.7)\end{array}$ & 42.3 & $\begin{array}{l}28(5 \text { to } \\
69)^{b}\end{array}$ & $\begin{array}{l}1.60 \\
(0.51)\end{array}$ & $\begin{array}{l}55.0 \\
(12.6)\end{array}$ & $3.3(\mathrm{NR})$ & \\
\hline $\begin{array}{l}\text { Wang, } 2015^{151} \\
\mathrm{n}=63 \\
\mathrm{RCT}, 12 \mathrm{w} \\
\text { Unclear }\end{array}$ & $\begin{array}{l}\text { Adults with moderate persistent } \\
\text { asthma according to GINA } \\
\text { guidelines, uncontrolled on } \\
\text { salmeterol/ fluticasone } 50 / 250 \mu \mathrm{g} \\
\text { BID with daily symptoms and use } \\
\text { of SABA }\end{array}$ & $\begin{array}{l}\text { Tiotropium 18 } \mu \mathrm{g} \\
\text { daily (HandiHaler) } \\
\mathrm{n}=33\end{array}$ & $\begin{array}{l}36.7 \\
(5.79)^{\mathrm{g}}\end{array}$ & 54.5 & NR & NR & NR & NR & $500^{h}$ \\
\hline
\end{tabular}




\begin{tabular}{|c|c|c|c|c|c|c|c|c|c|}
\hline $\begin{array}{l}\text { Study, Year, } \\
\text { n, } \\
\text { Acronym, } \\
\text { Study design, } \\
\text { Duration } \\
\text { Risk of bias }\end{array}$ & Study population & $\begin{array}{l}\text { Intervention } \\
\text { Comparisons }\end{array}$ & $\begin{array}{l}\text { Age } \\
\text { (y) } \\
\text { [mean } \\
\text { (SD)] }\end{array}$ & $\begin{array}{l}\text { Males } \\
\text { (\%) }\end{array}$ & $\begin{array}{l}\text { Duration } \\
\text { of } \\
\text { asthma } \\
\text { (y) [mean } \\
\text { (SD)] }\end{array}$ & $\begin{array}{l}\text { FEV1 (L) } \\
\text { [mean } \\
\text { (SD)] }\end{array}$ & $\begin{array}{l}\text { FEV1 \% } \\
\text { predicted } \\
\text { (L) } \\
\text { [mean } \\
\text { (SD)] }\end{array}$ & $\begin{array}{l}\text { Rescue } \\
\text { inhaler } \\
\text { use } \\
\text { (puffs/d) } \\
\text { [mean } \\
\text { (SD)] }\end{array}$ & $\begin{array}{l}\text { ICS dose } \\
\text { during } \\
\text { study } \\
\text { ( } \mu \text { g/d) } \\
\text { [mean } \\
(\mathrm{SD})]\end{array}$ \\
\hline & $\begin{array}{l}\text { Tiotropium was added on to } \\
\text { continued salmeterol/fluticasone } \\
50 / 250 \mu \mathrm{g} \text { BID }\end{array}$ & $\begin{array}{l}\text { Increase } \\
\text { salmeterol } \\
\text { /fluticasone to } \\
50 / 500 \mu \mathrm{B} \text { BID } \\
\text { (DPI) } \\
n=30\end{array}$ & $\begin{array}{l}35.3 \\
(5.89)^{\mathrm{g}}\end{array}$ & 53.3 & NR & NR & NR & NR & $1000^{\mathrm{h}}$ \\
\hline \multirow[t]{3}{*}{$\begin{array}{l}\text { Hamelmann, } \\
2016^{152} \\
\text { PensieTinA- } \\
\text { asthma } \\
n=392 \\
\text { RCT, 12w }\end{array}$} & \multirow{3}{*}{$\begin{array}{l}12-17 \text { years of age with severe } \\
\text { persistent asthma according to } \\
\text { GINA guidelines despite high- } \\
\text { dose ICS ( }>400 \mu \mathrm{g} / \mathrm{d} \text { in } 12-14 \mathrm{y} \text {, } \\
>800-1600 \mu \mathrm{g} / \mathrm{d} \text { of budesonide } \\
\text { equivalent if }>14 \mathrm{y} \text { ) with another } \\
\text { controller OR medium dose ICS } \\
\text { (200-400 } \mu \mathrm{g} / \mathrm{d} \text { budesonide } \\
\text { equivalent in } 12-14 \mathrm{y}, 400- \\
800 \mu \mathrm{g} / \mathrm{d} \text { in }>14 \mathrm{y}) \text { with two other } \\
\text { controllers; Symptomatic with } \\
\text { ACQ-7 } \geq 1.5 \text {. } \\
\text { Randomized therapies were } \\
\text { added on to ICS and other } \\
\text { controllers used prior to the } \\
\text { study }\end{array}$} & $\begin{array}{l}\text { Tiotropium } 5 \mu \mathrm{g} \\
\text { daily (Respimat) } \\
\mathrm{n}=130\end{array}$ & $\begin{array}{l}14.3 \\
(1.6)\end{array}$ & 63.8 & $7.3(4.0)$ & $2.6(0.7)$ & $\begin{array}{l}79.4 \\
(12.3)\end{array}$ & NR & $\begin{array}{l}776.7 \\
(381.2)^{\mathrm{d}, e}\end{array}$ \\
\hline & & $\begin{array}{l}\text { Tiotropium } 2.5 \mu \mathrm{g} \\
\text { daily (Respimat) } \\
n=127\end{array}$ & $\begin{array}{l}14.4 \\
(1.8)\end{array}$ & 63.0 & $8.0(3.9)$ & $2.5(0.6)$ & $79.8(9.9)$ & NR & $\begin{array}{l}727.8 \\
(343.6)^{d, e}\end{array}$ \\
\hline & & $\begin{array}{l}\text { Placebo } \\
n=135\end{array}$ & $\begin{array}{l}14.1 \\
(1.7)\end{array}$ & 58.5 & $8.0(3.7)$ & $2.5(0.6)$ & $\begin{array}{l}79.4 \\
(12.2)\end{array}$ & NR & $\begin{array}{l}736.6 \\
(347.9) d, e\end{array}$ \\
\hline
\end{tabular}

Abbreviations: ACQ=Asthma Control Questionnaire; BID=twice daily; d=day; DPI=dry powder inhaler; FEV1=forced expiratory volume in one second; GINA=Global Initiative for Asthma; ICS=inhaled corticosteroid; L=liter; LABA=long-acting $\beta 2$-agonist; LAMA=long-acting muscarinic antagonist; $n=$ patient sample size; NR=not reported;

$\mathrm{RCT}=$ randomized controlled trial; SABA=short-acting $\beta$-agonist; $\mathrm{SD}=$ standard deviation; $\mu \mathrm{g}=$ =microgram; $\mathrm{w}=\mathrm{week}$; $\mathrm{y}=\mathrm{year}$

${ }^{a}$ Concurrent therapies during the study in the tiotropium arm included leukotriene modifiers (25.3\%), theophylline (18.6\%), omalizumab (2.5\%), systemic steroids (6.8\%) and antihistamines (20.3\%). Concurrent therapies during the study in the placebo arm included leukotriene modifiers (27.5\%), theophylline (21.2\%), omalizumab (4.5\%), systemic steroids (5.0\%) and antihistamines (16.2\%)

bData reported as median (range)

'Data reported as median (interquartile range)

${ }^{\mathrm{d}}$ Data at baseline, randomized treatments were added on to continued use of ICS

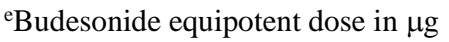


${ }^{\mathrm{f} C}$ Concurrent therapies during the study in the tiotropium arm included leukotriene modifiers (16.4\%), theophylline (14.2\%), omalizumab (2.7\%), systemic steroids (3.7\%) and antihistamines (14.2\%). Concurrent therapies during the study in the placebo arm included leukotriene modifiers (19.7\%), theophylline (12.8\%), omalizumab (6.0\%), systemic steroids (5.6\%) and antihistamines (8.1\%)

gData reported as mean (standard error)

hICS dose assumed due to fixed dosing with add-on therapy (tiotropium arm) or increased dose (salmeterol/fluticasone arm) used in trial

${ }^{\mathrm{i} C o n c u r r e n t}$ therapies during the treatment period in the tiotropium $5 \mu \mathrm{g}$ arm were systemic corticosteroids (3\%), short acting anticholinergic $(0.8 \%)$, long-acting $\beta_{2}$-agonists (82.3\%), theophylline (6.2\%) and leukotriene modifiers (78.5\%). In this arm, 33.1\% of patients were on 2 controllers while $66.9 \%$ were on three controllers. Concurrent therapies during the treatment period in the tiotropium $2.5 \mu \mathrm{g}$ arm were systemic corticosteroids ( $0.8 \%)$, long-acting $\beta_{2}$-agonists (79.5\%), theophylline (4.7\%) and leukotriene modifiers (81.9\%). In this arm, $33.9 \%$ of patients were on 2 controllers while $66.1 \%$ were on three controllers. Concurrent therapies during the treatment period in the placebo arm were systemic corticosteroids (1.5\%), long-acting $\beta 2$-agonists (85.9\%), theophylline (5.2\%) and leukotriene modifiers (80.7\%). In this arm, $28.2 \%$ of patients were on 2 controllers while $71.9 \%$ were on three controllers

\section{Table C-27. Study level outcomes for KQ2C}

\begin{tabular}{|c|c|c|c|c|c|c|}
\hline $\begin{array}{l}\text { Study, } \\
\text { Year, n, } \\
\text { Study } \\
\text { design, } \\
\text { Duration }\end{array}$ & Population $^{\mathrm{a}}$ & Exacerbations & Mortality & Asthma control & Quality of life & Healthcare utilization \\
\hline $\begin{array}{l}\text { Kerstjens, } \\
2012^{150} \\
\text { Study } 1 \\
n=459 \text { RCT, } \\
48 \mathrm{w}\end{array}$ & $\begin{array}{l}\text { Age: } 12 \mathrm{y}+ \\
\text { Severity/control: } \\
\text { Severe persistent/ } \\
\text { uncontrolled } \\
\text { ICS daily dose: } \\
\text { Medium to high }\end{array}$ & $\begin{array}{l}\text { Systemic corticosteroid: } \\
\text { RR } 0.73 \text { (0.54 to } 0.99) \\
\text { Asthma worsening: } \\
\text { RR } 0.79 \text { (0.67 to } 0.94) \\
\text { Requiring hospitalization: } \\
\text { RR } 1.33 \text { (0.54 to } 3.32)\end{array}$ & $\begin{array}{l}\text { All-cause: No } \\
\text { deaths occurred }\end{array}$ & $\begin{array}{l}\text { Composite measures: } \\
\text { ACQ-7 score: } \\
\text { MD -0.12 (-0.27 to } 0.03) \\
\text { ACQ-7 responder: } \\
\text { RR 0.78 (0.68 to } 0.88)^{c} \\
\text { ACQ-6 responder: } \\
\text { OR } 1.49 \text { (1.14 to } 1.9)^{c} \\
\text { ACQ-5 responder: } \\
\text { OR } 1.42(1.08 \text { to } 1.86)^{c} \\
\text { Spirometry:: } \\
\text { FEV1 peak: } \\
\text { MD } 0.07(0.00 \text { to } 0.14) \\
\text { FEV1 trough: } \\
\text { MD } 0.04(-0.03 \text { to } 0.11) \\
\text { FEV1 AUC: } \\
\text { MD } 0.07(0.00 \text { to } 0.14) \\
\text { FVC peak: } \\
\text { MD } 0.12(0.03 \text { to } 0.22) \\
\text { FVC trough: } \\
\text { MD } 0.11(0.02 \text { to } 0.20) \\
\text { FVC AUC: } \\
\text { MD } 0.12(0.04 \text { to } 0.21)\end{array}$ & $\begin{array}{l}\text { AQLQ: } \\
\text { MD } 0.038 \text { (-0.13 to } \\
0.2) \\
\text { AQLQ responder: } \\
\text { RR } 1.62(1.34 \text { to } \\
1.96)^{c}\end{array}$ & $\begin{array}{l}\text { Rescue medication use: } \\
\text { MD }-0.09 \text { (-0.47 to } 0.29)\end{array}$ \\
\hline
\end{tabular}




\begin{tabular}{|c|c|c|c|c|c|c|}
\hline $\begin{array}{l}\text { Study, } \\
\text { Year, n, } \\
\text { Study } \\
\text { design, } \\
\text { Duration }\end{array}$ & Population $^{a}$ & Exacerbations & Mortality & Asthma control & Quality of life & Healthcare utilization \\
\hline $\begin{array}{l}\text { Kerstjens, } \\
2012^{150} \\
\text { Study } 2 \\
n=453 \text { RCT, } \\
48 w\end{array}$ & $\begin{array}{l}\text { Age: } 12 \mathrm{y}+ \\
\text { Severity /control: } \\
\text { Severe persistent/ } \\
\text { uncontrolled } \\
\text { ICS daily dose: } \\
\text { Medium to high }\end{array}$ & $\begin{array}{l}\text { Systemic corticosteroid: } \\
\text { RR } 0.91 \text { (0.70 to } 1.19) \\
\text { Asthma worsening: } \\
\text { RR } 0.79 \text { (0.67 to } 0.93) \\
\text { Requiring hospitalization: } \\
\text { RR } 1.16 \text { (0.47 to } 2.89)\end{array}$ & $\begin{array}{l}\text { All-cause: } \\
\text { No deaths } \\
\text { occurred }\end{array}$ & $\begin{array}{l}\text { Composite measures: } \\
\text { ACQ-7 score: } \\
\text { MD -0.13 (-0.27 to 0.01) } \\
\text { ACQ-7 responder: } \\
\text { RR 0.78 (0.68 to } 0.88)^{c} \\
\text { ACQ-6 responder: } \\
\text { OR } 1.49 \text { (1.14 to } 1.9)^{c} \\
\text { ACQ-5 responder: } \\
\text { OR } 1.42(1.08 \text { to } 1.86)^{c} \\
\text { Spirometry:: } \\
\text { FEV1 peak: } \\
\text { MD } 0.15(0.08 \text { to } 0.22) \\
\text { FEV1 trough: } \\
\text { MD } 0.09(0.03 \text { to } 0.16) \\
\text { FEV1 AUC: } \\
\text { MD } 0.14(0.07 \text { to } 0.20) \\
\text { FVC peak: } \\
\text { MD } 0.12(0.02 \text { to } 0.21) \\
\text { FVC trough: } \\
\text { MD } 0.07(-0.02 \text { to } 0.16) \\
\text { FVC AUC: } \\
\text { MD } 0.11 \text { (0.02 to 0.20) }\end{array}$ & $\begin{array}{l}\text { AQLQ: } \\
\text { MD 0.14 (-0.03 to } \\
0.31) \\
\text { AQLQ responder: } \\
\text { RR } 1.62(1.34 \text { to } \\
1.96)^{\mathrm{C}}\end{array}$ & $\begin{array}{l}\text { Rescue medication use: } \\
\text { MD }-0.26 \text { (-0.71 to } 0.18)\end{array}$ \\
\hline $\begin{array}{l}\text { Wang, } \\
2015^{151} \\
n=63 \text { RCT, } \\
12 \mathrm{w}\end{array}$ & $\begin{array}{l}\text { Age: } 12 \mathrm{y}+ \\
\text { Severity/ control: } \\
\text { Moderate } \\
\text { persistent/ } \\
\text { uncontrolled } \\
\text { ICS daily dose: } \\
\text { Medium vs. high }\end{array}$ & NR & NR & $\begin{array}{l}\text { Composite measures: } \\
\text { ACT score: } \\
\text { MD -0.61 (-4.82 to 3.6) } \\
\text { Spirometry:: } \\
\text { NR }\end{array}$ & NR & NR \\
\hline
\end{tabular}




\begin{tabular}{|c|c|c|c|c|c|c|}
\hline $\begin{array}{l}\text { Study, } \\
\text { Year, n, } \\
\text { Study } \\
\text { design, } \\
\text { Duration }\end{array}$ & Population $^{\mathrm{a}}$ & Exacerbations & Mortality & Asthma control & Quality of life & Healthcare utilization \\
\hline $\begin{array}{l}\text { Hamelmann, } \\
2016^{152} \\
n=392 \text { RCT, } \\
12 \mathrm{w}\end{array}$ & $\begin{array}{l}\text { Age: } 12 \mathrm{y}+ \\
\text { Severity/control: } \\
\text { Severe persistent/ } \\
\text { uncontrolled }^{\mathrm{b}} \\
\text { ICS daily dose: } \\
\text { Medium to high }\end{array}$ & $\begin{array}{l}\text { Systemic corticosteroid: } \\
\text { RR } 1.58 \text { (0.17 to } 15.00) \\
\text { Asthma worsening: } \\
\text { RR } 0.69 \text { (0.43 to } 1.12)\end{array}$ & $\begin{array}{l}\text { All-cause: } \\
\text { No deaths } \\
\text { occurred }\end{array}$ & $\begin{array}{l}\text { Composite measures: } \\
\text { ACQ-7 score: } \\
\text { MD } 0.05 \text { (-0.11 to } 0.20) \\
\text { ACQ-7 responder: } \\
\text { RR } 0.99 \text { (0.88 to } 1.12) \\
\text { ACQ-6 score: } \\
\text { MD } 0.085 \text { (-0.08 to } 0.25) \\
\text { ACQ-6 responder: } \\
\text { RR } 1.00 \text { (0.88 to } 1.12) \\
\text { Spirometry: } \\
\text { FEV1 peak: } \\
\text { MD } 0.10(-0.01 \text { to } 0.21) \\
\text { FEV1 trough: } \\
\text { MD } 0.08(-0.03 \text { to } 0.20) \\
\text { FEV1 AUC: } \\
\text { MD } 0.10(0.00 \text { to } 0.20) \\
\text { FVC peak: } \\
\text { MD } 0.08(-0.04 \text { to } 0.19) \\
\text { FVC trough: } \\
\text { MD } 0.08(-0.04 \text { to } 0.20) \\
\text { FVC AUC: } \\
\text { MD } 0.07(-0.04 \text { to } 0.18)\end{array}$ & NR & $\begin{array}{l}\text { Rescue medication use: } \\
\text { MD }-0.03(-0.32 \text { to } 0.26)\end{array}$ \\
\hline
\end{tabular}

Abbreviations: ACQ=Asthma Control Questionnaire; ACT=Asthma Control Test; AQLQ=Asthma Quality of Life Questionnaire; AUC=area under the curve; FEV1=forced expiratory volume in one second; FVC=forced vital capacity; EPR=Expert Panel Review (Guidelines for the Diagnosis and Management of Asthma); ICS=inhaled corticosteroid; $\mathrm{MD}=$ mean difference; $\mathrm{n}=$ patient sample size; $\mathrm{NR}=$ not reported; $\mathrm{OR}=$ odds ratio; $\mathrm{PEF}=$ peak expiratory flow; RCT=randomized controlled trial; RR=relative risk; $\mathrm{SABA}=$ shortacting $\beta$-agonist; $w=$ weeks

${ }^{a}$ Age is categorized using study inclusion criteria and the age categories used in EPR-3 of 0-4y, 5-11y and $12 y+$. Severity is as reported per the study. Control was not always explicitly stated thus study criteria were applied to EPR-3 categories of control to determine asthma control status. ICS daily dose is categorized using the study's required ICS dose and the EPR-3 categories of low, medium and high

${ }^{\mathrm{b}}$ Required $\mathrm{ACQ} \geq 1.5$ for enrollment

cOutcome was not reported for study 1 and 2 separately, value reflects data from study 1 and 2 combined

${ }^{\mathrm{d} D a i l y}$ symptoms, daily SABA use, FEV1 \% predicted or PEF $60-80 \%$ 


\section{Appendix D. Risk of Bias Assessment}

Table D-1. Risk of bias assessment for KQ1a

\begin{tabular}{|c|c|c|c|c|c|c|c|c|}
\hline Study, Year & $\begin{array}{l}\text { Sequence } \\
\text { Generation }\end{array}$ & $\begin{array}{l}\text { Allocation } \\
\text { concealment }\end{array}$ & $\begin{array}{l}\text { Blinding of } \\
\text { participants, } \\
\text { personnel }\end{array}$ & $\begin{array}{l}\text { Blinding of } \\
\text { Outcome } \\
\text { assessors }\end{array}$ & $\begin{array}{l}\text { Incomplete } \\
\text { outcome data }\end{array}$ & $\begin{array}{l}\text { Selective } \\
\text { outcome } \\
\text { reporting }\end{array}$ & $\begin{array}{l}\text { Other sources } \\
\text { of bias }\end{array}$ & $\begin{array}{l}\text { Overall risk } \\
\text { of bias }\end{array}$ \\
\hline $\begin{array}{l}\text { Svedmyr, } \\
1999^{48}\end{array}$ & Unclear & Unclear & Unclear & Unclear & High & Unclear & Low & Unclear \\
\hline Ghirga, $2002^{46}$ & Unclear & Unclear & High & High & Low & Unclear & Low & Medium \\
\hline $\begin{array}{l}\text { Bacharier, } \\
2008^{44}\end{array}$ & Low & Low & Low & Low & Low & Unclear & Low & Low \\
\hline $\begin{array}{l}\text { Ducharme, } \\
2009^{45}\end{array}$ & Low & Low & Low & Low & High & Low & Low & Low \\
\hline Papi, $2009^{47}$ & Unclear & Unclear & Low & Low & Low & Low & Low & Low \\
\hline Zeiger, $2011^{49}$ & Low & Low & Low & Low & Low & Low & Low & Low \\
\hline
\end{tabular}


Table D-2. Risk of bias assessment for KQ1b

\begin{tabular}{|c|c|c|c|c|c|c|c|c|}
\hline Study, Year & $\begin{array}{l}\text { Sequence } \\
\text { Generation }\end{array}$ & $\begin{array}{l}\text { Allocation } \\
\text { concealment }\end{array}$ & $\begin{array}{l}\text { Blinding of } \\
\text { participants, } \\
\text { personnel }\end{array}$ & $\begin{array}{l}\text { Blinding of } \\
\text { Outcome } \\
\text { assessors }\end{array}$ & $\begin{array}{l}\text { Incomplete } \\
\text { outcome data }\end{array}$ & $\begin{array}{l}\text { Selective } \\
\text { outcome } \\
\text { reporting }\end{array}$ & $\begin{array}{l}\text { Other sources } \\
\text { of bias }\end{array}$ & $\begin{array}{l}\text { Overall risk } \\
\text { of bias }\end{array}$ \\
\hline $\begin{array}{l}\text { Lahdensuo, } \\
1996^{59}\end{array}$ & Low & Low & Unclear & Unclear & Low & Unclear $^{\mathrm{a}}$ & Low & Medium \\
\hline Foresi, $2000^{48}$ & Unclear & Unclear & Unclear & Unclear & Low & Uncleara $^{\mathrm{a}}$ & Low & Unclear \\
\hline $\begin{array}{l}\text { Colland, } \\
2004^{46}\end{array}$ & Unclear & Unclear & Unclear & Unclear & Low & Uncleara & Low & Unclear \\
\hline $\begin{array}{l}\text { FitzGerald, } \\
2004^{47}\end{array}$ & Low & Unclear & Low & Low & High & Unclear $^{\mathrm{a}}$ & Low & Low \\
\hline $\begin{array}{l}\text { Harrison, } \\
2004^{51}\end{array}$ & Low & Low & Low & Low & Low & Uncleara & Low & Low \\
\hline $\begin{array}{l}\text { Boushey, } \\
2005^{43}\end{array}$ & Low & Unclear & Low & Low & Low & Unclear $^{\mathrm{a}}$ & Low & Low \\
\hline Papi, $2007^{55}$ & Low & Low & Low & Low & Low & Low & Low & Low \\
\hline $\begin{array}{l}\text { Turpeinen, } \\
2007^{56}\end{array}$ & Low & Unclear & Low & Low & Low & Uncleara & Low & Low \\
\hline $\begin{array}{l}\text { Oborne, } \\
2009^{58}\end{array}$ & Low & Low & Low & Low & Low & Low & Low & Low \\
\hline $\begin{array}{l}\text { Martinez, } \\
2011^{52} \\
\end{array}$ & Low & Low & Low & Low & Low & Low $^{b}$ & Low & Low \\
\hline $\begin{array}{l}\text { Calhoun, } \\
2012^{44}\end{array}$ & Unclear & Low & Low & Low & Low & Low & Low & Low \\
\hline
\end{tabular}

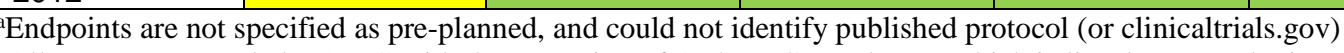

bAll outcomes awarded a "Yes" with the exception of Asthma Control Test, which is listed as an endpoint on clinicaltrials.gov but results on this outcome is not reported (unclear)

Table D-3. Risk of bias assessment for KQ1C, ICS and LABA controller and quick relief vs. ICS controller (same dose)

\begin{tabular}{|l|l|l|l|l|l|l|l|l|}
\hline Study, Year & $\begin{array}{l}\text { Sequence } \\
\text { Generation }\end{array}$ & $\begin{array}{l}\text { Allocation } \\
\text { concealment }\end{array}$ & $\begin{array}{l}\text { Blinding of } \\
\text { participants, } \\
\text { personnel }\end{array}$ & $\begin{array}{l}\text { Blinding of } \\
\text { Outcome } \\
\text { assessors }\end{array}$ & $\begin{array}{l}\text { Incomplete } \\
\text { outcome data }\end{array}$ & $\begin{array}{l}\text { Selective } \\
\text { outcome } \\
\text { reporting }\end{array}$ \\
\hline $\begin{array}{l}\text { Scicchitano, } \\
2004^{88}\end{array}$ & Low & Low & Low & Low & Low & Unclear \\
\hline Rabe, $2006^{86}$ & Unclear & Unclear & Low & Low & Low & Low \\
\hline Sovani, $2008^{91}$ & Low & Low & High & High & High & Low & Unclear \\
\hline
\end{tabular}

aEndpoints are not specified as pre-planned, and could not identify published protocol (or clinicaltrials.gov) 
Table D-4. Risk of bias assessment for KQ1C, ICS and LABA controller and quick relief vs. ICS controller (higher dose)

\begin{tabular}{|l|l|l|l|l|l|l|l|}
\hline Study, Year & $\begin{array}{l}\text { Sequence } \\
\text { Generation }\end{array}$ & $\begin{array}{l}\text { Allocation } \\
\text { concealment }\end{array}$ & $\begin{array}{l}\text { Blinding of } \\
\text { participants, } \\
\text { personnel }\end{array}$ & $\begin{array}{l}\text { Blinding of } \\
\text { Outcome } \\
\text { assessors }\end{array}$ & $\begin{array}{l}\text { Incomplete } \\
\text { outcome data }\end{array}$ & $\begin{array}{l}\text { Selective } \\
\text { outcome } \\
\text { reporting }\end{array}$ & $\begin{array}{l}\text { Other sources } \\
\text { of bias }\end{array}$ \\
\hline $\begin{array}{l}\text { O'Byrne, } \\
2005^{75}\end{array}$ & Low & Unclear & Low & Low & Low & Low & Low \\
\hline
\end{tabular}

Table D-5. Risk of bias assessment for KQ1C, ICS and LABA controller and quick relief vs. ICS and LABA controller (same dose)

\begin{tabular}{|c|c|c|c|c|c|c|c|c|}
\hline Study, Year & $\begin{array}{l}\text { Sequence } \\
\text { Generation }\end{array}$ & $\begin{array}{l}\text { Allocation } \\
\text { concealment }\end{array}$ & $\begin{array}{l}\text { Blinding of } \\
\text { participants, } \\
\text { personnel }\end{array}$ & $\begin{array}{l}\text { Blinding of } \\
\text { Outcome } \\
\text { assessors }\end{array}$ & $\begin{array}{l}\text { Incomplete } \\
\text { outcome data }\end{array}$ & $\begin{array}{l}\text { Selective } \\
\text { outcome } \\
\text { reporting } \\
\end{array}$ & $\begin{array}{l}\text { Other sources } \\
\text { of bias }\end{array}$ & $\begin{array}{l}\text { Overall risk } \\
\text { of bias }\end{array}$ \\
\hline $\begin{array}{l}\text { O'Byrne, } \\
2005^{75}\end{array}$ & Low & Unclear & Low & Low & Low & Low & Low & Low \\
\hline $\begin{array}{l}\text { Vogelmeier, } \\
2005^{96}\end{array}$ & Low & Low & High & High & Low & Unclear $^{\mathrm{a}}$ & Low & Medium $^{b}$ \\
\hline Rabe, $2006^{85}$ & Low & Low & Low & Low & Low & Unclearc & Low & Low \\
\hline $\begin{array}{l}\text { Atienza, } \\
2013^{62}\end{array}$ & Low & Low & Low & Low & Low & Low & Low & Low \\
\hline Papi, $2013^{76}$ & Low & Low & Unclear & Unclear & Low & Low & Low & Low \\
\hline Patel, $2013^{78}$ & Low & Low & High & High & Low & Low & Low & Medium $^{b}$ \\
\hline $\begin{array}{l}\text { Hozawa, } \\
2014^{70}\end{array}$ & Unclear & Unclear & High & High & Low & Unclear $^{\mathrm{c}}$ & Low & Medium \\
\hline $\begin{array}{l}\text { Takeyama, } \\
2014^{93}\end{array}$ & Unclear & Unclear & Unclear & Unclear & Unclear & Unclearc & Low & Unclear \\
\hline $\begin{array}{l}\text { Stallberg, } \\
2008^{92}\end{array}$ & Low & Low & High & High & Low & Low & Low & Medium \\
\hline
\end{tabular}

aAll outcomes were awarded an "unclear" with the exception of exacerbations, which is listed as being determined a priori (yes)

bAll outcomes were awarded "medium” with the exception of death (low)

'Endpoints are not specified as pre-planned, and could not identify published protocol (or clinicaltrials.gov) 
Table D-6. Risk of bias assessment for KQ1C, ICS and LABA controller and quick relief vs. ICS and LABA controller (higher dose)

\begin{tabular}{|c|c|c|c|c|c|c|c|c|}
\hline Study, Year & $\begin{array}{l}\text { Sequence } \\
\text { Generation }\end{array}$ & $\begin{array}{l}\text { Allocation } \\
\text { concealment }\end{array}$ & $\begin{array}{l}\text { Blinding of } \\
\text { participants, } \\
\text { personnel }\end{array}$ & $\begin{array}{l}\text { Blinding of } \\
\text { Outcome } \\
\text { assessors }\end{array}$ & $\begin{array}{l}\text { Incomplete } \\
\text { outcome data }\end{array}$ & $\begin{array}{l}\text { Selective } \\
\text { outcome } \\
\text { reporting }\end{array}$ & $\begin{array}{l}\text { Other sources } \\
\text { of bias }\end{array}$ & $\begin{array}{l}\text { Overall risk } \\
\text { of bias }\end{array}$ \\
\hline $\begin{array}{l}\text { Bousquet, } \\
2007^{68}\end{array}$ & Low & Low & Low & Low & Low & Low & Low & Low \\
\hline Kuna, $2007^{73}$ & Low & Low & Low & Low & Low & Unclear $^{\mathrm{a}}$ & Low & Low \\
\hline Pavord, $2009^{81}$ & Low & Unclear & Low & Low & Low & Low & Low & Low \\
\hline $\begin{array}{l}\text { Lundborg, } \\
2006^{107}\end{array}$ & Low & Unclear & High & High & Low & Unclear $^{a}$ & Low & Medium \\
\hline $\begin{array}{l}\text { Stallberg, } \\
2008^{92}\end{array}$ & Low & Low & High & High & Low & Low & Low & Medium \\
\hline
\end{tabular}

aEndpoints are not specified as pre-planned, and could not identify published protocol (or clinicaltrials.gov)

Table D-7. Risk of bias assessment for KQ1C, ICS and LABA controller and quick relief vs. ICS and LABA controller (lower dose)

\begin{tabular}{|l|l|l|l|l|l|l|l|l|}
\hline Study, Year & $\begin{array}{l}\text { Sequence } \\
\text { Generation }\end{array}$ & $\begin{array}{l}\text { Allocation } \\
\text { concealment }\end{array}$ & $\begin{array}{l}\text { Blinding of } \\
\text { participants, } \\
\text { personnel }\end{array}$ & $\begin{array}{l}\text { Blinding of } \\
\text { Outcome } \\
\text { assessors }\end{array}$ & $\begin{array}{l}\text { Incomplete } \\
\text { outcome data }\end{array}$ & $\begin{array}{l}\text { Selective } \\
\text { outcome } \\
\text { reporting }\end{array}$ & $\begin{array}{l}\text { Other sources } \\
\text { of bias }\end{array}$ & $\begin{array}{l}\text { Overall risk } \\
\text { of bias }\end{array}$ \\
\hline $\begin{array}{l}\text { Hozawa, } \\
2016^{\mathrm{xx}}\end{array}$ & Unclear & Unclear & High & High & Low & Unclear & Low & Medium \\
\hline
\end{tabular}

Endpoints are not specified as pre-planned, and could not identify published protocol (or clinicaltrials.gov)

Table D-8. Risk of bias assessment for KQ1C, ICS and LABA controller and quick relief vs. CBP

\begin{tabular}{|c|c|c|c|c|c|c|c|c|}
\hline Study, Year & $\begin{array}{l}\text { Sequence } \\
\text { Generation }\end{array}$ & $\begin{array}{l}\text { Allocation } \\
\text { concealment }\end{array}$ & $\begin{array}{l}\text { Blinding of } \\
\text { participants, } \\
\text { personnel }\end{array}$ & $\begin{array}{l}\text { Blinding of } \\
\text { Outcome } \\
\text { assessors }\end{array}$ & $\begin{array}{l}\text { Incomplete } \\
\text { outcome data }\end{array}$ & $\begin{array}{l}\text { Selective } \\
\text { outcome } \\
\text { reporting }\end{array}$ & $\begin{array}{l}\text { Other sources } \\
\text { of bias }\end{array}$ & $\begin{array}{l}\text { Overall risk } \\
\text { of bias }\end{array}$ \\
\hline Sears, $2008^{89}$ & Unclear & Unclear & High & High & Low & Low & Low & Medium $^{a}$ \\
\hline $\begin{array}{l}\text { Stallberg, } \\
2008^{92}\end{array}$ & Low & Low & High & High & Low & Low & Low & Medium \\
\hline Louis, $2009^{74}$ & Unclear & Unclear & High & High & Low & Low $^{b}$ & Low & Medium $^{a}$ \\
\hline Quirce, $2011^{83}$ & Unclear & Unclear & High & High & Low & Unclear $^{c}$ & Low & Medium $^{\mathrm{a}}$ \\
\hline $\begin{array}{l}\text { Soes- } \\
\text { Peterson, } \\
2011^{90}\end{array}$ & Unclear & Unclear & High & High & Low & Low & Low & Medium $^{a}$ \\
\hline $\begin{array}{l}\text { Riemersma, } \\
2012^{87}\end{array}$ & Unclear & Unclear & High & High & Low & Low & Low & Medium \\
\hline
\end{tabular}

"All outcomes were awarded "medium” with the exception of death (low) 
bAll outcomes awarded a “yes,” with the exception of the Asthma Control Questionnaire and forced expiratory volume. These were reported but not specified as endpoints on clinicaltrials.gov (unclear)

cThere is inconsistency between original and current secondary outcomes on clinicaltrials.gov (unclear). The primary endpoint is reported consistently across original and current secondary outcomes on clinicaltrials.gov (yes)

Table D-9. Risk of bias assessment for non-randomized studies, KQ1c

\begin{tabular}{|l|l|l|l|l|l|l|l|l|}
\hline $\begin{array}{l}\text { Study, } \\
\text { Year }\end{array}$ & $\begin{array}{l}\text { Representativeness } \\
\text { of exposed cohort }\end{array}$ & $\begin{array}{l}\text { Selection } \\
\text { of non- } \\
\text { exposed } \\
\text { cohort }\end{array}$ & $\begin{array}{l}\text { Ascertainment } \\
\text { of exposure }\end{array}$ & $\begin{array}{l}\text { Outcome of } \\
\text { interest not } \\
\text { present at } \\
\text { start of study }\end{array}$ & $\begin{array}{l}\text { Comparability } \\
\text { of cohorts }\end{array}$ & $\begin{array}{l}\text { Assessment } \\
\text { of outcome } \\
\text { up long } \\
\text { enough } \\
\text { of follow- } \\
\text { up of } \\
\text { cohorts }\end{array}$ & $\begin{array}{l}\text { Follow- } \\
\text { risk of } \\
\text { bias }\end{array}$ \\
\hline $\begin{array}{l}\text { Loh, } \\
2008^{106}\end{array}$ & Low & Low & Low & N/A & High ${ }^{\text {a }}$ & Low & Low \\
\hline $\begin{array}{l}\text { Kardos, } \\
2013^{71}\end{array}$ & Low & Low & Low & N/A & Low ${ }^{b}$ & Medium & Low & Low \\
\hline
\end{tabular}

${ }^{a}$ No information about matching of patient cohorts either for inclusion or analysis

${ }^{\mathrm{b}}$ Cohorts controlled/matched for analysis, but not inclusion

\section{Table D-10. Risk of bias assessment for KQ2a}

\begin{tabular}{|c|c|c|c|c|c|c|c|c|}
\hline Study, Year & $\begin{array}{l}\text { Sequence } \\
\text { Generation }\end{array}$ & $\begin{array}{l}\text { Allocation } \\
\text { concealment }\end{array}$ & $\begin{array}{l}\text { Blinding of } \\
\text { participants, } \\
\text { personnel }\end{array}$ & $\begin{array}{l}\text { Blinding of } \\
\text { Outcome } \\
\text { assessors }\end{array}$ & $\begin{array}{l}\text { Incomplete } \\
\text { outcome data }\end{array}$ & $\begin{array}{l}\text { Selective } \\
\text { outcome } \\
\text { reporting } \\
\end{array}$ & $\begin{array}{l}\text { Other sources } \\
\text { of bias }\end{array}$ & $\begin{array}{l}\text { Overall risk } \\
\text { of bias }\end{array}$ \\
\hline Peters, $2010^{19}$ & Unclear & Unclear & Low & Low & Low & Low & Low & Low \\
\hline $\begin{array}{l}\text { Bateman, } \\
2011^{108}\end{array}$ & Low & Low & Low & Low & Low & Low & Low & Low \\
\hline $\begin{array}{l}\text { Kerstjens, } \\
2015^{109} \\
\text { (Study } 1) \\
\end{array}$ & Low & Low & Low & Low & Low & Low & Low & Low \\
\hline $\begin{array}{l}\text { Kerstjens, } \\
2015^{109} \\
\text { (Study 2) }\end{array}$ & Low & Low & Low & Low & Low & Low & Low & Low \\
\hline Lee, $2015^{110}$ & Low & Low & Unclear & Unclear & Low & Low & Low & Unclear \\
\hline Ohta, $2015^{111}$ & Low & Low & Low & Low & Low & Low $^{a}$ & Low & Low \\
\hline $\begin{array}{l}\text { Hamelmann, } \\
2016^{113}\end{array}$ & Low & Unclear & Low & Low & Low & Low $^{b}$ & Low & Low \\
\hline $\begin{array}{l}\text { Paggiaro, } \\
2016^{112}\end{array}$ & Low & Low & Low & Low & Low & Low & Low & Low \\
\hline
\end{tabular}

${ }^{a}$ Exacerbations were not reported but are an objective in the clinicaltrials.gov protocol (no)

${ }^{b}$ Spirometry is not reported at the end of the treatment period and there is inconsistency on the timing of spirometry assessment on clinicaltrials.gov (unclear) 
Table D-11. Risk of bias assessment for KQ2b

\begin{tabular}{|c|c|c|c|c|c|c|c|c|}
\hline Study, Year & $\begin{array}{l}\text { Sequence } \\
\text { Generation }\end{array}$ & $\begin{array}{l}\text { Allocation } \\
\text { concealment }\end{array}$ & $\begin{array}{l}\text { Blinding of } \\
\text { participants, } \\
\text { personnel }\end{array}$ & $\begin{array}{l}\text { Blinding of } \\
\text { Outcome } \\
\text { assessors }\end{array}$ & $\begin{array}{l}\text { Incomplete } \\
\text { outcome data }\end{array}$ & $\begin{array}{l}\text { Selective } \\
\text { outcome } \\
\text { reporting }\end{array}$ & $\begin{array}{l}\text { Other sources } \\
\text { of bias }\end{array}$ & $\begin{array}{l}\text { Overall risk } \\
\text { of bias }\end{array}$ \\
\hline Peters, $2010^{19}$ & Unclear & Unclear & Low & Low & Low & Low & Low & Low \\
\hline $\begin{array}{l}\text { Bateman, } \\
2011^{108}\end{array}$ & Low & Low & Low & Low & Low & Low & Low & Low \\
\hline $\begin{array}{l}\text { Rajanandh, } \\
2014^{136}\end{array}$ & Low & Low & High & High & High & Unclear $^{a}$ & Low & High \\
\hline $\begin{array}{l}\text { Kerstjens, } \\
2015^{109} \\
\text { (Study 1) }\end{array}$ & Low & Low & Low & Low & Low & Low & Low & Low \\
\hline $\begin{array}{l}\text { Kerstjens, } \\
2015^{109} \\
\text { (Study 2) }\end{array}$ & Low & Low & Low & Low & Low & Low & Low & Low \\
\hline Lee, $2015^{110}$ & Low & Low & Unclear & Unclear & Low & Low & Low & Unclear \\
\hline $\begin{array}{l}\text { Rajanandh, } \\
2015^{137}\end{array}$ & Low & Low & High & High & Low & Unclear $^{b}$ & Low & Medium \\
\hline $\begin{array}{l}\text { Wechsler, } \\
2015^{138}\end{array}$ & Low & Low & High & Low $^{c}$ & Low & Low & Low & Low \\
\hline
\end{tabular}

aEndpoints are not specified as pre-planned, and could not identify published protocol (or clinicaltrials.gov)

bEndpoints are not specified as pre-planned, and could not identify published protocol (or clinicaltrials.gov)

'Blinded adjudication was used for exacerbation, hospitalization and death endpoints (yes). It is unclear if this blinding was present for the remaining outcomes (unclear)

Table D-12. Risk of bias assessment for KQ2c

\begin{tabular}{|c|c|c|c|c|c|c|c|c|}
\hline Study, Year & $\begin{array}{l}\text { Sequence } \\
\text { Generation }\end{array}$ & $\begin{array}{l}\text { Allocation } \\
\text { concealment }\end{array}$ & $\begin{array}{l}\text { Blinding of } \\
\text { participants, } \\
\text { personnel }\end{array}$ & $\begin{array}{l}\text { Blinding of } \\
\text { Outcome } \\
\text { assessors }\end{array}$ & $\begin{array}{l}\text { Incomplete } \\
\text { outcome data }\end{array}$ & $\begin{array}{l}\text { Selective } \\
\text { outcome } \\
\text { reporting }\end{array}$ & $\begin{array}{l}\text { Other sources } \\
\text { of bias }\end{array}$ & $\begin{array}{l}\text { Overall risk } \\
\text { of bias }\end{array}$ \\
\hline $\begin{array}{l}\text { Kerstjens, } \\
2012^{140} \\
\text { (Study } 1 \text { ) }\end{array}$ & Low & Low & Low & Low & Low & Low & Low & Low \\
\hline $\begin{array}{l}\text { Kerstjens, } \\
2012^{140} \\
\text { (Study 2) }\end{array}$ & Low & Low & Low & Low & Low & Low & Low & Low \\
\hline Wang, $2015^{141}$ & Unclear & Unclear & Unclear & Unclear & Low & Unclear $^{a}$ & Low & Unclear \\
\hline $\begin{array}{l}\text { Hamelmann, } \\
2016^{142}\end{array}$ & Low & Low & Low & Low & Low & Low & Low & Low \\
\hline
\end{tabular}

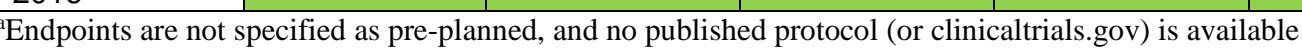




\section{Appendix E. Strength of Evidence Assessments}

Table E-1. Strength of evidence KQ1a, intermittent ICS with as-needed SABA vs. as-needed SABA

\begin{tabular}{|c|c|c|c|c|c|c|c|}
\hline Outcome & $\begin{array}{l}\text { N of studies } \\
\text { ( } \mathrm{n} \text { of patients) }\end{array}$ & $\begin{array}{l}\text { Study } \\
\text { limitations }\end{array}$ & Consistency & Directness & Precision & Publication bias & $\begin{array}{l}\text { Strength of } \\
\text { evidence } \\
\text { (rational) }\end{array}$ \\
\hline \multicolumn{8}{|l|}{ Exacerbations } \\
\hline $\begin{array}{l}\text { Requiring oral } \\
\text { corticosteroid }\end{array}$ & $\begin{array}{l}3 \\
(324)\end{array}$ & Low & Consistent & Direct & Imprecise & Undetected & $\begin{array}{l}\text { Moderate } \\
\text { (imprecise) }\end{array}$ \\
\hline $\begin{array}{l}\text { Requiring } \\
\text { hospitalization }\end{array}$ & 0 & NA & NA & NA & NA & NA & $\begin{array}{l}\text { Insufficient } \\
\text { (no evidence) }\end{array}$ \\
\hline Requiring ER visit & 0 & NA & NA & NA & NA & NA & $\begin{array}{l}\text { Insufficient } \\
\text { (no evidence) }\end{array}$ \\
\hline $\begin{array}{l}\text { Requiring ICU/ } \\
\text { ventilation }\end{array}$ & 0 & NA & NA & NA & NA & NA & $\begin{array}{l}\text { Insufficient } \\
\text { (no evidence) }\end{array}$ \\
\hline $\begin{array}{l}\text { Asthma-related } \\
\text { hospitalization }\end{array}$ & $\begin{array}{l}3 \\
(324)\end{array}$ & Low & Inconsistent & Direct & Imprecise & Undetected & $\begin{array}{l}\text { Low (inconsistent, } \\
\text { imprecise) }\end{array}$ \\
\hline Asthma-related ER visit & 0 & NA & NA & NA & NA & NA & $\begin{array}{l}\text { Insufficient } \\
\text { (no evidence) }\end{array}$ \\
\hline $\begin{array}{l}\text { Asthma-related } \\
\text { outpatient visit }\end{array}$ & 0 & NA & NA & NA & NA & NA & $\begin{array}{l}\text { Insufficient } \\
\text { (no evidence) }\end{array}$ \\
\hline $\begin{array}{l}\text { Asthma-related acute } \\
\text { care visit }\end{array}$ & $\begin{array}{l}3 \\
(324)\end{array}$ & Low & Consistent & Direct & Precise & Undetected & High \\
\hline \multicolumn{8}{|l|}{ Mortality } \\
\hline All-cause & 0 & NA & NA & NA & NA & NA & $\begin{array}{l}\text { Insufficient } \\
\text { (no evidence) }\end{array}$ \\
\hline Asthma-specific & 0 & NA & NA & NA & NA & NA & $\begin{array}{l}\text { Insufficient } \\
\text { (no evidence) }\end{array}$ \\
\hline \multicolumn{8}{|l|}{$\begin{array}{l}\text { Asthma control- } \\
\text { composite measures }\end{array}$} \\
\hline $\mathrm{ACT}$ & 0 & NA & NA & NA & NA & NA & $\begin{array}{l}\text { Insufficient } \\
\text { (no evidence) }\end{array}$ \\
\hline ACQ-7 score & 0 & NA & NA & NA & NA & NA & $\begin{array}{l}\text { Insufficient } \\
\text { (no evidence) }\end{array}$ \\
\hline ACQ-7 responder & 0 & NA & NA & NA & NA & NA & $\begin{array}{l}\text { Insufficient } \\
\text { (no evidence) }\end{array}$ \\
\hline \multicolumn{8}{|l|}{$\begin{array}{l}\text { Asthma control- } \\
\text { spirometry }\end{array}$} \\
\hline FEV1 peak & 0 & NA & NA & NA & NA & NA & $\begin{array}{l}\text { Insufficient } \\
\text { (no evidence) }\end{array}$ \\
\hline
\end{tabular}




\begin{tabular}{|c|c|c|c|c|c|c|c|}
\hline Outcome & $\begin{array}{l}\mathrm{N} \text { of studies } \\
\text { ( } \mathrm{n} \text { of patients) }\end{array}$ & $\begin{array}{l}\text { Study } \\
\text { limitations }\end{array}$ & Consistency & Directness & Precision & Publication bias & $\begin{array}{l}\text { Strength of } \\
\text { evidence } \\
\text { (rational) }\end{array}$ \\
\hline FEV1 trough & 0 & NA & NA & NA & NA & NA & $\begin{array}{l}\text { Insufficient } \\
\text { (no evidence) }\end{array}$ \\
\hline FEV1 AUC & 0 & NA & NA & NA & NA & NA & $\begin{array}{l}\text { Insufficient } \\
\text { (no evidence) }\end{array}$ \\
\hline FEV1 \% predicted & 0 & NA & NA & NA & NA & NA & $\begin{array}{l}\text { Insufficient } \\
\text { (no evidence) }\end{array}$ \\
\hline FVC peak & 0 & NA & NA & NA & NA & NA & $\begin{array}{l}\text { Insufficient } \\
\text { (no evidence) }\end{array}$ \\
\hline FVC trough & 0 & NA & NA & NA & NA & NA & $\begin{array}{l}\text { Insufficient } \\
\text { (no evidence) }\end{array}$ \\
\hline FVC AUC & 0 & NA & NA & NA & NA & NA & $\begin{array}{l}\text { Insufficient } \\
\text { (no evidence) }\end{array}$ \\
\hline FEV1/FVC & 0 & NA & NA & NA & NA & NA & $\begin{array}{l}\text { Insufficient } \\
\text { (no evidence) }\end{array}$ \\
\hline \multicolumn{8}{|l|}{ Quality of life } \\
\hline AQLQ score & 0 & NA & NA & NA & NA & NA & $\begin{array}{l}\text { Insufficient } \\
\text { (no evidence) }\end{array}$ \\
\hline AQLQ responder & 0 & NA & NA & NA & NA & NA & $\begin{array}{l}\text { Insufficient } \\
\text { (no evidence) }\end{array}$ \\
\hline PACQLQ score & $\begin{array}{l}2 \\
(270)\end{array}$ & Low & $\begin{array}{l}\text { Unknown } \\
\text { consistency } \\
\text { (single study) }\end{array}$ & Direct & Imprecise & Undetected & $\begin{array}{l}\text { Low (unknown } \\
\text { consistency, } \\
\text { imprecise) }\end{array}$ \\
\hline \multicolumn{8}{|l|}{ Healthcare utilization } \\
\hline $\begin{array}{l}\text { Daytime rescue } \\
\text { medication use, mean } \\
\text { puffs/day }\end{array}$ & $\begin{array}{l}1 \\
(166)\end{array}$ & Low & $\begin{array}{l}\text { Unknown } \\
\text { consistency } \\
\text { (single study) } \\
\end{array}$ & Direct & Precise & Undetected & Low \\
\hline $\begin{array}{l}\text { Nighttime rescue } \\
\text { medication use, mean } \\
\text { puffs/night }\end{array}$ & $\begin{array}{l}1 \\
(166)\end{array}$ & Low & $\begin{array}{l}\text { Unknown } \\
\text { consistency } \\
\text { (single study) }\end{array}$ & Direct & Precise & Undetected & Low \\
\hline Resource use & 0 & NA & NA & NA & NA & NA & $\begin{array}{l}\text { Insufficient } \\
\text { (no evidence) }\end{array}$ \\
\hline
\end{tabular}

Abbreviations: ACQ=Asthma Control Questionnaire; ACT=Asthma Control Test; AQLQ=Asthma Quality of Life Questionnaire; AUC=area under the curve; ER=emergency room; FVC=forced vital capacity; FEV1=forced expiratory volume in one second; ICU=intensive care unit; $n=$ patient sample size; N=number of studies; NA=not applicable;

PACQLQ=Pediatric Asthma Caregiver’s Quality of Life Questionnaire 
Table E-2. Strength of evidence KQ1a, intermittent ICS with as-needed SABA vs. ICS controller with as-needed SABA

\begin{tabular}{|c|c|c|c|c|c|c|c|}
\hline Outcome & $\begin{array}{l}\mathrm{N} \text { of studies } \\
\text { ( } \mathrm{n} \text { of patients) }\end{array}$ & $\begin{array}{l}\text { Study } \\
\text { limitations }\end{array}$ & Consistency & Directness & Precision & Publication bias & $\begin{array}{l}\text { Strength of } \\
\text { evidence } \\
\text { (rationale) }\end{array}$ \\
\hline \multicolumn{8}{|l|}{ Exacerbations } \\
\hline $\begin{array}{l}\text { Requiring oral } \\
\text { corticosteroid }\end{array}$ & $\begin{array}{l}1 \\
(278)\end{array}$ & Low & $\begin{array}{l}\text { Unknown } \\
\text { consistency } \\
\text { (single study) }\end{array}$ & Direct & Precise & Undetected & $\begin{array}{l}\text { Low (unknown } \\
\text { consistency) }\end{array}$ \\
\hline $\begin{array}{l}\text { Requiring } \\
\text { hospitalization }\end{array}$ & 0 & NA & NA & NA & NA & NA & $\begin{array}{l}\text { Insufficient } \\
\text { (no evidence) }\end{array}$ \\
\hline Requiring ER visit & 0 & NA & NA & NA & NA & NA & $\begin{array}{l}\text { Insufficient } \\
\text { (no evidence) }\end{array}$ \\
\hline $\begin{array}{l}\text { Requiring ICU/ } \\
\text { ventilation }\end{array}$ & 0 & NA & NA & NA & NA & NA & $\begin{array}{l}\text { Insufficient } \\
\text { (no evidence) }\end{array}$ \\
\hline $\begin{array}{l}\text { Asthma-related } \\
\text { hospitalization }\end{array}$ & $\begin{array}{l}1 \\
(278)\end{array}$ & Low & $\begin{array}{l}\text { Unknown } \\
\text { consistency } \\
\text { (single study) }\end{array}$ & Direct & Imprecise & Undetected & $\begin{array}{l}\text { Low (unknown } \\
\text { consistency, } \\
\text { imprecise) }\end{array}$ \\
\hline Asthma-related ER visit & 0 & NA & NA & NA & NA & NA & $\begin{array}{l}\text { Insufficient } \\
\text { (no evidence) }\end{array}$ \\
\hline $\begin{array}{l}\text { Asthma-related } \\
\text { outpatient visit }\end{array}$ & 0 & NA & NA & NA & NA & NA & $\begin{array}{l}\text { Insufficient } \\
\text { (no evidence) }\end{array}$ \\
\hline $\begin{array}{l}\text { Asthma-related acute } \\
\text { care visits }\end{array}$ & 0 & NA & NA & NA & NA & NA & $\begin{array}{l}\text { Insufficient } \\
\text { (no evidence) }\end{array}$ \\
\hline \multicolumn{8}{|l|}{ Mortality } \\
\hline All-cause & 0 & NA & NA & NA & NA & NA & $\begin{array}{l}\text { Insufficient } \\
\text { (no evidence) }\end{array}$ \\
\hline Asthma-specific & 0 & NA & NA & NA & NA & NA & $\begin{array}{l}\text { Insufficient } \\
\text { (no evidence) }\end{array}$ \\
\hline \multicolumn{8}{|l|}{$\begin{array}{l}\text { Asthma control- } \\
\text { composite measures }\end{array}$} \\
\hline ACT & 0 & NA & NA & NA & NA & NA & $\begin{array}{l}\text { Insufficient } \\
\text { (no evidence) }\end{array}$ \\
\hline ACQ-7 score & 0 & NA & NA & NA & NA & NA & $\begin{array}{l}\text { Insufficient } \\
\text { (no evidence) }\end{array}$ \\
\hline ACQ-7 responder & 0 & NA & NA & NA & NA & NA & $\begin{array}{l}\text { Insufficient } \\
\text { (no evidence) }\end{array}$ \\
\hline \multicolumn{8}{|l|}{$\begin{array}{l}\text { Asthma control- } \\
\text { spirometry }\end{array}$} \\
\hline FEV1 peak & 0 & NA & NA & NA & NA & NA & $\begin{array}{l}\text { Insufficient } \\
\text { (no evidence) }\end{array}$ \\
\hline FEV1 trough & 0 & NA & NA & NA & NA & NA & $\begin{array}{l}\text { Insufficient } \\
\text { (no evidence) }\end{array}$ \\
\hline
\end{tabular}




\begin{tabular}{|c|c|c|c|c|c|c|c|}
\hline Outcome & $\begin{array}{l}\mathrm{N} \text { of studies } \\
\text { ( } \mathrm{n} \text { of patients) }\end{array}$ & $\begin{array}{l}\text { Study } \\
\text { limitations }\end{array}$ & Consistency & Directness & Precision & Publication bias & $\begin{array}{l}\text { Strength of } \\
\text { evidence } \\
\text { (rationale) }\end{array}$ \\
\hline FEV1 AUC & 0 & NA & NA & NA & NA & NA & $\begin{array}{l}\text { Insufficient } \\
\text { (no evidence) }\end{array}$ \\
\hline FEV1 \% predicted & 0 & NA & NA & NA & NA & NA & $\begin{array}{l}\text { Insufficient } \\
\text { (no evidence) }\end{array}$ \\
\hline FVC peak & 0 & NA & NA & NA & NA & NA & $\begin{array}{l}\text { Insufficient } \\
\text { (no evidence) }\end{array}$ \\
\hline FVC trough & 0 & NA & NA & NA & $\mathrm{NA}$ & $\mathrm{NA}$ & $\begin{array}{l}\text { Insufficient } \\
\text { (no evidence) }\end{array}$ \\
\hline FVC AUC & 0 & NA & NA & NA & NA & NA & $\begin{array}{l}\text { Insufficient } \\
\text { (no evidence) }\end{array}$ \\
\hline FEV1/FVC & 0 & NA & NA & NA & NA & NA & $\begin{array}{l}\text { Insufficient } \\
\text { (no evidence) }\end{array}$ \\
\hline \multicolumn{8}{|l|}{ Quality of life } \\
\hline AQLQ score & 0 & NA & NA & $\mathrm{NA}$ & NA & NA & $\begin{array}{l}\text { Insufficient } \\
\text { (no evidence) }\end{array}$ \\
\hline AQLQ responder & 0 & NA & NA & NA & NA & NA & $\begin{array}{l}\text { Insufficient } \\
\text { (no evidence) }\end{array}$ \\
\hline PACQLQ score & 0 & NA & NA & $\mathrm{NA}$ & $\mathrm{NA}$ & $\mathrm{NA}$ & $\begin{array}{l}\text { Insufficient } \\
\text { (no evidence) }\end{array}$ \\
\hline \multicolumn{8}{|l|}{ Healthcare utilization } \\
\hline $\begin{array}{l}\text { Daytime rescue } \\
\text { medication use, mean } \\
\text { puffs/day }\end{array}$ & $\begin{array}{l}1 \\
(220)\end{array}$ & Low & $\begin{array}{l}\text { Unknown } \\
\text { consistency } \\
\text { (single study) }\end{array}$ & Direct & Imprecise & Undetected & $\begin{array}{l}\text { Low } \\
\text { (unknown } \\
\text { consistency, } \\
\text { imprecise) }\end{array}$ \\
\hline $\begin{array}{l}\text { Nighttime rescue } \\
\text { medication use, mean } \\
\text { puffs/night }\end{array}$ & $\begin{array}{l}1 \\
(220)\end{array}$ & Low & $\begin{array}{l}\text { Unknown } \\
\text { consistency } \\
\text { (single study) }\end{array}$ & Direct & Imprecise & Undetected & $\begin{array}{l}\text { Low } \\
\text { (unknown } \\
\text { consistency, } \\
\text { imprecise) }\end{array}$ \\
\hline Resource use & 0 & NA & NA & NA & $\mathrm{NA}$ & NA & $\begin{array}{l}\text { Insufficient } \\
\text { (no evidence) }\end{array}$ \\
\hline
\end{tabular}

Abbreviations: ACQ=Asthma Control Questionnaire; ACT=Asthma Control Test; AQLQ=Asthma Quality of Life Questionnaire; AUC=area under the curve; ER=emergency room; FVC=forced vital capacity; FEV1=forced expiratory volume in one second; ICU=intensive care unit; $n=$ patient sample size; N=number of studies; NA=not applicable; PACQLQ=Pediatric Asthma Caregiver's Quality of Life Questionnaire 
Table E-3. Strength of evidence KQ1a, intermittent ICS vs. no therapy

\begin{tabular}{|c|c|c|c|c|c|c|c|}
\hline Outcome & $\begin{array}{l}\mathrm{N} \text { of studies } \\
\text { ( } \mathrm{n} \text { of patients) }\end{array}$ & $\begin{array}{l}\text { Study } \\
\text { limitations }\end{array}$ & Consistency & Directness & Precision & Publication bias & $\begin{array}{l}\text { Strength of } \\
\text { evidence }\end{array}$ \\
\hline \multicolumn{8}{|l|}{ Exacerbations } \\
\hline $\begin{array}{l}\text { Requiring systemic } \\
\text { corticosteroid }\end{array}$ & $\begin{array}{l}1 \\
(26)\end{array}$ & Low & $\begin{array}{l}\text { Unknown } \\
\text { consistency } \\
\text { (single study) }\end{array}$ & Direct & Imprecise & Undetected & Insufficient \\
\hline $\begin{array}{l}\text { Requiring } \\
\text { hospitalization }\end{array}$ & 0 & NA & NA & NA & NA & NA & $\begin{array}{l}\text { Insufficient } \\
\text { (no evidence) }\end{array}$ \\
\hline Requiring ED visit & 0 & NA & NA & NA & NA & NA & $\begin{array}{l}\text { Insufficient } \\
\text { (no evidence) }\end{array}$ \\
\hline $\begin{array}{l}\text { Requiring ICU/ } \\
\text { ventilation }\end{array}$ & 0 & NA & NA & NA & NA & NA & $\begin{array}{l}\text { Insufficient } \\
\text { (no evidence) }\end{array}$ \\
\hline $\begin{array}{l}\text { Asthma-related } \\
\text { hospitalization }\end{array}$ & $\begin{array}{l}1 \\
(26)\end{array}$ & Low & $\begin{array}{l}\text { Unknown } \\
\text { consistency } \\
\text { (single study) }\end{array}$ & Direct & Imprecise & Undetected & Insufficient \\
\hline Asthma-related ER visit & $\begin{array}{l}1 \\
(26)\end{array}$ & Low & $\begin{array}{l}\text { Unknown } \\
\text { consistency } \\
\text { (single study) }\end{array}$ & Direct & Imprecise & Undetected & Insufficient \\
\hline $\begin{array}{l}\text { Asthma-related } \\
\text { outpatient visit }\end{array}$ & 0 & NA & NA & NA & NA & NA & $\begin{array}{l}\text { Insufficient } \\
\text { (no evidence) }\end{array}$ \\
\hline $\begin{array}{l}\text { Asthma-related acute } \\
\text { care visits }\end{array}$ & 0 & NA & NA & NA & NA & NA & $\begin{array}{l}\text { Insufficient } \\
\text { (no evidence) }\end{array}$ \\
\hline \multicolumn{8}{|l|}{ Mortality } \\
\hline All-cause & 0 & NA & NA & NA & NA & NA & $\begin{array}{l}\text { Insufficient } \\
\text { (no evidence) }\end{array}$ \\
\hline Asthma-specific & 0 & NA & NA & NA & NA & NA & $\begin{array}{l}\text { Insufficient } \\
\text { (no evidence) }\end{array}$ \\
\hline \multicolumn{8}{|l|}{$\begin{array}{l}\text { Asthma control- } \\
\text { composite measures }\end{array}$} \\
\hline $\mathrm{ACT}$ & 0 & NA & NA & NA & NA & NA & $\begin{array}{l}\text { Insufficient } \\
\text { (no evidence) }\end{array}$ \\
\hline ACQ-7 score & 0 & NA & NA & NA & NA & NA & $\begin{array}{l}\text { Insufficient } \\
\text { (no evidence) }\end{array}$ \\
\hline ACQ-7 responder & 0 & NA & NA & NA & NA & NA & $\begin{array}{l}\text { Insufficient } \\
\text { (no evidence) }\end{array}$ \\
\hline \multicolumn{8}{|l|}{$\begin{array}{l}\text { Asthma control- } \\
\text { spirometry }\end{array}$} \\
\hline FEV1 peak & 0 & NA & NA & NA & NA & NA & $\begin{array}{l}\text { Insufficient } \\
\text { (no evidence) }\end{array}$ \\
\hline FEV1 trough & 0 & NA & NA & NA & NA & NA & $\begin{array}{l}\text { Insufficient } \\
\text { (no evidence) }\end{array}$ \\
\hline
\end{tabular}




\begin{tabular}{|c|c|c|c|c|c|c|c|}
\hline Outcome & $\begin{array}{l}\mathrm{N} \text { of studies } \\
\text { ( } \mathrm{n} \text { of patients) }\end{array}$ & $\begin{array}{l}\text { Study } \\
\text { limitations }\end{array}$ & Consistency & Directness & Precision & Publication bias & $\begin{array}{l}\text { Strength of } \\
\text { evidence }\end{array}$ \\
\hline FEV1 AUC & 0 & NA & NA & NA & NA & NA & $\begin{array}{l}\text { Insufficient } \\
\text { (no evidence) }\end{array}$ \\
\hline FEV1 \% predicted & 0 & NA & NA & NA & NA & NA & $\begin{array}{l}\text { Insufficient } \\
\text { (no evidence) }\end{array}$ \\
\hline FVC peak & 0 & NA & NA & NA & NA & NA & $\begin{array}{l}\text { Insufficient } \\
\text { (no evidence) }\end{array}$ \\
\hline FVC trough & 0 & NA & NA & NA & NA & NA & $\begin{array}{l}\text { Insufficient } \\
\text { (no evidence) }\end{array}$ \\
\hline FVC AUC & 0 & NA & NA & NA & NA & NA & $\begin{array}{l}\text { Insufficient } \\
\text { (no evidence) }\end{array}$ \\
\hline FEV1/FVC & 0 & NA & NA & NA & NA & NA & $\begin{array}{l}\text { Insufficient } \\
\text { (no evidence) }\end{array}$ \\
\hline \multicolumn{8}{|l|}{ Quality of life } \\
\hline AQLQ score & 0 & NA & NA & NA & NA & NA & $\begin{array}{l}\text { Insufficient } \\
\text { (no evidence) }\end{array}$ \\
\hline AQLQ responder & 0 & NA & NA & NA & NA & NA & $\begin{array}{l}\text { Insufficient } \\
\text { (no evidence) }\end{array}$ \\
\hline PACQLQ score & 0 & NA & NA & NA & NA & NA & $\begin{array}{l}\text { Insufficient } \\
\text { (no evidence) }\end{array}$ \\
\hline \multicolumn{8}{|l|}{ Healthcare utilization } \\
\hline $\begin{array}{l}\text { Daytime rescue } \\
\text { medication use, mean } \\
\text { puffs/day }\end{array}$ & 0 & NA & NA & NA & NA & NA & $\begin{array}{l}\text { Insufficient } \\
\text { (no evidence) }\end{array}$ \\
\hline $\begin{array}{l}\text { Nighttime rescue } \\
\text { medication use, mean } \\
\text { puffs/night }\end{array}$ & 0 & NA & NA & NA & NA & NA & $\begin{array}{l}\text { Insufficient } \\
\text { (no evidence) }\end{array}$ \\
\hline Resource use & 0 & NA & NA & NA & NA & NA & $\begin{array}{l}\text { Insufficient } \\
\text { (no evidence) }\end{array}$ \\
\hline
\end{tabular}

Abbreviations: ACQ=Asthma Control Questionnaire; ACT=Asthma Control Test; AQLQ=Asthma Quality of Life Questionnaire; AUC=area under the curve; ER=emergency room; FVC=forced vital capacity; FEV1=forced expiratory volume in one second; ICU=intensive care unit; $n=$ patient sample size; $N=$ number of studies; $N A=$ not applicable; PACQLQ=Pediatric Asthma Caregiver’s Quality of Life Questionnaire; 
Table E-4. Strength of evidence KQ1b, intermittent ICS and ICS controller vs. ICS controller

\begin{tabular}{|c|c|c|c|c|c|c|c|}
\hline Outcome & $\begin{array}{l}\mathrm{N} \text { of studies } \\
\text { ( } \mathrm{n} \text { of } \\
\text { patients) }\end{array}$ & Study limitations & Consistency & Directness & Precision & Publication bias & $\begin{array}{l}\text { Strength of } \\
\text { evidence }\end{array}$ \\
\hline \multicolumn{8}{|l|}{ Exacerbations $\geq 12 y$} \\
\hline $\begin{array}{l}\text { Requiring oral } \\
\text { corticosteroid (full } \\
\text { population) }\end{array}$ & $\begin{array}{l}3 \\
(908)\end{array}$ & Low & Inconsistent & Direct & Imprecise & Undetected & $\begin{array}{l}\text { Low } \\
\text { (inconsistent, } \\
\text { imprecise) }\end{array}$ \\
\hline $\begin{array}{l}\text { Requiring oral } \\
\text { corticosteroid (of those } \\
\text { that started study } \\
\text { inhaler) }\end{array}$ & $\begin{array}{l}3 \\
(399)\end{array}$ & Low & Inconsistent & Direct & Imprecise & Undetected & $\begin{array}{l}\text { Low } \\
\text { (inconsistent, } \\
\text { imprecise) }\end{array}$ \\
\hline $\begin{array}{l}\text { Requiring } \\
\text { hospitalization }\end{array}$ & 0 & NA & NA & NA & NA & NA & $\begin{array}{l}\text { Insufficient } \\
\text { (no evidence) }\end{array}$ \\
\hline Requiring ER visit & 0 & NA & NA & NA & NA & NA & $\begin{array}{l}\text { Insufficient } \\
\text { (no evidence) }\end{array}$ \\
\hline $\begin{array}{l}\text { Requiring ICU/ } \\
\text { ventilation }\end{array}$ & 0 & NA & NA & NA & $\mathrm{NA}$ & $\mathrm{NA}$ & $\begin{array}{l}\text { Insufficient } \\
\text { (no evidence) }\end{array}$ \\
\hline $\begin{array}{l}\text { Requiring oral } \\
\text { corticosteroid, } \\
\text { unscheduled doctor } \\
\text { visit, ER, or unstable } \\
\text { asthma }\end{array}$ & $\begin{array}{l}1 \\
(98)\end{array}$ & Low & $\begin{array}{l}\text { Unknown (single } \\
\text { study) }\end{array}$ & Direct & Imprecise & Undetected & $\begin{array}{l}\text { Low } \\
\text { (unknown } \\
\text { consistency, } \\
\text { imprecise) }\end{array}$ \\
\hline $\begin{array}{l}\text { Asthma-related } \\
\text { hospitalization }\end{array}$ & $\begin{array}{l}1 \\
(115)\end{array}$ & Medium & $\begin{array}{l}\text { Unknown (single } \\
\text { study) }\end{array}$ & Direct & Imprecise & Undetected & $\begin{array}{l}\text { Insufficient } \\
\text { (risk of bias, } \\
\text { unknonw } \\
\text { consistency, } \\
\text { imprecise) }\end{array}$ \\
\hline $\begin{array}{l}\text { Asthma-related ER } \\
\text { visits }\end{array}$ & 0 & NA & NA & NA & NA & NA & $\begin{array}{l}\text { Insufficient } \\
\text { (no evidence) }\end{array}$ \\
\hline $\begin{array}{l}\text { Asthma-related } \\
\text { outpatient visit }\end{array}$ & $\begin{array}{l}2 \\
(505)\end{array}$ & Low & Inconsistent & Direct & Imprecise & Undetected & $\begin{array}{l}\text { Low } \\
\text { (inconsistent, } \\
\text { imprecise) }\end{array}$ \\
\hline $\begin{array}{l}\text { Asthma-related acute } \\
\text { care visit }\end{array}$ & 0 & NA & NA & NA & NA & NA & $\begin{array}{l}\text { Insufficient } \\
\text { (no evidence) }\end{array}$ \\
\hline Unstable asthma $^{\mathrm{a}}$ & $\begin{array}{l}1 \\
(98)\end{array}$ & Low & $\begin{array}{l}\text { Unknown (single } \\
\text { study) }\end{array}$ & Direct & Imprecise & Undetected & $\begin{array}{l}\text { Low } \\
\text { (unknown } \\
\text { consistency, } \\
\text { imprecise) }\end{array}$ \\
\hline $\begin{array}{l}2 \text { or } 3 \text { exacerbations } \\
\text { requiring oral } \\
\text { corticosteroid (full } \\
\text { population) }\end{array}$ & $\begin{array}{l}1 \\
(403)\end{array}$ & Low & $\begin{array}{l}\text { Unknown (single } \\
\text { study) }\end{array}$ & Direct & Imprecise & Undetected & $\begin{array}{l}\text { Low } \\
\text { (unknown } \\
\text { consistency, } \\
\text { imprecise) }\end{array}$ \\
\hline
\end{tabular}




\begin{tabular}{|c|c|c|c|c|c|c|c|}
\hline Outcome & $\begin{array}{l}\mathbf{N} \text { of studies } \\
\text { ( } \mathrm{n} \text { of } \\
\text { patients) }\end{array}$ & Study limitations & Consistency & Directness & Precision & Publication bias & $\begin{array}{l}\text { Strength of } \\
\text { evidence }\end{array}$ \\
\hline $\begin{array}{l}2 \text { or } 3 \text { exacerbations } \\
\text { requiring oral } \\
\text { corticosteroid (of those } \\
\text { starting the study } \\
\text { inhaler) }\end{array}$ & $\begin{array}{l}1 \\
(403)\end{array}$ & Low & $\begin{array}{l}\text { Unknown (single } \\
\text { study) }\end{array}$ & Direct & Imprecise & Undetected & $\begin{array}{l}\text { Low } \\
\text { (unknown } \\
\text { consistency, } \\
\text { imprecise) }\end{array}$ \\
\hline $\begin{array}{l}\text { Fall in PEF }<70 \% \text { from } \\
\text { baseline }\end{array}$ & $1(134)$ & Unclear & $\begin{array}{l}\text { Unknown (single } \\
\text { study) }\end{array}$ & Direct & Imprecise & Undeteced & $\begin{array}{l}\text { Low } \\
\text { (unknown } \\
\text { consistency, } \\
\text { imprecise) } \\
\end{array}$ \\
\hline \multicolumn{8}{|l|}{$\begin{array}{l}\text { Exacerbations } 4 \text { to } \\
11 y\end{array}$} \\
\hline $\begin{array}{l}\text { Requiring oral } \\
\text { corticosteroid }\end{array}$ & $\begin{array}{l}1 \\
(143)\end{array}$ & Low & $\begin{array}{l}\text { Unknown (single } \\
\text { study) }\end{array}$ & Indirect & Imprecise & Undetected & $\begin{array}{l}\text { Insufficient } \\
\text { (unknonw } \\
\text { consistency, } \\
\text { indirect) } \\
\end{array}$ \\
\hline $\begin{array}{l}\text { Requiring } \\
\text { hospitalization }\end{array}$ & $\begin{array}{l}1 \\
(29)\end{array}$ & Unclear & $\begin{array}{l}\text { Unknown (single } \\
\text { study) }\end{array}$ & Direct & Imprecise & Undetected & $\begin{array}{l}\text { Insufficient } \\
\text { (unknonw } \\
\text { consistency, } \\
\text { imprecise) } \\
\end{array}$ \\
\hline $\begin{array}{l}\text { Asthma-related } \\
\text { hospitalization }\end{array}$ & 0 & NA & NA & NA & NA & NA & $\begin{array}{l}\text { Insufficient } \\
\text { (no evidence) }\end{array}$ \\
\hline Asthma-related ER visit & 0 & NA & NA & NA & NA & NA & $\begin{array}{l}\text { Insufficient } \\
\text { (no evidence) }\end{array}$ \\
\hline $\begin{array}{l}\text { Asthma-related } \\
\text { hospitalization or ER } \\
\text { visit }\end{array}$ & 0 & NA & NA & NA & NA & NA & $\begin{array}{l}\text { Insufficient } \\
\text { (no evidence) }\end{array}$ \\
\hline $\begin{array}{l}\text { Asthma-related } \\
\text { outpatient visit }\end{array}$ & 0 & NA & NA & NA & NA & NA & $\begin{array}{l}\text { Insufficient } \\
\text { (no evidence) }\end{array}$ \\
\hline Treatment failure $^{b}$ & $\begin{array}{l}1 \\
(143)\end{array}$ & Low & $\begin{array}{l}\text { Unknown (single } \\
\text { study) }\end{array}$ & Indirect & Imprecise & Undetected & $\begin{array}{l}\text { Insufficient } \\
\text { (unknonw } \\
\text { consistency, } \\
\text { indirect, } \\
\text { imprecise) } \\
\end{array}$ \\
\hline \multicolumn{8}{|l|}{ Mortality } \\
\hline All-cause & 0 & NA & NA & NA & NA & NA & $\begin{array}{l}\text { Insufficient } \\
\text { (no evidence) }\end{array}$ \\
\hline Asthma-specific & 0 & NA & NA & NA & NA & NA & $\begin{array}{l}\text { Insufficient } \\
\text { (no evidence) }\end{array}$ \\
\hline
\end{tabular}




\begin{tabular}{|c|c|c|c|c|c|c|c|}
\hline Outcome & $\begin{array}{l}\mathbf{N} \text { of studies } \\
\text { ( } \mathrm{n} \text { of } \\
\text { patients) }\end{array}$ & Study limitations & Consistency & Directness & Precision & Publication bias & $\begin{array}{l}\text { Strength of } \\
\text { evidence }\end{array}$ \\
\hline ACT & 0 & NA & NA & NA & NA & NA & $\begin{array}{l}\text { Insufficient } \\
\text { (no evidence) }\end{array}$ \\
\hline ACQ-7 score & 0 & NA & NA & NA & NA & NA & $\begin{array}{l}\text { Insufficient } \\
\text { (no evidence) }\end{array}$ \\
\hline ACQ-7 responder & 0 & NA & NA & NA & NA & NA & $\begin{array}{l}\text { Insufficient } \\
\text { (no evidence) }\end{array}$ \\
\hline \multicolumn{8}{|l|}{$\begin{array}{l}\text { Asthma control- } \\
\text { spirometry } \geq 12 y\end{array}$} \\
\hline FEV1 peak & 0 & NA & NA & NA & NA & NA & $\begin{array}{l}\text { Insufficient } \\
\text { (no evidence) }\end{array}$ \\
\hline FEV1 trough & 0 & NA & NA & NA & NA & NA & $\begin{array}{l}\text { Insufficient } \\
\text { (no evidence) }\end{array}$ \\
\hline FEV1 AUC & 0 & NA & NA & NA & NA & NA & $\begin{array}{l}\text { Insufficient } \\
\text { (no evidence) }\end{array}$ \\
\hline FEV1 \% predicted & 0 & NA & NA & NA & NA & NA & $\begin{array}{l}\text { Insufficient } \\
\text { (no evidence) }\end{array}$ \\
\hline FVC peak & 0 & NA & NA & NA & NA & NA & $\begin{array}{l}\text { Insufficient } \\
\text { (no evidence) }\end{array}$ \\
\hline FVC trough & 0 & NA & NA & NA & NA & NA & $\begin{array}{l}\text { Insufficient } \\
\text { (no evidence) }\end{array}$ \\
\hline FVC AUC & 0 & NA & NA & NA & NA & NA & $\begin{array}{l}\text { Insufficient } \\
\text { (no evidence) }\end{array}$ \\
\hline FEV1/FVC & 0 & NA & NA & NA & NA & NA & $\begin{array}{l}\text { Insufficient } \\
\text { (no evidence) }\end{array}$ \\
\hline \multicolumn{8}{|l|}{$\begin{array}{l}\text { Asthma control- } \\
\text { spirometry } 4 \text { to } 11 y\end{array}$} \\
\hline FEV1 \% predicted & $\begin{array}{l}1 \\
(29)\end{array}$ & Unclear & $\begin{array}{l}\text { Unknown (single } \\
\text { study) }\end{array}$ & Direct & Imprecise & Undetected & $\begin{array}{l}\text { Insufficient } \\
\text { (Unclear ROB, } \\
\text { unknown } \\
\text { consistency, } \\
\text { imprecise) }\end{array}$ \\
\hline \multicolumn{8}{|l|}{ Quality of life $\geq 12 y$} \\
\hline AQLQ score & 0 & NA & NA & NA & NA & NA & $\begin{array}{l}\text { Insufficient } \\
\text { (no evidence) }\end{array}$ \\
\hline AQLQ responder & 0 & NA & NA & NA & NA & NA & $\begin{array}{l}\text { Insufficient } \\
\text { (no evidence) }\end{array}$ \\
\hline PACQLQ score & 0 & NA & NA & NA & NA & NA & $\begin{array}{l}\text { Insufficient } \\
\text { (no evidence) }\end{array}$ \\
\hline
\end{tabular}




\begin{tabular}{|c|c|c|c|c|c|c|c|}
\hline Outcome & $\begin{array}{l}\text { N of studies } \\
\text { ( } \mathrm{n} \text { of } \\
\text { patients) }\end{array}$ & Study limitations & Consistency & Directness & Precision & Publication bias & $\begin{array}{l}\text { Strength of } \\
\text { evidence }\end{array}$ \\
\hline PAQLQ score & $\begin{array}{l}1 \\
(143)\end{array}$ & Low & $\begin{array}{l}\text { Unknown (single } \\
\text { study) }\end{array}$ & Indirect & Precise & Undetected & $\begin{array}{l}\text { Low } \\
\text { (unknown } \\
\text { consistency, } \\
\text { indirect) } \\
\end{array}$ \\
\hline \multicolumn{8}{|l|}{$\begin{array}{l}\text { Healthcare utilization } \\
\geq 12 y\end{array}$} \\
\hline $\begin{array}{l}\text { Daytime rescue } \\
\text { medication use mean } \\
\text { puffs /day }\end{array}$ & 0 & NA & NA & NA & NA & NA & $\begin{array}{l}\text { Insufficient } \\
\text { (no evidence) }\end{array}$ \\
\hline $\begin{array}{l}\text { Nighttime rescue } \\
\text { medication use mean } \\
\text { puffs /night }\end{array}$ & 0 & NA & NA & NA & NA & NA & $\begin{array}{l}\text { Insufficient } \\
\text { (no evidence) }\end{array}$ \\
\hline Resource use & 0 & NA & NA & NA & NA & NA & $\begin{array}{l}\text { Insufficient } \\
\text { (no evidence) }\end{array}$ \\
\hline \multicolumn{8}{|l|}{$\begin{array}{l}\text { Healthcare utilization } \\
4 \text { to } 11 y\end{array}$} \\
\hline Albuterol puffs/ day & $\begin{array}{l}1 \\
(143)\end{array}$ & Low & $\begin{array}{l}\text { Unknown (single } \\
\text { study) }\end{array}$ & Indirect & Imprecise & Undetected & $\begin{array}{l}\text { Insufficient } \\
\text { (unknonw } \\
\text { consistency, } \\
\text { indirect, } \\
\text { imprecise) }\end{array}$ \\
\hline
\end{tabular}

Abbreviations: ACQ=Asthma Control Questionnaire; ACT=Asthma Control Test; AQLQ=Asthma Quality of Life Questionnaire; AUC=area under the curve; ER=emergency room; FVC=forced vital capacity; FEV1=forced expiratory volume in one second; ICU=intensive care unit; $n=$ patient sample size; N=number of studies; NA=not applicable; PACQLQ=Pediatric Asthma Caregiver’s Quality of Life Questionnaire; PAQLQ=Pediatric Asthma Quality of Life Questionnaire; y=years

${ }^{a}$ Defined as absence of stability, where stability was defined as morning peak expiratory flow $90 \%$ or more of mean baseline value on either of the two previous days, <4

inhalations of inhaled corticosteroid per day over the past 2 days, no nocturnal awakenings in the prior 2 nights and a total symptom score not exceeding mean baseline value more than 2 ordinal values over the previous 2 days

bDefined as any of following: (1) Hospitalization due to asthma; (2) Hypoxic seizure due to asthma; (3) Intubation due to asthma; (4) Requirement for a second burst of prednisone within any 6 months period; (5) Significant adverse event related to the use of a study medication. The only criterion for assignment of treatment failure during the trial was the requirement for a second burst of prednisone within any 6 month period 
Table E-4. Strength of evidence KQ1b, intermittent ICS vs. ICS controller

\begin{tabular}{|c|c|c|c|c|c|c|c|}
\hline Outcome & $\begin{array}{l}\mathrm{N} \text { of studies } \\
\text { ( } \mathrm{n} \text { of patients) }\end{array}$ & $\begin{array}{l}\text { Study } \\
\text { limitations }\end{array}$ & Consistency & Directness & Precision & Publication bias & $\begin{array}{l}\text { Strength of } \\
\text { evidence }\end{array}$ \\
\hline \multicolumn{8}{|l|}{ Exacerbations $\geq 12 y$} \\
\hline $\begin{array}{l}\text { Requiring oral } \\
\text { corticosteroid }\end{array}$ & $\begin{array}{l}1 \\
(149)\end{array}$ & Low & $\begin{array}{l}\text { Unknown } \\
\text { (single study) }\end{array}$ & Direct & Imprecise & Undetected & $\begin{array}{l}\text { Low } \\
\text { (unknown } \\
\text { consistency, } \\
\text { imprecise) }\end{array}$ \\
\hline $\begin{array}{l}\text { Requiring } \\
\text { hospitalization }\end{array}$ & $\begin{array}{l}1 \\
(149)\end{array}$ & Low & $\begin{array}{l}\text { Unknown } \\
\text { (single study) }\end{array}$ & Direct & Precise & Undetected & $\begin{array}{l}\text { Insufficient } \\
\text { (no events occurred) }\end{array}$ \\
\hline Requiring ER visit & 0 & NA & NA & NA & NA & NA & $\begin{array}{l}\text { Insufficient } \\
\text { (no evidence) }\end{array}$ \\
\hline $\begin{array}{l}\text { Requiring ICU/ } \\
\text { ventilation }\end{array}$ & 0 & NA & NA & NA & NA & NA & $\begin{array}{l}\text { Insufficient } \\
\text { (no evidence) }\end{array}$ \\
\hline $\begin{array}{l}\text { Asthma-related } \\
\text { hospitalization }\end{array}$ & 0 & NA & NA & NA & NA & NA & $\begin{array}{l}\text { Insufficient } \\
\text { (no evidence) }\end{array}$ \\
\hline Asthma-related ER visit & 0 & NA & NA & NA & NA & NA & $\begin{array}{l}\text { Insufficient } \\
\text { (no evidence) }\end{array}$ \\
\hline $\begin{array}{l}\text { Asthma-related } \\
\text { outpatient visit }\end{array}$ & 0 & NA & NA & NA & NA & NA & $\begin{array}{l}\text { Insufficient } \\
\text { (no evidence) }\end{array}$ \\
\hline $\begin{array}{l}\text { Asthma-related urgent } \\
\text { care visit }\end{array}$ & $\begin{array}{l}1 \\
(227)\end{array}$ & Low & $\begin{array}{l}\text { Unknown } \\
\text { (single study) }\end{array}$ & Direct & Imprecise & Undetected & $\begin{array}{l}\text { Low } \\
\text { (unknown } \\
\text { consistency, } \\
\text { imprecise) }\end{array}$ \\
\hline $\begin{array}{l}\text { Mild }^{\mathrm{c}} \text { or severe } \\
\text { exacerbation }\end{array}$ & $\begin{array}{l}1 \\
(228)\end{array}$ & Low & $\begin{array}{l}\text { Unknown } \\
\text { (single study) }\end{array}$ & Direct & Imprecise & Undetected & $\begin{array}{l}\text { Low } \\
\text { (unknown } \\
\text { consistency, } \\
\text { imprecise) }\end{array}$ \\
\hline Severe exacerbation $^{d}$ & $\begin{array}{l}1 \\
(228)\end{array}$ & Low & $\begin{array}{l}\text { Unknown } \\
\text { (single study) }\end{array}$ & Direct & Imprecise & Undetected & $\begin{array}{l}\text { Low } \\
\text { (unknown } \\
\text { consistency, } \\
\text { imprecise) }\end{array}$ \\
\hline \multicolumn{8}{|l|}{$\begin{array}{l}\text { Exacerbations } 4 \text { to } \\
11 y\end{array}$} \\
\hline $\begin{array}{l}\text { Requiring oral } \\
\text { corticosteroid }\end{array}$ & $\begin{array}{l}1 \\
(143)\end{array}$ & Low & $\begin{array}{l}\text { Unknown } \\
\text { (single study) }\end{array}$ & Indirect & Imprecise & Undetected & $\begin{array}{l}\text { Insufficient } \\
\text { (unknown } \\
\text { consistency, indirect, } \\
\text { imprecise) }\end{array}$ \\
\hline Treatment failure $^{a}$ & $\begin{array}{l}1 \\
(143)\end{array}$ & Low & $\begin{array}{l}\text { Unknown } \\
\text { (single study) }\end{array}$ & Indirect & Imprecise & Undetected & $\begin{array}{l}\text { Insufficient } \\
\text { (unknown } \\
\text { consistency, indirect, } \\
\text { imprecise) }\end{array}$ \\
\hline
\end{tabular}




\begin{tabular}{|c|c|c|c|c|c|c|c|}
\hline Outcome & $\begin{array}{l}\mathrm{N} \text { of studies } \\
\text { ( } \mathrm{n} \text { of patients) }\end{array}$ & $\begin{array}{l}\text { Study } \\
\text { limitations }\end{array}$ & Consistency & Directness & Precision & Publication bias & $\begin{array}{l}\text { Strength of } \\
\text { evidence }\end{array}$ \\
\hline All-cause mortality & 0 & NA & NA & NA & NA & NA & $\begin{array}{l}\text { Insufficient } \\
\text { (no evidence) }\end{array}$ \\
\hline Asthma-specific death & 0 & NA & NA & NA & NA & NA & $\begin{array}{l}\text { Insufficient } \\
\text { (no evidence) }\end{array}$ \\
\hline \multicolumn{8}{|l|}{$\begin{array}{l}\text { Asthma control- } \\
\text { composite measures }\end{array}$} \\
\hline ACT & 0 & NA & NA & NA & NA & NA & $\begin{array}{l}\text { Insufficient } \\
\text { (no evidence) }\end{array}$ \\
\hline ACQ-7 score & $\begin{array}{l}1 \\
(149)\end{array}$ & Low & $\begin{array}{l}\text { Unknown } \\
\text { (single study) }\end{array}$ & Direct & Precise & Undetected & $\begin{array}{l}\text { Low } \\
\text { (unknown } \\
\text { consistency) }\end{array}$ \\
\hline ACQ-7 responder & 0 & NA & NA & $\mathrm{NA}$ & NA & NA & $\begin{array}{l}\text { Insufficient } \\
\text { (no evidence) }\end{array}$ \\
\hline ACQ-5 score & $\begin{array}{l}1 \\
(227)\end{array}$ & Low & $\begin{array}{l}\text { Unknown } \\
\text { (single study) }\end{array}$ & Direct & Precise & Undetected & $\begin{array}{l}\text { Low } \\
\text { (unknown } \\
\text { consistency) }\end{array}$ \\
\hline ACQ-5 responder & 0 & NA & NA & NA & NA & NA & $\begin{array}{l}\text { Insufficient } \\
\text { (no evidence) }\end{array}$ \\
\hline \multicolumn{8}{|l|}{$\begin{array}{l}\text { Asthma control- } \\
\text { spirometry } \geq 12 y\end{array}$} \\
\hline FEV1 peak & 0 & NA & NA & NA & NA & NA & $\begin{array}{l}\text { Insufficient } \\
\text { (no evidence) }\end{array}$ \\
\hline FEV1 trough & $\begin{array}{l}2 \\
(564)\end{array}$ & Low & Consistent & Direct & Precise & Undetected & High \\
\hline FEV1 AUC & 0 & NA & NA & NA & NA & NA & $\begin{array}{l}\text { Insufficient } \\
\text { (no evidence) }\end{array}$ \\
\hline FEV1 \% predicted & $\begin{array}{l}3 \\
(713)\end{array}$ & Low & Consistent & Direct & Imprecise & Undetected & $\begin{array}{l}\text { Moderate } \\
\text { (imprecise) }\end{array}$ \\
\hline FVC peak & 0 & NA & NA & NA & NA & NA & $\begin{array}{l}\text { Insufficient } \\
\text { (no evidence) }\end{array}$ \\
\hline FVC trough & $\begin{array}{l}1 \\
(228)\end{array}$ & Low & $\begin{array}{l}\text { Unknown } \\
\text { (single study) }\end{array}$ & Direct & Precise & Undetected & $\begin{array}{l}\text { Low } \\
\text { (unknonw } \\
\text { consistency) }\end{array}$ \\
\hline FVC AUC & 0 & NA & NA & NA & NA & NA & $\begin{array}{l}\text { Insufficient } \\
\text { (no evidence) }\end{array}$ \\
\hline FEV1/FVC & 0 & NA & NA & NA & NA & NA & $\begin{array}{l}\text { Insufficient } \\
\text { (no evidence) }\end{array}$ \\
\hline FVC \% predicted & $\begin{array}{l}1 \\
(228)\end{array}$ & Low & $\begin{array}{l}\text { Unknown } \\
\text { (single study) }\end{array}$ & Direct & Imprecise & Undetected & $\begin{array}{l}\text { Low } \\
\text { (unknown } \\
\text { consistenct, } \\
\text { imprecsie) }\end{array}$ \\
\hline
\end{tabular}




\begin{tabular}{|c|c|c|c|c|c|c|c|}
\hline Outcome & $\begin{array}{l}N \text { of studies } \\
\text { ( } n \text { of patients) }\end{array}$ & $\begin{array}{l}\text { Study } \\
\text { limitations }\end{array}$ & Consistency & Directness & Precision & Publication bias & $\begin{array}{l}\text { Strength of } \\
\text { evidence }\end{array}$ \\
\hline \multicolumn{8}{|l|}{$\begin{array}{l}\text { Asthma control- } \\
\text { spirometry } 4 \text { to } 11 y\end{array}$} \\
\hline FEV1 \% predicted & $\begin{array}{l}1 \\
(143)\end{array}$ & Low & $\begin{array}{l}\text { Unknown } \\
\text { (single study) }\end{array}$ & Indirect & Imprecise & Undetected & $\begin{array}{l}\text { Insufficient } \\
\text { (unknown } \\
\text { consistency, indirect, } \\
\text { imprecise) }\end{array}$ \\
\hline \multicolumn{8}{|l|}{ Quality of life $\geq 12 y$} \\
\hline AQLQ score & $\begin{array}{l}2 \\
(376) \\
\end{array}$ & Low & Inconsistent & Direct & Precise & Undetected & $\begin{array}{l}\text { Moderate } \\
\text { (inconsistent) }\end{array}$ \\
\hline AQLQ responder & 0 & NA & NA & NA & NA & NA & $\begin{array}{l}\text { Insufficient } \\
\text { (no evidence) }\end{array}$ \\
\hline PACQLQ score & 0 & NA & NA & NA & NA & NA & $\begin{array}{l}\text { Insufficient } \\
\text { (no evidence) }\end{array}$ \\
\hline \multicolumn{8}{|c|}{ Quality of life 4 to $11 y$} \\
\hline PAQLQ score & $\begin{array}{l}1 \\
(143)\end{array}$ & Low & $\begin{array}{l}\text { Unknown } \\
\text { (single study) }\end{array}$ & Indirect & Precise & Undetected & $\begin{array}{l}\text { Low } \\
\text { (unknown } \\
\text { consistency, } \\
\text { indirect) }\end{array}$ \\
\hline \multicolumn{8}{|c|}{$\begin{array}{l}\text { Healthcare utilization } \\
\geq 12 y\end{array}$} \\
\hline Albuterol puffs/day & $\begin{array}{l}2 \\
(564)\end{array}$ & Low & Consistent & Direct & Imprecise & Undetected & $\begin{array}{l}\text { Moderate } \\
\text { (imprecise) }\end{array}$ \\
\hline Resource use & 0 & NA & NA & NA & NA & NA & $\begin{array}{l}\text { Insufficient } \\
\text { (no evidence) }\end{array}$ \\
\hline \multicolumn{8}{|c|}{$\begin{array}{l}\text { Healthcare utilization } \\
4 \text { to } 11 y\end{array}$} \\
\hline Albuterol puffs/day & $\begin{array}{l}1 \\
(143)\end{array}$ & Low & $\begin{array}{l}\text { Unknown } \\
\text { (single study) }\end{array}$ & Indirect & Precise & Undetected & Low \\
\hline
\end{tabular}

Abbreviations: ACQ=Asthma Control Questionnaire; ACT=Asthma Control Test; AQLQ=Asthma Quality of Life Questionnaire; AUC=area under the curve; ER=emergency room; FVC=forced vital capacity; FEV1=forced expiratory volume in one second; ICU=intensive care unit; $n=$ patient sample size; N=number of studies; NA=not applicable; PACQLQ=Pediatric Asthma Caregiver's Quality of Life Questionnaire; PAQLQ=Pediatric Asthma Quality of Life Questionnaire; y=years

a Defined as any of following: (1) Hospitalization due to asthma; (2) Hypoxic seizure due to asthma; (3) Intubation due to asthma; (4) Requirement for a second burst of prednisone within any 6 months period; (5) Significant adverse event related to the use of a study medication. The only criterion for assignment of treatment failure during the trial was the requirement for a second burst of prednisone within any 6 month period

'Defined as awakening at night owing to asthma or as a decrease in the morning peak expiratory flow rate to more than $20 \%$ below the baseline value, the use of more than three additional puffs per day of rescue medication (either albuterol or beclomethasone and albuterol) as compared with during the baseline for 2 or more consecutive days, or both. Single, isolated days on which mild exacerbation occurred were not counted

${ }^{\mathrm{d}}$ Defined as a decrease in the morning peak expiratory flow rate to more than $30 \%$ below the baseline value on 2 consecutive days or more than 8 puffs per day of rescue medication for 3 consecutive days or the need for treatment with oral corticosteroids, as judged by the investigator 
Table E-5. Strength of evidence KQ1c, ICS and LABA controller and quick relief vs. ICS controller (same dose)

\begin{tabular}{|c|c|c|c|c|c|c|c|}
\hline Outcome & $\begin{array}{l}\mathrm{N} \text { of studies } \\
\text { ( } \mathrm{n} \text { of patients) }\end{array}$ & Risk of bias & Consistency & Directness & Precision & Publication bias & $\begin{array}{l}\text { Strength of } \\
\text { evidence }\end{array}$ \\
\hline \multicolumn{8}{|l|}{ Exacerbations } \\
\hline $\begin{array}{l}\text { Requiring systemic } \\
\text { corticosteroid }\end{array}$ & 0 & NA & NA & NA & NA & NA & $\begin{array}{l}\text { Insufficient } \\
\text { (no evidence) }\end{array}$ \\
\hline $\begin{array}{l}\text { Requiring } \\
\text { hospitalization }\end{array}$ & 0 & NA & NA & NA & NA & NA & $\begin{array}{l}\text { Insufficient } \\
\text { (no evidence) }\end{array}$ \\
\hline Requiring ER visit & 0 & NA & NA & NA & NA & NA & $\begin{array}{l}\text { Insufficient } \\
\text { (no evidence) }\end{array}$ \\
\hline $\begin{array}{l}\text { Requiring ICU/ } \\
\text { ventilation }\end{array}$ & 0 & NA & NA & NA & NA & NA & $\begin{array}{l}\text { Insufficient } \\
\text { (no evidence) }\end{array}$ \\
\hline $\begin{array}{l}\text { Asthma-related } \\
\text { hospitalization }\end{array}$ & 0 & NA & NA & NA & NA & NA & $\begin{array}{l}\text { Insufficient } \\
\text { (no evidence) }\end{array}$ \\
\hline Asthma-related ER visit & 0 & NA & NA & NA & NA & NA & $\begin{array}{l}\text { Insufficient } \\
\text { (no evidence) }\end{array}$ \\
\hline $\begin{array}{l}\text { Asthma-related } \\
\text { hospitalization or ER } \\
\text { visit }\end{array}$ & 0 & NA & NA & NA & NA & NA & $\begin{array}{l}\text { Insufficient } \\
\text { (no evidence) }\end{array}$ \\
\hline $\begin{array}{l}\text { Asthma-related } \\
\text { outpatient visit }\end{array}$ & 0 & NA & NA & NA & NA & NA & $\begin{array}{l}\text { Insufficient } \\
\text { (no evidence) }\end{array}$ \\
\hline $\begin{array}{l}\text { Requiring systemic } \\
\text { corticosteroid, } \\
\text { hospitalization, or ER } \\
\text { visit }\end{array}$ & $\begin{array}{l}1 \\
(1890)\end{array}$ & Low & $\begin{array}{l}\text { Unknown } \\
\text { (single study) }\end{array}$ & Direct & Precise & Undetected & $\begin{array}{l}\text { Moderate } \\
\text { (unknown } \\
\text { consistency) }\end{array}$ \\
\hline $\begin{array}{l}\text { Requiring systemic } \\
\text { corticosteroid, } \\
\text { hospitalization, ER visit, } \\
\text { or PEF }<70 \%\end{array}$ & $\begin{array}{l}2 \\
(2586)\end{array}$ & Low & Consistent & Direct & Imprecise & Undetected & $\begin{array}{l}\text { Moderate } \\
\text { (imprecise) }\end{array}$ \\
\hline \multicolumn{8}{|l|}{ Mortality } \\
\hline All-cause & $\begin{array}{l}1 \\
(1890)\end{array}$ & Low & $\begin{array}{l}\text { Unknown } \\
\text { (single study) }\end{array}$ & Direct & Imprecise & Undetected & $\begin{array}{l}\text { Insufficient } \\
\text { (unknown } \\
\text { consistency, } \\
\text { imprecise) }\end{array}$ \\
\hline Asthma-specific & $\begin{array}{l}1 \\
(1890)\end{array}$ & Low & Consistent & Direct & Precise & Undetected & $\begin{array}{l}\text { Insufficient } \\
\text { (no events } \\
\text { occurred) }\end{array}$ \\
\hline \multicolumn{8}{|l|}{$\begin{array}{l}\text { Asthma control- } \\
\text { composite measures }\end{array}$} \\
\hline ACT & 0 & NA & NA & NA & NA & NA & $\begin{array}{l}\text { Insufficient } \\
\text { (no evidence) }\end{array}$ \\
\hline ACQ-5 score & 0 & NA & NA & NA & NA & NA & $\begin{array}{l}\text { Insufficient } \\
\text { (no evidence) }\end{array}$ \\
\hline
\end{tabular}




\begin{tabular}{|c|c|c|c|c|c|c|c|}
\hline Outcome & $\begin{array}{l}\mathrm{N} \text { of studies } \\
\text { ( } \mathrm{n} \text { of patients) }\end{array}$ & Risk of bias & Consistency & Directness & Precision & Publication bias & $\begin{array}{l}\text { Strength of } \\
\text { evidence }\end{array}$ \\
\hline ACQ-5 responder & 0 & NA & NA & NA & NA & NA & $\begin{array}{l}\text { Insufficient } \\
\text { (no evidence) }\end{array}$ \\
\hline \multicolumn{8}{|l|}{$\begin{array}{l}\text { Asthma control- } \\
\text { spirometry }\end{array}$} \\
\hline FEV1 & $\begin{array}{l}1 \\
(1890)\end{array}$ & Low & $\begin{array}{l}\text { Unknown } \\
\text { (single study) }\end{array}$ & Direct & Precise & Undetected & $\begin{array}{l}\text { Moderate } \\
\text { (unknown } \\
\text { consistency) }\end{array}$ \\
\hline FEV1 \% predicted & 0 & NA & NA & NA & $\mathrm{NA}$ & NA & $\begin{array}{l}\text { Insufficient } \\
\text { (no evidence) }\end{array}$ \\
\hline FVC & 0 & NA & NA & NA & NA & NA & $\begin{array}{l}\text { Insufficient } \\
\text { (no evidence) }\end{array}$ \\
\hline FEV1/ FVC & 0 & NA & NA & NA & NA & NA & $\begin{array}{l}\text { Insufficient } \\
\text { (no evidence) }\end{array}$ \\
\hline \multicolumn{8}{|l|}{ Quality of Life } \\
\hline AQLQ score & 0 & NA & NA & NA & NA & NA & $\begin{array}{l}\text { Insufficient } \\
\text { (no evidence) }\end{array}$ \\
\hline AQLQ responder & 0 & NA & NA & NA & NA & NA & $\begin{array}{l}\text { Insufficient } \\
\text { (no evidence) }\end{array}$ \\
\hline \multicolumn{8}{|l|}{ Healthcare Utilization } \\
\hline $\begin{array}{l}\text { Mean PRN inhalations/ } \\
\text { day }\end{array}$ & $\begin{array}{l}1 \\
(697)\end{array}$ & Low & $\begin{array}{l}\text { Unknown } \\
\text { (single study) }\end{array}$ & Direct & Imprecise & Undetected & $\begin{array}{l}\text { Low } \\
\text { (unknown } \\
\text { consistency, } \\
\text { imprecise) }\end{array}$ \\
\hline $\begin{array}{l}\text { Mean PRN inhalations/ } \\
\text { week }\end{array}$ & 0 & NA & NA & NA & NA & NA & $\begin{array}{l}\text { Insufficient } \\
\text { (no evidence) }\end{array}$ \\
\hline Resource use & 0 & NA & NA & NA & NA & NA & $\begin{array}{l}\text { Insufficient } \\
\text { (no evidence) }\end{array}$ \\
\hline
\end{tabular}

Abbreviations: ACQ=Asthma Control Questionnaire; ACT=Asthma Control Test; AQLQ=Asthma Quality of Life Questionnaire; ER=emergency room; FVC=forced vital capacity; FEV1=forced expiratory volume in one second; ICU=intensive care unit; $n=$ patient sample size; N=number of studies; NA=not applicable; PRN=pro re nata (i.e., asneeded 
Table E-6. Strength of evidence KQ1c, ICS and LABA controller and quick relief vs. ICS controller (higher dose)

\begin{tabular}{|c|c|c|c|c|c|c|c|}
\hline Outcome & $\begin{array}{l}\mathrm{N} \text { of studies } \\
\text { ( } \mathrm{n} \text { of patients) }\end{array}$ & Risk of bias & Consistency & Directness & Precision & Publication bias & $\begin{array}{l}\text { Strength of } \\
\text { evidence }\end{array}$ \\
\hline \multicolumn{8}{|l|}{ Exacerbations $\geq 12$ years } \\
\hline $\begin{array}{l}\text { Requiring systemic } \\
\text { corticosteroid }\end{array}$ & 0 & NA & NA & NA & NA & NA & $\begin{array}{l}\text { Insufficient } \\
\text { (no evidence) }\end{array}$ \\
\hline Requiring hospitalization & 0 & NA & NA & NA & NA & NA & $\begin{array}{l}\text { Insufficient } \\
\text { (no evidence) }\end{array}$ \\
\hline Requiring ED visit & 0 & NA & NA & NA & NA & NA & $\begin{array}{l}\text { Insufficient } \\
\text { (no evidence) }\end{array}$ \\
\hline Requiring ICU/ ventilation & 0 & NA & NA & NA & NA & NA & $\begin{array}{l}\text { Insufficient } \\
\text { (no evidence) }\end{array}$ \\
\hline $\begin{array}{l}\text { Requiring systemic } \\
\text { corticosteroid, } \\
\text { hospitalization, ER visit, or } \\
\text { PEF< } 70 \% \text { (increase in ICS } \\
\text { or other medication as well } \\
\text { for } 4 \text { to } 11 \text { year olds) }\end{array}$ & $\begin{array}{l}1 \\
(1851)\end{array}$ & Low & $\begin{array}{l}\text { Unknown } \\
\text { (single study) }\end{array}$ & Indirect & Precise & Undetected & $\begin{array}{l}\text { Low } \\
\text { (unknown } \\
\text { consistency, } \\
\text { indirect) }\end{array}$ \\
\hline $\begin{array}{l}\text { Requiring systemic } \\
\text { corticosteroids, } \\
\text { hospitalization, or ER visit } \\
\text { (increase in ICS or other } \\
\text { medication as well for } 4 \text { to } \\
11 \text { year olds) }\end{array}$ & $\begin{array}{l}1 \\
(1851)\end{array}$ & Low & $\begin{array}{l}\text { Unknown } \\
\text { (single study) }\end{array}$ & Indirect & Precise & Undetected & $\begin{array}{l}\text { Low } \\
\text { (unknown } \\
\text { consistency, } \\
\text { indirect) }\end{array}$ \\
\hline $\begin{array}{l}\text { Asthma-related } \\
\text { hospitalization }\end{array}$ & 0 & NA & NA & NA & NA & NA & $\begin{array}{l}\text { Insufficient } \\
\text { (no evidence) }\end{array}$ \\
\hline Asthma-related ER visit & 0 & NA & NA & NA & NA & NA & $\begin{array}{l}\text { Insufficient } \\
\text { (no evidence) }\end{array}$ \\
\hline $\begin{array}{l}\text { Asthma-related } \\
\text { hospitalization or ER visit }\end{array}$ & 0 & NA & NA & NA & NA & NA & $\begin{array}{l}\text { Insufficient } \\
\text { (no evidence) }\end{array}$ \\
\hline $\begin{array}{l}\text { Asthma-related outpatient } \\
\text { visit }\end{array}$ & 0 & NA & NA & NA & NA & NA & $\begin{array}{l}\text { Insufficient } \\
\text { (no evidence) }\end{array}$ \\
\hline \multicolumn{8}{|l|}{$\begin{array}{l}\text { Exacerbations } 4 \text { to } 11 \\
\text { years }\end{array}$} \\
\hline $\begin{array}{l}\text { Requiring systemic } \\
\text { corticosteroid, } \\
\text { hospitalization, ER visit, } \\
\text { increase in ICS or other } \\
\text { medication, or PEF < }>70 \%\end{array}$ & $\begin{array}{l}1 \\
(224)\end{array}$ & Low & $\begin{array}{l}\text { Unknown } \\
\text { (single study) }\end{array}$ & Indirect & Imprecise & Undetected & $\begin{array}{l}\text { Low } \\
\text { (unknown } \\
\text { consistency, } \\
\text { indirect) }\end{array}$ \\
\hline $\begin{array}{l}\text { Requiring systemic } \\
\text { corticosteroid, } \\
\text { hospitalization, or ER visit }\end{array}$ & $\begin{array}{l}1 \\
(224)\end{array}$ & Low & $\begin{array}{l}\text { Unknown } \\
\text { (single study) }\end{array}$ & Indirect & Imprecise & Undetected & $\begin{array}{l}\text { Low } \\
\text { (unknown } \\
\text { consistency, } \\
\text { indirect) }\end{array}$ \\
\hline
\end{tabular}




\begin{tabular}{|c|c|c|c|c|c|c|c|}
\hline Outcome & $\begin{array}{l}\mathrm{N} \text { of studies } \\
\text { ( } \mathrm{n} \text { of patients) }\end{array}$ & Risk of bias & Consistency & Directness & Precision & Publication bias & $\begin{array}{l}\text { Strength of } \\
\text { evidence }\end{array}$ \\
\hline $\begin{array}{l}\text { Asthma-related } \\
\text { hospitalization }\end{array}$ & 0 & NA & NA & NA & NA & NA & $\begin{array}{l}\text { Insufficient } \\
\text { (no evidence) }\end{array}$ \\
\hline Asthma-related ER visit & 0 & NA & NA & NA & NA & NA & $\begin{array}{l}\text { Insufficient } \\
\text { (no evidence) }\end{array}$ \\
\hline $\begin{array}{l}\text { Asthma-related } \\
\text { hospitalization or ER visit }\end{array}$ & 0 & NA & NA & NA & NA & NA & $\begin{array}{l}\text { Insufficient } \\
\text { (no evidence) }\end{array}$ \\
\hline $\begin{array}{l}\text { Asthma-related outpatient } \\
\text { visit }\end{array}$ & 0 & NA & NA & NA & NA & NA & $\begin{array}{l}\text { Insufficient } \\
\text { (no evidence) }\end{array}$ \\
\hline Mild exacerbation & $\begin{array}{l}1 \\
(224)\end{array}$ & Low & $\begin{array}{l}\text { Unknown } \\
\text { (single study) }\end{array}$ & Indirect & Precise & Undetected & $\begin{array}{l}\text { Low } \\
\text { (unknown } \\
\text { consistency, } \\
\text { indirect) }\end{array}$ \\
\hline \multicolumn{8}{|l|}{ Mortality } \\
\hline All-cause & 0 & NA & NA & NA & NA & NA & $\begin{array}{l}\text { Insufficient } \\
\text { (no evidence) }\end{array}$ \\
\hline Asthma-specific & 0 & NA & NA & NA & NA & NA & $\begin{array}{l}\text { Insufficient } \\
\text { (no evidence) }\end{array}$ \\
\hline \multicolumn{8}{|l|}{$\begin{array}{l}\text { Asthma control- } \\
\text { composite measures }\end{array}$} \\
\hline ACT & 0 & NA & NA & NA & NA & NA & $\begin{array}{l}\text { Insufficient } \\
\text { (no evidence) }\end{array}$ \\
\hline ACQ-5 score & 0 & NA & NA & NA & NA & NA & $\begin{array}{l}\text { Insufficient } \\
\text { (no evidence) }\end{array}$ \\
\hline ACQ-5 responder & 0 & NA & NA & NA & NA & NA & $\begin{array}{l}\text { Insufficient } \\
\text { (no evidence) }\end{array}$ \\
\hline \multicolumn{8}{|l|}{$\begin{array}{l}\text { Asthma control- } \\
\text { spirometry }\end{array}$} \\
\hline FEV1 & 0 & NA & NA & NA & NA & NA & $\begin{array}{l}\text { Insufficient } \\
\text { (no evidence) }\end{array}$ \\
\hline FEV1 \% predicted & 0 & NA & NA & NA & NA & NA & $\begin{array}{l}\text { Insufficient } \\
\text { (no evidence) }\end{array}$ \\
\hline FVC & 0 & NA & NA & NA & NA & NA & $\begin{array}{l}\text { Insufficient } \\
\text { (no evidence) }\end{array}$ \\
\hline FEV1/ FVC & 0 & NA & NA & NA & NA & NA & $\begin{array}{l}\text { Insufficient } \\
\text { (no evidence) }\end{array}$ \\
\hline \multicolumn{8}{|l|}{ Quality of Life } \\
\hline AQLQ score & 0 & NA & NA & NA & NA & NA & $\begin{array}{l}\text { Insufficient } \\
\text { (no evidence) }\end{array}$ \\
\hline AQLQ responder & 0 & NA & NA & NA & NA & NA & $\begin{array}{l}\text { Insufficient } \\
\text { (no evidence) }\end{array}$ \\
\hline
\end{tabular}




\begin{tabular}{|c|c|c|c|c|c|c|c|}
\hline Outcome & $\begin{array}{l}\mathrm{N} \text { of studies } \\
\text { ( } \mathrm{n} \text { of patients) }\end{array}$ & Risk of bias & Consistency & Directness & Precision & Publication bias & $\begin{array}{l}\text { Strength of } \\
\text { evidence }\end{array}$ \\
\hline Mean PRN inhalations/ day & 0 & NA & NA & NA & NA & NA & $\begin{array}{l}\text { Insufficient } \\
\text { (no evidence) }\end{array}$ \\
\hline $\begin{array}{l}\text { Mean PRN inhalations/ } \\
\text { week }\end{array}$ & 0 & NA & NA & $\mathrm{NA}$ & $\mathrm{NA}$ & $\mathrm{NA}$ & $\begin{array}{l}\text { Insufficient } \\
\text { (no evidence) }\end{array}$ \\
\hline Resource use & 0 & NA & NA & NA & NA & NA & $\begin{array}{l}\text { Insufficient } \\
\text { (no evidence) }\end{array}$ \\
\hline
\end{tabular}

Abbreviations: ACQ=Asthma Control Questionnaire; ACT=Asthma Control Test; AQLQ=Asthma Quality of Life Questionnaire; ER=emergency room; FVC=forced vital capacity; FEV1=forced expiratory volume in one second; ICU=intensive care unit; $\mathrm{n}=$ =patient sample size; N=number of studies; NA=not applicable; PRN=pro re nata (i.e., asneeded)

\section{Table E-7. Strength of evidence KQ1c, ICS and LABA controller and quick relief vs. ICS and LABA controller (same dose)}

\begin{tabular}{|c|c|c|c|c|c|c|c|}
\hline Outcome & $\begin{array}{l}\mathrm{N} \text { of studies } \\
\text { ( } \mathrm{n} \text { of } \\
\text { patients) }\end{array}$ & Risk of bias & Consistency & Directness & Precision & Publication bias & $\begin{array}{l}\text { Strength of } \\
\text { evidence }\end{array}$ \\
\hline \multicolumn{8}{|l|}{ Exacerbations $\geq 12 y$} \\
\hline $\begin{array}{l}\text { Requiring systemic } \\
\text { corticosteroid }\end{array}$ & $\begin{array}{l}2 \\
(3792)\end{array}$ & Low & Consistent & Direct & Precise & Undetected & High \\
\hline Requiring hospitalization & $\begin{array}{l}2 \\
(2224)\end{array}$ & Low & Inconsistent & Direct & Imprecise & Undetected & $\begin{array}{l}\text { Low } \\
\text { (inconsistent, } \\
\text { imprecise) }\end{array}$ \\
\hline Requiring ER visit & $\begin{array}{l}1 \\
(2091)\end{array}$ & Low & $\begin{array}{l}\text { Unknown } \\
\text { (single study) }\end{array}$ & Direct & Precise & Undetected & $\begin{array}{l}\text { Moderate } \\
\text { (unknown } \\
\text { consistency) }\end{array}$ \\
\hline Requiring ICU/ ventilation & $\begin{array}{l}1 \\
(1701)\end{array}$ & Low & $\begin{array}{l}\text { Unknown } \\
\text { (single study) }\end{array}$ & Direct & Precise & Undetected & $\begin{array}{l}\text { Insufficient } \\
\text { (no events } \\
\text { occurred) } \\
\end{array}$ \\
\hline $\begin{array}{l}\text { Requiring systemic } \\
\text { corticosteroid, } \\
\text { hospitalization, or ER visit }\end{array}$ & $\begin{array}{l}5 \\
(8483)\end{array}$ & Low & Consistent & Direct & Precise & Undetected & High \\
\hline $\begin{array}{l}\text { Requiring hospitalization } \\
\text { or ER visit }\end{array}$ & $\begin{array}{l}5 \\
(8313) \\
\end{array}$ & Low & Consistent & Direct & Precise & Undetected & High \\
\hline $\begin{array}{l}\text { Asthma-related outpatient } \\
\text { visits }\end{array}$ & 0 & NA & NA & NA & NA & NA & $\begin{array}{l}\text { Insufficient } \\
\text { (no data) }\end{array}$ \\
\hline $\begin{array}{l}\text { Requiring systemic } \\
\text { corticosteroid, } \\
\text { hospitalization, ER visit, or } \\
\text { unscheduled visit }\end{array}$ & $\begin{array}{l}1 \\
(2143)\end{array}$ & Medium & $\begin{array}{l}\text { Unknown } \\
\text { (single study) }\end{array}$ & Direct & Precise & Undetected & $\begin{array}{l}\text { Moderate } \\
\text { (unknown } \\
\text { consistency) }\end{array}$ \\
\hline Mild exacerbation & $\begin{array}{l}3 \\
(6037)\end{array}$ & Low & Inconsistent & Direct & Precise & Undetected & $\begin{array}{l}\text { Moderate } \\
\text { (unknown } \\
\text { consistency) }\end{array}$ \\
\hline
\end{tabular}




\begin{tabular}{|c|c|c|c|c|c|c|c|}
\hline Outcome & $\begin{array}{l}\mathrm{N} \text { of studies } \\
\text { ( } \mathrm{n} \text { of } \\
\text { patients) }\end{array}$ & Risk of bias & Consistency & Directness & Precision & Publication bias & $\begin{array}{l}\text { Strength of } \\
\text { evidence }\end{array}$ \\
\hline $\begin{array}{l}\text { Requiring systemic } \\
\text { corticosteroid, } \\
\text { hospitalization, ER visit, } \\
\text { increase in ICS or other } \\
\text { medication, or PEF < }<70 \% \\
\end{array}$ & $\begin{array}{l}1 \\
(341)\end{array}$ & Low & $\begin{array}{l}\text { Unknown } \\
\text { (single study) }\end{array}$ & Indirect & Precise & Undetected & $\begin{array}{l}\text { Low } \\
\text { (unknown } \\
\text { consistency, } \\
\text { indirect) }\end{array}$ \\
\hline $\begin{array}{l}\text { Exacerbations requiring } \\
\text { hospitalization, systemic } \\
\text { corticosteroids, ER, or } \\
\text { increase in ICS or other } \\
\text { medications }\end{array}$ & $\begin{array}{l}1 \\
(341)\end{array}$ & Low & $\begin{array}{l}\text { Unknown } \\
\text { (single study) }\end{array}$ & Indirect & Precise & Undetected & $\begin{array}{l}\text { Low } \\
\text { (unknown } \\
\text { consistency, } \\
\text { indirect) }\end{array}$ \\
\hline Mild exacerbations & $\begin{array}{l}1 \\
(341)\end{array}$ & Low & $\begin{array}{l}\text { Unknown } \\
\text { (single study) }\end{array}$ & Indirect & Precise & Undetected & $\begin{array}{l}\text { Low } \\
\text { (unknown } \\
\text { consistency, } \\
\text { indirect) }\end{array}$ \\
\hline \multicolumn{8}{|l|}{ Mortality $\geq 12 y$} \\
\hline All-cause & $\begin{array}{l}4 \\
(6782) \\
\end{array}$ & Low & Consistent & Direct & Imprecise & Undetected & $\begin{array}{l}\text { Moderate } \\
\text { (imprecise) }\end{array}$ \\
\hline Asthma-specific & $\begin{array}{l}4 \\
(6782)\end{array}$ & Low & Consistent & Direct & Precise & Undetected & $\begin{array}{l}\text { Insufficient } \\
\text { (no events } \\
\text { occurred) }\end{array}$ \\
\hline \multicolumn{8}{|l|}{$\begin{array}{l}\text { Asthma control- } \\
\text { composite measures } \geq \\
12 \mathrm{y}\end{array}$} \\
\hline $\mathrm{ACT}$ & $\begin{array}{l}1 \\
(63)\end{array}$ & Unclear & $\begin{array}{l}\text { Unknown } \\
\text { (single study) }\end{array}$ & Direct & Precise & Undetected & $\begin{array}{l}\text { Insufficient } \\
\text { (unknown } \\
\text { consistency) }\end{array}$ \\
\hline ACQ-5 score & $\begin{array}{l}3 \\
(4353)\end{array}$ & Low & Inconsistent & Direct & Imprecise & Undetected & $\begin{array}{l}\text { Low } \\
\text { (inconsistent, } \\
\text { imprecise) }\end{array}$ \\
\hline ACQ-5 responder & $\begin{array}{l}1 \\
(2091)\end{array}$ & Low & $\begin{array}{l}\text { Unknown } \\
\text { (single study) }\end{array}$ & Direct & Precise & Undetected & $\begin{array}{l}\text { Moderate } \\
\text { (unknown } \\
\text { consistency) } \\
\end{array}$ \\
\hline \multicolumn{8}{|l|}{$\begin{array}{l}\text { Asthma control- } \\
\text { spirometry } \geq 12 y\end{array}$} \\
\hline FEV1 & $\begin{array}{l}5 \\
(6343)\end{array}$ & Low & Inconsistent & Direct & Imprecise & Undetected & $\begin{array}{l}\text { Low } \\
\text { (inconsistent, } \\
\text { imprecise) }\end{array}$ \\
\hline FEV1 \% predicted & $\begin{array}{l}2 \\
(304) \\
\end{array}$ & Medium & Consistent & Direct & Precise & Undetected & $\begin{array}{l}\text { Moderate } \\
\text { (risk of bias) }\end{array}$ \\
\hline
\end{tabular}




\begin{tabular}{|c|c|c|c|c|c|c|c|}
\hline Outcome & $\begin{array}{l}\mathrm{N} \text { of studies } \\
\text { ( } \mathrm{n} \text { of } \\
\text { patients) }\end{array}$ & Risk of bias & Consistency & Directness & Precision & Publication bias & $\begin{array}{l}\text { Strength of } \\
\text { evidence }\end{array}$ \\
\hline FVC & $\begin{array}{l}1 \\
(1701)\end{array}$ & Low & $\begin{array}{l}\text { Unknown } \\
\text { (single study) }\end{array}$ & Direct & Imprecise & Undetected & $\begin{array}{l}\text { Low } \\
\text { (unknown } \\
\text { consistency, } \\
\text { imprecise) }\end{array}$ \\
\hline FEV1/ FVC & 0 & NA & NA & NA & NA & NA & $\begin{array}{l}\text { Insufficient } \\
\text { (no data) }\end{array}$ \\
\hline \multicolumn{8}{|l|}{ Quality of life $\geq 12 y$} \\
\hline AQLQ score & 0 & NA & NA & NA & NA & NA & $\begin{array}{l}\text { Insufficient } \\
\text { (no data) }\end{array}$ \\
\hline AQLQ responder & 0 & NA & NA & NA & NA & NA & $\begin{array}{l}\text { Insufficient } \\
\text { (no data) }\end{array}$ \\
\hline \multicolumn{8}{|l|}{$\begin{array}{l}\text { Healthcare utilization } \\
\geq 12 y\end{array}$} \\
\hline $\begin{array}{l}\text { Mean PRN inhalations/ } \\
\text { day }\end{array}$ & $\begin{array}{l}3 \\
(6006)\end{array}$ & Low & Inconsistent & Direct & Imprecise & Undetected & $\begin{array}{l}\text { Low } \\
\text { (inconsistent, } \\
\text { imprecise) }\end{array}$ \\
\hline $\begin{array}{l}\text { Mean PRN inhalations/ } \\
\text { week }\end{array}$ & $\begin{array}{l}2 \\
(93)\end{array}$ & Medium & Consistent & Direct & Imprecise & Undetected & $\begin{array}{l}\text { Low } \\
\text { (risk of bias, } \\
\text { imprecise) }\end{array}$ \\
\hline Resource use & 0 & NA & NA & NA & NA & NA & $\begin{array}{l}\text { Insufficient } \\
\text { (no data) }\end{array}$ \\
\hline
\end{tabular}

Abbreviations: ACQ=Asthma Control Questionnaire; ACT=Asthma Control Test; AQLQ=Asthma Quality of Life Questionnaire; ER=emergency room; FVC=forced vital capacity; FEV1=forced expiratory volume in one second; ICS=inhaled corticosteroid; ICU=intensive care unit; $n=$ patient sample size; $N=$ number of studies; NA=not applicable; $\mathrm{PEF}=$ peak expiratory flow; $\mathrm{PRN}=$ pro re nata (i.e., as-needed); $\mathrm{y}=\mathrm{year}$ 
Table E-8. Strength of evidence KQ1c, ICS and LABA controller and quick relief vs. ICS and LABA controller (higher dose)

\begin{tabular}{|c|c|c|c|c|c|c|c|}
\hline Outcome & $\begin{array}{l}\mathrm{N} \text { of studies } \\
\text { ( } \mathrm{n} \text { of patients) }\end{array}$ & Risk of bias & Consistency & Directness & Precision & Publication bias & $\begin{array}{l}\text { Strength of } \\
\text { evidence }\end{array}$ \\
\hline \multicolumn{8}{|l|}{ Exacerbations } \\
\hline $\begin{array}{l}\text { Requiring systemic } \\
\text { corticosteroid }\end{array}$ & $\begin{array}{l}1 \\
(2304)\end{array}$ & Low & $\begin{array}{l}\text { Unknown } \\
\text { (single study) }\end{array}$ & Direct & Precise & Undetected & $\begin{array}{l}\text { Moderate } \\
\text { (unknown } \\
\text { consistency) }\end{array}$ \\
\hline $\begin{array}{l}\text { Requiring } \\
\text { hospitalization }\end{array}$ & 0 & NA & NA & NA & NA & NA & $\begin{array}{l}\text { Insufficient } \\
\text { (no data) }\end{array}$ \\
\hline Requiring ER visit & 0 & NA & NA & NA & NA & NA & $\begin{array}{l}\text { Insufficient } \\
\text { (no data) }\end{array}$ \\
\hline $\begin{array}{l}\text { Requiring ICU/ } \\
\text { ventilation }\end{array}$ & 0 & NA & NA & NA & NA & NA & $\begin{array}{l}\text { Insufficient } \\
\text { (no data) }\end{array}$ \\
\hline $\begin{array}{l}\text { Asthma-related } \\
\text { hospitalization }\end{array}$ & 0 & NA & NA & NA & NA & NA & $\begin{array}{l}\text { Insufficient } \\
\text { (no data) }\end{array}$ \\
\hline Asthma-related ER visit & 0 & NA & NA & NA & NA & NA & $\begin{array}{l}\text { Insufficient } \\
\text { (no data) }\end{array}$ \\
\hline $\begin{array}{l}\text { Asthma-related } \\
\text { outpatient visit }\end{array}$ & 0 & NA & NA & NA & NA & NA & $\begin{array}{l}\text { Insufficient } \\
\text { (no data) }\end{array}$ \\
\hline $\begin{array}{l}\text { Requiring systemic } \\
\text { corticosteroid, } \\
\text { hospitalization, or ER } \\
\text { visit }\end{array}$ & $\begin{array}{l}3 \\
(6742)\end{array}$ & Low & Consistent & Direct & Precise & Undetected & High \\
\hline $\begin{array}{l}\text { Requiring } \\
\text { hospitalization or ER } \\
\text { visit }\end{array}$ & $\begin{array}{l}3 \\
(6742)\end{array}$ & Low & Consistent & Direct & Imprecise & Undetected & $\begin{array}{l}\text { Moderate } \\
\text { (imprecise) }\end{array}$ \\
\hline Mild exacerbation & $\begin{array}{l}2 \\
(3321)\end{array}$ & Low & Unknown $^{\mathrm{a}}$ & Direct & Precise & Undetected & $\begin{array}{l}\text { Moderate } \\
\text { (unknown } \\
\text { consistency) }\end{array}$ \\
\hline \multicolumn{8}{|l|}{ Mortality } \\
\hline All-cause & $\begin{array}{l}4 \\
(5757) \\
\end{array}$ & Low & Consistent & Direct & Imprecise & Undetected & $\begin{array}{l}\text { Moderate } \\
\text { (imprecise) }\end{array}$ \\
\hline Asthma-specific & $\begin{array}{l}4 \\
(5757)\end{array}$ & Low & Consistent & Direct & Precise & Undetected & $\begin{array}{l}\text { Insufficient } \\
\text { (no events } \\
\text { occurred) }\end{array}$ \\
\hline \multicolumn{8}{|l|}{$\begin{array}{l}\text { Asthma control- } \\
\text { composite measures }\end{array}$} \\
\hline $\mathrm{ACT}$ & 0 & NA & NA & NA & NA & NA & $\begin{array}{l}\text { Insufficient } \\
\text { (no data) }\end{array}$ \\
\hline ACQ-5 score & $\begin{array}{l}3 \\
(6559) \\
\end{array}$ & Low & Consistent & Direct & Precise & Undetected & High \\
\hline
\end{tabular}




\begin{tabular}{|c|c|c|c|c|c|c|c|}
\hline Outcome & $\begin{array}{l}\mathrm{N} \text { of studies } \\
\text { ( } \mathrm{n} \text { of patients) }\end{array}$ & Risk of bias & Consistency & Directness & Precision & Publication bias & $\begin{array}{l}\text { Strength of } \\
\text { evidence }\end{array}$ \\
\hline ACQ-5 responder & 0 & NA & NA & NA & NA & NA & $\begin{array}{l}\text { Insufficient } \\
\text { (no data) }\end{array}$ \\
\hline \multicolumn{8}{|l|}{$\begin{array}{l}\text { Asthma control- } \\
\text { spirometry }\end{array}$} \\
\hline FEV1 & $\begin{array}{l}2 \\
(4424)\end{array}$ & Low & Unknown $^{\mathrm{a}}$ & Direct & Precise & Undetected & $\begin{array}{l}\text { Moderate } \\
\text { (unknown } \\
\text { consistency) }\end{array}$ \\
\hline FVC & 0 & NA & NA & NA & NA & NA & $\begin{array}{l}\text { Insufficient } \\
\text { (no data) }\end{array}$ \\
\hline FEV1/FVC & 0 & NA & NA & NA & NA & NA & $\begin{array}{l}\text { Insufficient } \\
\text { (no data) }\end{array}$ \\
\hline \multicolumn{8}{|l|}{ Quality of life } \\
\hline AQLQ(S) score & $\begin{array}{l}2 \\
(4270)\end{array}$ & Low & Unknown $^{\mathrm{a}}$ & Direct & Precise & Undetected & $\begin{array}{l}\text { Moderate } \\
\text { (unknown } \\
\text { consistency) }\end{array}$ \\
\hline AQLQ responder & 0 & NA & NA & NA & NA & NA & $\begin{array}{l}\text { Insufficient } \\
\text { (no data) }\end{array}$ \\
\hline \multicolumn{8}{|c|}{ Healthcare utilization } \\
\hline $\begin{array}{l}\text { Mean PRN } \\
\text { inhalations/day }\end{array}$ & $\begin{array}{l}3 \\
(6559)\end{array}$ & Low & Consistent & Direct & Precise & Undetected & High \\
\hline Resource use & 0 & NA & NA & NA & NA & NA & $\begin{array}{l}\text { Insufficient } \\
\text { (no data) }\end{array}$ \\
\hline
\end{tabular}

Abbreviations: ACQ=Asthma Control Questionnaire; ACT=Asthma Control Test; AQLQ=Asthma Quality of Life Questionnaire; AQLQ(S)=standardized Asthma Quality of Life Questionnaire; ER=emergency room; FVC=forced vital capacity; FEV1=forced expiratory volume in one second; ICU=intensive care unit; $\mathrm{n}=$ patient sample size; N=number of studies; $\mathrm{NA}=$ not applicable; $\mathrm{PRN}=$ pro re nata (i.e., as-needed)

${ }^{a}$ A single 3-arm trial contributed two unique comparisons for this outcome. Thus, the consistency with an independent trial population is unknown

Table E-9. Strength of evidence KQ1c, ICS and LABA controller and quick relief vs. ICS and LABA controller (lower dose)

\begin{tabular}{|c|c|c|c|c|c|c|c|}
\hline Outcome & $\begin{array}{l}N \text { of studies } \\
\text { ( } n \text { of patients) }\end{array}$ & Risk of bias & Consistency & Directness & Precision & Publication bias & $\begin{array}{l}\text { Strength of } \\
\text { evidence }\end{array}$ \\
\hline \multicolumn{8}{|l|}{ Exacerbations } \\
\hline $\begin{array}{l}\text { Requiring systemic } \\
\text { corticosteroid }\end{array}$ & 0 & NA & NA & NA & NA & NA & $\begin{array}{l}\text { Insufficient } \\
\text { (no data) }\end{array}$ \\
\hline $\begin{array}{l}\text { Requiring } \\
\text { hospitalization }\end{array}$ & 0 & NA & NA & NA & NA & NA & $\begin{array}{l}\text { Insufficient } \\
\text { (no data) }\end{array}$ \\
\hline Requiring ER visit & 0 & NA & NA & NA & NA & NA & $\begin{array}{l}\text { Insufficient } \\
\text { (no data) }\end{array}$ \\
\hline $\begin{array}{l}\text { Requiring ICU/ } \\
\text { ventilation }\end{array}$ & 0 & NA & NA & NA & NA & NA & $\begin{array}{l}\text { Insufficient } \\
\text { (no data) }\end{array}$ \\
\hline $\begin{array}{l}\text { Asthma-related } \\
\text { hospitalization }\end{array}$ & 0 & NA & NA & NA & NA & NA & $\begin{array}{l}\text { Insufficient } \\
\text { (no data) }\end{array}$ \\
\hline
\end{tabular}




\begin{tabular}{|c|c|c|c|c|c|c|c|}
\hline Outcome & $\begin{array}{l}\mathrm{N} \text { of studies } \\
\text { ( } \mathrm{n} \text { of patients) }\end{array}$ & Risk of bias & Consistency & Directness & Precision & Publication bias & $\begin{array}{l}\text { Strength of } \\
\text { evidence }\end{array}$ \\
\hline Asthma-related ER visit & 0 & NA & NA & NA & NA & NA & $\begin{array}{l}\text { Insufficient } \\
\text { (no data) }\end{array}$ \\
\hline $\begin{array}{l}\text { Asthma-related } \\
\text { outpatient visit }\end{array}$ & 0 & NA & NA & NA & NA & NA & $\begin{array}{l}\text { Insufficient } \\
\text { (no data) }\end{array}$ \\
\hline \multicolumn{8}{|l|}{ Mortality } \\
\hline All-cause & 0 & NA & NA & NA & NA & NA & $\begin{array}{l}\text { Insufficient } \\
\text { (no data) }\end{array}$ \\
\hline Asthma-specific & 0 & NA & NA & NA & NA & NA & $\begin{array}{l}\text { Insufficient } \\
\text { (no data) }\end{array}$ \\
\hline \multicolumn{8}{|l|}{$\begin{array}{l}\text { Asthma control- } \\
\text { composite measures }\end{array}$} \\
\hline ACT & 0 & NA & NA & NA & NA & NA & $\begin{array}{l}\text { Insufficient } \\
\text { (no data) }\end{array}$ \\
\hline ACQ-5 score & $\begin{array}{l}1 \\
(30)\end{array}$ & Medium & $\begin{array}{l}\text { Unknown } \\
\text { (single study) }\end{array}$ & Direct & Imprecise & Undetected & $\begin{array}{l}\text { Insufficient } \\
\text { (risk of bias, } \\
\text { unknown } \\
\text { consistency, } \\
\text { imprecise) }\end{array}$ \\
\hline ACQ-5 responder & 0 & NA & NA & NA & NA & NA & $\begin{array}{l}\text { Insufficient } \\
\text { (no data) }\end{array}$ \\
\hline \multicolumn{8}{|l|}{$\begin{array}{l}\text { Asthma control- } \\
\text { spirometry }\end{array}$} \\
\hline FEV1 \% predicted & $\begin{array}{l}1 \\
(30)\end{array}$ & Medium & $\begin{array}{l}\text { Unknown } \\
\text { (single study) }\end{array}$ & Direct & Precise & Undetected & $\begin{array}{l}\text { Insufficient } \\
\text { (risk of bias, } \\
\text { unknown } \\
\text { consistency, } \\
\text { imprecise) }\end{array}$ \\
\hline FVC & 0 & NA & NA & NA & NA & NA & $\begin{array}{l}\text { Insufficient } \\
\text { (no data) }\end{array}$ \\
\hline FEV1/FVC & 0 & NA & NA & NA & NA & NA & $\begin{array}{l}\text { Insufficient } \\
\text { (no data) }\end{array}$ \\
\hline \multicolumn{8}{|l|}{ Quality of life } \\
\hline AQLQ(S) score & 0 & NA & NA & NA & NA & NA & $\begin{array}{l}\text { Insufficient } \\
\text { (no data) }\end{array}$ \\
\hline AQLQ responder & 0 & NA & NA & NA & NA & NA & $\begin{array}{l}\text { Insufficient } \\
\text { (no data) }\end{array}$ \\
\hline
\end{tabular}




\begin{tabular}{|c|c|c|c|c|c|c|c|}
\hline Outcome & $\begin{array}{l}\mathrm{N} \text { of studies } \\
\text { ( } \mathrm{n} \text { of patients) }\end{array}$ & Risk of bias & Consistency & Directness & Precision & Publication bias & $\begin{array}{l}\text { Strength of } \\
\text { evidence }\end{array}$ \\
\hline $\begin{array}{l}\text { Mean PRN } \\
\text { inhalations/week }\end{array}$ & $\begin{array}{l}1 \\
(30)\end{array}$ & Medium & $\begin{array}{l}\text { Unknown } \\
\text { (single study) }\end{array}$ & Direct & Imprecise & Undetected & $\begin{array}{l}\text { Insufficient } \\
\text { (risk of bias, } \\
\text { unknown } \\
\text { consistency, } \\
\text { imprecise) }\end{array}$ \\
\hline Resource use & 0 & NA & NA & NA & NA & NA & $\begin{array}{l}\text { Insufficient } \\
\text { (no data) }\end{array}$ \\
\hline
\end{tabular}

Table E-10. Strength of evidence KQ1C, ICS and LABA controller and quick relief vs. CBP

\begin{tabular}{|c|c|c|c|c|c|c|c|}
\hline Outcome & $\begin{array}{l}\mathrm{N} \text { of studies } \\
\text { ( } \mathrm{n} \text { of patients) }\end{array}$ & Risk of bias & Consistency & Directness & Precision & Publication bias & $\begin{array}{l}\text { Strength of } \\
\text { evidence }\end{array}$ \\
\hline \multicolumn{8}{|l|}{ Exacerbations } \\
\hline $\begin{array}{l}\text { Requiring systemic } \\
\text { corticosteroid }\end{array}$ & $\begin{array}{l}4 \\
(4935)\end{array}$ & Medium & Consistent & Direct & Imprecise & Undetected & $\begin{array}{l}\text { Low } \\
\text { (risk of bias, } \\
\text { imprecise) }\end{array}$ \\
\hline $\begin{array}{l}\text { Requiring } \\
\text { hospitalization }\end{array}$ & $\begin{array}{l}4 \\
(4935)\end{array}$ & Medium & Consistent & Direct & Imprecise & Undetected & $\begin{array}{l}\text { Low } \\
\text { (risk of bias, } \\
\text { imprecise) }\end{array}$ \\
\hline Requiring ER visit & $\begin{array}{l}4 \\
(4935)\end{array}$ & Medium & Consistent & Direct & Imprecise & Undetected & $\begin{array}{l}\text { Low } \\
\text { (risk of bias, } \\
\text { imprecise) }\end{array}$ \\
\hline $\begin{array}{l}\text { Requiring ICU/ } \\
\text { ventilation }\end{array}$ & 0 & NA & NA & NA & NA & NA & $\begin{array}{l}\text { Insufficient } \\
\text { (no data) }\end{array}$ \\
\hline $\begin{array}{l}\text { Asthma-related } \\
\text { hospitalization }\end{array}$ & 0 & NA & NA & NA & NA & NA & $\begin{array}{l}\text { Insufficient } \\
\text { (no data) }\end{array}$ \\
\hline Asthma-related ER visit & 0 & NA & NA & NA & NA & NA & $\begin{array}{l}\text { Insufficient } \\
\text { (no data) }\end{array}$ \\
\hline $\begin{array}{l}\text { Asthma-related } \\
\text { outpatient visit }\end{array}$ & 0 & NA & NA & NA & NA & NA & $\begin{array}{l}\text { Insufficient } \\
\text { (no data) }\end{array}$ \\
\hline $\begin{array}{l}\text { Requiring systemic } \\
\text { corticosteroid, } \\
\text { hospitalization, or ER } \\
\text { visit }\end{array}$ & $\begin{array}{l}6 \\
(6354)\end{array}$ & Medium & Consistent & Direct & Precise & Undetected & $\begin{array}{l}\text { Moderate } \\
\text { (risk of bias) }\end{array}$ \\
\hline \multicolumn{8}{|l|}{ Mortality } \\
\hline All-cause & $\begin{array}{l}4 \\
(4935) \\
\end{array}$ & Low & Consistent & Direct & Imprecise & Undetected & $\begin{array}{l}\text { Moderate } \\
\text { (imprecise) }\end{array}$ \\
\hline Asthma-specific & $\begin{array}{l}4 \\
(4935)\end{array}$ & Low & Consistent & Direct & Precise & Undetected & $\begin{array}{l}\text { Insufficient } \\
\text { (no events } \\
\text { occurred) }\end{array}$ \\
\hline
\end{tabular}




\begin{tabular}{|c|c|c|c|c|c|c|c|}
\hline Outcome & $\begin{array}{l}\mathrm{N} \text { of studies } \\
\text { ( } \mathrm{n} \text { of patients) }\end{array}$ & Risk of bias & Consistency & Directness & Precision & Publication bias & $\begin{array}{l}\text { Strength of } \\
\text { evidence }\end{array}$ \\
\hline ACT & 0 & NA & NA & NA & NA & NA & $\begin{array}{l}\text { Insufficient } \\
\text { (no data) }\end{array}$ \\
\hline ACQ-5 score & $\begin{array}{l}5 \\
(4996)\end{array}$ & Medium & Consistent & Direct & Precise & Undetected & $\begin{array}{l}\text { Moderate } \\
\text { (risk of bias) }\end{array}$ \\
\hline ACQ-5 responder & $\begin{array}{l}2 \\
(2166)\end{array}$ & Medium & Consistent & Direct & Precise & Undetected & $\begin{array}{l}\text { Moderate } \\
\text { (risk of bias) }\end{array}$ \\
\hline \multicolumn{8}{|l|}{$\begin{array}{l}\text { Asthma control- } \\
\text { spirometry }\end{array}$} \\
\hline FEV1 & $\begin{array}{l}1 \\
(271)\end{array}$ & Medium & $\begin{array}{l}\text { Unknown } \\
\text { (single study) }\end{array}$ & Direct & Precise & Undetected & $\begin{array}{l}\text { Low } \\
\text { (unknown } \\
\text { consistency) }\end{array}$ \\
\hline FEV1 \% predicted & $\begin{array}{l}1 \\
(102)\end{array}$ & Medium & $\begin{array}{l}\text { Unknown } \\
\text { (single study) }\end{array}$ & Direct & Precise & Undetected & $\begin{array}{l}\text { Low } \\
\text { (unknown } \\
\text { consistency) }\end{array}$ \\
\hline FVC & 0 & NA & NA & NA & NA & NA & $\begin{array}{l}\text { Insufficient } \\
\text { (no data) }\end{array}$ \\
\hline FEV1/ FVC & 0 & NA & NA & NA & $\mathrm{NA}$ & $\mathrm{NA}$ & $\begin{array}{l}\text { Insufficient } \\
\text { (no data) }\end{array}$ \\
\hline \multicolumn{8}{|l|}{ Quality of life } \\
\hline AQLQ score & 0 & NA & NA & NA & $\mathrm{NA}$ & NA & $\begin{array}{l}\text { Insufficient } \\
\text { (no data) }\end{array}$ \\
\hline AQLQ responder & 0 & NA & NA & NA & $\mathrm{NA}$ & NA & $\begin{array}{l}\text { Insufficient } \\
\text { (no data) }\end{array}$ \\
\hline \multicolumn{8}{|l|}{ Healthcare utilization } \\
\hline $\begin{array}{l}\text { Mean PRN inhalations/ } \\
\text { day }\end{array}$ & $\begin{array}{l}2 \\
(2404)\end{array}$ & Medium & Consistent & Direct & Precise & Undetected & $\begin{array}{l}\text { Moderate } \\
\text { (risk of bias) }\end{array}$ \\
\hline $\begin{array}{l}\geq 1 \text { day } w / P R N \\
\text { inhalation }\end{array}$ & $\begin{array}{l}2 \\
(1562)\end{array}$ & Medium & Inconsistent & Direct & Imprecise & Undetected & $\begin{array}{l}\text { Low } \\
\text { (inconsistent, } \\
\text { imprecise) }\end{array}$ \\
\hline Resource use & 0 & NA & NA & NA & NA & NA & $\begin{array}{l}\text { Insufficient } \\
\text { (no data) }\end{array}$ \\
\hline
\end{tabular}

Abbreviations: ACQ=Asthma Control Questionnaire; ACT=Asthma Control Test; AQLQ=Asthma Quality of Life Questionnaire; ER=emergency room; FVC=forced vital

capacity; FEV1=forced expiratory volume in one second; ICU=intensive care unit; $n=$ patient sample size; N=number of studies; NA=not applicable; PRN=pro re nata (i.e., asneeded) 
Table E-11. Strength of evidence KQ 2a, LAMA as add-on to ICS vs. doubling ICS dose

\begin{tabular}{|c|c|c|c|c|c|c|c|}
\hline Outcome & $\begin{array}{l}\mathrm{N} \text { of studies } \\
\text { ( } \mathrm{n} \text { of patients) }\end{array}$ & Risk of bias & Consistency & Directness & Precision & Publication bias & $\begin{array}{l}\text { Strength of } \\
\text { evidence }\end{array}$ \\
\hline \multicolumn{8}{|l|}{ Exacerbations } \\
\hline $\begin{array}{l}\text { Requiring systemic } \\
\text { corticosteroid }\end{array}$ & $\begin{array}{l}1 \\
(210)\end{array}$ & Low & $\begin{array}{l}\text { Unknown } \\
\text { (single study) }\end{array}$ & Direct & Imprecise & Undetected & $\begin{array}{l}\text { Low } \\
\text { (unknown } \\
\text { consistency, } \\
\text { imprecise) }\end{array}$ \\
\hline $\begin{array}{l}\text { Requiring } \\
\text { hospitalization }\end{array}$ & 0 & NA & NA & NA & NA & NA & $\begin{array}{l}\text { Insufficient } \\
\text { (no evidence) }\end{array}$ \\
\hline Requiring ER visit & 0 & NA & NA & NA & NA & NA & $\begin{array}{l}\text { Insufficient } \\
\text { (no evidence) }\end{array}$ \\
\hline $\begin{array}{l}\text { Requiring ICU/ } \\
\text { ventilation }\end{array}$ & 0 & NA & NA & NA & NA & NA & $\begin{array}{l}\text { Insufficient } \\
\text { (no evidence) }\end{array}$ \\
\hline $\begin{array}{l}\text { Asthma-related } \\
\text { hospitalization }\end{array}$ & 0 & NA & NA & NA & NA & NA & $\begin{array}{l}\text { Insufficient } \\
\text { (no evidence) }\end{array}$ \\
\hline Asthma-related ER visit & 0 & NA & NA & NA & NA & NA & $\begin{array}{l}\text { Insufficient } \\
\text { (no evidence) }\end{array}$ \\
\hline $\begin{array}{l}\text { Asthma-related } \\
\text { outpatient visit }\end{array}$ & 0 & NA & NA & NA & NA & NA & $\begin{array}{l}\text { Insufficient } \\
\text { (no evidence) }\end{array}$ \\
\hline Asthma worsening & 0 & NA & NA & NA & NA & NA & $\begin{array}{l}\text { Insufficient } \\
\text { (no evidence) }\end{array}$ \\
\hline $\begin{array}{l}\text { Requiring oral } \\
\text { corticosteroid or } \\
\text { increase in ICS or other } \\
\text { asthma medication }\end{array}$ & $\begin{array}{l}1 \\
(210)\end{array}$ & Low & $\begin{array}{l}\text { Unknown } \\
\text { (single study) }\end{array}$ & Direct & Imprecise & Undetected & $\begin{array}{l}\text { Low } \\
\text { (unknown } \\
\text { consistency, } \\
\text { imprecise) }\end{array}$ \\
\hline \multicolumn{8}{|l|}{ Mortality } \\
\hline All-cause & 0 & NA & NA & NA & NA & NA & $\begin{array}{l}\text { Insufficient } \\
\text { (no evidence) }\end{array}$ \\
\hline Asthma-specific & 0 & NA & NA & NA & NA & NA & $\begin{array}{l}\text { Insufficient } \\
\text { (no evidence) }\end{array}$ \\
\hline \multicolumn{8}{|l|}{$\begin{array}{l}\text { Asthma control- } \\
\text { composite measures }\end{array}$} \\
\hline ACT & 0 & NA & NA & NA & NA & NA & $\begin{array}{l}\text { Insufficient } \\
\text { (no evidence) }\end{array}$ \\
\hline ACQ-6 score & $\begin{array}{l}1 \\
(127)\end{array}$ & Low & $\begin{array}{l}\text { Unknown } \\
\text { (single study) }\end{array}$ & Direct & Precise & Undetected & $\begin{array}{l}\text { Low } \\
\text { (unknown } \\
\text { consistency) } \\
\end{array}$ \\
\hline ACQ-6 responder & 0 & NA & NA & NA & NA & NA & $\begin{array}{l}\text { Insufficient } \\
\text { (no evidence) }\end{array}$ \\
\hline
\end{tabular}




\begin{tabular}{|c|c|c|c|c|c|c|c|}
\hline Outcome & $\begin{array}{l}\mathrm{N} \text { of studies } \\
\text { ( } \mathrm{n} \text { of patients) }\end{array}$ & Risk of bias & Consistency & Directness & Precision & Publication bias & $\begin{array}{l}\text { Strength of } \\
\text { evidence }\end{array}$ \\
\hline FEV1 peak & 0 & NA & NA & NA & $\mathrm{NA}$ & NA & $\begin{array}{l}\text { Insufficient } \\
\text { (no evidence) }\end{array}$ \\
\hline FEV1 trough & $\begin{array}{l}1 \\
(118)\end{array}$ & Low & $\begin{array}{l}\text { Unknown } \\
\text { (single study) }\end{array}$ & Direct & Imprecise & Undetected & $\begin{array}{l}\text { Low } \\
\text { (unknown } \\
\text { consistency, } \\
\text { imprecise) }\end{array}$ \\
\hline FEV1 AUC & 0 & NA & NA & NA & $\mathrm{NA}$ & NA & $\begin{array}{l}\text { Insufficient } \\
\text { (no evidence) }\end{array}$ \\
\hline FEV1 \% predicted & 0 & NA & NA & $\mathrm{NA}$ & $\mathrm{NA}$ & NA & $\begin{array}{l}\text { Insufficient } \\
\text { (no evidence) }\end{array}$ \\
\hline FVC peak & 0 & NA & NA & $\mathrm{NA}$ & $\mathrm{NA}$ & NA & $\begin{array}{l}\text { Insufficient } \\
\text { (no evidence) }\end{array}$ \\
\hline FVC trough & 0 & NA & NA & NA & NA & NA & $\begin{array}{l}\text { Insufficient } \\
\text { (no evidence) }\end{array}$ \\
\hline FVC AUC & 0 & NA & NA & NA & NA & NA & $\begin{array}{l}\text { Insufficient } \\
\text { (no evidence) }\end{array}$ \\
\hline FEV1/FVC & 0 & NA & NA & NA & $\mathrm{NA}$ & $\mathrm{NA}$ & $\begin{array}{l}\text { Insufficient } \\
\text { (no evidence) }\end{array}$ \\
\hline \multicolumn{8}{|l|}{ Quality of life } \\
\hline AQLQ score & $\begin{array}{l}1 \\
(122)\end{array}$ & Low & $\begin{array}{l}\text { Unknown } \\
\text { (single study) }\end{array}$ & Direct & Precise & Undetected & $\begin{array}{l}\text { Low } \\
\text { (unknown } \\
\text { consistency) }\end{array}$ \\
\hline AQLQ responder & 0 & NA & NA & NA & NA & NA & $\begin{array}{l}\text { Insufficient } \\
\text { (no evidence) }\end{array}$ \\
\hline \multicolumn{8}{|l|}{ Healthcare utilization } \\
\hline $\begin{array}{l}\text { Rescue medication use, } \\
\text { puffs/24 hours }\end{array}$ & 0 & NA & NA & NA & NA & NA & $\begin{array}{l}\text { Insufficient } \\
\text { (no evidence) }\end{array}$ \\
\hline Resource use & 0 & NA & NA & NA & $\mathrm{NA}$ & NA & $\begin{array}{l}\text { Insufficient } \\
\text { (no evidence) }\end{array}$ \\
\hline
\end{tabular}

Abbreviations: ACQ=Asthma Control Questionnaire; ACT=Asthma Control Test; AQLQ=Asthma Quality of Life Questionnaire; AUC=area under curve; ER=emergency room; FVC=forced vital capacity; FEV1=forced expiratory volume in one second; ICS=inhaled corticosteroid; ICU=intensive care unit; $n=$ patient sample size; $N=$ number of studies;

NA=not applicable; 
Table E-12. Strength of evidence KQ2a, LAMA vs. placebo as add-on to ICS

\begin{tabular}{|c|c|c|c|c|c|c|c|}
\hline Outcome & $\begin{array}{l}\mathrm{N} \text { of studies } \\
\text { ( } \mathrm{n} \text { of patients) }\end{array}$ & Risk of bias & Consistency & Directness & Precision & Publication bias & $\begin{array}{l}\text { Strength of } \\
\text { evidence }\end{array}$ \\
\hline \multicolumn{8}{|l|}{ Exacerbations } \\
\hline $\begin{array}{l}\text { Requiring systemic } \\
\text { corticosteroid }\end{array}$ & $\begin{array}{l}5 \\
(3036) \\
\end{array}$ & Low & Consistent & Direct & Precise & Undetected & High \\
\hline $\begin{array}{l}\text { Requiring } \\
\text { hospitalization }\end{array}$ & 0 & NA & NA & NA & NA & NA & $\begin{array}{l}\text { Insufficient } \\
\text { (no evidence) }\end{array}$ \\
\hline Requiring ED visit & 0 & NA & NA & NA & NA & NA & $\begin{array}{l}\text { Insufficient } \\
\text { (no evidence) }\end{array}$ \\
\hline $\begin{array}{l}\text { Requiring ICU/ } \\
\text { ventilation }\end{array}$ & 0 & NA & NA & NA & NA & NA & $\begin{array}{l}\text { Insufficient } \\
\text { (no evidence) }\end{array}$ \\
\hline $\begin{array}{l}\text { Asthma-related } \\
\text { hospitalization }\end{array}$ & 0 & NA & NA & NA & NA & NA & $\begin{array}{l}\text { Insufficient } \\
\text { (no evidence) }\end{array}$ \\
\hline Asthma-related ER visit & 0 & NA & NA & NA & NA & NA & $\begin{array}{l}\text { Insufficient } \\
\text { (no evidence) }\end{array}$ \\
\hline $\begin{array}{l}\text { Asthma-related } \\
\text { outpatient visit }\end{array}$ & 0 & NA & NA & NA & NA & NA & $\begin{array}{l}\text { Insufficient } \\
\text { (no evidence) }\end{array}$ \\
\hline Asthma worsening & $\begin{array}{l}4 \\
(2420) \\
\end{array}$ & Low & Consistent & Direct & Precise & Undetected & High \\
\hline \multicolumn{8}{|l|}{ Mortality } \\
\hline All-cause mortality & $\begin{array}{l}6 \\
(3065)\end{array}$ & Low & Consistent & Direct & Precise & Undetected & $\begin{array}{l}\text { Insufficient } \\
\text { (no events } \\
\text { occurred) }\end{array}$ \\
\hline Asthma-specific deaths & $\begin{array}{l}6 \\
(3065)\end{array}$ & Low & Consistent & Direct & Precise & Undetected & $\begin{array}{l}\text { Insufficient } \\
\text { (no events } \\
\text { occurred) }\end{array}$ \\
\hline \multicolumn{8}{|l|}{$\begin{array}{l}\text { Asthma control- } \\
\text { composite measures }\end{array}$} \\
\hline ACT & 0 & NA & NA & NA & NA & NA & $\begin{array}{l}\text { Insufficient } \\
\text { (no evidence) }\end{array}$ \\
\hline ACQ-5 score & 0 & NA & NA & NA & NA & NA & $\begin{array}{l}\text { Insufficient } \\
\text { (no evidence) }\end{array}$ \\
\hline ACQ-5 responder & 0 & NA & NA & NA & NA & NA & $\begin{array}{l}\text { Insufficient } \\
\text { (no evidence) }\end{array}$ \\
\hline ACQ-6 score & 0 & NA & NA & NA & NA & NA & $\begin{array}{l}\text { Insufficient } \\
\text { (no evidence) }\end{array}$ \\
\hline ACQ-6 responder & 0 & NA & NA & NA & NA & NA & $\begin{array}{l}\text { Insufficient } \\
\text { (no evidence) }\end{array}$ \\
\hline ACQ-7 score & $\begin{array}{l}4 \\
(2304) \\
\end{array}$ & Low & Inconsistent & Direct & Precise & Undetected & $\begin{array}{l}\text { Moderate } \\
\text { (inconsistent) }\end{array}$ \\
\hline ACQ-7 responder & $\begin{array}{l}5 \\
(2680) \\
\end{array}$ & Low & Inconsistent & Direct & Precise & Undetected & $\begin{array}{l}\text { Moderate } \\
\text { (inconsistent) }\end{array}$ \\
\hline
\end{tabular}




\begin{tabular}{|c|c|c|c|c|c|c|c|}
\hline Outcome & $\begin{array}{l}\mathrm{N} \text { of studies } \\
\text { ( } \mathrm{n} \text { of patients) }\end{array}$ & Risk of bias & Consistency & Directness & Precision & Publication bias & $\begin{array}{l}\text { Strength of } \\
\text { evidence }\end{array}$ \\
\hline \multicolumn{8}{|l|}{$\begin{array}{l}\text { Asthma control- } \\
\text { spirometry }\end{array}$} \\
\hline FEV1 peak & $\begin{array}{l}4 \\
(2310)\end{array}$ & Low & Consistent & Direct & Precise & Undetected & High \\
\hline FEV1 trough & $\begin{array}{l}7 \\
(3173)\end{array}$ & Low & Consistent & Direct & Precise & Undetected & High \\
\hline FEV1 AUC & $\begin{array}{l}3 \\
(2310)\end{array}$ & Low & Consistent & Direct & Precise & Undetected & High \\
\hline FEV1 \% predicted & $\begin{array}{l}1 \\
(457)\end{array}$ & Low & $\begin{array}{l}\text { Unknown } \\
\text { (single study) }\end{array}$ & Direct & Precise & Undetected & $\begin{array}{l}\text { Low } \\
\text { (unknown } \\
\text { consistency) }\end{array}$ \\
\hline FVC peak & $\begin{array}{l}3 \\
(1853)\end{array}$ & Low & Consistent & Direct & Precise & Undetected & High \\
\hline FVC trough & $\begin{array}{l}5 \\
(2390)\end{array}$ & Low & Consistent & Direct & Precise & Undetected & High \\
\hline FVC AUC & $\begin{array}{l}3 \\
1859) \\
\end{array}$ & Low & Consistent & Direct & Precise & Undetected & High \\
\hline FEV1/FVC & 0 & NA & NA & NA & NA & NA & $\begin{array}{l}\text { Insufficient } \\
\text { (no evidence) }\end{array}$ \\
\hline \multicolumn{8}{|l|}{ Quality of life } \\
\hline AQLQ score & $\begin{array}{l}2 \\
(1461)\end{array}$ & Low & Consistent & Direct & Precise & Undetected & High \\
\hline AQLQ responder & 0 & NA & NA & $\mathrm{NA}$ & $\mathrm{NA}$ & NA & $\begin{array}{l}\text { Insufficient } \\
\text { (no evidence) }\end{array}$ \\
\hline AQLQ-mini score & $\begin{array}{l}1 \\
(253)\end{array}$ & Low & $\begin{array}{l}\text { Unknown } \\
\text { (single study) }\end{array}$ & Direct & Precise & Undetected & $\begin{array}{l}\text { Low } \\
\text { (unknown } \\
\text { consistency) }\end{array}$ \\
\hline AQLQ-S 12+ responder & $\begin{array}{l}1 \\
(397)\end{array}$ & Low & $\begin{array}{l}\text { Unknown } \\
\text { (single study) }\end{array}$ & Direct & Precise & Undetected & $\begin{array}{l}\text { Low } \\
\text { (unknown } \\
\text { consistency) }\end{array}$ \\
\hline \multicolumn{8}{|l|}{ Healthcare utilization } \\
\hline $\begin{array}{l}\text { Rescue medication use, } \\
\text { puffs/24 hours }\end{array}$ & $\begin{array}{l}7 \\
(3104)\end{array}$ & Low & Inconsistent & Direct & Precise & Undetected & $\begin{array}{l}\text { Moderate } \\
\text { (inconsistent) }\end{array}$ \\
\hline Resource use & 0 & NA & NA & NA & NA & NA & $\begin{array}{l}\text { Insufficient } \\
\text { (no evidence) }\end{array}$ \\
\hline
\end{tabular}

Abbreviations: ACQ=Asthma Control Questionnaire; ACT=Asthma Control Test; AQLQ=Asthma Quality of Life Questionnaire; AQLQ-S=Standardized Asthma Quality of Life Questionnaire; AUC=area under curve; ER=emergency room; FVC=forced vital capacity; FEV1=forced expiratory volume in one second; ICU=intensive care unit; n= patient sample size; N=number of studies; NA=not applicable 
Table E-13. Strength of evidence KQ2b, LAMA vs. LABA as add-on to ICS

\begin{tabular}{|c|c|c|c|c|c|c|c|}
\hline Outcome & $\begin{array}{l}\mathrm{N} \text { of studies } \\
\text { ( } \mathrm{n} \text { of patients) }\end{array}$ & Risk of bias & Consistency & Directness & Precision & Publication bias & $\begin{array}{l}\text { Strength of } \\
\text { evidence }\end{array}$ \\
\hline \multicolumn{8}{|l|}{ Exacerbations } \\
\hline $\begin{array}{l}\text { Requiring systemic } \\
\text { corticosteroid }\end{array}$ & $\begin{array}{l}4 \\
(2574)\end{array}$ & Low & Inconsistent & Direct & Imprecise & Undetected & $\begin{array}{l}\text { Low } \\
\text { (inconsistent, } \\
\text { imprecise) }\end{array}$ \\
\hline $\begin{array}{l}\text { Requiring } \\
\text { hospitalization }\end{array}$ & 0 & NA & NA & NA & NA & NA & $\begin{array}{l}\text { Insufficient } \\
\text { (no evidence) }\end{array}$ \\
\hline Requiring ER visit & 0 & NA & NA & NA & NA & NA & $\begin{array}{l}\text { Insufficient } \\
\text { (no evidence) }\end{array}$ \\
\hline $\begin{array}{l}\text { Requiring ICU/ } \\
\text { ventilation }\end{array}$ & 0 & NA & NA & NA & NA & NA & $\begin{array}{l}\text { Insufficient } \\
\text { (no evidence) }\end{array}$ \\
\hline $\begin{array}{l}\text { Asthma-related } \\
\text { hospitalization }\end{array}$ & 0 & NA & NA & NA & NA & NA & $\begin{array}{l}\text { Insufficient } \\
\text { (no evidence) }\end{array}$ \\
\hline Asthma-related ER visit & 0 & NA & NA & NA & NA & NA & $\begin{array}{l}\text { Insufficient } \\
\text { (no evidence) }\end{array}$ \\
\hline $\begin{array}{l}\text { Asthma-related } \\
\text { outpatient visit }\end{array}$ & 0 & NA & NA & NA & NA & NA & $\begin{array}{l}\text { Insufficient } \\
\text { (no evidence) }\end{array}$ \\
\hline Asthma worsening & $\begin{array}{l}1 \\
(1577)\end{array}$ & Low & $\begin{array}{l}\text { Unknown } \\
\text { (single study) }\end{array}$ & Direct & Precise & Undetected & $\begin{array}{l}\text { Moderate } \\
\text { (unknown } \\
\text { consistency) }\end{array}$ \\
\hline $\begin{array}{l}\text { Requiring oral } \\
\text { corticosteroid or } \\
\text { increase in ICS or other } \\
\text { asthma medication }\end{array}$ & $\begin{array}{l}1 \\
(210)\end{array}$ & Low & $\begin{array}{l}\text { Unknown } \\
\text { (single study) }\end{array}$ & Direct & Imprecise & Undetected & $\begin{array}{l}\text { Low } \\
\text { (unknown } \\
\text { consistency, } \\
\text { imprecise) }\end{array}$ \\
\hline \multicolumn{8}{|l|}{ Mortality } \\
\hline All-cause & $\begin{array}{l}4 \\
(3572)\end{array}$ & Low & Inconsistent & Direct & Imprecise & Undetected & $\begin{array}{l}\text { Low } \\
\text { (inconsistent, } \\
\text { imprecise) }\end{array}$ \\
\hline Asthma-specific & $\begin{array}{l}4 \\
(3572)\end{array}$ & Low & Inconsistent & Direct & Imprecise & Undetected & $\begin{array}{l}\text { Low } \\
\text { (inconsistent, } \\
\text { imprecise) }\end{array}$ \\
\hline \multicolumn{8}{|l|}{$\begin{array}{l}\text { Asthma control- } \\
\text { composite measures }\end{array}$} \\
\hline $\mathrm{ACT}$ & 0 & NA & NA & NA & NA & NA & $\begin{array}{l}\text { Insufficient } \\
\text { (no evidence) }\end{array}$ \\
\hline ACQ-5 score & 0 & NA & NA & NA & NA & NA & $\begin{array}{l}\text { Insufficient } \\
\text { (no evidence) }\end{array}$ \\
\hline ACQ-5 responder & 0 & NA & NA & NA & NA & NA & $\begin{array}{l}\text { Insufficient } \\
\text { (no evidence) }\end{array}$ \\
\hline
\end{tabular}




\begin{tabular}{|c|c|c|c|c|c|c|c|}
\hline Outcome & $\begin{array}{l}\mathrm{N} \text { of studies } \\
\text { ( } \mathrm{n} \text { of patients) }\end{array}$ & Risk of bias & Consistency & Directness & Precision & Publication bias & $\begin{array}{l}\text { Strength of } \\
\text { evidence }\end{array}$ \\
\hline ACQ-6 score & $\begin{array}{l}1 \\
(126)\end{array}$ & Low & $\begin{array}{l}\text { Unknown } \\
\text { (single study) }\end{array}$ & Direct & Imprecise & Undetected & $\begin{array}{l}\text { Low } \\
\text { (unknown } \\
\text { consistency, } \\
\text { imprecise) }\end{array}$ \\
\hline ACQ-6 responder & 0 & NA & NA & NA & NA & NA & $\begin{array}{l}\text { Insufficient } \\
\text { (no evidence) }\end{array}$ \\
\hline ACQ-7 score & $\begin{array}{l}2 \\
(1577) \\
\end{array}$ & Low & Consistent & Direct & Precise & Undetected & High \\
\hline ACQ-7 responder & $\begin{array}{l}2 \\
(1577)\end{array}$ & Low & Consistent & Direct & Precise & Undetected & High \\
\hline \multicolumn{8}{|l|}{$\begin{array}{l}\text { Asthma control- } \\
\text { spirometry }\end{array}$} \\
\hline FEV1 peak & $\begin{array}{l}2 \\
(1483) \\
\end{array}$ & Low & Consistent & Direct & Precise & Undetected & High \\
\hline FEV1 trough & $\begin{array}{l}6 \\
(3261) \\
\end{array}$ & Low & Consistent & Direct & Precise & Undetected & High \\
\hline FEV1 AUC & $\begin{array}{l}2 \\
(1483)\end{array}$ & Low & Consistent & Direct & Precise & Undetected & High \\
\hline FEV1 \% predicted & $\begin{array}{l}3 \\
(542)\end{array}$ & Medium & Inconsistent & Direct & Precise & Undetected & $\begin{array}{l}\text { Low } \\
\text { (risk of bias, } \\
\text { inconsistent) }\end{array}$ \\
\hline FVC peak & $\begin{array}{l}2 \\
(1483)\end{array}$ & Low & Consistent & Direct & Precise & Undetected & High \\
\hline FVC trough & $\begin{array}{l}2 \\
(1745)\end{array}$ & Low & Consistent & Direct & Precise & Undetected & High \\
\hline FVC AUC & $\begin{array}{l}2 \\
(1483)\end{array}$ & Low & Consistent & Direct & Precise & Undetected & High \\
\hline FEV1/FVC & 0 & NA & NA & NA & NA & NA & $\begin{array}{l}\text { Insufficient } \\
\text { (no evidence) }\end{array}$ \\
\hline \multicolumn{8}{|l|}{ Quality of life } \\
\hline AQLQ score & $\begin{array}{l}4 \\
(1982)\end{array}$ & Low & Consistent & Direct & Precise & Undetected & High \\
\hline AQLQ responder & 0 & NA & NA & NA & NA & NA & $\begin{array}{l}\text { Insufficient } \\
\text { (no evidence) }\end{array}$ \\
\hline AQLQ-mini score & $\begin{array}{l}1 \\
(262)\end{array}$ & Low & $\begin{array}{l}\text { Unknown } \\
\text { (single study) }\end{array}$ & Direct & Precise & Undetected & $\begin{array}{l}\text { Low } \\
\text { (unknown } \\
\text { consistency) }\end{array}$ \\
\hline AQLQ-S 12+ responder & 0 & NA & NA & NA & NA & NA & $\begin{array}{l}\text { Insufficient } \\
\text { (no evidence) }\end{array}$ \\
\hline
\end{tabular}




\begin{tabular}{|c|c|c|c|c|c|c|c|}
\hline Outcome & $\begin{array}{l}\mathrm{N} \text { of studies } \\
\text { ( } \mathrm{n} \text { of patients) }\end{array}$ & Risk of bias & Consistency & Directness & Precision & Publication bias & $\begin{array}{l}\text { Strength of } \\
\text { evidence }\end{array}$ \\
\hline $\begin{array}{l}\text { Rescue medication use, } \\
\text { puffs/24 hours }\end{array}$ & $\begin{array}{l}7 \\
(2450)\end{array}$ & Low & Inconsistent & Direct & Imprecise & Undetected & $\begin{array}{l}\text { Low } \\
\text { (inconsistent, } \\
\text { imprecise) }\end{array}$ \\
\hline Resource use & 0 & NA & NA & NA & NA & NA & $\begin{array}{l}\text { Insufficient } \\
\text { (no evidence) }\end{array}$ \\
\hline
\end{tabular}

Abbreviations: ACQ=Asthma Control Questionnaire; ACT=Asthma Control Test; AQLQ=Asthma Quality of Life Questionnaire; AQLQ-S= Standardized Asthma Quality of Life Questionnaire; AUC=area under curve; ER=emergency room; FVC=forced vital capacity; FEV1=forced expiratory volume in one second; h=hour; ICU=intensive care unit;

LAMA=long acting muscarinic antagonist; $n=$ patient sample size; $N=$ number of studies; $N A=$ not applicable

Table E-14. Strength of evidence KQ2a, LAMA vs. controller other than LABA as add-on to ICS

\begin{tabular}{|c|c|c|c|c|c|c|c|}
\hline Outcome & $\begin{array}{l}N \text { of studies } \\
\text { ( } n \text { of patients) }\end{array}$ & $\begin{array}{l}\text { Study } \\
\text { limitations }\end{array}$ & Consistency & Directness & Precision & Publication bias & $\begin{array}{l}\text { Strength of } \\
\text { evidence }\end{array}$ \\
\hline \multicolumn{8}{|l|}{ Exacerbations } \\
\hline $\begin{array}{l}\text { Requiring systemic } \\
\text { corticosteroid }\end{array}$ & 0 & NA & NA & NA & NA & NA & $\begin{array}{l}\text { Insufficient } \\
\text { (no evidence) }\end{array}$ \\
\hline $\begin{array}{l}\text { Requiring } \\
\text { hospitalization }\end{array}$ & 0 & NA & NA & NA & NA & NA & $\begin{array}{l}\text { Insufficient } \\
\text { (no evidence) }\end{array}$ \\
\hline Requiring ER visit & 0 & NA & NA & NA & NA & NA & $\begin{array}{l}\text { Insufficient } \\
\text { (no evidence) }\end{array}$ \\
\hline $\begin{array}{l}\text { Requiring ICU/ } \\
\text { ventilation }\end{array}$ & 0 & NA & $\mathrm{NA}$ & NA & $\mathrm{NA}$ & $\mathrm{NA}$ & $\begin{array}{l}\text { Insufficient } \\
\text { (no evidence) }\end{array}$ \\
\hline $\begin{array}{l}\text { Asthma-related } \\
\text { hospitalization }\end{array}$ & 0 & NA & NA & NA & NA & NA & $\begin{array}{l}\text { Insufficient } \\
\text { (no evidence) }\end{array}$ \\
\hline Asthma-related ER visit & 0 & NA & NA & NA & NA & NA & $\begin{array}{l}\text { Insufficient } \\
\text { (no evidence) }\end{array}$ \\
\hline $\begin{array}{l}\text { Asthma-related } \\
\text { outpatient visit }\end{array}$ & 0 & $\mathrm{NA}$ & NA & NA & NA & $\mathrm{NA}$ & $\begin{array}{l}\text { Insufficient } \\
\text { (no evidence) }\end{array}$ \\
\hline Asthma worsening & 0 & NA & NA & NA & NA & NA & $\begin{array}{l}\text { Insufficient } \\
\text { (no evidence) }\end{array}$ \\
\hline \multicolumn{8}{|l|}{ Mortality } \\
\hline All-cause & 0 & NA & NA & NA & NA & NA & $\begin{array}{l}\text { Insufficient } \\
\text { (no evidence) }\end{array}$ \\
\hline Asthma-specific & 0 & NA & NA & NA & NA & NA & $\begin{array}{l}\text { Insufficient } \\
\text { (no evidence) }\end{array}$ \\
\hline \multicolumn{8}{|l|}{$\begin{array}{l}\text { Asthma control- } \\
\text { composite measures }\end{array}$} \\
\hline $\mathrm{ACT}$ & 0 & NA & NA & NA & NA & NA & $\begin{array}{l}\text { Insufficient } \\
\text { (no evidence) }\end{array}$ \\
\hline ACQ-5 score & 0 & NA & NA & NA & NA & NA & $\begin{array}{l}\text { Insufficient } \\
\text { (no evidence) }\end{array}$ \\
\hline
\end{tabular}




\begin{tabular}{|c|c|c|c|c|c|c|c|}
\hline Outcome & $\begin{array}{l}\mathrm{N} \text { of studies } \\
\text { ( } \mathrm{n} \text { of patients) }\end{array}$ & \begin{tabular}{|l} 
Study \\
limitations
\end{tabular} & Consistency & Directness & Precision & Publication bias & $\begin{array}{l}\text { Strength of } \\
\text { evidence }\end{array}$ \\
\hline ACQ-5 responder & 0 & NA & NA & NA & NA & NA & $\begin{array}{l}\text { Insufficient } \\
\text { (no evidence) }\end{array}$ \\
\hline ACQ-6 score & 0 & NA & NA & NA & $\mathrm{NA}$ & $\mathrm{NA}$ & $\begin{array}{l}\text { Insufficient } \\
\text { (no evidence) }\end{array}$ \\
\hline ACQ-6 responder & 0 & NA & NA & NA & $\mathrm{NA}$ & NA & $\begin{array}{l}\text { Insufficient } \\
\text { (no evidence) }\end{array}$ \\
\hline ACQ-7 score & 0 & NA & NA & NA & NA & NA & $\begin{array}{l}\text { Insufficient } \\
\text { (no evidence) }\end{array}$ \\
\hline ACQ-7 responder & 0 & NA & NA & NA & NA & $\mathrm{NA}$ & $\begin{array}{l}\text { Insufficient } \\
\text { (no evidence) }\end{array}$ \\
\hline \multicolumn{8}{|l|}{$\begin{array}{l}\text { Asthma control- } \\
\text { spirometry }\end{array}$} \\
\hline FEV1 peak & 0 & NA & NA & NA & $\mathrm{NA}$ & NA & $\begin{array}{l}\text { Insufficient } \\
\text { (no evidence) }\end{array}$ \\
\hline FEV1 trough & 0 & NA & NA & NA & NA & NA & $\begin{array}{l}\text { Insufficient } \\
\text { (no evidence) }\end{array}$ \\
\hline FEV1 AUC & 0 & NA & NA & NA & $\mathrm{NA}$ & NA & $\begin{array}{l}\text { Insufficient } \\
\text { (no evidence) }\end{array}$ \\
\hline $\begin{array}{l}\text { FEV1 \% predicted } \\
\text { LAMA vs. montelukast }\end{array}$ & $\begin{array}{l}2 \\
(214)\end{array}$ & Medium & Consistent & Direct & Precise & Undetected & $\begin{array}{l}\text { Moderate } \\
\text { (risk of bias) }\end{array}$ \\
\hline $\begin{array}{l}\text { FEV1 \% predicted } \\
\text { LAMA vs. doxofylline }\end{array}$ & $\begin{array}{l}2 \\
(209)\end{array}$ & Medium & Consistent & Direct & Precise & Undetected & $\begin{array}{l}\text { Moderate } \\
\text { (risk of bias) }\end{array}$ \\
\hline FVC peak & 0 & NA & NA & NA & $\mathrm{NA}$ & NA & $\begin{array}{l}\text { Insufficient } \\
\text { (no evidence) }\end{array}$ \\
\hline FVC trough & 0 & NA & NA & NA & NA & NA & $\begin{array}{l}\text { Insufficient } \\
\text { (no evidence) }\end{array}$ \\
\hline FVC AUC & 0 & NA & NA & $\mathrm{NA}$ & NA & NA & $\begin{array}{l}\text { Insufficient } \\
\text { (no evidence) }\end{array}$ \\
\hline FEV1/FVC & 0 & NA & NA & NA & $\mathrm{NA}$ & NA & $\begin{array}{l}\text { Insufficient } \\
\text { (no evidence) }\end{array}$ \\
\hline \multicolumn{8}{|l|}{ Quality of life } \\
\hline AQLQ score & 0 & NA & NA & $\mathrm{NA}$ & $\mathrm{NA}$ & NA & $\begin{array}{l}\text { Insufficient } \\
\text { (no evidence) }\end{array}$ \\
\hline AQLQ responder & 0 & NA & NA & NA & NA & NA & $\begin{array}{l}\text { Insufficient } \\
\text { (no evidence) }\end{array}$ \\
\hline AQLQ-mini score & 0 & NA & NA & NA & $\mathrm{NA}$ & NA & $\begin{array}{l}\text { Insufficient } \\
\text { (no evidence) }\end{array}$ \\
\hline AQLQ-S 12+ responder & 0 & NA & NA & NA & NA & NA & $\begin{array}{l}\text { Insufficient } \\
\text { (no evidence) }\end{array}$ \\
\hline
\end{tabular}




\begin{tabular}{|c|c|c|c|c|c|c|c|}
\hline Outcome & $\begin{array}{l}\mathrm{N} \text { of studies } \\
\text { ( } \mathrm{n} \text { of patients) }\end{array}$ & $\begin{array}{l}\text { Study } \\
\text { limitations }\end{array}$ & Consistency & Directness & Precision & Publication bias & $\begin{array}{l}\text { Strength of } \\
\text { evidence }\end{array}$ \\
\hline $\begin{array}{l}\text { Rescue medication use, } \\
\text { puffs/24 hours } \\
\text { LAMA vs. montelukast }\end{array}$ & (214) & Medium & Inconsistent & Direct & Precise & Undetected & $\begin{array}{l}\text { Low } \\
\text { (risk of bias, } \\
\text { inconsistent) }\end{array}$ \\
\hline $\begin{array}{l}\text { Rescue medication use, } \\
\text { puffs/24 hours } \\
\text { LAMA vs. doxofylline }\end{array}$ & $\begin{array}{l}2 \\
(209)\end{array}$ & Medium & Inconsistent & Direct & Precise & Undetected & $\begin{array}{l}\text { Low } \\
\text { (risk of bias } \\
\text { inconsistent) }\end{array}$ \\
\hline Resource use & 0 & NA & NA & NA & NA & NA & $\begin{array}{l}\text { Insufficient } \\
\text { (no evidence) }\end{array}$ \\
\hline
\end{tabular}

Abbreviations: ACQ=Asthma Control Questionnaire; ACT=Asthma Control Test; AQLQ=Asthma Quality of Life Questionnaire; AQLQ-S= Standardized Asthma Quality of Life Questionnaire; AUC=area under curve; ER=emergency room; FVC=forced vital capacity; FEV1=forced expiratory volume in one second; h=hour; ICU=intensive care unit;

LAMA=long acting muscarinic antagonist; $n=$ patient sample size; $N=$ number of studies; $N A=n o t$ applicable

Table E-15. Strength of evidence KQ2C, LAMA and ICS and LABA vs. ICS and LABA

\begin{tabular}{|c|c|c|c|c|c|c|c|}
\hline Outcome & $\begin{array}{l}\mathrm{N} \text { of studies } \\
\text { ( } \mathrm{n} \text { of patients) }\end{array}$ & $\begin{array}{l}\text { Study } \\
\text { limitations }\end{array}$ & Consistency & Directness & Precision & Publication bias & $\begin{array}{l}\text { Strength of } \\
\text { evidence }\end{array}$ \\
\hline \multicolumn{8}{|l|}{ Exacerbations } \\
\hline $\begin{array}{l}\text { Requiring systemic } \\
\text { corticosteroid }\end{array}$ & $\begin{array}{l}3 \\
(1299)\end{array}$ & Low & Consistent & Direct & Imprecise & Undetected & $\begin{array}{l}\text { Moderate } \\
\text { (imprecise) }\end{array}$ \\
\hline $\begin{array}{l}\text { Requiring } \\
\text { hospitalization }\end{array}$ & $\begin{array}{l}2 \\
(907)\end{array}$ & Low & Consistent & Direct & Imprecise & Undetected & $\begin{array}{l}\text { Moderate } \\
\text { (imprecise) }\end{array}$ \\
\hline Requiring ER visit & 0 & NA & NA & NA & NA & NA & $\begin{array}{l}\text { Insufficient } \\
\text { (no evidence) }\end{array}$ \\
\hline $\begin{array}{l}\text { Requiring ICU/ } \\
\text { ventilation }\end{array}$ & 0 & NA & NA & NA & NA & NA & $\begin{array}{l}\text { Insufficient } \\
\text { (no evidence) }\end{array}$ \\
\hline $\begin{array}{l}\text { Asthma-related } \\
\text { hospitalization }\end{array}$ & 0 & NA & NA & NA & NA & NA & $\begin{array}{l}\text { Insufficient } \\
\text { (no evidence) }\end{array}$ \\
\hline Asthma-related ER visit & 0 & NA & NA & NA & NA & NA & $\begin{array}{l}\text { Insufficient } \\
\text { (no evidence) }\end{array}$ \\
\hline $\begin{array}{l}\text { Asthma-related } \\
\text { outpatient visit }\end{array}$ & 0 & NA & NA & NA & NA & NA & $\begin{array}{l}\text { Insufficient } \\
\text { (no evidence) }\end{array}$ \\
\hline Asthma worsening & $\begin{array}{l}3 \\
(1299)\end{array}$ & Low & Consistent & Direct & Precise & Undetected & High \\
\hline \multicolumn{8}{|l|}{ Mortality } \\
\hline All-cause & $\begin{array}{l}3 \\
(1299)\end{array}$ & Low & Consistent & Direct & Precise & Undetected & $\begin{array}{l}\text { Insufficient } \\
\text { (no events } \\
\text { occurred) }\end{array}$ \\
\hline Asthma-specific & $\begin{array}{l}3 \\
(1299)\end{array}$ & Low & Consistent & Direct & Precise & Undetected & $\begin{array}{l}\text { Insufficient } \\
\text { (no events } \\
\text { occurred) }\end{array}$ \\
\hline
\end{tabular}




\begin{tabular}{|c|c|c|c|c|c|c|c|}
\hline Outcome & $\begin{array}{l}\mathrm{N} \text { of studies } \\
\text { ( } \mathrm{n} \text { of patients) }\end{array}$ & $\begin{array}{l}\text { Study } \\
\text { limitations }\end{array}$ & Consistency & Directness & Precision & Publication bias & $\begin{array}{l}\text { Strength of } \\
\text { evidence }\end{array}$ \\
\hline ACT & $\begin{array}{l}1 \\
(63)\end{array}$ & Unclear & $\begin{array}{l}\text { Unknown } \\
\text { (single study) }\end{array}$ & Direct & Imprecise & Undetected & $\begin{array}{l}\text { Low } \\
\text { (unknown } \\
\text { consistency, } \\
\text { imprecise) }\end{array}$ \\
\hline ACQ-5 score & 0 & NA & NA & NA & NA & NA & $\begin{array}{l}\text { Insufficient } \\
\text { (no evidence) }\end{array}$ \\
\hline ACQ-5 responder & $\begin{array}{l}1 \\
(907)\end{array}$ & Low & $\begin{array}{l}\text { Unknown } \\
\text { (single study) }\end{array}$ & Direct & Imprecise & Undetected & $\begin{array}{l}\text { Low } \\
\text { (unknown } \\
\text { consistency, } \\
\text { imprecise) }\end{array}$ \\
\hline ACQ-6 score & $\begin{array}{l}1 \\
(338)\end{array}$ & Low & $\begin{array}{l}\text { Unknown } \\
\text { (single study) }\end{array}$ & Direct & Precise & Undetected & $\begin{array}{l}\text { Low } \\
\text { (unknown } \\
\text { consistency) }\end{array}$ \\
\hline ACQ-6 responder & $\begin{array}{l}2 \\
(1299)\end{array}$ & Low & Inconsistent & Direct & Imprecise & Undetected & $\begin{array}{l}\text { Low } \\
\text { (inconsistent, } \\
\text { imprecise) }\end{array}$ \\
\hline ACQ-7 score & $\begin{array}{l}3 \\
(1301)\end{array}$ & Low & Inconsistent & Direct & Precise & Undetected & $\begin{array}{l}\text { Moderate } \\
\text { (inconsistent) }\end{array}$ \\
\hline ACQ-7 responder & $\begin{array}{l}2 \\
(1299) \\
\end{array}$ & Low & Inconsistent & Direct & Precise & Undetected & $\begin{array}{l}\text { Moderate } \\
\text { (inconsistent) }\end{array}$ \\
\hline \multicolumn{8}{|l|}{$\begin{array}{l}\text { Asthma control- } \\
\text { spirometry }\end{array}$} \\
\hline FEV1 peak & $\begin{array}{l}3 \\
(1295)\end{array}$ & Low & Inconsistent & Direct & Precise & Undetected & $\begin{array}{l}\text { Moderate } \\
\text { (inconsistent) }\end{array}$ \\
\hline FEV1 trough & $\begin{array}{l}3 \\
(1295)\end{array}$ & Low & Inconsistent & Direct & Precise & Undetected & $\begin{array}{l}\text { Moderate } \\
\text { (inconsistent) }\end{array}$ \\
\hline FEV1 AUC & $\begin{array}{l}3 \\
(1295) \\
\end{array}$ & Low & Consistent & Direct & Precise & Undetected & High \\
\hline FEV1 \% predicted & 0 & NA & NA & NA & NA & NA & $\begin{array}{l}\text { Insufficient } \\
\text { (no evidence) }\end{array}$ \\
\hline FVC peak & $\begin{array}{l}3 \\
(1295)\end{array}$ & Low & Consistent & Direct & Precise & Undetected & High \\
\hline FVC trough & $\begin{array}{l}3 \\
(1295) \\
\end{array}$ & Low & Consistent & Direct & Precise & Undetected & High \\
\hline FVC AUC & $\begin{array}{l}3 \\
(1295) \\
\end{array}$ & Low & Consistent & Direct & Precise & Undetected & High \\
\hline FEV1/FVC & 0 & NA & NA & NA & NA & NA & $\begin{array}{l}\text { Insufficient } \\
\text { (no evidence) }\end{array}$ \\
\hline \multicolumn{8}{|l|}{ Quality of life } \\
\hline AQLQ score & $\begin{array}{l}2 \\
(907) \\
\end{array}$ & Low & Consistent & Direct & Precise & Undetected & High \\
\hline
\end{tabular}




\begin{tabular}{|c|c|c|c|c|c|c|c|}
\hline Outcome & $\begin{array}{l}\mathrm{N} \text { of studies } \\
\text { ( } \mathrm{n} \text { of patients) }\end{array}$ & $\begin{array}{l}\text { Study } \\
\text { limitations }\end{array}$ & Consistency & Directness & Precision & Publication bias & $\begin{array}{l}\text { Strength of } \\
\text { evidence }\end{array}$ \\
\hline AQLQ responder & $\begin{array}{l}1 \\
(907)\end{array}$ & Low & $\begin{array}{l}\text { Unknown } \\
\text { (single study) }\end{array}$ & Direct & Imprecise & Undetected & $\begin{array}{l}\text { Moderate } \\
\text { (unknown } \\
\text { consistency } \\
\text { imprecise) }\end{array}$ \\
\hline \multicolumn{8}{|l|}{ Healthcare utilization } \\
\hline $\begin{array}{l}\text { Rescue medication use, } \\
\text { puffs/24 hours }\end{array}$ & $\begin{array}{l}3 \\
(1302)\end{array}$ & Low & Inconsistent & Direct & Precise & Undetected & $\begin{array}{l}\text { Moderate } \\
\text { (inconsistent) }\end{array}$ \\
\hline Resource use & 0 & NA & NA & NA & NA & NA & Insufficient \\
\hline
\end{tabular}

Abbreviations: ACQ=Asthma Control Questionnaire; ACT=Asthma Control Test; AQLQ=Asthma Quality of Life Questionnaire; AUC=area under curve; ER=emergency room; FVC=forced vital capacity; FEV1=forced expiratory volume in one second; h=hour; ICU=intensive care unit; $\mathrm{n}=$ patient sample size; N=number of studies; $\mathrm{NA}=$ not applicable 


\section{Appendix F. Forest Plots}

Figure F-1. Asthma-related acute care visit: intermittent ICS with as-needed SABA vs. as-needed SABA

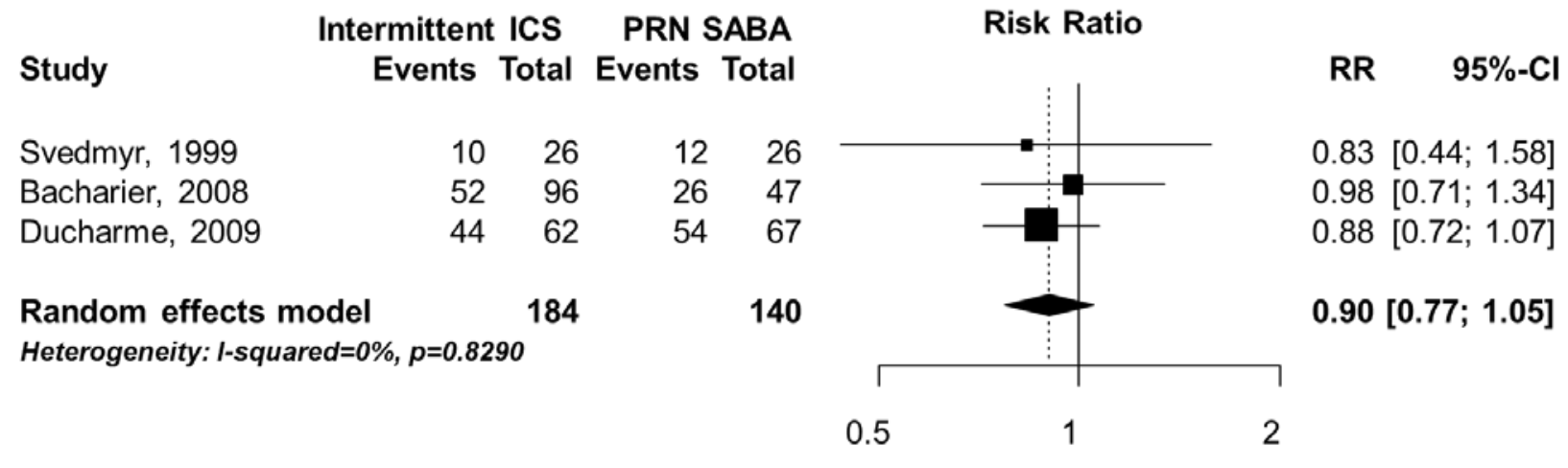

Asthma-Related Acute Care Visit

Figure F-2. Hospital admissions due to asthma: intermittent ICS with as-needed SABA vs. as-needed SABA

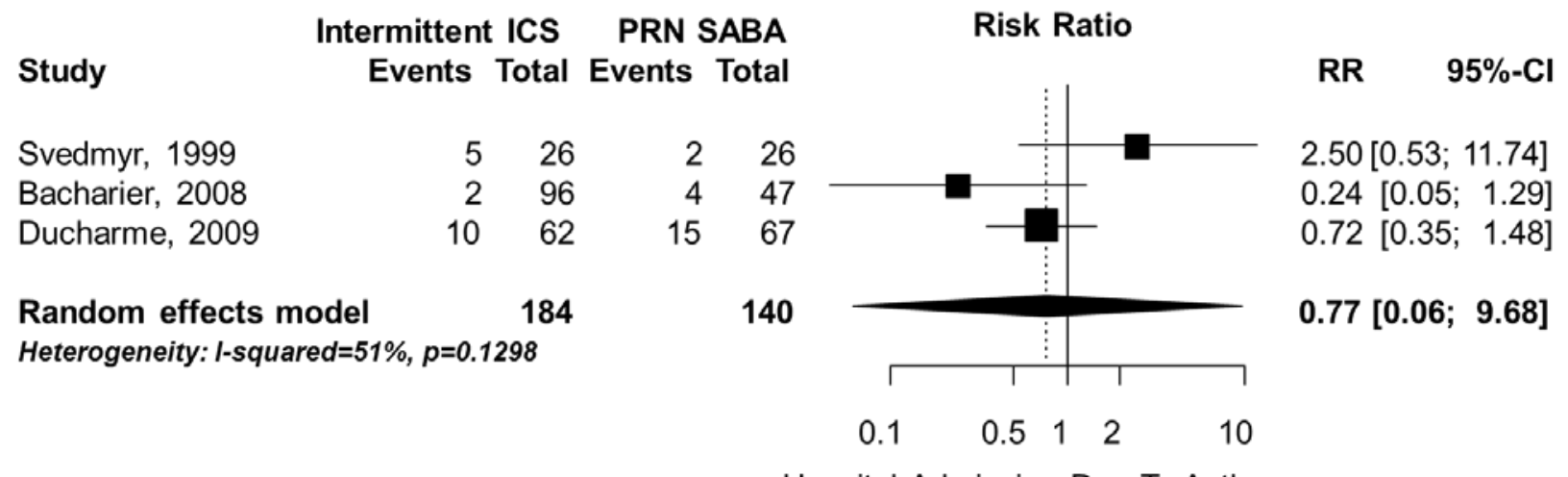

Hospital Admission Due To Asthma

Figure F-3. All-cause death: ICS and LABA controller and quick reliever vs. ICS and LABA controller (same dose)

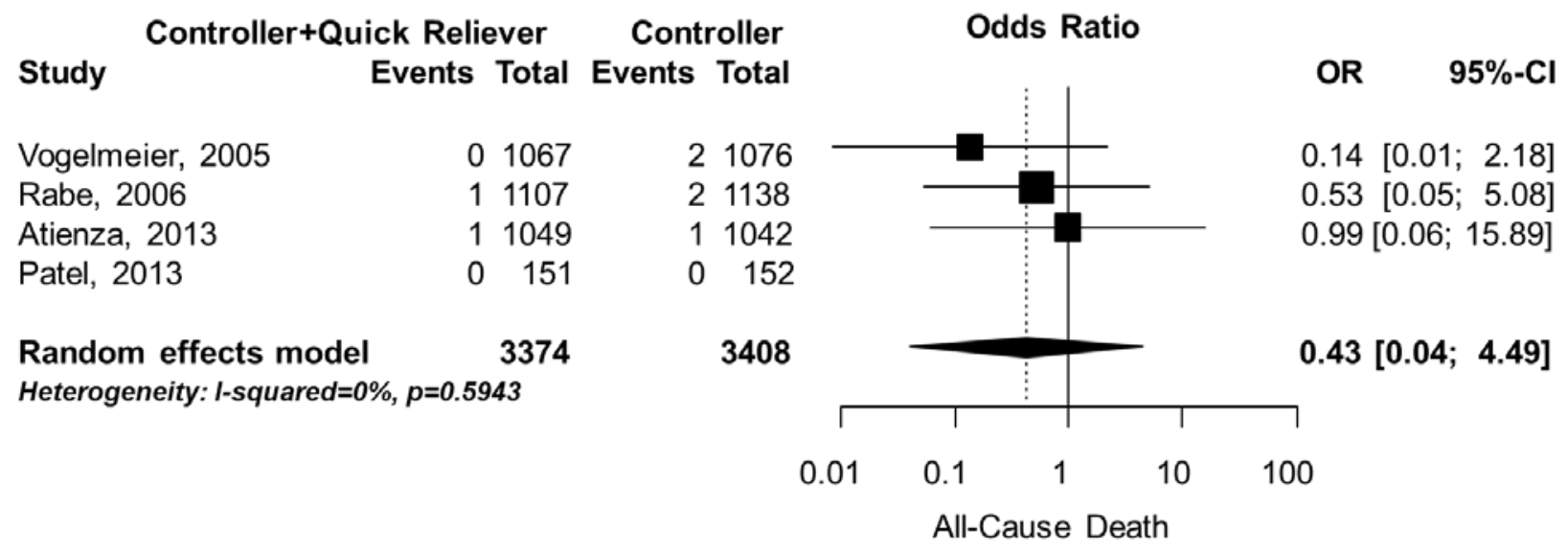


Figure F-4. Change in ACQ-5 mean score from baseline: ICS and LABA controller and quick reliever vs. ICS and LABA controller (same dose)

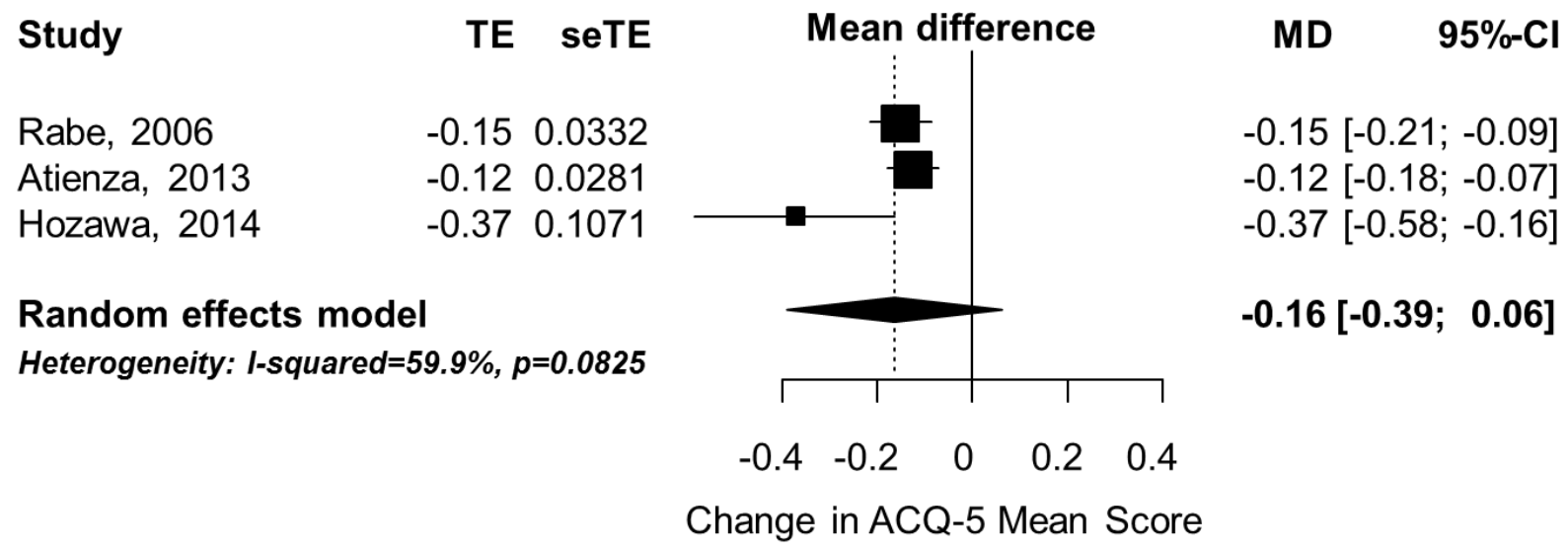

Figure F-5. Change in on-treatment FEV1 from baseline: ICS and LABA controller and quick reliever vs. ICS and LABA controller (same dose)

$\begin{array}{lrl}\text { Study } & \text { TE } & \text { seTE } \\ \text { Rabe, 2006 } & 0.08 & 0.0128 \\ \text { Atienza, 2013 } & 0.04 & 0.0125 \\ \text { Papi, 2013 } & 0.00 & 0.0204 \\ \text { Patel, 2013 } & 0.15 & 0.1071 \\ \text { Takeyama, 2014 } & 0.04 & 0.0102 \\ & \end{array}$

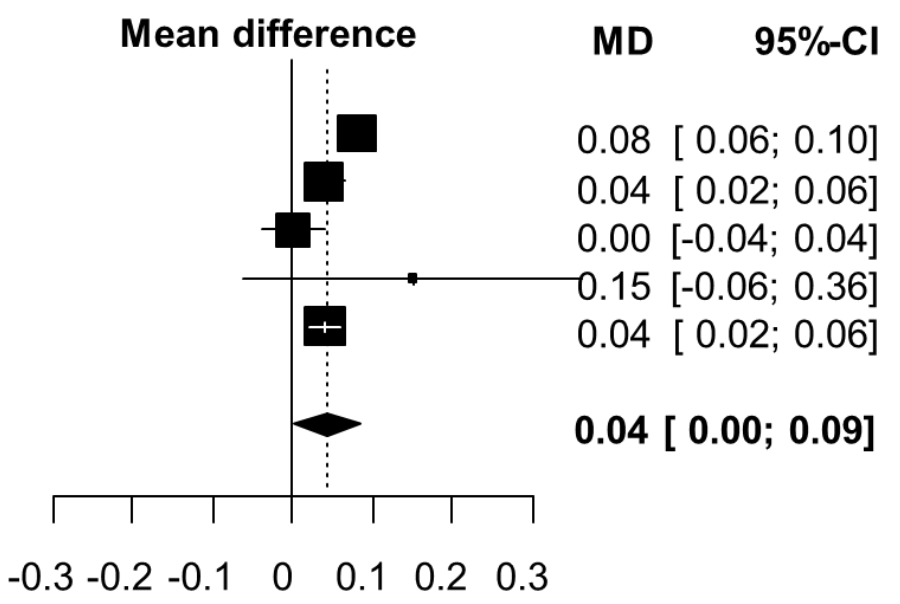

Change in On-Treatment FEV1

Figure F-6. Change in rescue medication use from baseline, mean inhalations per day: ICS and LABA controller and quick reliever vs. ICS and LABA controller (same dose)

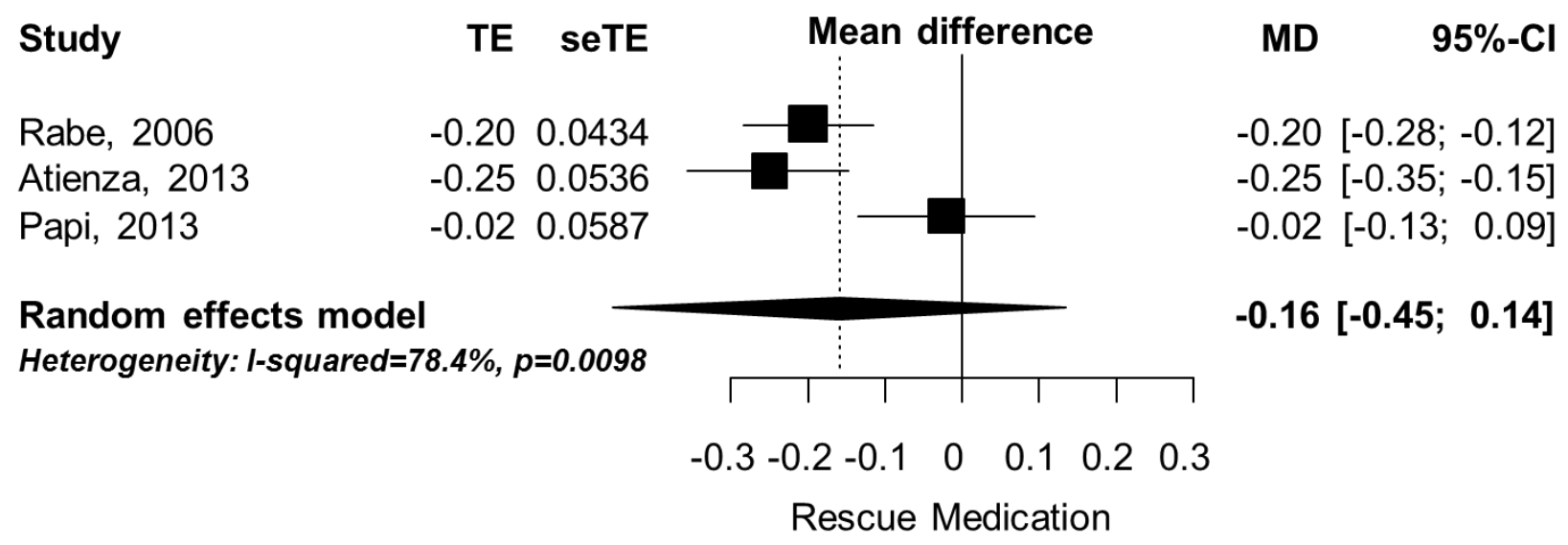


Figure F-7. All-cause death: ICS and LABA controller and quick reliever vs. ICS and LABA controller (higher dose)

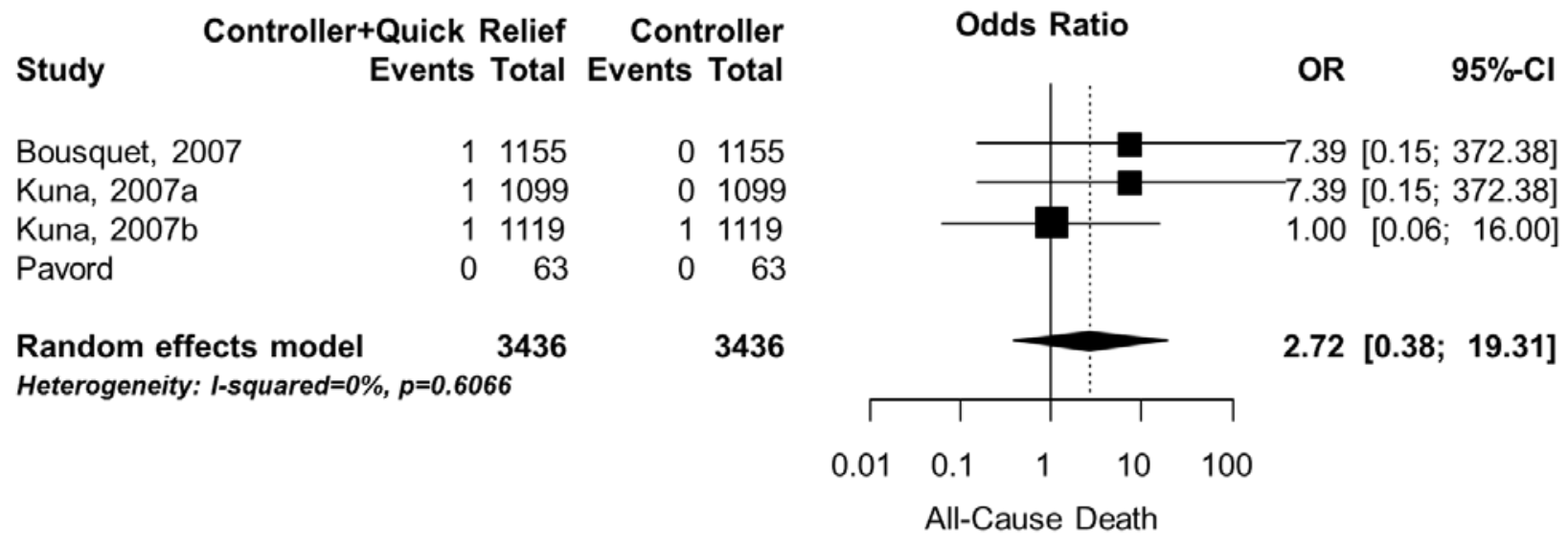

Figure F-8. All-cause death: ICS and LABA controller and quick reliever vs. CBP

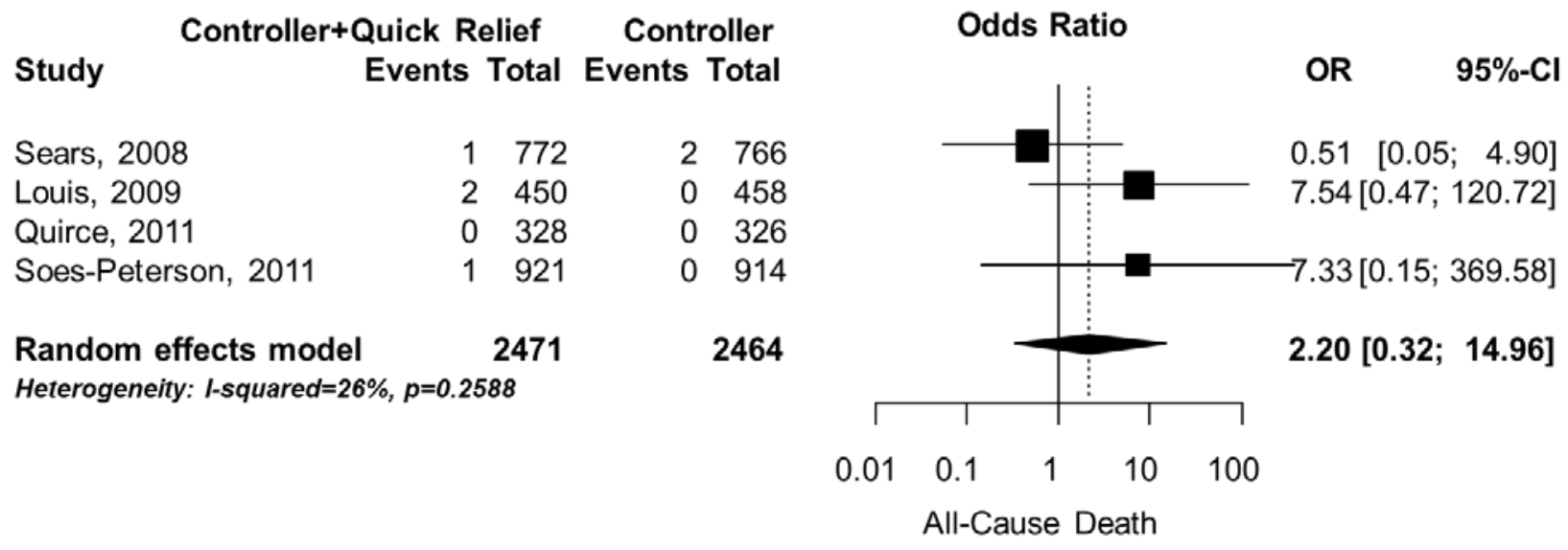

Figure F-9. Change in ACQ-5 mean score from baseline: ICS and LABA controller and quick reliever vs. CBP

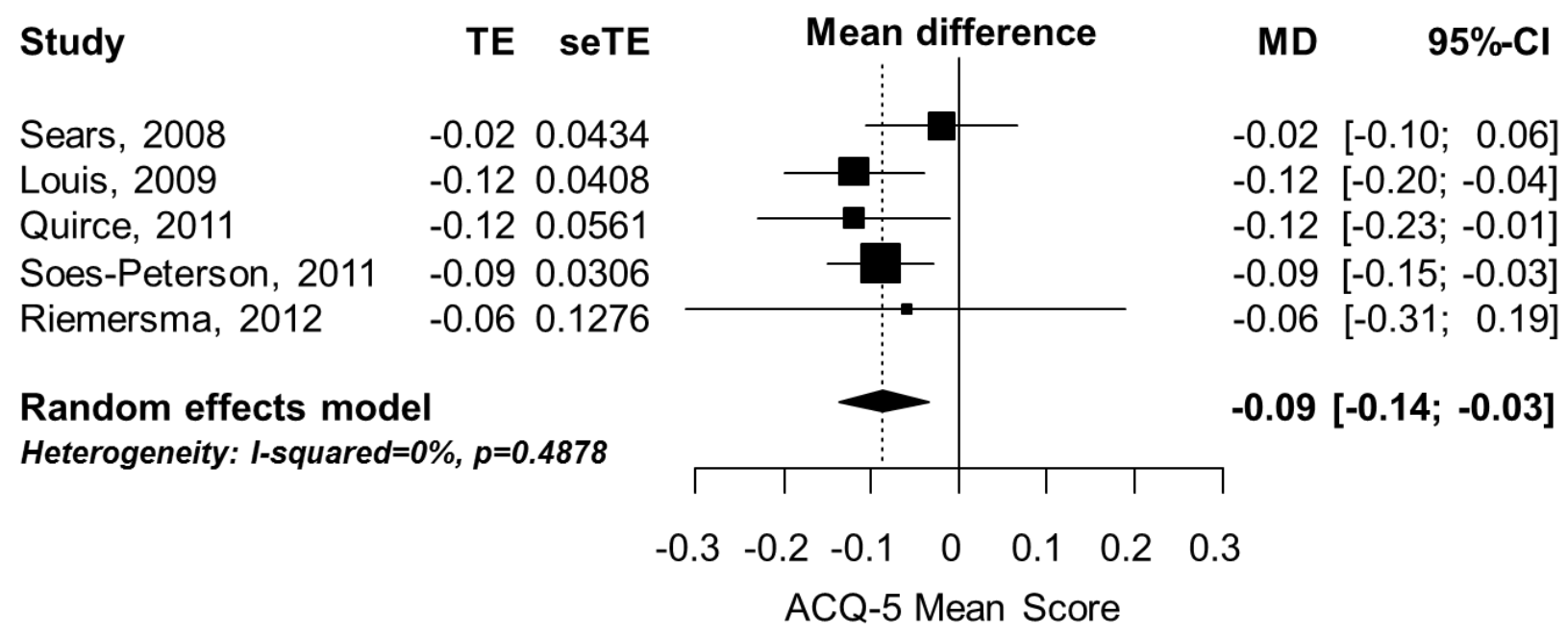


Figure F-10. Change in ACQ-7 score from baseline: LAMA vs. placebo as add-on to ICS

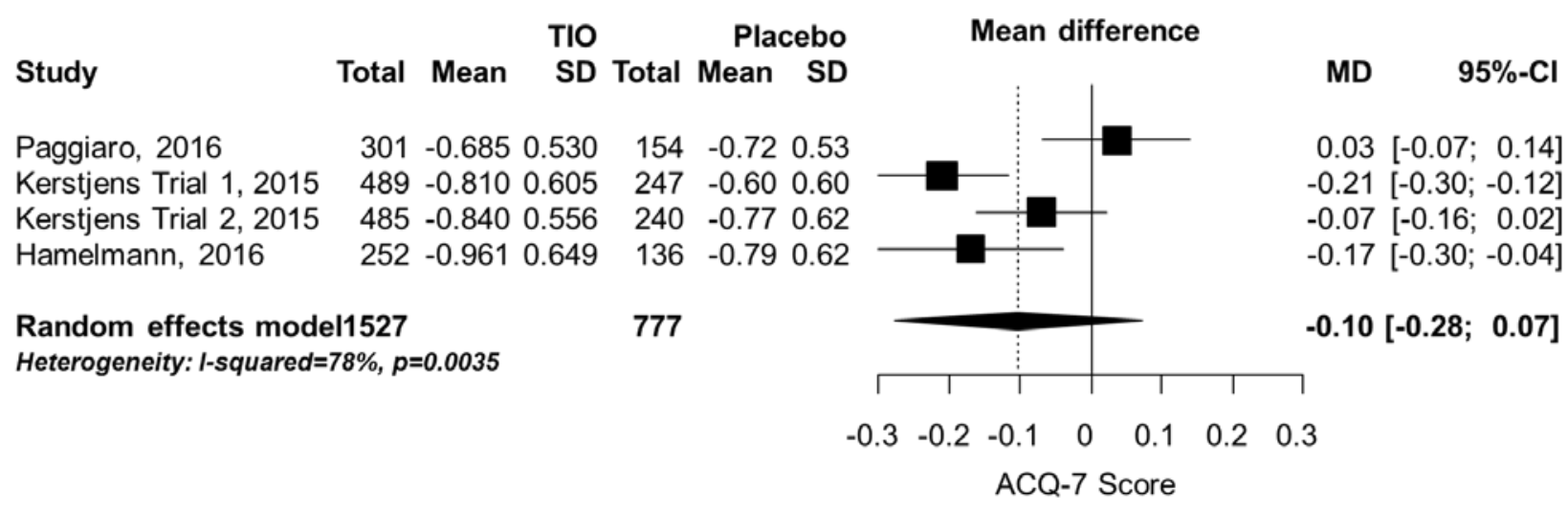

Figure F-11. ACQ-7 responder: LAMA vs. placebo as add-on to ICS

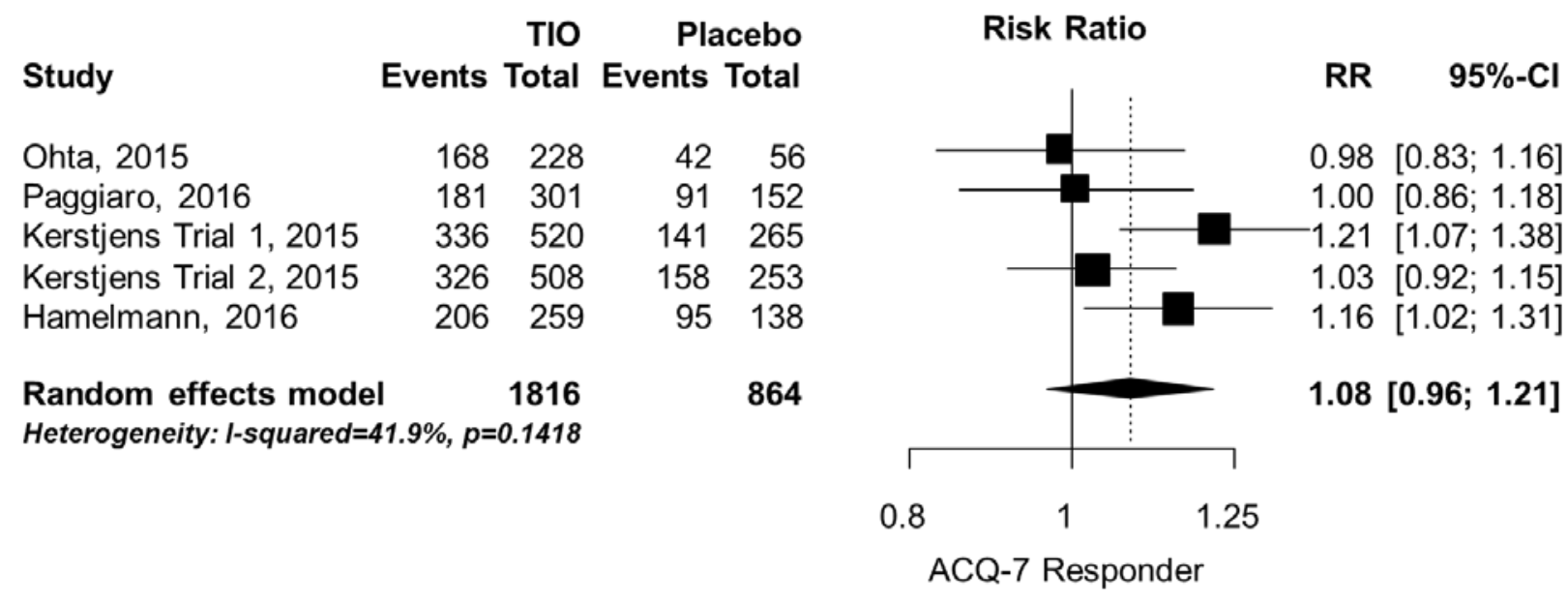

Figure F-12. Change in FEV1 peak from baseline: LAMA vs. placebo as add-on to ICS

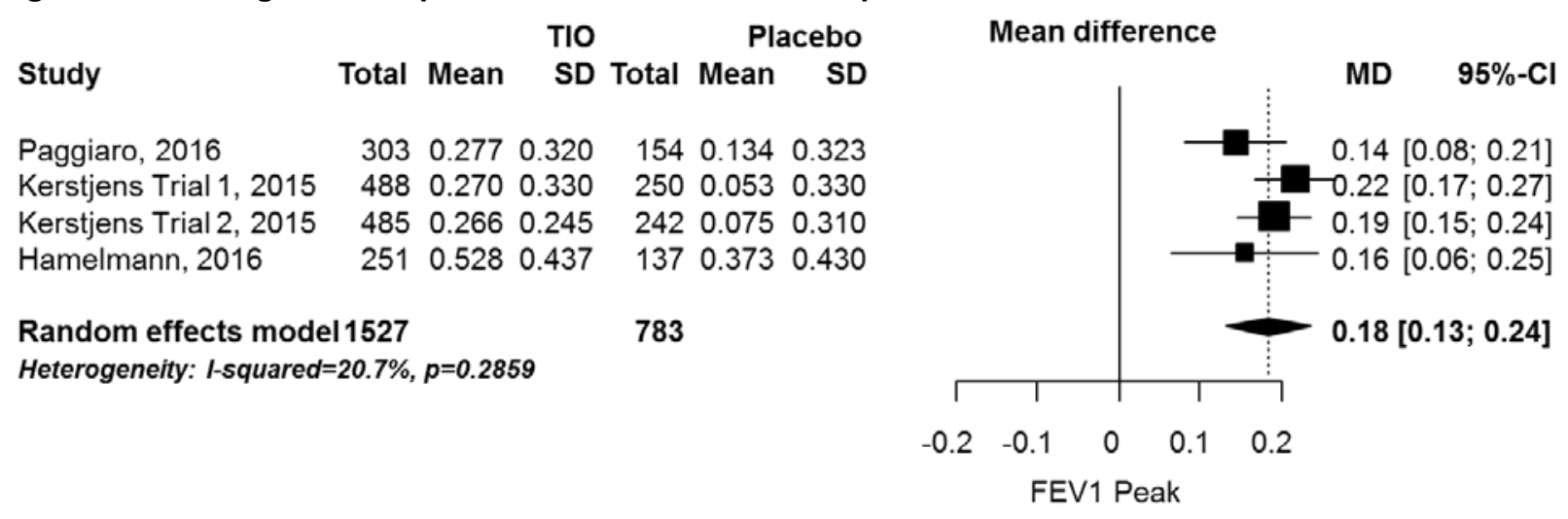


Figure F-13. Change in FEV1 trough from baseline: LAMA vs. placebo as add-on to ICS

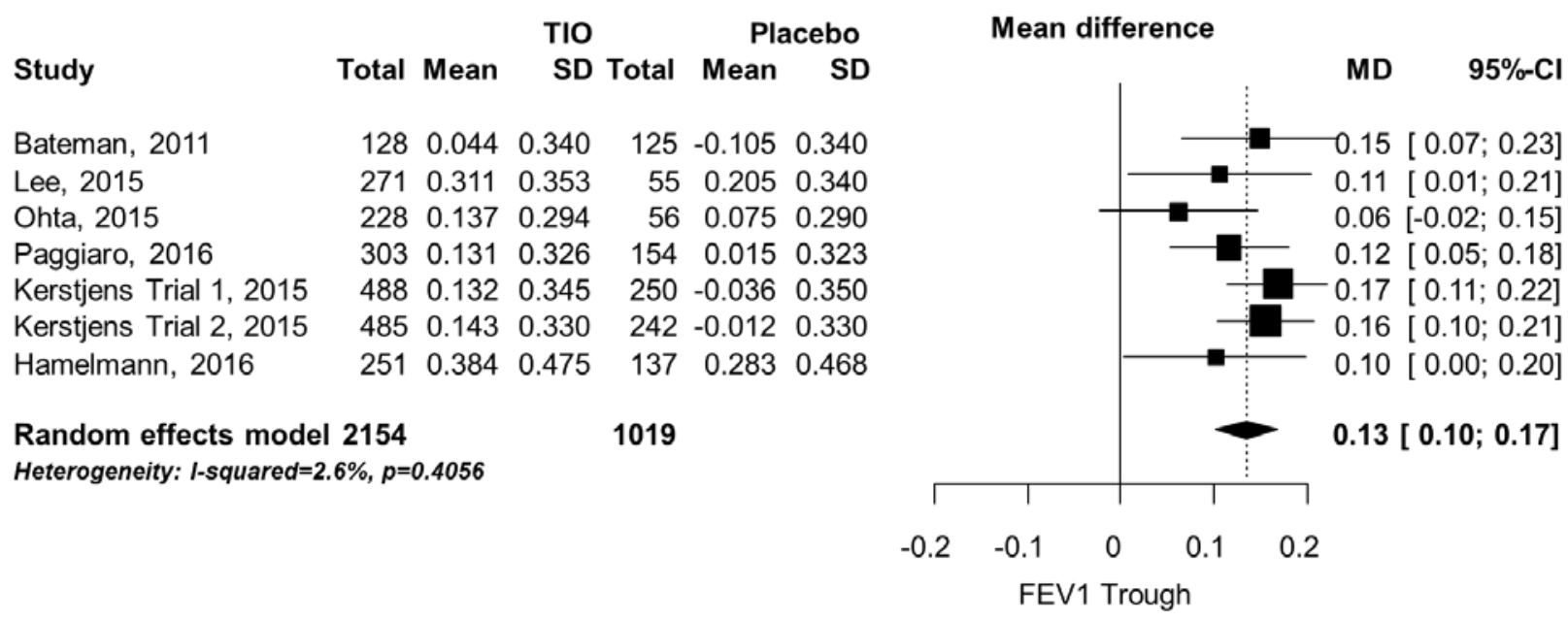

Figure F-14. Change in FEV1 AUC from baseline: LAMA vs. placebo as add-on to ICS

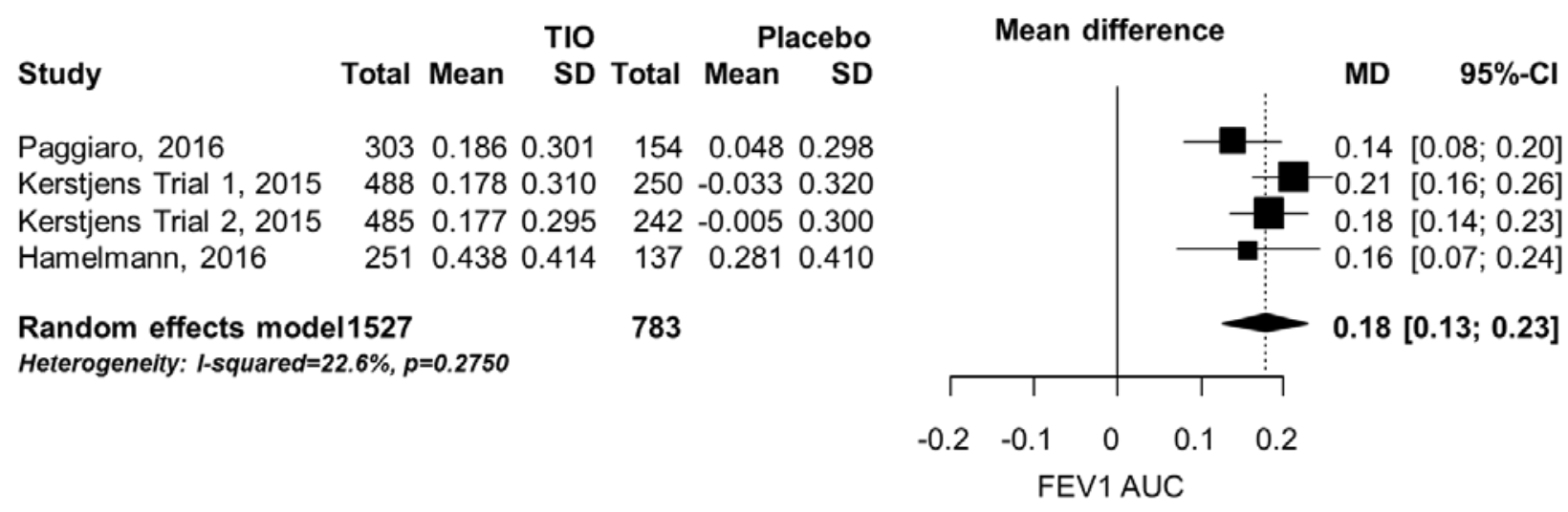

Figure F-15. Change in FVC peak from baseline: LAMA vs. placebo as add-on to ICS

\begin{tabular}{|c|c|c|c|c|c|c|}
\hline \multirow[b]{2}{*}{ Study } & \multirow[b]{2}{*}{ Total } & \multicolumn{3}{|c|}{ TIO } & \multicolumn{2}{|c|}{ Placebo } \\
\hline & & Mean & SD & Total & Mean & SD \\
\hline Kerstjens Trial 1, 2015 & 488 & 0.184 & 0.356 & 250 & 0.045 & 0.35 \\
\hline Kerstjens Trial 2, 2015 & 485 & 0.171 & 0.340 & 242 & 0.071 & 0.34 \\
\hline Hamelmann, 2016 & 251 & 0.411 & 0.492 & 137 & 0.331 & 0.48 \\
\hline $\begin{array}{l}\text { Zandom effects mo } \\
\text { Heterogeneity: I-square }\end{array}$ & & & & 629 & & \\
\hline
\end{tabular}

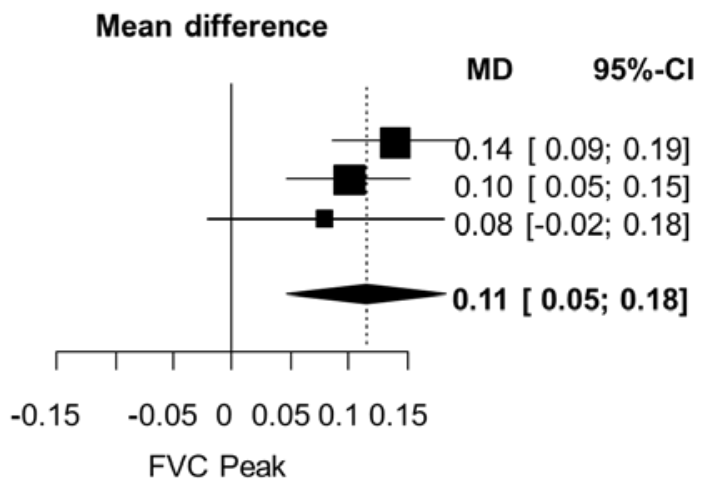


Figure F-16. Change in FVC trough from baseline: LAMA vs. placebo as add-on to ICS

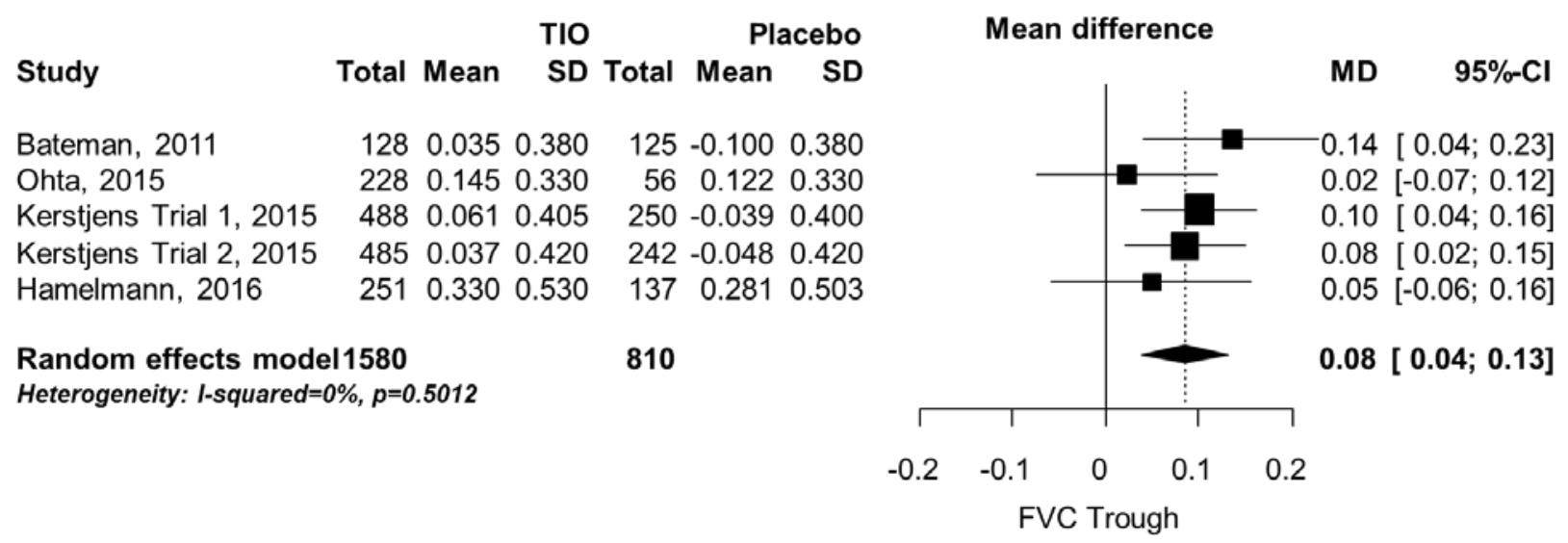

Figure F-17. Change in FVC AUC from baseline: LAMA vs. placebo as add-on to ICS

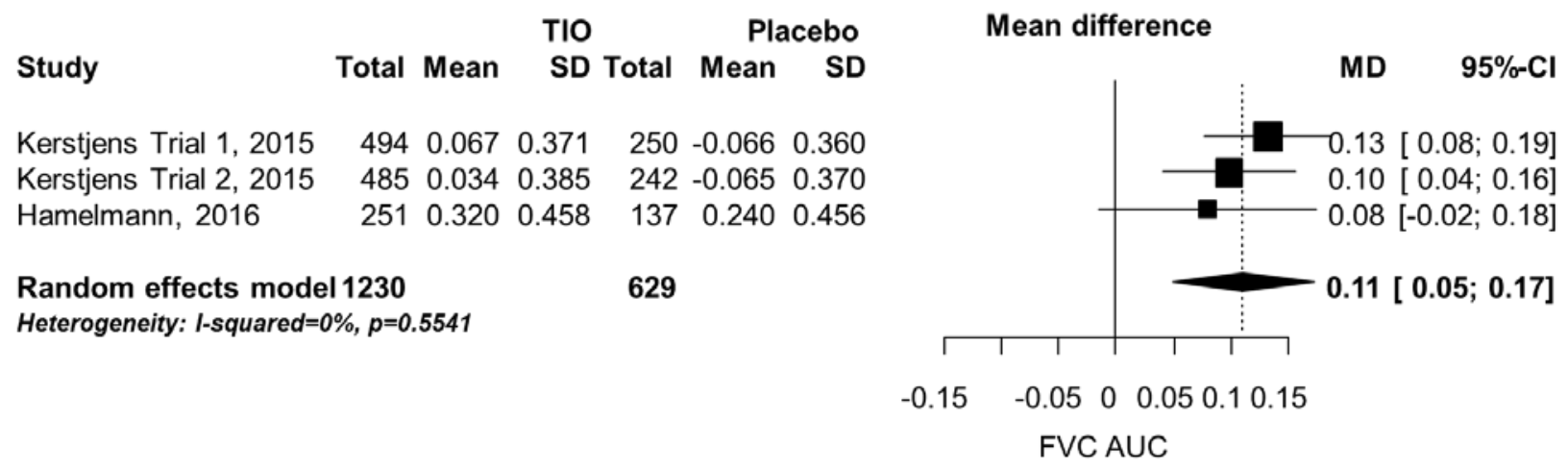

Figure F-18. Difference in rescue medication mean puffs in 24 hours: LAMA vs. placebo as add-on to ICS

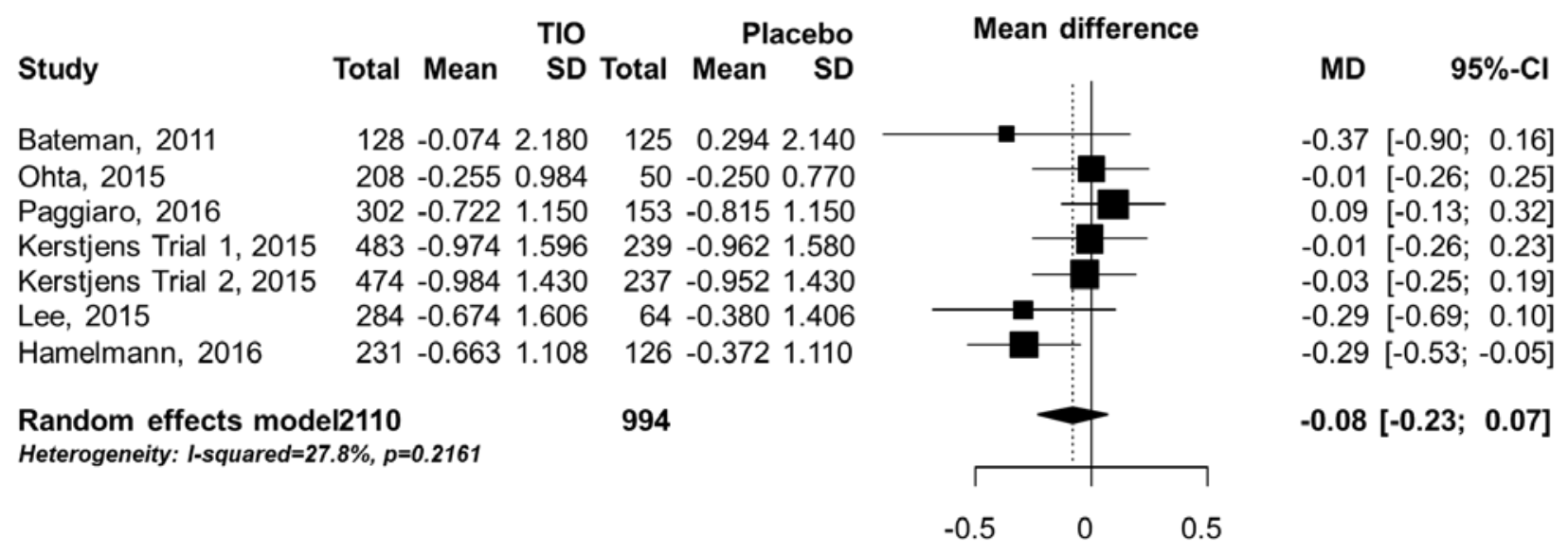

Rescue Medication Use 
Figure F-19. All-cause death: LAMA vs. LABA as add-on to ICS

\begin{tabular}{|c|c|c|c|c|}
\hline \multirow[b]{2}{*}{ Study } & \multicolumn{2}{|c|}{ LAMA } & \multicolumn{2}{|r|}{ LABA } \\
\hline & Events & Total & Events & Total \\
\hline Kerstjens Trial 1, 2015 & 0 & 526 & 0 & 275 \\
\hline Kerstjens Trial 2, 2015 & 0 & 506 & 0 & 266 \\
\hline Lee, 2015 & 0 & 271 & 0 & \\
\hline Wechsler, 2015 & 3 & 532 & 0 & 538 \\
\hline $\begin{array}{l}\text { Random effects model } \\
\text { Heterogeneity: } I \text {-squared }=\Lambda\end{array}$ & $\mathrm{NaN} \%, p$ & $\begin{array}{r}1835 \\
10000\end{array}$ & & \\
\hline
\end{tabular}

\section{Odds Ratio}

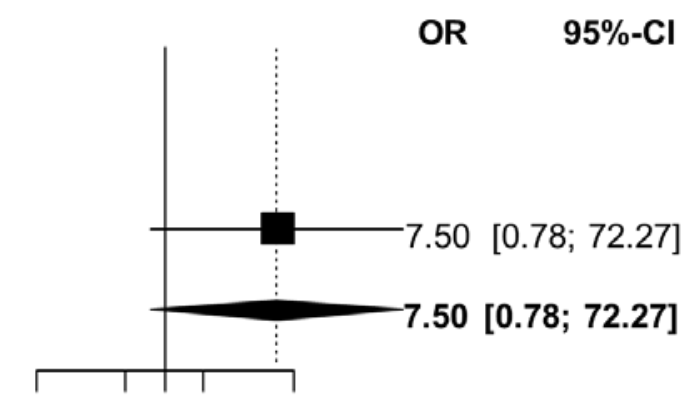

\section{$0.10 .512 \quad 10$ \\ All-Cause Death}

Figure F-20. Asthma-specific death: LAMA vs. LABA as add-on to ICS

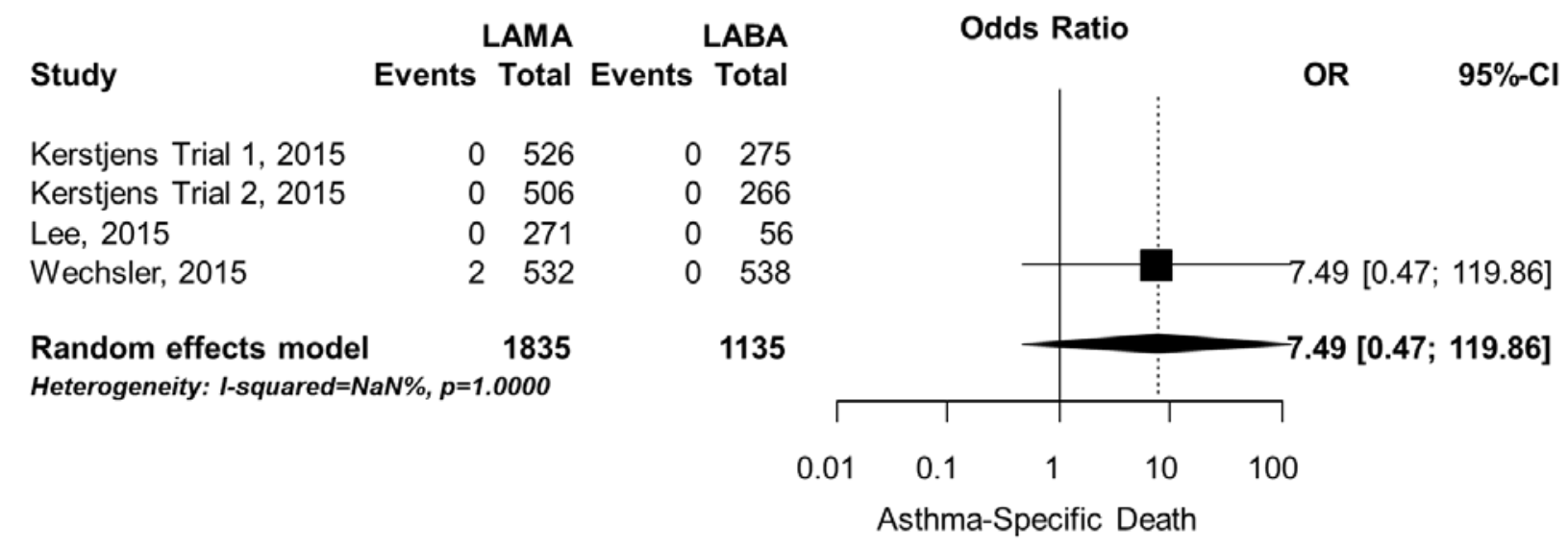

Figure F-21. Change in FEV1 trough from baseline: LAMA vs. LABA as add-on to ICS

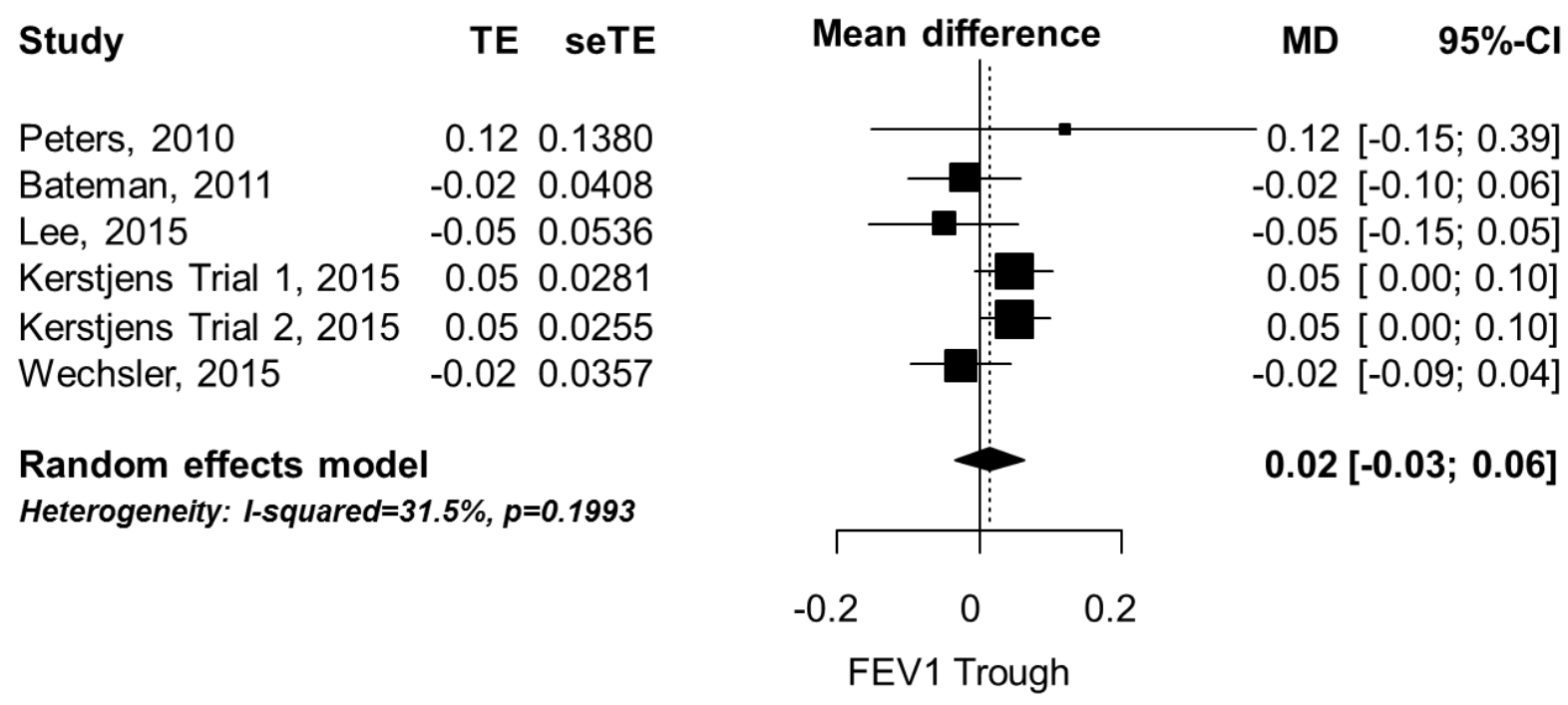


Figure F-22. Change in FEV1 \% predicted from baseline: LAMA vs. LABA as add-on to ICS

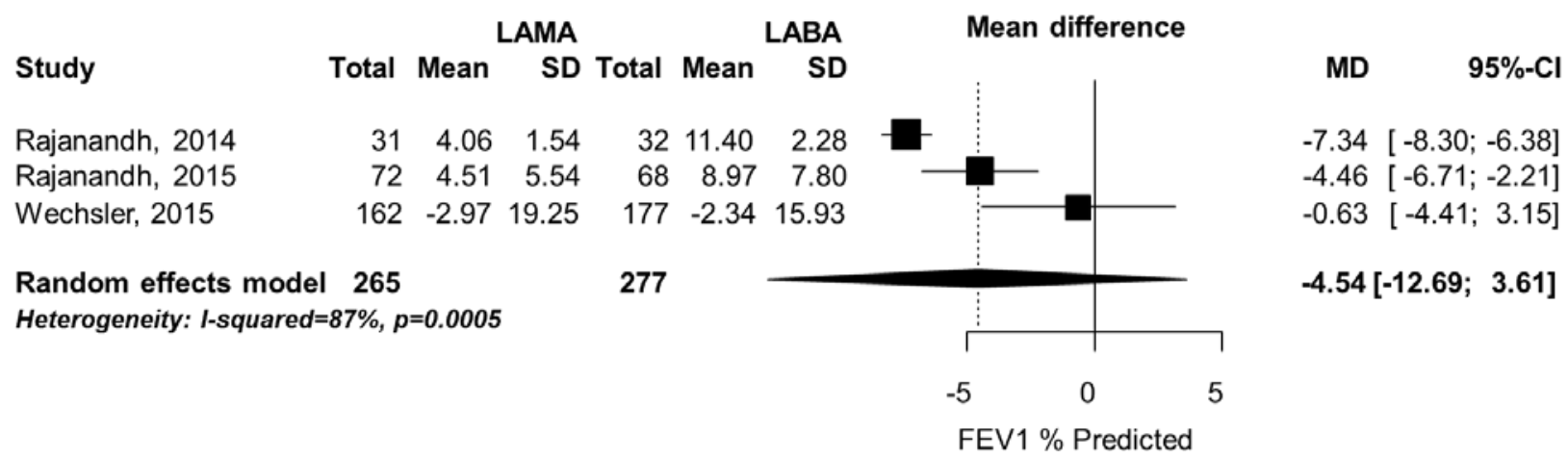

Figure F-23. Change in FVC trough from baseline: LAMA vs. LABA as add-on to ICS

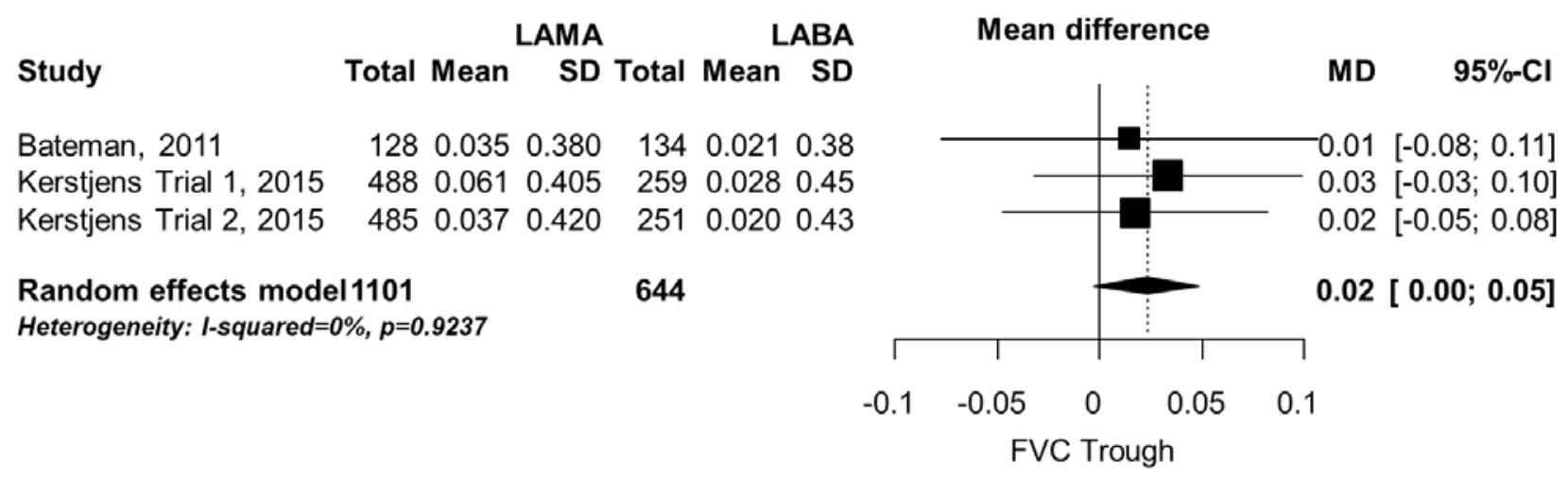

Figure F-24. Change in AQLQ score from baseline: LAMA vs. LABA as add-on to ICS

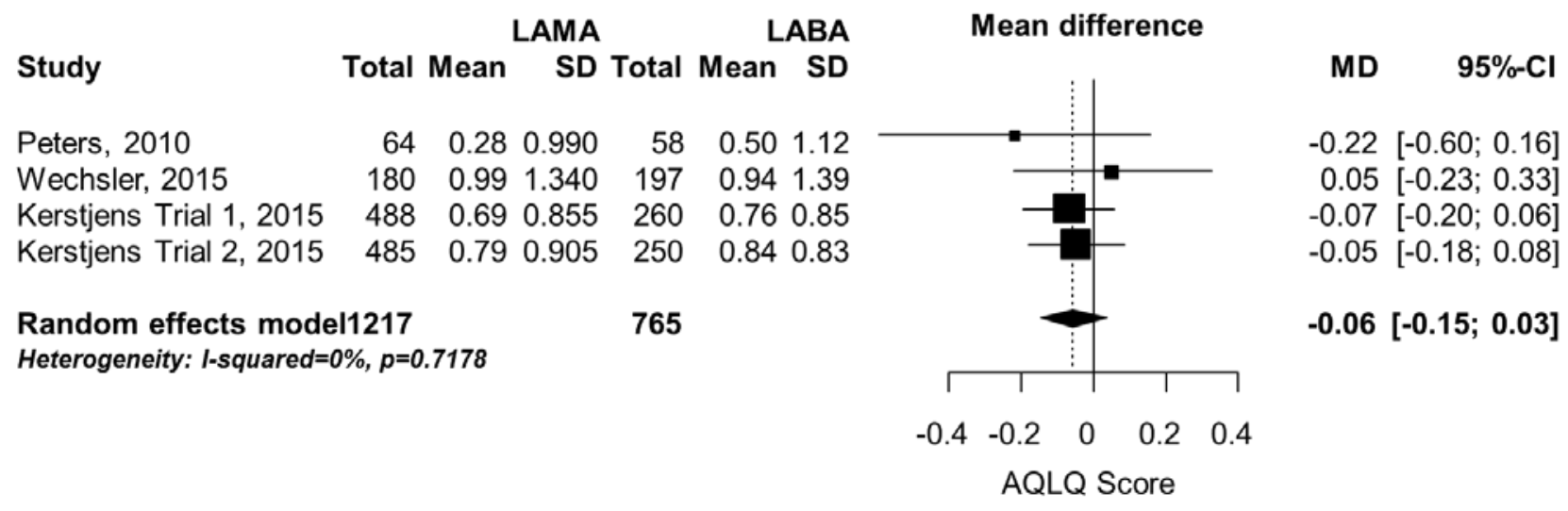


Figure F-25. Difference in rescue medication mean puffs in 24 hours: LAMA vs. LABA as add-on to ICS

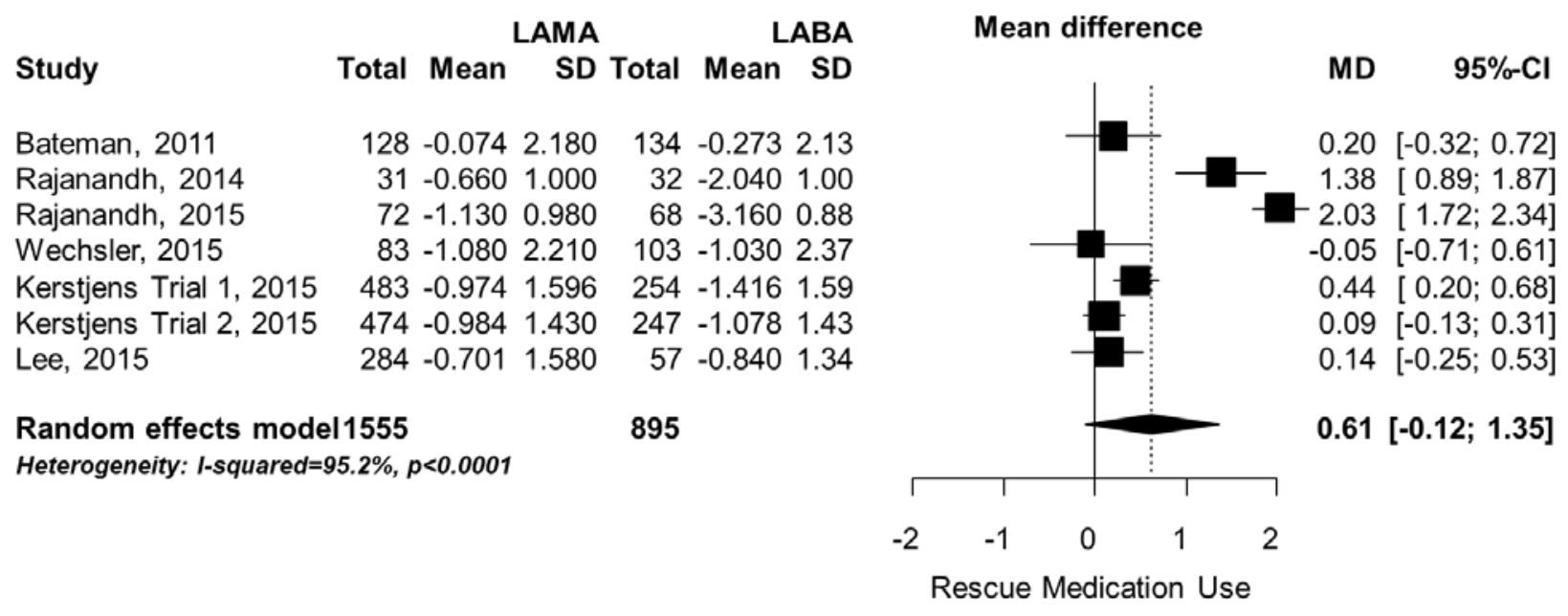

Figure F-26. Change in ACQ-7 score from baseline: LAMA added to ICS and LABA vs. ICS and LABA

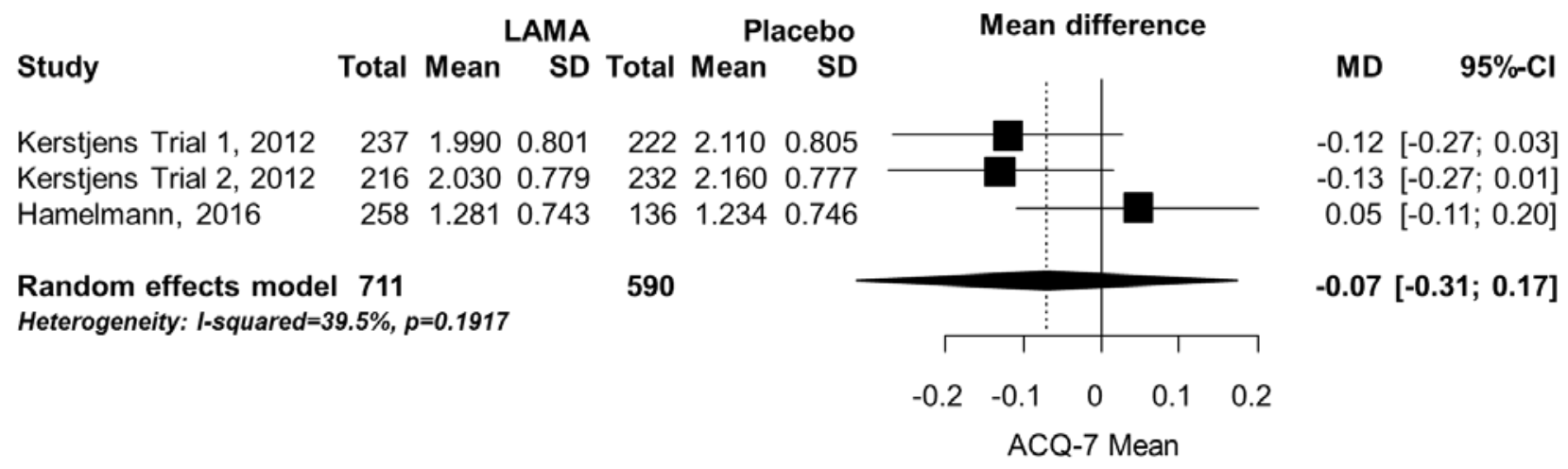

Figure F-27. Change in FEV1 peak from baseline: LAMA added to ICS and LABA vs. ICS and LABA

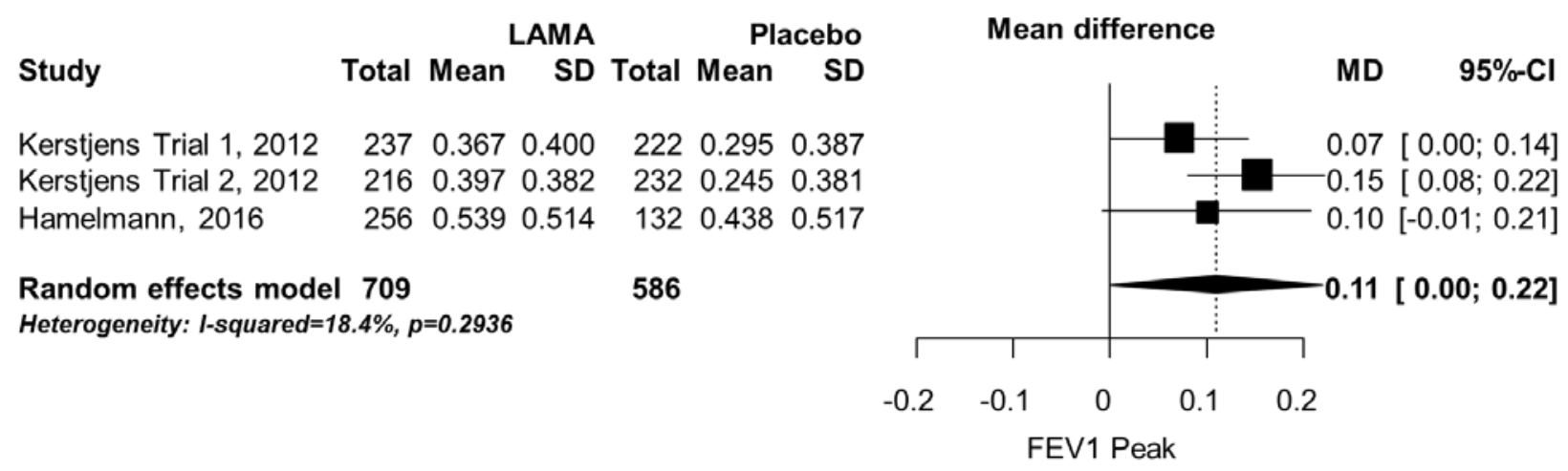


Figure F-28. Change in FEV1 trough from baseline: LAMA added to ICS and LABA vs. ICS and LABA

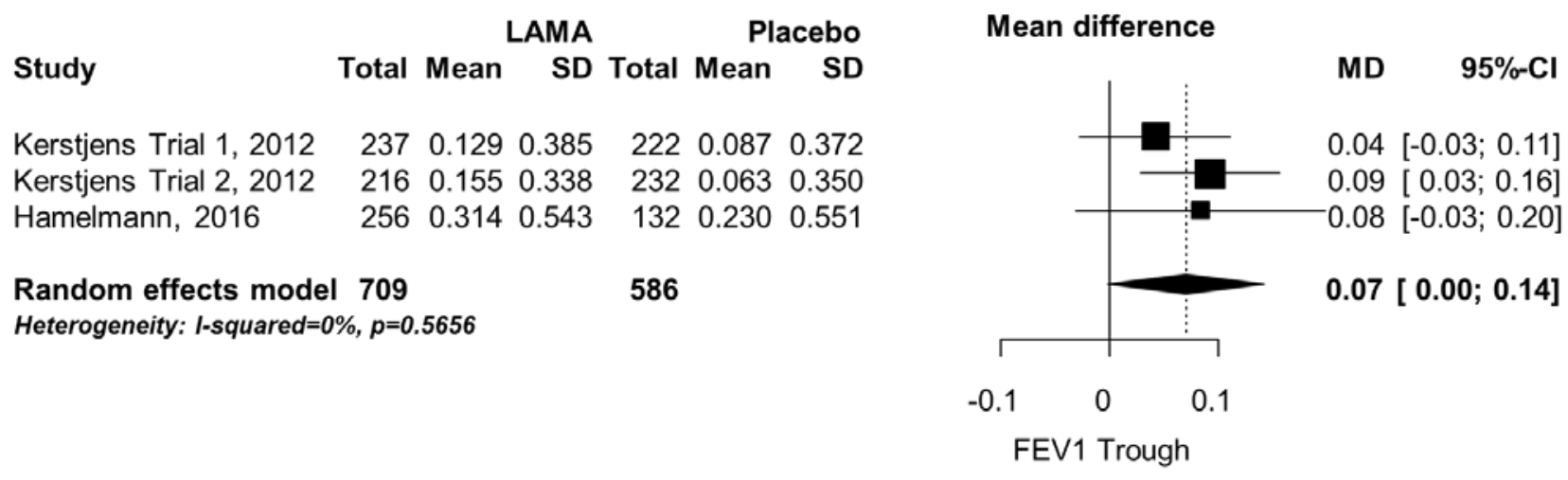

Figure F-29. Change in FEV1 AUC from baseline: LAMA added to ICS and LABA vs. ICS and LABA

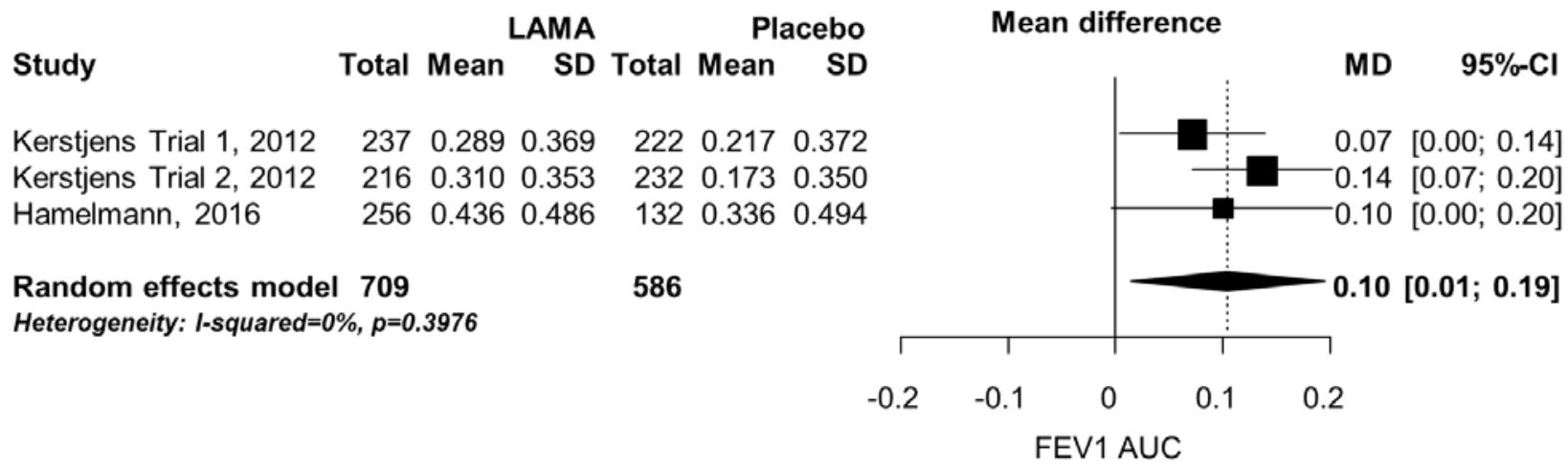

Figure F-30. Change in FVC peak from baseline: LAMA added to ICS and LABA vS. ICS and LABA

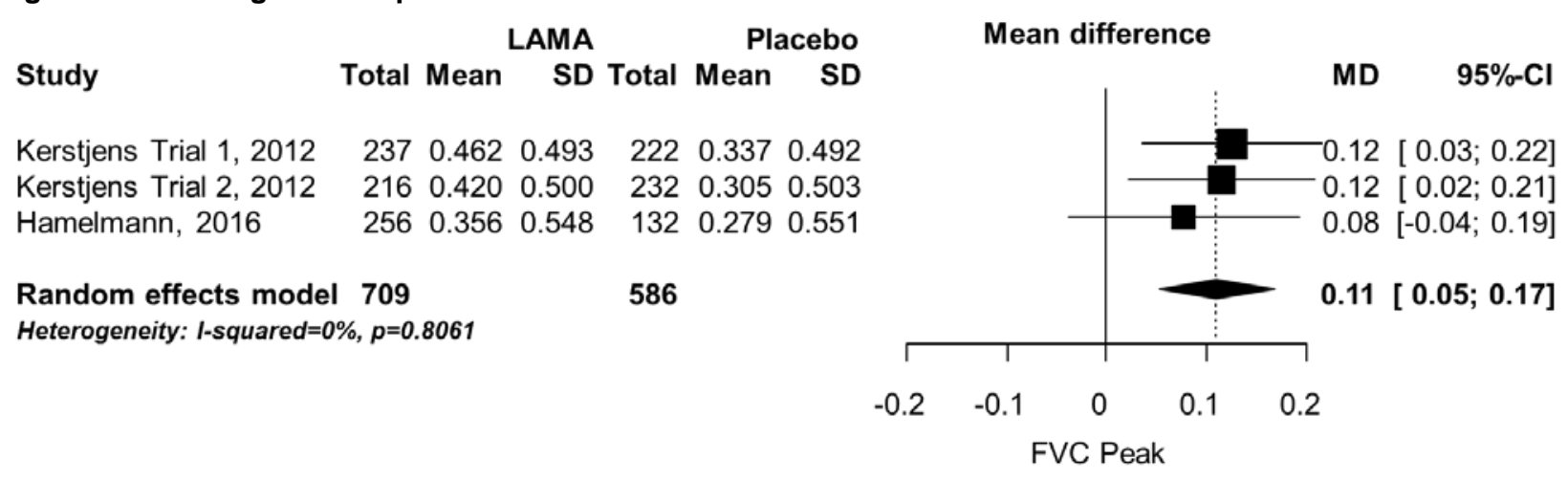


Figure F-31. Change in FVC trough from baseline: LAMA added to ICS and LABA vs. ICS and LABA

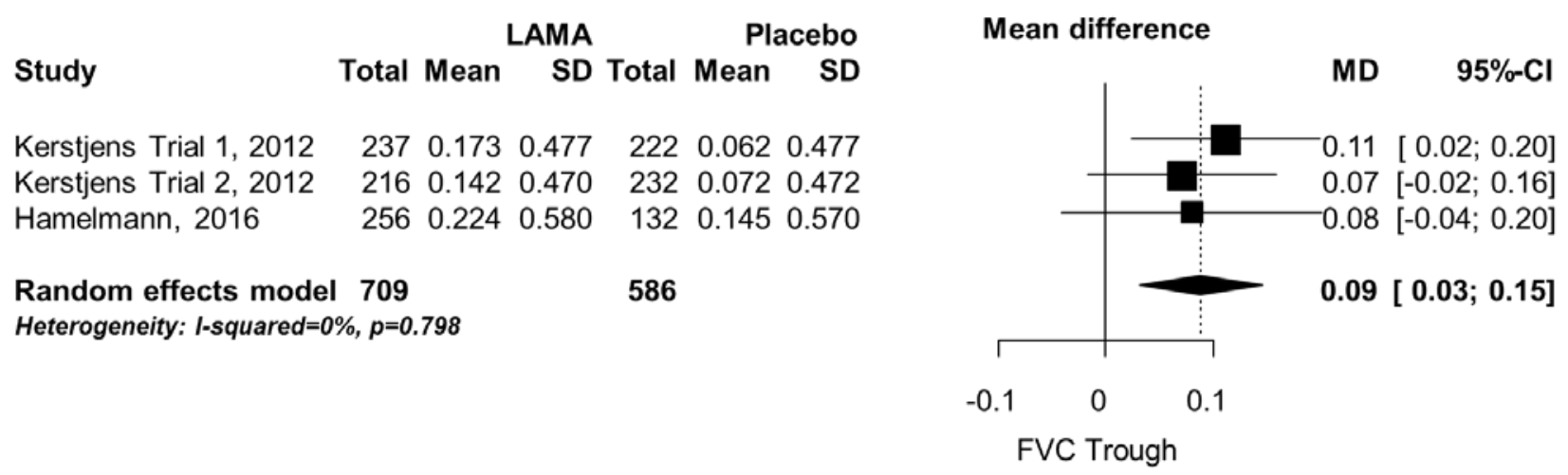

Figure F-32. Change in FVC AUC from baseline: LAMA added to ICS and LABA vS. ICS and LABA

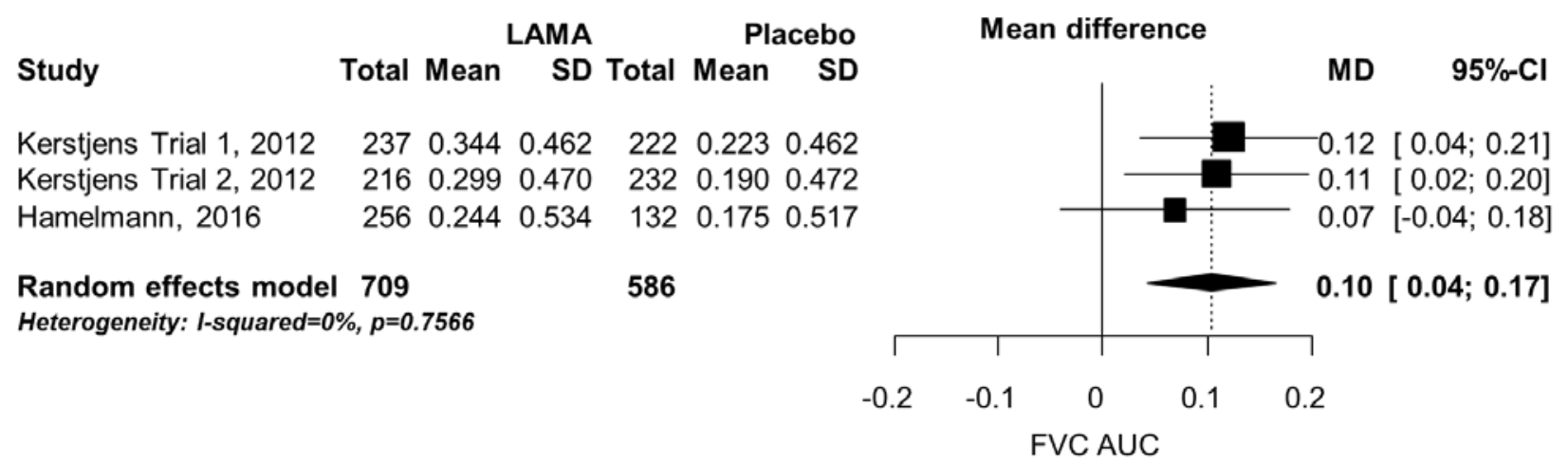

Figure F-33. Difference in rescue medication mean puffs in 24 hours: LAMA added to ICS and LABA vs. ICS and LABA

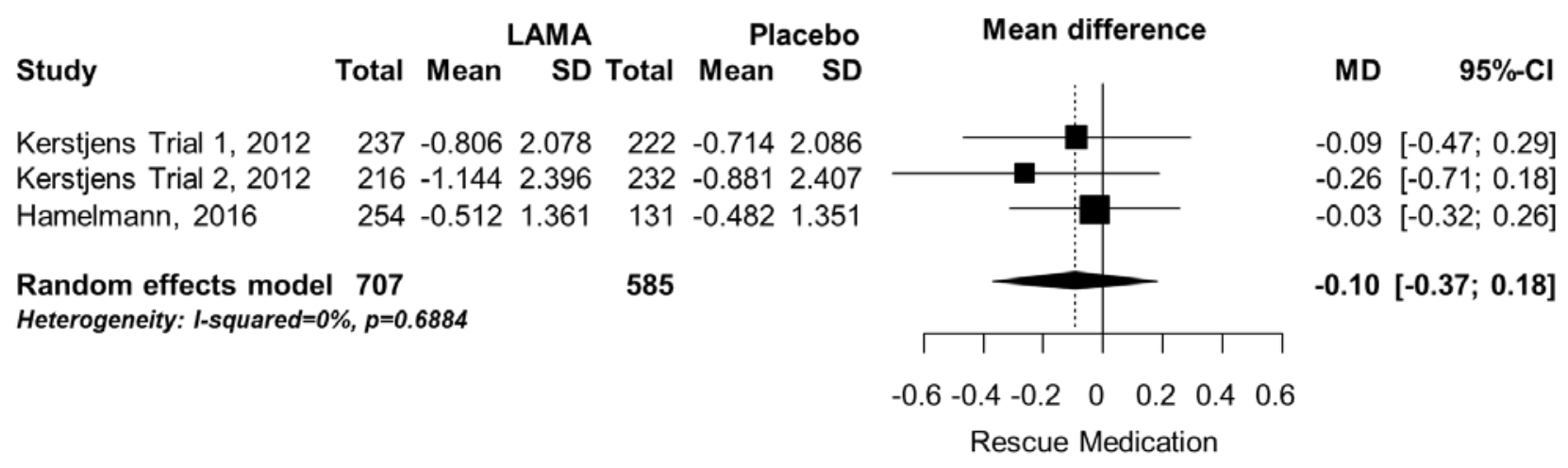

